\title{
Molekulargenetische Untersuchungen an Überresten präkolumbischer Neuwelt-Camelidae aus dem Palpa-Tal (Peru)
}

Dissertation zur Erlangung des Doktorgrades der Mathematisch-Naturwissenschaftlichen Fakultäten der Georg-August-Universität zu Göttingen

vorgelegt von

Rebecca Renneberg, geb. Schütt aus Remscheid 
D7

Referent: Prof. Dr. B. Herrmann

Koreferent Prof. Dr. R. Willmann

Termin der mündlichen Prüfung: 29.04.2008 
Diese Arbeit wurde angefertigt am Johann Friedrich Blumenbach Institut für Zoologie und Anthropologie, Abteilung Historische Anthropologie und Humanökologie der Georg-August Universität Göttingen im Rahmen des Projektes:

"NTG Projektverbund Nasca. Entwicklung und Adaption archäometrischer Techniken zur Erforschung der Kulturgeschichte“.

Das Projekt wurde gefördert durch das Bundesministerium für Bildung und Forschung (BMBF), Förderschwerpunkt "Neue naturwissenschaftliche Methoden und Technologien in den Geisteswissenschaften". FKZ: 03HEX1VP

Projektleiter: Prof. Dr. B. Herrmann 


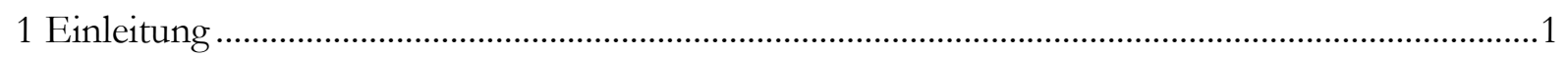

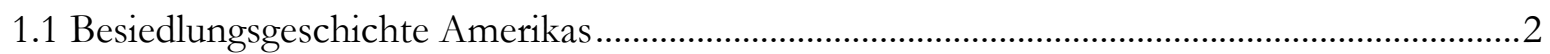

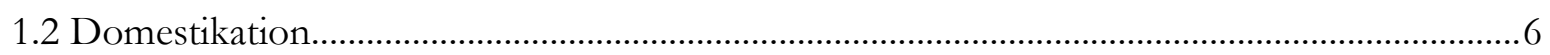

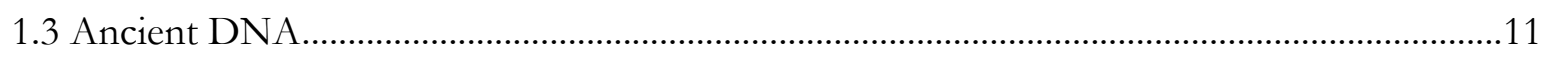

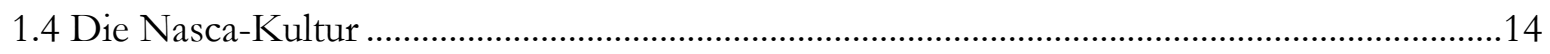

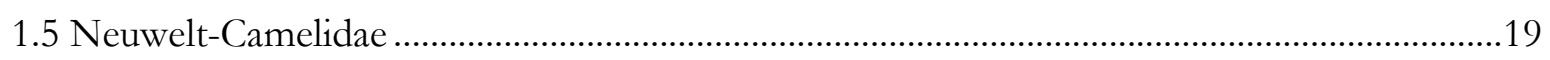

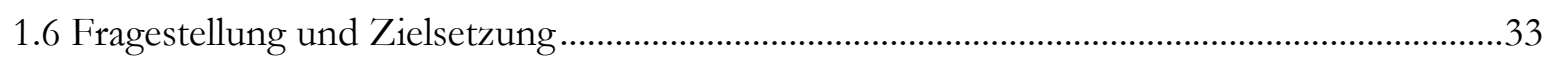

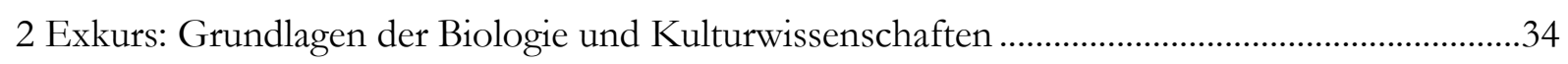

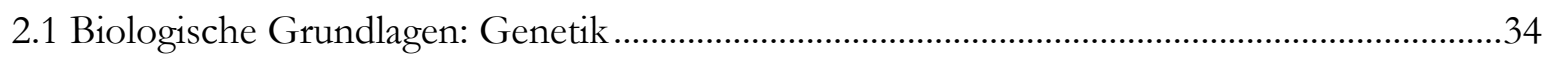

2.1.1 Mitochondriales Genom, Markersysteme und Speziesidentifikation..............................37

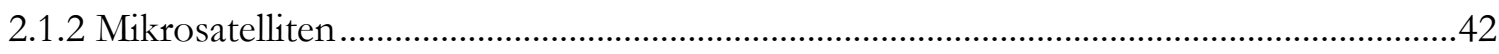

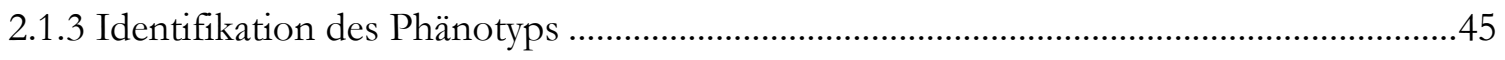

2.2 Biologische Grundlagen: Evolution und Systematik................................................................

2.2.1 Historischer Überblick und Formulierung der Evolutionstheorien..................................48

2.2.2 Evolutionsmechanismen und Systematik...........................................................................

2.3 Biologische Grundlagen: Populationsgenetik..............................................................................5

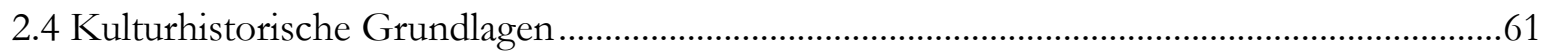

2.4.1 Definition von Kultur , Sozialsystemen, Zivilisation und Religion...................................61

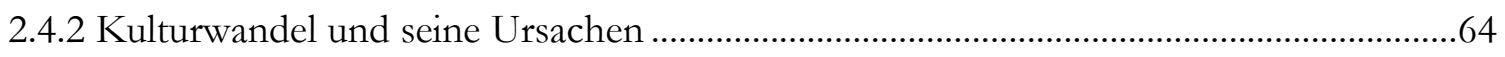

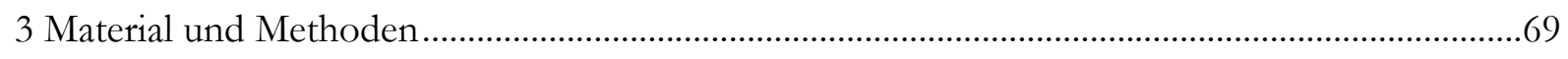

3.1 Rezentes Probematerial und Vergleichssequenzen ..........................................................69

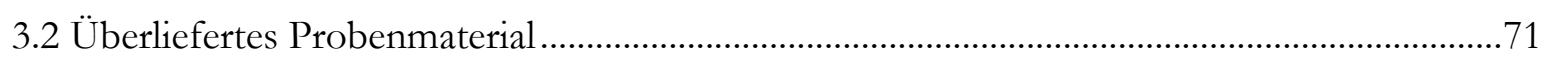

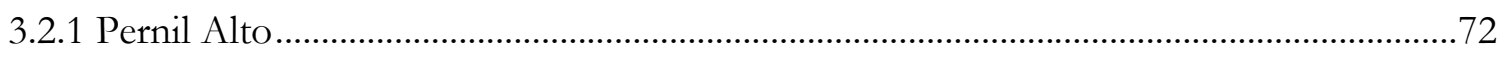

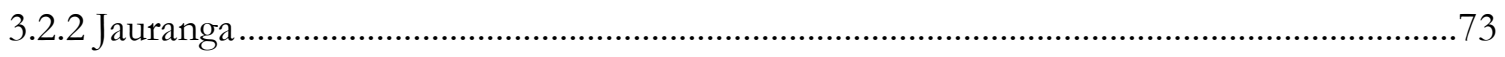

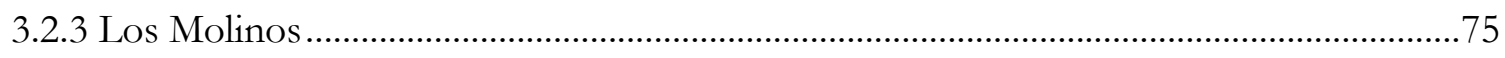

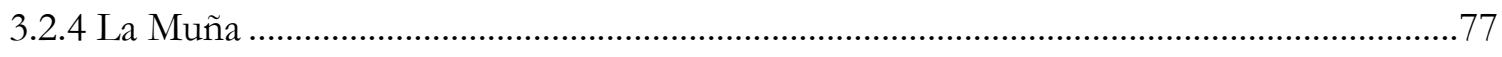

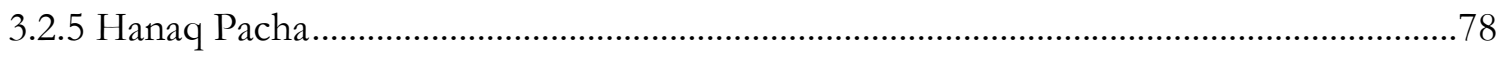

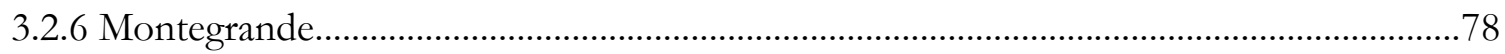

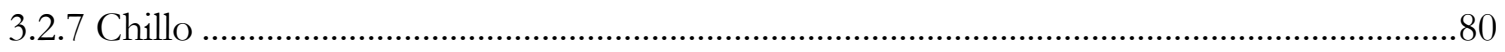

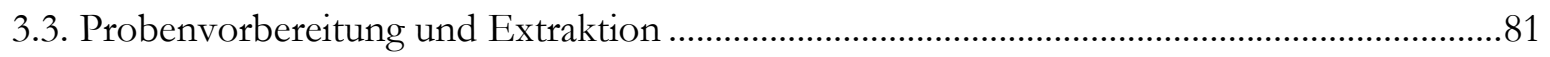

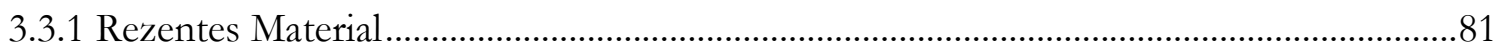

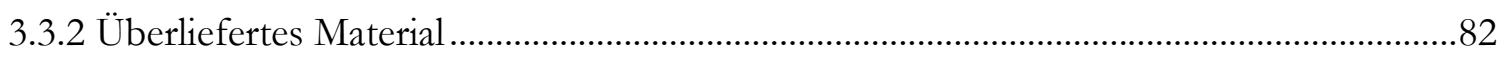

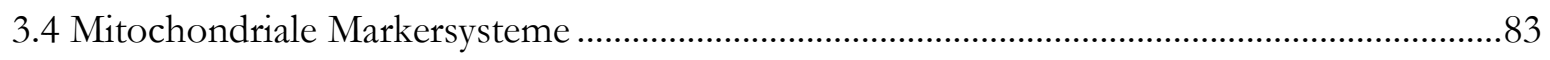

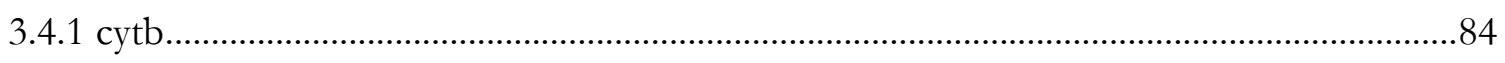

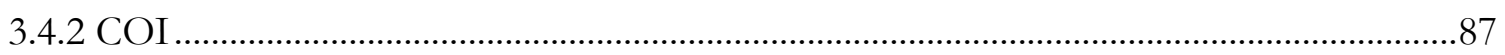




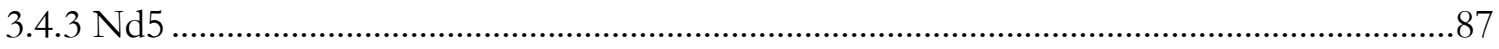

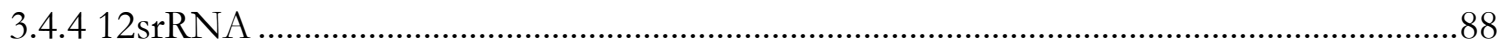

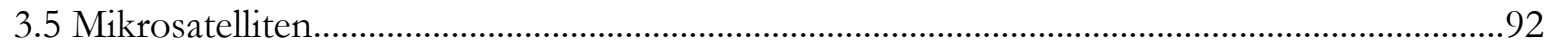

3.6 Analysesysteme zur Identifikation des Phänotyps................................................................97

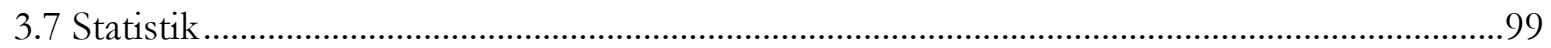

4 Typisierungsergebnisse und erste Ableitungen aus den Datensätzen ........................................... 100

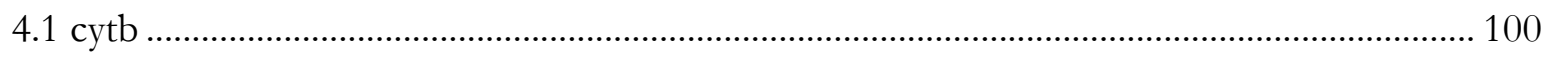

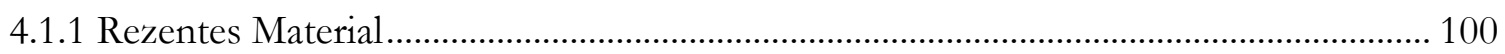

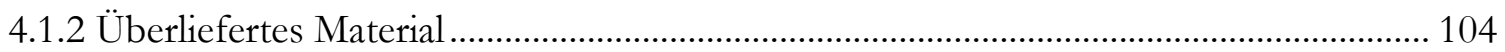

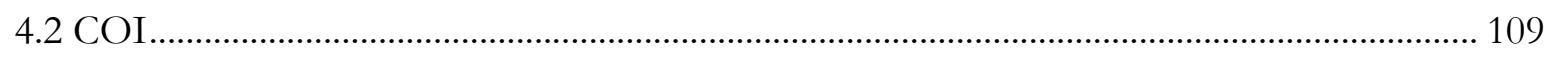

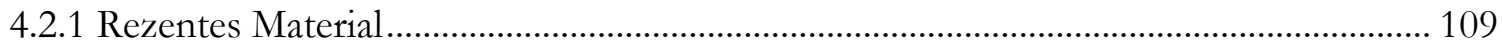

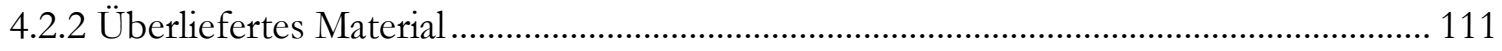

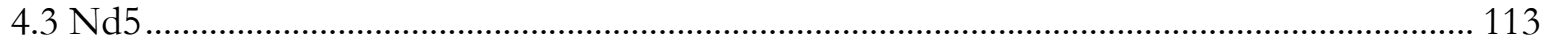

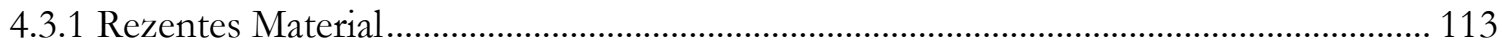

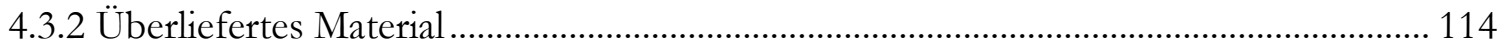

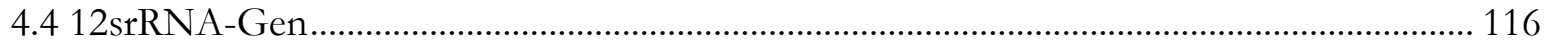

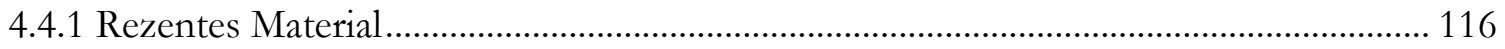

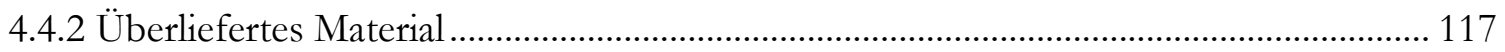

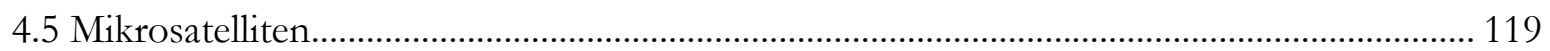

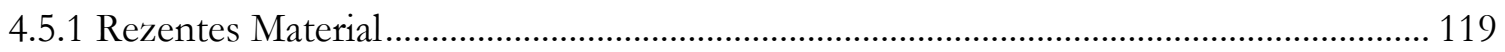

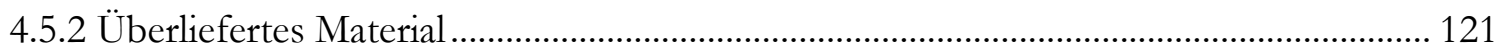

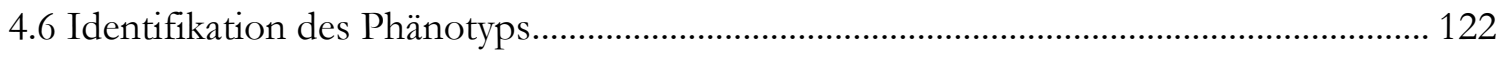

5 Auswertung und Beurteilung des Erhaltungszustandes der DNA des überlieferten

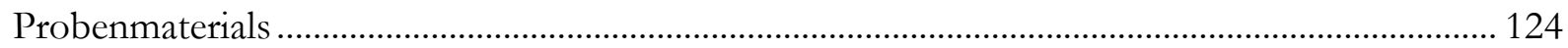

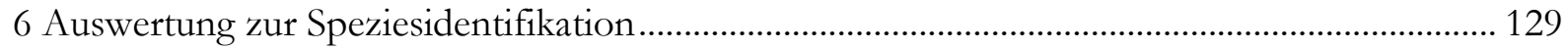

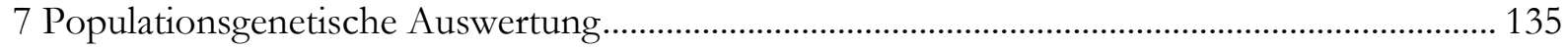

7.1 AMOVA und Diversitäten der gefundenen Haplotypen in rezenten Material................... 135

7.2 AMOVA, Diversitäten und Netzwerke der gefundenen Haplotypen in überliefertem

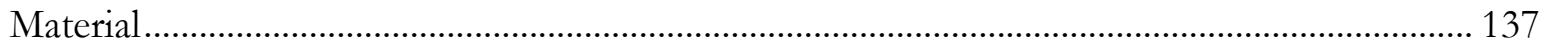

7.3 Zusammenführung der Ergebnisse des rezenten und überlieferten Materials..................... 142

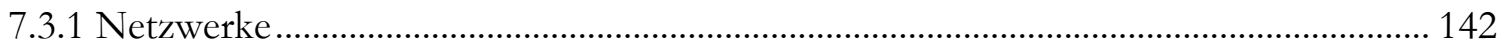

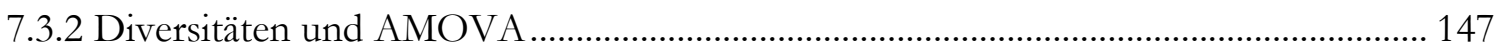

7.4 Variabilität der Mikrosatelliten in phänotypischen und genotypischen Spezies................... 149

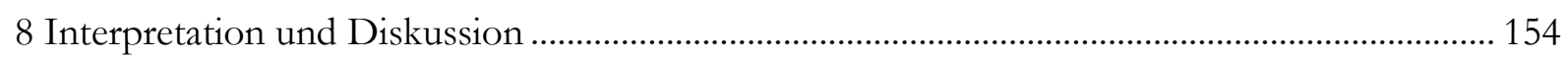

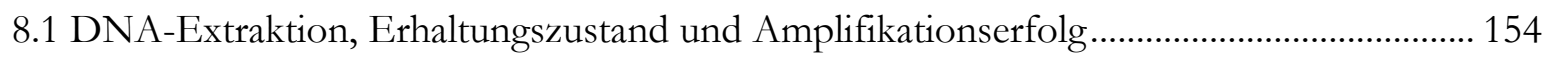




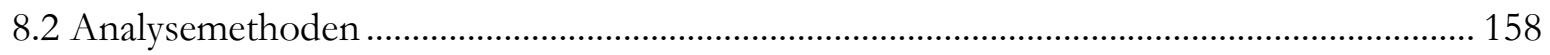

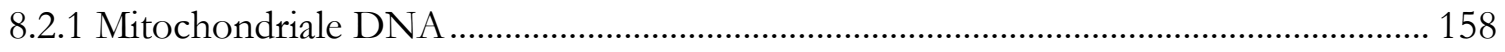

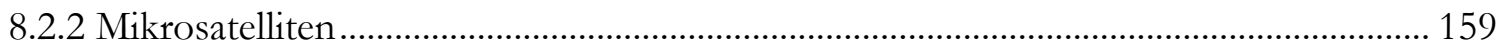

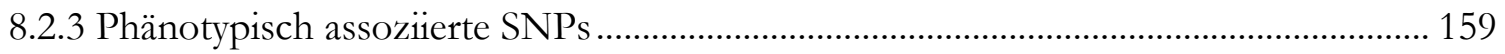

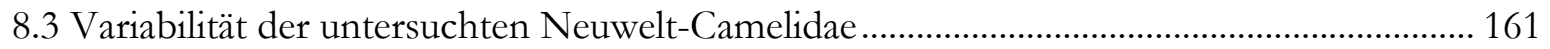

9 Diskussion: Speziesidentifikation und Phylogenetik der Neuwelt-Camelidae .............................. 165

10 Interpretation der erzielten Ergebnisse präkolumbischer Neuwelt-Camelidae und

Kontextualisierung dieser mit den Ergebnissen des Gesamtprojektes........................................... 169

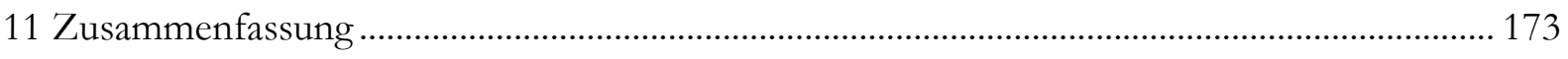

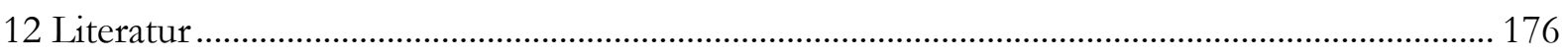

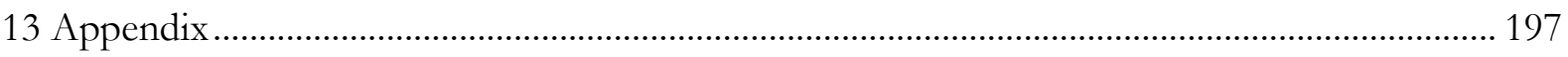

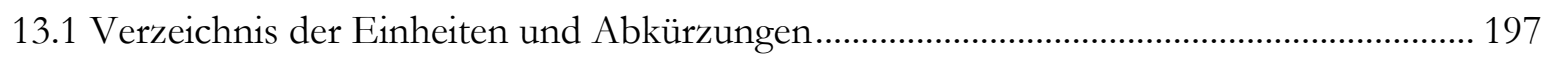

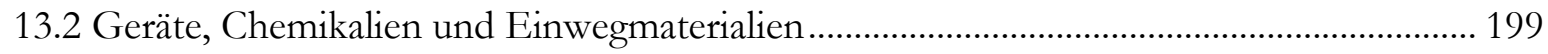

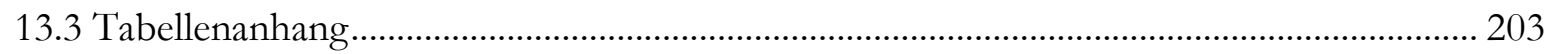

13.4 Dokumentation der Histologischen Knochenstruktur von Neuweltcamelidae

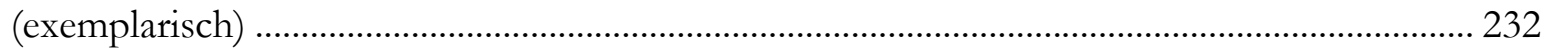




\section{Einleitung}

Die Erforschung von Kulturgeschichte ist zentrales Interesse in der Archäologie. Zunehmend stützt sich die Rekonstruktion vergangener Kulturen, auf die Verknüpfung der Ergebnisse unterschiedlicher Teildisziplinen. So liefern Archäologie, Geologie, Anthropologie und Biologie gemeinsam verlässliche Daten, die ein Gesamtbild der Kultur und ihrem kulturellen Wandel formen.

Ein solches Verbundprojekt zur Erforschung der Siedlungsgeschichte der präkolumbischen peruanischen Nasca Kultur (NTG Projektverbund Nasca. Entwicklung und Adaption archäometrischer Techniken zur Erforschung der Kulturgeschichte.) begann 2003. Das Projekt vereint die Disziplinen Archäologie, Chronometrie, Geophysik, Geomorphologie, Keramikrekonstruktion, Photogrammetrie, Metallurgie und Molekulare Anthropologie. Hauptziel ist die Erforschung der Kultur der Bewohner des Palpa-Tals, von der Erstbesiedlung (ca. 3800 v. Chr.) bis zur Kolonialisierung durch die Spanier (1530 n. Chr.), sowie die Kontextualisierung mit den Geoglyphen und ihrer Bedeutung. Das Forschungsgebiet umfasst die Region des Palpa-Tals, mit den Flüssen Río Grande, Río Palpa und Río Viscas. Es liegt ca. 40 km nördlich von Nasca (s. Abb. 1).

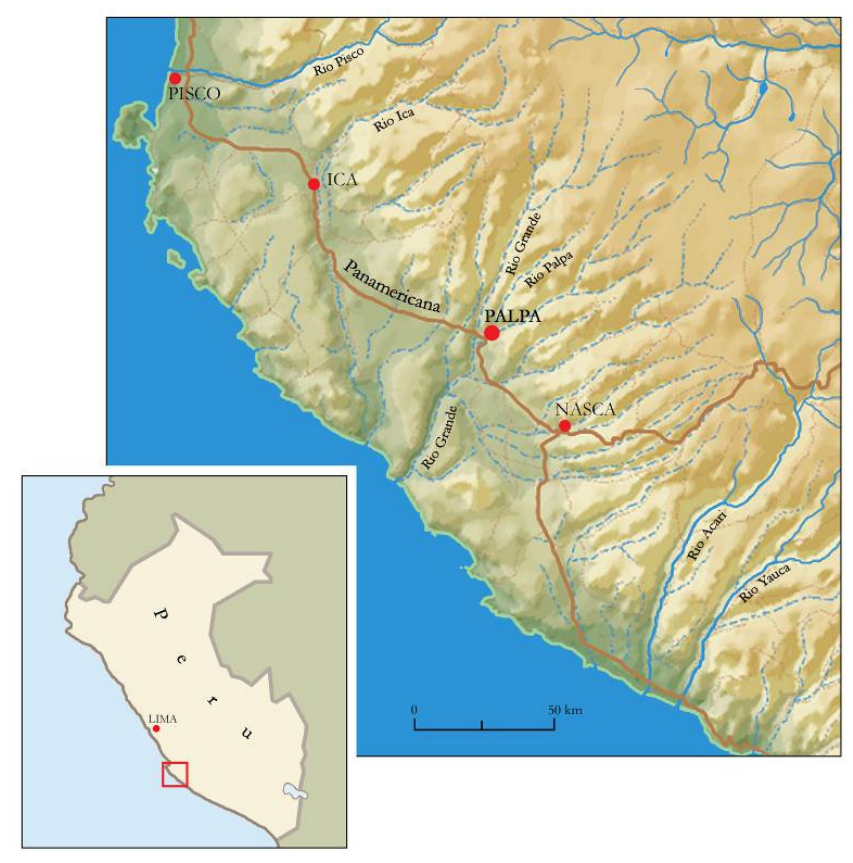

Abbildung 1: Lage des Palpa-Tals (Quelle: KAAK/DAI)

Für das Palpa-Tal konnte bisher ein Besiedlungszeitraum seit der Initialzeit (1800-800 v. Chr.) belegt werden. Prospektion und Datierung standen zunächst im Fokus. Die Erarbeitung einer 
numerischen Chronologie erfolgte. Die Analyse menschlicher und tierischer Überreste, in Addition zur Siedlungsarchäologie und geologischen Umweltrekonstruktion, sollten die Lebensumstände und Umweltbedingungen der Region im Wandel der Zeit erfassen. Die Hauptausgrabungen haben an sechs Fundorten statt gefunden: Pernil Alto, Jauranga, Los Molinos, La Muña, Parasmarca und Chillo. Neben einer Fülle an menschlichen Überresten, Keramik, Textilien und anderen Artefakten, enthielten die Funde auch immer tierischer Überreste. Neben wenigen Knochen von Cervis spec. (Hirschartige), Canis spec. (Hundeartige) und Cavia spec. (Echte Meerschweinchen), stammt die große Mehrzahl der Knochen von Neuwelt-Camelidae. Der natürliche Lebensraum der Neuwelt-Camelidae liegt in Höhen über 2000 m. Das Antreffen einer hohen Anzahl an Camelidae-Knochen im Palpa-Tal, das auf einer Höhe von 347 m ü. NN liegt, deutet also auf ein Importverfahren der (prä-)historischen Bevölkerung hin. Darüber hinaus besteht eine Vielzahl der gefundenen Textilien anteilig oder komplett aus tierischer Wolle. Welche Spezies genau vorliegen war bisher nicht bekannt, da eine morphologische Bestimmung (osteometrisch oder diametrisch an Wolle) der NeuweltCamelidae nur bedingt möglich ist. Die Speziesidentifikation dient jedoch der Aufklärung der ökonomischen Struktur und Subsistenzstrategien (Jagd auf wilde Tiere versus Handel mit dem Hochland versus Haltung). Die molekulargenetische Speziesbestimmung ist heute für eine Vielzahl von Arten möglich (s. z.B. Pfeiffer 2007), Neuwelt-Camelidae sind hier jedoch bisher nicht vertreten. Darüber hinaus können anhand der genetischen Komposition von Individuen verschiedener Spezies Aussagen über Phylogenetik (s. z.B. Ostrander und Wayne 2007) und Domestikationsprozessen (s. Kap. 1.2) getroffen werden.

Um einen Einstieg in die Thematik der vorliegenden Arbeit zu ermöglichen, wird im Folgenden kurz auf die Besiedlungs- und Kulturgeschichte Südamerikas eingegangen sowie Grundlagen der Domestikation und aDNA-Analytik vorgestellt. Bevor die Formulierung der Fragestellung und Zielsetzung erfolgt, werden die Nasca-Kultur, als Kulturperiode aus der die Untersuchungsobjekte stammen, sowie Charakteristika der Neuwelt-Camelidae beschrieben. Dies dient dem Verständnis der Fragestellung sowie als Diskussions-Grundlage der erzielten Ergebnisse dieser Arbeit.

\subsection{Besiedlungsgeschichte Amerikas}

Die Besiedlungsgeschichte Amerikas, ist seit der Entdeckung des amerikanischen Kontinents und seiner Ureinwohnern Bestandteil zahlreicher Forschungsgebiete. Johann F. Blumenbach unterteilte 1775 in seinem Werk „De Genetica Humani Varietate Nativa“ die Menschheit in vier Hauptrassen: Kaukasier, Mongolen, Amerikanische Indianer, und Afrikaner. Dabei 
beobachtete er die Ähnlichkeit zwischen Mongolen und Amerikanischen Indianer und folgerte eine enge Verwandtschaft dieser beiden Rassen. Er ging von mehreren Migrationen in den amerikanischen Kontinent aus, wobei die Eskimos als letztes eingewandert seien, da diese die meiste Ähnlichkeit zu den Mongolen aufweisen würden. Bis heute gibt es Spekulationen über transozeanische Kontakte, die z.B. anhand genetischer Untersuchungen von domestizierten Tieren und ihrer Ähnlichkeiten, begründet werden (s. z.B. Storey et al. 2007). Auch eine Besiedlung durch Seefahrer aus Europa oder dem Südpazifik werden immer wieder postuliert. Diese Theorien sind meist wissenschaftlich nicht haltbar. Genetisch und linguistisch ist heute belegt, dass die amerikanischen Ureinwohner von Asiaten abstammen, explizit von Sibirern. Neben spezifischen Allelen in autosomalen STRs, teilen sie sich die mitochondrialen Haplogruppen A, B, C und D (Eshleman et al. 2003). Die Besiedlung des NordAmerikanischen Kontinents wird heute auf ca. 20000 J. v. h. datiert. Eindeutig belegt ist, dass diese Besiedlung über die Beringstrasse erfolgte. Während der letzten Eiszeit war diese Passage begehbar und eine Migration nach Alaska war möglich. Die derzeit gängigste Theorie ist in Abbildung 2 dargestellt.

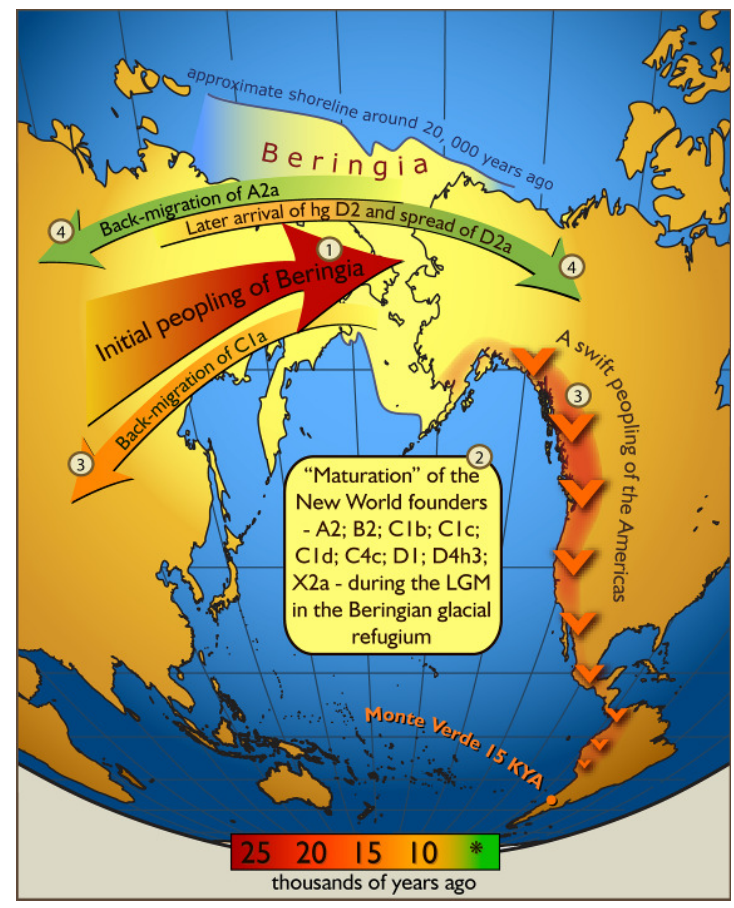

Abbildung 2: Theorie der Besiedlung Nord-Amerikas und Anzahl möglicher Besiedlungswellen (aus Tamm et al. 2007)

Es wird von mindesten zwei Besiedlungswellen und einem längeren Stillstand der Migrationsbewegungen in der Beringstrasse ausgegangen (genetische Untersuchungen, Tamm et al. 2007). Die Zahl der Besiedlungswellen könnte jedoch deutlich höher gewesen sein, da 
eine hohe Anzahl verschiedener mitochondrialer Haplotypen angetroffen wird (Wenke et al. 1995). Linguistisch werden drei Migrationswellen bestimmt. Die erste erfolgte durch die heute Amerind-sprachigen Populationen, die zweite durch Na-Dene-sprachige Gruppen und die dritte durch Aleut-sprachigen Gruppen (Crawford 1998). Eine Begründung der Ausbreitung sibirischer Jäger-Sammler Populationen in den amerikanischen Kontinent, wird in der ansteigenden Populationsgröße gesehen, die zu einer Spaltung der Gruppe führte (Crawford 1998). Die Expansionswege der Siedler in den Nordamerikanischen Kontinent und in den Süd-Amerikanischen Kontinent sind nicht eindeutig geklärt. Grund hierfür sind die Landeismassenverbreitungen während, und zum Ende, der letzten Eiszeit (s. Abb. 3).

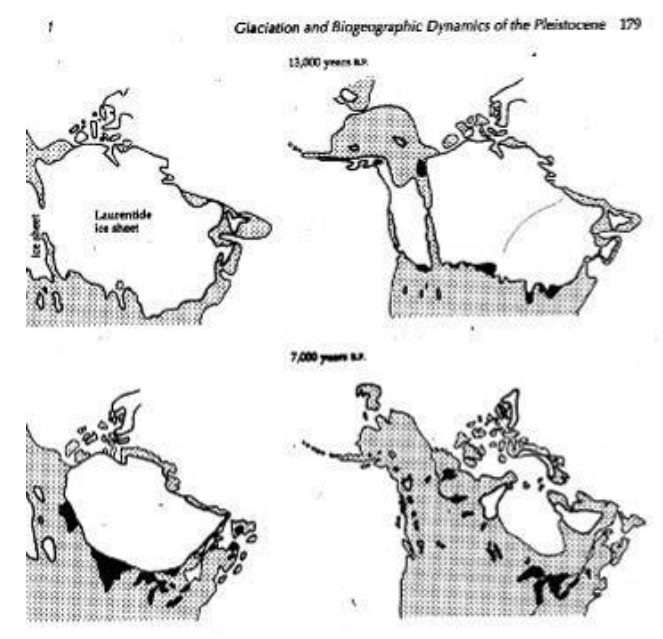

Abbildung 3: Landeismasse während des späten Pleistozäns und frühen Holozän (aus Pielou 1991)

Erst ab ca. 13000 J. v. h. war ein ca. 1500km breiter Korridor begehbar. Am westlichen Rand des Kontinents existierte ein zweiter kontinuierlich begehbarer Korridor. Die Frage welcher von beiden zur Besiedlung des Süd-Amerikanischen Kontinents genutzt wurde ist nicht geklärt. Die ersten Jäger Sammler Funde in Süd-Amerika datieren auf ca. 13000 J. v. h. (Chile, Monte-Verde) und 10000-11000 J. v. h. (Brasilien, Caverna da Pedra).

\section{Siedlungs- und Kulturgeschichte Süd-Amerikas}

Für das Pleistozän wird für Süd-Amerika von einer geringen Besiedlungsdichte ausgegangen. Zwei Theorien der Besiedlung werden derzeit angenommen. Bonavia und Monge (1999) nehmen zwei Besiedlungsrouten an, eine führte in das Amazonasbecken, die andere über die Anden in den Süden. Dillehay (2000) geht von einer Besiedlungsroute entlang des pazifischen und atlantischen Ozeans aus. Nachweisbar ist heute eine Ausbreitung der Proto-ArawakenKultur von Norden bis Süd-Westen und eine Ausbreitung der Tupian-Kultur in den SüdOsten (Crawford 1998). Das Holozän stellte durch den einsetzenden klimatischen Wandel 
neue Herausforderungen an die Jäger- und Sammler-Kulturen. Das frühe Holozän war geprägt von einer Neuentwicklung adaptiver Strategien. An den Küsten entwickelten die Bewohner neue Techniken des Fischfangs, was mit dem Ansteigen des Meeresspiegels assoziiert werden kann (Marchant et al. 2004). In den Anden entsteht eine koevolutive Beziehung zwischen den Menschen und den dort natürlich vorkommenden NeuweltCamelidae (Scheinsohn 2003). Die Artefakte dieser Zeit veränderten sich und repräsentieren damit die Entwicklung neuer Technologien. Um 5000 v. Chr. verändert sich die Bestattungspraxis und die ersten fardo funerario (Mumienbündel) entstanden. Das späte Holozän zeichnet sich durch die Ausbildung immer komplexerer Gesellschaftsformen aus. Der Austausch von Waren entstand (z.B. Obsidian und Spondylus; Smith and Schreiber 2005), Agrikultur (ca. 6000 v. Chr.) und Pastoralismus (ca. 4000 v. Chr.) entwickelten sich und die kulturellen Überreste zeigen eine Vielfalt der sozio-kulturellen Organisation in SüdAmerika. Die Sesshaftwerdung im Süd-Zentral-Andenraum kann für das Archaikum (2000 v. Chr.) belegt werden (Aldenderfer 1989). Abbildung 4 zeigt einen Überblick einiger Kulturen im Westen Südamerikas ab 1200 v. Chr. .

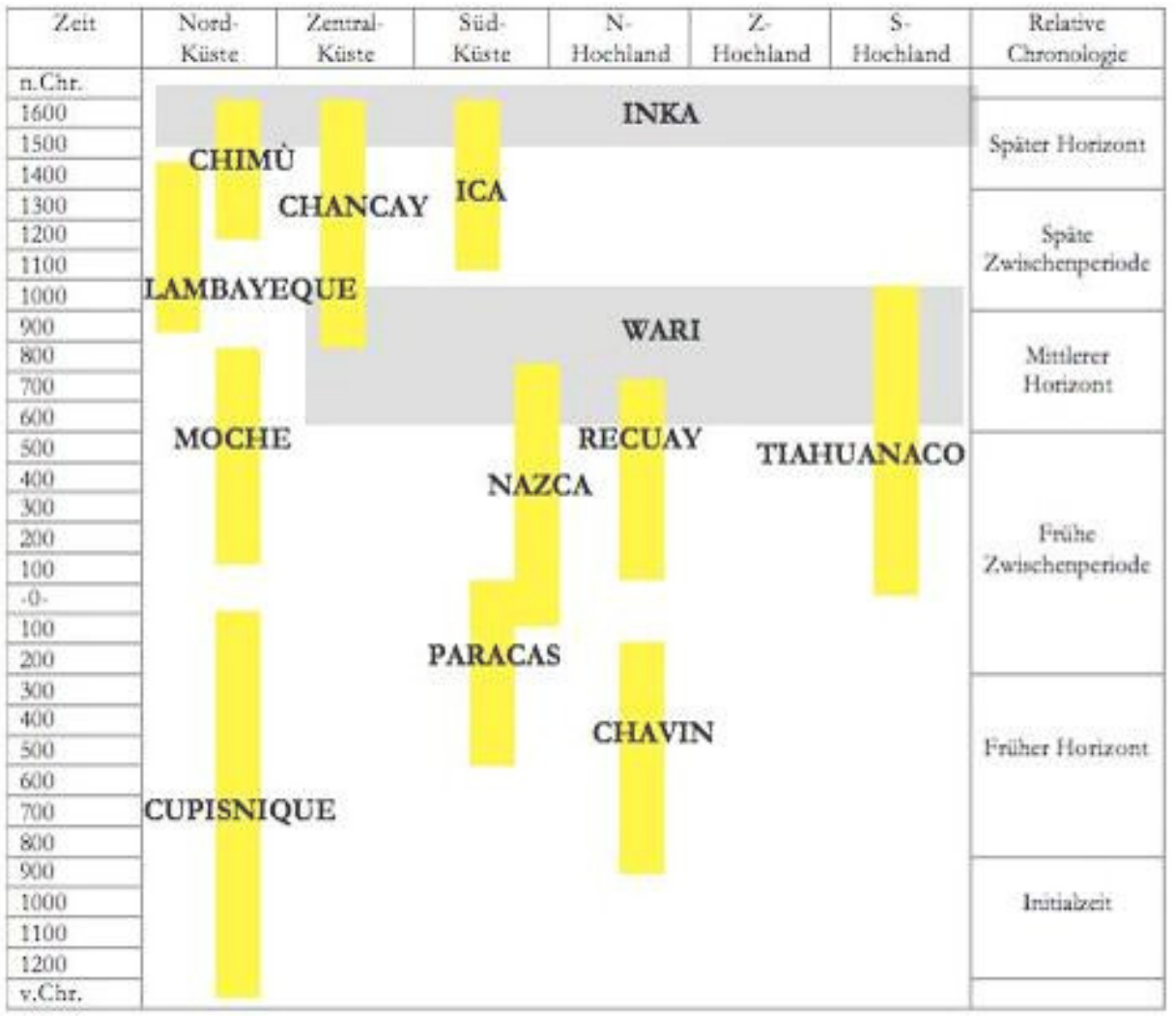

Abbildung 4: Kulturen im Westen Südamerikas im späten Holozän (nach Benson und Cook 2001)

An der Küste Perus entstanden noch vor Ausprägung der Agrikultur große Tempelanlagen, die auf ein komplexes politisches und religiöses System hinweisen (Moseley 1972). Die 
Aufgabe dieser Ritual-Komplexe erfolgte ca. 1000 v. Chr., an den Bauten lassen sich Verstärkungen nachweisen, die vermutlich vor Schlamm-Lawinen schützen sollten.

Die Region um den Titicaca-See ist seit ca. 10000 Jahren besiedelt. Zunächst durch JägerSammler-Kulturen, die ab ca. 2000 v. Chr. sedentär wurden. Ab 800 v. Chr. entwickelten sich Stämme und die Region war geprägt von dynamischen Prozessen, so dass für manche Populationen die Staaten-Definition getroffen werden kann (Stanish 2006). Die TiahuanacoKultur entwickelte sich aus diesen kleineren Gruppen und wurde zum Königreich. Die Subsistenzstrategie waren Agrikultur (ab ca. 800 v. Chr.) und intensive Herdenhaltung von Neuwelt-Camelidae. Die Domestikation des Lamas wird für diese Region ab ca. 5000-4000 v. Chr. angenommen (Wheeler 1995). Die Besiedlung der See umgebenden Region war abhängig von dessen Wasserstand und es konnten für verschiedene ökologische Bedingungen angepasste Strategien der Agrikultur nachgewiesen werden (Stanish 2006). Für die Tiahuanaco-Kultur ist keine militärische Territorialkontrolle zu belegen (Smith and Schreiber 2006). Der Untergang der Tiahuanaco-Kultur wird mit einer lang anhaltenden Dürre assoziiert (s. Abb. 23, Brooks 2006).

Die Siedlungsgeschichte Süd-Amerikas ist besonders für die Hochkulturen (Inka, Tiahuanaco, Wari) gut erforscht. Andere Kulturen wie z.B. die Nasca (s. Kap. 1.4) waren bis vor einigen Jahren nur bruchstückhaft erschlossen.

\subsection{Domestikation}

Domestikation bezeichnet den Prozess der intentionellen Zähmung und Zucht wilder Tiere und Pflanzen. Die Subsistenzstrategie die auf Domestikation von Tieren beruht wird als Pastoralismus bezeichnet. Auf Domestikation von Pflanzen beruhend, wird sie als Agrikultur bezeichnet.

Die biologische Definition sieht als Hauptkriterium der Domestikation die Zuchtkontrolle (also die Isolation von der Wildpopulation). Die soziale Bedeutung der Domestikation äußert sich in der Interaktion zwischen Menschen, bei der Tiere als Vehikel dienen (Russel 2002).

Bereits 1883 beschrieb Darwin in dem Werk "The variation of Animals and Plants under Domestication" die Veränderungen und Variabilitäten domestizierter Spezies. Er erkannte, dass neben der artifiziellen Selektion durch den Menschen auch natürliche Selektion zum Tragen kommt. Die artifizielle Selektion beschrieb er als unbewusst, da Tiere oder Pflanzen nicht nach ihrer Fitness, sondern nach Vorlieben, die das äußere Erscheinungsbild betreffen, ausgewählt wurden. Er beobachtete auch, dass der Prozess der Domestikation kein schneller 
geradliniger Erfolgsweg wäre, sondern stetigen Rückschlägen durch Reversionen zu ursprünglichen Charakteristika ausgesetzt sei. Er sah den Prozess der Domestikation als zeitaufwendigen Prozess. Die so entstandenen Varianten seien als Rassen zu bezeichnen, die eine große Variabilität in homologen Merkmalen aufweisen können (Darwin 2001).

Der Prozess der Domestikation enthält folgende Schritte: Abtrennung einer kleinen Gruppe von der Wildform, Zähmung und Habituation in Siedlungsnähe. Durch die neue Umgebung wirkt natürliche Selektion, artifizielle Selektion wirkt durch den Menschen (ökonomisch, kulturell oder ästhetisch motiviert). Die letztendlich sichtbare Veränderung setzt durch den genetischen Wandel ein (Clutton-Brock 1999).

Die meisten domestizierten Tiere weisen ähnliche Merkmalsveränderungen auf (Trut et al. 1999):

- Veränderung der Körpergröße zu einem Extrem (sehr groß oder sehr klein)

- Veränderungen der Haarstruktur (lockiger, kürzer oder länger)

- Veränderung der Haarfarbe (hohe Variabilität und Piebaldie)

- Veränderung der Schwanzform (Ringelschwänze, kürzere Schwänze)

- Verlust der Saisonalität

- frühere Maturität

- Prognathie

- dicke Fettschicht unter der Haut (Clutton-Brock 1999)

- Reduktion der Hirngröße und Reduktion der Schädelgröße (Kruska 2005)

- Retention juveniler Merkmale in adultem Zustand

Belyaev (1978) konnte diese Veränderungen in der Erst-Domestikation von Füchsen nachweisen. Es bedurfte 15-20 Generationen, bis die Füchse als domestiziert zu betrachten waren.

Nur rund zwanzig der heute existierenden Säugetier-Arten gelten als domestiziert, domestizierte Vogel-Arten gibt es sogar nur zehn, was proportional gesehen, gemessen an der Artenzahl, sehr wenig ist (Mignon-Grastreau 2005). In Abbildung 5 sind die wichtigsten domestizierten Arten und die Regionen ihrer Erstdomestikation verzeichnet. 


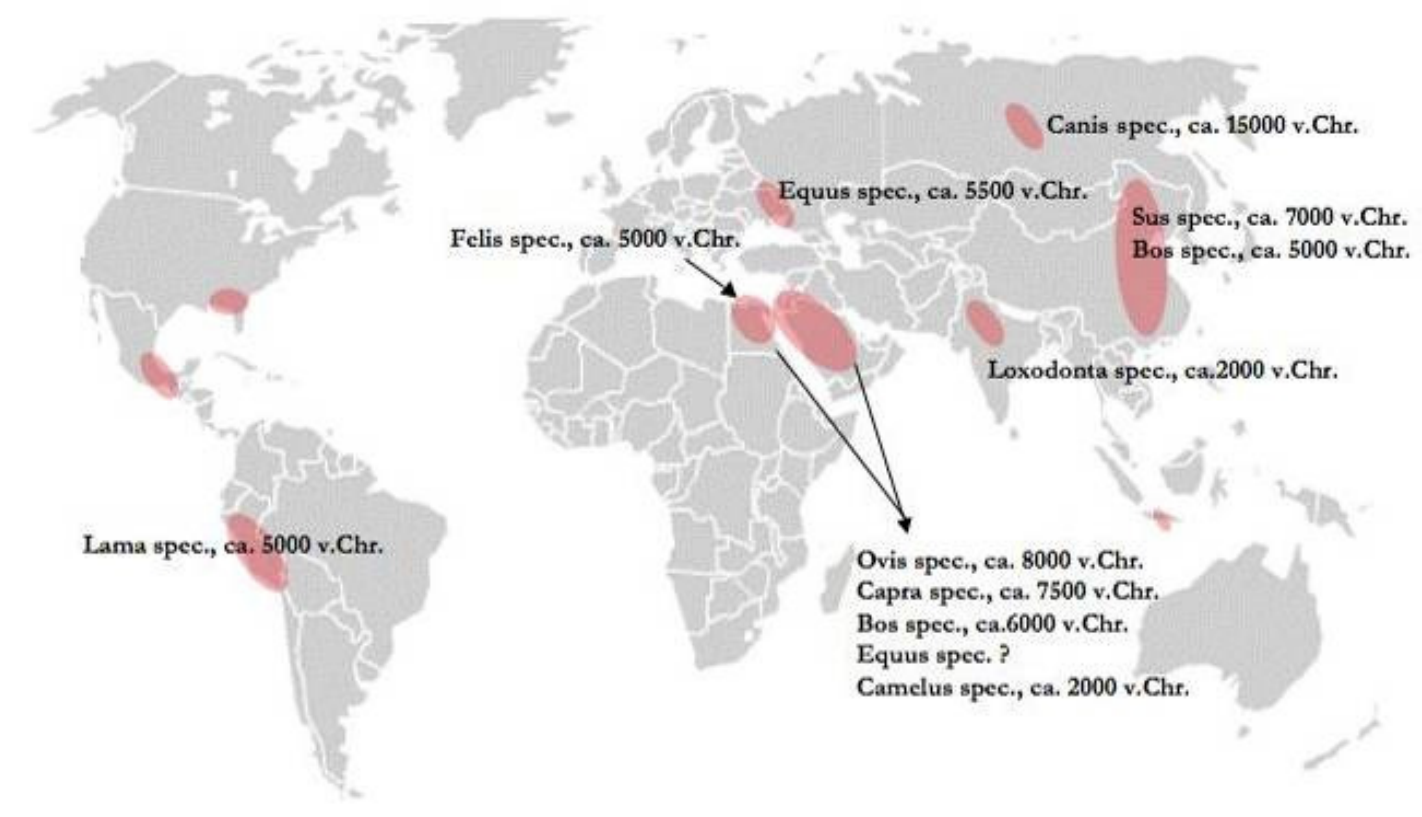

Abbildung 5: Domestikationszentren und Zeitpunkt der Domestikation einiger Säugetierarten (nach CluttonBrock 1999)

Die Begründung für die Domestikation so weniger Spezies liegt in den Charakteristika der Spezies selbst. Nach Diamond (2002) wird eine Spezies nicht domestiziert, wenn sie:

- $\quad$ einer Ernährung bedarf, die nicht vom Menschen gewährleistet werden kann

- langsame Wachstumsrate und Tragezeiten aufweist

- widerspenstiges Verhalten zeigt

- Sterilität in Gefangenschaft aufweist

- sich keinen sozialen Hierarchien unterwirft und

- $\quad$ eine Tendenz zur Panik in Kontakt oder Gefangenschaft zeigt.

Eine weitere Frage ist die nach der Ursache der Domestikation, denn der Mensch existierte bereits 200000 Jahre ohne Domestikation. Diamond (2002) sieht die Ursache der Tierdomestikation in der Extinktion großer Mammalia am Ende des Pleistozäns und die Entwicklung von Lagerungsstätten, die zu einem Wachstum der Populationen führte. Uerpmann (1996) dagegen sieht den Prozess eher als Zufallsereignis. Durch den klimatischen Wandel im frühen Holozän wurden die Lebensräume enger und Mensch und Tier lebten in kleineren Nischen zusammen. Die Konstellation der Lebensumstände führte so zunächst zu einer Symbiose, auf welche der Mensch wie z.B. mit der Aufzucht junger Tiere reagierte. Die Kenntnis über die Aufzucht konnte so weiter entwickelt werden und Domestikation konnte entstehen. Ingold (1996) sieht Domestikation als Reflektion einer ansteigenden Abhängigkeit 
von Mensch und Tier. Der Prozess ist nicht als geplant zu betrachten, sondern ist ein Resultat des Menschen aus seiner natürlichen Umgebung heraus. Die Aufzucht von Tieren ist nach ihm eine adaptive Anpassung.

Was auch immer die Ursachen für die Entscheidung zur Aufzucht von Tieren herbeiführte, klar ist, dass dieser Übergang zu verschiedenen Zeiten in verschiedenen Regionen unabhängig voneinander vollzogen wurde. In anderen Regionen dagegen wurde nie domestiziert. Dieser Unterschied liegt wohl maßgeblich an den Umständen denen eine Population ausgesetzt ist. Groh (1999) sieht die Begründung hierfür in der sozialen Logik von Populationen, die über die gewählte Subsistenzökonomie entscheidet, die wiederum auf Mußepräferenzen und Risikominimierungsstrategien zurückzuführen seien. Auch diese Theorie beruht letztendlich darauf, dass Entscheidungen über die Lebensart von den herrschenden Umweltbedingungen abhängen.

Nach Clutton-Brock (1999) können die heute als domestiziert bezeichneten Arten in zwei Großgruppen unterteilt werden: „Partner“ (Canis spec., Ovis spec., Capra spec., Sus spec., Bos taurus, Bos indicus und Equus spec.) und „Ausgebeutete Gefangene“ (Loxodonta spec., Felis spec., Lama spec., Camelus spec, Rangifera spec., Bos frontalis, Bos gaurus, Bos javanicus, Bos grunniens, Bubalis bubalus, Oryctolagus spec. und Mustela spec.). Partner zeichnen sich durch eine starke phänotypische Abweichung von der Wildform aus, die durch starken artifiziellen Selektionsdruck hervorgerufen wurde. Ausgebeutete Gefangene dagegen, ähneln dem Wild-Typus. Die natürliche Selektion wirkt deutlich stärker als die artifizielle, da auf die Paarung der Tiere wenig oder kein Einfluss genommen wird. Darüber hinaus zeigen ausgebeutete Gefangene meist eine optimale Anpassung an eine harsche Umwelt (z.B. Höhenadaption der Lama spec., Wüstenadaption Camelus spec.).

Die genetische Untersuchung lebender Individuen domestizierter Spezies kann Aufschluss über die Abstammung und einen Hinweis auf evt. Stammformen geben. Mitochondriale DNA eignet sich aufgrund ihrer gegenüber autosomalen DNA höheren Mutationsrate besonders für solche Untersuchungen (Tapio et al. 2003). Jedoch enthalten diese Ergebnisse keine Auskunft über den Zeitpunkt der Domestikation. Des Weiteren ergeben sich durch Rückkreuzungen, Hybridisierungen und Inzucht genetische Muster, die meist einen deutlich längeren Domestikationszeitraum vermuten lassen (Vila et al. 2005). Anhand archäologischer Funde dagegen sind zeitliche Einordnungen des Auftretens domestizierter Varianten möglich. Indirekte Merkmale können die Überreste von Pferchen, Speicheranlagen und Technologien 
sein (Zeder et al. 2006). Direkte Merkmale sind die Veränderungen der tierischen Überreste. Nach Legge (1996) sind fünf Merkmale zu beurteilen:

- Kriterium der Form und Größe von Knochen (Größenverminderung, Frakturen, Belastungsspuren etc.).

- Biogeographische Merkmale, wie das Vorkommen von Speziesüberresten außerhalb ihres natürlichen Verbreitungsgebiets.

- Paläogeographische Merkmale, wie die Anhäufung junger männlicher Tiere in Siedlungen.

- Merkmal der Speziesdominanz, d.h. eine Spezies tritt vermehrt in Siedlungen auf.

Anhand dieser Merkmale konnte zum Beispiel der Beginn der Domestikation der Ziege vor ca. 9500-10000 Jahren in den Zagros Bergen (Iran) belegt werden (Zeder und Hesse 2000).

Die Untersuchung der DNA von tierischen Überresten stellt eine weitere Zugangsmöglichkeit dar. Anhand der genetischen Muster können Ähnlichkeiten bzw. Transitionen zu heute lebenden Populationen (wild- und domestizierte Formen) nachgewiesen werden. Dank solcher Analysen kann der Status der Domestikation in einer Spezies zu einem bestimmten Zeitpunkt aufgedeckt und mögliche Abstammungen belegt oder widerlegt werden. Keyser-Traqui et al. (2005) konnten anhand der Untersuchung des $d$-loop in Überresten skythischer Pferde (3. Jh. v. h.) belegen, dass diese keine Ähnlichkeiten zum Przewalski-Pferd aufweisen. Die gefundenen Haplotypen sind jedoch in Züchtungen aus der Mongolei sowie Anatolien vertreten, so dass der geographische Ursprung der skythischen Pferde weiterhin unbekannt bleibt. Die Ergebnisse deuten jedoch auch auf eine mehrfache Domestikation des Pferdes hin.

Domestikation ist also der Ausdruck kultureller Veränderung, hin zu einer neuen Überlebensstrategie. Sie bewirkt, neben biologischen Konsequenzen für das Domestikat, auch eine Vielzahl biologischer Anpassungen (z.B. Laktosepersistenz) und Neuerungen für den Menschen. Die Genese einer Vielzahl von Krankheiten (z.B. Tuberkulose) war erst durch den engen Kontakt zwischen Vieh und Mensch und einer zunehmenden Populationsgröße möglich (Diamond 2002). Die ernährungsphysiologischen Vorteile der Agrikultur und des Pastoralismus führten jedoch zu einer breiten Adaption dieser Strategien (s. Abb. 6). Neben punktualistischer Neuerfindung dieser Strategien, fand eine Diffusion nach Europa statt. Anhand archäologischer Funde kann eine Ausbreitung der Agrikultur von Südwest-Asien nach Europa, mit einer Geschwindigkeit von ca. $1 \mathrm{~km}$ pro Jahr, belegt werden (Cavalli-Sforza 1996). Der Pastoralismus verbreitete sich wahrscheinlich durch die Migration nomadischer 
Gruppen. Der Übergang vom Jäger-Sammler-Dasein zur sedentären Lebensweise war kein einseitiger Prozess. Vielmehr ist davon auszugehen, dass vielerorts Jäger-Populationen in Dependenz von Populationen die Agrikultur betrieben, existierten (Gronenborn 1999). Bis heute existieren diese Mischformen der Subsistenzökonomie. In Abbildung 6 ist der Rückgang der Jäger-Sammler-Populationen in den letzten 10000 Jahre dargestellt.

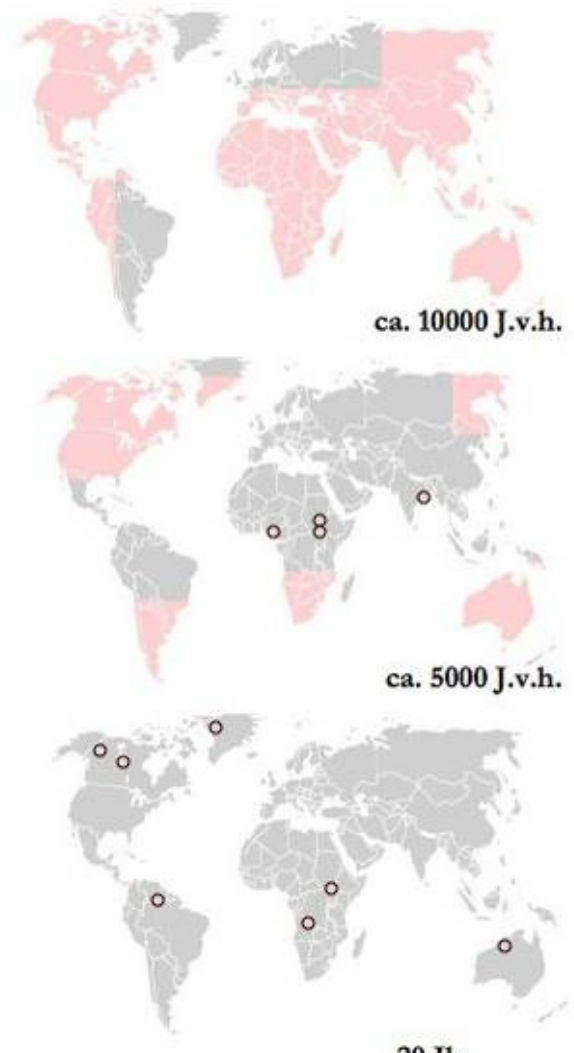

20.Jh.

Abbildung 6: Rückgang der Jäger-Sammler-Kulturen seit der Neolithisierung (nach Clutton-Brock 1999). Legende: rosa $=$ Subsistenzstrategie beruht auf Jagd und Sammeln

\subsection{Ancient DNA}

Als ancient DNA (aDNA) wird jene DNA bezeichnet, die aus Geweben toter Organismen gewonnen wird und an der Degradierung gewirkt hat.

Die Analyse alter DNA kann für viele Fragen biologischer oder sozi-ökologischer Natur einen Zugang bieten, insbesondere dann, wenn schriftliche Quellen fehlen. So konnte z.B. für menschliche Überreste von 38 Individuen aus einer bronzezeitlichen Höhle eindeutig eine verwandtschaftliche Beziehung, über drei Generationen hinweg, belegt werden (Schilz 2006). Auch Verwandtschaft auf höherer Ebene lässt sich nachweisen, so konnte z.B. für das Mammut eine engere Verwandtschaft zum asiatischen als zum afrikanischen Elefanten belegt 
werden (Krause et al. 2005). Auch wichtige Beiträge zum Prozess der Domestikation des Rindes (Bollongino et al. 2003) oder der Evolution des Homo sapiens (Ovchinikov et al. 2000) konnten anhand von aDNA-Untersuchungen erbracht werden.

Das Ausmaß der Degradierung der DNA eines verstorbenen Individuums hängt maßgeblich von seinem Liegemilieu ab. So ist z.B. die Erhaltung der DNA in Proben aus dem Permafrost (Römpler et al. 2006) deutlich besser, als z.B. von Proben die einem ariden Klima entstammen. Optimal sind eine kühle Temperatur, ein relatives Maß an Feuchtigkeit und die Abwesenheit von Mikroorganismen (Hummel 2003). Es gibt mehrere Angaben zur zeitlichen Überdauerung von aDNA. Willerslev und Cooper (2005) geben einen Zeitraum von $10 \mathrm{kyr}$ für die Überdauerung von 100-500bp in temperierten Zonen an, in Permafrost ist dieser Zeitraum auf 100 kyr ausdehnbar. Marota et al. (2004) geben an, dass DNA in Papyrus nach 532-672 Jahren nicht mehr zu analysieren ist. Hofreiter et al. (2001) schlagen einen generellen Überdauerungszeitraum von nicht mehr als 100000 Jahren für DNA vor. Diese Studien berücksichtigen meist nur einen bestimmten Faktor der Degradierung, Willerslev und Cooper beziehen sich hauptsächlich auf Temperatur, Marota et al. betrachten ausschließlich Papyrus bei Lagerung in temperierten Regionen. Eine universelle Studie zum Prozess des DNAAbbaus nach dem Tod eines Individuums existiert nicht, so dass im Prinzip nur der Versuch zeigen kann, ob ein (prä-)historisches Objekt noch analysefähige DNA enthält.

Die Prozesse der Degradierung spiegeln sich in der Quantität und der Qualität der aDNA wieder. Häufig sind quantitativ in aDNA-Extrakten ca. 1-10 Kopien intakter autosomaler Ziel-DNAs vorhanden (Westenthanner 2007). Mitochondriale DNA dagegen dürfte in einem etwas höheren Maße vorliegen, aber auch die Menge an mt-DNA in aDNA-Extrakten ist gering. Der aDNA-Erhaltungsgrad ist auch abhängig vom beprobten Skelettelement (Kleindorp 2006, Adler 2007) und Gewebetyp. Diese geringe Menge an authentischer alter DNA zeigt die Anfälligkeit für Kontaminationen mit rezenter DNA. In der forensischen DNA-Analytik können z.B. selbst einzelne Epithelzellen zur DNA-Analyse und Täterüberführung ausreichen (Schmidt pers. comm.). Wenn solche Kleinstmengen genügend sind, um z.B. vollständige genetische Fingerabdrücke zu liefern, dann sind sie zugleich potentielle Kontaminanten, die das eigentliche authentische Signal der zu untersuchenden alten Probe überlagern oder sich mit diesem vermischen können.

Die qualitativen und quantitativen Unterschiede zwischen aDNA und rezenter DNA beruhen auf Degradierungsprozessen. Prozesse, die qualitativ und quantitativ ersichtlich werden, sind 
Hydrolyse, die zu einer starken Fragmentierung führt, sowie Alkylierung und so genannte Maillard-Reaktionen, die starke Verknüpfungen innerhalb und unter den verschiedenen DNA-Strängen bewirken und so die Amplifikation der DNA verhindern (s. z.B. Willerslev und Cooper 2005, Hummel 2003). Die jedoch wahrscheinlich gravierendsten Prozesse, die rein qualitativer Natur sind, sind Oxidation und Hydrolyse einzelner Basen (Deaminierung), da diese Prozesse direkt auf die Sequenz wirken und damit zu falsch-positiven Ergebnissen in der Analyse führen können (Höss et al. 1996). Hofreiter et al. (2001) konnten in rund 10\% ihrer analysierten PCR-Produkte Substitutionen (Basenaustausche) feststellen. Binladen et al. (2006) geben an, dass ein Basenaustausch von Cytosin durch Thymin am häufigsten zu beobachten sei und kein Unterschied in der Substitutionsrate zwischen mitochondrialer und chromosomaler DNA feststellbar wäre. Gilbert et al. (2003) untersuchten die Wirkung der Deaminierung im mitochondrialen Genom und stellten fest, dass diese besonders häufig im nicht kodierenden Bereich zu beobachten ist. Sie konnten so genannte hotspots, also Positionen die deutlich häufiger mutieren als anderen, ausmachen.

Ein häufig auftretendes Phänomen in aDNA-Analysen ist der so genannte allelic dropout. Dies kann auf den hohen Degradierungsgrad zurückgeführt werden. Entweder das zu amplifizierende Produkt, oder der Bereich in dem die Primer ansetzen, liegt nicht mehr intakt vor. Dieses Phänomen jedoch als Authentizitätskriterium anzuführen (Willerslev und Cooper 2005) ist nicht sinnig, da auch in lebenden Personen allelic dropout beobachtet werden kann. Hier beruht das Phänomen meist auf Mutationen im Bereich der Primer-Bindungsstellen. Auch tendiert aDNA aufgrund der geringen Menge intakter DNA zu Stotterartefakten. Bei der Auswertung von aDNA müssen daher bestimmte Kriterien angewandt werden, die eine sichere Typisierung des jeweiligen Individuums ermöglichen (s. z.B. Clayton et al. 1998)

Die dargestellten Prozesse zeigen, dass die Analyseverfahren den spezifischen Bedingungen der aDNA angepasst sein müssen. Im Folgenden werden Lösungsstrategien zur Vermeidung Falsch-Positiver sowie dem geringen DNA-Gehalt Rechnung tragende Analysestrategien, die in dieser Arbeit zum Tragen gekommen sind, tabellarisch vorgestellt (Tab. 1). 
Tabelle 1: Problematik der a-DNA Analytik und Lösungsstrategien

\begin{tabular}{|c|c|c|}
\hline Problematik & Lösungsstrategien & Literatur \\
\hline \multirow[t]{7}{*}{$\begin{array}{l}\text { Kontaminations- } \\
\text { anfälligkeit }\end{array}$} & $\begin{array}{l}\text { Tragen von Einmalhandschuhen, Mundschutz, Schutzbrille und } \\
\text { Schutzkittel beim Umgang mit Probenmaterial und DNA-Extrakten }\end{array}$ & $\begin{array}{l}\text { Hummel } 2003 \text { S. } \\
134, \text { Willerslev und } \\
\text { Cooper } 2005\end{array}$ \\
\hline & Großflächiges Abtragen der Probenoberflächen & \\
\hline & Strikte Trennung von prä- und post PCR Bereichen & $\begin{array}{l}\text { Hummel } 2003 \mathrm{~S} . \\
133\end{array}$ \\
\hline & $\begin{array}{l}\text { Dekontaminierung von Arbeitsflächen (Chlor) und Reaktionsgefäßen } \\
\text { (UV-Bestrahlung) sowie allen Gegenständen (Pipettenspitzen etc.) die } \\
\text { mit dem Probenmaterial bzw. der aDNA in Verbindung kommen }\end{array}$ & $\begin{array}{l}\text { Willerslev und } \\
\text { Cooper } 2005 \\
\text { Hummel } 2003 \mathrm{~S} \text {. } \\
136 \mathrm{ff}\end{array}$ \\
\hline & $\begin{array}{l}\text { Multiplex-Typisierung erhöhen die Wahrscheinlichkeit den Eintrag } \\
\text { von Fremd-DNA zu erkennen }\end{array}$ & Hummel et al. 2000 \\
\hline & $\begin{array}{l}\text { Mehrfachamplifikation aus unabhängigen DNA-Extrakten zur } \\
\text { Konsistenzüberprüfung der Ergebnisse }\end{array}$ & Montiel et al. 2001 \\
\hline & Mitführen von Leer-Kontrollen im Verhältnis 1:5 in jeder PCR & $\begin{array}{l}\text { Willerslev und } \\
\text { Cooper } 2005\end{array}$ \\
\hline \multirow[t]{4}{*}{ Degradierung } & $\begin{array}{l}\text { Amplifikation von kurzen Produkten (bis } 600 \text { bp möglich, jedoch } \\
\text { meist deutlich kürzer) und Anpassung der PCR-Parameter }\end{array}$ & $\begin{array}{l}\text { Hummel } 2003 \mathrm{~S} . \\
102\end{array}$ \\
\hline & $\begin{array}{l}\text { Mehrfachamplifikation aus unabhängigen DNA-Extrakten zur } \\
\text { Konsistenzüberprüfung der Ergebnisse (Aufdeckung Falsch-Positiver } \\
\text { und Falsch-Negativer Ergebnisse) }\end{array}$ & Montiel et al. 2001 \\
\hline & $\begin{array}{l}\text { Multiplex-Amplifikation erhöhen die Wahrscheinlichkeit } \\
\text { Degradierung (wie allelic dropout o.ä.) zu erkennen }\end{array}$ & Hummel et al. 2000 \\
\hline & $\begin{array}{l}\text { Bei Verdacht auf Sequenz-Deaminierungsartefakte Sequenzierung } \\
\text { beider DNA-Stränge }\end{array}$ & Lutz et al. 1996 \\
\hline
\end{tabular}

Neben diesen in Tabelle 1 aufgeführten Handhabungsmöglichkeiten, gibt es eine Vielzahl weiterer Empfehlungen im Umgang mit aDNA (s. z.B. Willerslev und Cooper 2005), von denen nicht alle Anwendung in dieser Arbeit gefunden haben. Ein Vorschlag ist z.B. die unabhängige Reproduktion der Ergebnisse in einem zweiten Labor. Dies ist jedoch unnötig, wenn im ersten Labor bereits alle oben aufgeführten Kriterien befolgt werden. Auch das Klonieren von PCR-Produkten wird als Strategie zur Authentifizierung und Erkennung von Deaminierungsartefakten vorgeschlagen. Ein solches Verfahren ist unnötig, wenn die Amplifikation von aDNA aus unabhängig hergestellten DNA-Extrakten einer Probe erfolgt. Mit dieser Strategie können Deaminierungsartefakte aufgezeigt und die Authentizität belegt werden.

\subsection{Die Nasca-Kultur}

Die Nasca-Kultur existierte von ca. 100 v. Chr. bis 800 n. Chr. . Sie zeichnet sich durch eine eigene Ikonographie, repräsentiert in hochwertiger Keramik und hochwertigen Textilien, aus. Der Ausbreitungsraum erstreckte sich über ein Gebiet von der Paracas Halbinsel bis unterhalb des Río Trancas (s. Abb. 7). 


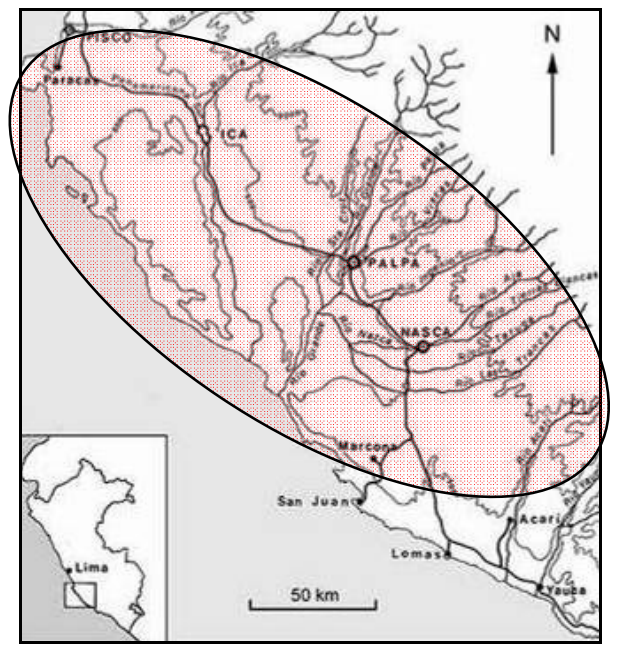

Abbildung 7: Verbreitungsraum der Nasca-Kultur (Quelle: KAAK/DAI)

Von der Pazifikküste bis zur Westkordillere der Anden ist eine Ausbreitung über eine Breite von ca. $100 \mathrm{~km}$ durch Siedlungsreste belegt. In diesem Gebiet konnte eine Siedlungskontinuität im Bereich des Palpa-Tals seit der Initialzeit (1800 v. Chr.) belegt werden. Die Nasca-Kultur entwickelte sich aus der Paracas-Kultur, mit der sie einige Verzierungsmuster der Keramik teilt. Anhand der Ikonographie kann die Nasca-Kultur in acht Phasen unterteilt werden (s. Abb. 6).

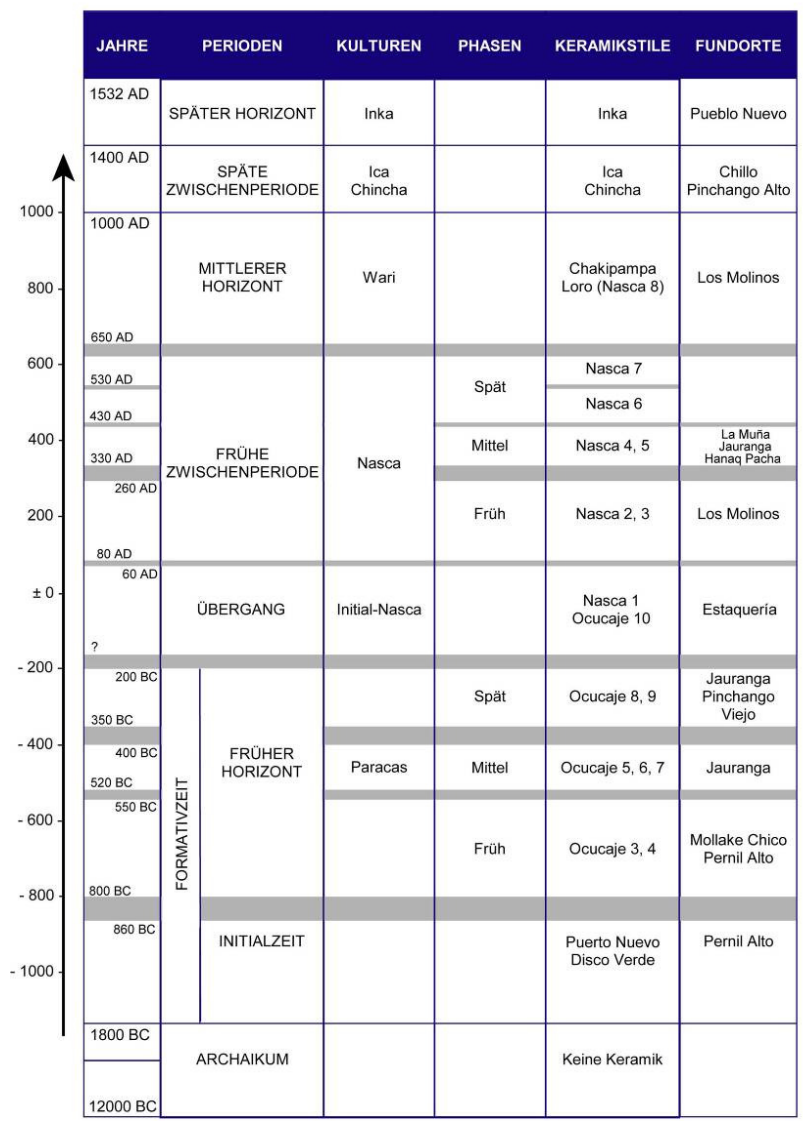

Abbildung 8: Chronologie der Nasca-Kultur (aus Unkel 2006) 
In den Stilen Nasca 1 und 2 stellt sich die Verzierung der Keramik noch als relativ natürlich dar und ähnelt deutlich der Paracas-Keramik. Silverman und Proulx (2002) sehen dies als Zeichen der Bevölkerungskontinuität. In Nasca 3 wandelten sich die Darstellungen auf der Keramik zu übernatürlichen mystischen Wesen, in Nasca 4 wurden vermehrt geometrische Symbole gezeichnet, in Nasca 5 zunehmend anthropomorphe Darstellungen. In Nasca 6 und Nasca 7 entstehen neue Formen und Wesen sowie die Darstellung von Trophäenschädel. In Nasca 8 vereinfachte sich die Bemalung der Keramik und es finden sich überwiegend geometrische Figuren. Rund dreißig Hauptmotive mit ca. 200 Varietäten lassen sich ausmachen, die ab der Phase Nasca 5 eine deutliche Veränderung erfahren haben (Silverman und Proulx 2002).

Die Textilien der Paracas-Kultur und der frühen Nasca-Kultur sind sehr hochwertig, und man kann an ihnen die Thematisierung von Fruchtbarkeit und Transformation ablesen (Frame 2001). Die Textilien in Nasca 3 werden schlichter und die thematische Darstellung findet nun überwiegend auf der Keramik statt (Proulx 2001). Dieser Übergang der textilen Darstellung hin zur keramischen Darstellung wird auf den zunehmenden Bedarf von Ritual-Keramik zurückgeführt (Silverman und Proulx 2002). Die Symbolik der Nasca deutet auf einen animistischen Glauben hin. Mit dem Auftreten neuer ikonographischer Symbole in der Phase Nasca 5 scheint ein zunehmender Fruchtbarkeitskult und das Auftreten kämpferischer Auseinandersetzungen assoziiert zu sein.

Als Schlüsselelement der Nasca-Kultur gelten die Geoglyphen. Diese sind großflächige Oberflächenzeichnungen die durch das Umordnen von Oberflächen-Gestein entstehen. Während der Paracas-Kultur wurden Geoglyphen überwiegend additiv erstellt, d.h. es wurden Steine aufgeschüttet um ein bestimmtes Bild zu erzielen. Während der Nasca-Kultur wurden die Geoglyphen substrativ, durch die Wegnahme der dunklen Oberflächen-Steine, angefertigt. Neben biomorphen Figuren, wie Katzen, Affen u. ä., existieren überwiegend geometrische Figuren und Linien (s. Abb. 9). Ein Übergang der biomorphen Figuren, hin zu großen geometrischen Formen ist ab Nasca 2 zu belegen. 


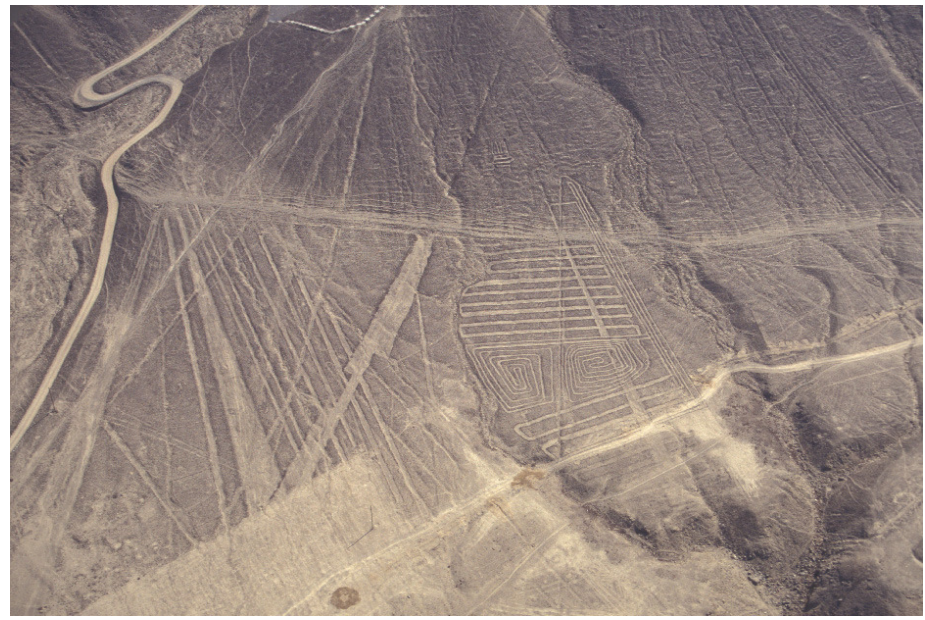

Abbildung 9: Trapez- Geoglyphe sowie mehrere einfache Linien (Quelle: KAAK/DAI)

Der Sinn und Nutzen der Geoglyphen ist ein umstrittenes Thema: Paul Kosoz sprach von einem großen astronomischen Buch, andere deuteten die Zeichnungen als religiöse Pfade (ceques). Die Untersuchungen, die Teil des Gesamtprojektes Nasca waren, zeigen jedoch deutlich eine Assoziation mit religiösen Handlungen und einem Wasserkult (Fruchtbarkeitskult, Lambers 2006). Darüber hinaus können sie als soziale Gebilde verstanden werden (Silverman und Proulx 2002). Die in den Geoglyphen dargestellten biomorphen Figuren sind auch als Petroglyphen (s. Abb.10) wieder zu finden.

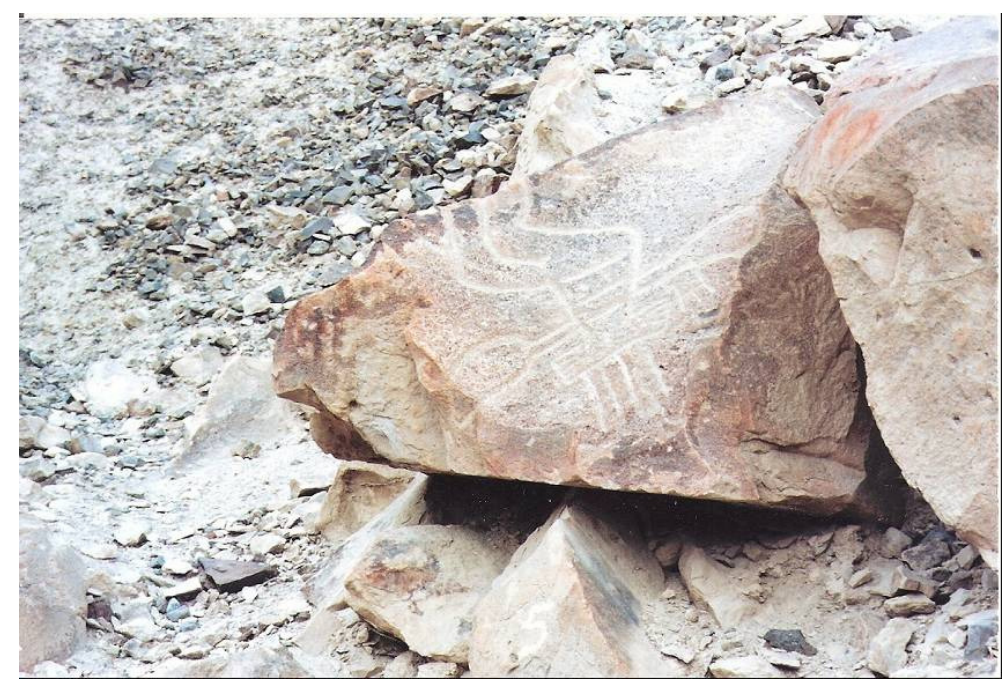

Abbildung 10: Petroglyphe in Chichictara (Palpa-Tal)

Die rituellen Handlungen der Nasca zeichnen sich durch eine Totenfürsorge (Isla und Reindel 2006) und rituelle Zentren (Silverman und Proulx 2002) aus. Die rituellen Zentren sind durch Großbauten gekennzeichnet, in denen Feinkeramik, Textilien, Masken, spezielle Ornamentik und Musikinstrumente als Artefakte zu finden sind. 
Die ökologischen Bedingungen zur Zeit der Nasca-Kultur stellten eine große Herausforderung für die Bewohner dar. In dem Verbreitungsgebiet der Nasca-Kultur können heute sechs Lebensräume unterschieden werden, die littorale Zone (Küstenstrang), die chala (500m ü. NN., Agrikulturfläche), die yunga (Quebrada über der chala 500-2300 ü. NN., Hauptsiedlungszonen), die lomas (Wüstenrand zur Andenkordillere im Winter, LomasVegetation aufgrund leichtem Niederschlags), die pampa galeras (puna über 4000 ü. NN., Camelidae) und die tieferen Taloasen (Agrikultur). Insgesamt kann das Gesamtgebiet als subtropische Halbwüste bezeichnet werden. Solche Gebiete sind besonders anfällig gegenüber hygrischen Veränderungen (Eitel 2006). Die Verschiebung des Wüstenrandes der Atacama ca. 2000 v. Chr. scheint der Auslöser des Übergangs von der akeramischen archaischen Periode zur Initialzeit zu sein (Eitel 2006). Eine Häufung der Siedlungen zu diesem Zeitpunkt in den Taloasen ist festzustellen (Reindel pers. comm.). Die Taloasen boten weite Flächen für die Agrikultur. Überwiegend wurden Mais, Erdnüsse, Bohnen, Manioc und Kartoffeln sowie Baumwolle angebaut (Silverman und Proulx 2002). Die Haltung von Camelidae in der Historie der Palpa-Region ist derzeit nicht zu belegen, jedoch repräsentieren sie das am Häufigsten genutzte Säugetier der Nasca-Zeit. Der Warenhandel mit Hochlandkulturen (Obsidian) ist ebenso belegt wie der Handel mit maritim-subsitenten Populationen (Spondylus-Muschel).

Die soziale Organisation der Nasca-Kultur ist nicht eindeutig geklärt. Silverman und Proulx (2002) gehen von der Organisation in ayllus aus. Dies sind Gruppen verwandter Personen, in denen die hierarchische Struktur abhängig von der Abstammung ist. Ayllus wären also nach Service (1971) als Stämme einzuordnen. Der Fundort Cahuachi gilt als religiöses Zentrum der frühen Nasca-Kultur. Nach Silverman und Proulx (2002) zeichneten sich die einzelnen Siedlungen durch das Teilen der gleichen religiösen Vorstellung unter getrennter soziopolitischer Organisation aus. In Nasca 3 kann jedoch für den Fundort Los Molinos eine klare Stratifizierung belegt werden (Isla und Reindel 2006). Zum Ende der Nasca 3 Phase wurde Los Molinos aufgegeben. Silverman und Proulx (2002) bezeichnen die Nasca 4 Phase als sozio-politisches Vakuum und sehen erst ab Nasca 5 einen starken Kulturwandel. Das Auftreten der patriarchalischen Symbolik und das Auftreten einer Stil-Vielfalt, deuten sie als Anzeichen für einen kulturellen Bruch, der mit einem Zerfall in kleine Teilpopulationen korreliert. Isla und Reindel (2006) dagegen sehen in der Phase Nasca 5 eine deutliche Stratifizierung der Gesellschaft, die besonders am Fundort La Muña deutlich wird. Sie deuten den Fundort Cahuachi als politisches Zentrum, das durch La Muña abgelöst wurde und interpretieren die soziale Struktur der Nasca-Kultur als Stammesfürstentum, welches sich zum primitiven Staat entwickelt haben könnte. 
Die Siedlungsdynamik während der Nasca-Zeit im Palpa-Tal sowie der Untergang der NascaKultur, können mit Umweltveränderungen in Verbindung gebracht werden. Die Aufgabe der Siedlung Los Molinos erfolgte vermutlich wegen anhaltender Dürre und monsoon-artigen Regenfällen. Die lang anhaltende Dürre um 700 n. Chr. führte wahrscheinlich zum Untergang der Nasca-Kultur (Eitel 2006).

Eine Wiederbesiedlung und Ausbildung urbaner Zentren in der Palpa-Region ist für den Zeitraum um 1200-1400 n. Chr. (LIP) belegt (Unkel et al. 2007). Zu diesem Zeitpunkt herrschte ein deutlich feuchteres Klima und die Region bot erneut eine Landschaft, die für Agrikultur genutzt werden konnte.

\subsection{Neuwelt-Camelidae}

Die Neuwelt-Camelidae sind die größten heimischen Säugetiere des südamerikanischen Kontinents. Sie gehören phylogenetisch zu der Ordnung Artiodactyla, Unterordnung Tylopoda, Familie Camelidae, Unterfamilie Lamini. Ihre Evolution begann im Eozän in Nordamerika (Janis et al. 1993). Die Einwanderung nach Süd-Amerika erfolgte im Pleistozän durch Hemiauchenia (Tamupolama). Im mittleren Pleistozän erfolgte die Entstehung der Formen Lama, Vicugna und Palaeolama. Ein 2 Mio. Jahre alter Fossilfund aus Peru, belegt die Existenz von Vicunjas zu diesem Zeitpunkt. Für sie ist ein größerer Verbreitungsraum als zum heutigen Zeitpunkt belegbar (Salas et al. 2003). Camelidae bildeten eine wichtige Ernährungsbasis für die Jäger-Sammler-Kulturen Südamerikas (Paunero et al. 2002). In Abbildung 11 ist die Evolution der Neuwelt-Camelidae dargestellt.

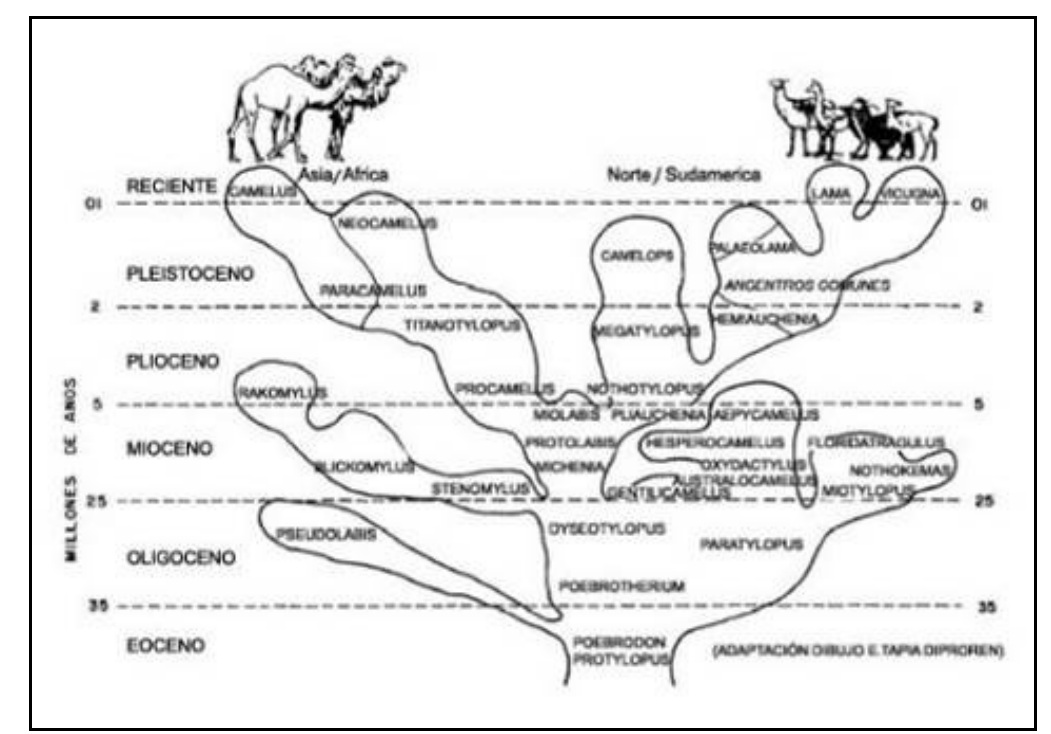

Abbildung 11: Evolution der Gattungen Lama und Vicugna (aus Bonacic 1991) 
Formen der Gattung Palaeolama wanderten wieder nach Nordamerika ein, (Fowler 1998). Heute werden die in Südamerika existierenden Camelidae in zwei Gattungen der Lamini, die Gattung der Lama mit Lama guanicoe (Guanako; Müller, 1776) und Lama glama (Lama; Linné, 1758), und die Gattung Vicugna, mit der Spezies Vicugna vicugna (Vikunja; Molina, 1782,) eingeteilt. Eine vierte Spezies ist anzutreffen, das Lama pacos (Alpaka; Linné, 1758), deren Phylogenetik nicht eindeutig geklärt ist. Lama pacos und Lama glama sind domestizierte Formen. Im Folgenden werden die deutschen Namen verwendet, um den derzeitigen Inkonsistenzen in der taxonomischen Einordnung Rechnung zu tragen.

\section{Charakteristika der Lamini und Taxonomie}

Das Vikunja lebt in Höhen von ca. 3700-4800 $\mathrm{m}$ in den semiariden Graslandschaften und der unfruchtbaren Pampas der Anden. Es erreicht eine Schulterhöhe von ca. 86-96 cm und wiegt zwischen 45-55 kg. Es lebt in strengen Territorien in Gruppen von 2-5 Weibchen und einem Männchen. Außerdem gibt es Herden aus bis zu 100 Männchen. Zwei Subspezies werden derzeit benannt. Zum Einen das Vicugna vicugna mensalis, das in Peru vorkommt und zum Anderen das Vicugna vicugna vicugna, das hauptsächlich in Argentinien anzutreffen ist und darüber hinaus auch in Bolivien existiert (Mengoni Gonalons et al. 2007). Die demographische Expansion erfolgte vermutlich im Pleistozän, als die so genannte aride Diagonale, die sich vom Golf von Guyaquil (Ecuador) bis zur Magellanstraße erstreckt, entstand (Marin et al. 2007). Beide Subspezies sind anhand der Sequenzabfolge im d-loop eindeutig voneinander abzugrenzen (Marin et al. 2007). Das Vikunja weist das feinste Haar der Neuwelt-Camelidae auf, die Fellfarbe ist gelblich hellbraun, der Bauch ist weiß gefärbt.

Das Guanako hat ein weites Verbreitungsgebiet, das von Meersspiegelniveau bis auf $4250 \mathrm{~m}$ Höhe reicht. Seine Lebensräume sind das feuchte archipelago der Tierra del Fuego (Patagonien), die Atacama (N-Chile) und das Strauchland der Anden. Es erreicht eine Schulterhöhe von 110-115 cm und ein Gewicht von 100-120 kg. Die Herdenorganisation ist der des Vikunjas ähnlich, jedoch zeigen Guanakos ein gemäßigtes Territorialverhalten und können über weite Strecken migrieren (Fowler 1998). Derzeit werden vier Subspezies benannt, das Guanicoe guanicoe guanicoe und das Guanicoe guanicoe cacsiliensis, die hauptsächlich im Süden vorkommen, das Guanicoe guanicoe huanacus, das überwiegend im Norden vorkommt und Guanicoe guanicoe voglii, das vornehmlich in den höheren Lage vorkommt (Mengoni Gonalons 2007). Genetisch können nur die Subspezies cacsiliensis und guanicoe unterschieden werden (Gonzales 2006). 
Seine Fellfärbung ist ein helles rot-braun mit einem weißen Bauch, das Gesicht ist schwarz gefärbt.

Das Lama lebt in Höhen von 2300-4000 m. Da es sich bei ihm jedoch um eine domestizierte Spezies handelt, die auch als Tragetier genutzt wird, ist es auch in geringeren Höhen anzutreffen. Sein Lebensraum ist also als kultureller Lebensraum zu verstehen. Es erreicht eine Schulterhöhe von 102-119 cm und ein Gewicht von 113-250 kg. Man unterscheidet die Typen mit starkem Nackenhaar (chaku, lanuda und tapara) und die mit kurzem Nackenfell (ccara und pelada). Seine Fellfarbe reicht von einfarbig, schwarz, braun, oder weiß bis zu vielfarbigen Tieren und es konnten 16 unterschiedliche Fellfarben ausgemacht werden (Campero et al. 2004).

Das Alpaka lebt in Höhen von 4400-4800 m. Bei dieser domestizierten Spezies handelt es sich weitestgehend um einen Wolllieferanten und es ist rund um den Titicaca-See, die Puna NordChiles und Zentral-Peru verbreitet. Es erreicht eine Schulterhöhe von 76-96 cm und ein Gewicht von 55-90 kg. Man unterscheidet zwei Typen anhand der Wollqualität: das buacaya, mit leicht gekräuseltem und gerade herabhängendem Fell, und das suri, das nicht gekräuseltes, jedoch stark gelocktes Fell aufweist. Derzeit sind 22 unterschiedliche Fellfarben am Alpaka festgestellt worden, die entweder einfarbig, oder in Kombination auftreten.

Für alle vier Spezies ist eine extreme Dezimierung der Populationen durch die Spanier belegt. Nach Schätzungen wurden rund $90 \%$ der vorkommenden Bestände ausgelöscht (Wheeler et al. 1995). Dies hatte eine starke Zurückdrängung der Arten in höher gelegene Gebiete zur Folge (Wheeler 1992). Die Verbreitung und die Verdrängung der Camelidae durch die Spanier sind in Abbildung 12 dargestellt. 


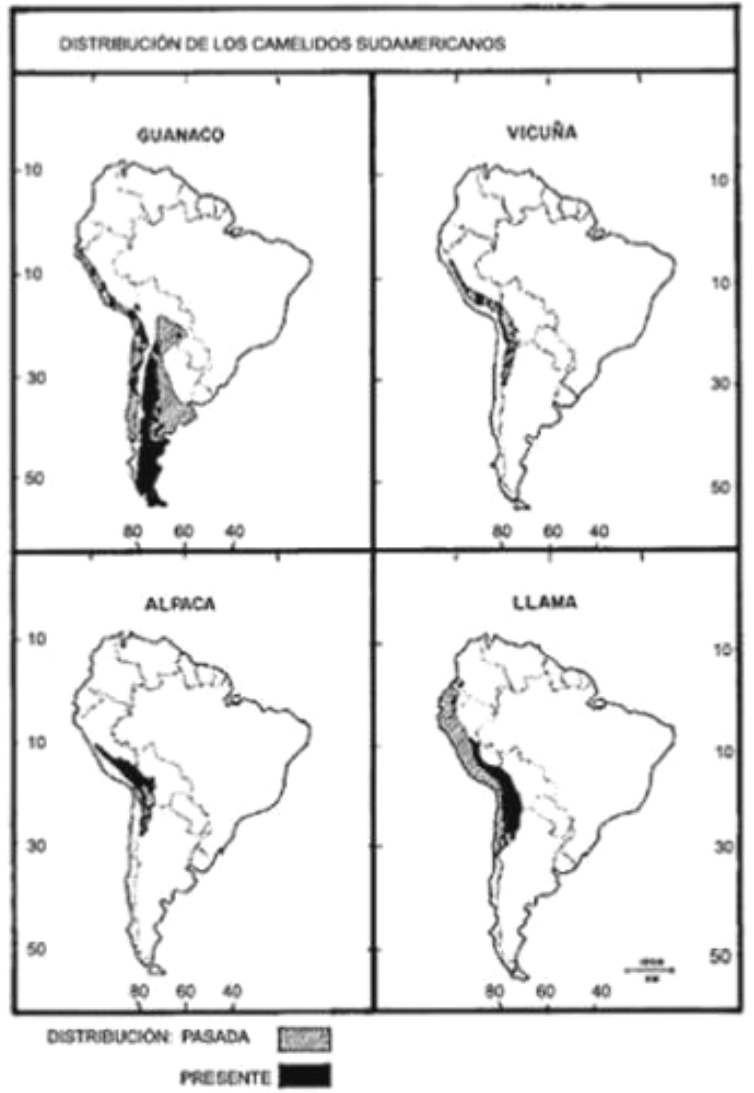

Abbildung 12: Verbreitungsgebiet der Camelidae vor (grau) und nach (schwarz) der Eroberung durch die Spanier (aus Bonacic 1991)

Der Körperbau und die Physiologie der Neuwelt-Camelidae stimmen weitestgehend überein. Die vier Spezies sind untereinander frei kreuzbar und produzieren fertile Nachkommen. Eine Kreuzung durch künstliche Befruchtung zwischen Alpaka und Dromedar (Camelus dromedarius) brachte ein lebensfähiges Cria (Jungtier) hervor (Skidmore 1999). Ob dieser Hybrid fruchtbar ist, ist derzeit nicht bekannt.

Camelidae weisen, im Gegensatz zu anderen Säugetieren, elliptische Erythrozyten und eine erhöhte Anzahl an Leukozyten (Ø 16200, Rinder Ø 8000) auf (Fowler 1998). Darüber hinaus, weist ihr Hämoglobin eine höhere Affinität zur Sauerstoffbindung auf. Bereits bei Sauerstoffpartialdrücken von 20-22 mmHg erreichen sie eine 50 \%ige Sättigung des Blutes. In anderen Säugetierspezies, die nicht im Hochland leben, wird dies erst ab 27-44 mmHg erreicht. Auf Meeresspiegelniveau weisen Alpakas eine deutliche Reduktion dieser Affinität auf (Reynafarje 1975). Die Affinität Sauerstoff zu binden ist also als Höhenadaption anzusehen. Die Atemfrequenz in den Neuwelt-Camelidae ist nicht erhöht (Mortola und Lanthier 2005). 
Die Ausprägung von Haarfarben in Camelidae erfolgt über Melaningenese und Melanosomen (Cecchi et al. 2004), über Assoziationen der Farbausprägung mit bestimmten Genen, ist derzeit nichts bekannt.

Wie die Wiederkäuer fermentieren Camelidae im vorderen Darm. Der Darm gliedert sich jedoch nicht in vier Kompartemente, sondern nur in drei, und der Darm bläht sich nicht auf. Ihr Gaumen ist weich und elongiert und die Atmung erfolgt hauptsächlich nasal. Die Weibchen haben keinen Östrogenzyklus, die Ovulation erfolgt induziert durch das Sperma des Männchens. Der Reproduktionszyklus ist in den Wildformen saisonal und liegt im Spätsommer bis Frühherbst (Februar bis April), die Tragezeit beträgt 11-12 Monate. LamaFeten und Neugeborene haben eine höhere Sauerstoffaufnahme als adulte Individuen (Llanos 2007). Das Immunsystem der Cria beginnt erst ab dem zweiten Monat zu funktionieren, bis dahin ist es in seiner Immunantwort abhängig von den Immunoglobulinen, die es über die Muttermilch aufnimmt (Wernery et al. 2001). Camelidae weisen eine geringe Affinität zu Tuberkulose und anderen typischen Rinder- bzw. Schafkrankheiten auf. Die Untersuchung der Immunoglobuline der Camelidae hat gezeigt, dass diese nur aus so genannten schweren Ketten bestehen (Nguyen et al. 2002, Wernery et al. 2001, Su et al. 2002 und Omidfar et al. 2004). Diese so genannten schweren Ketten weisen ein niedriges Molekulargewicht auf und können das betreffende Gewebe schneller penetrieren (Wernery et al. 2001). Ob diese Besonderheit auf eine Höhenadaption oder eine epidemiologische Ursache zurückgeht, ist derzeit nicht geklärt. Bisher wurden immungenetischen Marker (IL1, IL6 und TNF) nur zur phylogenetischen Rekonstruktion herangezogen (Odbileg et al. 2005).

Alle Neuwelt-Camelidae weisen 74 Chromosomen (72 Autosomen und 2 Gonosomen) auf (Vidal-Rioja et al. 1987). Für Camelidae stehen derzeit eine Vielzahl Mikrosatellitenmarker zur Verfügung, die für den Vaterschaftsnachweis (Rodríguez et al. 2004) und die Variabilitätserfassung genutzt werden (z.B. Maté et al. 2005). Für Vikunjas konnte so belegt werden, dass die Subspezies Vicugna vicugna vicugna im Grenzgebiet zwischen Bolivien und Chile eine höhere Heterozygotenrate in Mikrosatelliten als Vicugna vicugna mensalis aufweisen (Sarno et al. 2004). Etwas südlicher dagegen unterscheiden sich die beiden Subspezies nicht in ihren Heterozygotenraten (Norambuene und Peredes 2003). Wheeler et al. (2002) zeigte dass Lamas deutlich diverser sind als Vikunjas. Guanakos sind ebenfalls diverser als Vikunjas (Maté et al. 2005). Die Guanako Populationen der Tierra del Fuego (Patagonien), die seit Ende der letzten Eiszeit isoliert sind, zeigen eine deutliche Reduktion der Heterozygotenrate, wie auch eine geringere Diversität des Cytochrom b-Gens (Sarno et al. 2001). In anderen genetischen 
Abschnitten, wie z.B. dem 18sr-RNA-Gen ist kaum Diversität nachzuweisen (Semorile et al. 1994). Die meisten Mikrosatelliten-Marker sind auch in Altwelt-Camelidae anwendbar (s. z.B. Mariasegaram et al. 2002, Jianlin et al. 2000). Die Camelidae konnten anhand der Untersuchung von SINEs als monophyletisch dargestellt werden (Lin et al. 2001).

Zwischen den vier Spezies in Süd-Amerika gibt es in der Skelettmorphologie lediglich Größenunterschiede. Am Fuß tragen die Camelidae die Schwielen, die aus einem elastischen Bindegewebe besteht und auf die der Name Schwielensohler (Tylopoda) zurückgeht. Der Fuß hat zwei Zehenendglieder, die mit je einem Zehennagel versehen sind. Die zweiten und dritten Phalangen sind horizontal ausgerichtet, so dass der Gang hierüber erfolgt (s. Abb. 13 A und C). An den Autopodien sind die Phalangen I, II und V reduziert, die Metacarpalia 3 und 4 sind zu einem Kanonenbein verwachsen. Die Metacarpalia 1, 2 und 5 sind reduziert (s. Abb. 13 B). An den jeweiligen Phalangen 1 ist in der Artikulation zum Kanonenbein je ein Os sesamoideum assoziiert (s. Abb. 13 C). Dies verursacht einen größeren Abstand zum Knochen, der einen stärkeren Sehnenansatz zur größeren Kraftübertragung auf den Fuß ermöglicht. Camelidae sind Passgänger, d.h. die Extremitäten einer Körperseite bewegen sich gleichzeitig.

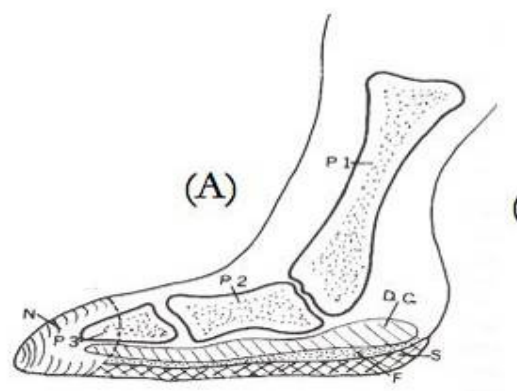

(B)

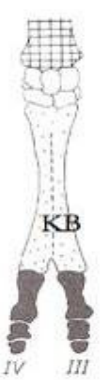

(C)

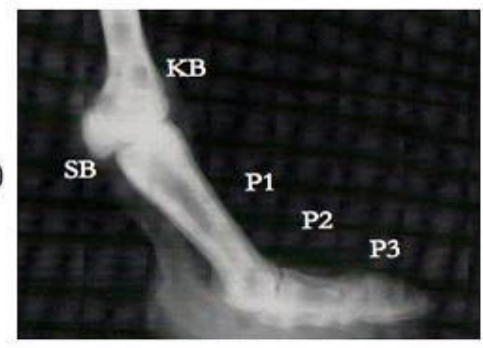

Abbildung 13: (A) Autopodium in lateraler Ansicht. aus Fowler 1998); (B) Autopodium in der Aufsicht (aus Pflumm 1996) (C) Radiographie, laterale Ansicht Autopodium. (aus Fowler 1998). Legende: $\mathrm{N}=\mathrm{Nagel}, \mathrm{P}=$ Phalangen, $\mathrm{DC}=$ Zehenpolster, $\mathrm{F}=$ Sohlenpolster, $\mathrm{S}=$ Schwiele. $\mathrm{IV}$ und III $=$ Phalangen, $\mathrm{KB}=$ Kanonenbein $\mathrm{SB}=$ Os sesamoideum

In den Extremitäten sind Fibula und Ulna reduziert. Eine weitere Besonderheit liegt in der Artikulation von Tibia und Tarsus: der Calcaneus ist im Vergleich mit anderen Artiodactyla Spezies überproportional vergrößert (s. Abb. 14). Die Camelidae haben einen hochmobilen Hals mit sieben Cervical-Wirbeln, ab dem dritten cervicalen Wirbel formt der Processus transversale einen U-förmigen Kanal an der ventralen Seite des Halses. Die Thorakal-Wirbel (zwölf) haben einen auffälligen Processus spinosum. Camelidae haben zwölf Rippen-Paare. Es folgen sieben Lumbal-Wirbel, von denen der letzte verkürzt ist, die dorsalen Processus spinosa sind vertikal ausgerichtet. Die Sakral-Wirbel (fünf) sind deutlich kleiner als die lumbalen, der Processus spinosum des ersten Sakral-Wirbels ist minimal. Die Caudal-Wirbel 
variieren in ihrer Anzahl von 10-15. Das Os coxae zeigt keine Abweichungen gegenüber dem Bauplan in anderen Artiodactyla Spezies.

(A)

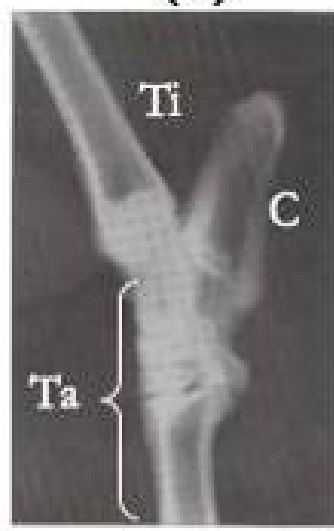

(B)

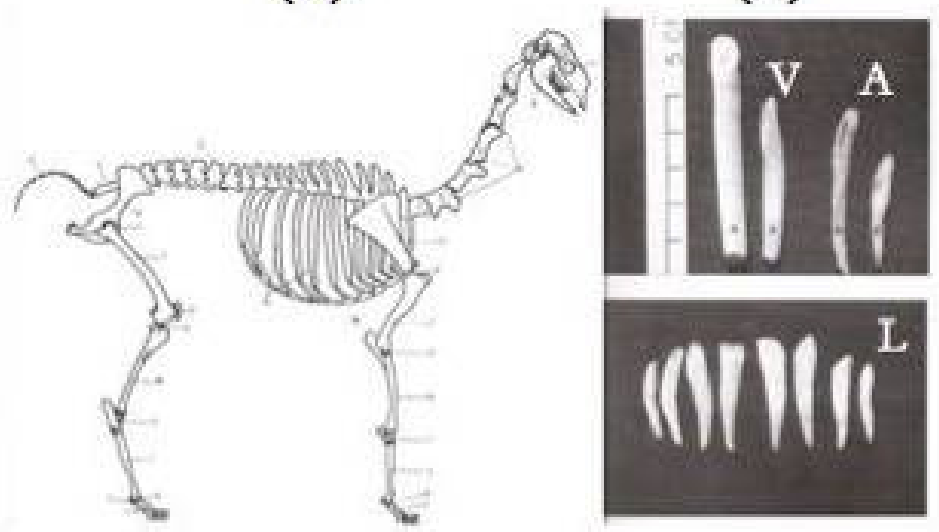

Abbildung 14: (A) Radiographie laterale Ansicht der Artikulation von Tibia und Tarsus mit übergroßem Calcaneus; (B) Skelett der Camelidae; (C) Incisivi von Vikunja (V), Alpaka (A) und Lama (L) (aus Fowler 1998). Legende: $\mathrm{Ti}=$ Tibia, $\mathrm{Ta}=$ Tarsus, $\mathrm{C}=$ Calcaneus

Der einzige morphologische Unterschied der Neuwelt-Camelidae ist an den Incisivi zu erkennen. Die Zahnformel des Milchgebisses ist: I 1/3, C 1/1, PM 2-3/1-2 x2, die des permanenten Gebisses lautet: I 1/3, C 1/1, PM 1-2/1-2 und M 3/3 x2 (Payer et al. 2001). Die Incisivi des permanenten Gebisses von Vikunjas sind stetig nachwachsend, wurzellos und ähneln im Aufbau denen der Rodentia (Miller 1960). Der Zahnschmelz ist nur auf labialer Seite vollständig ausgebildet und die occlusale Oberfläche besteht aus Dentin, so dass ein meißellartiger Zahn entsteht. Die Incisivi des Milchgebisses dagegen sind bewurzelt, Zahnschmelz liegt jedoch auch hier nur labial vor. Die Incisivi von Lama und Guanako dagegen sind löffelartig und bewurzelt. Zahnschmelz liegt sowohl labial als auch lingual auf und bedeckt auf der lingualen Seite ca. 1/3 des Zahns. Alpakas zeigen eher meißelförmige Incisivi, die bewurzelt sind und nur auf labialer Seite Zahnschmelz ausprägen.

Dieser Unterschied in der Zahnmorphologie hat zur Einteilung der Lamini in zwei Genera geführt. Entsprechend gilt, dass all jene, die bewurzelte Incisivi aufweisen, in die Gattung Lama und diejenigen mit nachwachsenden Incisivi in die Gattung Vicugna gehören. Entsprechend wären Alpakas und Lamas Domestikate des Guanakos (Abb. 15 A; Riviere 1997). Zu einem ähnlichen Ergebnis kommen Bruford et al. (2003) anhand der Untersuchung von mitochondrialer DNA und Mikrosatelliten. Hierbei zeigte sich dass fast alle untersuchten Individuen der domestizierten Spezies einen mitochondrialen Guanako-Haplotypen 
aufweisen. Sie räumen ein, dass dieses Ergebnis auch auf Hybridisierungs-Ereignisse zwischen den domestizierten Spezies beruhen könnte. Drei genetische Studien kamen zu dem Ergebnis, dass das Alpaka eine Mischform aus Guanako und Vikunja ist (Abb. 15 B). Zwei der Studien beruhten auf der Untersuchung des Cytochrom b-Gens (Kessler et al. 2002 und Stanley et al. 1994), die dritte Studie basierte auf der Untersuchung der Gene 12s- und 28s-rRNA (VidalRioja et al. 1994). Zwei Studien dagegen postulieren eine Abstammung des Lamas vom Guanako und die Abstammung des Alpakas vom Vikunja (s. Abb. 15 C). Beide Studien beruhen auf der Untersuchung des Cytochrom b-Gens (Palma et al. 1998 und Kadwell et al. 2001). Kadwell et al. (2001) haben darüber hinaus Mikrosatelliten in die Untersuchung mit einbezogen. Palma et al. (1998) nimmt an, dass das Lama auf die Subspezies Lama guanicoe buanacus zurückgeht und das Alpaka auf die Subspezies Vicugna vicugna mensalis. Diese These ist nicht wirklich neu, denn schon Darwin (2001) bezeichnet das Alpaka als Domestikat des Vikunjas.
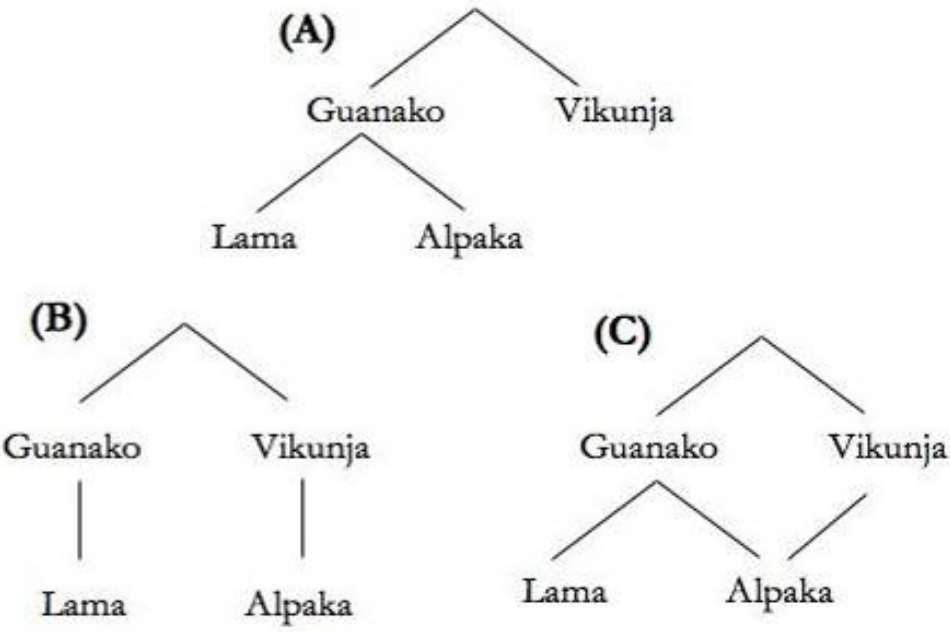

Abbildung 15: Thesen zur Artverwandtschaft der Neuwelt-Camelidae (näheres im Text)

Die Taxonomie der Neuwelt-Camelidae enthält eine Vielzahl von Unklarheiten. Die in zwei Gattungen unterteilten Guanakos und Vikunjas können fertile Nachkommen produzieren, sie sind nicht reproduktiv isoliert. Mengoni Gonalons und Yacobaccio (2006) bezeichnen sie jedoch als sympatrische Arten, da sie in ihren natürlichen Lebensräumen nicht frei paaren. Nach dem biologischen Speziesbegriff wären sie jedoch als eine Art anzusehen, da keine reproduktive Isolation vorliegt. Gleiches gilt für Lamas und Alpakas.

Des Weiteren könnte die morphologische Variation der Incisivi auf ernährungsbedingte Adaption zurückgeführt werden. Unterschiede in der Morphologie von Zähnen, beruhend auf Adaption an regionale Ernährungsgewohnheiten, sind z.B. für Subspezies der Gorilla bekannt (Uchida 1998). Der Ähnlichkeitsgrad der Incisivi des juvenilen Vikunjas und des adulten 
Alpakas kann in der Retention von juvenilen Merkmalen in adulten Individuen, die in domestizierten Formen häufig auftritt, begründet werden.

Gentry (2004) schlägt vor, domestizierte Formen als Varianten anzusehen und diese mit dem Namen ihrer Ursprungsspezies zu versehen. Minelli (1993) verdeutlicht am Beispiel der Neuwelt-Camelidae die Schwierigkeit der Benennung domestizierter Formen und schlägt ebenfalls die Benennung domestizierter Formen mit den Namen ihrer Wildformen vor. Dies wäre im Fall der Neuwelt-Camelidae angebracht, da zwischen Guanako und Lama morphologisch, außer Größenunterschieden, kein weiterer Unterschied feststellbar ist. Gleiches gilt für Vikunjas und Alpakas und wird das Merkmal der Schneidezähne als Adaption an unterschiedliche geographisch-ökologischen Bedingungen gesehen, so müssten alle vier Typen als Cline ein und derselben Art verstanden werden.

Die Ergebnisse genetischer Untersuchungen der letzten Jahre repräsentieren nur einen Bruchteil der ursprünglichen Populationen und einen Zeitraum von 6000-7000 Jahren Zuchtgeschichte, in der Hybridisierung immer wieder Abänderungen der genetischen Profile bewirkte. Wheeler (1995) berichtet, aufgrund diametrischer Studien, dass die Haarstruktur 1400 Jahre alter Alpaka-Mumien (El Yaral, Peru) deutlich feiner war als die rezenter Alpakas.

Dies ist ein weiterer Indikator für Hybridisierungen mit Lamas oder Guanakos. Die genetische Untersuchung der Überreste von prä-kolumbischen Neuwelt-Camelidae könnte hier einen Beitrag zur Klärung der phylogenetischen Beziehungen leisten.

\section{Domestikation und Kulturgeschichte der Neuwelt-Camelidae}

Die Erfassung der Domestikation der Neuwelt-Camelidae erfolgt über verschiedene Merkmale (Mengoni Gonalons und Yacobaccio 2006). Die Dental-Morphologie kann zwar das Vorkommen von Alpakas und Vikunjas aufdecken, Guanakos und Lamas können so jedoch nicht unterschieden werden. Osteometrisch werden alle vier Arten anhand von Größenunterschieden der Langknochen differenziert. Hierfür werden meist die proximalen Phalangen herangezogen. Das Auftreten von Clines erschwert diese Methodik und die meisten Tiere im Norden sind deutlich größer als die im Süden. Mittlerweile existieren für bestimmte Gebiete genügend Referenzdaten über die Längenvariationen der Camelidae-Knochen, so dass hier eine osteometrische Methodik gut angewendet werden kann. So zum Beispiel in dem Süd-Zentral-Anden-Raum, für den ein eindeutiger Größenanstieg von Vikunja über Alpaka zu Guanako und zu Lama belegt ist (Mengoni Gonalons und Yacobaccio 2006). Auch anhand der Haarstruktur wird eine Speziesidentifikation vollzogen. Hierbei kann nur zwischen 
Vikunja, Guanako und domestiziert unterschieden werden. Die Problematik dieser Methoden, liegt in der mangelnden Kenntnis der phänotypischen Variabilität prä-kolumbischer Camelidae-Populationen, so dass die erwirtschafteten Ergebnisse immer mit Vorsicht zu betrachten sind.

Indirekte Belege der Domestikation sind der Anstieg von Camelidae-Funden in Siedlungen und ihr archäologischer Kontext. Hier können das Auftreten von Pferchen, Dung, Textilien aus Camelidae-Wolle und das Auftauchen von Camelidae-Darstellungen auf Keramik Auskunft geben. Es existiert eine Vielzahl morphologischer Arbeiten zur Erfassung des Anstiegs von Camelidae-Knochen in Siedlungsnähe. In Tabelle 2 sind einige Arbeiten und ihre Ergebnisse zusammengefasst.

Tabelle 2: Fundorte und Anstieg der prozentualen Anteile an Camelidae in den tierischen Überresten

\begin{tabular}{|c|c|c|c|c|c|c|c|}
\hline Fundort & Land & $\begin{array}{l}\text { Höhe ü. } \\
\text { NN }\end{array}$ & Datierung & Siedlungsart & $\begin{array}{c}\% \\
\text { Camelidae }\end{array}$ & Spezies & Referenz \\
\hline Atacama & N-Chile & $2000 \mathrm{~m}$ & $\begin{array}{l}9700 \text { v. } \\
\text { Chr. }\end{array}$ & Lager & / & $\mathrm{V}$ & $\begin{array}{l}\text { Kuch et al. } \\
2002\end{array}$ \\
\hline Inca-Cueva & $\begin{array}{c}\text { NW- } \\
\text { Argentinien }\end{array}$ & 3650 & $\begin{array}{l}8600 \text { v. } \\
\text { Chr. }\end{array}$ & Lager & 10 & V? & $\begin{array}{c}\text { Yacobaccio et } \\
\text { al. } 1994\end{array}$ \\
\hline Asana & S-Peru & $3400 \mathrm{~m}$ & $\begin{array}{l}7500 \text { v. } \\
\text { Chr. }\end{array}$ & Lager & / & $\mathrm{V}$ & $\begin{array}{c}\text { Aldenderfer } \\
1989\end{array}$ \\
\hline Tambillo & N-Chile & $2300 \mathrm{~m}$ & $\begin{array}{l}7500 \text { v. } \\
\text { Chr. }\end{array}$ & Lager & 48 & / & Hesse 1982 \\
\hline Inca Cueva & N-Chile & $3650 \mathrm{~m}$ & $\begin{array}{l}5200 \text { v. } \\
\text { Chr. }\end{array}$ & Lager & / & G,L? & $\begin{array}{c}\text { Yacobaccio et } \\
\text { al. } 2003\end{array}$ \\
\hline Hornilos & $\begin{array}{c}\text { NW- } \\
\text { Argentinien }\end{array}$ & $4020 \mathrm{~m}$ & $\begin{array}{l}6300 \text { v. } \\
\text { Chr. }\end{array}$ & Lager & 49 & $\mathrm{~V}, \mathrm{G}$ & $\begin{array}{c}\text { Yacobaccio et } \\
\text { al. } 2000\end{array}$ \\
\hline Puripica 1 & N-Chile & $3250 \mathrm{~m}$ & $\begin{array}{l}2500 \mathrm{v} . \\
\text { Chr. }\end{array}$ & Basislager & 76 & G,L,A? & Hesse 1982 \\
\hline Tulan 52 & N-Chile & $3200 \mathrm{~m}$ & $\begin{array}{l}2300 \text { v. } \\
\text { Chr. }\end{array}$ & Basislager & 86 & G,L,A? & Hesse 1982 \\
\hline Huaricoto & N-Peru & $?$ & $\begin{array}{l}2200 \text { v. } \\
\text { Chr. }\end{array}$ & Basislager & Anstieg & / & Burger 1985 \\
\hline $\begin{array}{c}\text { Inca Cueva } \\
7\end{array}$ & $\begin{array}{c}\text { NW- } \\
\text { Argentinien }\end{array}$ & $3600 \mathrm{~m}$ & $\begin{array}{l}2000 \text { v. } \\
\text { Chr. }\end{array}$ & $\begin{array}{l}\text { Zeremoniales } \\
\text { Zentrum }\end{array}$ & 50 & $\mathrm{~L}$ & $\begin{array}{l}\text { Yacobaccio u. } \\
\text { Aschero } 1999\end{array}$ \\
\hline $\begin{array}{c}\text { Inca Cueva } \\
7\end{array}$ & $\begin{array}{c}\text { NW- } \\
\text { Argentinien }\end{array}$ & $3600 \mathrm{~m}$ & $\begin{array}{l}2000 \text { v. } \\
\text { Chr. }\end{array}$ & Pferch & / & $\bar{L}$ & $\begin{array}{l}\text { Yacobaccio u. } \\
\text { Aschero } 1999\end{array}$ \\
\hline Asana & S-Peru & $3400 \mathrm{~m}$ & $\begin{array}{l}1600 \mathrm{v} . \\
\text { Chr. }\end{array}$ & Basislager & Anstieg & / & $\begin{array}{c}\text { Aldenderfer } \\
1998\end{array}$ \\
\hline $\begin{array}{c}\text { Alero } \\
\text { Unquillar }\end{array}$ & $\begin{array}{c}\text { NW- } \\
\text { Argentinien }\end{array}$ & $3700 \mathrm{~m}$ & $\begin{array}{l}1500 \mathrm{v} . \\
\text { Chr. }\end{array}$ & Lager & 93 & $\bar{L}$ & $\begin{array}{c}\text { Yacobaccio et } \\
\text { al. } 1997\end{array}$ \\
\hline Tulan 85 & N-Chile & $2300 \mathrm{~m}$ & 600 v. Chr. & 1 & Anstieg & 1 & Dransart 1991 \\
\hline Chavin & N-Peru & $3150 \mathrm{~m}$ & $\begin{array}{l}900-200 \text { v. } \\
\text { Chr. }\end{array}$ & rurale Siedlung & Anstieg & G,L & $\begin{array}{c}\text { Miller und } \\
\text { Burger (1995) }\end{array}$ \\
\hline Cahuachi & Z-Peru & / & 0 & $\begin{array}{c}\text { Zeremoniales } \\
\text { Zentrum }\end{array}$ & $/$ & A & $\begin{array}{l}\text { Valdez et al. } \\
\text { (2001) }\end{array}$ \\
\hline
\end{tabular}

Legende: $\mathrm{N}=$ Nord, NW = Nordwest, $\mathrm{S}=$ Süd, Z = Zentral, $\mathrm{G}=$ Guanako, V = Vikunja, L = Lama, A = Alpaka

Seit dem Archaikum entwickelten sich die Camelidae zum wichtigsten Fleischlieferanten SüdAmerikas und löste das Wild ab. Yacobaccio (2003) sieht die Funde in Inca Cueva (5200 v. 
Chr.) als Beginn der Domestikation des Lamas. Abgeschlossen sei dieser Prozess erst $3000 \mathrm{v}$. Chr., da erst hier die Knochengrößen denen rezenter Lamas gleichen. Stahl (2007) datiert das Auftauchen domestizierter Lamaformen in den Nord-Anden (Peru, Ecuador) auf ca. 500 v. Chr., er konnte nur geringe Anteile von Camelidae-Knochen bestimmen. Mengoni Gonalons (2007) datiert den Beginn der Domestikation in den Süd-Zentral-Anden auf ca. 5300 v. Chr. in Höhen von 3000 m. Browman (1989) datiert den Beginn der Domestikation auf ca. 7000 v. Chr. und bestimmt zwei Domestikationszentren. Junin (N-Peru) als Domestikationszentrum der Alpakas und die Region rund um den Titicaca-See als Domestikationszentrum der Lamas. Die Wollproduktion im Süden tritt erst ab einem Zeitpunkt um 500 n. Chr. auf, die Funde von Tieren an der Küste Perus (700 v. Chr.) deutet er als Anzeichen des Handels mit dem Hochland. Mengoni Gonalons und Yacobaccio (2006) sehen dagegen mehrere unabhängige Domestikationen des Lamas. Der Ursprung des Alpakas liegt nach ihren Ergebnissen eher im Süd-Zentral-Andenraum. Wheeler (1995) bestimmt die Region der Domestikation des Alpakas rund um Telarmachay (N-Peru), die Funde von Alpaka Incisivi stützen diese These. Über das Auftreten von Pathologien (Abb. 16A; Tulan 52, 1800 v. Chr.) und den Fund von Pferchen (Abb. 16B; Tulan 54, 380 v. Chr.) konnte in N-Chile eine stetige Zunahme der Domestikation belegt werden (Cartajena et al. 2007).

(A)

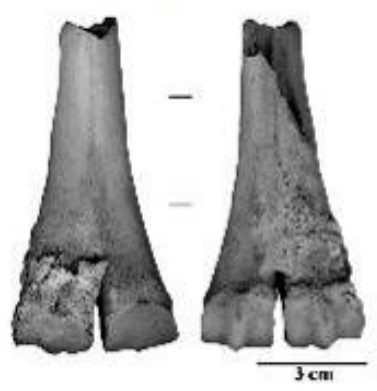

(B)

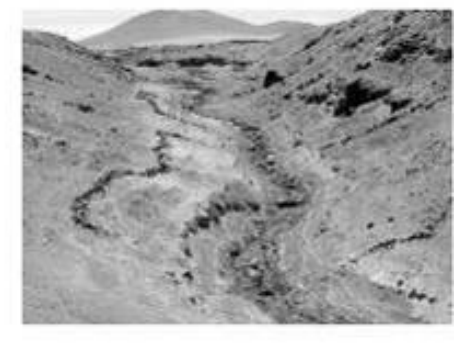

Abbildung 16: (A) Knochen Pathologien des Kanonenbeins, an dem rechten Condylus ist deutlich Periostitis ossificans zu erkennen; (B) Überreste einer Pferchstruktur (aus Cartajena 2007)

Miller und Burger (1995) geben an, dass am Fundort Chavin de Huantar (Chavin-Kultur, 900200 v. Chr.) überwiegend große Camelidae gefunden wurden. Dies deutet auf die Nutzung der Camelidae zum Verzehr. Darüber hinaus belegen sie, dass in den Talgebieten keine ganzen Tiere aufzufinden seien, was auf den Verzehr von char'ki hindeutet. Char'ki sind große Fleischpakete, die, ohne das Fleisch vom Knochen zu lösen, getrocknet wurden (Miller und Burger 1995). Nach Aldenderfer (1998) wird der Camelidae-Körper bei der Schlachtung in fünf große Pakete zerteilt (s. Abb. 17), die Autopodien werden bei diesem Verfahren abgetrennt und nicht weiter verarbeitet. 


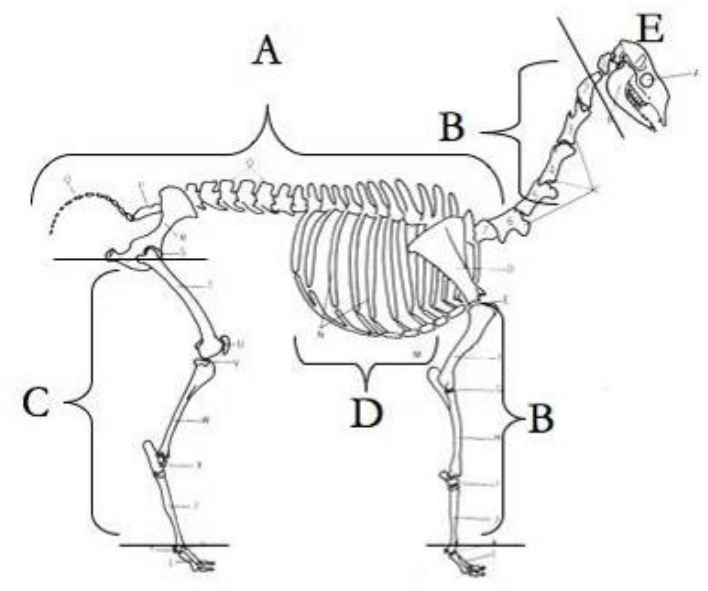

Abbildung 17: Pakete in die der Camelidae-Körper bei der Schlachtung geteilt wird (nach Aldenderfer 1998)

Die größten Fleischmassen können hierbei aus den Bereichen A, B und C (s. Abb. 17) gewonnen werden, so dass diese überwiegend zur char'ki Produktion verwendet werden (Aldenderfer 1998). Für den Andenraum ist der Schlepp-Effekt (Burger 1985), also der Transport von char'ki, eindeutig belegt.

Der kulturelle Nutzen der Camelidae war vielseitig. Als ökonomisches Produkt wurden Lamas als Tragetiere und Fleischlieferanten genutzt, das Alpaka überwiegend zur Wollproduktion. Darüber hinaus wurde die Haut der Camelidae zur Lederproduktion und der Dung als Bauund Heizstoff genutzt (Mengoni Gonalons und Yacobaccio 2006). In rituellen Handlungen spielten sie ebenfalls eine bedeutende Rolle. So wurden in der Atacama zehn mumifizierte Camelidae gefunden (Wheeler 1992), vier davon konnten anhand der Wollstruktur als Alpakas, sechs als Lamas bestimmt werden. Die Funde wurden auf 600 n. Chr. datiert und werden aufgrund der Fundsituation als Opfergaben eingeschätzt. Auch in zeremoniellen Zentren wurden Camelidae Knochen neben anderen Opfergaben wie Textilien, oder Keramik gefunden (Silverman und Proulx 2001). Die traditionelle chaku-Jagd der Inka ist ebenfalls ein Beispiel für rituelle Handlungen mit Camelidae. Hierbei wurden Vikunjas zusammengetrieben, einzelne Tiere geschoren, einige wenige für den Verzehr, sowie alte und kranke Tiere, getötet (Darwin 2001). Die Wolle der Vikunjas stand jedoch nur der Elite zur Verfügung (Dransart 1991). Die Darstellung von Camelidae auf Textilien, Keramik und Stein (s. Abb. 18) belegen ihre kulturelle Bedeutung. 


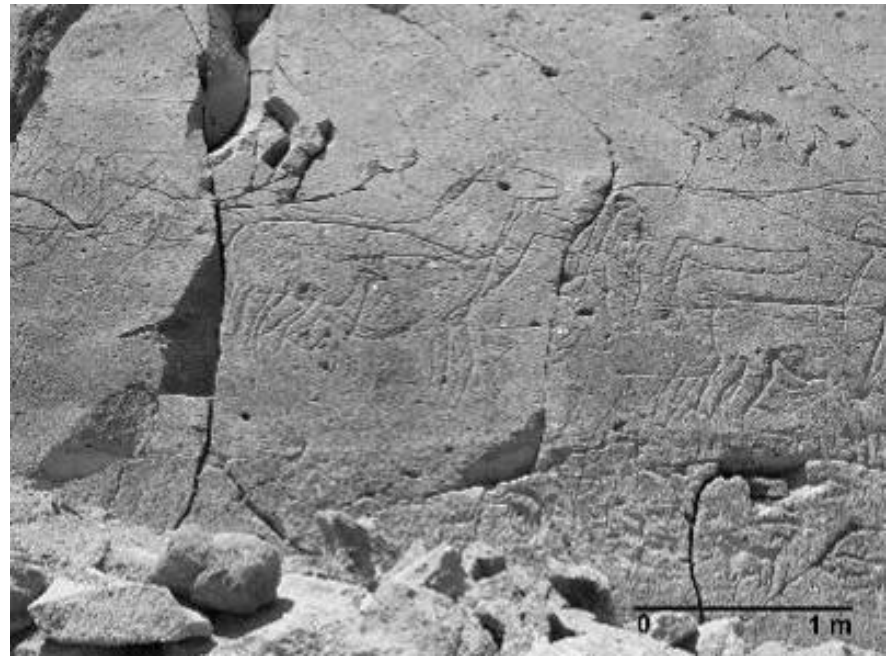

Abbildung 18: Darstellung von Camelidae als Petroglyphe (aus Cartajena 2007)

Entscheidend ist, dass der Anstieg der Funde von Camelidae-Knochen zunächst mit der Sesshaftwerdung und dem darauf folgendem Anstieg der sozialen Stratifikation der Kulturgruppen assoziiert ist.

Fraglich ist bis heute, ob die Subsistenzstrategie der Camelidae-Halter als Pastoralismus bezeichnet werden kann. Funde aus Conchopata (550 n. Chr., Wari-Kultur, Z-Peru) belegen zwei unterschiedliche Herdenstrategien. Anhand der Untersuchung stabiler Isotopen konnte belegt werden, dass es Tiere gab, die mit Mais gefüttert wurden und andere die überwiegend Gras gefressen haben. Clutton-Brock (1999) ordnet die Camelidae in die Gruppe der ausgebeuteten Gefangenen, beruhend auf der Tatsache, dass wenig Zuchtkontrolle herrscht. Die Herdenstrategien der Wari-Kultur sind bis heute in den Anden erhalten. Es gibt die del cerro - Haltung (3900-4600 m), bei der sich die Tiere frei bewegen dürfen. Der Halter wählt lediglich das Männchen zur Paarung aus und es wird keine Aufzucht der Jungtiere durch den Menschen betrieben. In unregelmäßigen Abständen werden die Tiere gezählt. Des Weiteren gibt es die del campo Haltung, bei denen eine Kontrolle der Gruppenbewegung erfolgt. Es wird Zuchtkontrolle beider Geschlechter betrieben und Jungtiere werden auch durch den Menschen aufgezogen (Rabey 1989). Lamas und Alpakas werden in beiden Fällen gemeinsam gehalten. Eindeutig ist, dass die Zucht und Haltung der Neuwelt-Camelidae durch den Import von Schafen, Rindern etc. seit der spanischen Invasion an Bedeutung verloren hat (Wheeler 1995).

\section{Neuwelt-Camelidae bei den Nasca}

Über die Bedeutung der Camelidae in der Nasca-Kultur ist wenig bekannt. Silverman und Proulx (2001) geben an, dass die tierische Nahrung hauptsächlich aus Camelidae bestand und 
Wolle der Alpakas bis an die Küste bekannt war. In Cahuachi wurden sie als rituelles Objekt genutzt. In der Ikonographie sind Jagdszenen sowie Menschen die Camelidae führen vertreten. Es gibt nur wenige Hinweise auf lokale Aufzucht, dagegen sind Karawansereien bekannt (Valdez 1988). Die Textilien der Nasca bestehen zum Großteil aus Baumwolle, jedoch enthalten die meisten auch Anteile von tierischer Wolle (Biermann 2001). Ob es sich hierbei um Alpaka-, Lama-, Guanako- oder Vikunja-Wolle handelt ist bisher nicht bekannt. Die einzige umfassende Studie zur Speziesbestimmung an tierischen Überresten am Fundort Cahuachi (100 v. Chr. bis 500 n. Chr.), über osteometrische Methodik, deutet auf die Anwesenheit von Alpakas (Valdez 2001). Welche Spezies während der Nasca Zeit hauptsächlich genutzt wurden, ist bisher jedoch weitestgehend unbekannt. 


\subsection{Fragestellung und Zielsetzung}

Die Nutzung von Camelidae könnte, im Gesamtkontext des Projektverbundes, einen Beitrag zur Klärung der sozioökonomischen Organisation, also der Subsistenzstrategie und der Frage nach möglichen Handelsbeziehungen, der Nasca-Kultur leisten. Es soll geklärt werden, welche Spezies innerhalb des überlieferten Knochematerials vertreten sind und aus welcher Wolle die hochwertigen Nasca-Textilien hergestellt wurden. Die Bestimmung der Spezies könnte Aufschluss über Ernährungsgewohnheiten sowie möglichen Handel mit dem Hochland geben. Sollten zum Beispiel überwiegend Vikunjas oder Guanakos vertreten sein, so ließe dass auf überwiegend Jagd oder Import derer Produkte schließen. Die Anwesenheit von Alpakas würde auf ausgeprägten Handel mit dem Hochland hinweisen. Lamas könnten ebenfalls den Handel belegen, jedoch auch Hinweise auf Haltung bzw. Karawansereien im Tal geben. Über das Gesamtbild der vertretenen Spezies in Knochen- und Textil-Material könnte eine Aussage darüber getroffen werden, ob die Tiere selbst oder die Wolle importiert wurde. Darüber hinaus soll, anhand der Ergebnisse der jeweiligen Fundorte, ein möglicher Unterschied der Speziesnutzung über die Zeitdauer von ca. 2400 Jahren (800 v. Chr. - 1400 n. Chr.) überprüft werden. Die Anwesenheit domestizierter Spezies würde immer Handelsbeziehungen zum Hochland belegen, dies wäre ein weiterer Hinweis auf die Existenz von Stammesfürstentümern, oder sogar der Staatenausbildung während der Nasca-Zeit.

Hierfür soll ein System zur Speziesidentifikation der Neuwelt-Camelidae entwickelt werden und besonderes Augenmerk auf die Anwendbarkeit dieses Systems an historischem Material gerichtet sein. Neben der Identifikation der Spezies soll auch die genetische Variabilität der DNA des überlieferten Materials bestimmt werden. Hierfür sollen zunächst Analysesysteme der mitochondrialen DNA sowie für Mikrosatelliten an rezenter DNA entwickelt werden und auf überliefertes Material angewandt werden.

Die Ergebnisse rezenter Populationen und des historischen Materials sollen darüber hinaus phylogenetisch ausgewertet werden. So soll ein Beitrag zur Untersuchung der phylogenetischen Beziehung der Neuwelt-Camelidae geleistet werden. 
2 Exkurs: Grundlagen der Biologie und Kulturwissenschaften

Da die vorliegende Arbeit sowohl für Biologen als auch Angehörige kulturwissenschaftlicher Fachbereiche von Interesse ist, sollen im Folgenden Grundlagen der Biologie und der Kulturwissenschaften erläutert werden. Dies soll ein grundlegendes Verständnis der Fragestellung und der zu ihrer Beantwortung genutzten Methoden auch für fachfremde Wissenschaftler ermöglichen. Darüber hinaus sind die hier geschilderten Grundlagen Vorraussetzung für das Verstehen der Interpretation und Diskussion der in dieser Arbeit erwirtschafteten Ergebnisse.

\subsection{Biologische Grundlagen: Genetik}

Die Gene stellen die Grundlage jedes existierenden Lebewesens dar. Sie bestimmt die Form, die Fähigkeiten und die Fitness eines Individuums. Das eukaryotische Genom besteht aus zwei Hauptkomponenten: die chromosomalen DNA, die in jeder Zelle in einfacher Kopie vorliegt und DNA der Organellen (Mitochondrien oder Chloroplasten), die in bis zu tausendfacher Kopienzahl pro Zelle (je nach Gewebetyp) vorliegen kann (Robin und Wong 1988).

Die Desoxyribonukleinsäure (DNA), das Grundgerüst des Genoms, unterliegt einem universellen Code. Sie wird durch die zwei Purinbasen Guanin (G) und Adenin (A) sowie den zwei Pyrimidinbasen Cytosin (C) und Thymin (T) determiniert. In Ribonukleinsäure (RNA) liegt anstelle des Thymins die Base Uracil (U) vor. Je drei Basen bilden in kodierenden Bereichen (Exone) ein so genanntes Basentriplet, das genau eine Aminosäure codiert. Unterschiedliche Basentriplets können allerdings ein und dieselbe Aminosäure codieren. Die Codierung der Aminosäuren ist, wie das Grundgerüst der DNA, ebenfalls universell. Selten treten Abweichungen auf, so z.B. im mitochondrialen Genom (Buselmeier und Tariverdian 2006, S. 14).

Informationen über die komplette Sequenz des Genoms (organell und chromosomal) liegen bisher von 636 Spezies vor. Die Mehrzahl machen hier Bakterien aus (594 Spezies), für Mammalia liegen bisher nur für den Menschen (Homo sapiens) und die Hausmaus (Mus musculus) Informationen über das Gesamtgenom vor. In Tabelle 3 sind neben den beiden Säugetierarten die einzige Insektenart (Drosophila melanogaster) und die einzige Nematoden-Art (Caenorhabditis elegans) gelistet. Diese vier Spezies stellen die einzigen derzeit komplett sequenzierten Spezies der Metazoa dar. 
Tabelle 3: Auflistung der Charakteristika des Genoms verschiedener Spezies

\begin{tabular}{|l|l|l|l|l|}
\hline & Chromosomenanzahl & Mb chromosomal & Gene chromosomal & bp mitochondrial \\
\hline Homo sapiens & 46 & 3000 & $20000-25000$ & 16564 \\
\hline Mus musculus & 40 & 3400 & 30000 & 16299 \\
\hline Drosophila melanogaster & 7 & 132 & 13601 & 19517 \\
\hline Caenorhabditis elegans & 6 & 100 & 19099 & 13794 \\
\hline
\end{tabular}

Legende: $\mathrm{Mb}=$ Mega Basenpaare, $\mathrm{bp}=$ Basenpaare

Im menschlichen chromosomalen Genom sind nur rund 5\% hoch konserviert, d.h. die Mutationsrate in diesen Bereichen ist gering. Derzeit wird angenommen, dass zwischen 20000-25000 Gene (Exone) existieren die für Proteine kodieren. Rund weitere 3000 Gene kodieren Transfer RNA (t-RNA), Ribosomale RNA (r-RNA), Small Nuclear RNA (sn-RNA) und Small Nucleolar RNA (sno-RNA) (HumanGenomeProject). Rund 95\% des menschlichen Kern-Genoms sind nicht kodierend. Ähnliches gilt für das Genom der Hausmaus. Diese nicht kodierenden Abschnitte (Introne) werden in allen Spezies gleich unterteilt: Tandemwiederholte nichtkodierende DNA und Transposon DNA.

Tandemwiederholte DNA kann in drei Klassen unterteilt werden, die Satelliten-DNA, die aus 5-171 Wiederholungseinheiten bestehen kann, die Minisatelliten-DNA, die aus 9-64 Wiederholungseinheiten besteht und die Mikrosatelliten-DNA (s. Kap. 2.1.2) die aus maximal 12 Wiederholungseinheiten besteht.

Transposon-DNA sind verstreute nicht kodierende repetitive Einheiten, die man auch als springende DNA bezeichnet, da sie ihre Lokalisation im menschlichen Genom verändern (transponieren) können. Man unterscheidet Retrotransposons und DNA-Transposons. Innerhalb der Retrotransposons unterscheidet man Long Interspersed Nuclear Elements (LINEs), sie transponieren unabhängig, Short Interspersed Nuclear Elements (SINEs), die nur mit Hilfe der von den LINEs produzierten Proteine transponieren können und Long Terminal Repeats (LTRs), sie können sowohl autonom als auch nicht autonom transponieren.

Die nicht kodierenden Bereiche des chromosomalen und des organellen Genoms sind weniger vor DNA-Veränderungen (Mutationen) geschützt. Die Mutationsrate für humane autosomale Mikrosatelliten liegt z.B. bei ca. 7 x $10^{-3}$ (Brinkmann et al. 1998), die Mutationsrate für die menschliche Gene liegt nach der Formel von Haldane (1932) bei ca. $10^{-4}$ bis $10^{-6}$, in der Realität weisen die meisten Gene jedoch eine niedrigere Mutationsrate (ca. 10 $0^{-6}$ ) auf (s. z.B. Buselmaier und Tariverdian b 2007, S. 78) . Die Mutationsrate des gesamten kodierenden mitochondrialen Genoms liegt dagegen bei 0,0017 × $10^{-6}$ (Pakendorf und Stoneking 2005), die der nicht kodierenden hypervariblen Regionen I und II (HVRI und HVRII) des mitochondrialen Genoms bei 0,075-0,162 × 10-6. Mutationen können das gesamte Genom, 
das Chromosom oder das Gen betreffen. In Tabelle 4 sind die wichtigsten Mutationsarten aufgeführt und beschrieben.

Tabelle 4: Mutationen

\begin{tabular}{|l|l|l|}
\hline Klasse der Mutation & Art der Mutation & Beschreibung \\
\hline Genommutation & Aneuploidie & Verlust oder Gewinn eines Chromosoms \\
\hline \multirow{4}{*}{ Chromosomenmutation } & Deletionen & Abschnitte des Chromosoms gehen verloren \\
\cline { 2 - 3 } & Duplikationen & Abschnitte des Chromosoms werden verdoppelt \\
\cline { 2 - 3 } & Inversionen & Abschnitte des Chromosoms werden um $180^{\circ}$ gedreht \\
\cline { 2 - 3 } & Translokationen & Abschnitte des Chromosoms werden an anderer Stelle eingebaut \\
\hline \multirow{5}{*}{ Genmutationen } & $\begin{array}{l}\text { Substitutionen } \\
\text { (Punktmutation) }\end{array}$ & Transition $=\mathrm{C}<>$ T, Transversion A $<>\mathrm{G}$ \\
\cline { 2 - 3 } & Insertion (Punktmutation) & Neueinbau einer oder mehrere Basen \\
\cline { 2 - 3 } & Duplikation (Punktmutation) & Verdopplung einer oder mehrere Basen durch crossing-over \\
\cline { 2 - 3 } & Deletion (Punktmutation) & Verlust eines Basenpaars oder Basentriplets (frame--shift-mutation) \\
\cline { 2 - 3 } & Trinukleotidwiederholungen & $\begin{array}{l}\text { Einbau oder Verlust von drei Basen aus einer heterogenen } \\
\text { Wiederholungssequenz }\end{array}$ \\
\hline
\end{tabular}

Mutationen sind aus evolutiver Sicht nicht als Fehlbildungen zu sehen, vielmehr boten sie die Möglichkeit die heute anzutreffende biologische Diversität auszubilden. Es ist also sinnvoller, sie im Falle einer nicht pathologischen Veränderung (silent mutations) als Polymorphismen (Vielgestaltigkeiten) zu bezeichnen. Wie in Tabelle 3 ersichtlich wird, können sich Spezies in Chromosomenanzahl, Basenanzahl, aber auch in ihrer Basenabfolge, unterscheiden. Jede Spezies erhält so ihre eigene genetische Identität. Aber nicht nur auf dem Speziesniveau sind Mutationen ein wichtiges Unterscheidungsmerkmal. So bieten z.B. Mikrosatelliten, aufgrund ihrer relativ hohen Polymorphie, die Möglichkeit, Individuen zu unterscheiden.

Die Untersuchung von Unterschieden in den Genomen bietet heute eine Vielzahl von Möglichkeiten. So findet die Analyse genetischer Variationen neben der klinischen Genetik (Immungenetik, Humangenetik etc.) auch in einer Vielzahl spezialisierter Teilgebiete der naturwissenschaftlichen Anwendung statt. Beispiele hierfür sind z. B. die Populationsgenetik sowie die Rekonstruktion von Besiedlungsgeschichte (s. z.B. Krings et al. 1999) und Phylogenetik (Rekonstruktion des phylogenetischen Systems anhand genetischer Merkmale, s. z.B. Johns und Avise 1998), selbst die Rekonstruktion des äußeren Erscheinungsbildes ist möglich (z.B. Vage et al. 1997 für Füchse).

Die Untersuchungsmethoden von Mutationen und DNA-Sequenzen sind vielseitig. Hier soll kurz auf die wichtigsten Methoden eingegangen werden. Die Polymerasekettenreaktion (PCR) ist eine Reaktion in der mit Hilfe so genannter Primer (18-30 bp lange Start- bzw. Endsequenzen) ein spezifisches Fragment der DNA vervielfältigt (amplifiziert) wird (Mullis und Faloona 1987). PCRs können mit nur einem Primerpaar (Singleplex), oder mehreren Primern (Multiplex), durchgeführt werden. Die so entstandenen Fragmente stehen dann weiteren Analysen in ausreichender Menge zur Verfügung. Folgeanalysen können die 
Fragmentlängenanalyse (Auftrennung der Fragmente nach der Länge), die Restriktionsfragmentlängenanalyse (RFLP-Analyse, Spaltung der Fragmente mit Hilfe Sequenzspezifischer Endonucleasen), die Direkt-Sequenzierung (direkte Betrachtung der Basenabfolge) oder die SNP-Analyse (Analyse von Punktmutationen) sein.

Derzeit ist es gebräuchlich, anhand rezenter Populationen Rückschlüsse auf die evolutive Entwicklung dieser Populationen zu ziehen. Die geschieht anhand statistischer Methodik, die einen Hinweis auf Entwicklungen liefern kann. Einen tatsächlichen Einblick in die Entwicklungsgeschichte bietet sie jedoch nicht. Daher gewinnt die Untersuchung alter DNA (aDNA, in überliefertem Material enthaltene DNA, s. Kap. 1.3) immer mehr an Bedeutung. Im Folgenden sollen nun die genetischen Strukturen genauer vorgestellt werden, die zur phylogenetischen, phänotypischen und populationsgenetischen Rekonstruktion bestens geeignet sind.

\subsubsection{Mitochondriales Genom, Markersysteme und Speziesidentifikation}

Das mitochondriale Genom befindet sich in den Mitochondrien und liegt in jeder tierischen Zelle (je nach Energiebedarf) in mehrfacher Kopie vor. Es ist eine zirkuläre Sequenz, organisiert in einem schweren guaninreichen Strang und einem leichten cytosinreichen Strang. Die mitochondriale DNA kodiert die Proteine der Zellatmung (Zitronensäurezyklus). Obwohl die mitochondrialen Genome verschiedener Metazoa Spezies unterschiedlich lang sein können, sind in der Regel 37 kodierende Bereiche realisiert (mit Ausnahme einiger weniger Spezies, s. Tab. 5), die rund 95\% des Genoms einnehmen. Dreizehn der mitochondrialen Gene sind kodierend für Proteine, weitere 24 für strukturelle ribosomale Ribonukleinsäuren (rRNAs). Neben den kodierenden Bereichen liegt in allen Organismen ein nicht kodierender Bereich, der so genannte $d$-loop (auch Hypervariablen Regionen I und II), vor.

Tabelle 5: Spezies und Länge ihres mitochondrialen Genoms

\begin{tabular}{|l|l|l|l|}
\hline Spezies & $\mathrm{bp}$ & Anz. der proteinkod. Gene & Anz. der strukturellen RNA kod. Gene \\
\hline Homo sapiens & 16564 & 13 & 24 \\
\hline Mus musculus & 16299 & 13 & 24 \\
\hline Lama pacos & 16652 & 13 & 24 \\
\hline Camelus dromedarius & 16643 & 13 & 24 \\
\hline Camelus bactrianus ferrus & 16680 & 13 & 24 \\
\hline Camelus bactrianus (dom.) & 16659 & 13 & 24 \\
\hline Bos indicus & 16341 & 13 & 24 \\
\hline Sus scrofa & 16631 & 13 & 24 \\
\hline Capra bircus & 16640 & 13 & 24 \\
\hline Ovis aries & 16616 & 13 & 24 \\
\hline Drosophila melanogaster & 19517 & 13 & 24 \\
\hline Caenorbabditis elegans & 14420 & 12 (kein ATP8) & 24 \\
\hline
\end{tabular}

Legende: $\mathrm{bp}=$ Basenpaare, Anz. $=$ Anzahl, kod. $=$ kodierend

In Abbildung 19 sind alle zwölf protein-kodierenden sowie zwei rRNA-Gene dargestellt. 


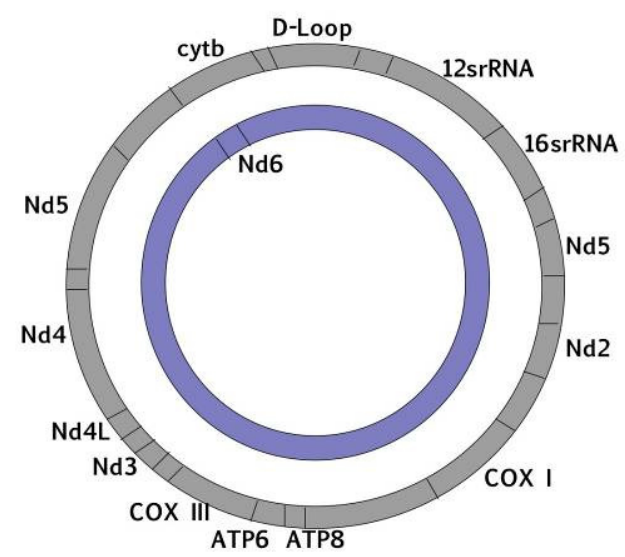

Abbildung 19: Lage der protein-kodierenden Gene sowie zweier rRNA-Gene auf dem Mitochondrium

Durch evolutive Prozesse, wie Mutationen im Zusammenspiel mit natürlicher Selektion, Gendrift und bottleneck-Situationen (s. Kap. 2.2.2), sind in verschiedenen Spezies und in verschiedenen Individuen unterschiedliche Basenabfolgen in der mitochondrialen Sequenz realisiert, obwohl die Funktion beibehalten wurde. Diese Eigenschaft, verbunden mit dem uniparental maternalen Vererbungsweg, bietet eine Vielzahl von Anwendungsmöglichkeiten in der Verwandtschaftsanalytik auf der Generationen-Ebene, bis hin zur Identifikation von phylogenetischen Beziehungen.

Die verschiedenen Polymorphismen, die ein Individuum im haploiden Genom aufweist (haploide Genome sind: mt-DNA, Y-chromosomale DNA oder lediglich die Chromosomen eines Elternteils), nennt man Haplotyp. Haplotypen können aufgrund spezifischer Polymorphismen, die in mehreren Individuen auftreten als Haplogruppen zusammengefasst werden. Die Bestimmung solcher Haplogruppen kann entweder durch die Analyse einzelner Single Nucleotide Polymorphisms (SNPs) erfolgen, oder durch die Sequenzierung einzelner Abschnitte. Je mehr Abschnitte untersucht werden, desto sicherer ist die Zuordnung zu einer bestimmten Haplogruppe bzw. der Nachweis der Verwandtschaft (Rokas 2005).

Die Analyse des menschlichen mitochondrialen Genoms konnte z.B. belegen, dass alle heut lebenden Menschen auf eine gemeinsame "Urmutter" zurückzuführen sind ("Out of Africa Hypothese“, Wilson und Cann 1992). Darüber hinaus wird besonders in den letzten Jahren deutlich, dass die Gene des mitochondrialen Genoms nicht selektionsneutral sind. So konnte z.B. ein Zusammenhang zwischen Mutationen in den mt-Genen und klimatischen Konditionen hergestellt werden kann. Mishmar et al. (2003) konnten einen Unterschied in der Variabilität der Gene Cytochrom b, ATP6 und Cytochrom Oxidase I in Populationen 
verschiedener klimatischer Zonen feststellen. Populationen gemäßigter und tropischer Klimazonen zeigen Variabilität in anderen Genen als Populationen aus arktischen Regionen. Daraus wird gefolgert, dass das Klima einen möglichen Selektionsfaktor darstellt. Ruiz-Pesini et al. (2004) konnten anhand der gefundenen Polymorphismen in mitochondrialen Genomen, von Individuen verschiedener biogeographischer Herkunft, nachweisen, dass adaptive Selektion in arktischen Regionen zu einer Anreicherung spezifischer Polymorphismen in den Genen der Atmungskette geführt hat.

Analog zu der Erforschung der Herkunft des Menschen, werden heute viele Untersuchungen zur Abstammung und Herkunft domestizierter Spezies durchgeführt. Anhand der Untersuchung kompletter mt-Genome konnte die Anzahl der Urmütter heute domestizierter Schafe (Ovis aries, Linné 1758) auf zwei eingegrenzt werden (Hindleder et al. 1998). Lai et al. (2007) konnte die Abstammung des domestizierten chinesischen Yaks auf das europäische Hausrind (Bos taurus, Linné 1758) zurückführen. Die Untersuchungen des europäischen Hausrindes sind vielseitig. Hier sollen zwei Untersuchungen erwähnt werden, die von besonderem Interesse sind. Beja-Perreira et al. (2006) konnten anhand der Untersuchung von aDNA nachweisen, dass in Süd-Europa eine Einzüchtung afrikanischer Rinder stattgefunden haben muss, Bollongino et al. (2003) zeigten anhand der Untersuchung neolithischer RinderDNA einen deutlichen Unterschied zwischen dem europäischen Wildrind (Bos primigeminus) und ihren Funden, die vermutlich vom domestizierten Rind (Bos taurus) abstammen. An diesen beiden Beispielen wird deutlich, dass der Prozess der Domestikation des Rindes noch weitestgehend unverstanden ist und die aDNA-Analytik einen wichtigen Beitrag zur Klärung der Herkunft und des Ursprungs leisten kann.

Die Abstammung der verschiedenen Hunderassen (Canis lupus familiaris) kann heute weitestgehend beantwortet werden. Alle heute existierenden Rassen lassen sich in vier Großgruppen einteilen (Ostrander und Wayne 2005). Die Arbeitsgruppe Leonard et al. (2002) konnte anhand der Untersuchung der HVR-Regionen von Hunden aus Alaska und Südamerika klar belegen, dass der Südamerikanische Hund im Pleistozän mit dem Menschen in den Kontinent eingewandert sein muss. Savolainen et al. (2002) geben die höchste phylogeographische Varianz in Ostasien liegend an, was einen dortigen Ursprung der Hunderassen nahe legt. Die Untersuchung von aDNA aus Hundeknochen zeigt jedoch einen wahrscheinlichen Ursprung des Hundes in Osteuropa (Verginelli et al. 2005). Die Abweichungen in den Ergebnissen können auf die gewählte Stichprobe und auf die gewählten Methoden der statistischen Auswertung beruhen. Bjornerfeldt et al. (2006) konnten belegen, dass die Evolutionsrate nichtsynonymer Mutationen im mt-Genom bei Hunderassen deutlich 
höher ist als in Wölfen (Canis lupus), dieses Phänomen wird auf den nicht existierenden natürlichen Selektionsdruck in domestizierten Tieren zurückgeführt. Vergleicht man Hunde und Wölfe, so muss dieses Phänomen in die Auswertung mit einbezogen werden.

Die Rekonstruktion des phylogenetischen Systems der Tiere wird ebenfalls immer häufiger anhand mt-DNA vollzogen. Johns und Avise (1998) verglichen rund 2000 Sequenzen des cytb-Gens verschiedener Wirbeltiere und konnten einen nahezu identischen Stammbaum zum bereits existierenden erstellen. Ursing et al. (2000) konnten jedoch die Verwandtschaft der Paarhufer (Artiodactyla) anhand des kompletten mt-Genoms nicht klären, da hier die Schweine (Suinae) nicht eindeutig einzuordnen waren.

Die Identifikation von Spezies, wird heute hauptsächlich in der Lebensmittel-Industrie und der Forensischen Analytik (s. z.B. Pfeiffer 2007, Kitano et al. 2007) angewendet. Ziel ist es hierbei klar abzugrenzen, welche Spezies vorliegt, um sicher zu stellen, dass z.B. Hundefutter tatsächlich das enthält was angegeben ist (Marin et al. 2007). Bei der Untersuchung von musealen oder archäologischen Funden können anhand der genetischen Speziesidentifikation Aussagen über Herstellungsmaterialien, wie z.B. Pergamente aus Rinder- oder Ziegenleder (Burger et al. 2000), getroffen werden.

Die aufgeführten Beispiele zeigen die Stärken der Untersuchung mitochondrialer DNA, jedoch weisen sie bereits auch auf ihre Schwächen hin.

Inkonsistenzen in den Ergebnissen verschiedener Arbeitsgruppen treten durch mehrere Faktoren auf. Besonders zu erwähnen ist hier die Wahl der Stichprobe. Bei der Untersuchung von domestizierten Spezies darf nicht vergessen werden, dass die Herden-Haltung zu einer drastischen Reduktion des Genpools führt. So ist bekannt, dass jede Woche rund ein bis zwei Züchtungen der heute existierenden domestizierten Spezies verloren gehen können (Scherf 1995). Dies bedeutet, dass das genetische Material einer Vielzahl von Nachfahren durch den Prozess der Domestikation nicht mehr nachweisbar ist. Untersucht man ausschließlich eine bestimmte Population, so repräsentiert sie nur das aktuelle Bild, nicht jedoch den Domestikations- und Abstammungsprozess per se.

Hier kann die Untersuchung von aDNA durchaus eine Erweiterung des komplexen Bildes liefern, jedoch muss auch hier beachtet werden, dass es sich nur um einen Ausschnitt einer existierenden Genvielfalt handelt. 
Der Vererbungsweg der mt-DNA hat sowohl Vorteile als auch Nachteile. Nachteilig ist, dass es sich hierbei lediglich um die Untersuchung der maternalen Abstammung eines Individuums handelt, die paternalen Anteile werden nicht erfasst und so bleiben z.B. evt. Rückkreuzungen mit wilden männlichen Individuen unentdeckt. Von Vorteil ist, dass es sich bei ihr um ein nahezu nicht rekombinantes Genom handelt (Pakendorf und Stoneking 2005). Eine paternale Vererbung des mitochondrialen Genoms ist bisher nur für die Miesmuschel belegt (Pakendorf und Stoneking 2005). Dennoch gibt es immer wieder Berichte über Heteroplasmien (das Vorliegen von zwei verschiedenen mt-Genomen). Bandelt et al. (2005) führten dieses Phänomen hauptsächlich auf Fehler bei der Bearbeitung (Kontamination, Probenvertausch oder Fehler beim Einstellen in Datenbanken) zurück. Schwartz und Vissing (2002) dagegen berichten von einem Fall der eindeutigen Heteroplasmie. Hier lag im Muskelgewebe des untersuchten Mannes zu 90\% die paternale mt-DNA vor, im Blut konnte jedoch nur die mtDNA der Mutter bestimmt werden. Diese Mosaikbildung beruht wahrscheinlich auf einen Fehler in der Ubiquitination der Spermien mt-DNA, die normalerweise bis zur dritten embryonische Teilung sämtliche paternale mt-DNA zerstört (Sutovsky et al. 1999). Untersuchungen der Ubiquitination haben gezeigt, dass diese Spezies spezifisch ist (Sutovsky et al. 2000). Dies könnte erklären, warum z.B. Kreuzungen von Hausrindern (Bos taurus) und Gaurn (Bos gaurus) rekombinante mt-Genome aufweisen (Rokas und Caroll 2003). Ähnliches konnte in Hausmäusen (Mus musculus) und Fruchtfliegen (Drosophila spec.) nachgewiesen werden (McVean 2002). Statistisch gesehen ist es möglich, dass mt-DNA rekombiniert (Wiuf 2001). Auch wenn die Bedeutung der Rekombination mitochondrialer DNA im evolutiven Prozess eine wichtige Rolle gespielt haben dürfte (Korpelainen 2004), ist sie bei der Untersuchung von humaner DNA eher als nebensächlich $\mathrm{zu}$ betrachten. Bei der Untersuchung von Domestikation muss sie jedoch, aufgrund vielfältiger Zuchtprozesse wie z.B. Kreuzungen, als möglich angesehen werden und darf daher nicht außer Betracht gelassen werden.

Die Wahl des untersuchten Gens kann sich ebenfalls auf die Qualität der erwirtschafteten Erkenntnisse bezüglich der Artverwandtschaft auswirken. Zardoya und Meyer (1996) untersuchten die Qualität der mt-Gene hinsichtlich der Auftrennung zur Bestimmung der Artverwandtschaft. Als gute Marker benennen sie Nd4, Nd5, Nd2, cytb und COI, der Marker ATP6 dagegen wird, aufgrund seiner hohen Konservativität, als nicht ausreichend eingestuft. Russo et al. (1996) kommen zu einem ähnlichen Ergebnis und stufen Nd5, cytb und COI als am Besten geeignet ein. Sie fügen hinzu, dass es bei Anwendung dieser Gene keinen Unterschied macht, welche statistische Methode angewandt wird, da alle zum Ziel führen. 
Wie bereits in Kap. 2.1 erwähnt, ist die Mutationsrate des mitochondrialen Genoms ähnlich niedrig wie die des chromosomalen Genoms. Eine Ausnahme bildet die Hypervariable Region. Hier wird die Mutationsrate mit 0,075 - 0,165 x 10-6, in manchen Bereichen sogar mit $0,47 \times 10^{-6}$ (mutational hotspots) angegeben (Pakendorf und Stoneking 2005). Dieser Bereich ist aufgrund seiner hohen Mutationsrate nicht zur Speziesunterscheidung geeignet, da ein hier auftretender Polymorphismus zum Einen auf einen Art-Unterschied, zum Anderen aber auch auf eine individuellen Unterschied zurückgeführt werden kann. Dieser Bereich eignet sich jedoch hervorragend, um die maternale Variabilität und Verwandtschaft einer Population zu erfassen.

Erwähnt sei an der dieser Stelle die Verwendung molekularer Daten zur Bestimmung von Divergenzzeitpunkten, also des Zeitpunktes an denen sich zwei Arten voneinander abgegrenzt haben. Ausgehend von der heute bekannten Mutationsrate einzelner Gene wird hochgerechnet, welcher Zeitraum zum Erreichen einer bestimmten Polymorphie benötigt wurde (Zuckerkandel und Pauling 1962). Das mitochondriale Genom wird hier als "molekulare Uhr" verwendet. Hauptkritik an einem solchen Verfahren ist, dass die Mutationsraten als konstant angenommen werden (s. z.B. Shields 2004), d.h. Zufallsereignisse, genetische Drift, bottleneck-Situationen und natürliche Selektion werden völlig außer acht gelassen. Auch Prozesse wie Rekombination und Rückmutationen werden bei ihr nicht bedacht. Eine eigentliche Kalibrierung der molekularen Uhr ist also nicht möglich und die meisten Divergenzzeiträume werden deutlich älter datiert, als sie durch Fossilien belegt werden können. Douzery et al. (2004) schlagen eine molekulare Uhr vor, die nicht global, sondern angepasst an unterschiedlich anzunehmende Mutationsraten kalibriert wird. Ihr Modell der Bayesian relaxed molecular clock zeigt eine deutlich verbesserte Auftrennung, die weitestgehend mit paläontologischen Daten übereinstimmt. Eine Anwendung der molekularen Uhr muss also stets unter Berücksichtung des Evolutionsprozesses und ihrer Steuermechanismen erfolgen.

\subsubsection{Mikrosatelliten}

Mikrosatelliten sind Sequenzen tandemartiger, einfacher Sequenzwiederholungen. Sie werden als Short Tandem Repeats (STRs) bezeichnet (Edwards et al. 1991) und machen ca. $2 \%$ des Genoms aus. Sie kommen im nuklearen Genom, genauso wie im mitochondrialen Genom, vor (s. z.B. Jarne und Lagode 1996). Die häufigste Wiederholungseinheit sind Dinukleotide, 
wobei CA-Wiederholungen die Mehrzahl ausmachen. Tri- und Tetranukleotide sind seltener. Ein gemeinsames Merkmal der STRs ist, dass sie nicht kodierend sind und daher ein hohes $\mathrm{Ma}$ an Polymorphie aufweisen. Auf Ebene der autosomalen Chromosomen liegen sie immer biallelisch (zweifach) vor und ihre Vererbung erfolgt kodominant. Besitzt ein Individuum in einem STR (an einem Locus) auf beiden Chromosomen die gleiche Anzahl an Wiederholungseinheiten, so gilt dieser Locus als homozygot. Weist er unterschiedliche Ausprägungen auf, so gilt er als heterozygot. Die Anwendung der STR-Analyse liegt hauptsächlich im Bereich der Verwandtschafts- und Populationsanalytik. Aufgrund ihrer Eigenschaften zeichnen sie das $\mathrm{Maß}$ an Variabilität eines Individuums oder einer Population auf. Die Häufigkeit in der ein Allel in einer Population auftritt, wird als Frequenz bezeichnet. Die Rate der Heterozygoten für einen Locus, die sich aus der Anzahl der möglichen Allele (Allelrange) und ihrer Kombinationen herleitet, ist ein Maß der Variabilität. Die Heterozygotenrate ist ein Indikator für die Eignung eines STRs zur Unterscheidung von Individuen. Die Mutationsrate von autosomalen STRs wird zwischen 0 und $7 \times 10^{-3}$ angegeben. Mutationen sind meist ein single step Ereignis, welches auf slippage-Ereignisse (eine Fehlanlagerung der homologen DNA-Stränge), während der Zellteilung, zurückzuführen ist. Erfolgt keine Reparatur dieses Fehlpaarung, erfolgt der Zugewinn/Verlust einer oder mehrerer Wiederholungseinheiten. Die hohe Mutationsrate erklärt auch, warum STRs so hoch polymorph sind.

Die Wahl, welchen STR man untersucht, beruht jedoch nicht nur auf seiner Variabilität, auch seine Analysierbarkeit sollte bedacht werden. Nach Urquhart et al. (1994) soll der STR möglich wenig "Stottern". Das Stottern eines Allels ergibt sich durch das so genannte slippage. Dies kann nicht nur bei der Zellteilung auftreten, sondern auch bei der Amplifikation (Vermehrung) eines STRs. Hier kommt es zu Fehlern bei der Wiederanlagerung der beiden denaturierten DNA-Stränge und es entstehen Produkte, die um eine Wiederholungseinheit verschobenen sind (Hauge und Litt 1993). Meist sind diese eine Wiederholungseinheit kürzer, als der eigentliche STR (Hite et al. 1996). Dies führt zu Fehlinterpretationen bei der Auswertung der Ergebnisse. Die Tendenz zum slippage ist bei Dinukleotidwiederholungen am Höchsten, in Tri- und Tetranukleotiden kommt es deutlich seltener vor (Urquart et al. 1995). Daher wird, z.B. bei der Bestimmung des genetischen Fingerabdrucks, überwiegend auf Tetranukleotide zurückgegriffen.

Für menschliche STRs existiert eine vorgegebene Nomenklatur (s. z.B. Butler 2001). Bei Tieren hingegen existiert, außer für Rinder, kein Konsens über die Nomenklatur von STRs. 
Für die meisten Allele gibt es lediglich eine Größendefinition anhand des amplifizierten Produktes. Hier wird meistens von Fragmentlängenbereichen gesprochen, die den flankierenden Bereich des STRs mit einschließen, d.h. eine tatsächliche Aussage über die Anzahl der Wiederholungseinheiten wird nicht getroffen. Einer Verschiebung der Primer für einen bekannten Locus kann zur Veränderung der ursprünglichen Länge des zu amplifizierenden Fragmentes führen, da hierbei der analysierte umgebende Bereich des STRs verlängert oder verkürzt wird. Ein Grund der Veränderung von Primern kann das Erstellen von Multiplex-Ansätzen (s. z.B. Kimpton et al. 1993) sein. Die Analyse von STRs in aDNA erfordert meist eine drastische Verkürzung der Produkte und damit eine Veränderung der Primer (s. z.B. Schilz et al. 2004). Eine Vergleichbarkeit der Ergebnisse mit denen anderer Arbeitsgruppen ist, ohne einheitliche Nomenklatur, nicht mehr gegeben. Hier kann nur noch ein Vergleich der Variabilität in den Populationen durchgeführt werden.

STRs eignen sich aufgrund ihrer hohen Polymorphie hervorragend zur Verwandtschaftsklärung oder Individualtypisierung. So existieren, z.B. für Katzen, MultiplexAssays zur Bestimmung der Vaterschaft (Lipinski et al. 2007). Besonders in der Zucht von hochwertigen Tieren spielt die Abstammung eine wichtige Rolle und es besteht ein großes Interesse an der Rekonstruktion von Stammbäumen. In Herden, in denen die Individuen frei paaren dürfen (s. z.B. Gomez-Rya et al. 2008), kann die STR-Analyse Elternschaften aufklären. Aber auch die Erfassung von Variabilität einzelner Rinder-Herden ist von großem Interesse (s. z.B. Egito et al. 2007). Daneben können auch die Herkunft und die Rate von Inzucht einzelner Herden erfasst werden (s. z.B. Bicalho et al. 2006).

Anhand von STRs können auch evolutive Prozesse auf Populationsebene nachvollzogen werden. Eine deutliche Verringerung der Heterozygotenrate in einer Population gegenüber anderen Populationen kann z.B. auf einen bottleneck- oder Gründer-Effekt (s. Kap. 2.2.2) hinweisen (Luikart et al. 1998).

Zusammenfassend sind STRs ein guter Indikator für die Variabilität von Population und dienen der Individualtypisierung. Für die Phylogenetik sind sie weniger geeignet, da die meisten Loci nicht universell und daher nicht untereinander vergleichbar sind. 


\subsubsection{Identifikation des Phänotyps}

Der Phänotyp ist das äußere Erscheinungsbild eines Individuums. Neben morphologischen Eigenschaften, beschreibt er auch die physiologischen Eigenschaften eines Individuums. Die phylogenetische Systematik, die Artverwandtschaft hauptsächlich auf die morphologischen Charakteristika der Individuen zurückführt, bedient sich überwiegend des Phänotyps. Der Phänotyp hängt jedoch vom Genotyp (die Gesamtheit aller genetischen Merkmale) eines Individuums ab. Der Phänotyp ist das Ergebnis der Evolution, da Selektion nicht am Genotyp, sondern am Phänotyp, also der Anpassung an bestimmte Umweltbedingungen, ansetzt (Wiesemüller et al. 2003, S.73). Schon Darwin erkennt 1883 in seinem Werk „The variation of Animals and Plants under Domestication" (Darwin 2001, Kapitel XXV, S. 175-176), dass domestizierte Tiere bezüglich ihrer Erscheinung eine Variabilität aufweisen, die unter natürlichen Umständen letal wäre. Farbvariationen sind ein deutlich sichtbares, greifbares Merkmal des Phänotypus und können Ausdruck des evolutiven Prozesses sein. Das weiße Fell des Polarhasen (Lepus arcticus) z.B. bietet ihm in seiner natürlichen Umgebung (Grönland) einen guten Schutz vor Fressfeinden, im europäischen Mischwald dagegen wäre er leichte Beute. Der Schneehase (Lepus timidus) dagegen, der ein Tundra-Bewohner ist, vollzieht einen Farbwechsel des Fells, so dass er im Winter weiß und den Rest des Jahres graubraun ist. Die Pigmentierung als Teil des Phänotypus stellt also ein wichtiges Adaptationskriterium dar. Die Farbpigmente eines Individuums werden in den so genannten Melanozyten (Pigmentzellen) gebildet. Die Melanozyten wurden nach dem zuerst bekannten Pigment, dem schwarzen Melanin, benannt (Westerhof 2006). Melanozyten liegen in der Epidermis (Stratum spinosum), in den Haarfollikeln und dem Stroma der Iris. Bei nachtaktiven Tieren liegen darüber hinaus im so genannten Tapetum lucidum des Auges, das direkt hinter der Netzhaut liegt, Pigmentzellen vor.

In den Melanozyten werden die Proteine Eumelanin (ein schwarz-braunes Pigment) und Phäomelanin (ein rot-gelbes Pigment) gebildet. Diese werden dann in so genannten Melanosomen gespeichert und in die Zellen des jeweiligen Gewebes transportiert. Das Verhältnis beider Proteine zueinander ist ausschlaggebend für die Farbausprägung des Gewebes. In Tieren mit dunkler Fellfarbe existiert z.B. kaum oder gar kein Phäomelanin in den Keratinzellen des Haars. In Abbildung 20 ist die Entstehung der beiden Farbpigmentproteine dargestellt. 


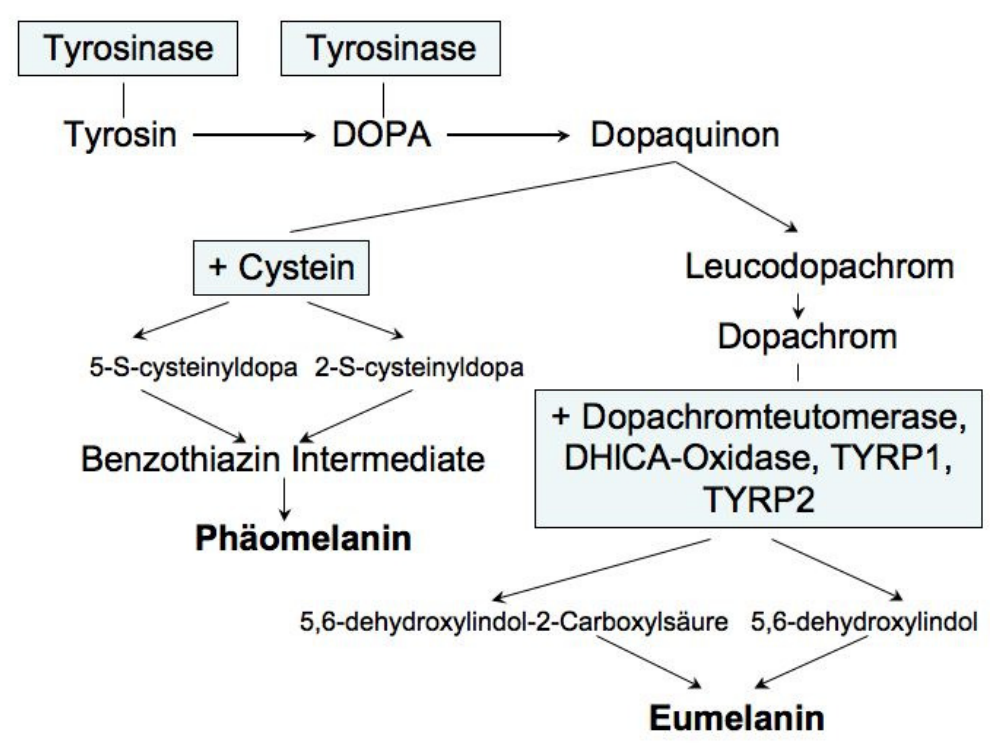

Abbildung 20: Darstellung der Melaningenese, nach Kobayashi et al. 1995

Die Produktion und der Transport der Farbpigmente sind abhängig von einer Vielzahl an Enzymen, die wiederum durch verschiedenen Gene determiniert werden. Die Variabilität der Farbausprägung beruht auf Punktmutationen (SNPs) in diesen Genen.

Einige der wichtigsten Gene, die mit der Ausprägung von Haarfarben assoziiert sind, sollen kurz vorgestellt werden.

Der Melanocortin-Rezeptor 1 (MC1R) spielt eine Schlüsselrolle bei der Aktivierung der Melaningenese (Rees 2000). Das hierfür codierende Gen liegt auf dem Chromosom 16 (16q24.3) und seine Aktivierung führt zu einer Erhöhung des cAMP-Spiegels, der wiederum, durch die Bindung des Hormons $\alpha$-MSH, die Tyrosinase Aktivität beeinflusst (Busca und Gallotti 2000). Mutationen in diesem Gen sind unter anderem mit der schwarzen Farbe bei einigen Fuchsarten (Vage et al. 1997) oder der Farbvariabilität in Kaninchen (Fontanesi et al. 2006) assoziiert.

Das Agouti-Signaling-Protein (ASIP) ist der Antagonist zum MC1R Gen und erhöht im aktiven Zustand die Produktion von Phäomelanin (Bonilla et al. 2005). Es liegt auf Chromosom 20 (20q11.2-q12) und bei Aktivierung verhindert es die Bindung von $\alpha$-MSH und die Eumelanin-Produktion wird gebremst. Die Ausschüttung von ASIP reguliert also letztendlich, ob und wie viel Melanin produziert wird. Mutationen in diesem Gen werden in Pferden mit einer dunkeln Fellfarbe assoziiert (Rieder et al. 2001). In Rindern (Royo et al. 2005), Schweinen (Kim et al. 2004) und Hunden (Kerns et al. 2004) konnte bisher jedoch keine Assoziation zwischen Mutationen im ASIP-Gen und Farbausprägung nachgewiesen werden. 
Das Tyrosinase Gen (TYR) sowie das Tyrosinase-assozzierte-Protein1-Gen (TYRP1) exprimieren die Schlüsselenzyme in der Melaningenese (s. Abb. 20). Mutationen in diesen Genen können zu Albinismus führen (s. z.B. Schmidt-Künzel et al. 2005). Sie sind auf Chromosom11 (11q14-q12) lokalisiert. Neben ihrer Rolle in der Ausprägung von Albinismus, sind sie jedoch auch mit der Ausprägung von Leuzismus bzw. Piebaldismus (scheckig) assoziiert (Norton et al. 2007). So erhält z.B. der Dalmatiner seine Flecken durch Mutationen im TYRP1-Gen (Cargill et al. 2005). In anderen Spezies wie Katzen und Kühen (Lyons et al. 2005 und Berryere et al. 2003) werden Mutationen in den Genen TYR und TYRP mit einfachen Farbänderungen, wie brauner oder roter Fellfarbe, assoziiert.

Die Analyse der Pigment-Gene dient nicht nur der reinen Bestimmung von Farbausprägungen, sie werden auch für die Rekonstruktion phylogenetischer Beziehungen eingesetzt. So konnten Klungland et al. (1999) anhand der Analyse des MC1R-Gens in Artiodactyla den Stammbaum dieser nachverfolgen und die bisher angenommene Artverwandtschaft bestätigen. Die phylogenetischen Beziehungen der Primaten konnten anhand des ASIP-Gens bestätigt werden (Mundy und Kelly 2006). Die Gene der Pigmentierung stellen, durch ihren hohen Grad an Konservation und bei Sequenzierung des gesamten Gens, ein geeignetes Werkzeug zur Rekonstruktion von Stammbäumen dar. Bei Betrachtung relativ kurzer Abschnitte dieser Gene sollten jedoch keine Rückschlüsse auf phylogenetische Beziehungen gezogen werden, da die gefundenen Mutationen auch auf anderen Prozessen (wie z.B. Domestikation, s. Kap. 1.2) beruhen können.

\subsection{Biologische Grundlagen: Evolution und Systematik}

Evolution bezeichnet den Wandel und die Manifestation von Merkmalen in einer Population. Diese Merkmale können biologischer und kultureller Natur sein. Im Folgenden werden die biologische Evolution und ihre Steuermechanismen erläutert. Unter Systematik versteht man die Gliederung von Elementen zur Übersichtsgewinnung. Hier soll auf die biologische Systematik eingegangen werden, in der versucht wird, die heute existente biologische Diversität hinsichtlich Ähnlichkeiten/Verschiedenartigkeit zu ordnen. Die Grundzüge der Populationsgenetik, also die Erfassung der genetischen Variabilität von und zwischen Populationen, werden dargestellt und sollen dem Verständnis der in dieser Arbeit erfolgten statistischen Auswertungen der Ergebnisse dienen. 
2.2.1 Historischer Überblick und Formulierung der Evolutionstheorien

Schon in der Antike beschäftigten sich die Menschen mit der Ordnung der biologischen Vielfalt. Aristoteles ordnete in seinem Werk "Scala naturae" Organismen je nach Grad ihrer Perfektion, in der äußeren Gestalt und ihrem Lebensraum. Bis zum Zeitalter der Aufklärung existierte zwar ein Blick für die Variabilität, eine Begründung für diese sah man jedoch in Gott als kreierendem Wesen. Das 18. Jh. war zum Einen geprägt durch den wissenschaftlichen Fortschritt, zum Anderen durch die Bewegung der Säkularisierung, in der die Abkehr von ideologischen Vorstellungen, hin zu einer Erkenntnis der Phänomene, durch das Mittel der Vernunft, erlangt werden sollte (s. z.B. Schneiders 2001). Carl von Linné schuf mit seinem Werk "Systema naturae" 1735 ein monumentales Werk der Systematik. Er war der Erste, dem es gelang eine umfangreiche Ordnung der Tiere und Pflanzen durch hierarchisches Strukturieren zu erstellen. Linné führte die binäre Nomenklatur, also die Vergabe von Gattungs- und ArtNamen, ein. Er erkannte auch, dass Hybride in der Natur vorkommen, die eine Speziesunterscheidung erschweren. Linné sortierte jedoch lediglich, die Ursache für die Entstehung der Mannigfaltigkeit sah er in Gott. Neben Linné gab es in dem Zeitalter der Aufklärung eine Vielzahl weiterer Wissenschaftler die versuchten eine Ordnung in die Vielfalt des Lebens zu bringen und die maßgeblich durch Georges Leclerc de Buffon (1707-1788) und Louis Daubenton (1716-1880) hervorgebrachte vergleichende Anatomie entstand. Georges Cuvier (1769-1832), obwohl eigentlich Paläontologe, systematisierte eine Vielzahl von Organismen und stellte diese in seinem Buch "Règne animal" 1817 vor. Er postulierte, dass die Ähnlichkeiten zwischen Spezies auf die gleiche Funktion zurückzuführen seien und Form und Funktion kausal abhängig wären. Er konnte bei seiner Forschung eine Konstanz der Arten ausmachen. Bei Ausgrabungen fiel ihm auf, dass Fossilien in bestimmten chronologischen Erdschichten zu finden sind, in anderen aber gänzlich fehlen. Dies führte zu seiner Annahme, dass Spezies durch universale Katastrophen ausgelöscht werden. Simultan zu Cuvier stellte Étienne Geoffrey de Saint-Hillaire (1772-1844) in seinem Werk „Philosophie anatomique“ die Theorie eines gemeinsamen Bauplanes von Vertebraten und Invertebraten vor. Er benannte diese Gemeinsamkeiten als Analogien. Charles Lyell (1779-1845) stand Cuvier kritisch gegenüber, da er bei seinen geologischen Forschungen keinerlei universelle Katastrophen ausmachen konnte. Er vermischte in seinem Buch "Principals of geology" (1830) die Ansätze des Aktualismus, also die Theorie der Gleichförmigkeit geologischer Prozesse über die Jahrtausende, von James Hutton (Theory of the Earth, 1785) mit der von ihm entwickelten Idee des Gradualismus, also der langsamen stetigen Entwicklung und Summierung kleinster Wandlungsprozesse. Karl Ernst von Baer (1792-1876) beschäftigte sich mit der 
Embryonalentwicklung von Lebewesen, er erkannte zwar die Ähnlichkeiten der Embryonen höherer und niederer Tiere, einen Zusammenhang zwischen Ontogenese und Phylogenese lehnte er jedoch strikt ab (Storch et al. 2001, S. 11f). Erst durch die Arbeit von Jean Baptiste Lamarck (1744-1829) entstand die erste Evolutionstheorie. Diese basiert auf der Annahme, dass Spezies durch Gebrauch oder Nichtgebrauch von Organen entstehen und diese Eigenschaften an ihre Nachkommen vererbt werden. Er schuf die "teleologische Evolutionstheorie“ in der jeder Wandel zielgerichtet und zweckdienlich ist. Die „Abtrennung der Biologie von Gott“ (Mayr 2000) gelang jedoch erst Charles Darwin 1859 mit seinem Werk "On the Origin of species by means of natural slection: or the preservation of favoured races in the struggle of life“. Aufgrund der Erfassung von Organismen, die er während seiner Weltreise beobachtet hatte, stellte er die These auf, dass alle existierenden Arten Deszendenz aufweisen. Diese Deszendenz verliefe jedoch nicht graduell, sondern würde sich an vielen Stellen verzweigen. Dieser Prozess des Wandels sei ein stetiger und allmählicher. Zu einem ähnlichen Ergebnis kam zeitgleich Alfred Russel Wallace (1823-1913), der aufgrund seiner langjährigen Freilandforschung ähnliche Prozesse beobachten konnte. Jedoch beschrieb Wallace lediglich die Wirkung der Evolution, eine Erkenntnis der Ursache fehlte. Darwin jedoch konnte einen Grund für den Wandel der Arten benennen. Er bemerkte, dass Arten in der Regel mehr Nachwuchs produzieren, als für die Erhaltung der Art nötig wäre. Hierdurch entstünde eine zunehmende Konkurrenz um die vorhandenen Ressourcen ("struggle for life"). In einem solchen Konkurrenzkampf würden jedoch nur diejenigen überleben, die eine bessere Anpassung an ihre Umwelt aufweisen ("survival of the fittest"). Dies wiederum führt zu einer Anhäufung der Merkmale der Überlebenden, was wiederum zu einem allmählichen Wandel der Art führt. Diesen Gesamtprozess bezeichnete Darwin als natürliche Selektion. Darwins Theorie hat im Wesentlichen bis heute bestand. Weitere wichtige Entdeckungen des 19. Jh. waren z.B. die Beobachtung des Auftretens von Homologien, also die Realisation von Merkmale mit gleicher evolutionärer Herkunft die unterschiedlicher Funktion seien können, und von Analogien, also Merkmale mit unterschiedlicher Herkunft jedoch gleicher Funktion, durch Richard Owen ("Lectures on Comparative Anatomy and Physiology", 1834). Trotz dieser Beobachtungen war Owen bekennender Gegner von Charles Darwin.

Gregor Mendel (1822-1914) begründete aufgrund seiner Kreuzungsversuche mit Erbsenpflanzen die Vererbungslehre und formulierte die "Mendelschen Regeln" die bis heute bestand haben. Diese belegen, dass äußerliche Merkmale durch die Vererbung definiert werden. Richard von Hertwig und Oskar Hertwig entwickelten 1881 gemeinsam die Coelomtheorie. Sie beschrieben die Funktion des mittleren Keimblatts (Mesoderm) in einer Vielzahl von Gewebetieren (Eumetazoa). Ernst Haeckel formulierte 1874: „Die Ontogenie ist 
eine kurze Recapitulation der Phylogenie.“ (Haeckel 1874, S. 7). Damit drückt er seine Beobachtung aus, dass während der Ontogenese der gemeinsame Ursprung aller Arten ersichtlich wird. Haeckel und August Weissmann (1834-1914) sind die Wissenschaftler, die maßgeblich zur Verbreitung Darwins Schriften in Deutschland beigetragen haben. Weissmann machte den Evolutionsprozess hauptsächlich an der Beobachtung von Keimzellen fest. Er nahm an, dass Veränderungen nur über das Keimplasma weitergegeben werden.

Zu Beginn des 20. Jh. wurde das Forschungsfeld der Genetik stark fokussiert. Thomas Hunt Morgan (1866-1945) konnte anhand seiner Drosophila-Forschung belegen, dass das Vererbungsmaterial nicht im Keimplasma liegt, sondern in Chromosomen organisiert ist. Er kartierte für Drosophila eine Vielzahl von Genen. Oswald Avery publiziert 1944 einen Artikel, in dem er verschiedene Proteine von Pneumokokken untersuchte und feststellte, dass die Erbinformation in der DNA lokalisiert ist. 1953 publizierten James Watson (1928) und Francis Crick (1916-2004) ihr Modell der Nukleinsäuren, die so genannte DNA-Doppelhelix, oder auch Watson-Crick-Modell. Zeitgleich entstand die "synthetische Evolutionstheorie". Geprägt hat diesen Begriff Julian Huxley in seinem Werk "Evolution: A Modern Synthesis" 1944. Als wichtigste Vertreter sind neben Julian Huxley, Sewall Wright (1889-1988), Ronald Fisher (1890-1962), Theodosius Dobzhansky (1900-1975), John Haldane (1892-1964), George Gaylord Simpson (1902-1984) und Ernst Mayr (1904-2005) zu nennen. Die synthetische Evolutionstheorie sieht die Population als kleinste Einheit an der Evolution ansetzen kann. Als Mechanismus wird die natürliche Selektion gesehen und die Evolution wird als gradueller Wandel, also als Summierung kleiner Veränderungen, verstanden. Um die evolutiven Prozesse zu erkennen wird nicht nur die Variabilität in der Morphologie der Individuen einer Population, sondern auch ihre genetische Variabilität betrachtet. Auch der Zusammenhang zwischen Biologie und Ökologie wird berücksichtigt.

Zwei weitere Evolutionstheorien sollen an dieser Stelle kurz erwähnt werden: die "Systemtheorie der Evolution" (Riedel 1978 in Wagner und Laubichler 2004) und die "Hydroskeletttheorie" (auch "Frankfurter Theorie" genannt, Gutmann 1995).

Rupert Riedel gibt an, dass bestimmte Evolutionsprozesse als nicht-adaptiv zu sehen sind, dies beruhe auf die Konditionen des „Systems der Funktionen des Organismus“, die er als body plan bezeichnet. Die Rate mit der eine Spezies zur Evolution befähigt ist, sieht er als Freiheitsgrad dieses Plans, der durch Präadaptionen möglich sei. Er fügt der natürlichen (äußeren) Selektion den Begriff der inneren Selektion hinzu, welche die Last des Organismus darstellt, d.h. dass an einem Organismus die äußere Selektion nur ansetzen kann, wenn die innerlichen Konditionen dies zulassen. Die epigenetische Landschaft eines Organismus ist also nicht rein zufällig veränderbar, sondern ist von seinen Systemzusammenhängen abhängig. 
Die Hydroskeletttheorie verfolgt einen ähnlichen Ansatz wie die Rupert Riedls. Auch hier wird nicht die Population, sondern der Organismus an sich betrachtet. Die Theorie stützt sich maßgeblich auf konstruktionsmorphologische Untersuchungen hydraulischer Räume der Organismen. Hierbei wird nicht die Phylogenese untersucht, sondern die Anagenese, also der graduelle Merkmalswandel, den ein Organismus bis zur Artabspaltung durchläuft. Die natürliche Selektion spielt auch hier eine untergeordnete Rolle, da die Konstruktion des Organismus selbst die Veränderung (also letztendlich die Evolution) bestimmt, verursacht und richtet. Damit erlaubt sie dem Organismus bestimmte ökologische Nischen zu erschließen. Die Hydroskeletttheorie hat bisher eine Vielzahl möglicher Abstammungsprozesse nachvollzogen, die Ergebnisse sind überwiegend mit denen molekulargenetischer Ergebnisse kongruent. Die Möglichkeiten dieses Ansatzes sollten daher nicht unterschätzt werden. Da ihre Anwendung jedoch eine relativ neue Forschungsrichtung ist, soll sich im Folgenden überwiegend an der synthetischen Evolutionstheorie orientiert werden.

\subsubsection{Evolutionsmechanismen und Systematik}

Um die Entstehung von Arten zu untersuchen, muss zunächst der Artbegriff definiert werden.

Die existierenden Artkonzepte können in zwei Komplexe, basierend auf ihrem Untersuchungsansatz, unterteilt werden: merkmals-basierte und prozess-basierte Artkonzepte (Lowe et al. 2005, S. 190ff). Tabelle 6 fasst die gängigen Artkonzepte zusammen.

Tabelle 6: Artkonzepte und ihre Prinzipien

\begin{tabular}{|l|l|l|}
\hline Basis & Konzept-Name & Prinzip \\
\hline Merkmal & Taxonomische Spezies & $\begin{array}{l}\text { Eine Art definiert sich über gemeinsame morphologische Merkmale, die } \\
\text { nur ein geringes Maß an Variabilität aufweisen. (Linné) }\end{array}$ \\
\cline { 2 - 3 } & $\begin{array}{l}\text { Numerisch taxonomische } \\
\text { Spezies }\end{array}$ & $\begin{array}{l}\text { Eine Art definiert sich über phänetisch determinierte Merkmale, die sie } \\
\text { gegenüber anderen Arten unterscheiden (Sokal und Crovello 1970). }\end{array}$ \\
\cline { 2 - 3 } & Phylogenetische Spezies & $\begin{array}{l}\text { Eine Art ist die kleinste Gruppe von Individuen, in denen parentale } \\
\text { Muster der Abstammung und Ahnenschaft erkenntlich werden } \\
\text { (Crarcraft 1983). }\end{array}$ \\
\cline { 2 - 4 } & Evolutionäre Spezies & $\begin{array}{l}\text { Eine Art zeichnet sich durch eine ihr eigenen Evolutionslinie aus, die } \\
\text { ihre Identität beibehält (Simpson 1961, Wiley 1978). }\end{array}$ \\
\cline { 2 - 3 } & Biologische Spezies & $\begin{array}{l}\text { Eine Art ist eine Gruppe potentiell fruchtbarer natürlicher Populationen, } \\
\text { die reproduktiv von anderen isoliert ist. (Dobzhansky 1939, Mayr 1947). }\end{array}$ \\
\cline { 2 - 3 } & Spezies & $\begin{array}{l}\text { Eine Art teilt sich ein identisches Paarungssystem, dass nur von dieser } \\
\text { als solches erkannt wird (Patterson 1985). }\end{array}$ \\
\cline { 2 - 3 } & Öbäsive Spezies & $\begin{array}{l}\text { Eine Art wird durch bestimmte kohäsive Kräfte, die nur ihr eigen sind, } \\
\text { bestimmt (Templeton 1989). }\end{array}$ \\
\cline { 2 - 3 } & Ökologische Spezies & $\begin{array}{l}\text { Eine Art zeichnet sich durch die Besetzung einer gemeinsamen } \\
\text { okologischen Nische aus, welche die gleiche genetische Entwicklung } \\
\text { voraussetzt (van Valen 1976). }\end{array}$ \\
\cline { 2 - 3 } & Ökogenetische Spezies & $\begin{array}{l}\text { Jede Art zeichnet sich durch einen einzigartigen Weg des Lebens } \\
\text { (genetisch und ökologisch) aus, der zu Reproduktionsbarrieren führt } \\
\text { (Levin 2000). }\end{array}$ \\
\hline
\end{tabular}


Jedes dieser Artkonzepte enthält Ansätze, die in die Beurteilung von Spezies angebracht sind. Die merkmalsorientierten Artbegriffe, speziell das der phylogenetischen Spezies, beruht auf morphologischen Unterschieden und einzigartigen Neukombinationen. Als Kritikpunkt kann genau dieses beurteilende Verfahren angebracht werden, da dies von Subjektivität geprägt ist (s. z.B. Mayer 2000a und Meier und Willmann 2000a). Die Artkonzepte der kohäsiven, ökologischen und ökogenetischen Spezies sind zwar in der Lage einen Zustand zu beschreiben, jedoch beantworten sie nicht die Frage nach dem Grund für Speziesbildung (Mayr 2000a). Das biologische Artkonzept erscheint als einziges sinnvoll, da es sich von der reinen Beurteilung äußerlichen Merkmalen distanziert und die Biologie der Tiere an die erste Stelle setzt.

Das Konzept der biologischen Spezies bedarf einiger weiterer Ausführungen. Die reproduktive Isolation, die zu einer Spezies führt, wurde von Dobzhansky (1937) definiert. Sie kann entweder präzygotischer (verhinderte Paarung und Befruchtung) oder postzygotischer (Auswirkungen erst nach der Befruchtung) Natur sein. Präzygotische Barrieren von Populationen können die geographische Trennung, Unterschiede in den Verhaltensmodi und der Anatomie sowie die Inkompatibilität von Gameten sein. Postzygotische Barrieren können die Sterblichkeit von Hybriden, eine verringerte Fruchtbarkeit von Hybriden oder die Sterilität von Nachkommen der Hybriden sein. Haldane (1922, nach Coyne 1985) beschreibt, dass wenn innerhalb der Nachkommen zweier Individuen unterschiedlicher Spezies ein Geschlecht abwesend, selten oder steril ist, so sei dieses Geschlecht das heterogametische Geschlecht. Ein Beispiel hierfür ist z.B. dass Hybrid-Nachkommen von Rind (Bos taurus) und Yak (Bos gruniens) Fertilität aufweisen, wenn sie weiblich (XX) sind. Sämtliche männliche Nachkommen (XY) sind hingegen steril (Takase et al. 2002).

Die Entstehung von neuen Arten kann als genetische Differenzierung einer Population, die zu reproduktiver Isolation führt, gesehen werden. Sie kann allopatrisch, also durch reproduktive Isolation mit geographischer Isolation, oder sympatrisch, also durch reproduktive Isolation ohne geographische Isolation, verlaufen. Ein Extrembeispiel der allopatrische Speziation ist die adaptive Radiation. Sie bezeichnet die Migration von vielen Spezies in ein neues geographisches Areal (z.B. Inselmodell). Da hier neue Nischen offen stehen, kommt es zu einer schnellen und explosionsartigen Anpassung und damit zu der Neuentstehung von Eigenschaften und der Bildung endemischer Arten. Die Modi der Speziation können am Besten anhand der genetischen Struktur einer Population nachvollzogen werden. Nach dem Hardy-Weinberg-Gesetz ändert sich der Genpool einer Population nicht, wenn weder Migration, Selektion, noch Mutationen wirken und sich die Individuen zufällig paaren (Panmixie). Die Population gilt dann als ideal und die Allelfrequenz bleibt konstant. Die 
Mikroevolution, also die Evolution auf Populationsniveau, geht jedoch von einem Wandel in der genetischen Zusammensetzung einer Population aus. Mechanismen hierfür sind entweder adaptiv oder nicht. Als einziger adaptiver Mechanismus gilt die natürliche Selektion. Nicht adaptiv sind: die genetische Drift (Sewall-Wright-Effekt), sie bezeichnet die zufällige Veränderung des Genpools, der Genfluss, also der Austausch von Genmaterial zwischen Populationen, und Mutationen (s. Kap. 2.1). Ein weiterer nicht-adaptiver Mechanismus ist die nicht-zufälligen Paarung, d.h. einige Individuen der Population haben einen höheren Reproduktionserfolg als andere. Zwei Extrem- Beispiele der genetischen Drift sind der bottleneck- und der Gründer-Effekt. Beide bewirken eine deutliche Reduktion des Genpools, der bottleneck-Effekt ist jedoch das Resultat einer Katastrophe (z.B. epidemische Ereignisse), der Gründer-Effekt bezeichnet dagegen die Isolation eines Teils einer Population, der andernorts eine neue Population gründet. Entstehen Arten durch Gründer-Effekte kann man dies als saltationale Speziation bezeichnen. Auch Hybride können zur Neubildung von Arten führen (s. z.B. Mavárez et al. 2006). Hybride sind entweder flüchtig, d.h. sie entstehen lokal durch sekundären Kontakt zweier artverwandter Individuen, werden jedoch von der Selektion benachteiligt und haben wenige oder keine Nachkommen, oder sie weisen ein Merkmalsmosaik auf, dass die Invasion in ein bestehendes Habitat oder ein neues ermöglicht. So sind z.B. die meisten polyploiden Pflanzenarten durch Hybridisierung entstanden (Steen et al. 2000).

Introgression ist ein weiterer Mechanismus der Speziation, hier reichern sich bestimmte Allele in einem Genpool an und es bildet sich eine neue Spezies.

Morphologische Varianten müssen nicht immer artspezifisch sein. Änderungen eines Charakters des Phänotyps können geographisch determiniert sein, man spricht hier von so genannten Clines (Huxley 1938), die in der Regel mehrere Subspezies umfassen. Auch morphologisch identische, jedoch geographisch isolierte Arten kommen vor, diese werden dann als Con- oder Zwillingsspezies benannt, wenn keine reproduktive Isolation vorliegt.

Die Ordnung der Arten wird in der Systematik vollzogen. Hierfür gibt es drei verschiedene Ansätze: Die Phänetik (Numerische Klassifikation), Evolutionäre Systematik und die Kladistik (Phylogenetische Systematik). Die Phänetik orientiert sich an messbaren Unterschieden der Arten. Diese gemessenen Distanzen werden dann in Divergenzmatrices übersetzt (s. Kap. 2.3) und erlauben so eine Rekonstruktion der Aufspaltung von Arten. Die populationsgenetischen Methoden, die zur Stammbaumrekonstruktion angewendet werden, können dieser Systematik zugeordnet werden. Die Evolutionäre Systematik hat es sich zum Ziel gemacht nicht nur die Abspaltungsfolge von Arten zu rekonstruieren, sondern darüber hinaus auch den 
Entstehungszeitpunkt neuer einzelner Merkmale zu erkennen. Mayr (1974) bezeichnet diese Vorgehensweise als Rekonstruktion typologischer Ähnlichkeitsmaßstäbe, die auf homologen (gleiche Abstammung eines Merkmals) sowie analogen (gleiche Funktion eines Merkmals, jedoch konvergente Evolution) Merkmalen festgemacht wird. Die phylogenetische Systematik rekonstruiert die zeitliche Reihenfolge der Entstehung neuer Arten, ihre Darstellungsform ist das Kladogramm. Ihre Methodik beruht hauptsächlich auf der Untersuchung von Homologien, wobei diese aufgrund ihrer Abstammung determiniert werden. Merkmale sind entweder abgeleitet (Apomorphien) oder ursprünglich (Plesiomorphien). Teilen sich zwei Spezies ein gemeinsam abgeleitetes Merkmal, so nennt man dies Synapomorphie. Die Kriterien für homologe Merkmale wurden von Remane (1952) festgelegt. Diese sind das Kriterium der Lage, der Kontinuität und der spezifischen Qualität.

Eine wichtige Einheit der Systematik ist das Taxon. Es bezeichnet eine systematische Einheit von einer Gruppe von Lebewesen. Ein Taxon kann sich aus Arten, Gattungen, Familien o.ä. zusammensetzen, je nach dem auf welcher hierarchischen Ebene man systematisiert. Ein Taxon wird als monophyletisch bezeichnet, wenn ein gemeinsamer Vorfahr alle Arten des Taxon hervorgebracht hat, polyphyletisch bezeichnet die Abstammung von mehreren Vorfahren, die nicht allen Arten gleich sind, und paraphyletisch die Abstammung eines Taxon von einem Vorfahr, der auch andere Taxa hervorgebracht hat.

Egal für welches System man sich entscheidet, alle basieren auf Gradualismus, d.h. dem langsamen und stetigen Wandel von Merkmalen. Eldrege und Gould (1972) greifen die Frage des Gradualismus der Evolution auf. Ihrer Meinung nach können die Fossil-Funde nicht mit Gradualismus erklärt werden. Sie nehmen an, dass Spezies schnell entstehen und nur aus einer kleinen Ursprungspopulation hervorgehen und lediglich in der Peripherie zu finden sind. Hieraus folgern sie, dass ein solches Ereignis nicht im Faunenschnitt festzustellen wäre. Sie benennen ihre Theorie der rapiden Entwicklung als Punktualismus. Millien (2006) konnte belegen, dass Spezies in geographischer Isolation eine bis zu drei Mal höhere Evolutionsrate aufweisen. Er erklärt dieses Phänomen mit einer hohen Kapazität der Organismen zur Anpassung an neue ökologische Bedingungen. Dies ist jedoch kein Beleg für Punktualismus, denn auch wenn der morphologische Wandel schneller abläuft, ist er gradueller Natur. Blumler (1996, S. 38) geht davon aus, dass die Wahrheit der Evolutionsgeschwindigkeit zwischen Punktualismus und Gradualismus liegt, da es durchaus zu punktualistischen Ereignissen kommt, aber Gradualismus parallel vorliegen kann. Für welches Modell man sich hier entscheidet, ist auch abhängig vom betrachteten Zeitraum. Gerechnet auf die Gesamtexistenz einer Spezies, ist ihre Evolution tatsächlich als rapide zu betrachten, 
betrachtet man jedoch den Zeitraum der Evolution an sich, so sieht man keine spontane Veränderung der Spezies, sondern einen stetigen graduellen Wandel.

Die Erkenntnis über die Evolution einer Spezies, bedarf also der Betrachtung einer Vielzahl an Mechanismen und der Betrachtung der ökologischen Bedingungen. Eine Verknüpfung der biologischen Komponenten mit denen der Ökologie ist unverzichtbar.

\subsection{Biologische Grundlagen: Populationsgenetik}

Die Populationsgenetik beschäftigt sich mit der Untersuchung der genetischen Zusammensetzung einer Population. Neben der Anwendbarkeit von genetischen Systemen in der Populationsuntersuchung, werden die statistischen Auswertungsmöglichkeiten dargestellt. In Tabelle 7 sind die wichtigsten genetischen Marker und ihr Potential in der Populationsgenetik dargestellt.

Tabelle 7: Darstellung möglicher Marker und ihrer Anwendung (nach Lowe et al. 2005)

\begin{tabular}{|c|c|c|c|}
\hline Marker & Anwendung & Vorteil & Nachteil \\
\hline Allozyme & $\begin{array}{l}\text { Gendiversität, } \\
\text { Populationsstruktur, } \\
\text { Hybridisierung, } \\
\text { Introgression, Genfluss, } \\
\text { Polyploidie }\end{array}$ & $\begin{array}{l}\text { Gut untersucht, } \\
\text { einfach zu } \\
\text { analysieren, günstig }\end{array}$ & Geringe Polymorphie \\
\hline $\begin{array}{l}\text { Restriktionsfragmentlängenpoly- } \\
\text { morphismen (RFLPs) }\end{array}$ & $\begin{array}{l}\text { Gendiversität, } \\
\text { Populationsstruktur, } \\
\text { Hybridisierung, } \\
\text { Introgression, Genfluss, } \\
\text { Phylogenie und } \\
\text { Phylogeographie }\end{array}$ & $\begin{array}{l}\text { Sehr spezifisch, } \\
\text { kodominante } \\
\text { Vererbung }\end{array}$ & $\begin{array}{l}\text { Hohe DNA-Menge } \\
\text { benötigt, Mutation muss } \\
\text { Restriktionsstelle } \\
\text { aufweisen }\end{array}$ \\
\hline Mikrosatelliten & $\begin{array}{l}\text { Gendiversität, } \\
\text { Populationsstruktur, } \\
\text { Genfluss, } \\
\text { Verwandtschaft }\end{array}$ & $\begin{array}{l}\text { kodominante } \\
\text { Vererbung, hohe } \\
\text { Mutationsrate }\end{array}$ & $\begin{array}{l}\text { Neuentwicklung teuer, } \\
\text { Stotterer, gelegentlich } \\
\text { nicht speziesspezifisch }\end{array}$ \\
\hline $\begin{array}{l}\text { Amplifizierterfragmentlängen- } \\
\text { Polymorphismus (AFLPs) }\end{array}$ & $\begin{array}{l}\text { Gendiversität, } \\
\text { Populationsstruktur, } \\
\text { Kreuzungsstudien }\end{array}$ & hochpolymorph & $\begin{array}{l}\text { Hohe DNA-Menge nötig, } \\
\text { Produkthomologien }\end{array}$ \\
\hline Sequenzen & $\begin{array}{l}\text { Gendiversität, } \\
\text { Populationsstruktur, } \\
\text { Hybridisierung, } \\
\text { Introgression, Genfluss, } \\
\text { Polyploidie, Phylogenie, } \\
\text { Phylogeopraphie, } \\
\text { Verwandtschaft }\end{array}$ & $\begin{array}{l}\text { Einfach und } \\
\text { hochqualitativ, } \\
\text { hohe } \\
\text { Vergleichbarkeit, } \\
\text { Universalprimer } \\
\text { erhältlich }\end{array}$ & $\begin{array}{l}\text { teuer, } \\
\text { Heterozygotieerkennung } \\
\text { schwierig }\end{array}$ \\
\hline
\end{tabular}

Genetische Diversität bezeichnet den Anteil von Variation in einer Population, anders ausgedrückt beschreibt sie die Reichhaltigkeit an Allelen oder polymorpher Loci in einer Population. Nei (1973) bezeichnet sie als Ausdruck der erwarteten Heterozygoten in der Gesamtpopulation, mit p als Frequenz des iten von K Allelen. 


$$
\mathrm{H}_{(\mathrm{T})}=1-\sum_{\mathrm{i}=1}^{\mathrm{i}=\mathrm{K}} \overline{\mathrm{p}}_{\mathrm{i}}^{2}
$$

Die Frequenz eines Allels in einer Population errechnet sich anhand der Häufigkeit des Allels im homo- $\left(\mathrm{n}_{\mathrm{ii}}\right)$ sowie im heterozygoten Zustand $\left(\mathrm{n}_{\mathrm{ij}}\right)$, relativ zur Individuenzahl der Population $(\mathrm{N})$.

$$
\mathrm{p}_{\mathrm{i}}=\frac{2 \mathrm{n}_{\mathrm{ii}}+\sum_{\mathrm{j}=1}^{\mathrm{k}} \mathrm{n}_{\mathrm{ij}}}{2 \mathrm{~N}}
$$

Für haploide Genome haben Pons und Petit (1996) eine an Nei (1973) angelehnte Formel entwickelt. Nach ihnen setzt sich die Diversität $\left(h_{T}\right)$ aus der Frequenz des iten Haplotypus $\left(p_{\mathrm{j}}\right)$, und der anderer Haplotypen $\left(\mathrm{p}_{\mathrm{j}}\right)$ der Population sowie der Distanz $\left(\boldsymbol{\pi}_{\mathrm{ij}}\right)$ zwischen den Haplotypen zusammen.

$$
\mathrm{h}_{\mathrm{T}}=\sum_{\mathrm{ij}} \pi_{\mathrm{ij}} \mathrm{p}_{\mathrm{i}} \mathrm{p}_{\mathrm{j}}
$$

Die genetische Differenzierung beschreibt die Verteilung von Variationen innerhalb und zwischen Populationen. Sie wird anhand der Diversitätsindices $\left(\mathrm{H}_{\mathrm{T}}, \mathrm{D}_{\mathrm{ST}}, \mathrm{H}_{\mathrm{S}}\right)$ berechnet. Sie sind Ausdruck der Diversität innerhalb von Populationen $\left(\mathrm{H}_{\mathrm{S}}\right)$ und zwischen Populationen $\left(\mathrm{D}_{\mathrm{ST}}\right)$ sowie der totalen Diversität $\left(\mathrm{H}_{\mathrm{T}}\right)$.

$$
\mathrm{H}_{\mathrm{T}}=\mathrm{D}_{\mathrm{ST}}+\mathrm{H}_{\mathrm{S}}
$$

Der Koeffizient der Differenzierung $\left(G_{\mathrm{ST}}\right)$ ergibt sich aus dem Verhältnis der Interpopulations- Diversität zur totalen Diversität (Nei 1973).

$$
\mathrm{G}_{\mathrm{ST}}=\mathrm{D}_{\mathrm{ST}} / \mathrm{H}_{\mathrm{T}}
$$

Wright (1952, nach Lowe et al. 2005) brachte die Differenzierung der Population auf drei Ebenen. Hierfür benutzte er die Werte der erwarteten Heterozygoten in der totalen Population $\left(\mathrm{H}_{\mathrm{T}}\right)$, die durchschnittliche erwartete Anzahl der Heterozygoten in der Population $\left(\mathrm{H}_{\mathrm{S}}\right)$ und der durchschnittlichen Heterozygotie pro Individuum $\left(\mathrm{H}_{\mathrm{I}}\right)$. Hieraus berechnete er den Koeffizient der Inzucht, beruhend auf der Divergenz von der beobachteten Heterozygotie gegenüber der erwarteten, unter der Vorraussetzung der Panmixie:

$$
\mathrm{F}_{\mathrm{IS}}=\left(\mathrm{H}_{\mathrm{S}}-\mathrm{H}_{\mathrm{I}}\right) / \mathrm{H}_{\mathrm{S}}
$$

Der Index der Fixierung beschreibt die Reduktion der Heterozygotie, innerhalb einer Population relativ zur totalen Population, bedingt durch Selektion oder genetische Drift:

$$
\mathrm{F}_{\mathrm{ST}}=\left(\mathrm{H}_{\mathrm{T}}-\mathrm{H}_{\mathrm{S}}\right) / \mathrm{H}_{\mathrm{T}}
$$


Der Gesamtkoeffizient der Inzucht beschreibt die Reduktion der Heterozygotie von Individuen relativ zur Population, verursacht durch nicht zufällige Paarung.

$$
\mathrm{F}_{\mathrm{IT}}=\left(\mathrm{H}_{\mathrm{T}}-\mathrm{H}_{\mathrm{I}}\right) / \mathrm{H}_{\mathrm{T}}
$$

Die Beziehung dieser Werte zueinander kann als

$$
1-\mathrm{F}_{\mathrm{IT}}=\left(1-\mathrm{F}_{\mathrm{IS}}\right)\left(1-\mathrm{F}_{\mathrm{ST}}\right)
$$

angegeben werden.

Die Anwendung der F-Statistik auf mitochondriale DNA ist nicht möglich, da hier kein Heterozygoten-Status vorliegt. Die Analyse Molekularer Varianz (AMOVA, Excoffier et al. 1992) eignet sich sowohl für die Analyse haploider, als auch der Analyse diploider Datensätze. Sie basiert auf der Berechnung so genannter Distanz-Matrices, aus denen die VarianzKomponenten definierter Gruppen abgeleitet werden. Die Varianz-Komponenten sind die Varianz innerhalb von Gruppen $\left(\sigma_{\mathrm{a}}^{2}\right)$, zwischen Populationen $\left(\boldsymbol{\sigma}_{\mathrm{b}}^{2}\right)$ und innerhalb der Populationen $\left(\sigma_{\mathrm{c}}^{2}\right)$. Die Gesamt-Varianz $\left(\sigma^{2}\right)$ ist die Summe dieser drei Komponenten. Anhand dieser drei Varianz-Werte können drei Ebenen der Korrelation berechnet werden. Die Varianz-Korrelation der Daten innerhalb einer Population, relativ zum insgesamt betrachteten Datensatz $\left(\Phi_{\mathrm{ST}}\right)$, ergibt sich aus der Summe der Varianz innerhalb von Gruppen $\left(\sigma_{\mathrm{a}}^{2}\right)$ und der Varianz zwischen Populationen $\left(\sigma_{\mathrm{b}}{ }^{2}\right)$, relativ zur Gesamt-Varianz $\left(\sigma^{2}\right)$.

$$
\Phi_{\mathrm{ST}}=\sigma_{\mathrm{a}}^{2}+\sigma_{\mathrm{b}}^{2} / \sigma^{2}
$$

Die Varianz-Korrelation zwischen Daten innerhalb von Gruppen $\left(\sigma_{a}^{2}\right)$, relativ zur GesamtVarianz $\left(\sigma^{2}\right)$, ergibt sich wie folgt:

$$
\Phi_{\mathrm{CT}}=\sigma_{\mathrm{a}}^{2} / \sigma^{2}
$$

Die Varianz-Korrelation zwischen der Varianz von Populationen, relativ zur Varianz der betrachteten Subgruppe von Populationen $\left(\Phi_{\mathrm{SC}}\right)$, ergibt sich aus der Varianz zwischen Populationen $\left(\sigma_{\mathrm{b}}{ }^{2}\right)$, relativ zur Summe der Varianz zwischen $\left(\sigma_{\mathrm{b}}{ }^{2}\right)$ und innerhalb von Populationen $\left(\sigma_{\mathrm{c}}^{2}\right)$.

$$
\Phi_{\mathrm{SC}}=\sigma_{\mathrm{b}}^{2} / \sigma_{\mathrm{b}}^{2}+\sigma_{\mathrm{c}}^{2}
$$

Hat man bezüglich einer Population eine bestimmte Hypothese der Entstehung der genetischen Zusammensetzung, so kann man diese mit Hilfe des Bayes-Theorem überprüfen. Hierbei wird die Wahrscheinlichkeit der Hypothese $\left(\mathrm{p}_{\mathrm{H} / \mathrm{d}}\right)$ anhand der Wahrscheinlichkeit, dass 
die Hypothese $(H)$ die experimentellen Daten $(d)$ liefert $\left(\mathrm{p}_{\mathrm{d} / \mathrm{H}}\right)$, multipliziert mit der a priori Wahrscheinlichkeit, dass die Hypothese wahr ist $\left(\mathrm{p}_{\mathrm{H}}\right)$, relativ zur a priori Wahrscheinlichkeit, dass die experimentelle Daten auftreten $\left(\mathrm{p}_{\mathrm{d}}\right)$, berechnet. Ein Beispiel für die Anwendung des Bayes-Theorem, ist z.B. die Berechnung von Paternitätswahrscheinlichkeit.

$$
\mathrm{p}_{\mathrm{H} / \mathrm{d}}=\frac{\mathrm{p}_{\mathrm{d} / \mathrm{H}} \times \mathrm{p}_{\mathrm{H}}}{\mathrm{p}_{\mathrm{d}}}
$$

Die genetische Distanz beschreibt die Ähnlichkeiten zwischen Individuen, oder Gruppen von Individuen. Der $\mathrm{F}_{\mathrm{ST}_{\mathrm{T}}}$-Wert kann ein Maß hierfür sein. Nach Nei (1978) ergibt sich die Distanz aus den Wahrscheinlichkeiten für das Auftreten gemeinsamer Allele innerhalb und zwischen Population. Er definiert die Wahrscheinlichkeit, für das Auftreten eines Allels aus Population $\mathrm{X}$, dass das gleiche Allel ist wie aus Population $\mathrm{Y}\left(\mathrm{j}_{\mathrm{XY}}\right)$ und die Wahrscheinlichkeiten, dass zwei zufällig ausgewählte Allele aus Population X $\left(\mathrm{j}_{\mathrm{X}}\right)$, bzw. Population $\mathrm{Y}\left(\mathrm{j}_{\mathrm{Y}}\right)$, gleich sind. Die Distanz ergibt sich dann aus dem Verhältnis der Wahrscheinlichkeiten zwischen Populationen und der innerhalb von Populationen. Hierzu werden die arithmetischen Mittelwerte $(J)$ der Wahrscheinlichkeiten genutzt.

$$
\mathrm{D}=-\ln \mathrm{J}_{\mathrm{XY}} / \sqrt{ } \mathrm{J}_{\mathrm{X}} \mathrm{J}_{\mathrm{Y}}
$$

Linkage disequilibrium beschreibt das nicht zufällige Auftreten gleicher genetischer Merkmale in Individuen, das jedoch nicht auf tatsächliches genetisches linkage zurückzuführen ist. Es wird durch Selektion, Gründereffekte oder genetische Drift verursacht und ist damit ein Indikator für anagenetische Prozesse. Es kann durch die Analyse der Varianz in der Anzahl von Loci, in denen sich Paare unterscheiden, identifiziert werden (s. z.B. Maynard-Smith et al. 1993). Der Index der Assoziation ( $\mathrm{I}_{A}, \mathrm{Ma}$ für das linkage disequilibrium) ergibt sich aus der beobachteten Varianz $\left(V_{D}\right)$ relativ zur erwarteten Varianz $\left(V_{E}\right)$, unter Berücksichtigung der Anzahl der untersuchten Marker (L).

$$
\mathrm{I}_{\mathrm{A}}=1 /(\mathrm{L}-1)\left(\left(\mathrm{V}_{\mathrm{D}} / \mathrm{V}_{\mathrm{E}}\right)-1\right)
$$

Ausgehend von der Vermutung, dass Populationen mit hohem Differenzierungsgrad ein niedriges $\mathrm{Maß}$ an Genfluss, gegenüber Populationen mit niedrigem Differenzierungsgrad, aufweisen, lässt sich anhand der $\mathrm{F}_{\mathrm{ST}_{\mathrm{T}}}$-Werte, die Anzahl von Migrationen pro Generation $\left(\mathrm{N}_{\mathrm{m}}\right)$ bestimmen (Whrigt 1932 in Lowe et al. 2005).

$$
\mathrm{N}_{\mathrm{m}}=\left(1-\mathrm{F}_{\mathrm{ST}}\right) / 4 \mathrm{~F}_{\mathrm{ST}}
$$


Wenn $\mathrm{N}_{\mathrm{m}}<1$, so ist es wahrscheinlich, dass Populationen nach einem gewissen Zeitraum divergieren. Ist $\mathrm{N}_{\mathrm{m}}>1$, so bleibt ein genetischer Austausch zwischen den Populationen bestehen.

Das Auftreten von bottleneck-Situationen führt zu einer drastischen Verringerung der genetischen Variabilität, aufgrund der drastischen Reduktion der Populationsgröße. Die Rate der Heterozygoten am beobachteten Zeitpunkt $\left(\mathrm{H}_{\mathrm{t}}\right)$ ergibt sich aus dem Verlust von Heterozygoten pro Generation und der Heterozygotenrate $\left(\mathrm{H}_{0}\right)$ vor dem bottleneck-Ereignis (Lowe et al. 2005).

$$
\mathrm{H}_{\mathrm{t}}=\left(1-1 / 2 \mathrm{~N}_{\mathrm{e}}\right)^{\mathrm{t}} \times \mathrm{H}_{0}
$$

Nei (1987) schlägt zur Erkennung von bottleneck-Effekten die Untersuchung der Wahrscheinlichkeiten für das gemeinsame Auftreten eines Allels in Population X und Y $\left(\mathrm{J}_{\mathrm{XY}}\right)$ in Relation zu dem Anteil Homozygoter Individuen einer Population, die eine bottleneckSituation durchlaufen hat $\left(J_{x}\right)$, zu betrachten.

$$
\mathrm{I}=\mathrm{J}_{\mathrm{XY}} / \mathrm{J}_{\mathrm{X}}
$$

Die Rekonstruktion von Speziesbäumen anhand genetischer Daten erfolgt durch Untersuchung orthologer Sequenzen, d.h. die untersuchten Sequenzen der Spezies gehören zur gleichen Genfamilie und sind hinsichtlich ihrer Lage im Genom identisch. Der phylogenetische Stammbaum zeigt die historischen Beziehungen der Populationen zueinander auf. Interspezifische Verwandtschaft lässt sich durch Kladogramme (relative Abstammung von gemeinsamen Ahnen), additive Bäume (Maß des Wandels bestimmt Abstand zu gemeinsamen Ahnen), ultrametrische Bäume (additive Bäume, bei denen zusätzlich das Maß des Wandels, in Form von Verzweigungslängen, angegeben wird) und Netzwerke (Verbindungen aller Individuen zueinander, unabhängig von Ahnen) darstellen (s. Abb. 21).

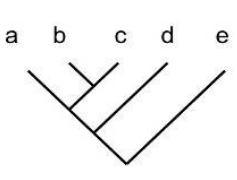

A

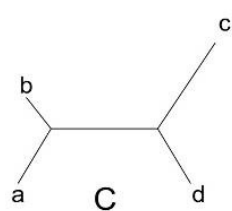

C

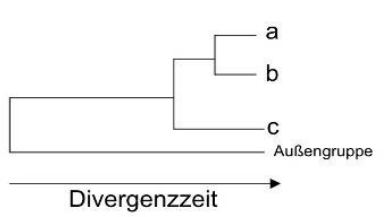

B

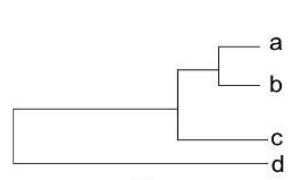

D

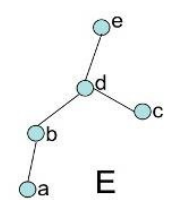

Abbildung 21: Darstellung der verschiedenen Bäume, A: Kladogramm, B: phylogenetischer Baum, C: additiver Baum, D: ultrametrischer Baum, E: Netzwerk 
Die Erstellung von Bäumen erfolgt entweder durch Distanz-Methoden oder diskreten Methoden. Erstellt man von Sequenzdaten paarweise Distanz-Matrices, so können diese Matrices durch ein Vergleichsverfahren in Bäume umgewandelt werden. Mit Hilfe der "ungewichteten Paar-Gruppierung mit arithmetischen Mitteln" (UPGMA, Sneath und Sokal 1973) wird die geringste Distanz zwischen zwei Individuen als Basispunkt definiert und von ihr ausgehend alle weiteren Individuen nach Grad ihrer Distanz hinzugefügt. Man erhält so einen ultrametrischen Baum. Die Methode des neighbour-joining (NJ, Saitou und Nei 1987) berechnet nicht nur einen Ausgangpunkt für alle untersuchten Individuen, sondern errechnet die Beziehungen der Individuen zueinander.

Nei (1978) gibt an, dass die genetische Identität (I) zwischen zwei Populationen größer als 0,85 sein muss, um die Zugehörigkeit zu ein und derselben Spezies zu belegen. Die genetische Distanz (D) kann als negativer natürlicher Logarithmus der Identität berechnet werden.

$$
\mathrm{D}=-\ln \mathrm{I}
$$

Dies wiederum bedeutet, dass zwei Population zu einer Spezies gehören wenn ihre genetische Distanz kleiner als 0,16 ist. Die Distanz-Methoden produzieren Bäume, die einen guten Ausgangpunkt für die diskreten Methoden darstellen. Sie geben jedoch keine Auskunft über den tatsächlichen Zeitraum, der zur Populationstrennung nötig war.

Diskrete Methoden sind das Maximale-Parsimonie-Verfahren und das MaximaleWahrscheinlichkeits-Verfahren, hier wird jeder Charakter (z.B. jede auftretende Mutation) als einzelne Information verwendet. Bei dem Maximale-Parsimonie-Verfahren, werden alle untersuchten Individuen anhand der wenigsten Änderungen der Charaktere, die nötig sind um von Spezies A zu Spezies B zu gelangen, sortiert. Hierbei werden eine Vielzahl von Bäumen berechnet, die in einem Konsensus-Baum zusammengefügt werden. Bei dem MaximaleWahrscheinlichkeits-Verfahren, wird die Wahrscheinlichkeit zum Auftreten der einzelnen Charaktere berechnet und anhand dieser Wahrscheinlichkeiten werden die untersuchten Individuen sortiert, d.h. ein Individuum mit einer unwahrscheinlichen Charakterausprägung ist weiter vom Ursprung entfernt, als ein Individuum mit wahrscheinlicher Charakterausprägung. Parsimonie-Verfahren und Distanz-Verfahren sind in der Regel auf alle genetischen Daten anwendbar, das Maximale-Wahrscheinlichkeits-Verfahren ist hauptsächlich auf Sequenzdaten anwendbar, da die hiermit bearbeiteten Daten einen evolutiven Charakter aufweisen müssen (Lowe et al. 2005, S. 184).

Ein Verfahren, dass auf alle vier Methoden anwendbar ist und eine genauere Verwandtschaftsaufdeckung erlaubt, ist das so genannte bootstrap-Verfahren (Wiesemüller et al. 2002). Hierbei werden zufällig, aus dem Gesamtdatensatz, einige Datensätze gelöscht und ein Baum erstellt. Dieses Verfahren wird 100-1000 Mal wiederholt. Je häufiger einzelne 
Datensätze in den erstellten Bäumen vorkommen, desto wahrscheinlicher ist ihre Monophylie und ihnen wird ein bootstrap-Wert größer als 75-80 zugewiesen.

Für die meisten der hier vorgestellten genetischen Auswertungsverfahren gibt es kommerziell zu erwerbende Computer-Programme, welche den Arbeitsaufwand deutlich verringern. Dennoch sollten diese Programme nur verwendet werden, wenn ihre Funktionsweise verstanden wurde, damit die gezielte Erwirtschaftung aussagefähiger Resultate gewährleistet wird.

\subsection{Kulturhistorische Grundlagen}

Wie in der Biologie, wird das Erfassen von Kulturen und ihrem Wandel als Evolution bezeichnet. Um kulturelle Vielfalt zu ordnen, wird auch hier systematisiert und kategorisiert, um den Wandlungsprozess zu erkennen und zu beurteilen. Hierzu muss zunächst definiert werden, was Kultur ist und an welchen Funktionen ein Wandlungsprozess ansetzen kann. Auch der Prozess der Wandlung und ihr Auslöser müssen betrachtet werden. Das Folgende hat keinen Anspruch auf Vollständigkeit, soll jedoch einen Einstieg in die Thematik für fachfremde Wissenschaftler ermöglichen.

\subsubsection{Definition von Kultur, Sozialsystemen, Zivilisation und Religion}

Der Begriff Kultur entstammt dem lateinischen „cultura“ und bedeutet Bearbeitung, Bebauung oder Anbau (Stowasser et al. 1991). Metaphorisch bezeichnet sie die Veredlung oder die Verehrung. Abgeleitet von dieser ursprünglichen Bedeutung gibt es eine Vielzahl von Definitionen.

Edward B. Tylor definierte 1871 Kultur als jenes komplexe Ganze, das Wissen, Glauben, Kunst, Moral, Gesetz, Brauch und alle anderen Fähigkeiten und Gewohnheiten umfasst, die sich der Mensch als Mitglied der Gesellschaft erworben hat (Tylor 1958).

Julian Huxley (1887-1975) definiert, wie Leslie White (1900-1975), dass Kultur aus drei Subsystemen besteht: Mentefakte (= Ideologie), Artefakte (= Technologie) und Soziofakte (= Soziologie) (Fellmann 1996). Mentefakte bezeichnen das System aus Ideen, Glauben und Wissen einer Kultur, die kommunikativ weiter gegeben werden. Artefakte bezeichnen die materiellen Objekte einer Kultur und die Technologie mit der diese erschaffen werden. Soziofakte sind die soziale Organisation einer Kultur, die ihre strukturelle Verhaltensweise bestimmt. 
Weber (1956) definierte Kultur als ein „mit Sinn und Bedeutung bedachter endlicher Ausschnitt aus der sinnlosen Unendlichkeit des Weltgeschehens.“. Damit sieht er Kultur als Ausdruck sozialen Handelns.

Parson und Shils (1990) definieren Kultur als Organisation von Werten, Normen und Symbolen, welche die Wahl der Akteure lenken und die Interaktion zwischen Individuen limitiert.

Die Definition von Spradley und McCurd (1987) integriert als weiteres Merkmal die Ökologie, in der die Kultur existiert: Kultur ist erlernt und geteilt. Darüber hinaus ist sie adaptiv. Menschen bewältigen die Anforderungen ihrer natürlichen und sozialen Umgebung durch ihr tradiertes Wissen. Diese Definition impliziert auch, dass Kultur dynamischen Prozessen ausgesetzt ist.

Roseberry (1989) formuliert, dass Kultur zum Einen eine Darstellung des Sozialen verkörpert, da sie ein Produkt von Aktivitäten ist, zum Anderen ist sie sozial bestimmt, da sie Teil des Kontextes ist, in dem Aktivitäten stattfinden.

Zusammenfassend kann man Kultur also als Gesamtheit menschlicher Aktionen und ihrer Produkte bezeichnen, sie ist Ausdruck und Bestandteil eines sozialen Gefüges.

Um Kulturwandel zu verstehen, muss zunächst betrachtet werden, welche Sozialsysteme Menschen bilden können.

Die soziale Organisation kann in fünf Stadien unterteilt werden: Banden, Stämme (Sippen), Stammesfürstentümer, Staaten und Königreiche (Service 1971). Königreiche gehen meist aus Staaten hervor, jedoch steigt der Staatsregierende zu einem Gott ähnlichem Wesen auf. In Tabelle 8 sind die wichtigsten Charakteristika der ersten vier Stadien gelistet.

Tabelle 8: Charakteristika der Sozialen Organisation (nach Service 1971)

\begin{tabular}{|c|c|c|c|c|}
\hline & Banden & Stämme & Stammesfürstentümer & Staaten \\
\hline Populationsgröße & $25-50$ & $>100$ & $>1000$ & $>100000$ \\
\hline Subsistenzstrategie & $\begin{array}{l}\text { jagen und } \\
\text { sammeln }\end{array}$ & $\begin{array}{l}\text { Hortikultur und } \\
\text { Pastoralismus }\end{array}$ & $\begin{array}{l}\text { nicht-mechanisierte } \\
\text { Agrikultur }\end{array}$ & $\begin{array}{l}\text { intensive Agrikultur und } \\
\text { Handel }\end{array}$ \\
\hline Ökonomie & $\begin{array}{l}\text { generalisierte } \\
\text { Reziprozität }\end{array}$ & $\begin{array}{l}\text { Reziprozität und } \\
\text { Teilredistribution }\end{array}$ & Redistribution & Märkte \\
\hline Sozialstruktur & $\begin{array}{l}\text { egalitär, Anführer } \\
\text { nur in spezifischer } \\
\text { Situation }\end{array}$ & $\begin{array}{l}\text { einsetzende Status } \\
\text { Unterschiede, } \\
\text { jedoch nicht starr } \\
\text { und permanent }\end{array}$ & $\begin{array}{l}\text { klassifizierte } \\
\text { Gesellschaft }\end{array}$ & $\begin{array}{l}\text { definierte Klassen, hoch } \\
\text { stratifiziert }\end{array}$ \\
\hline Abstammung & kognat & direkt & direkt & kognat und direkt \\
\hline Politisches System & $\begin{array}{l}\text { nicht-zentralisiert, } \\
\text { Konsens - } \\
\text { Entscheidungen, } \\
\text { Macht durch } \\
\text { Einfluss, nur } \\
\text { zeitweise Anführer }\end{array}$ & $\begin{array}{l}\text { nicht-zentralisiert, } \\
\text { Teilzeit Anführer } \\
\text { basierend auf Alter } \\
\text { o.ä., Macht durch } \\
\text { Fähigkeiten und } \\
\text { Wissen, „erreichter } \\
\text { Status“ }\end{array}$ & $\begin{array}{l}\text { zentralisiert, General } \\
\text { Autorität, aufgrund des } \\
\text { Geburtsrechtes. } \\
\text { „zugeschriebener } \\
\text { Status““ }\end{array}$ & $\begin{array}{l}\text { zentralisierte Autorität, } \\
\text { mit formellen } \\
\text { Verwaltungsapparaten, } \\
\text { Macht wird durch das } \\
\text { Gesetz verliehen }\end{array}$ \\
\hline Beispiel & $\begin{array}{l}\text { bis in die 60er } \\
\text { Jahre Inuit (Arktis) }\end{array}$ & $\begin{array}{l}\text { Yanomamo } \\
\text { (Brasilien) }\end{array}$ & $\begin{array}{l}\text { Bargawata } \\
\text { (Nordmarokko) }\end{array}$ & $\begin{array}{l}\text { Ägypten und } \\
\text { Mesopotamien } 5500 \mathrm{~J} \text {. } \\
\text { v. h. }\end{array}$ \\
\hline
\end{tabular}


Ein weiteres wichtiges Unterscheidungsmerkmal ist das der ruralen und urbanen Lebensweise. Unter die rurale Lebensweise fallen die sozialen Organisationen der Banden und Stämme. Stammesfürstentümer und Staaten weisen neben urbanen Zentren auch rurale Strukturen in der Peripherie auf. Urbane Strukturen können Städte und Staaten sein. Eine Stadt ist eine Siedlung aus über 5000 Individuen, die dort lebende Bevölkerung ist nicht selbst produzierend und abhängig vom Hinterland. Ihre ökonomische Struktur kann auf Märkte, Taxation oder Redistribution beruhen. Die Stadt ist idiosynkratisch, also ein Baustein eines komplexen Systems, sie enthält öffentliche Großbauten, Straßen und hat ein hochzentralisiertes administratives System (Whitehouse und Wilkins 1986). Die Stadt kann unterschiedliche Kulturen beherbergen. Der Staat besteht aus mehreren Städten sowie ruralen Strukturen, er zeichnet sich durch territoriale Souveränität und administrative Hierarchie aus.

Zivilisation bezeichnet die kulturelle Einheit von Gesellschaften mit ähnlichem Wertesystem. Ihre Definition ist ähnlich vielseitig wie die der Kultur. Sanders und Price (1968) definieren Zivilisation basierend auf Sozialstruktur. Als maßgebliche Indikatoren sehen sie die Stratifikation der Gesellschaft, monumentale Bauten und Siedlungshierarchien. Darüber hinaus geben sie an, dass eine Zivilisation immer staatenbasiert, aber nicht städtebasiert sein muss. Einen ähnlichen Ansatz verfolgt Trigger (2003), der Zivilisation ebenfalls an der Sozialstruktur einer Gesellschaft festmacht. Er geht hierbei von Klassenhierarchie aus, die auf Surplus-Strategie beruht. Sie beinhaltet Spezialisten und ist komplex organisiert, die staatliche Organisation ist hierarchisch und Macht und Recht werden zentral verwaltet. Wolf (1982) dagegen sieht die Zivilisation als Raum für kulturelle Interaktion. Sie besteht aus einer tributären Gesellschaft, die hegemonisch organisiert ist und in der das ideologische Modell von allen Teilnehmern natürliche Akzeptanz erfährt. Burger (1992) formuliert, dass Zivilisationen aus dem Zugewinn an Kunst und Wissenschaft entstehen. Hierfür ist eine komplexe Gesellschaft und kulturelle Zusammengehörigkeit nötig. Das soziale System ist hierarchisch geordnet und es existieren Spezialisten.

Diese vier Definitionen lassen den Zivilisationsbegriff nur für Stammesfürstentümer und Staaten zu. Dies würde wiederum bedeuten, dass Banden und Stämme als nicht zivilisiert zu betrachten sind. Eine Definition der Zivilisation, die eine Anwendung auch auf Stämme und Banden zulässt, ist die der „Funktionellen Interdependenz“ (Wenke 1981). Sie geht davon aus, dass Einheiten von Menschen voneinander abhängig sind, da sie nicht alles für ihr kulturelles und physisches Überleben beitragen können. Dies setzt lediglich ein geringes $\mathrm{Maß}$ an Stratifizierung voraus, da der Austausch auch von einem kurzzeitigen Anführer durchgeführt werden kann. 
Ein Bestandteil der Kultur, und damit auch der Zivilisation, ist das Subsystem der Mentefakte. Spezifisch der Glaube an übernatürliche Wesen und Kräfte scheint allen Kulturen gleich zu sein. Dieser Glaube kann in fünf Kategorien unterteil werden (Cancik et al. 1998):

- Animatismus, er bezeichnet den Glauben an etwas nicht personifiziertes, ungesehenes, das potenziell überall vorliegt, wie z.B. Naturkräfte. Es tritt besonders häufig in Kleingesellschaften auf.

- Animismus, er bezeichnet den Glauben an personifizierte Naturerscheinungen.

Diese Personifikationen, z.B. Naturgottheiten, zeichnen sich durch Charakteristika aus (z.B. Geschlecht o.ä.)

- Ancestrale Seelen, dies ist der Glaube an die Seele der Verstorbenen, die besonders gehuldigt werden müssen.

- Götter und Göttinnen, sie besitzen Identitäten und Attribute und herrschen. Man unterscheidet in Monotheismus und Polytheismus. Polytheismus zeichnet sich immer durch eine hierarchische Struktur innerhalb der Götter aus.

- kleinere übernatürliche Wesen, diese sind in der Regel eine Art Glücks- oder Unglücksbringer, die Bezug zum alltäglichen Leben haben.

Der Glaube einer Kultur ist abhängig, von ihren spezifischen gesellschaftlichen Naturverhältnissen. So sehen z.B. Swanson und Lenert (Cancik et al. 1998, S. 325) einen Zusammenhang zwischen der Komplexität einer Gesellschaft und der Komplexität des Götterglaubens. Brelich (Cancik et al. 1998, S. 325) sieht z.B. den Ackerbau als Vorraussetzung für die Entwicklung von Polytheismus. Klimatische Veränderungen wirken sich ebenfalls auf den Glauben von Kulturen aus. Für Mesopotamien konnte das Auftreten und die Intensivierung des Glaubens an den Sturm-Gott, mit den wechselnden klimatischen Bedingungen in dieser Region belegt werden (Green 2003). Die Artefakte, die aus der Ebene der Mentefakte und Soziofakte hervorgehen, sind also der Ausdruck einer Kultur, die wiederum ein Spiegel ökologischer Begebenheiten sein kann.

\subsubsection{Kulturwandel und seine Ursachen}

Um Kulturwandel zu erklären gibt es eine Vielzahl theoretischer Ansätze, von denen nur einige erwähnt werden sollen. Childe (in Redman 1978) prägte die evolutionistische Theorie. Er geht von rational-ökonomischen Entscheidungen aus, die zur Staatenbildung führen. Die 
Entstehung der Agrikultur führt zu einem Überschuss an Nahrung, was wiederum zur Expansion der Populationen führt. Diese nun größeren Populationen bieten die Möglichkeit der Arbeitsteilung, also der Spezialisierung bestimmter Personen. Diese Vielzahl an Spezialisierung führt zu einer Erweiterung der Technologien, und Märkte entstehen, die wiederum zu einem Ungleichgewicht der Verteilung von Reichtum führen. Dieses Ungleichgewicht verursacht einen Sozialdruck, der nur durch ein politisches, zentralisiert verwaltendes, System aufgelöst werden kann. Der Selbsterhaltungstrieb der Individuen bewirkt die Akzeptanz der hierarchischen Gesellschaft. Diese Theorie geht von einer unilinearen Evolutionsrichtung aus.

Max Weber (in Bendix 1960) definierte drei Formen der politischen Machtverteilung: charismatische Herrschaft, aufgrund von Abstammung, traditionelle Herrschaft und legale Herrschaft. Die charismatische Herrschaft bezeichnet er als instabil und potentiell durch traditionelle Herrschaft ablösbar. Diese birgt jedoch die Gefahr der Ablehnung durch die Gesellschaft, was wiederum zu einer Ablösung durch legale Herrschaft führen kann. Dieser Wandlungsprozess, hin zu einem bürokratischen System, beruhe auf rationalen Entscheidungen.

Wittfogel (1962) formulierte die hydraulische Theorie für asiatische Kulturentwicklung. Sie geht davon aus, dass intensive Agrikultur einer Organisation der Bewässerungssysteme bedarf. Diese Organisation liegt in der Hand einiger weniger Mitglieder der Gesellschaft, die über das nötige Wissen verfügen. Diese Mitglieder bilden nach und nach die elitäre Schicht der Gesellschaft, denen die Macht über die Bewässerungssysteme innewohnt.

Steward (1976) ging davon aus, dass Kulturwandel primär von Technologie und Ökonomie bestimmt ist. Sekundäre Faktoren seien Ideologie, Religion und das politische System. Seine Theorie wird auch als multilineare Evolution bezeichnet.

Carneiro (2000) formulierte die Theorie des Zwanges. Aufgrund von Agrikultur kommt es zu einem Populationswachstum, der einen Kampf um Ressourcen zufolge hat. Dies führt zu einer Notwendigkeit militärischer Einheiten, die wiederum einer Verwaltung bedürfen. Das so entstandene Kontrollorgan kann das Militär für die Tributeintreibung und die Ressourcenverteilung einsetzen, was zur Stratifizierung der Gesellschaft führt.

McAdam (1966) formulierte die These der Multi-Ursachen Erklärung für den Kulturwandel. Gesellschaftswandel, Kulturwandel und Umweltwandel sind nach ihm eng verknüpft. Ein Umweltwandel, hin zu einer höheren Ressourcenvielfalt, würde zum Ressourcenkampf führen. Die Teile der Gesellschaft, die diesem Kampf unterliegen, müssten dann zukünftig Tribut an die Sieger abgeben, was eine Stratifizierung der Gesellschaft verursachen würde. Dieser Prozess ist mit dem Wachstum der Population zu verknüpfen. 
Ein weiterer Faktor, der den Theorien Carneiros und McAdams abzuleiten ist, ist der des Besitzes. Wo hingegen vor dem Einsetzen der intensiven Agrikultur überwiegend usufruct als Nutzungsprinzip von Fläche galt, setzen mit der Stratifizierung von Gesellschaften auch die Nutzungsansprüche der Weide- und Anbauflächen ein, die ebenfalls einer Verwaltung bedürfen.

Als Basisprozesse des Kulturwandels gelten Diffusion und Evolution. Diffusion bezeichnet die Migration von Kultur oder Technologie in eine andere (s. z.B. Dixon 1928). Evolution ist hier wie in der Biologie zu verstehen und beinhaltet Mechanismen der Isolation und Selektion. Technologien entstehen bei ihr aufgrund der natürlichen Anpassung.

Binford (2001) definierte die Nischen-Füllung, als Prozess des Kulturwandels. Durch die Besetzung neuer offener Nischen entstehen neue Organisationskollektive. Prentiss und Chatters (2003) sehen den Prozess der Dezimierung und Diversifikation als Antrieb für Kulturwandel. Hierbei sehen sie günstige, oder sich wandelnde Umweltbedingungen als ausschlaggebend für die Veränderbarkeit von Populationen und der ihnen innewohnenden Kultur. Die Migrationsbewegungen von Menschen versucht man heute mit genetischen Untersuchungen zu verstehen. Bei demischer Diffusion existiert ein genetischer Gradient, der Verteilung von Genmustern (Cavalli-Sforza 1996). Anhand dieser Untersuchungen wird derzeit belegt, dass Agrikultur in Eurasien durch Diffusion, also Migrationen von Menschen die bereits Agrikultur betrieben, verbreitet wurde. Ob dieses Modell auch für Süd-Amerika gilt ist derzeit nicht bekannt. Die Tatsache, dass jedoch Subsitenzökonomie-Modelle wie Agrikultur (s. Abb. 22) und Pastoralismus unabhängig voneinander mehrfach entwickelt worden sind, zeigt, dass Kulturwandel sowohl auf Diffusion als auch auf Evolution beruhen kann.

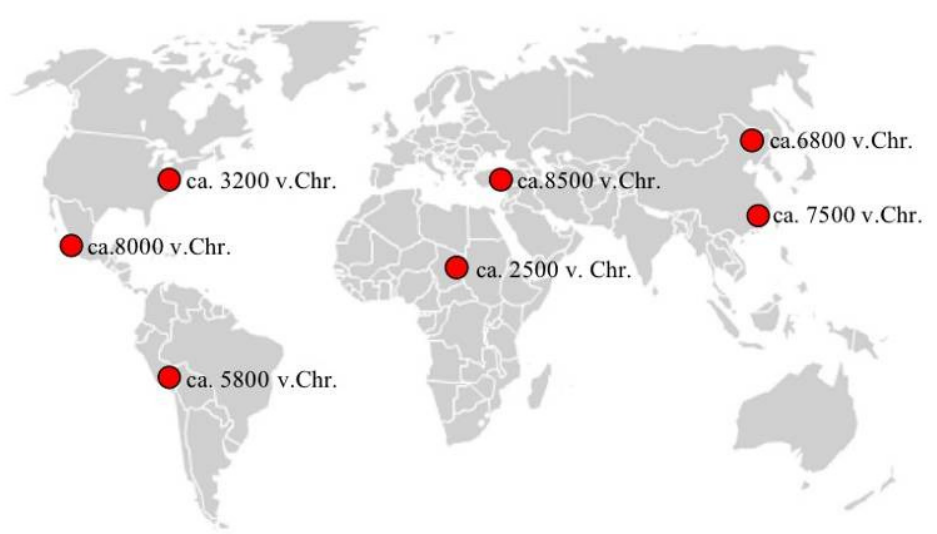

Abbildung 22: Zentren der unabhängigen Transition zu Agrikultur und ihren Entstehungszeitpunkten (nach Olsson 2001) 
Der einsetzende Klimawandel zwischen $8000-10000$ J. v. h. wird heute als Hauptantriebsfaktor für die Entwicklung der Sesshaftwerdung und damit der Entstehung von Agrikultur gesehen. In diesem Zeitalter setzt die Extinktion der großen Mammalia ein, die letztendlich eine Folge der klimatischen Veränderungen war (Barnosky et al. 2004). Die Erwärmung und häufige Überflutungen zwangen die Menschen neue Überlebensstrategien zu wählen, wie z.B. spezialisierter Jagd oder eine teilsedentäre Lebensweise. Wilde Getreidearten wuchsen unter den neuen Bedingungen vermehrt und boten eine neue Möglichkeit der Nahrungsquelle (Diamond 2005). Zwischen dem frühen und dem späten Holozän (ca. $5200 \mathrm{~J}$. v. h.) setzte erneut ein klimatischer Wandel ein und die Temperaturen gingen wieder leicht zurück (Thompson et al. 2006). Diese erneute Veränderung führte zu vermindertem Niederschlag und einer zunehmenden Siedlungsdichte an Flüssen (Brooks 2006). Issar und Zohar (2004) assoziieren die Entstehung der Agrikultur im mittleren Osten direkt mit den klimatischen Veränderungen, hin zu einer Temperatursteigerung und deutlich trockeneren Bedingungen. Darüber hinaus geben sie an, dass die urbane Revolution ebenso mit klimatischen Bedingungen zusammenhängt.

In Abbildung 23 ist eine vergleichende Zusammenfassung von klimatischen Veränderungen und Kulturwandel dargestellt.

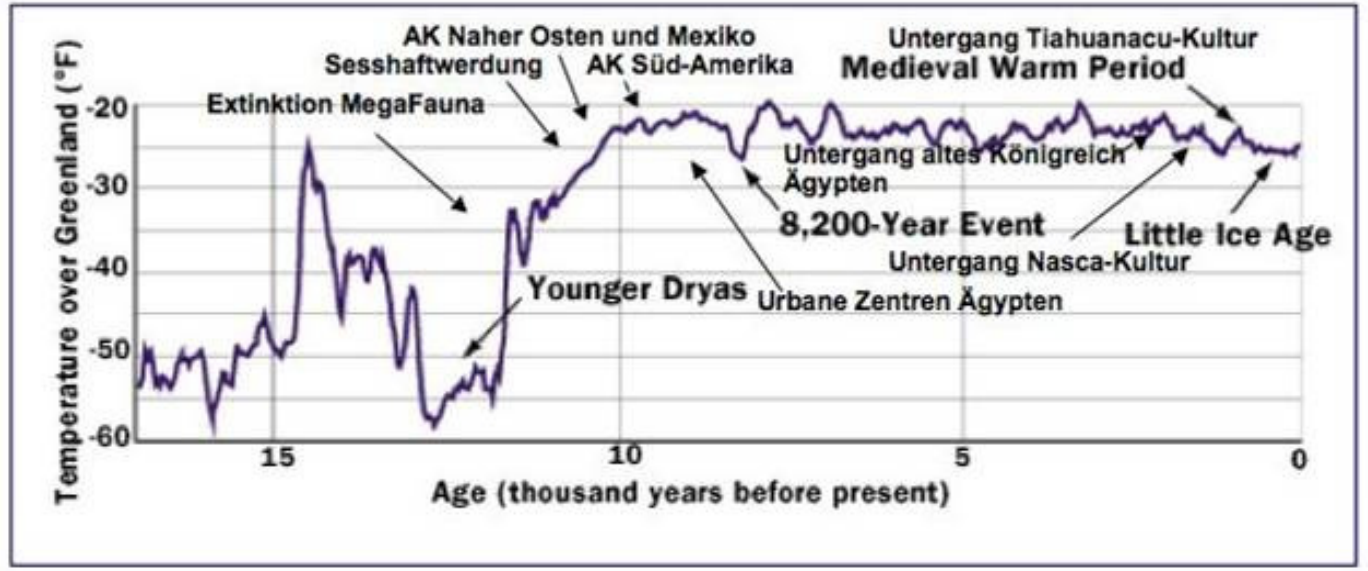

Abbildung 23: Temperaturschwankungen der letzten 17000 Jahre (aus Alley 2002) und Zusammenhänge mit Kulturwandel (nach Brooks 2004 und 2006, Eitel et al. 2006 )

Die Korrelation zwischen Klimawandel und dem damit verbundenem Umweltwandel spielten auch bei der Besiedelung des amerikanischen Kontinents durch die Europäer eine entscheidende Rolle. So verschwand beispielsweise um 1587 die Gründer-Population von Roanoke (Stahle et al. 1998). Dieses Aussterben einer Population konnte mit einer lang anhaltenden Dürre assoziiert werden. Die Umweltphänomene die zum Kulturwandel führen, müssen also nicht immer globaler Natur sein. 
Die Lebens- und Überlebensstrategien, die Populationen wählen, sind also entscheidend für die Entwicklung und Ausprägung ihrer Kultur. Multiple Faktoren sollten daher bei der Untersuchung von Kulturentstehung und Kulturwandel erfasst werden. 
3 Material und Methoden

\subsection{Rezentes Probenmaterial und Vergleichssequenzen}

Zur Entwicklung von Systemen zur genetischen Untersuchung der Neuwelt-Camelidae, musste zunächst ein rezentes Vergleichskollektiv gewonnen werden. Die Akquise rezenten Probenmaterials erfolgte im Juli und August 2005. Hierbei wurden alle zoologischen Gärten in Deutschland sowie die Haustiergenetik in Göttingen und ein privater Halter kontaktiert. Es konnten so 43 Proben von insgesamt acht Standorten gesammelt werden. In Tabelle 9 sind die Proben und alle zugänglichen Informationen bezüglich Phänotyp sowie Verwandtschaft verzeichnet.

Tabelle 9: Proben rezenter Neuwelt-Camelidae

\begin{tabular}{|c|c|c|c|c|c|c|c|}
\hline Name & Spezies & Probenmaterial & Probenherkunft & Geschlecht & Bes. Merkmale & Haarfarbe & Int.Bez. \\
\hline & Lama & Haare & Haustiergenetik Gö & weiblich & 1 & schwarz & La 1 \\
\hline & Lama & Haare & Haustiergenetik Gö & weiblich & 1 & weiß & $\mathrm{La} 2$ \\
\hline & Lama & Haare & Haustiergenetik Gö & weiblich & $/$ & weiß & \begin{tabular}{|l|}
$\mathrm{La} 3$ \\
\end{tabular} \\
\hline & Lama & Haare & Haustiergenetik Gö & weiblich & 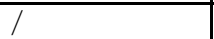 & schwarz & $\mathrm{La} 4$ \\
\hline & Lama & Haare & Haustiergenetik Gö & $?$ & Fohlen von La 4 & schwarz & La 5 \\
\hline & Lama & Blut & Haustiergenetik Gö & $?$ & Fohlen von La 3 & weiß & $\mathrm{La} 6$ \\
\hline Sara & Lama & Haare & Zoo Hannover & weiblich & & rot & La 7 \\
\hline Sindbad & Lama & Haare & Zoo Hannover & männlich & & weiß & \begin{tabular}{|l|}
$\mathrm{La} 8$ \\
\end{tabular} \\
\hline Sarotti & Lama & Haare & Zoo Hannover & männlich & & dunkelbraun & \begin{tabular}{|l|}
$\mathrm{La} 9$ \\
\end{tabular} \\
\hline Flocke & Lama & Haare & Zoo Hannover & weiblich & & weiß & La10 \\
\hline K01 & Alpaka & Haare & Tiergarten Nürnberg & weiblich & & rot-braun & Alp 1 \\
\hline K02 & Alpaka & Haare & Tiergarten Nürnberg & weiblich & & rot-braun & Alp 2 \\
\hline K03 & Alpaka & Haare & Tiergarten Nürnberg & weiblich & & rot-braun & Alp 3 \\
\hline Pepe & Alpaka & Haare & Tiergarten Nürnberg & männlich & & \begin{tabular}{|l|} 
rot-braun \\
\end{tabular} & Alp 4 \\
\hline Nueve & Alpaka & Haare & Tiergarten Nürnberg & weiblich & & rot-braun & Alp 5 \\
\hline Runa & Alpaka & Haare & Zucht Zürich/Peru & weiblich & & schwarz-braun & Alp 6 \\
\hline Graziella & Alpaka & Haare & Zucht Zürich/Peru & weiblich & & grau & Alp 7 \\
\hline 178 & Alpaka & Haare & Zucht Zürich/Peru & weiblich & & grau & Alp 8 \\
\hline Coco & Alpaka & Haare & Zucht Zürich/Peru & weiblich & & grau-braun & Alp 9 \\
\hline \multirow[t]{2}{*}{ Conny } & Alpaka & Haare & Zucht Zürich/Peru & weiblich & & beige-braun & Alp 10 \\
\hline & Alpaka & Haare & Zoo Hannover & weiblich & Mutter Alp 12 & grau-schwarz & Alp11 \\
\hline Maja & Alpaka & Haare & Zoo Hannover & weiblich & Tochter Alp11 & \begin{tabular}{|l} 
schwarz \\
\end{tabular} & Alp 12 \\
\hline Euatjuk & Alpaka & Haare & Zoo Hannover & weiblich & & rot-braun & Alp 13 \\
\hline Wilhelm & Alpaka & Haare & Zoo Hannover & männlich & & rot-braun & Alp 14 \\
\hline $0,1 \mathrm{Ko} 2$ & Guanako & Haare & Tiergarten Nürnberg & weiblich & & beige & Gua 1 \\
\hline $0,1 \mathrm{~K} 03$ & Guanako & Haare & Tiergarten Nürnberg & weiblich & & rötlich-beige & Gua 2 \\
\hline $0,1 \mathrm{~K} 04$ & Guanako & Haare & Tiergarten Nürnberg & weiblich & & rötlich-beige & Gua 3 \\
\hline \multirow[t]{2}{*}{ Petro } & Vikunja & Haare & Zoo Hannover & männlich & & beige & Vic 1 \\
\hline & Vikunja & Haare & Zoo Hannover & weiblich & & beige & Vic 2 \\
\hline Aika & Vikunja & Haare & Zoo Hannover & weiblich & & beige & Vic 3 \\
\hline Queda & Vikunja & Haare & Zoo Hannover & weiblich & & weiß & Vic 4 \\
\hline Xenia & Vikunja & Haare & Zoo Hannover & weiblich & & rötlich-beige & Vic 5 \\
\hline Mara & Vikunja & Haare & Zoo Hannover & weiblich & & beige & Vic 6 \\
\hline \multirow[t]{3}{*}{ Dolores } & Vikunja & Haare & Zoo Halle & weiblich & & hellbraun & Vic 7 \\
\hline & Vikunja & Haare & Zoo Halle & weiblich & & hellbraun & Vic 8 \\
\hline & Vikunja & Haare & Zoo Dresden & männlich & & hellbraun & Vic9 \\
\hline Zorro & Vikunja & Haare & Zoo Hellabrunn München & männlich & & hellbraun & Vic10 \\
\hline Rosita & Vikunja & Haare & Zoo Hellabrunn München & weiblich & & hellbraun & Vic11 \\
\hline Elias & Vikunja & Haare & Zoo Hellabrunn München & männlich & & hellbraun & Vic12 \\
\hline Lola & Vikunja & Haare & Zoo Hellabrunn München & weiblich & & hellbraun & Vic13 \\
\hline Eugen & Vikunja & Haare & Zoo Hellabrunn München & männlich & & hellbraun & Vic14 \\
\hline Ricarda & Vikunja & Haare & Zoo Hellabrunn München & weiblich & & hellbraun & Vic15 \\
\hline Ramona & Vikunja & Haare & Zoo Hellabrunn München & weiblich & & \begin{tabular}{|l|} 
hellbraun \\
\end{tabular} & Vic16 \\
\hline
\end{tabular}

Legende: Int.Bez = Interne Bezeichnung, Gö = Göttingen, ? = nicht bekannt 
Darüber hinaus standen Sequenzen zur Methodenentwicklung und als Vergleichsdaten über die Datenbank NCBI Entrez Nucleotide (http://www.ncbi.nlm.nih.gov/sites/entrez) zur Verfügung. In Tabelle 10 sind die Sequenzen, die zur Methodenentwicklung genutzt wurden, verzeichnet.

Tabelle 10: Sequenzen die zur Methodenentwicklung genutzt wurden

\begin{tabular}{|l|l|l|}
\hline Zugangs-Nummer & Spezies & Sequenztyp \\
\hline NC 002504 & Lama pacos & Mitochondrium komplett \\
\hline AF305231 & Lama pacos & VOLP10 \\
\hline AF305228 & Lama pacos & VOLP03 \\
\hline AF305237 & Lama pacos & VOLP67 \\
\hline AF237493 & Lama guanicoe & LgU68 \\
\hline AF237491 & Lama guanicoe & LgU52 \\
\hline AF237488 & Lama guanicoe & LgU49 \\
\hline AF091125 & Lama glama & LCA66 \\
\hline AF445641 & Bos taurus & MC1R \\
\hline DQ530056 & Ovis aries & MC1R (mRNA) \\
\hline EF392681 & Sus scrofa & MC1R \\
\hline AB241551 & Homo sapiens & MC1R \\
\hline AF001295 & Homo sapiens & TYRP1 \\
\hline AF400250 & Bos taurus & TYRP1 (mRNA) \\
\hline DQ645492 & Ovis aries & TYRP1 \\
\hline AY052751 & Canis lupus familiaris & TYRP1 (mRNA) \\
\hline AL035458 & Homo sapiens & ASIP \\
\hline BC102291 & Bos taurus & ASIP (mRNA) \\
\hline BC009122 & Mus musculus & ASIP \\
\hline
\end{tabular}

Die mRNA Sequenzen wurden mit Hilfe des Programms EditSeq des Lasergene Software Pakets (DNAStar) in DNA-Sequenzen umgeschrieben.

Seit September 2007 existieren auch Referenzsequenzen für das MC1R Gen der NeuweltCamelidae. Diese konnten nicht mehr in die Methodenentwicklung mit einbezogen werden, wurden jedoch als Vergleichsmaterial herangezogen. In Tabelle 11 sind die Vergleichssequenzen und ihre Zugangsnummer verzeichnet.

Tabelle 11: Sequenzen die als Vergleichsmaterial dienten

\begin{tabular}{|l|l|l|l|}
\hline Zugangsnummer & Spezies & Sequenztyp & Publikation \\
\hline NC 002504 & Lama pacos & Mitochondrium komplett & nein \\
\hline AY 535253 & Lama glama argentinia & Cytochrom b komplett & nein \\
\hline AY 535252 & Lama glama ccara & Cytochrom b komplett & nein \\
\hline AY 535251 & Lama glama chaku & Cytochrom b komplett & nein \\
\hline AY 535258 & Lama guanicoe cacsiliensis 1 & Cytochrom b komplett & nein \\
\hline AY 535257 & Lama guanicoe cacsiliensis 2 & Cytochrom b komplett & nein \\
\hline AY 535256 & Lama guanicoe cacsiliensis 3 & Cytochrom b komplett & nein \\
\hline AY 535276 & Lama guanicoe huanacus 1 & Cytochrom b komplett & nein \\
\hline AY 535275 & Lama guanicoe buanacus 2 & Cytochrom b komplett & nein \\
\hline AY 535274 & Lama guanicoe huanacus 3 & Cytochrom b komplett & nein \\
\hline AY 535273 & Lama guanicoe huanacus 4 & Cytochrom b komplett & nein \\
\hline AY 535272 & Lama guanicoe huanacus 5 & Cytochrom b komplett & nein \\
\hline AY 535271 & Lama guanicoe buanacus 6 & Cytochrom b komplett & nein \\
\hline AY 535270 & Lama guanicoe huanacus 7 & Cytochrom b komplett & nein \\
\hline AY 535269 & Lama guanicoe huanacus 8 & Cytochrom b komplett & nein \\
\hline AY 535268 & Lama guanicoe huanacus 9 & Cytochrom b komplett & nein \\
\hline AY 535267 & Lama guanicoe buanacus 10 & Cytochrom b komplett & nein \\
\hline
\end{tabular}




\begin{tabular}{|l|l|l|l|}
\hline Zugangsnummer & Spezies & Sequenztyp & Publikation \\
\hline AY 535266 & Lama guanicoe huanacus 11 & Cytochrom b komplett & nein \\
\hline AY 535265 & Lama guanicoe buanacus 12 & Cytochrom b komplett & nein \\
\hline AY 535264 & Lama guanicoe buanacus 13 & Cytochrom b komplett & nein \\
\hline AY 535263 & Lama guanicoe buanacus 14 & Cytochrom b komplett & nein \\
\hline AY 535262 & Lama guanicoe huanacus 15 & Cytochrom b komplett & nein \\
\hline AY 535261 & Lama guanicoe huanacus 16 & Cytochrom b komplett & nein \\
\hline AY 535260 & Lama guanicoe buanacus 17 & Cytochrom b komplett & nein \\
\hline AY 535259 & Lama guanicoe buanacus 18 & Cytochrom b komplett & nein \\
\hline AY 535284 & Lama guanicoe guanicoe 1 & Cytochrom b komplett & nein \\
\hline AY 535283 & Lama guanicoe guanicoe 2 & Cytochrom b komplett & nein \\
\hline AY 535282 & Lama guanicoe guanicoe 3 & Cytochrom b komplett & nein \\
\hline AY 535281 & Lama guanicoe guanicoe 4 & Cytochrom b komplett & nein \\
\hline AY 535280 & Lama guanicoe guanicoe 5 & Cytochrom b komplett & nein \\
\hline AY 535279 & Lama guanicoe guanicoe 6 & Cytochrom b komplett & nein \\
\hline AY 535278 & Lama guanicoe guanicoe 7 & Cytochrom b komplett & nein \\
\hline AY 535277 & Lama guanicoe guanicoe 8 & Cytochrom b komplett & nein \\
\hline AY 535250 & Lama pacos huacaya & Cytochrom b komplett & nein \\
\hline AY 535249 & Lama pacos suri & Cytochrom b komplett & nein \\
\hline AY 535254 & Vicugna vicugna mensalis & Cytochrom b komplett & nein \\
\hline AY 535255 & Vicugna vicugna vicugna & Cytochrom b komplett & nein \\
\hline EU220010 & Lama pacos & MC1R (seit 0907) & nein \\
\hline EU135880 & Lama pacos & MC1R (seit 0907) & nein \\
\hline
\end{tabular}

\section{2 Überliefertes Probenmaterial}

Insgesamt wurden zwei Probenakquisen für überliefertes Material durchgeführt. Die erste erfolgte im April 2005 durch Herrn Dr. Markus Reindel (DAI). Hierbei wurden insgesamt 68 Proben vor Ort entnommen, darunter waren 37 Zahn- und Knochenproben von fünf Fundorten und 31 Textilien von drei Fundorten. Im März 2006 wurden weitere 119 Zahnund Knochenproben von sechs Fundorten und neun Textilproben von einem Fundort entnommen. Die Fundorte und ihre Lage im Palpa-Tal sind in Abbildung 24 verzeichnet. Die Proben aus Pernil Alto, Los Molinos, Hanaq Pacha und Montegrande entstammen Trockenbodenlagerung, die der Fundorte Jauranga, La Muña und Chillo entstammen Feuchtbodenlagerung. Es wurden nur solche Proben entnommen, die äußerlich sichtbar keinerlei Degradierungsspuren, wie z.B. Brushitbildung oder andere starke Strukturauflösungen, aufwiesen.

Da die Proben nicht direkt ausgeführt werden durften, erfolgte der Transport nach Deutschland erst rund sechs Monate nach der Probenentnahme. Die Proben lagerten bis zu ihrem Eintreffen in Göttingen bei Raumtemperatur, danach wurden sie in der Tiefkühlkammer bei $-20^{\circ} \mathrm{C}$ gelagert. Die Proben erhielten eine interne Bezeichnung, die sich aus dem ersten und letzten Buchstaben des Fundortes zusammensetzt (Bsp. Jauranga = JA). Hinzu kamen für die tierischen Knochen- und Zahnfunde der Zusatz A (animales) und für Textilien ein $\mathrm{T}$ (textilias). Die Textilien erhielten darüber hinaus eine Farbangabe nach 
folgendem Schema: a (rot), b (grün), c (blau), d (gelb), e (braun) und f (schwarz). Die folgenden Fundortbeschreibungen wurden den Publikationen Reindel und Isla (2001), Reindel et al. (2005) und Reindel und Isla (2006) entnommen.

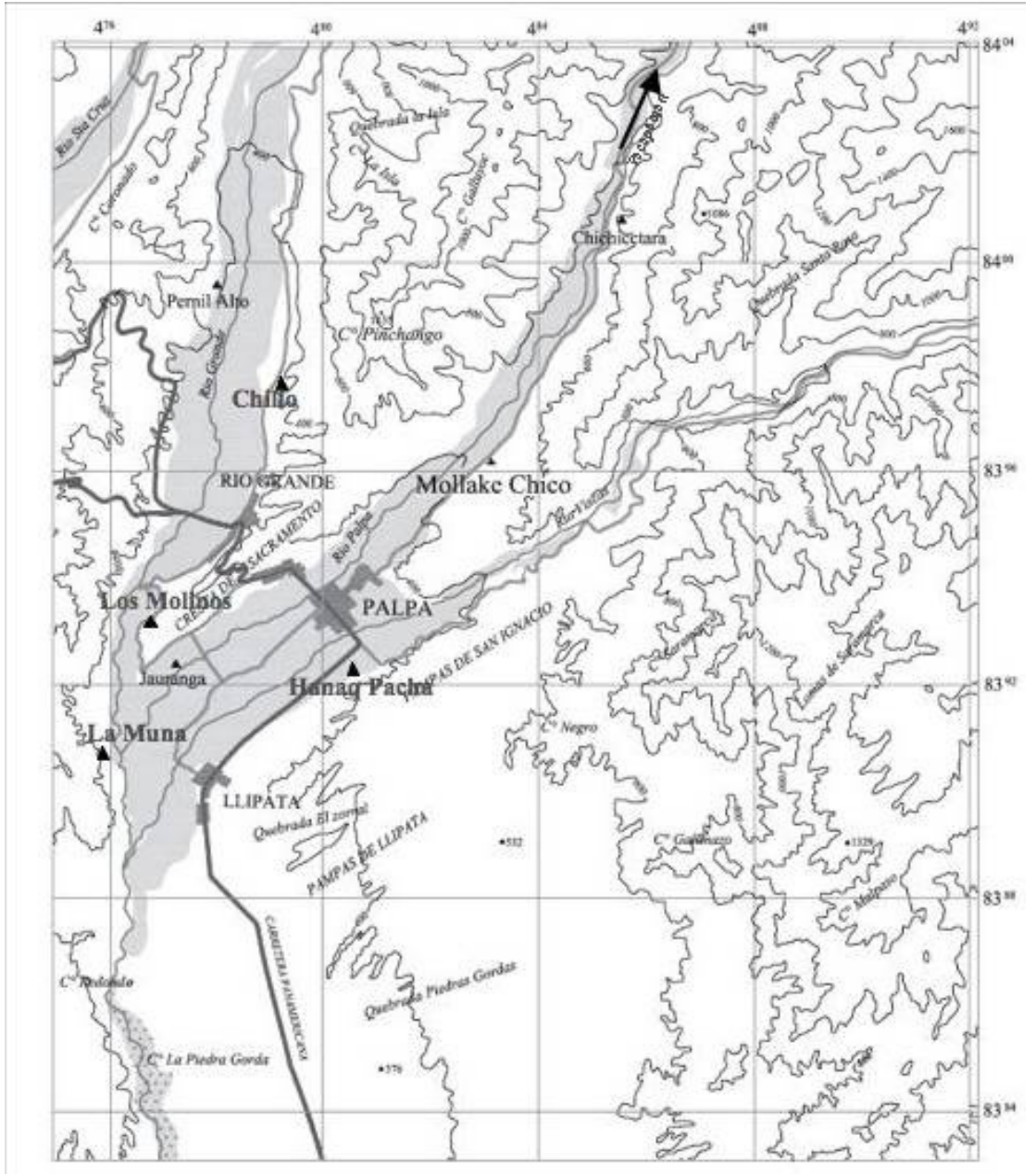

Abbildung 24: Fundorte und ihre Lage im Palpa-Tal

\subsubsection{Pernil Alto}

Der Fundort Pernil Alto liegt im mittleren Río Grande Tal. Siedlungsreste konnten hier für das Archaikum, die Initialzeit und die frühe Paracas-Zeit nachgewiesen werden. Gebäudereste deuten auf eine weitläufige Terassenanlage hin, die seit der frühen Paracas-Zeit genutzt wurde. Für einen Gebäudekomplex (40 x 20 m) konnte eine Nutzung über den gesamten Sielungszeitraum nachgewiesen werden. Im Grabungsbereich des Gebäudes wurden Bestattungen aus dem Archaikum, der frühen Paracas-Zeit und der Nasca-Zeit identifiziert. An tierischen Grabbeigaben wurden unter anderem ein Hirschgeweih (Bestattung aus dem Archaikum) sowie einige Camelidae-Knochen gefunden. Es konnten insgesamt acht Proben vom Fundort Pernil Alto gewonnen werden (s. Tab. 12). In Abbildung 25 sind exemplarisch zwei Proben abgebildet. 
Tabelle 12: Proben des Fundortes Pernil Alto

\begin{tabular}{|l|l|l|l|l|}
\hline Probennr. & Zeitstellung & Material & Probenentnahme/Erhalt & Int. Bez. \\
\hline 1002 & Initialzeit & Fragment des Os temporale & $0306 / 0906$ & AOA 1 \\
\hline 1003 & $/$ & Olecranon & $0306 / 0906$ & AOA 2 \\
\hline 1004 & Initialzeit & Condylus des Kanonenbeins & $0306 / 0906$ & AOA 3 \\
\hline 1005 & mehrere & Dens molaris & $0306 / 0906$ & AOA 4 \\
\hline 1006 & mehrere & Patella & $0306 / 0906$ & AOA 5 \\
\hline 1007 & Initialzeit & Vertebra caudalis & $0306 / 0906$ & AOA 6 \\
\hline 1008 & Initialzeit & Pars petrosa & $0306 / 0906$ & AOA 7 \\
\hline 1009 & Spät-Paracas & Patella & $0306 / 0906$ & AOA 8 \\
\hline
\end{tabular}

/ = nicht bekannt, Int. Bez.= Interne Bezeichnung
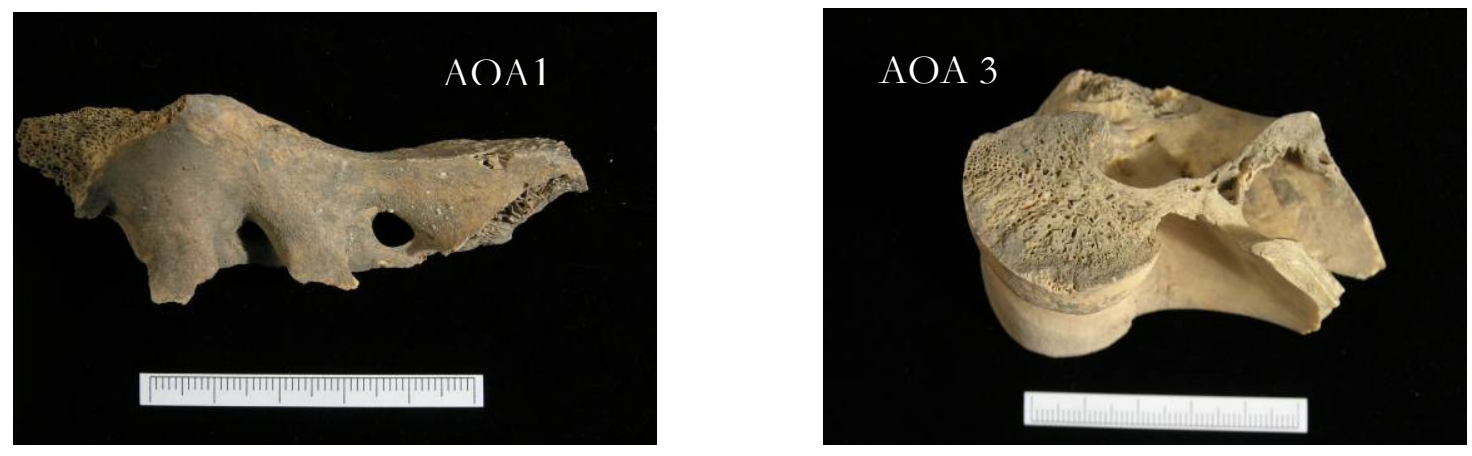

Abbildung 25: li.: Fragment des Os temporale, AOA1 re.: Condylus Kanonenbein, AOA3

\subsubsection{Jauranga}

Der Fundort Jauranga wurde in der mittleren und späten Paracas-Zeit genutzt. Neben einfachen Lehmziegelbauten wurden zahlreiche Keramiken der Paracas-Zeit, Siedlungsreste, tierische Überreste (s. Abb. 26) und mehrere Gräber gefunden. Eine durchgehende Besiedlung von $600-200$ v. Chr. gilt als erwiesen, danach wurde Jauranga bis in die Nasca-Zeit hinein als Bestattungsplatz genutzt. Handelsbeziehungen zu maritimen und andinen Populationen konnten durch Spondylus- und Obsidianfunde belegt werden. Monumentalbauten konnten jedoch nicht identifiziert werden.

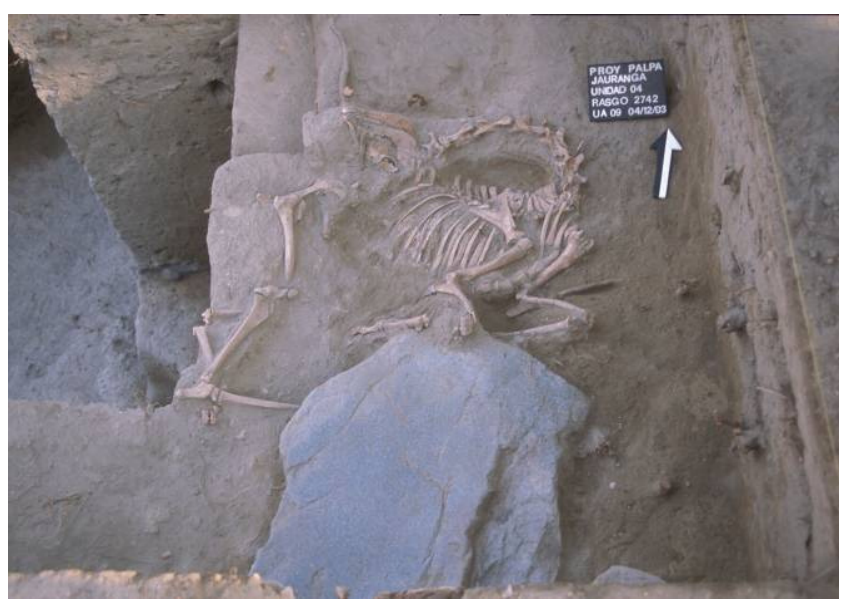

Abbildung 26: Camelidae-Fund in Jauranga (Quelle: KAAK/DAI) 
Das tierische Material aus Jauranga wies zum Teil Brandspuren auf. Es wurden nur solche Proben entnommen, die keine Verbrennungsspuren aufwiesen (s. Abb. 27). In Tabelle 13 sind die entnommenen Proben aufgeführt.

Tabelle 13: Proben aus Jauranga

\begin{tabular}{|c|c|c|c|c|}
\hline Probennr. & Zeitstellung & Material & Probenentnahme/Erhalt & Int. Bez. \\
\hline 642 & Mittel-Paracas & Phalanges 1 & $0405 / 1005$ & JAA 1 \\
\hline 643 & Mittel-Paracas & Phalanges 1 & $0405 / 1005$ & JAA 2 \\
\hline 644 & Mittel-Paracas & Phalanges 1 & $0405 / 1005$ & JAA 3 \\
\hline 645 & Spät-Paracas & Phalanges 1 & $0405 / 1005$ & JAA 4 \\
\hline 646 & Spät-Paracas & Phalanges 1 & $0405 / 1005$ & JAA 5 \\
\hline 647 & Spät-Paracas & Phalanges 1 & $0405 / 1005$ & JAA 6 \\
\hline 648 & Spät-Paracas & Mandibularfragment, 2x Dens molaris & $0405 / 1005$ & $\mathrm{JAA} 7$ \\
\hline 649 & Spät-Paracas & Dens incisivus & $0405 / 1005$ & JAA 8 \\
\hline 650 & Spät-Paracas & Dentes pulverisiert & $0405 / 1005$ & JAA 9 \\
\hline 651 & Spät-Paracas & Phalanges 1 & $0405 / 1005$ & JAA 10 \\
\hline 937 & I & Diaphyse & $0306 / 0906$ & JAA 11 \\
\hline 938 & Mittel-Paracas & $2 \times$ Dens molaris & $0306 / 0906$ & JAA 12 \\
\hline 939 & Spät-Paracas & $2 \times$ Dens molaris & $0306 / 0906$ & JAA 13 \\
\hline 940 & Mittel-Paracas & Patella & $0306 / 0906$ & JAA 14 \\
\hline 941 & Mittel-Paracas & Patella & $0306 / 0906$ & JAA 15 \\
\hline 942 & Spät-Paracas & Dens molaris & $0306 / 0906$ & JAA 16 \\
\hline 955 & Spät-Paracas & Pars petrosa & $0306 / 0906$ & JAA 17 \\
\hline 956 & Spät-Paracas & Fragment & $0306 / 0906$ & JAA 18 \\
\hline 957 & Spät-Paracas & Patella & $0306 / 0906$ & JAA 19 \\
\hline 958 & / & Pars petrosa & $0306 / 0906$ & JAA 20 \\
\hline 975 & Spät-Paracas & Fragmente Dentes & $0306 / 0906$ & JAA 21 \\
\hline 976 & Spät-Paracas & Epiphyse? & $0306 / 0906$ & JAA 22 \\
\hline 977 & Spät-Paracas & Epiphyse? & $0306 / 0906$ & JAA 23 \\
\hline 1010 & Spät-Paracas & Patella & $0306 / 0906$ & JAA 24 \\
\hline 1011 & Mittel-Paracas & Patella & $0306 / 0906$ & JAA 25 \\
\hline 1012 & Spät-Paracas & Patella & $0306 / 0906$ & JAA 26 \\
\hline 1013 & Spät-Paracas & Vertebra sacralis & $0306 / 0906$ & JAA 27 \\
\hline 1014 & Spät-Paracas & Pars petrosa & $0306 / 0906$ & JAA 28 \\
\hline 1015 & / & $\begin{array}{l}\text { a: Pars petrosa re., b: Pars petrosa re., } \\
\text { c: Dentes molaris Dentes incisivi }\end{array}$ & $0306 / 0906$ & JAA 29 \\
\hline 1016 & Mittel-Paracas & Patella & $0306 / 0906$ & JAA 30 \\
\hline
\end{tabular}

Legende: Int. Bez. = Interne Bezeichnung, / = keine genaue zeitliche Einordnung möglich
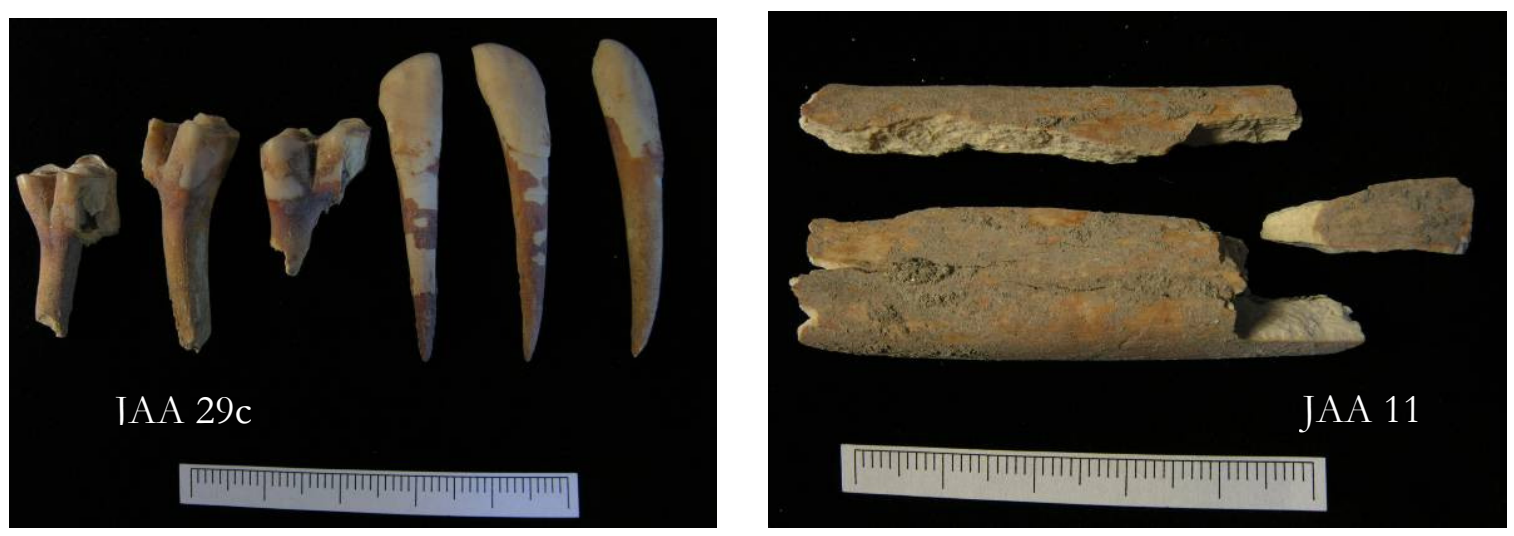

Abbildung 27: li.: Dentes incisivi und molaris JAA 29c, re. : Diaphysenfragmente JAA11 


\subsubsection{Los Molinos}

Der Fundort Los Molinos wurde in der frühen und mittleren Nasca-Zeit genutzt. Los Molinos wird als regionales Zentrum dieser Zeitstellung angesprochen, da es Monumentalbauten aufweist (s. Abb. 28). Die Aufgabe der Siedlung erfolgte aufgrund starker Regenfälle und die Gebäude wurden nur noch als Bestattungsplatz genutzt. Angrenzend an die Siedlung, konnte ein Gräberfeld ausgemacht werden. Neben zahlreichen Tierknochen (s. Abb. 29), wurden in Los Molinos eine Vielzahl hochwertiger Textilien gefunden. In Tabelle 14 sind die entnommenen Proben gelistet.

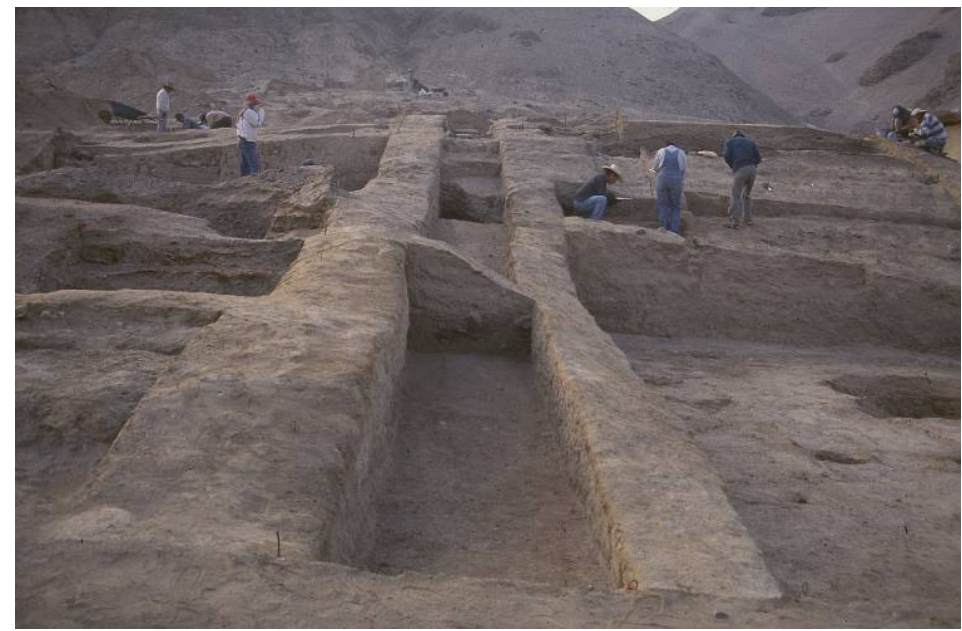

Abbildung 28: Ausgrabungen am Fundort Los Molinos (Quelle: KAAK/DAI)

Tabelle 14:Proben aus Los Molinos

\begin{tabular}{|l|l|l|l|l|}
\hline Probennr. & Zeitstellung & Material & Probenentnahme/Erhalt & Int. Bez. \\
\hline 672 & OF (?) & Dens incisivus & $0405 / 1005$ & MSA 1 \\
\hline 673 & OF (?) & Dens incisivus & $0405 / 1005$ & MSA 2 \\
\hline 675 & OF (?) & Epiphyse Kanonenbein & $0405 / 1005$ & MSA 3 \\
\hline 676 & OF (?) & Epiphyse Kanonenbein & $0405 / 1005$ & MSA 4 \\
\hline 677 & OF (?) & Phalanges 1 & $0405 / 1005$ & MSA 5 \\
\hline 678 & OF (?) & Phalanges 1 & $0405 / 1005$ & MSA 6 \\
\hline 748 & OF (N5) & Phalanges 1 & $0405 / 1005$ & MSA 7 \\
\hline 749 & Früh-Nasca & Phalanges 1 & $0405 / 1005$ & MSA 8 \\
\hline 750 & Früh-Nasca & Phalanges 1 & $0405 / 1005$ & MSA 9 \\
\hline 751 & Früh-Nasca & Phalanges 1 & $0405 / 1005$ & MSA 10 \\
\hline 752 & I & Phalanges 1 & $0405 / 1005$ & MSA 11 \\
\hline 753 & Früh Nasca & Phalanges 1 & $0405 / 1005$ & MSA 12 \\
\hline 754 & Früh Nasca & Phalanges 1 & $0405 / 1005$ & MSA 13 \\
\hline 943 & Früh Nasca & Os sesamoideum & $0306 / 0906$ & MSA 14 \\
\hline 944 & Früh Nasca & Os sesamoideum, Diaphyse & $0306 / 0906$ & MSA 15 \\
\hline 945 & Früh Nasca & Diaphyse & $0306 / 0906$ & MSA 16 \\
\hline 946 & Früh Nasca & Dens molaris, Fragment & $0306 / 0906$ & MSA 17 \\
\hline 947 & Früh Nasca & Patella & $0306 / 0906$ & MSA 18 \\
\hline 948 & OF (N3) & Vertebra caudalis & $0306 / 0906$ & MSA 19 \\
\hline 949 & Früh Nasca & Epiphyse Tibia & $0306 / 0906$ & MSA 20 \\
\hline 950 & Früh Nasca & Vertebrae (vermutlich Canis spec.) & $0306 / 0906$ & MSA 21 \\
\hline 951 & Früh Nasca & Pars petrosa & $0306 / 0906$ & MSA 22 \\
\hline 952 & OF (N3) & Patella & $0306 / 0906$ & MSA 23 \\
\hline 953 & OF (?) & Epiphyse ? & $0306 / 0906$ & MSA 24 \\
\hline 954 & Früh Nasca & Vertebra thoracalis & $0306 / 0906$ & MSA 25 \\
\hline 959 & Früh Nasca & Fragment & $0306 / 0906$ & MSA 27 \\
\hline 960 & MittelNasca & Vertebra sacralis &
\end{tabular}




\begin{tabular}{|c|c|c|c|c|}
\hline Probennr. & Zeitstellung & Material & Probenentnahme/Erhalt & Int. Bez. \\
\hline 961 & Früh Nasca & Vertebra cervicalis & $0306 / 0906$ & MSA 28 \\
\hline 962 & Früh Nasca & Pars petrosa & $0306 / 0906$ & MSA 29 \\
\hline 963 & / & $3 \times$ Dens molaris & $0306 / 0906$ & MSA 30 \\
\hline 964 & / & Epiphyse Kanonenbein & $0306 / 0906$ & MSA 31 \\
\hline 965 & OF (?) & Patella & $0306 / 0906$ & MSA 32 \\
\hline 966 & Paracas & Olecranon & $0306 / 0906$ & MSA 33 \\
\hline 967 & $\mathrm{OF}(?)$ & Dens molaris & $0306 / 0906$ & MSA 34 \\
\hline 968 & l & Pars petrosa & $0306 / 0906$ & MSA 35 \\
\hline 969 & OF (?) & Patella & $0306 / 0906$ & MSA 36 \\
\hline 978 & Früh Nasca & Diaphyse & $0306 / 0906$ & MSA 37 \\
\hline 979 & MittelNasca & Pars petrosa & $0306 / 0906$ & MSA 38 \\
\hline 980 & MittelNasca & Fragment Vertebra cervicalis & $0306 / 0906$ & MSA 39 \\
\hline 981 & OF (?) & $2 \times$ Dens molaris & $0306 / 0906$ & MSA 40 \\
\hline 982 & Früh Nasca & Vertebra caudalis & $0306 / 0906$ & MSA 41 \\
\hline 983 & MittelNasca & Vertebra cervicalis & $0306 / 0906$ & MSA 42 \\
\hline 986 & OF (?) & Pars petrosa & $0306 / 0906$ & MSA 43 \\
\hline 987 & Früh Nasca & Epiphyse? & $0306 / 0906$ & MSA 44 \\
\hline 988 & Früh Nasca & $\begin{array}{l}\text { a: Pars petrosa li., b: Pars petrosa re., } \\
\text { c: Dens molaris }\end{array}$ & $0306 / 0906$ & MSA 45 \\
\hline 989 & OF (N3-5) & Dens molaris & $0306 / 0906$ & MSA 46 \\
\hline 990 & Früh Nasca & Pars petrosa & $0306 / 0906$ & MSA 47 \\
\hline 991 & Früh Nasca & Dens molaris & $0306 / 0906$ & MSA 48 \\
\hline 700 & MittelNasca & Webearbeit f & $0405 / 1005$ & MST 1 \\
\hline 702 & MittelNasca & Wollfäden $\mathrm{a}, \mathrm{b}$ & $0405 / 1005$ & MST 2 \\
\hline 703 & MittelNasca & Wollfäden $\mathrm{a}, \mathrm{b}$ & $0405 / 1005$ & MST 3 \\
\hline 704 & MittelNasca & Wollfäden a & $0405 / 1005$ & MST 4 \\
\hline 706 & Früh Nasca & Haarflechte a, b, c, d & $0405 / 1005$ & MST 5 \\
\hline 707 & Früh Nasca & Haarflechte a, e & $0405 / 1005$ & MST 6 \\
\hline 708 & Früh Nasca & Zwirn a & $0405 / 1005$ & MST 7 \\
\hline 709 & Früh Nasca & Zwirn b & $0405 / 1005$ & MST 8 \\
\hline 710 & Früh Nasca & Zwirn a, c & $0405 / 1005$ & MST 9 \\
\hline 713 & Früh Nasca & Fransen a, d & $0405 / 1005$ & MST 10 \\
\hline 714 & Früh Nasca & Fransen $\mathrm{a}, \mathrm{b}, \mathrm{d}, \mathrm{e}$ & $0405 / 1005$ & MST 11 \\
\hline 715 & MittelNasca & Fransen a, d & $0405 / 1005$ & MST 12 \\
\hline 716 & OF (N4-5) & Webearbeit c, e +B & $0405 / 1005$ & MST 13 \\
\hline 717 & OF (N4-5) & Webearbeit a, b, d +B & $0405 / 1005$ & MST 14 \\
\hline 718 & OF (N4-5) & Webearbeit b $+\mathrm{B}$ & $0405 / 1005$ & MST 15 \\
\hline 719 & OF (N4-5) & Fransen a, d & $0405 / 1005$ & MST 16 \\
\hline 720 & OF (N4-5) & Fransen $\mathrm{f}$ & $0405 / 1005$ & MST 17 \\
\hline 721 & OF (N4-5) & Fransen a, e & $0405 / 1005$ & MST 18 \\
\hline 722 & OF (N4-5) & Haargeflecht a & $0405 / 1005$ & MST 19 \\
\hline 723 & Früh-Nasca & Haargeflecht $a, b$ & $0405 / 1005$ & MST 20 \\
\hline 724 & Früh-Nasca & Wollfäden d & $0405 / 1005$ & MST 21 \\
\hline 726 & Früh-Nasca & Haargeflecht a & $0405 / 1005$ & MST 22 \\
\hline 729 & Früh-Nasca & Wollfäden a & $0405 / 1005$ & MST 23 \\
\hline 733 & $\mathrm{OF}(\mathrm{N} 5)$ & Webarbeit a, b, d, e & $0405 / 1005$ & MST 24 \\
\hline
\end{tabular}

Legende: Int. Bez. = Interne Bezeichnung, $\mathrm{OF}=$ Oberflächenfund, ? = Zeitstellung unbekannt, / = Zeitstellung konnte nicht zugeordnet werden, $\mathrm{N}=$ Nasca
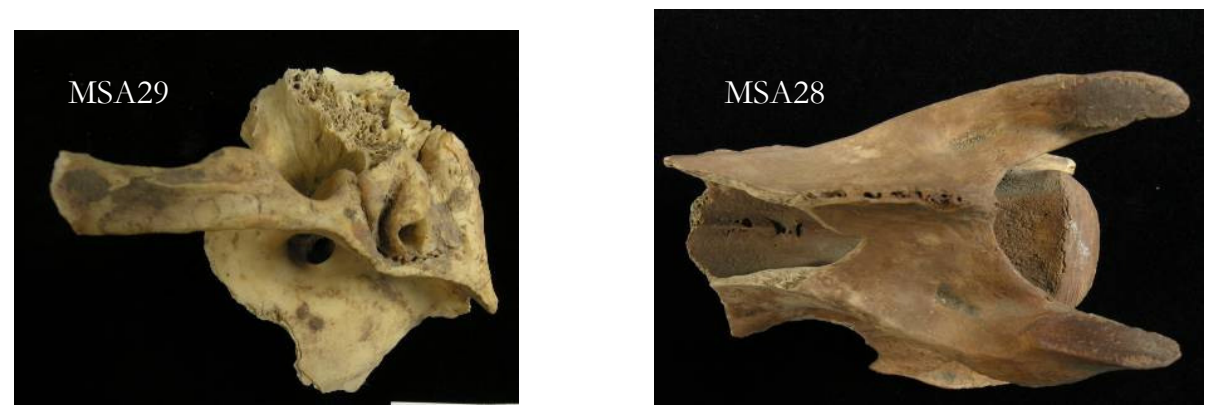

Abbildung 29: li.: Pars petrosa MSA29, re.: Vertebra cervicalis MSA28 


\subsubsection{La Muña}

La Muña übernahm die Funktion des Siedlungszentrums nach der Aufgabe von Los Molinos. In La Muña konnte die erste Nekropole der Nasca-Zeit entdeckt werden. Die Grabkammern (s. Abb. 30) waren größtenteils geplündert, jedoch konnten noch Goldfunde, Feinkeramik und Schmuckstücke geborgen werden. Diese reich ausgestatteten Gräber deuten auf eine stratifizierte Gesellschaft. Auch La Muña wurde wegen Überflutungen aufgegeben.

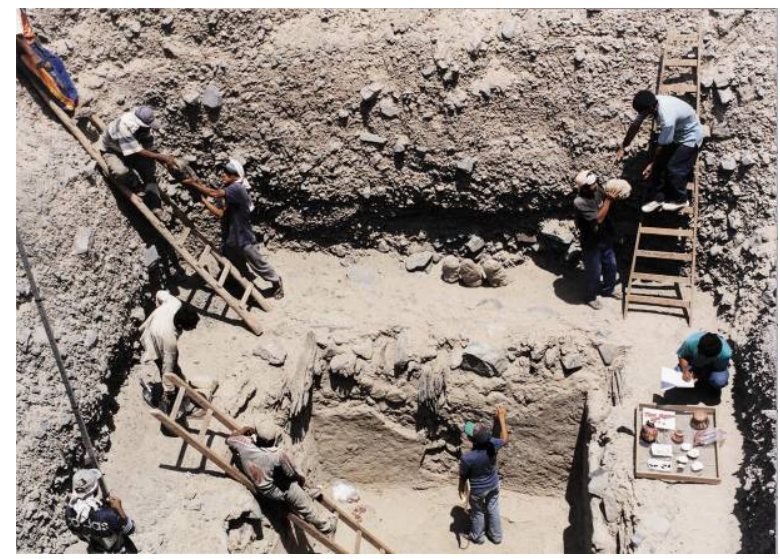

Abbildung 30: Ausgrabungen an einem Schachtkammergrab in La Muña (Quelle: KAAK/DAI)

In Tabelle 15 sind die entnommenen Proben des Fundortes La Muña verzeichnet. In Abbildung 31 sind exemplarisch zwei Proben dargestellt.

Tabelle 15: Proben des Fundortes La Muña

\begin{tabular}{|l|l|l|l|l|}
\hline Probennr. & Zeitstellung & Material & Probenentnahme/Erhalt & Int. Bez. \\
\hline 755 & Mittel-Nasca & Phalanges 1 & $0405 / 1005$ & MAA 1 \\
\hline 756 & Mittel-Nasca & Phalanges 1 & $0405 / 1005$ & MAA 2 \\
\hline 757 & Mittel-Nasca & Phalanges 1 & $0405 / 1005$ & MAA 3 \\
\hline 758 & Mittel-Nasca & Phalanges 1 & $0405 / 1005$ & MAA 4 \\
\hline 759 & Mittel-Nasca & Phalanges 1 & $0405 / 1005$ & MAA 5 \\
\hline 760 & Mittel-Nasca & Mandibula mit Dentes praemolaris & $0405 / 1005$ & MAA 6 \\
\hline 761 & Mittel-Nasca & Phalanges 1 & $0405 / 1005$ & MAA 7 \\
\hline 762 & Mittel-Nasca & Mandibularfragment & $0405 / 1005$ & MAA 8 \\
\hline 763 & Mittel-Nasca & Mandibularfragment & $0405 / 1005$ & MAA 9 \\
\hline 764 & Mittel-Nasca & Phalanges 1 & $0405 / 1005$ & MAA 10 \\
\hline 970 & Mittel-Nasca & a: Pars petrosa b: Dens molaris & $0306 / 0906$ & MAA 11 \\
\hline 971 & Mittel-Nasca & Mandibularfragment & $0306 / 0906$ & MAA 12 \\
\hline 972 & Mittel-Nasca & Pars petrosa & $0306 / 0906$ & MAA 13 \\
\hline 973 & Mittel-Nasca & Dens molaris & $0306 / 0906$ & MAA 14 \\
\hline 974 & Mittel-Nasca & Dens incisivus & $0306 / 0906$ & MAA 15 \\
\hline 984 & Mittel-Nasca & Dens molaris & $0306 / 0906$ & MAA 16 \\
\hline 985 & Mittel-Nasca & Os sesamoideum, Diaphyse & $0306 / 0906$ & MAA 17 \\
\hline 992 & Mittel-Nasca & Epiphyse Femur & $0306 / 0906$ & MAA 18 \\
\hline 993 & Mittel-Nasca & Patella & $0306 / 0906$ & MAA 19 \\
\hline 994 & Mittel-Nasca & Vertebra thoracalis & $0306 / 0906 / 0906$ & MAA 20 \\
\hline 995 & Mittel-Nasca & Fragment Scapula & $0306 / 0906$ & MAA 21 \\
\hline 996 & Mittel-Nasca & Vertebra sacralis & $0306 / 0906$ & MAA 22 \\
\hline 997 & Mittel-Nasca & a: Pars petrosa li., b: Pars petrosa re. & MAA 23 \\
\hline 998 & Mittel-Nasca & Pars petrosa (evt. Canis spec.) & MAA 24 \\
\hline 999 & Mittel-Nasca & Pars petrosa & & MAA 25 \\
\hline & & &
\end{tabular}




\begin{tabular}{|l|l|l|l|l|}
\hline Probennr. & Zeitstellung & Material & Probenentnahme/Erhalt & Int. Bez. \\
\hline 1001 & Mittel-Nasca & $\begin{array}{l}\text { a: Pars petrosa re. b: Pars petrosa re. } \\
\text { c: Dentes molaris und incisivi }\end{array}$ & $0306 / 0906$ & MAA 26 \\
\hline 697 & Mittel-Nasca & Zwirn e & $0405 / 1005$ & MAT 1 \\
\hline 725 & Mittel-Nasca & Haarflechte e, f & $0405 / 1005$ & MAT 2 \\
\hline
\end{tabular}

Legende: Int. Bez. = Interne Bezeichnung
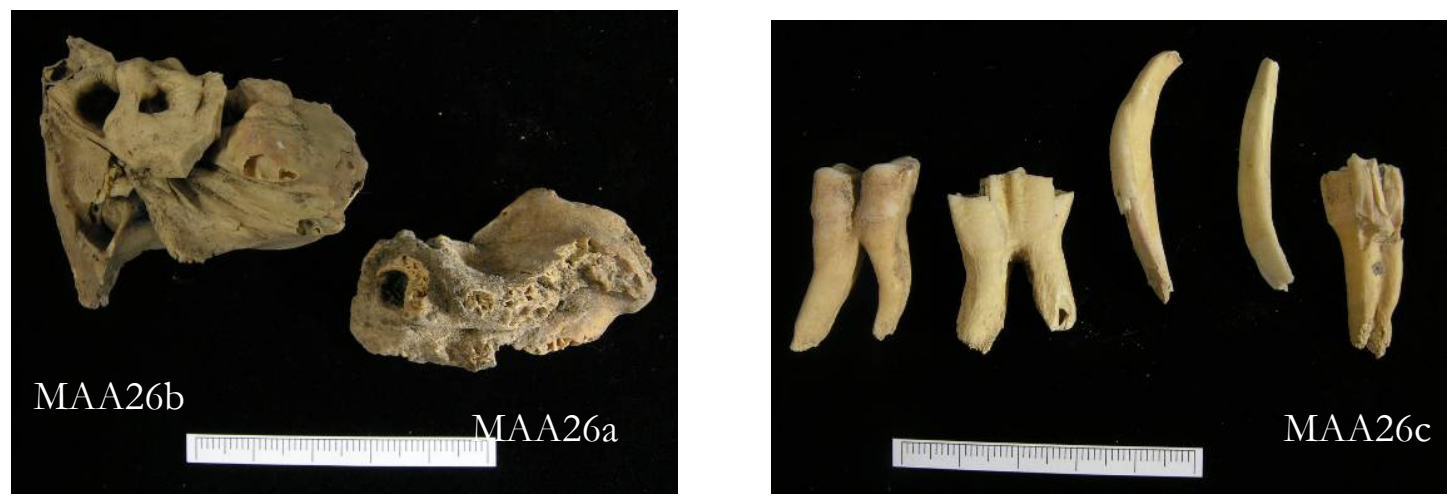

Abbildung 31: li.: Partes petrosae MAA 26, re.: Incisivi und Molaren MAA26

\subsubsection{Hanaq Pacha}

Dieser Fundort ist ein Gräberfeld aus der Phase Nasca 5. Es wurde bei den Bauarbeiten zum heutigen Grabungshaus in Palpa entdeckt. Neben 21 Bestattungen enthielt es zahlreiche Keramikfunde und tierische Überreste. Da es sich hier um ein sehr kleines Areal handelt, konnten nur zwei Proben entnommen werden (s. Tab. 16)

Tabelle 16: Proben des Fundortes Hanaq Pacha

\begin{tabular}{|l|l|l|l|l|}
\hline Probennr. & Zeitstellung & Material & Probenentnahme/Erhalt & Interne Bez. \\
\hline 652 & Mittel-Nasca & Mandibularfragment & $0405 / 1005$ & PAA 1 \\
\hline 653 & Mittel-Nasca & Phalanges 1 & $0405 / 1005$ & PAA 2 \\
\hline
\end{tabular}

\subsubsection{Montegrande}

Der Fundort Montegrande wurde bisher nicht ergraben, die zeitliche Einordnung erfolgte aufgrund der Beurteilung von Oberflächenfunden. Er besteht aus einer Spät-Nasca zeitlichen Siedlung und einem höher gelegenen LIP-zeitlichen Gräberfeld. Auf dem Gräberfeld konnte eine Vielzahl Mumienbündel gefunden werden, die jedoch zwischen September 2005 und März 2006 größtenteils durch Grabräuber zerstört wurden. Eine Besonderheit der Siedlung ist die Anhäufung von Camelidae-Knochen in ihrer Peripherie (s. Abb. 32). Oberflächlich sind überwiegend Knochen der Extremitäten und Schädel-Knochen (s. Abb. 32) zu finden. Eine genaue Deutung dieser Häufung an Camelidae-Überresten als Vorhandensein einer Karawanserei, eines Schlachthaus oder Zeugnis eines epidemischen Ereignisses, war ohne Ausgrabungen nicht möglich. Die Beprobung einer Vielzahl von Oberflächenfunden (s. Tab. 17 und Abb. 33) und ihre genetische Untersuchung sollen zur Klärung dieser Frage beitragen. 

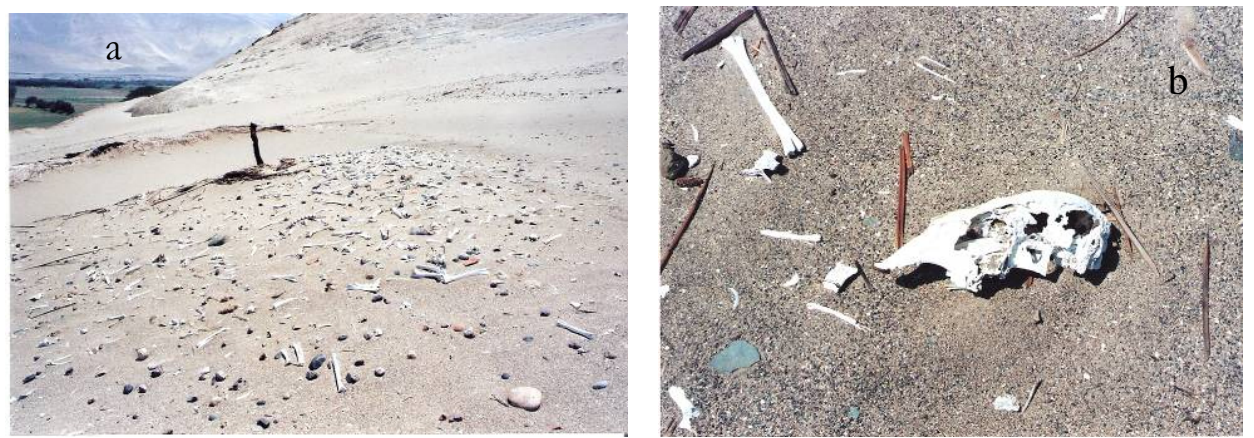

Abbildung 32: Verstreute Camelidae-Knochen in Montegrande. a: Blick über das Knochenfeld hin zur Siedlung, b: Camelidae-Schädel

Tabelle 17: Proben des Fundortes Montegrande

\begin{tabular}{|c|c|c|c|c|}
\hline Probennr. & Zeitstellung & Material & Probenentnahme/Erhalt & Int. Bez. \\
\hline 683 & OF (N8?) & Dens molaris & $0405 / 1005$ & GEA 1 \\
\hline 684 & OF (N8?) & Dens molaris & $0405 / 1005$ & GEA 2 \\
\hline 1018 & OF (N8?) & Mandibularfragment 4x Dens molaris & $0306 / 0906$ & GEA 4 \\
\hline 1019 & OF (N8?) & Mandibularfragment 3x Dens molaris & $0306 / 0906$ & GEA 5 \\
\hline 1020 & OF (N8?) & $\begin{array}{l}\text { Mandibularfragment } 2 x \text { Dens molaris } \\
\text { und } 4 x \text { Dens incisivus }\end{array}$ & $0306 / 0906$ & GEA 6 \\
\hline 1021 & OF (N8?) & Mandibularfragment 2x Dens molaris & $0306 / 0906$ & GEA 7 \\
\hline 1022 & OF (N8?) & Mandibularfragment 4x Dens incisivus & $0306 / 0906$ & GEA 8 \\
\hline 1023 & OF (N8?) & Mandibularfragment 2x Dens incisivus & $0306 / 0906$ & GEA 9 \\
\hline 1024 & OF (N8?) & Dens molaris & $0306 / 0906$ & GEA 10 \\
\hline 1025 & OF (N8?) & Pars petrosa li. & $0306 / 0906$ & GEA 11 \\
\hline 1026 & OF (N8?) & Pars petrosa li. & 0306/0906 & GEA 12 \\
\hline 1027 & OF (N8?) & Pars petrosa li. & $0306 / 0906$ & GEA 13 \\
\hline 1028 & OF (N8?) & Pars petrosa re. & $0306 / 0906$ & GEA 14 \\
\hline 1029 & OF (N8?) & Pars petrosa re. & $0306 / 0906$ & GEA 15 \\
\hline 1030 & OF (N8?) & Pars petrosa li. & $0306 / 0906$ & GEA 16 \\
\hline 1031 & OF (N8?) & Pars petrosa re. & $0306 / 0906$ & GEA 17 \\
\hline 1032 & OF (N8?) & Pars petrosa li. & $0306 / 0906$ & GEA 18 \\
\hline 691 & OF (N8/LIP?) & Haarflechte d, e +B & $0405 / 1005$ & GET 1 \\
\hline 692 & OF (N8/LIP?) & Fransen $a, d+B$ & $0405 / 1005$ & GET 2 \\
\hline 693 & OF (N8/LIP?) & Fransen $\mathrm{d}, \mathrm{e}+\mathrm{B}$ & $0405 / 1005$ & GET 3 \\
\hline 694 & OF (N8/LIP?) & Fransen $b, d, e+B$ & $0405 / 1005$ & GET 4 \\
\hline 695 & OF (N8/LIP?) & Webearbeit a $+\mathrm{B}$ & $0405 / 1005$ & GET 5 \\
\hline 1032 & OF (N8/LIP?) & Webearbeit a, e +B & $0306 / 0906$ & GET 6 \\
\hline 1033 & OF (N8/LIP?) & Webearbeit $\mathrm{a}+\mathrm{B}$ & $0306 / 0906$ & GET 7 \\
\hline 1034 & OF (N8/LIP?) & Webearbeit a +B & $0306 / 0906$ & GET 8 \\
\hline 1035 & OF (N8/LIP?) & Wolle e & $0306 / 0906$ & GET 9 \\
\hline 1037 & OF (N8/LIP?) & Webearbeit e, $\mathrm{f}$ & $0306 / 0906$ & GET 10 \\
\hline 1038 & OF (N8/LIP?) & Webearbeit a, b, d +B & $0306 / 0906$ & GET 11 \\
\hline 1039 & OF (N8/LIP?) & Webearbeit b +B & $0306 / 0906$ & GET 12 \\
\hline 1040 & OF (N8/LIP?) & Webearbeit a, b, e, f +B & $0306 / 0906$ & GET 13 \\
\hline 1017 & OF (N8/LIP?) & Haare e & $0306 / 0906$ & GET 14 \\
\hline
\end{tabular}

Legende: Int.Bez. = Interne Bezeichnung, OF = Oberflächenfund, N = Nasca, ? = Zeitliche Einordnung unsicher
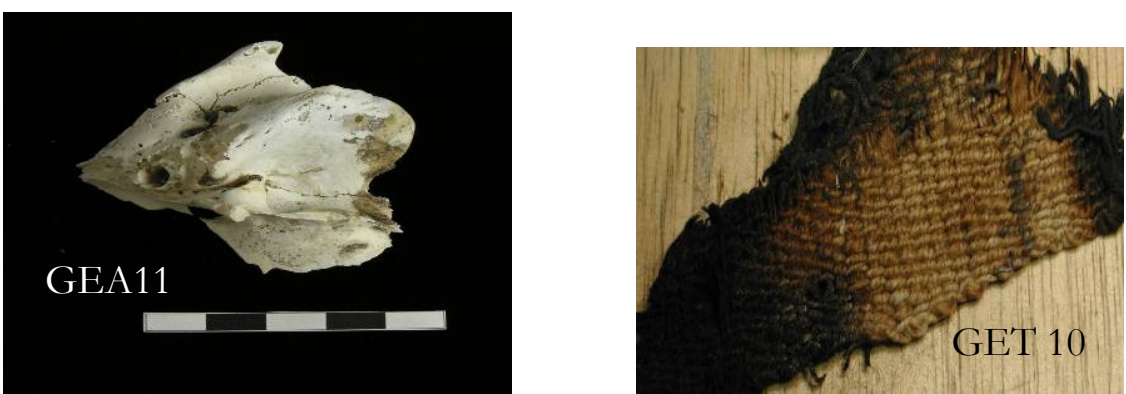

Abbildung 33: li.: Pars petrosa GEA11, li.: Webearbeit GET10 


\subsubsection{Chillo}

Chillo konnte in die späte Zwischenperiode datiert werden. Unterhalb dieser Siedlung konnte ein Mülldepot, das reichhaltige Funde enthielt, ausgemacht werden. Die Nutzung dieses Depots erfolgte über einen Zeitraum von ca. 200 Jahren. In den Abfallschichten konnte eine Vielzahl tierischer Knochen gefunden werden. In Tabelle 18 sind die entnommenen Proben gelistet und in Abbildung 34 zwei Proben dargestellt.

Tabelle 18: Proben des Fundortes Chillo

\begin{tabular}{|l|l|l|l|l|}
\hline Probennr. & Zeitstellung & Material & Probenentnahme/Erhalt & Int. Bez. \\
\hline 913 & LIP & Vertebra thoracalis, I & $0306 / 0906$ & COA 1 \\
\hline 914 & LIP & Phalanges 1 & $0306 / 0906$ & COA 2 \\
\hline 916 & LIP & Vertebra caudalis, Ph: Phalanges 1 & $0306 / 0906$ & COA 4 \\
\hline 917 & LIP & Vertebra thoracalis & $0306 / 0906$ & COA 5 \\
\hline 918 & LIP & Dens incisivus, Dens molaris & $0306 / 0906$ & COA 6 \\
\hline 919 & LIP & Calcaneus & $0306 / 0906$ & COA 7 \\
\hline 920 & LIP & Vertebra thoracalis & $0306 / 0906$ & COA 8 \\
\hline 921 & LIP & Vertebra thoracalis, Phalanges 3 & $0306 / 0906$ & COA 9 \\
\hline 922 & & (mit Weichgewebe) & & \\
\hline 923 & LIP & Epiphyse ? & $0306 / 0906$ & COA 10 \\
\hline 924 & LIP & Vertebra thoracalis & $0306 / 0906$ & COA 11 \\
\hline 925 & LIP & Vertebra thoracalis & $0306 / 0906$ & COA 12 \\
\hline 926 & LIP & Epiphyse Femur & $0306 / 0906$ & COA 13 \\
\hline 927 & LIP & Epiphyse Femur & $0306 / 0906$ & COA 14 \\
\hline 928 & LIP & Vertebra thoracalis, Diaphyse & $0306 / 0906$ & COA 15 \\
\hline 929 & LIP & Epiphyse ? mit Weichgewebe & $0306 / 0906$ & COA 16 \\
\hline 930 & LIP & Dens molaris, Diaphyse & $0306 / 0906$ & COA 17 \\
\hline 931 & LIP & Dens molaris & $0306 / 0906$ & COA 18 \\
\hline 932 & LIP & Epiphyse Kanonenbein & $0306 / 0906$ & COA 19 \\
\hline 933 & LIP & Epiphyse Kanonenbein & $0306 / 0906$ & COA 20 \\
\hline 934 & LIP & Dens molaris & $0306 / 0906$ & COA 21 \\
\hline 935 & LIP & Dens molaris & $0306 / 0906$ & COA 22 \\
\hline 936 & LIP & Dens molaris & $0306 / 0906$ & COA 23 \\
\hline 1000 & LIP & Vertebra thoracalis, Costa, Metatarsus & $0306 / 0906$ & \\
\hline & & & & \\
\hline
\end{tabular}

Legende: Int. Bez. = Interne Bezeichnung
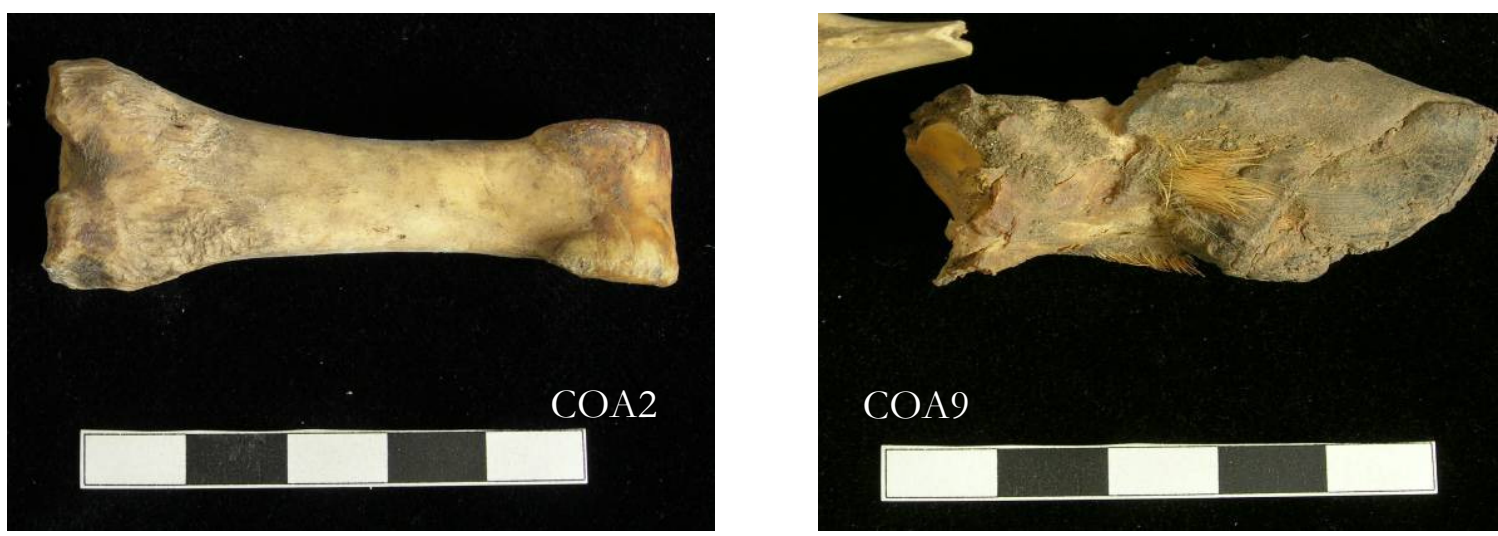

Abbildung 34: li.: Phalanges 1 COA2, re.: Phalanges 3 mit Weichgewebe COA9 
3.3. Probenvorbereitung und Extraktion

\subsubsection{Rezentes Material}

Blut

Die Extraktion der DNA aus der einzigen Blutprobe erfolgte solitär, um mögliche Kreuzkontaminationen zu vermeiden. Die Funktionsweise des EZ1Biorobot (Qiagen) ist bei Schmidt (2004) beschrieben. Die Blutprobe (La6) wurde wie folgt bearbeitet:

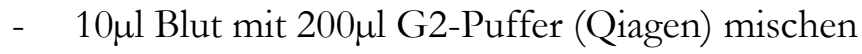

- Einsatz des Gesamt-Ansatzes in die Extraktion

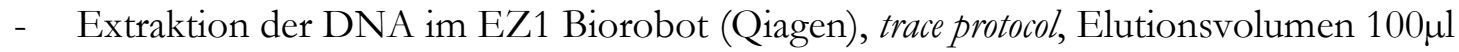
Ein Lyseschritt ist hier nach Angaben des Herstellers nicht erforderlich, da der Extraktor selbst einen Lysepuffer verwendet, der bei dem Einsatz von zellreichem flüssigem Material ausreichend ist.

Haare

In allen derzeit gängigen Protokollen zur Extraktion von DNA aus Haaren wird HCL als Reagenz zur Lösung der Keratinstruktur verwendet (z.B. Graffy et al. 2005, McNevin et al. 2005a, Pfeiffer et al. 2004). Gilbert et al. (2005) konnten nachweisen, dass Kontaminationen an Haaren selten bis gar nicht vorkommen, da das Keratin eine Bindung von Fremd-DNA verhindert. Eine Analyse von STRs aus Haar-Extrakten kann nur dann erfolgen, wenn neben dem Haarschaft auch die Wurzel mit extrahiert wird (McNevin et al. 2005b). Dies wurde bei der Auswahl der Haare, die in die Extraktion eingesetzt wurden, berücksichtigt. Ein Waschschritt der Haare erfolgte nicht, da zum Einen das Kontaminationsrisiko gering war, zum Anderen mit Camelidae-spezifischen Analysesystemen gearbeitet wurde, so dass Kontaminationen durch den Probennehmer oder die Probenbearbeiter nicht ins Gewicht fallen würden. Bei allen Arbeiten wurde jedoch nach den in Kap. 1.3 aufgeführten Kriterien gearbeitet, da diese in den Laboren, die auch für die aDNA-Analytik verwendet werden, durchgeführt wurden. Nach den Vorversuchen erbrachte das folgende Protokoll die besten Ergebnisse und wurde standardisiert angewendet.

Lyseprotokoll:

- 10-15 Haare +340 $\mu$ l Lysepuffer (s. Tab. 19)

- vortexen

- Inkubation im Thermorüttler für $24 \mathrm{~h}$ bei $37^{\circ} \mathrm{C}$ (bis alle Haare gelöst waren)

- $\quad+4,25 \mu l$ Proteinase K

- Inkubation für $2 \mathrm{~h}$ bei $56^{\circ}$ 
Tabelle 19: Zusammensetzung des Lysepuffers pH 8.0 (nach Pfeiffer et al. 2004):

\begin{tabular}{|l|l|l|}
\hline Konzentration & Substanz & Für V=25ml \\
\hline $100 \mathrm{mM}$ & Tris-HCL & $0,303 \mathrm{~g}$ \\
\hline $100 \mathrm{mM}$ & $\mathrm{NaCL}$ & $0,146 \mathrm{~g}$ \\
\hline $3 \mathrm{mM}$ & $\mathrm{CaCl}(0,5 \mathrm{M})$ & $150 \mu \mathrm{l}$ \\
\hline $39 \mathrm{mM}$ & DTT & $0,1503 \mathrm{~g}$ \\
\hline $2 \%$ & SDS & $0,5 \mathrm{~g}$ \\
\hline
\end{tabular}

Extraktionsprotokoll:

- Einsatz von $200 \mu \mathrm{l}$ Überstand des Lysats

- Extraktion im EZ1Biorobot (Qiagen), trace protocol, 50 $\mu$ l Elutionsvolumen

Von jeder Probe wurden mindestens zwei unabhängige DNA-Extrakte angefertigt, deren Lagerung bei $-18^{\circ} \mathrm{C}$ erfolgte.

\subsection{2 Überliefertes Material}

\section{Knochen und Zäbne}

Aus den Knochen wurde je ein 1 x $1 \mathrm{~cm}$ großes Stück mit einer Dentalbohrmaschine (K10, $\mathrm{KaVo})$ auf die ein Diamantsägeblatt aufgesetzt wurde, entnommen. Der Ort der Beprobung war abhängig vom Knochenelement. An Vertebrae wurde ein Stück des Corpus, an Phalangen ein Diaphysenstück, an Partes petrosae ein Stück neben dem Porus acusticus internus, an Diaphysen und Fragmenten je nach Erhaltungszustand und an Epiphysen ein Stück, das sowohl dichtes, als auch spongiöses Material umfasste, entnommen.

Von Zähnen wurde nur die Zahnwurzel verwendet, die mit Hilfe des Dentalbohrers von der Krone getrennt wurde. Lagen Dentes molaris vor, so wurden diese verwendet.

Das weitere Vorgehen war für Knochen und Zähne gleich. Die Oberflächen wurden abgetragen und das Probenstück pulverisiert, der genaue Prozess der Zerkleinerung ist bei Hummel (2003) nachzulesen. Standardisiert wurden von dem gewonnenen Probenmehl je 0,1g mit $500 \mu \mathrm{l}$ EDTA ( $\mathrm{pH} \mathrm{8,} \mathrm{0,5} \mathrm{M)} \mathrm{versetzt} \mathrm{und} \mathrm{für} 18 \mathrm{~h}$ (Probenrotator, $37^{\circ} \mathrm{C}$ ) inkubiert. Anschließend erfolgte die Zugabe von $20 \mu$ Proteinase K und eine weitere Inkubation für $2 \mathrm{~h}$ bei $56^{\circ} \mathrm{C}$. Das nicht gelöste Knochenmehl wurde durch Zentrifugation (3 min, $6000 \mathrm{rpm}$ ) am Gefäßboden gesammelt und $200 \mu \mathrm{l}$ des Überstandes in die Extraktion eingesetzt. Diese

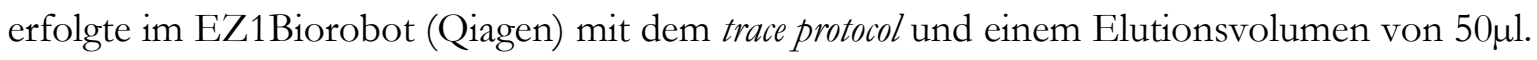
Von jeder Probe wurden zwei unabhängige Extrakte angefertigt. Von den Proben, die einen guten Amplifikationserfolg zeigten, wurden zwei weitere Extrakte angefertigt.

Für einige der Proben wurden von unterschiedlichen Knochenelementen Extrakte angefertigt, diese sind in den Tabellen 12-18 durch den Zusatz a, b und c gekennzeichnet. Es wurden so insgesamt 164 Extrakte aus den 156 entnommenen Fundnummerproben angefertigt. 
Textilien

Für die Textilien ist anzunehmen, dass die verwendete Wolle für ein Textilstück von mehr als einem Individuum stammt. Haare unterschiedlicher Farbe stammen eventuell ebenfalls von unterschiedlichen Individuen. Die Färbung von Haaren erfolgte wahrscheinlich ausgehend von ihrer Grundfarbe (schwarze Haare werden anders gefärbt als weiße). Um die mögliche Individuenanzahl pro angefertigtem Extrakt aus jeder Textilie zu minimieren, wurden pro Textilie und Extrakt nur Fasern der gleichen Farbe verwendet, so dass z.B. für die Probe GET11 drei Extrakte angefertigt wurden, da diese aus roten, grünen und gelben Fasern bestand. Insgesamt erhöhte sich durch dieses Verfahren die Probenanzahl von 40 auf insgesamt 69 Proben.

Die Textilien wurden zunächst mechanisch von anhaftenden Partikeln befreit und in einzelne Fasern getrennt. Diese wurden, mit einem Skalpell, in 0,5 cm große Stücke geschnitten. Für die Extraktion wurden zwei bis fünf dieser Stücke verwendet, je nach Dicke der Faser. Die Lyse und Extraktion wurden nach folgendem Protokoll durchgeführt:

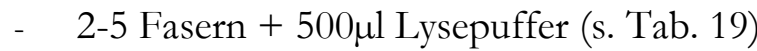

- vortexen

- Inkubation im Thermorüttler bei $37^{\circ} \mathrm{C}$ (bis Fasern komplett gelöst waren)

- $\quad+6,25 \mu$ Proteinase K

- Inkubation für $2 \mathrm{~h}$ bei $56^{\circ}$

- Zentrifugation 3min, 6000rpm

- Einsatz von $200 \mu l$ Überstand in die Extraktion

- Extraktion im EZ1Biorobot (Qiagen), trace protocol, 50 $\mu$ l Elutionsvolumen

Für jede Probe wurden zwei unabhängige Extrakte angefertigt. Von den Proben, die einen guten Amplifikationserfolg zeigten, wurden zwei weitere Extrakte angefertigt.

\subsection{Mitochondriale Markersysteme}

Die Auswahl mitochondrialer Marker orientierte sich am derzeitigen Forschungsstand (s. Kap. 2.1.1) und ihrer Anwendbarkeit in aDNA. Augenmerk lag hierbei auf der Möglichkeit Variabilität von Populationen zu erfassen und auf der Eignung des Fragments zur Speziesidentifikation. Neben dem Cytochrom b-Gen (cytb, np14154-14148), wurden Systeme für die Untersuchung der Gene Cytochrom c Oxidase I (COI, np5326-6870), NADHDehoydrogenase 5 (Nd5, np11746-13566) und 12srRNA (np66-1033) entwickelt. Die Entwicklung aller Primer erfolgte mit der Software PrimerSelect des Lasergene Software Pakets (DNAStar) und folgte den Regel von Hummel (2003, S. 96ff). Die Primer wurden so gewählt, dass sie ausschließlich Camelidae-spezifische-DNA amplifizieren. 
Von der Blutprobe wurde $1 \mu \mathrm{l}$, von den Haarproben 1-2 $\mu$ und von den überlieferten Proben 5-10 $\mu \mathrm{l}$ (je nach Qualität der Proben) DNA-Extrakt in die Amplifikationen eingesetzt. Die Zyklenzahl der Amplifikationen betrug für rezente Proben 35-38, für überliefertes Material 40-50. Für rezente DNA wurde je eine Amplifikation pro erstelltem Extrakt durchgeführt. Für alte DNA wurden in der Regel pro hergestelltem Extrakt zwei Amplifikationen durchgeführt. Für die Analyse der Fragmente 12srRNA-Gen, COI und Nd5 wurde pro aDNA-Extrakt nur eine Amplifikation durchgeführt, da diese nur in solchen Proben amplifiziert wurden, für die bereits reproduzierte Ergebnisse über die Cytochrom b-Analyse vorlagen. In den Fällen in denen sequenziert wurde, erfolgte nur dann die Sequenzierung des L-Stranges, wenn der Verdacht auf Deaminierungsartefakte vorlag.

Bei allen Arbeiten wurden die in Kapitel 1.3 geschilderten Regeln zur Kontaminationsprävention befolgt.

\subsection{1 cytb}

Zunächst wurden anhand der Referenzsequenz für Lama pacos (NC 002504), im Vergleich mit der Referenzsequenz eines Vikunjas (AY535255), Primer für die Synthese eines 526 bp großen Fragmentes entwickelt. Diese wurde an je einem Individuum pro Typus (Lama, Alpaka, Vikunja und Guanako) getestet. Nach der erfolgreichen Amplifikation dieser, wurden Primer für die Synthese kürzerer Fragmente entwickelt (277 bp, 198 bp, 177 bp, 151 bp und 131 bp). Die Wahl des amplifizierten Bereiches orientierte sich an der Variabilität des Fragmentes. Da der hintere Bereich des 526 bp Fragmentes im Vergleich zum vorderen Bereich sehr wenige Polymorphismen aufwies, erfolgten die Verkürzungen durch das Ausklammern des hinteren Bereiches. Bereits für die Amplifikation des längsten Fragmentes mussten so genannte wobble-Primer erstellt werden. Dies sind Primer die an mehr als einer Base ansetzen können, da in ihnen anstelle einer spezifischen eine unspezifische Base eingebaut ist. Zur Erfassung der in den Primersequenzen liegenden polymorphen Stellen, wurden die Fragmente cytb5 und cytb6 entwickelt. Die Primer dieser Fragmente liegen vor, bzw. hinter denen der Fragmente 3 und 4, ihre Primer enthalten jedoch ebenfalls wobblePositionen. Diese Strategie sollte die Erfassung der kompletten Sequenz über 276 bp, auch in stark degradierten Proben, ermöglichen. In Abbildung 35 ist das Amplifikationsschema dargestellt, in Tabelle 20 sind die verwendeten Primer gelistet. 


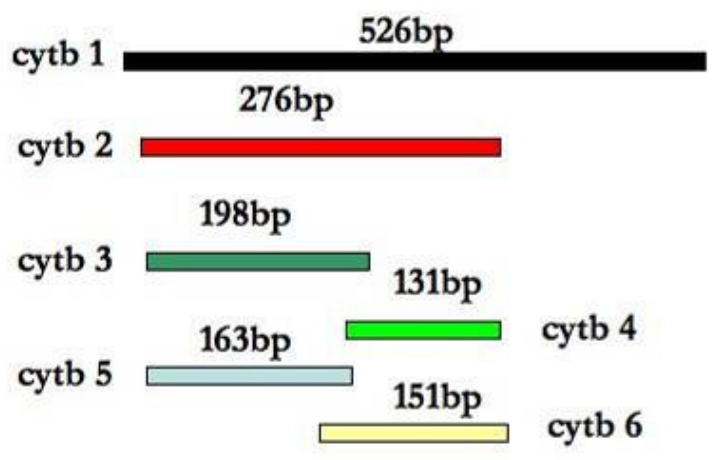

Abbildung 35: Schema der entwickelten Amplifikationssysteme des cytb-Gens

Tabelle 20: Primer zur Amplifikation von Fragmenten des cytb-Gens

\begin{tabular}{|c|c|c|c|c|c|}
\hline Fragment & Primername & Primersequenz $5{ }^{`} 3^{\prime}$ & $\begin{array}{l}\text { bp- } \\
\text { Primer }\end{array}$ & $\begin{array}{l}\text { np- } \\
\text { Bereich }\end{array}$ & Produktlänge \\
\hline \multirow[t]{2}{*}{ cytb 1} & Lama_upper & GGYGCCTCYATATTCTTCTTCATCTG & 26 & \multirow{2}{*}{$\begin{array}{l}14392- \\
14918\end{array}$} & \multirow[t]{2}{*}{ 526bp } \\
\hline & Lama_lower & GGTTAGCGGRGGTATAGTTRTCG & 23 & & \\
\hline \multirow[t]{2}{*}{ cytb 2} & Cytbshort_upper & CCTCYATATTCTTCATCTGC & 20 & \multirow{2}{*}{$\begin{array}{l}14419- \\
14695\end{array}$} & \multirow[t]{2}{*}{276} \\
\hline & Cytbshort_lower & AAGAATCGTGTAAGGGTGG & 19 & & \\
\hline \multirow[t]{2}{*}{ cytb 3} & Cytbshort_upper & CCTCYATATTCTTCATCTGC & 20 & \multirow{2}{*}{$\begin{array}{l}14419- \\
14614\end{array}$} & \multirow[t]{2}{*}{198} \\
\hline & Cytb3_lower & TTGCYGAGAGTAGRTTTGTAAT & 22 & & \\
\hline \multirow[t]{2}{*}{ cytb 4} & Cytb4_upper & TGAGGGGCAACAGTAA & 16 & \multirow{2}{*}{$\begin{array}{l}14580- \\
14711\end{array}$} & \multirow[t]{2}{*}{131} \\
\hline & Cytb4_lower & ATAAAGTGGAAGGCGAAGAATC & 22 & & \\
\hline \multirow[t]{2}{*}{ cytb 5} & Cytb5_upper & TTGTATATYCMCGTRGGTCGT & 21 & \multirow{2}{*}{$\begin{array}{l}14410- \\
14583\end{array}$} & \multirow[t]{2}{*}{163} \\
\hline & Cytb5_lower & AAAATGATATTTGKCCTCATGGRAG & 25 & & \\
\hline \multirow[t]{2}{*}{ cytb 6} & Cytb6_upper & AGGMCAAATATCATTTTGAGGGGCAACAGT & 30 & \multirow{2}{*}{$\begin{array}{l}14564- \\
14715\end{array}$} & \multirow[t]{2}{*}{151} \\
\hline & Cytb6_lower & GTAAGATAAAGTGGAAGGCGAAGAATCGTG & 30 & & \\
\hline
\end{tabular}

Legende: $\mathrm{bp}=\mathrm{B}$ asenpaare, $\mathrm{np}=$ Nukleotidposition in der mitochondrialen DNA, $\mathrm{Y}=\mathrm{C}$ oder T, $\mathrm{R}=\mathrm{A}$ oder $\mathrm{G}$, $\mathrm{M}=\mathrm{A}$ oder $\mathrm{C}, \mathrm{K}=\mathrm{G}$ oder $\mathrm{T}$

Die PCR-Reaktionen setzten sich wie in Tabelle 21 gelistet zusammen.

Tabelle 21: Zusammensetzung der PCR-Ansätze

\begin{tabular}{|l|l|l|l|l|l|l|}
\hline Komponenten & cytb1 & cytb2 & cytb 3 & cytb 4 & cytb 5 & cytb 6 \\
\hline $\mathrm{MgCl}_{2} 2,5 \mathrm{mM}$ & $4 \mu \mathrm{l}$ & $4 \mu \mathrm{l}$ & $4 \mu \mathrm{l}$ & $4 \mu \mathrm{l}$ & $4 \mu \mathrm{l}$ & $4 \mu \mathrm{l}$ \\
\hline Buffer II & $5 \mu \mathrm{l}$ & $5 \mu \mathrm{l}$ & $5 \mu \mathrm{l}$ & $5 \mu \mathrm{l}$ & $5 \mu \mathrm{l}$ & $5 \mu \mathrm{l}$ \\
\hline dNTPs & $8 \mu \mathrm{l}$ & $7 \mu \mathrm{l}$ & $7 \mu \mathrm{l}$ & $7 \mu \mathrm{l}$ & $7 \mu \mathrm{l}$ & $7 \mu \mathrm{l}$ \\
\hline Taq-Polymerase $(3 \mathrm{U})$ & $0,3 \mu \mathrm{l}$ & $0,3 \mu \mathrm{l}$ & $0,3 \mu \mathrm{l}$ & $0,3 \mu \mathrm{l}$ & $0,3 \mu \mathrm{l}$ & $0,3 \mu \mathrm{l}$ \\
\hline Primer_upper & $1,0 \mu \mathrm{l}(0,5 \mu \mathrm{M})$ & $0,5 \mu \mathrm{l}(0,1 \mu \mathrm{M})$ & $0,75 \mu \mathrm{l}(0,15 \mu \mathrm{M})$ & $0,75 \mu \mathrm{l}(0,15 \mu \mathrm{M})$ & $1 \mu \mathrm{l}(0,5 \mu \mathrm{M})$ & $1 \mu \mathrm{l}(0,5 \mu \mathrm{M})$ \\
\hline Primer_lower & $1,0 \mu \mathrm{l}(0,5 \mu \mathrm{M})$ & $0,5 \mu \mathrm{l}(0,1 \mu \mathrm{M})$ & $0,75 \mu \mathrm{l}(0,15 \mu \mathrm{M})$ & $0,75 \mu \mathrm{l}(0,15 \mu \mathrm{M})$ & $1 \mu \mathrm{l}(0,5 \mu \mathrm{M})$ & $1 \mu \mathrm{l}(0,5 \mu \mathrm{M})$ \\
\hline DNA & $1-2 \mu \mathrm{l}$ & $1-10 \mu \mathrm{l}$ & $1-10 \mu \mathrm{l}$ & $1-10 \mu \mathrm{l}$ & $1-10 \mu \mathrm{l}$ & $1-10 \mu \mathrm{l}$ \\
\hline $\mathrm{H}_{2} \mathrm{O}$ & $27,7-28,7 \mu \mathrm{l}$ & $22,7-31,7 \mu \mathrm{l}$ & $22,2-31,2 \mu \mathrm{l}$ & $22,2-31,2 \mu \mathrm{l}$ & $22,2-31,2 \mu \mathrm{l}$ & $22,7-31,7 \mu \mathrm{l}$ \\
\hline
\end{tabular}

Die Amplifikationen wurden mit folgenden Parametern im Mastercycler (Eppendorf) durchgeführt (s. Tab. 22).

Tabelle 22: Amplifikationsparameter

\begin{tabular}{|c|c|c|c|c|c|c|}
\hline & cytb1 & cytb2 & cytb 3 & cytb 4 & cytb 5 & cytb 6 \\
\hline Initial & $94^{\circ} \mathrm{C} 11 \mathrm{~min}$ & $94^{\circ} \mathrm{C} 11 \mathrm{~min}$ & $94^{\circ} \mathrm{C} 11 \mathrm{~min}$ & $94^{\circ} \mathrm{C} 11 \mathrm{~min}$ & $94^{\circ} \mathrm{C} 11 \mathrm{~min}$ & $94^{\circ} \mathrm{C} 11 \mathrm{~min}$ \\
\hline \multirow{3}{*}{ Cycling } & $94^{\circ} \mathrm{C} 1 \mathrm{~min}$ & $94^{\circ} \mathrm{C} 1 \mathrm{~min}$ & $94^{\circ} \mathrm{C} 1 \mathrm{~min}$ & $94^{\circ} \mathrm{C} 1 \mathrm{~min}$ & $94^{\circ} \mathrm{C} 1 \mathrm{~min}$ & $94^{\circ} \mathrm{C} 1 \mathrm{~min}$ \\
\hline & $63^{\circ} \mathrm{C} 1 \mathrm{~min}$ & $55^{\circ} \mathrm{C} 1 \mathrm{~min}$ & $55^{\circ} \mathrm{C} 1 \mathrm{~min}$ & $58^{\circ} \mathrm{C} 1 \mathrm{~min}$ & $53,5^{\circ} \mathrm{C} 1 \mathrm{~min}$ & $61^{\circ} \mathrm{C} 1 \mathrm{~min}$ \\
\hline & $72^{\circ} \mathrm{C} 2 \mathrm{~min}$ & $72^{\circ} \mathrm{C} 2 \mathrm{~min}$ & $72^{\circ} \mathrm{C} 1 \mathrm{~min}$ & $72^{\circ} \mathrm{C} 1 \mathrm{~min}$ & $72^{\circ} \mathrm{C} 1 \mathrm{~min}$ & $72^{\circ} \mathrm{C} 1 \mathrm{~min}$ \\
\hline Zyklenzahl & 35 & $35-40$ & $40-50$ & $40-50$ & $40-50$ & $40-50$ \\
\hline Soak & $10^{\circ} \mathrm{C} 10 \mathrm{~min}$ & $10^{\circ} \mathrm{C} 10 \mathrm{~min}$ & $10^{\circ} \mathrm{C} 10 \mathrm{~min}$ & $10^{\circ} \mathrm{C} 10 \mathrm{~min}$ & $10^{\circ} \mathrm{C} 10 \mathrm{~min}$ & $10^{\circ} \mathrm{C} 10 \mathrm{~min}$ \\
\hline
\end{tabular}


Der Amplifikationserfolg wurde auf einem 2,5\%igen Agarosegel überprüft, die Geldokumentation erfolgte mit dem Gerät Gel Jet Imager (INTAS). Zur Bestimmung der Sequenzabfolge der entstanden Fragmente mussten diese zunächst aufgereinigt werde. Dies erfolgte mit dem MiniElute ${ }^{\mathrm{TM}}$ PCR-Purification-Kit (Qiagen), nach Angaben des Herstellers. Hierauf folgte das Ansetzen der Taq-Cycle-Sequencing-Reaktion mit dem Big-Dye-Terminator-Kit (BDT-Kit, PE Applied Biosystems). Ein Reaktionsansatz enthielt $2 \mu \mathrm{l}$ BDT, $3 \mu \mathrm{l}$ 5xSequencing Buffer, 0,25 $\mu \mathrm{M}$ Primer (upper oder lower) und 1-3 $\mu \mathrm{l}$ aufgereinigtes PCRProdukt. Um das Reaktionsvolumen von $20 \mu \mathrm{l}$ zu erreichen, wurde der Reaktionsansatz mit HPLC- $\mathrm{H}_{2} \mathrm{O}$ (Merck) aufgefüllt. Es wurde pro Ansatz ein Tropfen Mineralöl (NUJOL, Perkin Elmer Cetus) hinzugefügt, die Amplifikation erfolgte im DNA Thermal Cyler Typ TC1 (Perkin Elmer Cetus). Die Amplifikationsparameter sind in Tabelle 23 gelistet.

Tabelle 23: Amplifikationsparameter der Taq-Cycle-Sequencing-Reaktion

\begin{tabular}{|l|l|l|l|l|l|l|}
\hline & cytb1 & cytb2 & cytb 3 & cytb 4 & cytb 5 & cytb 6 \\
\hline Initial & $96^{\circ} \mathrm{C} 5 \mathrm{~min}$ & $96^{\circ} \mathrm{C} 5 \mathrm{~min}$ & $96^{\circ} \mathrm{C} 5 \mathrm{~min}$ & $96^{\circ} \mathrm{C} 5 \mathrm{~min}$ & $96^{\circ} \mathrm{C} 5 \mathrm{~min}$ & $96^{\circ} \mathrm{C} 5 \mathrm{~min}$ \\
\hline \multirow{4}{*}{$\mathrm{Cycling}$} & $96^{\circ} \mathrm{C} 10 \mathrm{sec}$ & $96^{\circ} \mathrm{C} 10 \mathrm{sec}$ & $96^{\circ} \mathrm{C} 10 \mathrm{sec}$ & $96^{\circ} \mathrm{C} 10 \mathrm{sec}$ & $96^{\circ} \mathrm{C} 10 \mathrm{sec}$ & $96^{\circ} \mathrm{C} 10 \mathrm{sec}$ \\
\cline { 2 - 7 } & $55^{\circ} \mathrm{C} 5 \mathrm{sec}$ & $50^{\circ} \mathrm{C} 5 \mathrm{sec}$ & $50^{\circ} \mathrm{C} 5 \mathrm{sec}$ & $55^{\circ} \mathrm{C} 5 \mathrm{sec}$ & $50^{\circ} \mathrm{C} 5 \mathrm{sec}$ & $55^{\circ} \mathrm{C} 5 \mathrm{sec}$ \\
\cline { 2 - 7 } & $60^{\circ} \mathrm{C} 4 \mathrm{~min}$ & $60^{\circ} \mathrm{C} 4 \mathrm{~min}$ & $60^{\circ} \mathrm{C} 4 \mathrm{~min}$ & $60^{\circ} \mathrm{C} 4 \mathrm{~min}$ & $60^{\circ} \mathrm{C} 4 \mathrm{~min}$ & $60^{\circ} \mathrm{C} 4 \mathrm{~min}$ \\
\hline Zyklenzahl & 30 & 30 & 25 & 25 & 25 & 25 \\
\hline
\end{tabular}

Die Annealing-Temperatur der Taq-Cycle-Sequencing-Reaktion orientiert sich an der optimalen Annealing-Temperatur des jeweiligen Primers, die um ca. $5^{\circ} \mathrm{C}$ unterschritten wird. Die Zyklenzahl ist abhängig von der Länge des Fragments.

Zur Entfernung überschüssiger ddNTPs aus dieser Reaktion, welche die Sequenz-Analyse erschweren, wurden die Sequenzierprodukte mit dem NucleoSeq-Kit (Machery \& Nagel) nach Angabe des Herstellers aufgereinigt. Das so gewonnene Produkt wurde komplett in ein Probengefäß überführt und in das Sequenzier-Gerät (310er, PE Applied Biosystems) eingebracht. Die elektrophoretische Auftrennung erfolgte mit Hilfe des Performance-OptimizedPolymer 6 (POP6), die Auswertung der Signale erfolgte mit Hilfe der Geräte zugehörigen Software ABI Prism ${ }^{\mathrm{TM}}$ Sequencing Analysis (PE Applied Biosystems). Die Auswertung der Sequenzen erfolgte unter Verwendung der Programme SeqMan und MegAling des Lasergene Software Pakets (DNAStar).

Neben der Direkt-Sequenzierung der Produkte, erfolgte zunächst auch eine RFLP-Analyse, die im Rahmen einer Staatsexamensarbeit, mit dem Ziel eines einfachen Speziesidentifikationssytems, entwickelt wurde (Koch 2006). Diese stellte sich jedoch im Verlauf dieser Arbeit als unzureichend, bezüglich der Speziesproblematik, heraus und wurde nicht mehr verwendet. Die so gewonnen Ergebnisse fließen nicht in die Auswertung mit ein. 


\subsubsection{COI}

Anhand der Referenzsequenz Lama pacos (NC 002504) wurde ein System zur Analyse eines $121 \mathrm{bp}$ langen Fragments des COI-Gens entwickelt. In Tabelle 24 sind die AmplifikationsPrimer dargestellt.

Tabelle 24: Primer zur Amplifikation eines 121bp-langens Fragments des Gens COI

\begin{tabular}{|l|l|l|l|l|}
\hline & Primersequenz 5` ${ }^{`}$ & bp-Primer & np-Bereich & Produktlänge \\
\hline COI_upper & GCGCTTGGGCTGGGATAGT & 19 & $5420-5522$ & \multirow{2}{*}{$121 \mathrm{bp}$} \\
\hline COI_lower & AATGCGTGGGCCGTAACAA & 19 & & \\
\hline
\end{tabular}

Legende: $b p=$ Basenpaare, $n p=$ Nukleotidposition, $G=$ Guanin, $A=$ Adenin, $T=$ Thymin, $C=$ Cytosin

Der Ansatz der Amplifikations-Reaktion sowie ihre Parameter sind in Tabelle 25 aufgeführt.

Die Amplifikationen erfolgten im Mastercycler (Eppendorf).

Tabelle 25: Zusammensetzung der PCR-Reaktion und ihre Amplifikationsparameter

\begin{tabular}{|c|c|c|c|}
\hline Komponenten & & Parameter & \\
\hline $\mathrm{MgCl}_{2} 2,5 \mathrm{mM}$ & $4 \mu \mathrm{l}$ & Initial & $94^{\circ} \mathrm{C} 11 \mathrm{~min}$ \\
\hline Buffer II & $5 \mu \mathrm{l}$ & \multirow{3}{*}{ Cycling } & $94^{\circ} \mathrm{C} 1 \mathrm{~min}$ \\
\hline dNTPs & $7 \mu \mathrm{l}$ & & $56^{\circ} \mathrm{C} 1 \mathrm{~min}$ \\
\hline Taq-Polymerase $(1,5 \mathrm{U})$ & $0,3 \mu \mathrm{l}$ & & $72^{\circ} \mathrm{C} 1 \mathrm{~min}$ \\
\hline Primer_upper & $0,6 \mu \mathrm{l}(0,12 \mu \mathrm{M})$ & Zyklenzahl & $35-50$ \\
\hline Primer_lower & $0,6 \mu \mathrm{l}(0,12 \mu \mathrm{M})$ & Soak & $10^{\circ} \mathrm{C} 10 \mathrm{~min}$ \\
\hline DNA & $1-10 \mu \mathrm{l}$ & & \\
\hline $\mathrm{H}_{2} \mathrm{O}$ & $22,5-31,5 \mu \mathrm{l}$ & & \\
\hline
\end{tabular}

Der Amplifikationserfolg wurde auf einem 2,5\%igen Agarosegel überprüft und mit dem Gerät Gel Jet Imager (INTAS) dokumentiert. Die Aufreinigung und das Ansetzen der Taq-CycleSequencing-Reaktion erfolgte analog zu der Anwendung für die Fragmente des cytb (s. S. 86). Die Annealing-Temperatur betrug hier $50^{\circ} \mathrm{C}$ und es wurden 25 Zyklen durchgeführt. Analyse und Auswertung der Sequenzen erfolgte wie bei den Produkten des cytb.

\subsubsection{Nd5}

Die Entwicklung der Primer zur Amplifikation eines Fragmentes aus dem Nd5-Gen erfolgte anhand der Referenzsequenz Lama pacos (NC 002504). Die Primer sind in Tabelle 26 gelistet.

Tabelle 26: Primer zur Amplifikation eines 135bp langen Fragments des Nd5-Gens

\begin{tabular}{|l|l|l|l|l|}
\hline & Primersequenz 5 - 3` & bp-Primer & np-Bereich & Produktlänge \\
\hline Nd5_upper & ACTCCCGTCTCCGCCCTACTAC & 22 & $12473-$ & $135 \mathrm{bp}$ \\
\hline Nd5_lower & GGTGGTGATTGCGCCTAAACA & 21 & 12608 & \\
\hline
\end{tabular}

Legende: $\mathrm{bp}=$ Basenpaare, $\mathrm{np}=$ Nukleotidposition, $\mathrm{G}=$ Guanin, $\mathrm{A}=$ Adenin, $\mathrm{T}=$ Thymin, $\mathrm{C}=$ Cytosin

Amplifikations-Komponenten und PCR-Parameter sind in Tabelle 27 aufgeführt. Die Amplifikationen erfolgten im Mastercycler (Eppendorf). 
Tabelle 27: Zusammensetzung der PCR-Reaktion und ihre Amplifikationsparameter

\begin{tabular}{|c|c|c|c|}
\hline Komponenten & & Parameter & \\
\hline $\mathrm{MgCl}_{2} 2,5 \mathrm{mM}$ & $4 \mu \mathrm{l}$ & Initial & $94^{\circ} \mathrm{C} 11 \mathrm{~min}$ \\
\hline Buffer II & $5 \mu \mathrm{l}$ & \multirow{3}{*}{ Cycling } & $94^{\circ} \mathrm{C} 1 \mathrm{~min}$ \\
\hline dNTPs & $7 \mu \mathrm{l}$ & & $58^{\circ} \mathrm{C} 1 \mathrm{~min}$ \\
\hline Taq-Polymerase $(1,5 \mathrm{U})$ & $0,3 \mu \mathrm{l}$ & & $72^{\circ} \mathrm{C} 1 \mathrm{~min}$ \\
\hline Primer_upper & $0,6 \mu \mathrm{l}(0,12 \mu \mathrm{M})$ & Zyklenzahl & $35-50$ \\
\hline Primer_lower & $0,6 \mu \mathrm{l}(0,12 \mu \mathrm{M})$ & Soak & $10^{\circ} \mathrm{C} 10 \mathrm{~min}$ \\
\hline DNA & $1-10 \mu \mathrm{l}$ & & \\
\hline $\mathrm{H}_{2} \mathrm{O}$ & $22,5-31,5 \mu \mathrm{l}$ & & \\
\hline
\end{tabular}

Der Amplifikationserfolg wurde wie für cytb (s. S. 86) überprüft. Die Folgeanalysen der Produkte sind analog zu den cytb-Produkten durchgeführt worden (s. S. 86). Die AnnealingTemperatur des Taq-Cycle-Sequencing betrug $55^{\circ} \mathrm{C}$ und es wurden 25 Zyklen durchgeführt.

\subsubsection{2srRNA}

Für das 12srRNA-Gen wurden zunächst zwei Primersysteme für die Amplifikation eines 470bp und eines 332bp langen Fragmentes entwickelt. Beide Fragmente wurden in allen rezenten Proben amplifiziert und sequenziert, um polymorphe speziesidentifizierende Stellen zu detektieren. In Tabelle 28 sind die Amplifikations-Primer gelistet.

Tabelle 28: Primersequenzen zur Amplifikation zweier Fragmente des 12srRNA-Gens

\begin{tabular}{|l|l|l|l|l|}
\hline & Primersequenz 5 - 3 & bp-Primer & np-Bereich & Produktlänge \\
\hline 12sF_upper & AGCCTTTCTATTAGTTTCTGA & 21 & $82-$ & $470 \mathrm{bp}$ \\
\hline 12sF_lower & GAGCGATTTTGTTATTGTAATC & 22 & 551 & \\
\hline 12sB_upper & AGGACTTGGCGGTGCTTCATA & 21 & $88-$ & $332 \mathrm{bp}$ \\
\hline 12sB_lower & GGTGTGTGCGTGCTTCATGG & 20 & 918 & \\
\hline
\end{tabular}

Legende: $\mathrm{bp}=$ Basenpaare, $\mathrm{np}=$ Nukleotidposition, $\mathrm{G}=$ Guanin, $\mathrm{A}=$ Adenin, $\mathrm{T}=$ Thymin, $\mathrm{C}=$ Cytosin

Die Zusammensetzung der PCR und ihre Parameter sind Tabelle 29 zu entnehmen. Die Sequenzanalyse und Auswertung erfolgte wie bei cytb (s. S. 86), die Annealing Temperatur des Taq-Cycle-Sequencing betrug $50^{\circ} \mathrm{C}$ und es wurden 30 Zyklen durchgeführt

Tabelle 29: Zusammensetzung der PCR und ihre Parameter

\begin{tabular}{|l|l|l|l|}
\hline Komponenten & & Parameter & \\
\hline $\mathrm{MgCl}_{2} 2,5 \mathrm{mM}$ & $4 \mu \mathrm{l}$ & Initial & $94^{\circ} \mathrm{C} 11 \mathrm{~min}$ \\
\hline Buffer II & $5 \mu \mathrm{l}$ & \multirow{3}{*}{ Cycling } & $94^{\circ} \mathrm{C} 1 \mathrm{~min}$ \\
\cline { 1 - 2 } dNTPs & $7 \mu \mathrm{l}$ & & $55^{\circ} \mathrm{C} 1 \mathrm{~min}$ \\
\cline { 2 - 2 } Taq-Polymerase $(1,5 \mathrm{U})$ & $0,3 \mu \mathrm{l}$ & $72^{\circ} \mathrm{C} 1 \mathrm{~min}$ \\
\hline Primer_upper & $0,625 \mu \mathrm{l}(0,25 \mu \mathrm{M})$ & Zyklenzahl & 35 \\
\hline Primer_lower & $0,625 \mu \mathrm{l}(0,25 \mu \mathrm{M})$ & Soak & $10^{\circ} \mathrm{C} 10 \mathrm{~min}$ \\
\hline DNA & $2 \mu \mathrm{l}$ & & \\
\cline { 1 - 1 } $\mathrm{H}_{2} \mathrm{O}$ & $30,45 \mu \mathrm{l}$ & & \\
\cline { 1 - 2 } & & &
\end{tabular}


Im vorderen Fragment konnten insgesamt zwölf polymorphe Stellen und sechs Haplotypen detektier werden, im hinteren neun polymorphe Stellen und zehn Haplotypen. (siehe Appendix Tab.83). Drei im vorderen Bereich liegende Stellen (np 189, 193 und 247) zeigten sich als gut abgrenzend zwischen Vikunja, Guanako und Lama, Alpakas verhielten sich ambivalent. In Tabelle 30 sind sie Basenausprägungen an diesen Positionen dargestellt.

Tabelle 30: Polymorphismen des 12srRNA-Gens die eine Speziesidentifikation ermöglichen

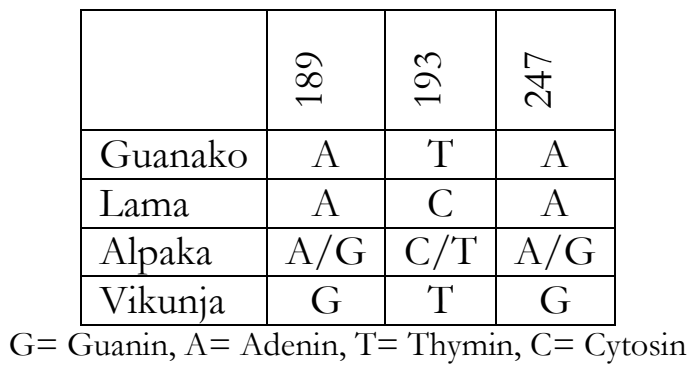

Eine generelle Identifikation der Spezies einer Probe ist hiermit möglich (s. Abb. 37), wenn bereits durch andere Systeme ausgeschlossen werden konnte, dass es sich um ein Alpaka handelt.

Um den Zeitraum der Analyse zu verkürzen, wurde eine so genannte Hyb-Probe-Assay auf dem LightCycler $^{\circledR} 2.0$ Instrument (Real-Time PCR System, Roche) entwickelt. Die Funktionsweise des LightCycler ist u. a. bei Adler (2006) nachzulesen. Das Prinzip des Hyb-Probe-Assay basiert auf dem Fluoreszenz-Resonanz-Energie-Transfer (FRET) und einer anschließenden Schmelzkurven-Analyse zur Genotypisierung von SNPs. Hierbei wird die Energie eines Fluoresenzmarkierten-Oligonukleotids (Donor-Sonde) durch LED-Anregung auf ein zweites Oligonukleotid übertragen (Akzeptor-Sonde) und ein Lichtsignal emittiert (s. Abb. 36). Die Sonden sind in der Lage mit der zu untersuchenden DNA zu hybridisieren. Während der PCR steigt die Anzahl hybridisierter Oligonukleotide und das emittierte Lichtsignal steigt proportional zur Anzahl angelagerter Sonden.
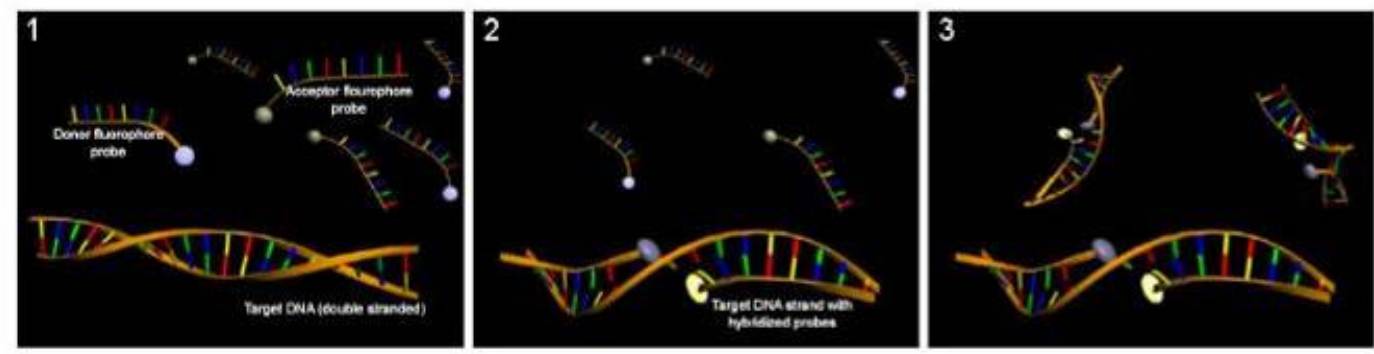

Abbildung 36: Prinzip des Hyb-Probe-Assay, näheres im Text (Quelle: www.roche-applied-science.com)

Liegt eine Abweichung in den Oligonukleotiden gegenüber der zu untersuchenden Sequenz vor, so ist das entstandene Donor-Akzeptor-Hybrid instabil. Diese Tatsache macht man sich 
bei der Genotypisierung zu nutze. Wird eine Schmelzkurven-Analyse durchgeführt, so löst sich die Bindung zwischen Donor und Akzeptor und die Stärke des Floureszenzsignals nimmt ab. Instabile Hybride schmelzen bei geringeren Temperaturen als stabile.

Zur Detektion der polymorphen Stellen wurden ein Primerpaar und zwei Sondensysteme mit der Software Light Cycler ${ }^{\circledR}$ Probe Design 2.0 (Roche) entwickelt. In Tabelle 31 sind die Primerpaare, Sonden und ihre Detektionsstellen aufgeführt.

Tabelle 31: Primersequenzen und Sondendesign

\begin{tabular}{|c|c|c|c|c|c|}
\hline & Primersequenz 5`-3 & $\begin{array}{l}\text { bp- } \\
\text { Primer }\end{array}$ & $\begin{array}{l}\text { np- } \\
\text { Bereich }\end{array}$ & \multicolumn{2}{|l|}{ Produktlänge } \\
\hline 12s_upper & CAGCCTTTCTATTAGTTTCTGAT & 23 & \multirow{2}{*}{$\begin{array}{l}81- \\
310\end{array}$} & \multirow{2}{*}{\multicolumn{2}{|c|}{$229 \mathrm{bp}$}} \\
\hline 12s_lower & GGCACGAAATTTACCAACC & 19 & & & \\
\hline Sondenname & Sondensequenz & Farbstoff & Detektiert & $\begin{array}{l}\text { Stabil bei } \\
\text { Base }\end{array}$ & $\begin{array}{l}\text { Instabil bei } \\
\text { Base }\end{array}$ \\
\hline 247AP & AACGAAAGTTTGACTAAGT & LC670 & \multirow[t]{2}{*}{247} & \multirow[t]{2}{*}{ G } & \multirow[t]{2}{*}{ A } \\
\hline $247 \mathrm{SP}$ & AGCAGTGACAAGAATTAAGTTAT & - & & & \\
\hline 189AP & GCACACAACCCCGTAGCTAACG & - & 189 & A & G \\
\hline 189SP & GCCTTGCTTGGCCACACCCC & LC610 & 193 & $\mathrm{C}$ & $\mathrm{T}$ \\
\hline
\end{tabular}

Legende: $\mathrm{bp}=$ Basenpaare, $\mathrm{np}=$ Nukleotidposition, $\mathrm{G}=$ Guanin, $\mathrm{A}=$ Adenin, $\mathrm{T}=$ Thymin, $\mathrm{C}=$ Cytosin

Das Sondensystem 189 detektiert zwei Polymorphismen, so dass bei der SchmelzkurvenAnalyse, je nach Basenausprägung der untersuchten Probe, drei Schmelztemperaturen möglich sind, die niedrigste bei der Ausprägung G/T, die mittlere bei A/T und die höchste bei A/C (s. Abb. 37). Eine mittlere Schmelztemperatur könnte auch bei dem Genotyp G/C angetroffen werden, dieser wurde jedoch kein einziges Mal bei der Sequenzanalyse detektiert.
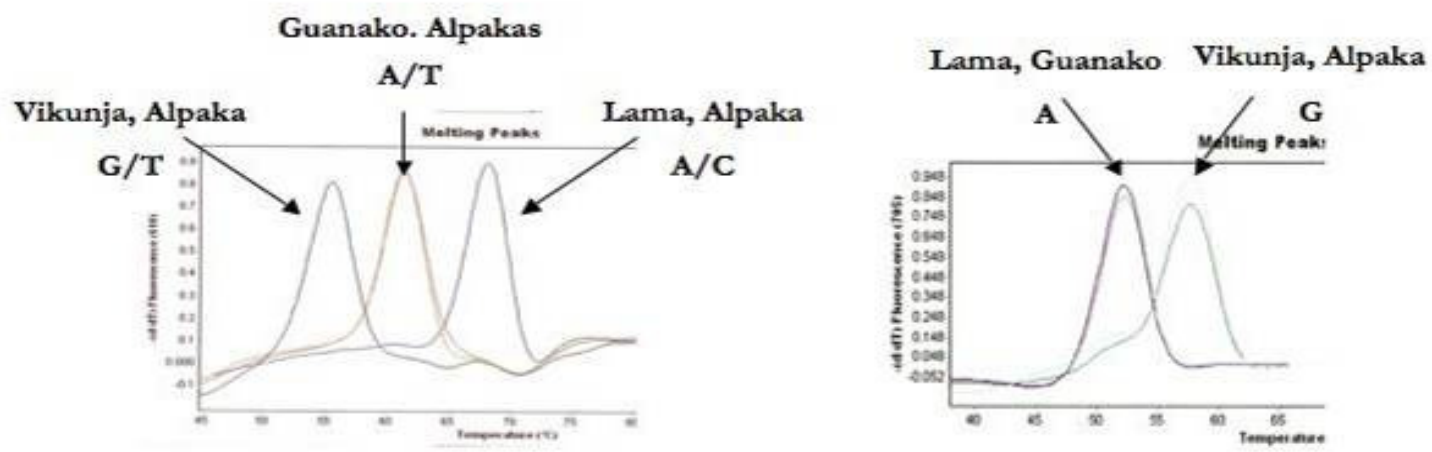

Abbildung 37: Schmelzkurvenanalyse zur Genotypisierung des 12srRNA-Gens

Die Zusammensetzung der PCR, ihre Amplifikationsparameter und die Parameter der Schmelzkurvenanalyse sind in Tabelle 32 gelistet. Die Schmelzkurvenanalyse wurde mit einer Anfangstemperatur von $94^{\circ} \mathrm{C}$ und einer Endtemperatur von $40^{\circ} \mathrm{C}$ durchgeführt. 
Tabelle 32: Zusammensetzung der PCR und ihre Parameter

\begin{tabular}{|c|c|c|c|}
\hline Komponenten & & Parameter & \\
\hline MultiplexMastermix (Roche) & $4 \mu 1$ & Initial & $94^{\circ} \mathrm{C} 11 \mathrm{~min}$ \\
\hline 12s_upper & $0,6 \mu 1$ & \multirow{3}{*}{ Cycling } & $94^{\circ} \mathrm{C} 10 \mathrm{~s}$ \\
\hline 12s_lower & $0,3 \mu 1$ & & $55^{\circ} \mathrm{C} 10 \mathrm{~s}$ \\
\hline $181 \mathrm{AP}$ & $1,0 \mu 1$ & & $72^{\circ} \mathrm{C} 10 \mathrm{~s}$ \\
\hline 181SP & $0,5 \mu 1$ & Zyklenzahl & 50 \\
\hline $247 \mathrm{AP}$ & $1,0 \mu 1$ & Soak & $30^{\circ} \mathrm{C} 30 \mathrm{~s}$ \\
\hline $247 \mathrm{SP}$ & $0,5 \mu 1$ & & \\
\hline $\mathrm{H}_{2} \mathrm{O}$ & $0-7,7 \mu 1$ & & \\
\hline DNA & $2-9,7 \mu 1$ & & \\
\hline
\end{tabular}

Die Auswertung der Schmelzkurvenanalyse wurde mit dem Programm Light Cycler ${ }^{\circledR}$ Software 4.1 (Roche) durchgeführt.

Alternativ kann, um Lamas und Guanakos zu unterscheiden, nach der Bestimmung des Polymorphismus 247 mit Hilfe der Sondenmethodik, der Polymorphismus 193 per Restriktionsverdau analysiert werden. In Abbildung 38 sind die umgebende Sequenz des Polymorphismus 193 sowie die Erkennungsstelle des Enzyms dargestellt. Ist ein T an der Position 193 realisiert, so wird das ursprünglich 229 bp lange Fragment in ein 112 bp und ein 117 bp langes Fragment geschnitten.

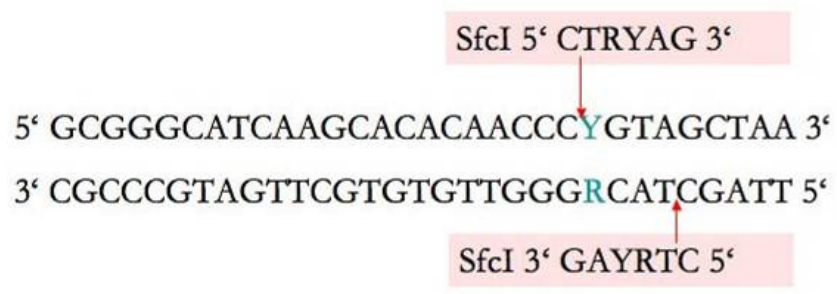

Abbildung 38: Restriktionsstelle des Enzyms SfcI, grün markiert die polymorphe Stelle 193

Für die Untersuchung des Polymorphismus muss zunächst eine konventionelle PCR durchgeführt werden. Die PCR wurde pro Probe wie folgt angesetzt: $5 \mu$ l PufferII, $4 \mu \mathrm{l}$ $\mathrm{MgCL}_{2}, 7 \mu \mathrm{l}$ dNTPs, 0,3 $\mu \mathrm{l}$ Taq-Polymerase, 0,6 $\mu \mathrm{l}$ je Primer (12s_upper und 12s_lower), $5 \mu \mathrm{l}$ DNA-Extrakt und 27,5 $\mu \mathrm{l} \quad \mathrm{H}_{2} \mathrm{O}$. Die Amplifikation erfolgte mit einem initialen Schritt von $94^{\circ} \mathrm{C}$ für $11 \mathrm{~min}$, den Zyklenparametern $94^{\circ} \mathrm{C} 1 \mathrm{~min}, 48^{\circ} \mathrm{C} 1 \mathrm{~min}, 72^{\circ} \mathrm{C} 1 \mathrm{~min}$ für $50 \mathrm{Zyklen}$ und einem anschließenden Endschritt von $10^{\circ} \mathrm{C}$ für $10 \mathrm{~min}$. Der Restriktionsverdau wurde pro Probe mit $2 \mu \mathrm{l}$ Puffer (NEB4), $2 \mu$ Enzym, 0,2 $\mu$ l BSA (10xBSA) $5 \mu$ l amplifiziertes Produkt und $10,8 \mu \mathrm{l} \mathrm{H}_{2} \mathrm{O}$ angesetzt. Es erfolgte eine Inkubation für $12 \mathrm{~h}$ bei $37^{\circ} \mathrm{C}$. Der Amplifikationserfolg und Erfolg des Restriktionsverdaus wurden auf einem 2,5\%igen Agarosegel überprüft. Da der Enzymverdau zu so genannten sticky ends führt, die bei 
Raumtemperatur wieder anlagern würden, wurde das Produkt direkt nach der Inkubation aufgebracht. Das Gel wurde bei 110 V laufen gelassen, was der optimalen Auftrennung der verdauten Produkte dient.

3.5 Mikrosatelliten

\section{Entwicklung der Multiplex-PCR}

Zur Detektion autosomaler DNA-Abschnitte wurde ein Multiplex-STR-Analysesystem entwickelt. Hierzu wurden zunächst, anhand bereits bekannter Mikrosatelliten-Sequenzen (s. Tab. 10) für Neuwelt-Camelidae, Primer entwickelt, die kürzere, auch für die aDNA-Analytik geeignete, Fragmente amplifizieren. Die Auswahl der Marker erfolgte anhand der angegebenen Heterozygotenraten und Allelranges, die ein Maß für die Variabilität dieser Marker darstellen. Um eine Analyse der Fragmentlängen zu ermöglichen, wurden jeweils die upper-Primer farbmarkiert. Jedes so entwickelte Primersystem wurde zunächst in Single-PlexAnsätzen getestet und auf seine Analysierbarkeit überprüft. In Tabelle 33 sind die Primer, ihre Farbmarkierung sowie die Publikationen, in denen die Marker als erstes beschrieben wurden, aufgeführt. In Abbildung 39 ist das Schema der Multiplex dargestellt.

Tabelle 33: Mikrosatelliten-Marker und Primersequenzen

\begin{tabular}{|c|c|c|c|}
\hline & Primersequenz $5{ }^{`} 3^{`}$ & Farbmarkierung & Publikation \\
\hline VOLP10_upper & CCCAGTCCT"TTCTCCTTTCCT & 6-FAM & \multirow[t]{6}{*}{ Obreque et al. 1998} \\
\hline VOLP10_lower & TTGGGGTTACTTGTT'TACAATCATC & - & \\
\hline VOLP03_upper & GAAGGTGGTAGAAGAGAATCAGAC & HEX & \\
\hline VOLP03_lower & CGACAGCAAGGCACAGGA & - & \\
\hline VOLP67_upper & TTAGAGGGTCTATCCAGTTTC & NED & \\
\hline VOLP67_lower & AAGGTAAAGAGAGAGTAAATT & - & \\
\hline LgU52_upper & СТTTCCTTTCСТCTCCATATTACATT & 6-FAM & \multirow[t]{4}{*}{ Sarno et al. 2000} \\
\hline LgU52_lower & CTTCCATAACTGCAGGAGTCAAT & - & \\
\hline LgU68_upper & GCTCTCCCAGGGATGTAGTTTT & NED & \\
\hline LgU68_lower & GGCTAAAGTGGGTGTGAGAGTC & - & \\
\hline LCA66_upper & CAGCGTCCAAATAGTCATCAGAA & HEX & \multirow[t]{2}{*}{ Penedo et al. 1999} \\
\hline LCA66_lower & GTTGTTGTT'TTCCAGACAAGACTC & - & \\
\hline
\end{tabular}

6-FAM = blaue Farbmarkierung, HEX = grüne Farbmarkierung, NED = gelbe Farbmarkierung 


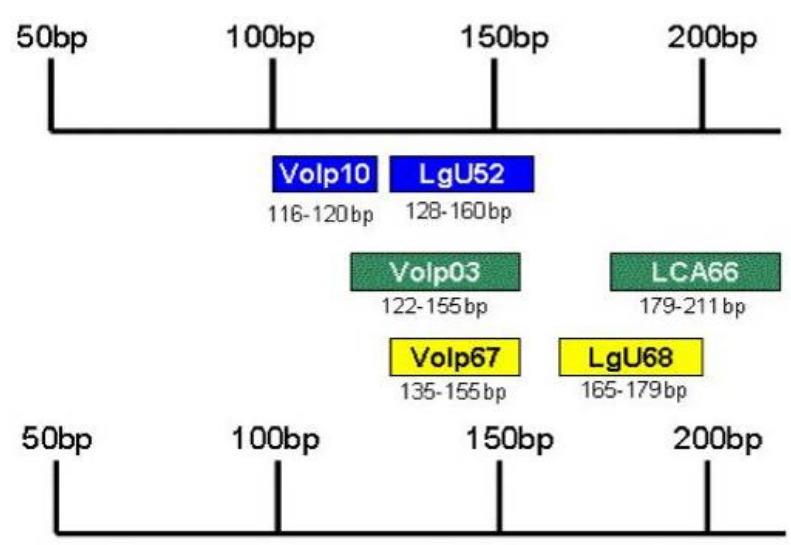

Abbildung 39: Schema der Lamaplex. Legende: blau = 6-FAM, grün = HEX, gelb = NED, bp = Basenpaare

Alle sechs Marker bestehen aus Dinukleotid-Wiederholungseinheiten. Diese Tatsache erforderte eine Anpassung der PCR-Parameter, um das Stottern (s. Kap. 2.1.2) zu verringern. Es wurden die Konzentrationen der Primer im Multiplex-Ansatz über eine Gradienten-PCR getestet und optimal eingestellt. Darüber hinaus wurde die PCR im Two-Step-Verfahren durchgeführt. Bei diesem PCR-Verfahren wird auf den Elongationsschritt verzichtet und die Annealing-Temperatur sehr spezifisch für die Primer-Bindung gewählt. Dies verringert die Produktion unspezifischer PCR-Produkte und eine Fehlpaarung der Primer. Die Zusammensetzung des "Lamaplex"-Primerset, der PCR und ihre Parameter sind Tabelle 34 zu entnehmen.

Tabelle 34: Zusammensetzung des Primerset und der PCR der Lamaplex sowie ihre Parameter

\begin{tabular}{|c|c|c|c|c|c|c|}
\hline Primer & $\mu \mathrm{M}$ & Für 1Probe & & & & \\
\hline VOLP10 upper & 0,1 & $0,05 \mu \mathrm{l}$ & & & & \\
\hline VOLP10 lower & 0,1 & $0,05 \mu \mathrm{l}$ & & & & \\
\hline Lgu52 upper & 0,5 & $0,25 \mu \mathrm{l}$ & & & Parameter & \\
\hline Lgu52 lower & 0,5 & $0,25 \mu \mathrm{l}$ & PCR-Ansatz & & Initial & $95^{\circ} \mathrm{C} 15 \mathrm{~min}$ \\
\hline VOLP03 upper & 0,3 & $0,15 \mu \mathrm{l}$ & MultiplexMastermix (Qiagen) & $12,5 \mu \mathrm{l}$ & Cycling & $94^{\circ} \mathrm{C} 1 \mathrm{~min}$ \\
\hline VOLP03 lower & 0,3 & $0,15 \mu \mathrm{l}$ & Primerset & $1,94 \mu \mathrm{l}$ & & $57^{\circ} \mathrm{C} \mathrm{30s}$ \\
\hline LCA66 upper & 0,25 & $0,12 \mu \mathrm{l}$ & Ampuwa & $0,56-9,56 \mu 1$ & Zyklenzahl & $35-55$ \\
\hline LCA66 lower & 0,25 & $0,12 \mu \mathrm{l}$ & DNA & $1-10 \mu \mathrm{l}$ & Time Delay & $60^{\circ} \mathrm{C} 30 \mathrm{~min}$ \\
\hline Lgu68 upper & 0,2 & $0,10 \mu \mathrm{l}$ & & & Soak & $10^{\circ} \mathrm{C} 1 \mathrm{~min}$ \\
\hline Lgu68 lower & 0,2 & $0,10 \mu \mathrm{l}$ & & & & \\
\hline Volp67 upper & 0,6 & $0,3 \mu \mathrm{l}$ & & & & \\
\hline Volp67 lower & 0,6 & $0,3 \mu \mathrm{l}$ & & & & \\
\hline SUMME MM & & $1,94 \mu \mathrm{l}$ & & & & \\
\hline
\end{tabular}

Der Amplifikationserfolg wurde auf einem 2,5\%igen Agarosegel überprüft und mit dem Gel Jet Imager (INTAS) dokumentiert. Die Fragmentlängenanalyse erfolgte auf dem DNASequencer Modell 373 (PE Applied Biosystems). Hier wurden pro Probe zu je 1-3 $\mu$ l PCRProdukt (je nach Produktstärke), 0,3 $\mu$ l GS-ROX-500 (Längestandard, PE Applied 
Biosystems), 0,5 $\mu \mathrm{l}$ Schwerelösung (PE Applied Biosystems) und $2 \mu$ l Formamid zugegeben. Dieses Gemisch wurde nach einem Denaturierungsschritt $\left(96^{\circ} \mathrm{C}, 2 \mathrm{~min}\right)$ auf einem $6 \%$ igen PAA-Gel aufgetrennt. Es wurde die Lauflänge von $26 \mathrm{~cm}$ gewählt, um eine möglichst hohe Auftrennung der Fragmente zu ermöglichen und um Stotter-Artefakte in der Auswertung erkennen zu können. Die Daten wurden mit der ABI Prism ${ }^{\mathrm{TM}}$ GeneScan-Collection-Software gesammelt und mit der Software Gene Scan Analysis ausgwertet (beide PE Applied Biosystems). Näheres zur Funktionsweise des 373er Sequenziergerätes und der Software ist z.B. bei Schilz (2006) nachzulesen.

\section{Sequenzierung und Nomenklatur der Allele}

Bei der Auswertung der Daten fiel auf, dass einige der Marker eine sehr große AllelSpannweite aufweisen und die Produktlängen nicht mit der erwarteten Produktlänge übereinstimmten. Beispielsweise wiesen Produkte in einem Lauf eine Länge von 115,4 bp, im nächsten Lauf eine Länge von 116,6 bp auf. Diese Inkonsistenzen können auf die unvollständige Anlagerung des terminalen A im Delay-Schritt der PCR, die Laufeigenschaften der Produkte während der Fragmentlängenanalysen oder auf tatsächliche Längenunterschiede zurückgehen. Um eine Vorstellung über die Wiederholungsstruktur der Fragmente und ihrer umgebenden Bereiche zu erhalten, wurden alle anzutreffenden Allele der einzelnen Systeme sequenziert. Dies diente auch der Zuweisung von Allelbezeichnungen. Beispielsweise wurde eine Wiederholungseinheit von sieben TC fortführend als Allel 7 des entsprechenden Markers bezeichnet. Darüber hinaus ermöglichten die Erkenntnisse aus der Sequenzanalyse das Erstellen einer Allelleiter und einer Standardisierung der Auswertung.

Die Sequenzierung von Wiederholungsstrukturen ist schwieriger, als die Sequenzierung anderer Strukturen, da es zur Basenunterdrückung durch die Formierung sekundärer Strukturen kommen kann, welche durch die DNA-Polymerase hervorgerufen wird (Zhao et al. 2000). Dies führt zu einem Sequenzabbruch direkt hinter der Wiederholungsstruktur. Ein weiteres Problem stellt die Länge der Sequenz dar, denn bei der Sequenzierung wird die Anfangssequenz meist nicht richtig dargestellt und beginnt hinter dem Primer, ca. 10 bp versetzt. Um diesen Anforderungen gerecht zu werden, wurden sowohl der obere als auch der untere Strang sequenziert. Hierfür wurden die Primer in unfarbmarkierter Form eingesetzt. Jedes Fragment wurde in einer Singleplex-PCR generiert, zu 12,5 $\mu$ l MultiplexMastermix (Qiagen) wurde je Primer 0,5 $\mu \mathrm{l}$ eines 10 pmol-Primeraliqots, $1 \mu \mathrm{l}$ DNA und 10,5 $\mu \mathrm{l} \mathrm{H2O}$ gegeben, die Amplifikationsparameter waren denen der Multiplex-PCR gleich. Die 
Aufreinigung der Produkte sowie die Zusammensetzung des Taq-Cycle-SequencingReaktionsansatzes wurden wie für die Produkte des cytb durchgeführt (s. S. 86). Die AnnealTemperatur der Sequenzierreaktion betrug $55^{\circ} \mathrm{C}$, die Denaturierungszeit wurde von 10 auf 15 Sekunden angehoben, um mögliche Fehlpaarungen effektiver zu lösen. Nach der zweiten Aufreinigung wurden die Produkte erneut denaturiert $\left(95^{\circ} \mathrm{C}, 5 \mathrm{~min}\right)$ um weitere eventuelle Fehlpaarungen abzutrennen. Die Sequenzierung und Analyse erfolgten auf dem SequenzierGerät Modell 310 (PE Applied Biosystems) mit dem Polymer POP6 und der Verwendung der Software ABI PrismTM Sequencing Analysis (PE Applied Biosystems). Die Auswertung erfolgte mit Hilfe der Software SeqMan und MegAling des Lasergene Software Pakets (DNAStar). In Abbildung 40 sind exemplarisch drei sequenzierte Allele der rezenten DNA abgebildet, in Abbildung 41 sind die Wiederholungseinheiten der einzelnen Marker dargestellt. Im Marker LCA66 kann es zu Substitutionen C/T in der Wiederholungseinheit kommen (s. Gua1 in Abb. 40). Da hierbei jedoch keine Wiederholungseinheit entfällt, wurde das entstandene Allel fortlaufend gezählt. Im Marker LgU52 kommt es zu Insertionen von 30 bp innerhalb der eigentlichen Wiederholungseinheit von $(\mathrm{TG})_{10}$. Da es sich hierbei um eine Sequenz-Insertion, die keine Wiederholungseinheiten aufweist, handelt, wurde dieses Allel durch den Zusatz i30 gekennzeichnet.

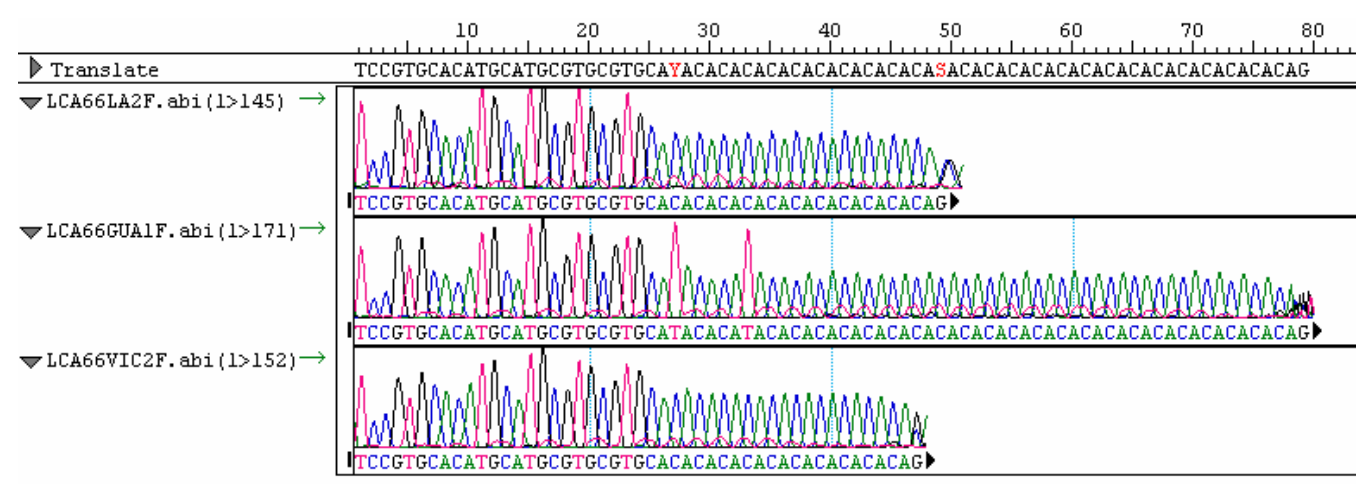

Abbildung 40: Elektropherogramme der Proben La2 (Allel 13), Gua1 (Allel 27) und Vic2 (Allel 12)

\begin{tabular}{|c|c|c|}
\hline Volp 10 & LgU52 & Volp03 \\
\hline$(\mathrm{GT})_{n}$ & (TG), & $(\mathrm{TG})_{n} \mathrm{TCTGTC}(\mathrm{TG})_{n}$ \\
\hline$n=4-9$ & $\begin{array}{c}n=5-13 \\
10 i 30\end{array}$ & $n=8-26$ \\
\hline LCA66 & Volp67 & LgU68 \\
\hline$(\mathrm{CA})_{n}$ & (GT), & (GT), \\
\hline$n=11-27$ & $n=4-20$ & $n=9 \cdot 24$ \\
\hline
\end{tabular}

Abbildung 41: Marker und ihre Wiederholungseinheiten sowie ihr Allelrange. Legende: $\mathrm{n}=$ Länge der Wiederholungseinheiten 


\section{Erstellen der Allelleiter}

Das Erstellen der Allelleiter erfolgte durch die Amplifikation der beobachteten vorkommenden Allele jedes Markers im Singleplex-Ansatz. Zu 12,5 $\mu$ l MultiplexMastermix (Qiagen) wurden je 0,5 $\mu$ l pro Primer (Multiplex-Primer, farbmarkiert), $1 \mu \mathrm{l}$ DNA-Extrakt und 10,5 $\mu \mathrm{H} \mathrm{H}_{2} \mathrm{O}$ gegeben. Die Amplifikationsparameter waren die der Multiplex-PCR. Die Zusammensetzung und Wahl der Proben für die Allelleiter sind in Tabelle 35 gelistet. In Abbildung 42 ist die Allelleiter dargestellt.

Tabelle 35: Individuen und Allele zur Erstellung einer Allelleiter

\begin{tabular}{|c|c|c|c|c|}
\hline Marker & Individuum & Allel & Mischungsverhältnis System & Mischungsverhältnis Gesamt \\
\hline \multirow[t]{2}{*}{ VOLP10 } & Alp11 & $6 / 7$ & \multirow[t]{2}{*}{$2: 1$} & \multirow[b]{2}{*}{ 2: } \\
\hline & Alp13 & $7 / 7$ & & \\
\hline \multirow[t]{2}{*}{ LgU52 } & Vic10 & $5 / 7$ & \multirow[t]{2}{*}{$5: 1$} & \multirow[b]{2}{*}{ 1: } \\
\hline & Vic9 & $5 / 10$ & & \\
\hline \multirow[t]{3}{*}{ VOLP67 } & La6 & $13 / 17$ & \multirow{3}{*}{$1: 3: 3$} & \multirow{3}{*}{ 2: } \\
\hline & Vic5 & $13 / 18$ & & \\
\hline & Alp11 & $13 / 17$ & & \\
\hline \multirow[t]{3}{*}{ VOLP03 } & Alp2 & $8 / 8$ & \multirow{3}{*}{$1: 2: 2$} & \multirow{3}{*}{ 3: } \\
\hline & Alp10 & $20 / 21$ & & \\
\hline & Vic3 & $22 / 22$ & & \\
\hline \multirow[t]{5}{*}{ LgU68 } & Gua1 & $11 / 15$ & \multirow{5}{*}{$4: 2: 2: 5: 1$} & \multirow{5}{*}{ 1: } \\
\hline & Vic1 & $16 / 17$ & & \\
\hline & Vic6 & $17 / 17$ & & \\
\hline & Vic7 & $17 / 20$ & & \\
\hline & Alp7 & $18 / 18$ & & \\
\hline \multirow[t]{4}{*}{ LCA66 } & Gua1 & $26 / 26$ & \multirow{4}{*}{$2: 1: 2: 3$} & \multirow{4}{*}{2} \\
\hline & Vic7 & $12 / 14$ & & \\
\hline & Alp1 & $14 / 14$ & & \\
\hline & Alp11 & $14 / 14$ & & \\
\hline
\end{tabular}

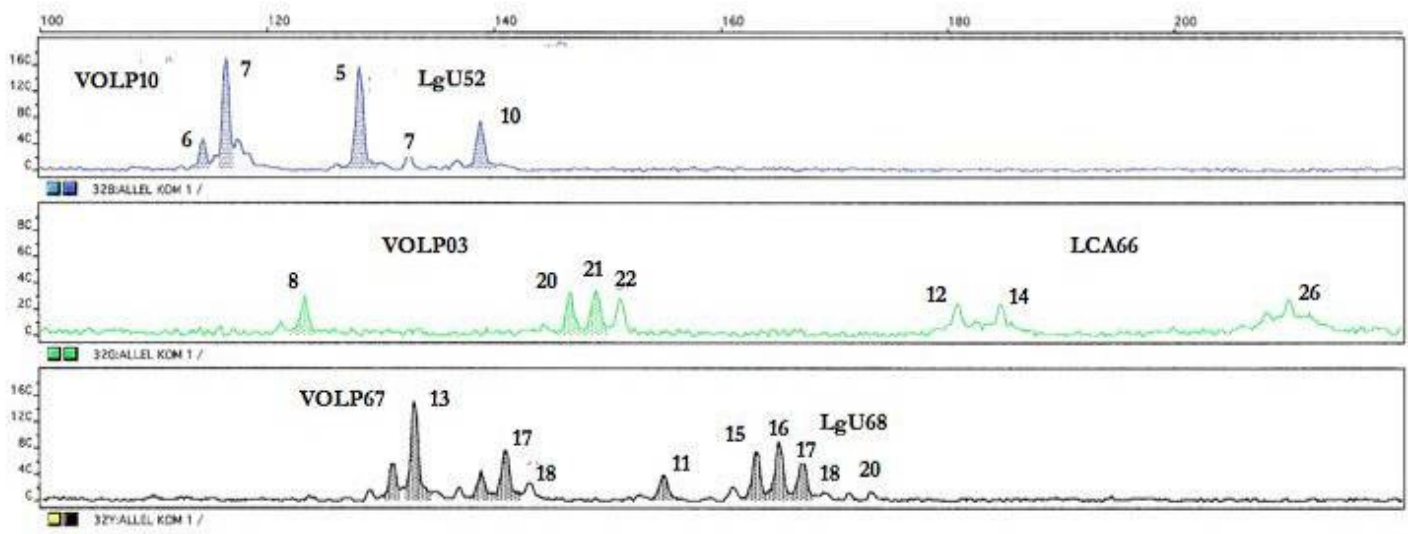

Abbildung 42: Lamaplex-Allelleiter

Die Allelleiter erlaubte auch eine Übertragung der Anwendung vom Sequenzier-Gerät Model 373 auf das Modell 310 (PE Applied Biosystems). Zur Analyse wurden pro Probe je 1-3 $\mu \mathrm{l}$ Multiplex-Amplifikationsprodukt mit 0,3 $\mu$ l GS-Rox-500 (PE Applied Biosystems) und $12 \mu \mathrm{l}$ High-Dye-Formamid versetzt. Nach Denaturierung $\left(95^{\circ} \mathrm{C}, 5 \mathrm{~min}\right)$ wurden die Proben direkt auf den Sequenzierer aufgebracht. Die elektrophoretische Auftrennung erfolgte mit Hilfe des 
High-Performance-Polymer 4 (POP4) und die Daten wurden mit der Software ABI Prism ${ }^{\mathrm{TM}}$ GeneScan-Collection-Software (PE Applied Biosystems) gesammelt. Die Auswertung erfolgte mit der Software GeneScanAnalysis (PE Applied Biosystems). Bei jeder Fragmentlängenanalyse wurde die Allelleiter als eigenständige Probe behandelt und mitgeführt, um eventuellen Laufunterschieden gerecht zu werden.

\subsection{Analysesysteme zur Identifikation des Phänotyps}

Für die Untersuchung von SNPs, die mit der Ausprägung von Fellfarbe assoziiert sind, wurde zunächst der aktuelle Forschungsstand erfasst. Für Neuwelt-Camelidae waren keinerlei genetische Untersuchungen zugänglich. Lediglich zur Vererbung der Fellfarbe konnten Informationen gesammelt werden. Aus Kreuzungsbeobachtungen wird gefolgert, dass schwarz ein rezessives Gen ist und ein Piebaldie-Gen existiert (Merriweather \& Merriweather 2003).

Die Gene MC1R, ASIP und TYRP1 sind in einer Vielzahl von Spezies untersucht und weisen meist eine hohe Assoziation mit Fellfarben-Ausprägung auf. Für den Marker MC1R wurden die Sequenzen von Ovis aries, Sus scrofa, Homo sapiens sowie Bos taurus verglichen und in den konserviertesten Regionen wobble-Primer entworfen. Für das Gen ASIP wurden Primer für polymorphe Exone aus Royo et al. (2005), die an Bos taurus entwickelt wurden, nach einem Speziesvergleich übernommen. Ebenso wurde für das Gen TYRP1 verfahren (Primer aus Beryerre et al. 2003) mit Ausnahme des Markers TYRP1 Exon 5. Hier wurden die Primer nach dem Speziesvergleich als wobble-Primer entwickelt. In Tabelle 36 sind alle verwendeten Primer gelistet.

Tabelle 36: Primer zur Detektion phänotypisch assoziierter SNPs

\begin{tabular}{|c|c|c|c|}
\hline Primername & Primersequenz $5{ }^{`} 3^{`}$ & Publikation & $\begin{array}{l}\text { Anlagerungs- } \\
\text { Temperatur }\end{array}$ \\
\hline MC1Ra_upper & AGAGGMGGCTGCTGGSTTCC & - & \multirow[t]{2}{*}{$58^{\circ} \mathrm{C}$} \\
\hline MC1Ra_lower & CKTGTGGTKGTAGTAGGYGAT & - & \\
\hline MC1Rb_upper & GACCGCTACRTSTCCATCTTCTA & - & \multirow[t]{2}{*}{$58^{\circ} \mathrm{C}$} \\
\hline MC1Rb_lower & AGCACTGCAGCACCTCYTG & - & \\
\hline ASIPEx2_upper & CTTCTCTGTCTCACTCAGGCCTC & \multirow[t]{6}{*}{ Royo et al. 2005} & \multirow[t]{2}{*}{$56^{\circ} \mathrm{C}$} \\
\hline ASIPEx2_lower & CTTGATTCCTCCAGAATTGTTCT & & \\
\hline ASIPEx3_upper & CTGTCTCCAGGTTCTGCAGCCAG & & \multirow[t]{2}{*}{$59^{\circ} \mathrm{C}$} \\
\hline ASIPEx3_lower & TTCAGTGCTTGAGGTCAGGAC & & \\
\hline ASIPEx4_upper & GACGTCTAGTCCGAGGAGTTC & & \multirow[t]{2}{*}{$58^{\circ} \mathrm{C}$} \\
\hline ASIPEx4_lower & AGCATCGGGGTCT'T'TCAAATGA & & \\
\hline TYRP1Ex2_upper & GGATTTTCCTCTACGTGCTTCAGTC & \multirow{6}{*}{$\begin{array}{l}\text { Berryere et al. } \\
2003\end{array}$} & \multirow[t]{2}{*}{$58^{\circ} \mathrm{C}$} \\
\hline TYRP1Ex2_lower & CTATGAGAACCCTCTGGTCACAGG & & \\
\hline TYRP1Ex3_upper & GTCAGGAGAAATCTTCTGGACTTAAG & & \multirow[t]{2}{*}{$58^{\circ} \mathrm{C}$} \\
\hline TYRP1Ex3_lower & TACATACCTGCATGTCTTTCTCCAG & & \\
\hline TYRP1Ex5_upper & TGCAGGCSCCGSTGGGCAATTS & & \multirow[t]{2}{*}{$58^{\circ} \mathrm{C}$} \\
\hline TYRP1Ex5_lower & GCCTTCCACTGTGTTTCGGAAACTG & & \\
\hline
\end{tabular}

Legende: $\mathrm{A}=$ Adenin, $\mathrm{C}=$ Cytosin, $\mathrm{T}=$ Thymin, $\mathrm{G}=$ Guanin, $\mathrm{Y}=\mathrm{C}$ oder $\mathrm{T}, \mathrm{R}=\mathrm{A} \operatorname{oder} \mathrm{G}, \mathrm{S}=\mathrm{G}$ oder $\mathrm{C}, \mathrm{K}$ $=\mathrm{G}$ oder $\mathrm{T}, \mathrm{M}=\mathrm{A}$ oder $\mathrm{C}$ 
Die Zusammensetzung der Amplifikation war immer: 12,5 $\mu$ l MultiplexMastermix (Qiagen), $0,2 \mu \mathrm{M}$ pro Primer, $2 \mu \mathrm{l}$ DNA und 8,5 $\mu \mathrm{H}_{2} \mathrm{O}$. Die Amplifikationsparameter waren für die Initialphase $95^{\circ} \mathrm{C}$ für $15 \mathrm{~min}$, die Zyklusparameter waren $94^{\circ} \mathrm{C}$ für $1 \mathrm{~min}$, die Anlagerungsphase wurde für $1 \mathrm{~min}$ durchgeführt (Temperaturen s. Tab. 36) und die Elongation für $2 \mathrm{~min}$ bei $72^{\circ} \mathrm{C}$. Ein Abbruch der Reaktion wurde durch einen Abkühlungsschritt auf $10^{\circ} \mathrm{C}$ für 10 min erzielt.

Die Systeme TYRP1-Ex2 und TYRP1-Ex5 zeigten keinen Amplifikationserfolg und wurden nicht weiter verwendet. Die Systeme MC1Ra, ASIP-Ex2 und ASIP-Ex4 wiesen Produktlängen über 1000 bp auf. Da die Sequenzierung eines solch langen Fragmentes mit den zur Verfügung stehenden Geräten nicht möglich ist, wurden diese verworfen. Die Systeme MC1Rb, TYRP1Ex3 und ASIPEx3 zeigten gute Amplifikationsergebnisse und wurden in je zwei rezenten Individuen, die unterschiedliche Fellfarben aufwiesen, amplifiziert und sequenziert. Die Sequenzanalyse erfolgte wie auf Seite 86 beschrieben. Die AnnealTemperatur der Taq-Cycle-Sequencing-Reaktion betrug $55^{\circ} \mathrm{C}$ und es wurden 30 Zyklen durchgeführt.

Im System MC1R konnten keine mit der Fellfarbe assoziierten Polymorphismen gefunden werden. Im Marker TYRP1Ex3 konnten zwei polymorphe Stellen detektiert werden, von denen eine (G/A) möglicherweise mit der Ausprägung von Piebaldie und schwarzer Gesichtsfarbe assoziiert ist. Für den Marker ASIPEx3 konnten drei Polymorphismen erkannt werden, von denen einer (C/A) eventuell mit der Ausprägung hellbrauner Fellfarbe (WildTyp) assoziiert ist. Für diese beiden Polymorphismen wurde eine SNP-Analyse mit Hilfe der SingleBaseExtension (SBE) entwickelt. Informationen zur Funktionsweise dieser Analysemethode sind z.B. bei Schmidt (2004) nachzulesen. Die Primer zur Synthetisierung der Fragmente wurden verkürzt, um auch eine Amplifikation in alten Proben zu ermöglichen und so genannte SBE-Primer wurden entwickelt. Die Primer sind Tabelle 37 zu entnehmen.

Tabelle 37: Primer zur Amplifikation eines Abschnittes des TYRP1- und ASIP-Gens sowie SBE-Primer zur Genotypisierung

\begin{tabular}{|c|c|c|c|c|}
\hline & Primersequenz $5 ` 3^{`}$ & $\begin{array}{l}\text { Poly-A- } \\
\text { Schwanz }\end{array}$ & Produktlänge & $\begin{array}{l}\text { Anneal- } \\
\text { Temperatur }\end{array}$ \\
\hline TYRP1_upper & ACCCACTACTACTCCGTCAA & & \multirow[t]{2}{*}{ 143bp } & \multirow[t]{2}{*}{$55^{\circ} \mathrm{C}$} \\
\hline TYRP1_lower & ATACCCTGCATGTCTTTCT & & & \\
\hline SBE_TYRP1_r & GTACCTGTGCCACGTGAGAAA 21 & 9 & $30 \mathrm{bp}$ & - \\
\hline ASIP_upper & GGGCGACAACGCCGAAA & & \multirow{2}{*}{$105 \mathrm{bp}$} & \multirow{2}{*}{$65^{\circ} \mathrm{C}$} \\
\hline ASIP_lower & AGTCGGCTTGCCTGCGTCCTT & & & \\
\hline SBE_ASIP_r & GGTTGTAGCGCACGCTGTT & 11 & $40 \mathrm{bp}$ & - \\
\hline
\end{tabular}

Legende: $\mathrm{r}=$ reverse, $\mathrm{bp}=$ Basenpaare, $\mathrm{A}=$ Adenin, $\mathrm{G}=$ Guanin, $\mathrm{C}=$ Cytosin, $\mathrm{T}=$ Thymin

Die Amplifikation erfolgte im Singleplex Ansatz. Die PCR setzte sich wie folgt zusammen: 12,5 $\mu \mathrm{l}$ MultiplexMastermix (Qiagen), 0,24 $\mu \mathrm{M}$ pro Primer, 1-11,9 $\mu \mathrm{l}$ DNA-Extrakt und 0 bis 
10,9 $\mu \mathrm{l} \mathrm{H}_{2} \mathrm{O}$. Die Amplifikationsbedingungen waren wie jene zur Amplifikation der Fragmente für die Sequenzierung, die Temperaturen des Anlagerungsschrittes sind Tabelle $37 \mathrm{zu}$ entnehmen.

Für die SBE-Analyse wurden die Amplifikationsprodukte zunächst aufgereinigt. Zu $1 \mu$ SAP (ShrimpAlkalinePhospatase, PE Applied Biosystems) und 2 U ExoI (PE Applied Biosystems) wurden 2,5 $\mu \mathrm{l}$ amplifiziertes Produkt gegeben. Konnten für eine Probe beide Systeme

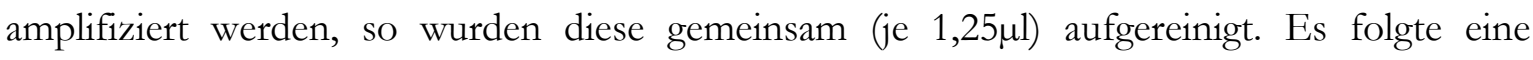
Inkubation bei $37^{\circ} \mathrm{C}$ für $1 \mathrm{~h}$ und anschließend für 15 min bei $75^{\circ} \mathrm{C}$. Für die SNP-Analyse erfolgte die SBE-Reaktion, mit Hilfe des ABI Prism ${ }^{\circledR}$ Snapshot ${ }^{\circledR}$ Multiplex Kit (PE Applied Biosystems). Es wurden zu 2,5 $\mu \mathrm{l}$ Snapshot-Multiplex-Mix 1,5 $\mu$ l aufgereinigtes Produkt und je $0,5 \mu \mathrm{l}$ SBE-Primer gegeben. Wurde nur ein Fragment untersucht so wurde auf ein Gesamtvolumen von $5 \mu \mathrm{l}$ mit $\mathrm{H}_{2} \mathrm{O}$ aufgefüllt. Die Reaktion erfolgte bei $96^{\circ} \mathrm{C}$ für $10 \mathrm{~s}, 55^{\circ} \mathrm{C}$ für $5 \mathrm{~s}$ und $60^{\circ} \mathrm{C}$ für $30 \mathrm{~s}$. Es wurden 25 Zyklen durchgeführt. Von den entstandenen Produkten wurde je $1 \mu \mathrm{l}$ mit 0,25 $\mu \mathrm{l} \mathrm{LIZ} \mathrm{(Längenstandard,} \mathrm{PE} \mathrm{Applied} \mathrm{Biosystems)} \mathrm{und} 12 \mu \mathrm{l}$ High-Dye-Formamid versetzt. Nach Denaturierung $\left(95^{\circ} \mathrm{C}, 5 \mathrm{~min}\right)$ wurde die Probe auf das Sequenzier-Gerät Modell 310 (PE Applied Biosystems) aufgebracht und auf dem Polymer POP4 aufgetrennt. Die Daten wurden mit der ABI Prism ${ }^{\mathrm{TM}}$ GeneScan-Collection-Software gesammelt und mit der Software GeneScanAnalysis ausgewertet (beide PE Applied Biosystems).

Die Ausprägung der Polymorphismen kann entweder homozygot (nur ein Peak pro System), oder heterozygot (zwei Peaks pro System) sein. Da die SBE-Primer auf dem unteren Strang der DNA ansetzen, werden die Polymorphismen im Elektropherogramm in der Farbe der komplementären Base angezeigt.

\subsection{Statistik}

Die statistische und phylogenetische Auswertung der Ergebnisse erfolgte mit den Programmen Molecular Evolutionary Genetics Analysis (MEGA) Software Version 4.0. (Tamura et al. 2007), Geneious - Research in a Flash (Biomatters), DnaSP (Rozas et al. 2003) und Arlequin (Excoffier 2000). Die statistischen Grundlagen dieser Programme sind die in Kapitel 2.3 vorgestellten Formeln und Hypothesen. 
4 Typisierungsergebnisse und erste Ableitungen aus den Datensätzen

Im Folgenden werden nun die Ergebnisse vorgestellt und die Systeme einzeln ausgewertet, bevor in Kapitel 5, 6 und 7 die Auswertungen bezüglich des Erhaltungszustandes, der Speziesidentifikation und der Populationsgenetik erfolgen. Es wurden nur reproduzierte Ergebnisse in die Auswertung mit einbezogen. Proben die zwar analysiert, jedoch nicht reproduziert werden konnten, sind im Appendix aufgeführt. Ein Ergebnis galt als reproduziert wenn es aus einer Amplifikation pro unabhängig hergestelltem DNA-Extrakt erlangt werden konnte.

$4.1 \mathrm{cytb}$

\subsubsection{Rezentes Material}

Die Amplifikation und Sequenzierung des 276 bp langen Fragmentes war in allen Proben erfolgreich.

Die Sequenzdaten wurden mit Hilfe der Alpaka-Referenz-Sequenz (NC 002504) ausgwertet. Dies erfolgte ohne Berücksichtigung der Primersequenzen, so dass ein Bereich von Position 14439-14676 erfasst wurde. Bei der Auswertung konnten keine Heteroplasmien beobachtet werden.

Es konnten 15 polymorphe Stellen ausgemacht werden, welche die Unterscheidung von neun Haplotypen erlaubte. Dies entspricht einer Nukleotid-Diversität von 0,06. In Tabelle 38 sind die gefundenen polymorphen Stellen und die Individuen in denen sie vorkommen gelistet.

Tabelle 38: Angetroffene Haplotypen in rezenten Neuwelt-Camelidae

\begin{tabular}{|c|c|c|c|c|c|c|c|c|c|c|c|c|c|c|c|}
\hline & 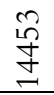 & $\underset{⿱}{\stackrel{+}{+}}$ & $\underset{\stackrel{n}{Z}}{\stackrel{n}{ \pm}}$ & 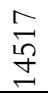 & $\begin{array}{l}\stackrel{\infty}{\sim} \\
\stackrel{\sim}{\sim} \\
\stackrel{\sim}{+}\end{array}$ & $\begin{array}{l}\stackrel{g}{+} \\
\stackrel{\text { I }}{ \pm}\end{array}$ & $\begin{array}{l}\infty \\
\stackrel{\infty}{n} \\
\stackrel{n}{+} \\
\end{array}$ & 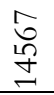 & 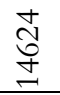 & 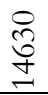 & 告 & \begin{tabular}{l}
$\infty$ \\
\multirow{+}{+}{} \\
$\stackrel{+}{+}$
\end{tabular} & 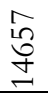 & $\begin{array}{l}8 \\
\text { O্ণ } \\
\stackrel{+}{+}\end{array}$ & 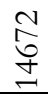 \\
\hline Ref. & A & $\mathrm{C}$ & $\mathrm{C}$ & $\mathrm{T}$ & $\mathrm{C}$ & $\mathrm{T}$ & $\mathrm{T}$ & A & $\mathrm{T}$ & $\mathrm{C}$ & A & A & A & A & $\mathrm{C}$ \\
\hline Vic1, 10-12 & G & $\mathrm{T}$ & $\mathrm{T}$ & $\mathrm{C}$ & G & $\mathrm{C}$ & $\mathrm{C}$ & $*$ & $\mathrm{C}$ & $\mathrm{T}$ & G & G & $*$ & $*$ & $\mathrm{~T}$ \\
\hline Vic 2-9 13,14 & G & $\mathrm{T}$ & $\mathrm{T}$ & $\mathrm{C}$ & $\mathrm{T}$ & $*$ & $\mathrm{C}$ & * & $\mathrm{C}$ & $\mathrm{T}$ & $G$ & G & * & * & * \\
\hline Vic 15,16 Alp1-3 & G & $\mathrm{T}$ & $\mathrm{T}$ & $\mathrm{C}$ & $\mathrm{T}$ & $*$ & $\mathrm{C}$ & $*$ & $\mathrm{C}$ & $\mathrm{T}$ & G & G & $*$ & $*$ & $\mathrm{~T}$ \\
\hline Alp 4, 5, 6, 8, 10, 13,14 & $*$ & $\mathrm{~T}$ & $\mathrm{~T}$ & $\mathrm{C}$ & $\mathrm{T}$ & $*$ & $\mathrm{C}$ & $*$ & $\mathrm{C}$ & $\mathrm{T}$ & G & G & $*$ & $*$ & $\mathrm{~T}$ \\
\hline Alp 11,12 La7, 9, 10, Gua1 & $*$ & $*$ & $*$ & * & $*$ & $\mathrm{C}$ & $*$ & $*$ & $*$ & $*$ & $*$ & $*$ & $*$ & $*$ & $*$ \\
\hline La1, 3-6 & $*$ & $*$ & $*$ & $*$ & $*$ & $*$ & $*$ & $*$ & $*$ & * & $*$ & $*$ & G & $*$ & $*$ \\
\hline La2, Alp7, 9 & $*$ & * & $*$ & * & $*$ & * & $*$ & $*$ & * & $*$ & $*$ & * & $*$ & $*$ & $*$ \\
\hline $\mathrm{La} 8$ & $*$ & $*$ & $*$ & * & $*$ & $\mathrm{C}$ & $\mathrm{C}$ & $\mathrm{C}$ & $*$ & * & $*$ & $*$ & * & G & $\mathrm{T}$ \\
\hline Gua 2,3 & $*$ & $*$ & $*$ & * & $*$ & $\mathrm{C}$ & $\mathrm{C}$ & $\mathrm{C}$ & $*$ & $*$ & $*$ & $*$ & $G$ & $G$ & $\mathrm{~T}$ \\
\hline
\end{tabular}

Legende: Ref. $=$ Referenzsequenz, $\mathrm{A}=$ Adenin, $\mathrm{G}=$ Guanin, $\mathrm{C}=$ Cytosin, $\mathrm{T}=$ Thymin $*=$ stimmt mit der Referenzsequenz überein

Die Mutter-Kind-Paare La3 und La5, La4 und La6 sowie Alp11 und Alp12 wiesen jeweils die gleichen Polymorphismen auf. 
Wurden die Sequenzen aus der Datenbank in die Auswertung mit einbezogen (36 Sequenzen, s. Kap. 3.1) so erhöhte sich die Anzahl polymorpher Stellen auf 35, die Anzahl der Haplotypen auf 26. Dies entspricht einer Nukleotid-Diversität von 0,15. Es erfolgte eine Benennung anhand der phänotypischen Spezies sowie ihrer Stellung im rekonstruierten Stammbaum (s. Abb. 43). Die Rekonstruktion des phylogenetischen Stammbaums erfolgte mit Hilfe der Software MEGA, unter Verwendung der Methodik UPGMA bootsptrap und den Distanzberechnungen nach Nei (s. Kap. 2.3). In Tabelle 38 sind die Haplotypen, ihre polymorphen Stellen sowie ihre Häufigkeit verzeichnet.

Tabelle 39: Benennung der Haplotypen und ihre polymorphen Stellen im Nukleotid-Bereich 14439-14676 und ihre Häufigkeit in phänotypischen Spezies

\begin{tabular}{|c|c|c|}
\hline Haplotyp & Polymorphismen & Häufigkeit \\
\hline V1 & 453G, 474T, 513T, 517C, 528G, 549C, 558C, 624C, 630T, 645G, 648G, 672T & $4 \mathrm{~V}$ \\
\hline V2 & $\begin{array}{c}\text { 448T, 449T, 453G, 474T, 504C, 513T, 517C, 528G, 549C, 558C, 603C, 612A, 624C, } \\
\text { 630T, 645G, 648G, 672T }\end{array}$ & $1 \mathrm{~V}$ \\
\hline V3 & 453G, 474T, 513T, 517C, 528T, 549C, 558C, 624C, 630T, 645G, 648G & $9 \mathrm{~V}$ \\
\hline AV1 & 453G, 474T, 513T, 517C, 528T, 549C, 558C, 624C, 630T, 645G, 648G, 672T & $2 \mathrm{~V}, 3 \mathrm{~A}$ \\
\hline LV1 & 453G, 474T, 513T, 517C, 528T, 549C, 558C, 603C, 624C, 630T, 645G, 648G, 672T & $1 \mathrm{~V}, 1 \mathrm{~L}$ \\
\hline AV2 & 474T, 513T, 517C, 528T, 549C, 558C, 624C, 630T, 645G, 648G, 672T & $7 \mathrm{~A}$ \\
\hline LV2 & $\begin{array}{l}453 \mathrm{G}, \text { 474T, 513T, 517C, 527A, 528G, 532C, 549C, 558C, 603C, 624C, 625C, 630T, } \\
\text { 645G, 648G, 653T, 655A, 672T }\end{array}$ & $1 \mathrm{~L}$ \\
\hline ALG1 & $549 \mathrm{C}$ & $2 \mathrm{~A}, 3 \mathrm{~L}, 3 \mathrm{G}$ \\
\hline L1 & $657 \mathrm{G}$ & $5 \mathrm{~L}$ \\
\hline LA1 & $-/-$ & $1 \mathrm{~L}, 2 \mathrm{~A}$ \\
\hline A1 & 549C, 564G, 672T & $1 \mathrm{~A}$ \\
\hline A2 & 543C, 549C, 603C, 657T & $1 \mathrm{~A}$ \\
\hline LG1 & 549C, 558C, 567C, 660G, 672T & $1 \mathrm{~L}$ \\
\hline G1 & 546A, 549C, 558C, 597C, 660G, 672T & $1 \mathrm{G}$ \\
\hline G2 & 549C, 558C, 567C, 603C, 660G, 672T & $4 \mathrm{G}$ \\
\hline G3 & 549C, 558C, 567C, 589C, 603C, 660G, 672T & $1 \mathrm{G}$ \\
\hline LG2 & 459C, 549C, 558C, 567C, 603C, 634C, 672T & $1 \mathrm{~L}$ \\
\hline G4 & 492G, 549C, 558C, 567C, 603C, 660G, 672T & $8 \mathrm{G}$ \\
\hline G5 & 492G, 549C, 558C, 567C, 603C, 672T & $1 \mathrm{G}$ \\
\hline G6 & 492G, 549C, 558C, 555G, 567C, 603C, 660G, 672T & $1 \mathrm{G}$ \\
\hline G7 & 549C, 555G, 558C, 567C, 603C, 660G, 672T & $4 \mathrm{G}$ \\
\hline G8 & 549C, 558C, 567C, 657G, 660G, 672T & $2 \mathrm{G}$ \\
\hline G9 & 549C, 555G, 558C, 567C, 585A, 603C, 655A, 657G, 660G, 672T & $1 \mathrm{G}$ \\
\hline G10 & 549C, 555G, 558C, 567C, 585A, 603C, 657C, 660G, 672T & $1 \mathrm{G}$ \\
\hline G11 & 549C, 555G, 558C, 567C, 603C, 657G, 660G, 672T & $3 G$ \\
\hline G12 & 549C, 555G, 558C, 567C, 603C, 625C, 657G, 660G, 672T & $2 \mathrm{G}$ \\
\hline
\end{tabular}

Legende: Polymorphismen: $\mathrm{C}=$ Cytosin, $\mathrm{T}=$ Thymin, $\mathrm{A}=$ Adenin, $\mathrm{G}=$ Guanin; Vorkommen: $\mathrm{L}=\mathrm{Lama}, \mathrm{V}=$ Vikunja, $\mathrm{A}=$ Alpaka, $\mathrm{G}=$ Guanako

Diese Haplotypen lassen sich in zwei Großgruppen unterteilen. Die Gruppe Guanako besteht aus den Haplotypen G1-G12, LG1, LA1, L1, ALG1, A1 und A2. Die Gruppe Vikunja besteht aus den Haplotypen LV1, LV2, AV1, AV2, V1, V2 und V3. Die Unterteilung erfolgte anhand des phylogenetischen Stammbaums (s. Abb. 43).

Um die Sequenzen auch mit denen des überlieferten Materials vergleichen zu können, in denen überwiegend kürzere Sequenzen analysiert werden konnten, wurden die Sequenzen in einen vorderen Bereich (101 bp, np 14453-14554) und einen hinteren Bereich (81 bp, np 
14595-14676) unterteilt. Für diese Bereiche erfolgten ebenfalls die Benennungen der Haplotypen und die Rekonstruktionen des phylogenetischen Stammbaums anhand der angetroffenen Sequenzen. Im vorderen Bereich konnten 13 polymorphe Stellen detektiert und elf Haplotypen definiert werden. Diese sind in Tabelle 40 dargestellt. Des Weiteren wird Auskunft über die Tiere in denen sie angetroffen werden gegeben.

Tabelle 40: Haplotypen und polymorphe Stellen im vorderen Bereich (np 14453 - 14554) des cytb und ihre Häufigkeit in phänotypischen Spezies

\begin{tabular}{|l|c|l|}
\hline Haplotyp & Polymorphismen & Häufigkeit \\
\hline V1 & 453G, 474T, 513T, 517C, 528G, 549C & $4 \mathrm{~V}$ \\
\hline V2 & 453G, 474T, 504C, 513T, 517C, 528G, 549C & $1 \mathrm{~V}$ \\
\hline AVL1 & 453G, 474T, 513T, 517C, 528G & $12 \mathrm{~V}, 3 \mathrm{~A}, 1 \mathrm{~L}$ \\
\hline AV1 & $474 T, 513 \mathrm{~T}, 517 \mathrm{C}, 528 \mathrm{G}$ & $7 \mathrm{~A}$ \\
\hline LV1 & 453G, 474T, 513T, 517C, 527A, 528G, 532C & $1 \mathrm{~L}$ \\
\hline ALG1 & 549C & $3 \mathrm{~A}, 4 \mathrm{~L}, 21 \mathrm{G}$ \\
\hline LA1 & $-/-$ & $6 \mathrm{~L}, 2 \mathrm{~A}$ \\
\hline A1 & 543C, 549C & $1 \mathrm{~A}$ \\
\hline G1 & 546A, 549C & $1 \mathrm{G}$ \\
\hline LG1 & 459C, 549C & $1 \mathrm{~L}$ \\
\hline G2 & 492G, 549C & $10 \mathrm{G}$ \\
\hline
\end{tabular}

Legende: Polymorphismen: $\mathrm{C}=$ Cytosin, $\mathrm{T}=$ Thymin, $\mathrm{A}=$ Adenin, $\mathrm{G}=$ Guanin; Vorkommen: $\mathrm{L}=\mathrm{Lama}, \mathrm{V}=$ Vikunja, $\mathrm{A}=$ Alpaka, $\mathrm{G}=$ Guanako

Die Haplotypen lassen sich in zwei Hauptgruppen unterteilen (s. Abb. 43): Die Gruppe Guanako mit den Haplotypen G1, G2, LG1, A1, LA1 und ALG1 sowie die Gruppe Vikunja mit den Haplotypen V1, V2, AVL1, AV1 und LV1. Die Gruppe Vikunja weist weniger Haplotypen, jedoch mehr polymorphe Stellen, als die Gruppe Guanako auf.

Im hinteren Bereich des cytb sind 13 polymorphe Stellen zu bestimmen, welche die Unterteilung in 18 Haplotypen erlauben. In Tabelle 41 sind diese gelistet.

Tabelle 41: Haplotypen und polymorphe Stellen im hinteren Bereich (np 14595 - 14676) des cytb und ihre Häufigkeit in phänotypischen Spezies

\begin{tabular}{|l|c|l|}
\hline Haplotyp & Polymorphismen & Häufigkeit \\
\hline AV1 & 624C, 630T, 645G, 648G, 672T & $6 \mathrm{~V}, 10 \mathrm{~A}$ \\
\hline V1 & 603C, 612T, 624C, 630T, 645G, 648G, 672T & $1 \mathrm{~V}$ \\
\hline V2 & 624C, 630T, 645G, 648G & $9 \mathrm{~V}$ \\
\hline LV1 & 603C, 624C, 630T, 645G, 648G, 672T & $1 \mathrm{~V}, 1 \mathrm{~L}$ \\
\hline LV2 & 603C, 624C, 625C, 630T, 645G, 648G, 653T, 655A, 672T & $1 \mathrm{~L}$ \\
\hline ALG1 & $-/-$ & $4 \mathrm{~A}, 4 \mathrm{~L}, 3 \mathrm{G}$ \\
\hline L1 & $657 \mathrm{G}$ & $5 \mathrm{~L}$ \\
\hline A1 & $672 \mathrm{~T}$ & $1 \mathrm{~A}$ \\
\hline A2 & 603C, 657T & $1 \mathrm{~A}$ \\
\hline LG1 & $660 \mathrm{G}, 672 \mathrm{~T}$ & $1 \mathrm{~L}, 1 \mathrm{G}$ \\
\hline G1 & 603C, 660G, 672T & $17 \mathrm{G}$ \\
\hline G2 & 603C, 634C, 660G, 672T & $1 \mathrm{G}$ \\
\hline LG2 & $603 \mathrm{C}, 672 \mathrm{~T}$ & $1 \mathrm{~L}, 1 \mathrm{G}$ \\
\hline G3 & 657G, 660G, 672T & $2 \mathrm{G}$ \\
\hline G4 & 603C, 655A, 657G, 660G, 672T & $1 \mathrm{G}$ \\
\hline G5 & 603C, 657C, 660G, 672T & $1 \mathrm{G}$ \\
\hline G6 & 603C, 657G, 660G, 672T & $3 \mathrm{G}$ \\
\hline G7 & 603C, 625C, 657G, 660G, 672T & $2 \mathrm{G}$ \\
\hline
\end{tabular}

Legende: Polymorphismen: $\mathrm{C}=$ Cytosin, $\mathrm{T}=$ Thymin, $\mathrm{A}=$ Adenin, $\mathrm{G}=$ Guanin; Vorkommen: $\mathrm{L}=\mathrm{Lama}, \mathrm{V}=$ Vikunja, $\mathrm{A}=$ Alpaka, $\mathrm{G}=$ Guanako 
Die Haplotypen ALG1, L1, A1, A2, LG1, LG2 und G1-G7 lassen sich in die Gruppe Guanako unterteilen, die Haplotypen AV1, V1, V2, LV1 und LV2 in die Gruppe Vikunja (s. Abb. 43).

In Abbildung 43 sind die, sich aus den angetroffenen Haplotypen ergebenden, phylogenetischen Stammbäume dargestellt. Die Astlängen entsprechen nicht den tatsächlichen Distanzen. Die bootstrap-Werte lagen bei $\sim 90 \%$.

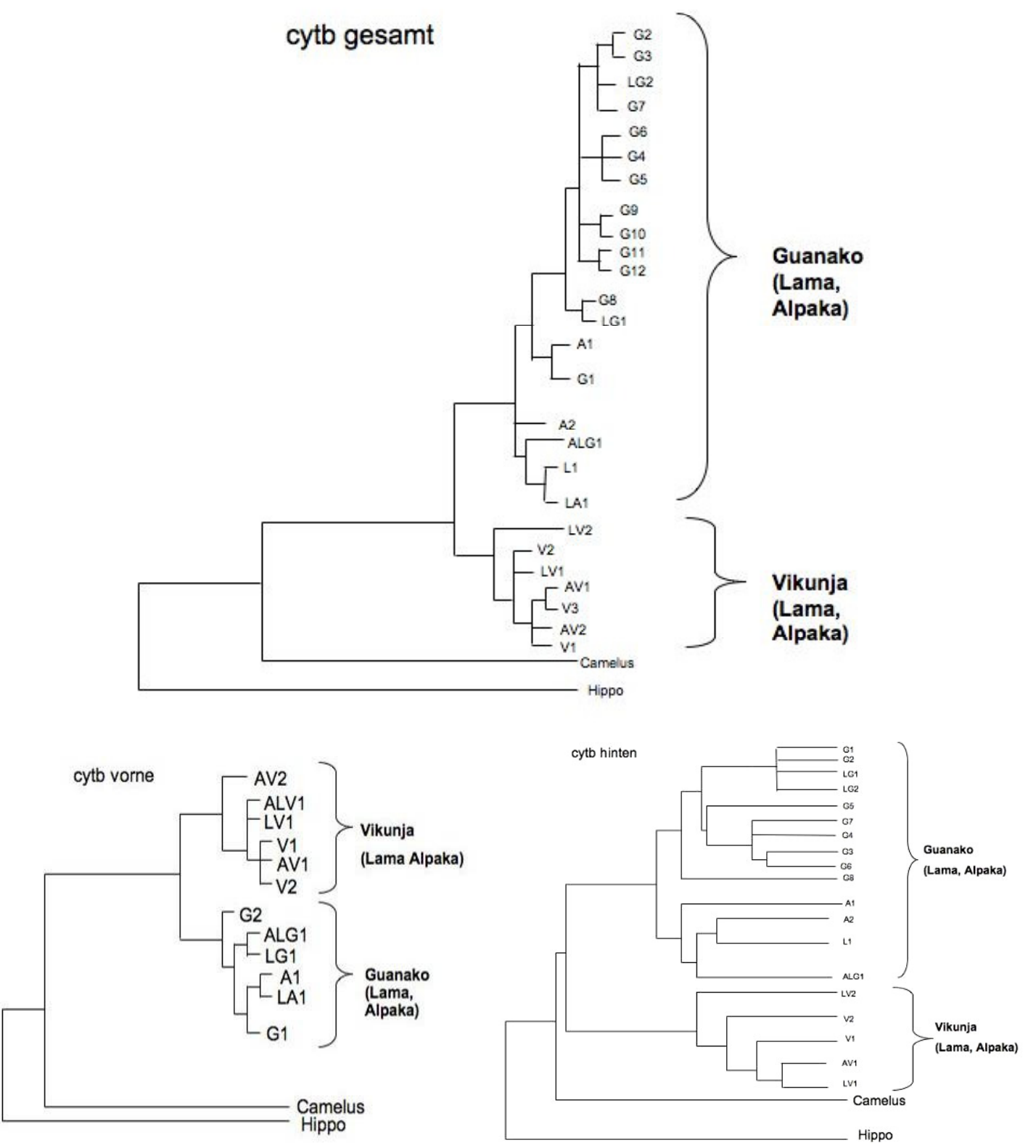

Abbildung 43: Phylogenetische Stammbäume die sich aus den Haplotypen der cytb-Sequenzen ergeben (näheres im Text)

Im Stammbaum des Gesamt-Fragmentes und dem des hinteren Bereiches, lassen sich innerhalb der Guanako-Gruppe zwei weitere Gruppen unterscheiden, jene die nur aus Guanakos besteht (obere Äste) und jene die aus Lamas, Alpakas und Guanakos besteht. Innerhalb der Vikunja-Gruppe ist eine klare Unterteilung nicht möglich, hier sind in der Gesamtgruppe Lamas, Alpakas und Vikunjas enthalten. 


\subsection{2 Überliefertes Material}

Für 55 der insgesamt 233 Extrakte war eine Amplifikation von Fragmenten des cytb möglich. Dies entspricht einem Amplifikationserfolg von rund 23,6\%. Betrachtet man nur die Knochen und Zähne so konnte für 38 von 164 Proben eine positive Amplifikation erfolgen (24\%). Von 40 Textilien konnten 17 Proben erfolgreich amplifiziert werden (42,5\%). Reproduzierte Ergebnisse liegen für 36 Knochen- und Zahnproben (22\%) sowie 14 textile Proben (20,3 \%) vor, dies entspricht einem Gesamterfolg von 21,5 \%. Für die Proben JAA29 und COA4 konnte aus allen beprobten Knochenelementen DNA amplifiziert werden, diese sind in der Auswertung als Einzelproben behandelt worden. Für die textilen Proben, die in unterschiedlicher Farbgebung Ergebnisse erbrachten, wurde ebenso verfahren. Das Gesamtfragment konnte für 20 Knochenproben und eine textile Probe bestimmt werden. In elf dieser Proben gelang die Amplifikation des langen Fragmentes cytb 2, in zehn Proben gelang die Auswertung des gesamten Bereiches anhand der überlappenden Fragmente. In allen Proben konnte eine sichere Auswertung der Sequenz von Position 14439 - 14677 erfolgen, so dass die ausgewertete Sequenzlänge 238 bp beträgt. In Tabelle 42 sind die erfolgreich analysierten Proben, ihre polymorphen Stellen und Haplotypen sowie das hierfür amplifizierte Fragment gelistet.

Tabelle 42: Polymorphismen, Haplotypen und erfolgreiche Fragmente in überliefertem Material

\begin{tabular}{|c|c|c|c|c|c|c|c|c|c|c|c|c|c|c|c|c|c|c|c|c|c|c|}
\hline & $\stackrel{n}{\stackrel{n}{f}}$ & 守 & $\stackrel{\mathfrak{g}}{\underset{f}{\Xi}}$ & 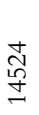 & $\begin{array}{l}\stackrel{ }{N} \\
\stackrel{\sim}{ \pm}\end{array}$ & $\begin{array}{l}\stackrel{9}{+} \\
\stackrel{+}{+}\end{array}$ & $\begin{array}{l}\stackrel{g}{+} \\
\stackrel{+}{ \pm}\end{array}$ & $\begin{array}{l}\stackrel{2}{\llcorner} \\
\stackrel{2}{7} \\
\stackrel{+}{Z}\end{array}$ & $\begin{array}{l}\infty \\
\stackrel{n}{10} \\
\stackrel{+}{+}\end{array}$ & $\begin{array}{l}\text { 유 } \\
\stackrel{+}{J}\end{array}$ & $\begin{array}{l}\text { } \\
\text { fે }\end{array}$ & 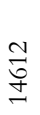 & 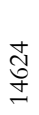 & 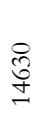 & 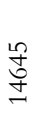 & $\begin{array}{l}\text { 品 } \\
\text { I }\end{array}$ & $\begin{array}{l}\vec{n} \\
\text { 方 }\end{array}$ & $\begin{array}{l}\text { 菅 } \\
\stackrel{+}{+}\end{array}$ & $\begin{array}{l}\text { 응 } \\
\text { + }\end{array}$ & \begin{tabular}{l} 
No \\
\multirow{2}{*}{}
\end{tabular} & 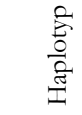 & 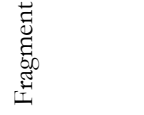 \\
\hline Ref. & $\mathrm{A}$ & $\mathrm{T}$ & $\mathrm{A}$ & $\mathrm{C}$ & $G$ & $\mathrm{~T}$ & $\mathrm{~T}$ & $\mathrm{~A}$ & $\mathrm{~T}$ & $\mathrm{~A}$ & $\mathrm{~T}$ & $G$ & $\mathrm{~T}$ & $\mathrm{C}$ & $\mathrm{A}$ & $\mathrm{A}$ & $\mathrm{T}$ & $\mathrm{A}$ & $\mathrm{A}$ & $\mathrm{C}$ & LA1 & \\
\hline JAA29a & $*$ & $*$ & $*$ & $*$ & $*$ & $*$ & $*$ & $*$ & $*$ & $*$ & $*$ & $*$ & $*$ & $*$ & $*$ & $*$ & $*$ & $*$ & $*$ & $*$ & LA1 & cytb2,5 \\
\hline JAA29b & $*$ & * & $*$ & $*$ & $*$ & $*$ & $*$ & $*$ & $*$ & $*$ & $*$ & $*$ & $*$ & $*$ & $*$ & $*$ & $*$ & $*$ & $*$ & $*$ & LA1 & cytb4,5 \\
\hline JAA29c & $*$ & $*$ & $*$ & $*$ & $*$ & $*$ & $*$ & $*$ & $*$ & $*$ & $*$ & $*$ & $*$ & $*$ & $*$ & $*$ & $*$ & $*$ & $*$ & $*$ & LA1 & cytb4,5 \\
\hline MSA2 & $*$ & $*$ & $*$ & $*$ & $*$ & $*$ & $*$ & $*$ & $*$ & $*$ & $*$ & $\mathrm{R}$ & $*$ & $*$ & $*$ & $*$ & $*$ & $*$ & $*$ & $*$ & LA1 & cytb2,4 \\
\hline MSA29 & $*$ & * & $*$ & $*$ & $*$ & $*$ & $*$ & $*$ & $*$ & $*$ & $*$ & $*$ & $*$ & $*$ & $*$ & $*$ & $*$ & $*$ & $*$ & $*$ & LA1 & cytb2,3,4,5 \\
\hline MSA30 & $*$ & * & $*$ & $*$ & $*$ & $*$ & $*$ & $*$ & $*$ & $*$ & $*$ & $*$ & $*$ & $*$ & $*$ & $*$ & $*$ & $*$ & $*$ & $*$ & LA1 & cytb4,5 \\
\hline MST3b & $*$ & * & $*$ & $*$ & $*$ & $*$ & $\mathrm{C}$ & $G$ & $\mathrm{C}$ & $\mathrm{C}$ & $\mathrm{C}$ & $\mathrm{R}$ & $*$ & $*$ & $*$ & $*$ & $*$ & G & $G$ & $\mathrm{~T}$ & G11 & cytb3,4,5 \\
\hline GEA1 & nd & * & $*$ & $*$ & $*$ & $*$ & $\mathrm{C}$ & $*$ & $*$ & $*$ & $*$ & $*$ & $*$ & $*$ & $*$ & $*$ & $\mathrm{C}$ & $*$ & G & $\mathrm{T}$ & LG3 & cytb4,5,6 \\
\hline GEA6 & $*$ & * & $*$ & $*$ & $*$ & $\mathrm{C}$ & $\mathrm{C}$ & $*$ & $\mathrm{C}$ & $\mathrm{C}$ & $\mathrm{C}$ & $\mathrm{A}$ & $*$ & $*$ & $*$ & $*$ & $\mathrm{C}$ & $*$ & $G$ & $\mathrm{~T}$ & G13 & cytb2,3,4,5 \\
\hline GEA7 & nd & nd & $*$ & $*$ & $*$ & $*$ & $\mathrm{C}$ & $*$ & $*$ & $*$ & $\mathrm{C}$ & $\mathrm{A}$ & $*$ & $*$ & $*$ & $*$ & $*$ & $*$ & $*$ & $*$ & L3 & cytb3,4,5 \\
\hline GEA9 & $*$ & $\mathrm{C}$ & $*$ & $*$ & $*$ & $*$ & $\mathrm{C}$ & $*$ & $\mathrm{C}$ & $\mathrm{C}$ & $\mathrm{C}$ & $\mathrm{A}$ & $*$ & $*$ & $*$ & $*$ & $*$ & $*$ & $G$ & $\mathrm{~T}$ & G14 & cytb3,4,5 \\
\hline GEA15 & nd & nd & * & $*$ & $*$ & $*$ & $\mathrm{C}$ & $*$ & $*$ & $*$ & $\mathrm{C}$ & $\mathrm{A}$ & $*$ & $*$ & $*$ & $*$ & $*$ & $*$ & $*$ & $*$ & L3 & cytb3,4,5 \\
\hline COA2 & nd & nd & $*$ & $*$ & $*$ & $*$ & $\mathrm{C}$ & $*$ & $\mathrm{C}$ & $\mathrm{C}$ & $*$ & $*$ & $*$ & $*$ & $*$ & $*$ & $*$ & $*$ & $G$ & $\mathrm{~T}$ & LG1 & cytb2,3,4,5 \\
\hline COA4 & nd & $*$ & $*$ & $*$ & $*$ & $\mathrm{C}$ & $\mathrm{C}$ & $*$ & $\mathrm{C}$ & $\mathrm{C}$ & $\mathrm{C}$ & $\mathrm{A}$ & $*$ & $*$ & $*$ & $*$ & $\mathrm{C}$ & $*$ & $\mathrm{G}$ & $\mathrm{T}$ & G13 & cytb2,4,5 \\
\hline COA6 & $*$ & $*$ & $*$ & $*$ & $*$ & $*$ & $*$ & $*$ & $*$ & $*$ & $\mathrm{C}$ & $\mathrm{A}$ & $*$ & $*$ & $*$ & $*$ & $*$ & $*$ & $*$ & $*$ & L2 & cytb2,3,4 \\
\hline COA7 & $*$ & $\mathrm{C}$ & $*$ & $*$ & $*$ & $*$ & $\mathrm{C}$ & $*$ & $\mathrm{C}$ & $\mathrm{C}$ & $\mathrm{C}$ & $\mathrm{A}$ & $*$ & $*$ & $*$ & $*$ & $*$ & $*$ & $G$ & $\mathrm{~T}$ & G14 & cytb3,4,5 \\
\hline COA8 & $*$ & $*$ & $\mathrm{G}$ & $\mathrm{T}$ & $*$ & $*$ & $\mathrm{C}$ & $*$ & $*$ & $*$ & $\mathrm{C}$ & $\mathrm{A}$ & $*$ & $*$ & $*$ & $*$ & $*$ & $*$ & $*$ & $*$ & L3 & cytb3,4,5 \\
\hline COA11 & nd & nd & nd & $*$ & $*$ & $*$ & $\mathrm{C}$ & $*$ & $*$ & $*$ & $\mathrm{C}$ & $\mathrm{A}$ & $\mathrm{C}$ & $\mathrm{T}$ & $G$ & $G$ & $*$ & $*$ & $*$ & $\mathrm{~T}$ & V4 & cytb3,4 \\
\hline COA13 & $*$ & $\mathrm{C}$ & $*$ & $*$ & $*$ & $*$ & $\mathrm{C}$ & $*$ & $\mathrm{C}$ & $\mathrm{C}$ & $\mathrm{C}$ & $\mathrm{A}$ & $*$ & $*$ & $*$ & $*$ & $*$ & $*$ & $\mathrm{G}$ & $\mathrm{T}$ & G14 & cytb2,3,4,5 \\
\hline COA14 & nd & $*$ & $*$ & $*$ & $*$ & $*$ & $\mathrm{C}$ & $*$ & $*$ & $*$ & $*$ & $*$ & $*$ & $*$ & $*$ & $*$ & $*$ & $*$ & $*$ & $*$ & ALG1 & cytb3,4,5 \\
\hline COA17 & $*$ & $\mathrm{C}$ & $*$ & $*$ & $*$ & $*$ & $\mathrm{C}$ & $*$ & $\mathrm{C}$ & $\mathrm{C}$ & $\mathrm{C}$ & $\mathrm{A}$ & $*$ & $*$ & $*$ & $*$ & $*$ & $*$ & $\mathrm{G}$ & $\mathrm{T}$ & G14 & cytb2,3,4,5,6 \\
\hline COA21 & nd & $*$ & $*$ & $*$ & $*$ & $*$ & $*$ & $*$ & $*$ & $*$ & $\mathrm{C}$ & $\mathrm{R}$ & $*$ & $*$ & $*$ & $*$ & $*$ & $*$ & $*$ & $*$ & $\mathrm{~L} 2$ & cytb2,4,5 \\
\hline COA25 & $*$ & * & $*$ & $*$ & $\mathrm{~A}$ & $*$ & $\mathrm{C}$ & $*$ & $*$ & $*$ & $\mathrm{C}$ & $\mathrm{R}$ & $*$ & $*$ & $*$ & $*$ & $*$ & $*$ & $*$ & $*$ & L3 & cytb2,3,4,5 \\
\hline
\end{tabular}

Legende: Ref. $=$ Referenzsequenz, $\mathrm{A}=$ Adenin, $\mathrm{G}=$ Guanin, $\mathrm{C}=$ Cytosin, $\mathrm{T}=$ Thymin $*=$ stimmt mit der Referenzsequenz überein, $n d=$ nicht definiert, $R=A$ oder $G$ 
Die Proben MSA2, MST3b, COA21 und COA25 wiesen eine Heteroplasmie an der Position 14612 auf. In den Proben COA21 und COA25 konnte diese nur auf dem oberen Strang detektiert werden, auf dem unteren Strang konnte nur ein $G$ typisiert werden. In den Proben MSA2 und MST3b war diese Position auf beiden Strängen als R ausgeprägt.

Es konnten insgesamt zehn Haplotypen und 19 polymorphe Stellen bestimmt werden, dies entspricht einer Nukleotid-Diversität von 0,08. Obwohl eine deutlich kleinere Stichprobe gegenüber den Untersuchungen in rezenten Tieren vorliegt, weist das überlieferte Material, eine anteilig größere Anzahl Haplotypen (10/21 gegenüber 26/79) sowie sechs Haplotypen, die nicht im rezenten Material typisiert werden konnten, auf.

Die Analyse des vorderen Fragmentes (np 14453 - 14554) konnte für 41 Proben erfolgen. In Abbildung 44 ist die Überprüfung des Amplifikationserfolges exemplarisch dargestellt. Es sind Proben zu sehen, in denen das Fragment 5 (s. Kap. 3.4.1) amplifiziert wurde.

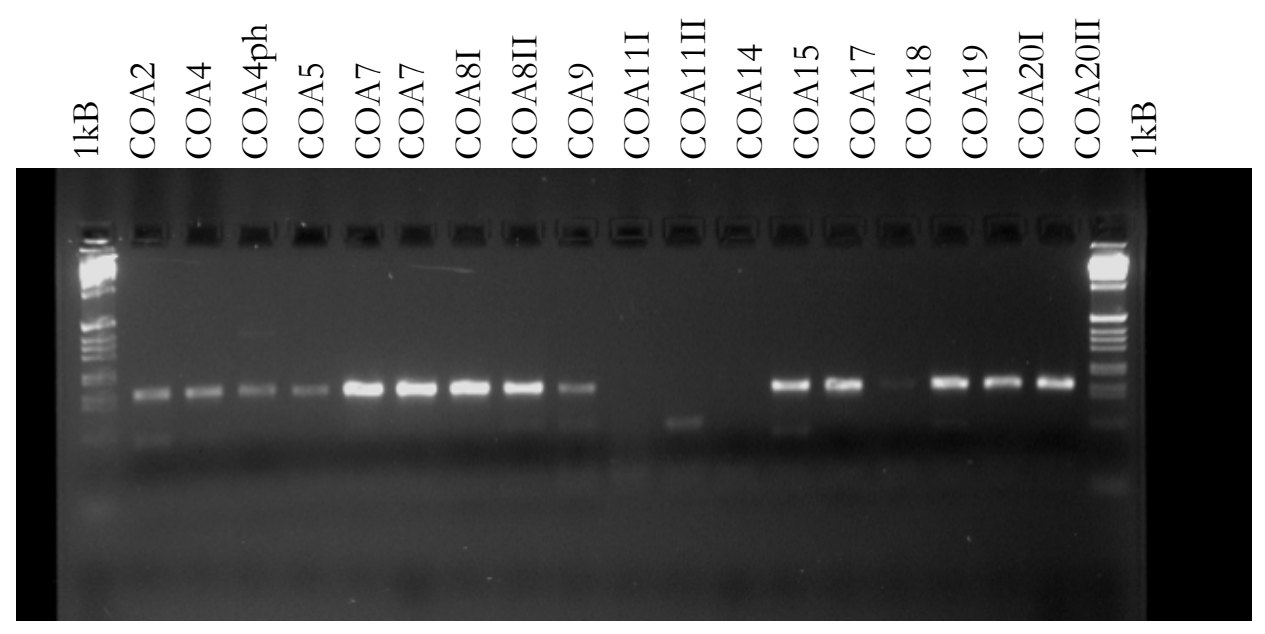

Abbildung 44: Überprüfung des Amplifikationserfolges der PCR 5.16

In den Proben, die einen positiven Amplifikationserfolg aufwiesen, konnte auch immer eine Sequenzierung erfolgen. In Tabelle 43 sind die sequenzierten Proben, ihre polymorphen Stellen und Haplotypen sowie das in ihnen amplifizierte Fragment aufgeführt. 
Tabelle 43: Polymorphismen und Haplotypen im vorderen Bereich des cytb in überliefertem Material

\begin{tabular}{|c|c|c|c|c|c|c|c|c|c|c|c|c|c|c|}
\hline & 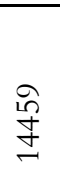 & $\underset{⿱}{\stackrel{N}{J}}$ & $\underset{\stackrel{+}{+}}{\stackrel{+}{+}}$ & $\underset{\stackrel{N}{f}}{\stackrel{+}{-}}$ & 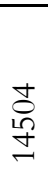 & 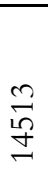 & $\stackrel{ }{\stackrel{ }{7}}$ & $\begin{array}{l}\stackrel{+}{\sim} \\
\stackrel{\sim}{ \pm}\end{array}$ & 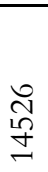 & \begin{tabular}{l}
$\infty$ \\
\multirow{N}{*}{} \\
$\stackrel{్}{ \pm}$
\end{tabular} & $\begin{array}{l}\stackrel{q}{+} \\
\stackrel{1}{+} \\
\stackrel{+}{+}\end{array}$ & $\begin{array}{l}\stackrel{g}{+} \\
\stackrel{+}{ \pm}\end{array}$ & 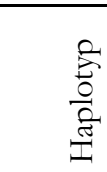 & 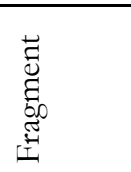 \\
\hline Ref. & $\mathrm{T}$ & $G$ & $\mathrm{C}$ & $\mathrm{A}$ & $\mathrm{T}$ & $\mathrm{C}$ & $\mathrm{T}$ & $\mathrm{C}$ & $G$ & $\mathrm{C}$ & $\mathrm{T}$ & $\mathrm{T}$ & LA1 & \\
\hline AOA8 & $*$ & $*$ & $*$ & $*$ & $*$ & $*$ & $*$ & $*$ & $*$ & $*$ & $*$ & $*$ & LA1 & cytb5 \\
\hline JAA29a & $*$ & * & * & $*$ & $*$ & $*$ & $*$ & $*$ & $*$ & $*$ & $*$ & $*$ & LA1 & cytb2,5 \\
\hline JAA29b & $*$ & $*$ & $*$ & $*$ & $*$ & $*$ & $*$ & $*$ & $*$ & $*$ & $*$ & $*$ & LA1 & cytb5 \\
\hline JAA29c & $*$ & $*$ & $*$ & $*$ & $*$ & $*$ & $*$ & $*$ & $*$ & $*$ & $*$ & $*$ & LA1 & cytb5 \\
\hline MSA2 & * & * & * & $*$ & $*$ & $*$ & $*$ & $*$ & $*$ & $*$ & $*$ & $*$ & LA1 & cytb2 \\
\hline MSA29 & $*$ & $*$ & $*$ & $*$ & $*$ & $*$ & $*$ & $*$ & $*$ & $*$ & $*$ & $*$ & LA1 & cytb3 \\
\hline MSA30 & $*$ & $*$ & $*$ & $*$ & $*$ & $*$ & $*$ & $*$ & $*$ & $*$ & $*$ & $*$ & LA1 & cytb5 \\
\hline MSA31 & $*$ & * & $*$ & $*$ & $*$ & $*$ & $*$ & $*$ & $*$ & $*$ & $*$ & $\mathrm{C}$ & ALG1 & cytb5 \\
\hline MST3b & * & * & $*$ & * & $*$ & $*$ & $*$ & $*$ & $*$ & $*$ & $*$ & $\mathrm{C}$ & ALG1 & cytb3 \\
\hline MST5c & $*$ & * & $*$ & $*$ & $\mathrm{C}$ & $\mathrm{T}$ & $\mathrm{C}$ & $*$ & $*$ & $G$ & $*$ & $\mathrm{C}$ & V3 & cytb5 \\
\hline MST7a & * & * & $*$ & $*$ & $\mathrm{C}$ & $\mathrm{T}$ & $\mathrm{C}$ & $*$ & $*$ & G & $*$ & $\mathrm{C}$ & V3 & cytb5 \\
\hline MST9c & $*$ & * & $\mathrm{T}$ & $*$ & $\mathrm{C}$ & $\mathrm{T}$ & $\mathrm{C}$ & $*$ & $*$ & G & * & $\mathrm{C}$ & V2 & cytb5 \\
\hline MST13e & $*$ & * & $\mathrm{T}$ & $*$ & $\mathrm{C}$ & $\mathrm{T}$ & $\mathrm{C}$ & $*$ & $*$ & $\mathrm{G}$ & $*$ & $\mathrm{C}$ & $\mathrm{V} 2$ & cytb5 \\
\hline MST24a & $*$ & $*$ & $\mathrm{~T}$ & $*$ & $\mathrm{C}$ & $\mathrm{T}$ & $\mathrm{C}$ & $*$ & $*$ & $G$ & $*$ & $\mathrm{C}$ & V2 & cytb5 \\
\hline GEA1 & $*$ & $*$ & $*$ & $*$ & $*$ & $*$ & $*$ & $*$ & $*$ & $*$ & $*$ & $\mathrm{C}$ & ALG1 & cytb5 \\
\hline GEA6 & $*$ & $*$ & $*$ & $*$ & $*$ & $*$ & $*$ & $*$ & $*$ & $*$ & $\mathrm{C}$ & $\mathrm{C}$ & ALG2 & cytb2,3,5 \\
\hline GEA7 & nd & $*$ & $*$ & $*$ & $*$ & $*$ & $*$ & $*$ & $*$ & $*$ & $*$ & $\mathrm{C}$ & ALG1 & cytb3,5 \\
\hline GEA8 & $*$ & $\mathrm{C}$ & $\mathrm{T}$ & $*$ & $*$ & $\mathrm{~T}$ & $\mathrm{C}$ & $*$ & $*$ & $\mathrm{~T}$ & $*$ & $*$ & AV3 & cytb5 \\
\hline GEA9 & $\mathrm{C}$ & $*$ & $*$ & $*$ & $*$ & $*$ & $*$ & $*$ & $*$ & $*$ & $*$ & $\mathrm{C}$ & LG1 & cytb3,5 \\
\hline GEA10 & $*$ & * & * & $*$ & $*$ & $*$ & $*$ & $*$ & $*$ & $*$ & $*$ & $\mathrm{C}$ & ALG1 & cytb5 \\
\hline GEA15 & nd & $*$ & $*$ & $*$ & $*$ & $*$ & $*$ & $*$ & $*$ & $*$ & $*$ & $\mathrm{C}$ & ALG1 & cytb3,5 \\
\hline GET1a & $*$ & * & $\mathrm{T}$ & $*$ & $*$ & $\mathrm{~T}$ & $\mathrm{C}$ & $*$ & $*$ & $\mathrm{C}$ & $*$ & $*$ & AV2 & cytb5 \\
\hline GET9d & $*$ & $*$ & $*$ & $*$ & $*$ & $*$ & $*$ & $*$ & $*$ & $*$ & $*$ & $*$ & LA1 & cytb5 \\
\hline GET7a & * & * & * & $*$ & $*$ & $*$ & $*$ & $*$ & $*$ & $*$ & $*$ & $*$ & LA1 & cytb3 \\
\hline GET13a & $*$ & $*$ & $\mathrm{~T}$ & $*$ & $*$ & $\bar{T}$ & $\mathrm{C}$ & $*$ & $*$ & $\mathrm{C}$ & $*$ & $*$ & AV2 & cytb5 \\
\hline GET13f & $*$ & $*$ & $*$ & $*$ & $*$ & $*$ & $*$ & $*$ & $*$ & $*$ & $*$ & $*$ & LA1 & cytb5 \\
\hline $\mathrm{COA} 2$ & nd & nd & $*$ & $*$ & $*$ & $*$ & $*$ & $*$ & $*$ & $*$ & $*$ & $\mathrm{C}$ & ALG1 & cytb2,3,5 \\
\hline COA4 & $*$ & $*$ & $*$ & $*$ & $*$ & $*$ & $*$ & $*$ & $*$ & $*$ & $\mathrm{C}$ & $\mathrm{C}$ & ALG2 & cytb2,5 \\
\hline COA4ph & nd & * & $*$ & $*$ & $*$ & $*$ & $*$ & $*$ & $*$ & $*$ & $*$ & $\mathrm{C}$ & ALG1 & cytb5 \\
\hline COA5 & nd & $\mathrm{Y}$ & $*$ & $*$ & $*$ & $*$ & $*$ & $*$ & $*$ & $*$ & $*$ & $*$ & LA1 & cytb5 \\
\hline COA6 & * & $*$ & $*$ & $*$ & $*$ & $*$ & $*$ & $*$ & $*$ & $*$ & $*$ & $*$ & LA1 & cytb2,3 \\
\hline COA7 & $\mathrm{C}$ & $*$ & $*$ & $*$ & $*$ & $*$ & $*$ & $*$ & $*$ & $*$ & $*$ & $\mathrm{C}$ & LG1 & cytb3,5 \\
\hline COA8 & * & * & $*$ & $G$ & $*$ & $*$ & $*$ & $\mathrm{~T}$ & $*$ & $*$ & $*$ & $\mathrm{C}$ & G3 & cytb3,5 \\
\hline COA9 & $*$ & $*$ & $*$ & $*$ & $*$ & $*$ & $*$ & $*$ & $*$ & $*$ & $*$ & $*$ & LA1 & cytb5 \\
\hline COA11 & nd & nd & nd & nd & $*$ & $*$ & $*$ & $*$ & $*$ & $*$ & $*$ & $\mathrm{C}$ & ALG1 & cytb3 \\
\hline COA12 & nd & $\mathrm{C}$ & $\mathrm{T}$ & $*$ & $*$ & $\mathrm{~T}$ & $\mathrm{C}$ & $*$ & $*$ & $\mathrm{~T}$ & $*$ & $*$ & AV3 & cytb5 \\
\hline COA13 & $\mathrm{C}$ & $*$ & $*$ & $*$ & $*$ & $*$ & $*$ & $*$ & $*$ & $*$ & $*$ & $\mathrm{C}$ & LG1 & cytb2,3 \\
\hline COA14 & $*$ & $*$ & $*$ & $*$ & $*$ & $*$ & $*$ & $*$ & $*$ & $*$ & $*$ & $\mathrm{C}$ & ALG1 & cytb3,5 \\
\hline COA15 & $*$ & $*$ & $*$ & $*$ & $*$ & $*$ & $*$ & $*$ & $*$ & $*$ & $*$ & $\mathrm{C}$ & ALG1 & cytb5 \\
\hline COA17 & $\mathrm{C}$ & $*$ & $*$ & $*$ & $*$ & $*$ & $*$ & $*$ & $*$ & $*$ & $*$ & $\mathrm{C}$ & LG1 & cytb2,3,5 \\
\hline COA18 & nd & $*$ & * & $*$ & $*$ & $\mathrm{~T}$ & $\mathrm{C}$ & $*$ & $*$ & $\mathrm{~T}$ & $*$ & $*$ & AV4 & cytb5 \\
\hline COA19 & nd & $\mathrm{C}$ & $*$ & $*$ & $*$ & $*$ & $*$ & $*$ & $*$ & $*$ & $*$ & $\mathrm{C}$ & LG2 & cytb3,5 \\
\hline COA20 & nd & $*$ & $*$ & $*$ & $*$ & $\mathrm{~T}$ & $\mathrm{C}$ & $*$ & $*$ & $\mathrm{~T}$ & $*$ & $*$ & AV4 & cytb5 \\
\hline COA21 & $*$ & $*$ & $*$ & $*$ & $*$ & $*$ & $*$ & $*$ & $*$ & $*$ & $*$ & $*$ & LA1 & cytb2,5 \\
\hline COA25 & $*$ & $*$ & $*$ & $*$ & $*$ & $*$ & $*$ & $*$ & $\mathrm{~A}$ & $*$ & $*$ & $\mathrm{C}$ & LG3 & cytb2,3,5 \\
\hline
\end{tabular}

Legende: Ref. $=$ Referenzsequenz, $\mathrm{A}=$ Adenin, $\mathrm{G}=$ Guanin, $\mathrm{C}=$ Cytosin, $\mathrm{T}=$ Thymin $*=$ stimmt mit der Referenzsequenz überein, nd $=$ nicht definiert, $\mathrm{Y}=\mathrm{C}$ oder $\mathrm{T}$

In der Probe COA5 konnte die Position 14472 nicht eindeutig bestimmt werden. Es zeigte sich in den einzelnen Sequenzierungen entweder ein T oder ein C. 
Eine Heteroplasmie trat nicht auf.

Es konnten insgesamt zwölf Haplotypen mit zwölf polymorphen Stellen in 45 typisierten Proben angetroffen werden. Sieben der Haplotypen konnten nur in überliefertem Material nachgewiesen werden. Sieben der Proben entstammen Fundnummern, die mehr als ein Probenstück enthielten, bzw. entstammten mehrfarbigen Textilien. In der Probe COA4 konnten für das Extrakt aus dem Vertebra und das aus dem Phalanges unterschiedliche Haplotypen typisiert werden (s. Tab. 43), so dass davon auszugehen ist, dass es sich hierbei um zwei unterschiedliche Individuen handelt. Die Extrakte der Probe JAA29 zeigten gleiche Haplotypen (s. Tab. 43), obwohl zwei rechte Pars petrosa sowie Dentes beprobt wurden. Es handelt sich hierbei also um mindestens zwei Individuen, die den gleichen Haplotyp aufweisen. Die Extrakte der Textilie GET13 weisen zwei unterschiedliche Haplotypen auf (s. Tab. 43). Für die roten Fasern konnte ein Haplotyp welcher der Vikunja-Gruppe angehört, für die schwarzen Fasern ein Haplotyp welcher der Gruppe Guanako angehört, typisiert werden. Die Textilie wurde also aus Wolle von mindestens zwei Individuen unterschiedlicher Typen hergestellt. Insgesamt weist das überlieferte Material eine höhere Diversität auf als das rezente Material, obwohl eine geringere Stichprobenanzahl vorlag.

Im hinteren Bereich des cytb (np 14595 - 14676) konnte für 39 Proben erfolgreich eine Amplifikation und Sequenzierung durchgeführt werden. In Abbildung 45 ist exemplarische ein Elektropherogramm der Probe GEA10 für die Fragmente 4 und 6 dargestellt.

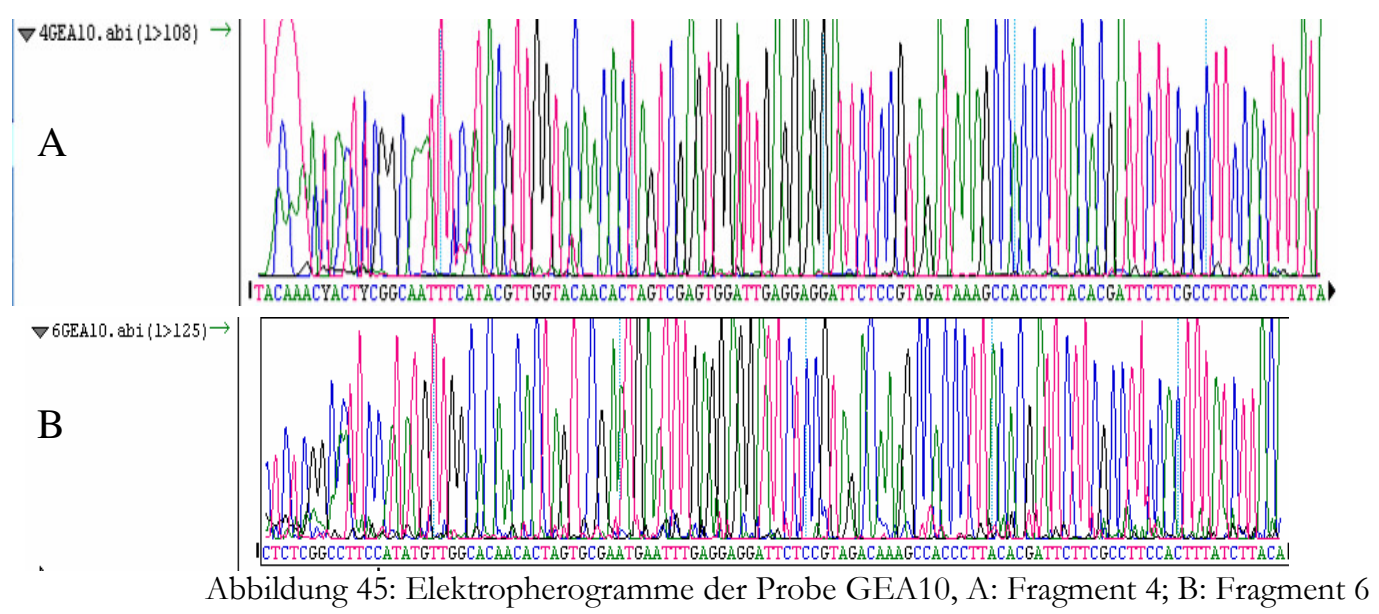

Es konnten 13 polymorphe Stellen detektiert und 13 Haplotypen definiert werden. Sieben der Haplotypen konnten ausschließlich in alten Proben typisiert werden. Insgesamt weist das hintere Fragment, bezogen auf die Gesamtlänge der untersuchten Sequenz, die höchste Nukleotid-Diversität auf.

Für die Extrakte der Probe JAA29 wurde der gleiche Haplotyp bestimmt (s. Tab. 44). Die Probe COA4 zeigte für das Extrakt aus einem Vertebra und das Extrakt aus einem Phalanges 
unterschiedliche Haplotypen. (s. Tab. 44) Die Extrakte der Probe GET13 wiesen ebenfalls unterschiedliche Ergebnisse auf (s. Tab. 44). Die braunen Fasern zeigten einen der VikunjaGruppe zugehörigen, die schwarzen Fasern einen der Guanako-Gruppe zugehörigen, Haplotypen. Dies zeigt, dass diese Textilie aus der Wolle von Tieren unterschiedlicher Typen gefertigt wurde. In Tabelle 44 sind die Haplotypen, ihre polymorphen Stellen sowie das hierfür analysierte Fragment aufgeführt.

Tabelle 44: Haplotypen und polymorphe Stellen im hinteren Bereich des cytb in überliefertem Material

\begin{tabular}{|c|c|c|c|c|c|c|c|c|c|c|c|c|c|c|c|}
\hline & 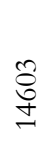 & $\begin{array}{l}\stackrel{N}{\sigma} \\
\stackrel{+}{ \pm}\end{array}$ & $\begin{array}{l}\text { त్ర } \\
\stackrel{+}{ \pm}\end{array}$ & $\begin{array}{l}\stackrel{+}{J} \\
\stackrel{+}{\leftrightarrows}\end{array}$ & 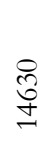 & 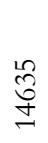 & 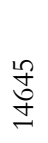 & \begin{tabular}{l}
$\infty$ \\
\multirow{+}{+}{} \\
$\stackrel{+}{ \pm}$
\end{tabular} & $\begin{array}{l}\overrightarrow{i n} \\
\stackrel{+}{+}\end{array}$ & $\begin{array}{l}\text { ñ } \\
\stackrel{2}{+} \\
\stackrel{+}{-}\end{array}$ & 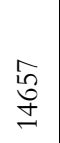 & $\begin{array}{l}\text { : } \\
\stackrel{0}{+} \\
\end{array}$ & $\begin{array}{l}\text { N } \\
\stackrel{+}{+}\end{array}$ & $\begin{array}{l}\text { a } \\
0 \\
\frac{0}{2} \\
\text { I }\end{array}$ & 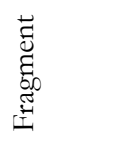 \\
\hline Ref. & $\mathrm{T}$ & G & $\mathrm{C}$ & $\mathrm{T}$ & $\mathrm{C}$ & $\mathrm{C}$ & $\mathrm{A}$ & $\mathrm{A}$ & $\mathrm{T}$ & $G$ & $\mathrm{~A}$ & $\mathrm{~A}$ & $\mathrm{C}$ & ALG1 & \\
\hline AOA8 & $*$ & $*$ & $*$ & $*$ & $*$ & * & $*$ & $*$ & $*$ & $*$ & $*$ & $*$ & $*$ & ALG1 & cytb4 \\
\hline JAA29a & $*$ & $*$ & $*$ & $*$ & $*$ & $*$ & $*$ & $*$ & $*$ & $*$ & $*$ & $*$ & $*$ & ALG1 & cytb2,4 \\
\hline JAA29b & $*$ & $*$ & $*$ & $*$ & $*$ & $*$ & * & $*$ & $*$ & $*$ & $*$ & $*$ & $*$ & ALG1 & cytb4 \\
\hline JAA29c & $*$ & $*$ & $*$ & $*$ & $*$ & $*$ & $*$ & $*$ & $*$ & $*$ & $*$ & $*$ & $*$ & ALG1 & cytb4 \\
\hline MSA2 & $*$ & $\mathrm{R}$ & $*$ & $*$ & $*$ & $*$ & $*$ & $*$ & $*$ & $*$ & $*$ & $*$ & $*$ & ALG1 & cytb2,4 \\
\hline MSA29 & $*$ & $*$ & $*$ & * & $*$ & * & * & $*$ & $*$ & * & $*$ & $*$ & * & ALG1 & cytb2,4 \\
\hline MSA30 & $*$ & $*$ & $*$ & $*$ & $*$ & $*$ & $*$ & $*$ & $*$ & $*$ & $*$ & $*$ & $*$ & ALG1 & cytb4,6 \\
\hline MSA31 & nd & nd & nd & nd & $*$ & $*$ & * & $*$ & $*$ & * & $*$ & * & * & ALG1 & cytb6 \\
\hline MST3b & $\mathrm{C}$ & $\mathrm{R}$ & $*$ & $*$ & $*$ & $*$ & $*$ & $*$ & $*$ & * & G & $G$ & $\mathrm{~T}$ & G6 & cytb4 \\
\hline MST11a & $\mathrm{C}$ & $\mathrm{A}$ & $*$ & $\mathrm{C}$ & $\mathrm{T}$ & $*$ & G & $G$ & $*$ & $*$ & $*$ & $*$ & $\mathrm{~T}$ & V1 & cytb4 \\
\hline GEA1 & $*$ & $*$ & $*$ & $*$ & $*$ & $*$ & $*$ & $*$ & $\mathrm{C}$ & $*$ & $*$ & $G$ & $\overline{\mathrm{T}}$ & G10 & cytb4,6 \\
\hline GEA5 & nd & nd & nd & nd & nd & $*$ & $*$ & $*$ & C & $*$ & $*$ & $\mathrm{G}$ & $\mathrm{T}$ & G10 & cytb4 \\
\hline GEA6 & $\mathrm{C}$ & $\mathrm{A}$ & $*$ & $*$ & $*$ & $*$ & $*$ & $*$ & $\mathrm{C}$ & $*$ & $*$ & $G$ & $\mathrm{~T}$ & G11 & cytb2,4 \\
\hline GEA7 & $\mathrm{C}$ & $\mathrm{A}$ & $*$ & $*$ & $*$ & $*$ & $*$ & $*$ & $*$ & $*$ & $*$ & $*$ & $*$ & L2 & cytb4 \\
\hline GEA8 & nd & nd & nd & $\mathrm{C}$ & $\mathrm{T}$ & $*$ & $\bar{G}$ & $G$ & $*$ & $*$ & $*$ & $*$ & $\overline{\mathrm{T}}$ & AV1 & cytb4,6 \\
\hline GEA9 & $\mathrm{C}$ & $\mathrm{A}$ & $*$ & $*$ & $*$ & $*$ & $*$ & $*$ & $*$ & $*$ & $*$ & $G$ & $\overline{\mathrm{T}}$ & G9 & cytb4 \\
\hline GEA10 & * & * & $*$ & $*$ & $*$ & $*$ & $*$ & $*$ & $*$ & $*$ & $*$ & * & $*$ & ALG1 & cytb4,6 \\
\hline GEA13 & $\mathrm{C}$ & $\mathrm{A}$ & $*$ & $\mathrm{C}$ & $\mathrm{T}$ & $*$ & G & G & $*$ & $*$ & $*$ & $*$ & $\mathrm{~T}$ & V1 & cytb4 \\
\hline GEA15 & $\mathrm{C}$ & $\mathrm{A}$ & $*$ & $*$ & $*$ & $*$ & $*$ & $*$ & $*$ & * & $*$ & $*$ & $*$ & L2 & cytb4 \\
\hline GET7a & $\mathrm{C}$ & $\mathrm{A}$ & nd & nd & nd & nd & nd & nd & nd & nd & nd & nd & nd & $?$ & cytb4 \\
\hline GET9d & $*$ & $*$ & $*$ & $*$ & $*$ & $*$ & $*$ & $*$ & $*$ & $*$ & $*$ & $*$ & $*$ & ALG1 & cytb4 \\
\hline GET10f & $\mathrm{C}$ & $\mathrm{A}$ & $*$ & $\mathrm{C}$ & $\mathrm{T}$ & $*$ & $G$ & G & $*$ & $*$ & $*$ & $*$ & $\overline{\mathrm{T}}$ & V1 & cytb4 \\
\hline GET13e & nd & $*$ & $*$ & $\mathrm{C}$ & $\mathrm{T}$ & $*$ & $G$ & $G$ & $*$ & $*$ & $*$ & $*$ & $\overline{\mathrm{T}}$ & AV1 & cytb4 \\
\hline GET 13f & nd & nd & nd & nd & $*$ & $*$ & $*$ & $*$ & $*$ & * & $*$ & $*$ & $*$ & ALG1 & cytb4 \\
\hline COA2 & $*$ & $*$ & $*$ & $*$ & $*$ & $*$ & $*$ & $*$ & * & $*$ & $*$ & $G$ & $\overline{\mathrm{T}}$ & LG1 & cytb2,4,6 \\
\hline COA4 & $\mathrm{C}$ & $\mathrm{A}$ & $*$ & $*$ & $*$ & $*$ & $*$ & $*$ & $\mathrm{C}$ & $*$ & $*$ & $G$ & $\mathrm{~T}$ & G8 & cytb2,4,6 \\
\hline COA4ph & nd & nd & nd & nd & $*$ & $*$ & $*$ & $*$ & $*$ & $*$ & $*$ & $*$ & $*$ & ALG1 & cytb4,6 \\
\hline COA5 & $*$ & $*$ & $*$ & $*$ & $*$ & $*$ & $*$ & $*$ & $*$ & $*$ & $*$ & $*$ & $*$ & ALG1 & cytb4,6 \\
\hline COA6 & $\mathrm{C}$ & $\mathrm{A}$ & $*$ & * & $*$ & $*$ & $*$ & $*$ & $*$ & $*$ & $*$ & $*$ & * & L2 & cytb2,4 \\
\hline COA7 & $\mathrm{C}$ & $\mathrm{A}$ & $*$ & $*$ & $*$ & $*$ & $*$ & $*$ & $*$ & * & $*$ & $\mathrm{G}$ & $\mathrm{T}$ & G9 & cytb4 \\
\hline COA8 & $\mathrm{C}$ & $\mathrm{A}$ & $*$ & $*$ & $*$ & $*$ & $*$ & $*$ & $*$ & $*$ & $*$ & $*$ & $*$ & L2 & cytb4 \\
\hline COA9 & nd & nd & nd & nd & $*$ & $*$ & $*$ & $*$ & $*$ & $\bar{A}$ & $*$ & $*$ & $*$ & L3 & cytb4 \\
\hline COA11 & $\mathrm{C}$ & $\mathrm{A}$ & * & $\mathrm{C}$ & $\mathrm{T}$ & $*$ & $G$ & G & $*$ & $*$ & $*$ & $*$ & $\mathrm{~T}$ & V1 & cytb4 \\
\hline \begin{tabular}{|l} 
COA12 \\
\end{tabular} & $\mathrm{C}$ & $*$ & $*$ & $\mathrm{C}$ & $\mathrm{T}$ & $*$ & $G$ & G & $*$ & * & $*$ & $\mathrm{G}$ & $\mathrm{T}$ & LV1 & cytb4 \\
\hline COA13 & $\mathrm{C}$ & $\mathrm{A}$ & $*$ & $*$ & $*$ & $*$ & $*$ & $*$ & $*$ & $*$ & $*$ & $\mathrm{G}$ & $\mathrm{T}$ & G9 & cytb2,4 \\
\hline COA14 & $*$ & $*$ & $*$ & $*$ & $*$ & * & $*$ & $*$ & $*$ & $*$ & $*$ & $*$ & $*$ & ALG1 & cytb4 \\
\hline COA15 & nd & nd & * & $*$ & $*$ & * & $*$ & $*$ & $*$ & $*$ & $*$ & $*$ & $*$ & ALG1 & cytb4,6 \\
\hline COA17 & $\mathrm{C}$ & $\mathrm{A}$ & * & * & * & * & * & $*$ & * & * & $*$ & $\bar{G}$ & $\overline{\mathrm{T}}$ & G9 & cytb2,4,6 \\
\hline \begin{tabular}{|l} 
COA18 \\
\end{tabular} & nd & nd & $\mathrm{T}$ & $\mathrm{C}$ & $\mathrm{T}$ & $\mathrm{T}$ & G & G & $*$ & $*$ & $*$ & $*$ & $\mathrm{~T}$ & V3 & cytb4,6 \\
\hline COA19 & $\mathrm{C}$ & $\mathrm{A}$ & $*$ & $*$ & $*$ & * & * & $*$ & $*$ & $*$ & $*$ & $*$ & * & L2 & cytb4,6 \\
\hline \begin{tabular}{|l|} 
COA20 \\
\end{tabular} & $\mathrm{C}$ & $\mathrm{A}$ & $*$ & $\mathrm{C}$ & $\mathrm{T}$ & $*$ & G & G & $*$ & $*$ & $*$ & $*$ & $\mathrm{~T}$ & V1 & cytb4,6 \\
\hline COA21 & $\mathrm{C}$ & $\mathrm{R}$ & * & $*$ & $*$ & $*$ & $*$ & * & $*$ & $*$ & $*$ & $*$ & $*$ & L2 & cytb2,4 \\
\hline COA25 & $\mathrm{C}$ & $\mathrm{R}$ & $*$ & * & $*$ & $*$ & * & $*$ & $*$ & * & $*$ & $*$ & * & $\mathrm{L} 2$ & cytb2,4 \\
\hline
\end{tabular}




\subsection{COI}

\subsubsection{Rezentes Material}

Die Amplifikation des Fragmentes war in allen 43 Proben möglich. Die Sequenzierung war jedoch nur für 41 der Proben erfolgreich. Es konnte eine sichere Auswertung eines 101 bp langen Fragments zwischen den Nukleotid-Positionen 5422-5523 erfolgen. Die typisierten Polymorphismen sind in Tabelle 45 aufgeführt.

Tabelle 45: Polymorphismen im Fragment des COI-Gens

\begin{tabular}{|c|c|c|c|c|c|c|}
\hline & $\underset{\mathscr{m}}{\stackrel{m}{n}}$ & $\stackrel{m}{\tilde{q}}$ & $\underset{n}{\text { f }}$ & $\underset{i}{\stackrel{f}{f}}$ & $\begin{array}{c}\hat{\infty} \\
\text { i⿱ } \\
i n\end{array}$ & $\underset{\dot{j}}{\stackrel{\partial}{n}}$ \\
\hline Ref. & $\mathrm{C}$ & $\bar{A}$ & A & $\mathrm{G}$ & $\mathrm{C}$ & $\mathrm{C}$ \\
\hline $\mathrm{La} 1$ & $*$ & $*$ & * & $*$ & * & $*$ \\
\hline La 2 & $*$ & * & $*$ & $*$ & $*$ & $*$ \\
\hline $\mathrm{La} 3$ & $*$ & $*$ & * & $*$ & $*$ & * \\
\hline La 4 & $*$ & * & $*$ & $*$ & $*$ & $*$ \\
\hline La 5 & $*$ & * & * & $*$ & $*$ & * \\
\hline $\mathrm{La} 6$ & $*$ & * & * & $*$ & $*$ & $*$ \\
\hline La 7 & $*$ & * & $\bar{G}$ & $\mathrm{~A}$ & $*$ & $*$ \\
\hline $\mathrm{La} 8$ & $*$ & $*$ & $*$ & $*$ & $*$ & * \\
\hline La 9 & $*$ & * & $\mathrm{G}$ & $*$ & $*$ & * \\
\hline La 10 & $*$ & $*$ & $\bar{G}$ & $*$ & $*$ & $*$ \\
\hline Gua 1 & $*$ & $*$ & $\mathrm{G}$ & $*$ & $*$ & $*$ \\
\hline Gua 2 & $*$ & * & $*$ & $\mathrm{~A}$ & $*$ & * \\
\hline Gua 3 & $*$ & * & $*$ & $\mathrm{~A}$ & * & * \\
\hline Alp1 & $*$ & $*$ & * & $\mathrm{A}$ & $\mathrm{T}$ & $\mathrm{T}$ \\
\hline Alp2 & $*$ & $*$ & $*$ & $\mathrm{~A}$ & $\overline{\mathrm{T}}$ & $\overline{\mathrm{T}}$ \\
\hline Alp3 & $*$ & $*$ & $*$ & $\mathrm{~A}$ & $\mathrm{~T}$ & $\mathrm{~T}$ \\
\hline Alp4 & $\mathrm{T}$ & * & $*$ & $\mathrm{~A}$ & $\overline{\mathrm{T}}$ & $\overline{\mathrm{T}}$ \\
\hline Alp5 & $\mathrm{T}$ & * & * & $\mathrm{A}$ & $\overline{\mathrm{T}}$ & $\overline{\mathrm{T}}$ \\
\hline Alp6 & $*$ & $*$ & $*$ & $\mathrm{~A}$ & $\mathrm{~T}$ & $\mathrm{~T}$ \\
\hline Alp7 & $*$ & $*$ & $*$ & $*$ & $*$ & $*$ \\
\hline Alp8 & $*$ & $*$ & $*$ & $\mathrm{~A}$ & $\mathrm{~T}$ & $\mathrm{~T}$ \\
\hline Alp9 & $*$ & * & $*$ & $*$ & $*$ & * \\
\hline Alp10 & $*$ & $*$ & $*$ & $*$ & $*$ & * \\
\hline Alp11 & $*$ & $*$ & $*$ & $*$ & $*$ & $*$ \\
\hline Alp12 & $*$ & $*$ & $*$ & $*$ & $*$ & $*$ \\
\hline Alp14 & $*$ & $*$ & $*$ & $\mathrm{~A}$ & $\mathrm{~T}$ & $\mathrm{~T}$ \\
\hline Vic1 & $\mathrm{T}$ & G & $*$ & $\mathrm{~A}$ & $\overline{\mathrm{T}}$ & $\overline{\mathrm{T}}$ \\
\hline Vic2 & $*$ & $*$ & $*$ & $\mathrm{~A}$ & $\mathrm{~T}$ & $\mathrm{~T}$ \\
\hline Vic3 & $*$ & * & $*$ & $\mathrm{~A}$ & $\mathrm{~T}$ & $\mathrm{~T}$ \\
\hline Vic4 & $*$ & $*$ & $*$ & $\mathrm{~A}$ & $\mathrm{~T}$ & $\mathrm{~T}$ \\
\hline Vic5 & $*$ & $*$ & $*$ & A & $\mathrm{T}$ & $\mathrm{T}$ \\
\hline Vic6 & $*$ & * & $*$ & $\mathrm{~A}$ & $\overline{\mathrm{T}}$ & $\overline{\mathrm{T}}$ \\
\hline Vic7 & $*$ & $*$ & $*$ & $\mathrm{~A}$ & $\mathrm{~T}$ & $\mathrm{~T}$ \\
\hline Vic8 & $*$ & $*$ & $*$ & $\mathrm{~A}$ & $\mathrm{~T}$ & $\mathrm{~T}$ \\
\hline Vic9 & $\mathrm{T}$ & $*$ & $*$ & $\mathrm{~A}$ & $\bar{T}$ & $\mathrm{~T}$ \\
\hline Vic10 & $\mathrm{T}$ & G & $*$ & $\mathrm{~A}$ & $\mathrm{~T}$ & $\mathrm{~T}$ \\
\hline Vic12 & $*$ & $*$ & $*$ & $\mathrm{~A}$ & $\overline{\mathrm{T}}$ & $\overline{\mathrm{T}}$ \\
\hline Vic13 & $*$ & * & $*$ & $\mathrm{~A}$ & $\mathrm{~T}$ & $\mathrm{~T}$ \\
\hline Vic14 & $*$ & $*$ & $*$ & $\mathrm{~A}$ & $\overline{\mathrm{T}}$ & $\bar{T}$ \\
\hline Vic15 & $\mathrm{T}$ & $\bar{G}$ & $*$ & $\mathrm{~A}$ & $\overline{\mathrm{T}}$ & $\overline{\mathrm{T}}$ \\
\hline Vic16 & $\mathrm{T}$ & $G$ & $*$ & $\mathrm{~A}$ & $\mathrm{~T}$ & $\mathrm{~T}$ \\
\hline
\end{tabular}

Legende: Ref. $=$ Referenz, $\mathrm{T}=$ Thymin, $\mathrm{G}=$ Guanin, $\mathrm{A}=$ Adenin, $\mathrm{C}=$ Cytosin. ${ }^{*}=$ wie Referenzsequenz

Die Mutter-Kind-Paare La3 und La5, La4 und La6 sowie Alp11 und Alp12, wiesen jeweils dieselben Polymorphismen auf. 
Insgesamt konnten in dem rezenten Material sieben Haplotypen und sechs polymorphen Stellen detektiert werden. Folgende Haplotypen wurden definiert (Tab. 46).

Tabelle 46: Haplotypen, ihre polymorphen Stellen und ihre Häufigkeit in phänotypischen Spezies

\begin{tabular}{|l|c|l|}
\hline Haplotyp & Polymorphismen & Häufigkeit \\
\hline LA1 & $-/-$ & $7 \mathrm{~L}, 4 \mathrm{~A}$ \\
\hline L1 & $5442 \mathrm{G}, 5472 \mathrm{~A}$ & $1 \mathrm{~L}$ \\
\hline LG1 & $5442 \mathrm{G}$ & $2 \mathrm{~L}, 1 \mathrm{G}$ \\
\hline G1 & $5472 \mathrm{~A}$ & $2 \mathrm{G}$ \\
\hline AV1 & $5472 \mathrm{~A}, 5487 \mathrm{~T}, 5499 \mathrm{~T}$ & $6 \mathrm{~A}, 10 \mathrm{~V}$ \\
\hline AV2 & $5431 \mathrm{~T}, 5472 \mathrm{~A}, 5487 \mathrm{~T}, 5499 \mathrm{~T}$ & $2 \mathrm{~A}, 1 \mathrm{~V}$ \\
\hline V1 & $5431 \mathrm{~T}, 5433 \mathrm{G}, 5472 \mathrm{~A}, 5487 \mathrm{~T}, 5499 \mathrm{~T}$ & $4 \mathrm{~V}$ \\
\hline
\end{tabular}

Legende: Polymorphismen: $\mathrm{T}=$ Thymin, $\mathrm{G}=$ Guanin, $\mathrm{A}=$ Adenin, $\mathrm{C}=$ Cytosin. Häufigkeit: $\mathrm{L}=$ Lama, $\mathrm{A}=$ Alpaka, $\mathrm{G}=$ Guanako, $\mathrm{V}=$ Vikunja

Anhand dieser Haplotypen wurde ein phylogenetischer Stammbaum mit der Software MEGA, unter den Bedingungen UPGMA bootsptrap, rekonstruiert (Abb. 46). Die bootstrap-Werte lagen bei $\sim 100 \%$

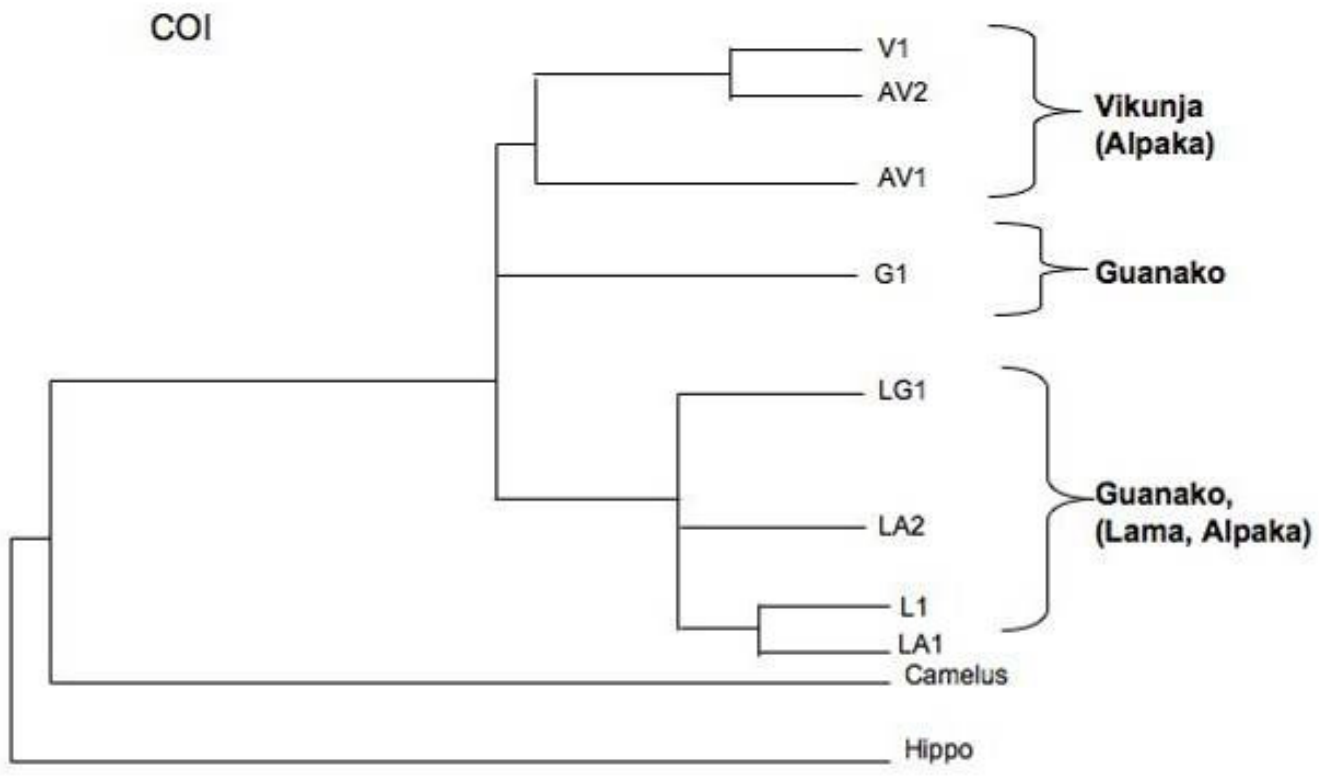

Abbildung 46: Phylogenetischer Stammbaum anhand der typisierten Sequenzen im COI (näheres im Text)

Es ergeben sich zwei Gruppen sowie eine Zwischengruppe (s. Abb. 46). Der Haplotyp G1 liegt insgesamt näher an dem der Vikunja-Gruppe. Die Mischgruppe aus Lamas, Alpakas und Guanakos bildet eine weitere Einheit. Die Gesamt-Distanz beträgt 0,025. 


\subsection{2 Überliefertes Material}

Die Amplifikation des Fragmentes war nur in solchen Proben erfolgreich, für die bereits reproduzierte Ergebnisse aus den Analysen des cytb-Gens vorlagen. Es konnte in 34 Proben amplifiziert werden. In zwei Knochen- und neun Textil-Proben, die im cytb-Gen gute Ergebnisse zeigten, konnte kein Amplifikat erzielt werden. Für jede Probe wurde aus zwei unterschiedlichen Extrakten je eine Amplifikation durchgeführt. In Abbildung 47 ist exemplarisch die Überprüfung des Amplifikationserfolges auf einem Agarosegel dargestellt.

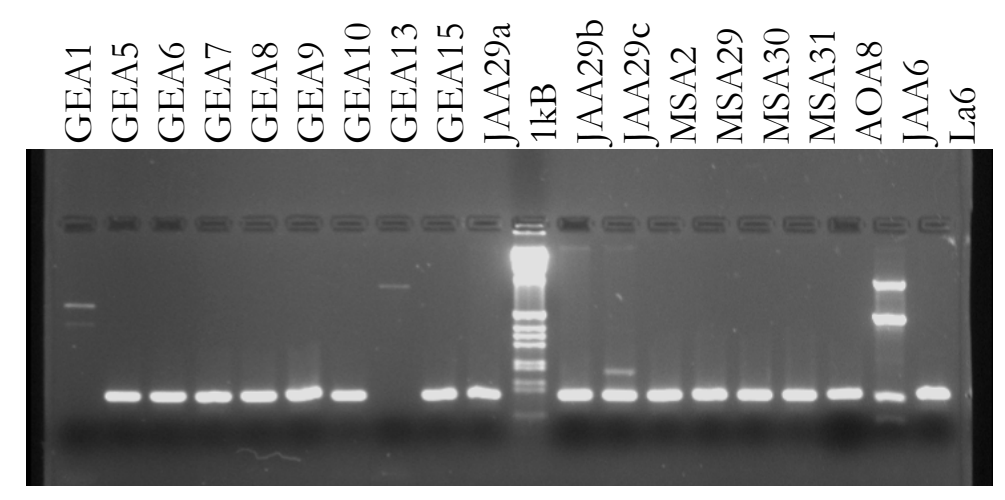

Abbildung 47: Agarosegel-Bild der PCR COI3

Für alle Proben mit Amplifikationserfolg konnte die Sequenzierung sowie die Auswertung des 101 bp langen Fragmentes durchgeführt werden. Mit Ausnahme der Probe JAA6, hier konnte zwar das gesuchte Produkt amplifiziert werden, jedoch lagen auch unspezifische Produkte vor (s. Abb. 47), die zu einer Mischsequenz führten, welche die Auswertung verhinderte, da sie die echten Sequenz überlagerte.

Es konnten keine Heteroplasmien festgestellt werden. In Abbildung 48 ist exemplarisch ein Elektropherogramm der Probe COA11 dargestellt.

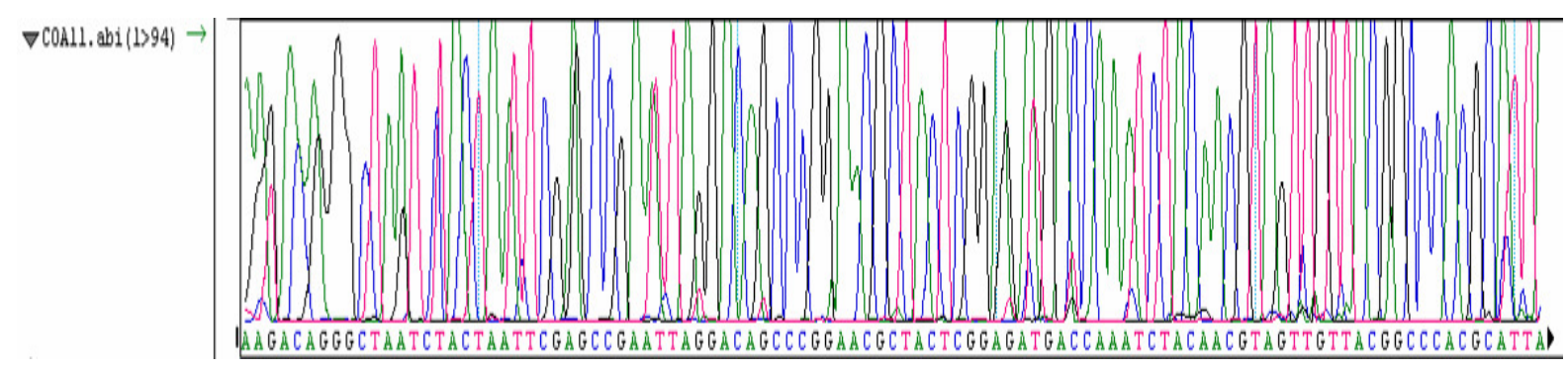

Abbildung 48: Sequenz-Elektropherogramm der Probe COA11 im Fragment COI 
Es konnten neun polymorphe Stellen, welche die Einteilung in neun Haplotypen erlaubte, festgestellt werden. In Tabelle 47 sind die erfolgreich typisierten Individuen, ihre polymorphen Stellen sowie ihre Haplotypen aufgeführt.

Tabelle 47: Polymorphe stellen und typisierte Haplotypen im Fragment des COI-Gens

\begin{tabular}{|c|c|c|c|c|c|c|c|c|c|c|}
\hline & $\underset{\tilde{v}}{\stackrel{\tilde{n}}{ }}$ & $\stackrel{\widetilde{f}}{\stackrel{n}{n}}$ & $\underset{i n}{F}$ & $\stackrel{\text { Y }}{\stackrel{H}{*}}$ & $\begin{array}{l}\text { ț } \\
\text { 㟧 }\end{array}$ & $\underset{\text { If }}{\stackrel{N}{N}}$ & $\begin{array}{l}+ \\
\stackrel{+}{+} \\
\stackrel{5}{n}\end{array}$ & 京 & হু & 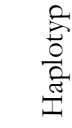 \\
\hline Ref. & $\mathrm{C}$ & $\mathrm{A}$ & $\mathrm{T}$ & $\mathrm{A}$ & $\mathrm{C}$ & $G$ & $\mathrm{~T}$ & $\mathrm{C}$ & $\mathrm{C}$ & LA1 \\
\hline AOA8 & $*$ & $*$ & $\mathrm{C}$ & $\mathrm{G}$ & $*$ & $*$ & $*$ & $*$ & $*$ & LG3 \\
\hline JAA29a & $*$ & $*$ & * & $\mathrm{G}$ & $*$ & $*$ & $*$ & $*$ & $*$ & LG1 \\
\hline JAA29b & $*$ & $*$ & $*$ & $G$ & $*$ & $*$ & $*$ & $*$ & $*$ & LG1 \\
\hline JAA29c & $*$ & $*$ & $*$ & $G$ & $*$ & $*$ & $*$ & $*$ & $*$ & LG1 \\
\hline MSA2 & $*$ & $*$ & $*$ & $*$ & $*$ & $*$ & $*$ & $*$ & $*$ & LA1 \\
\hline MSA29 & $*$ & $*$ & * & $*$ & $*$ & $*$ & $*$ & $*$ & $*$ & LA1 \\
\hline MSA31 & $*$ & $*$ & $*$ & $*$ & $*$ & $\mathrm{~A}$ & $*$ & $*$ & $*$ & G1 \\
\hline MST7a & $\mathrm{T}$ & $G$ & * & * & $*$ & $\mathrm{~A}$ & * & $\mathrm{T}$ & $\mathrm{T}$ & V1 \\
\hline GEA5 & $*$ & $*$ & $*$ & $G$ & $\mathrm{~T}$ & $*$ & $*$ & $\mathrm{~T}$ & $*$ & LG2 \\
\hline GEA6 & $*$ & $*$ & $*$ & $*$ & $*$ & $\mathrm{~A}$ & $*$ & $\mathrm{~T}$ & $*$ & G2 \\
\hline GEA7 & $*$ & $*$ & * & $*$ & $*$ & $*$ & $*$ & $*$ & $*$ & LA1 \\
\hline GEA8 & * & $*$ & * & * & $*$ & $\mathrm{~A}$ & * & $\mathrm{T}$ & $\mathrm{T}$ & AV1 \\
\hline GEA9 & $*$ & $*$ & $*$ & $*$ & $*$ & $\mathrm{~A}$ & $*$ & $*$ & $*$ & G1 \\
\hline GEA10 & $*$ & $*$ & $*$ & $G$ & $*$ & $*$ & $*$ & $*$ & $*$ & LG1 \\
\hline GEA15 & $*$ & $*$ & $*$ & $G$ & $*$ & $*$ & $*$ & $*$ & $*$ & LG1 \\
\hline GET7a & $*$ & $*$ & * & $*$ & $*$ & $*$ & $*$ & $*$ & $*$ & LA1 \\
\hline GET9d & $*$ & $*$ & $*$ & $*$ & $*$ & $\mathrm{~A}$ & $*$ & $\mathrm{~T}$ & $\mathrm{~T}$ & AV1 \\
\hline GET13a & $*$ & $*$ & $*$ & $*$ & $*$ & $\mathrm{~A}$ & $*$ & $\mathrm{~T}$ & $\mathrm{~T}$ & AV1 \\
\hline GET $13 \mathrm{f}$ & $*$ & $*$ & $*$ & $*$ & $*$ & $*$ & $*$ & $*$ & $*$ & LA1 \\
\hline $\mathrm{COA} 2$ & $*$ & $*$ & $*$ & $*$ & $*$ & $\mathrm{~A}$ & $*$ & $*$ & $*$ & G1 \\
\hline COA4 & $*$ & $*$ & * & $*$ & $*$ & $\mathrm{~A}$ & $*$ & $\mathrm{~T}$ & $*$ & G2 \\
\hline COA4ph & $*$ & $*$ & $*$ & $*$ & $*$ & $*$ & $*$ & $*$ & $*$ & LA1 \\
\hline COA5 & $*$ & $*$ & $*$ & $*$ & $*$ & $*$ & $*$ & $*$ & $*$ & LA1 \\
\hline COA6 & $*$ & $*$ & $*$ & $*$ & $*$ & $*$ & $*$ & $*$ & $*$ & LA1 \\
\hline COA7 & $*$ & $*$ & * & $*$ & $*$ & $\mathrm{~A}$ & $*$ & * & $*$ & G1 \\
\hline COA8 & $*$ & $*$ & $*$ & $G$ & $*$ & $*$ & $*$ & $*$ & $*$ & LG1 \\
\hline COA9 & $*$ & $*$ & $*$ & $*$ & $*$ & $*$ & $*$ & $*$ & $*$ & LA1 \\
\hline COA11 & $*$ & $*$ & $*$ & $*$ & $*$ & $*$ & $*$ & $*$ & $*$ & LA1 \\
\hline COA12 & $*$ & $*$ & $*$ & $*$ & $*$ & $\mathrm{~A}$ & $*$ & $\mathrm{~T}$ & $\mathrm{~T}$ & AV1 \\
\hline COA13 & $*$ & $*$ & $*$ & $*$ & $*$ & $\mathrm{~A}$ & * & $*$ & $*$ & G1 \\
\hline COA14 & $*$ & $*$ & $*$ & $G$ & $*$ & $*$ & $*$ & $*$ & $*$ & LG1 \\
\hline COA15 & $*$ & $*$ & $*$ & $*$ & $*$ & $*$ & $*$ & $*$ & $*$ & LA1 \\
\hline COA17 & $*$ & $*$ & $*$ & $*$ & $*$ & $\mathrm{~A}$ & $*$ & $*$ & $*$ & G1 \\
\hline COA18 & $*$ & $*$ & $*$ & $*$ & $*$ & $\mathrm{~A}$ & $\mathrm{C}$ & $\mathrm{T}$ & $\mathrm{T}$ & AV3 \\
\hline COA19 & $*$ & $*$ & $*$ & $*$ & $*$ & $*$ & $*$ & $*$ & $\mathrm{~T}$ & LA2 \\
\hline COA20 & $*$ & $*$ & $*$ & $*$ & $*$ & $\mathrm{~A}$ & $*$ & $\mathrm{~T}$ & $\mathrm{~T}$ & AV1 \\
\hline COA21 & $*$ & $*$ & $*$ & $*$ & $*$ & $*$ & $*$ & $*$ & $*$ & LA1 \\
\hline COA25 & $*$ & $*$ & $*$ & $*$ & $*$ & $*$ & $*$ & $*$ & $*$ & LA1 \\
\hline
\end{tabular}

Legende: Ref. $=$ Referenzsequenz, $\mathrm{A}=$ Adenin, $\mathrm{G}=$ Guanin, $\mathrm{C}=$ Cytosin, $\mathrm{T}=$ Thymin $*=$ stimmt mit der Referenzsequenz überein

Das überlieferte Material weist eine höhere Diversität gegenüber dem rezenten Material auf. Für die Proben JAA29, COA4 und GET13 konnten die Ergebnisse bezüglich Individuenanzahl (s. S. 107) bestätig werden. 
$4.3 \mathrm{Nd} 5$

\subsubsection{Rezentes Material}

Das Nd5-Fragment konnte in allen 43 rezenten Proben erfolgreich amplifiziert und typisiert werden. Insgesamt konnte der Bereich zwischen Nukleotidposition 12499-12610 (111bp) erfolgreich ausgewertet werden. Es konnten insgesamt zehn polymorphe Stellen detektiert werden. Diese sind in Tabelle 48 aufgeführt.

Tabelle 48: Polymorphismen im amplifizierten Bereich des Nd5-Gens

\begin{tabular}{|c|c|c|c|c|c|c|c|c|c|c|}
\hline & $\stackrel{ }{\stackrel{0}{n}}$ & 옴 & 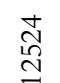 & 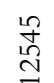 & $\begin{array}{l}\overrightarrow{i n} \\
\stackrel{2}{\mathfrak{n}}\end{array}$ & $\begin{array}{l}\text { ồ } \\
\stackrel{\leftrightarrow}{I}\end{array}$ & 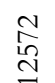 & $\begin{array}{l}\stackrel{n}{\bumpeq} \\
\stackrel{2}{a}\end{array}$ & $\begin{array}{l}\vec{\infty} \\
\stackrel{1}{\Im} \\
\end{array}$ & $\begin{array}{l}\stackrel{+}{\infty} \\
\stackrel{1}{N}\end{array}$ \\
\hline Ref. & G & G & A & $\mathrm{C}$ & G & $\mathrm{C}$ & C & G & $\mathrm{T}$ & G \\
\hline $\mathrm{La} 1$ & * & * & * & * & * & * & * & * & $*$ & * \\
\hline $\mathrm{La} 2$ & $*$ & $*$ & $*$ & $*$ & * & $*$ & $*$ & $*$ & $*$ & $*$ \\
\hline La 3 & * & * & * & $*$ & $*$ & $*$ & * & $*$ & * & $*$ \\
\hline $\mathrm{La} 4$ & * & * & * & * & * & * & * & * & * & $*$ \\
\hline La 5 & * & * & * & $*$ & $*$ & * & * & * & * & * \\
\hline $\mathrm{La} 6$ & * & $\mathrm{A}$ & * & * & * & * & * & $*$ & * & * \\
\hline La 7 & * & * & * & * & * & * & * & $*$ & $\mathrm{C}$ & * \\
\hline $\mathrm{La} 8$ & $*$ & $*$ & * & $*$ & $*$ & * & $*$ & * & * & $*$ \\
\hline La 9 & * & * & * & * & * & * & * & * & $\mathrm{C}$ & $*$ \\
\hline La 10 & $*$ & $*$ & $*$ & $*$ & $*$ & $*$ & $*$ & * & $\mathrm{C}$ & $*$ \\
\hline Gua 1 & * & * & * & * & * & * & * & $*$ & $\bar{C}$ & * \\
\hline Gua 2 & * & * & * & * & * & * & $\mathrm{T}$ & $*$ & $\mathrm{C}$ & * \\
\hline Gua 3 & $*$ & $*$ & $*$ & $*$ & $*$ & * & $\mathrm{T}$ & * & $\mathrm{C}$ & $*$ \\
\hline Alp1 & * & * & * & $\mathrm{T}$ & A & $\mathrm{T}$ & $\mathrm{T}$ & $\mathrm{A}$ & * & * \\
\hline Alp2 & * & $*$ & $*$ & $\mathrm{~T}$ & $\mathrm{~A}$ & $\mathrm{~T}$ & $\mathrm{~T}$ & A & $*$ & $*$ \\
\hline Alp3 & $*$ & $*$ & $*$ & $\mathrm{~T}$ & $\mathrm{~A}$ & $\mathrm{~T}$ & $\mathrm{~T}$ & A & $*$ & $*$ \\
\hline Alp4 & * & * & * & $\mathrm{T}$ & A & $\mathrm{T}$ & $\mathrm{T}$ & A & * & * \\
\hline Alp5 & $*$ & $*$ & $*$ & $\overline{\mathrm{T}}$ & $\bar{A}$ & $\overline{\mathrm{T}}$ & $\overline{\mathrm{T}}$ & $\mathrm{A}$ & $*$ & $*$ \\
\hline Alp6 & * & * & $\mathrm{G}$ & $\bar{T}$ & $\bar{A}$ & $\bar{T}$ & $\bar{T}$ & $\begin{array}{l}A \\
\end{array}$ & $*$ & * \\
\hline Alp7 & $*$ & $*$ & $*$ & $*$ & $*$ & $*$ & $*$ & $*$ & $*$ & $*$ \\
\hline Alp8 & $*$ & $*$ & $\mathrm{G}$ & $\bar{T}$ & $\bar{A}$ & $\bar{T}$ & $\overline{\mathrm{T}}$ & A & * & * \\
\hline Alp9 & * & * & * & * & * & * & * & $*$ & * & * \\
\hline Alp10 & $*$ & $*$ & $*$ & $*$ & $*$ & * & $*$ & * & $*$ & * \\
\hline Alp11 & $*$ & $*$ & $*$ & $*$ & $*$ & $*$ & $*$ & * & $\mathrm{C}$ & A \\
\hline Alp12 & $*$ & $*$ & * & $*$ & $*$ & $*$ & $*$ & * & $\mathrm{C}$ & $\mathrm{A}$ \\
\hline Alp13 & $*$ & $*$ & $\mathrm{G}$ & $\bar{T}$ & A & $\bar{T}$ & $\bar{T}$ & $\mathrm{~A}$ & $*$ & * \\
\hline Alp14 & * & * & G & $\mathrm{T}$ & A & $\mathrm{T}$ & $\mathrm{T}$ & A & * & * \\
\hline Vic1 & $*$ & $*$ & $*$ & $\overline{\mathrm{T}}$ & $\mathrm{A}$ & $\overline{\mathrm{T}}$ & $\overline{\mathrm{T}}$ & $\mathrm{A}$ & $*$ & * \\
\hline Vic2 & * & * & $\mathrm{G}$ & $\bar{T}$ & $\mathrm{~A}$ & $\mathrm{~T}$ & $\mathrm{~T}$ & A & $*$ & * \\
\hline Vic3 & $*$ & $*$ & $\mathrm{G}$ & $\mathrm{T}$ & A & $\bar{T}$ & $\bar{T}$ & A & * & * \\
\hline Vic4 & $*$ & $*$ & $\mathrm{G}$ & $\overline{\mathrm{T}}$ & $\mathrm{A}$ & $\overline{\mathrm{T}}$ & $\overline{\mathrm{T}}$ & A & $*$ & * \\
\hline Vic5 & * & * & G & $\mathrm{T}$ & A & $\mathrm{T}$ & $\mathrm{T}$ & A & * & * \\
\hline Vic6 & $*$ & $*$ & $\mathrm{G}$ & $\overline{\mathrm{T}}$ & $\bar{A}$ & $\overline{\mathrm{T}}$ & $\mathrm{T}$ & $\mathrm{A}$ & $*$ & * \\
\hline Vic7 & * & * & $\mathrm{G}$ & $\bar{T}$ & $\mathrm{~A}$ & $\mathrm{~T}$ & $\mathrm{~T}$ & \begin{tabular}{|l|}
$A$ \\
\end{tabular} & $*$ & * \\
\hline Vic8 & $*$ & $*$ & $\mathrm{G}$ & $\bar{T}$ & $\mathrm{~A}$ & $\bar{T}$ & $\mathrm{~T}$ & $\mathrm{~A}$ & * & * \\
\hline Vic9 & $*$ & $*$ & $\mathrm{G}$ & $\overline{\mathrm{T}}$ & $\bar{A}$ & $\overline{\mathrm{T}}$ & $\mathrm{T}$ & $\mathrm{A}$ & * & * \\
\hline Vic10 & C & * & * & $\mathrm{T}$ & A & $\mathrm{T}$ & $\mathrm{T}$ & A & * & * \\
\hline Vic11 & $*$ & $*$ & $*$ & $\mathrm{~T}$ & A & $\mathrm{T}$ & $\mathrm{T}$ & $\mathrm{A}$ & $*$ & * \\
\hline Vic12 & * & * & $\mathrm{G}$ & $\overline{\mathrm{T}}$ & $\mathrm{A}$ & $\overline{\mathrm{T}}$ & $\mathrm{T}$ & \begin{tabular}{|l|}
$A$ \\
\end{tabular} & * & * \\
\hline Vic13 & $*$ & $*$ & $\mathrm{G}$ & $\overline{\mathrm{T}}$ & $\bar{A}$ & $\overline{\mathrm{T}}$ & $\mathrm{T}$ & $\mathrm{A}$ & * & * \\
\hline Vic14 & $*$ & $*$ & $\mathrm{G}$ & $\overline{\mathrm{T}}$ & $\bar{A}$ & $\overline{\mathrm{T}}$ & $\mathrm{T}$ & $\mathrm{A}$ & * & * \\
\hline Vic15 & $*$ & $*$ & $*$ & $\bar{T}$ & A & $\mathrm{T}$ & $\mathrm{T}$ & $\mathrm{A}$ & $*$ & $*$ \\
\hline Vic16 & * & * & * & $\overline{\mathrm{T}}$ & $\mathrm{A}$ & $\mathrm{T}$ & $\mathrm{T}$ & $\mathrm{A}$ & * & * \\
\hline
\end{tabular}

Legende: Ref. $=$ Referenzsequenz, $\mathrm{A}=$ Adenin, $\mathrm{G}=$ Guanin, $\mathrm{C}=$ Cytosin, $\mathrm{T}=$ Thymin $*=$ stimmt mit der Referenzsequenz überein 
Die Mutter-Kind-Paare La3 und La5, La4 und La6 sowie Alp11 und Alp12, wiesen jeweils die gleichen Polymorphismen auf.

Aus den Sequenzen ergab sich die Bestimmung von acht Haplotypen. Die Benennung orientierte sich an der Mehrzahl phänotypischer Spezies, in denen diese typisiert werden konnten. In Tabelle 49 sind die Haplotypen, ihre polymorphen stellen und ihr Vorkommen gelistet.

Tabelle 49: Definition der Haplotypen und ihr Vorkommen

\begin{tabular}{|c|c|c|}
\hline Haplotyp & Polymorphismen & Vorkommen \\
\hline LA1 & $-/-$ & $7 \mathrm{~L}, 3 \mathrm{~A}$ \\
\hline L1 & $516 \mathrm{~A}$ & $1 \mathrm{~L}$ \\
\hline LG1 & $581 \mathrm{C}$ & $3 \mathrm{~L}, 1 \mathrm{G}$ \\
\hline G1 & $572 \mathrm{~T}, 581 \mathrm{C}$ & $2 \mathrm{G}$ \\
\hline AV1 & $545 \mathrm{~T}, 551 \mathrm{~A}, 569 \mathrm{~T}, 572 \mathrm{~T}, 575 \mathrm{~A}$ & $5 \mathrm{~A}, 4 \mathrm{~V}$ \\
\hline AV2 & 524G, 545T, 551A, 569T, 572T, 575A & $4 \mathrm{~A}, 11 \mathrm{~V}$ \\
\hline A1 & 581C, 584A & $2 \mathrm{~A}$ \\
\hline V1 & 510C, 545T, 551A, 569T, 572T, 575A & $1 \mathrm{~V}$ \\
\hline
\end{tabular}

Legende: Polymorphismen: $\mathrm{T}=$ Thymin, $\mathrm{G}=$ Guanin, $\mathrm{A}=$ Adenin, $\mathrm{C}=$ Cytosin. Vorkommen: $\mathrm{L}=$ Lama, $\mathrm{A}=$ Alpaka, $\mathrm{G}=$ Guanako, $\mathrm{V}=$ Vikunja

Anhand dieser Haplotypen wurde ein genetischer Stammbaum mit Hilfe der Software MEGA und der Methode UPGMA bootstrap erstellt (Abb. 49). Die bootstrap-Werte lagen bei $\sim 95 \%$.

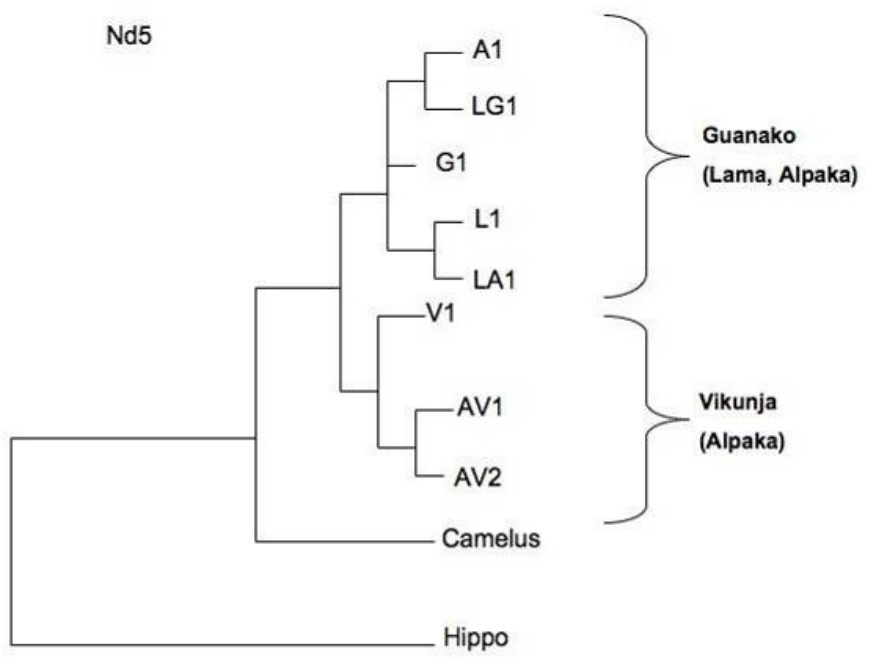

Abbildung 49: Stammbaum aufgrund der Sequenzvariabilität im Nd5-Gen

Die genetische Distanz der gefundenen Haplotypen kann mit 0,032 angegeben werden. Eine Unterteilung erfolgt in die Großgruppen Vikunja und Guanako.

\subsection{2 Überliefertes Material}

In insgesamt 28 Proben konnte das Fragment des Nd5-Gens amplifiziert werden, 25 davon waren Knochen-Proben, drei textile Proben. Die Amplifikation war nur in Proben erfolgreich, 
die bereits im cytb- und COI-Gen typisiert werden konnten. In Abbildung 50 ist exemplarisch der Amplifikationserfolg dargestellt.

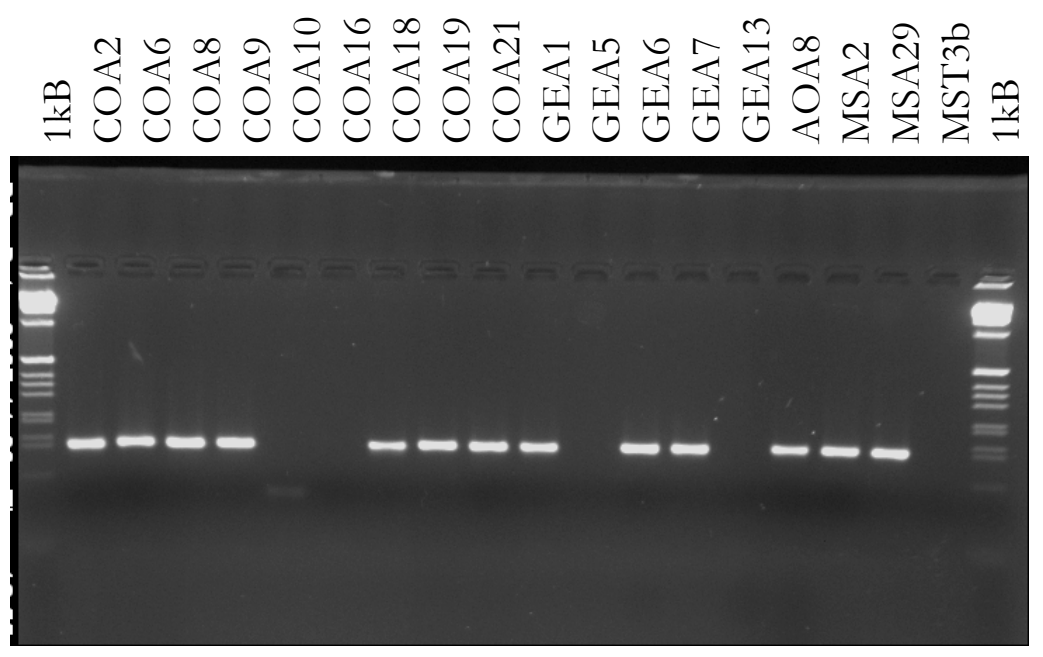

Abbildung 50: Amplifikationsprodukte auf einem Agarosegel der PCR Nd5 4

In allen Proben in denen das Produkt erfolgreich amplifiziert wurde, waren die Sequenzierung sowie die Auswertung des 111 bp langen Fragmentes möglich. Die Probe GEA1 zeigte trotz mehrfach erfolgreicher Amplifikation Sequenzen, deren Basen nicht eindeutig zuzuordnen waren, und konnte nicht ausgewertet werden. In Abbildung 51 ist exemplarisch das Elektropherogramm der Probe COA4 zu sehen.

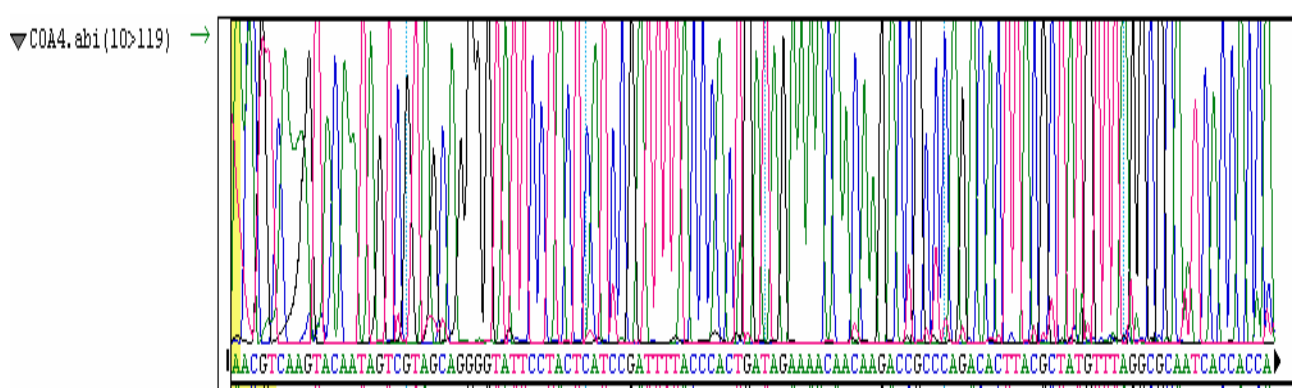

Abbildung 51: Elektropherogramm der Probe COA4

Es konnten insgesamt zehn polymorphe Stellen und acht Haplotypen festgestellt werden (Tab. 50). Hierunter befanden sich drei Haplotypen, die nur in dem überlieferten Material nachgewiesen werden konnten. In der Probe GEA10 konnte eine Heteroplasmie an der Position 12548 festgestellt werden. Diese wurde in allen Sequenzierungen (2 forward, 2 reverse) gleichermaßen festgestellt. Für die Proben COA4 und JAA29 konnten die Ergebnisse bezüglich der Individuenanzahl bestätigt werden (s. S. 107). 
Tabelle 50: Polymorphismen und Haplotypen des überlieferten Materials für das Nd5-Gen

\begin{tabular}{|c|c|c|c|c|c|c|c|c|c|c|c|}
\hline & 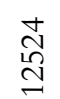 & $\stackrel{\widehat{N}}{\stackrel{\overbrace{}}{\sim}}$ & 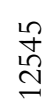 & $\begin{array}{l}\sqrt{n} \\
\stackrel{2}{ } \\
\stackrel{7}{2}\end{array}$ & 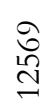 & $\begin{array}{l}\mathfrak{N} \\
\stackrel{2}{\Omega} \\
\stackrel{n}{-}\end{array}$ & $\begin{array}{l}10 \\
\stackrel{10}{\Omega} \\
\stackrel{1}{\simeq}\end{array}$ & $\begin{array}{l}\hat{N} \\
\text { in } \\
\stackrel{N}{-}\end{array}$ & $\begin{array}{l}\vec{\infty} \\
\stackrel{\leftrightarrow}{\Omega} \\
\stackrel{్}{్}\end{array}$ & 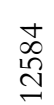 & $\begin{array}{l}\text { 0 } \\
\text { त } \\
\text { I }\end{array}$ \\
\hline Ref. & A & $\mathrm{C}$ & $\mathrm{C}$ & G & $\mathrm{C}$ & $\mathrm{C}$ & G & $\mathrm{C}$ & $\mathrm{T}$ & G & LA1 \\
\hline JAA29a & $*$ & $*$ & $*$ & $*$ & $*$ & * & $*$ & $*$ & $\mathrm{C}$ & $*$ & LG1 \\
\hline JAA29b & $*$ & * & $*$ & $*$ & * & * & * & $*$ & $\mathrm{C}$ & $*$ & LG1 \\
\hline JAA29c & $*$ & $*$ & $*$ & $*$ & $*$ & $*$ & $*$ & $*$ & $\mathrm{C}$ & $*$ & LG1 \\
\hline MSA2 & $*$ & $*$ & $*$ & $*$ & $*$ & $*$ & $*$ & $*$ & $*$ & $*$ & LA1 \\
\hline MSA29 & $*$ & $*$ & $*$ & $*$ & $*$ & $*$ & $*$ & $*$ & $*$ & $*$ & LA1 \\
\hline MSA30 & $*$ & $*$ & $*$ & $*$ & $*$ & $*$ & $*$ & $*$ & $*$ & $*$ & LA1 \\
\hline MSA31 & $*$ & $*$ & $*$ & $*$ & $*$ & $*$ & $\mathrm{~T}$ & * & $\mathrm{C}$ & $*$ & G1 \\
\hline MST13e & G & $*$ & $\mathrm{~T}$ & $\mathrm{~A}$ & $\mathrm{~T}$ & $\mathrm{~T}$ & $\mathrm{~A}$ & $*$ & $*$ & $*$ & AV2 \\
\hline GEA6 & * & $*$ & $*$ & $*$ & $*$ & $*$ & $*$ & $*$ & $*$ & $*$ & LA1 \\
\hline GEA8 & $G$ & $*$ & $\mathrm{~T}$ & $\mathrm{~A}$ & $\mathrm{~T}$ & $\mathrm{~T}$ & $\mathrm{~A}$ & $*$ & $*$ & $*$ & AV2 \\
\hline GEA10 & $*$ & $*$ & $*$ & $*$ & $*$ & $*$ & $*$ & $*$ & $\mathrm{C}$ & $\mathrm{R}$ & A1 \\
\hline GEA15 & $*$ & $*$ & $*$ & $*$ & $*$ & $*$ & $*$ & $*$ & $\mathrm{C}$ & $*$ & LG1 \\
\hline GET9d & $*$ & $*$ & * & $*$ & $*$ & * & $*$ & $*$ & $*$ & $*$ & LA1 \\
\hline GET 13f & $*$ & $*$ & $*$ & $*$ & $*$ & $*$ & $*$ & $*$ & $*$ & $*$ & LA1 \\
\hline COA2 & $*$ & $*$ & $*$ & $*$ & $*$ & $*$ & $*$ & $*$ & $*$ & $*$ & LA1 \\
\hline COA4 & $*$ & $*$ & $*$ & $*$ & $*$ & $*$ & $*$ & $*$ & $*$ & $*$ & LA1 \\
\hline COA4ph & $*$ & $*$ & $*$ & $*$ & $*$ & $*$ & $*$ & $*$ & $\mathrm{C}$ & $*$ & LG1 \\
\hline COA5 & $*$ & $*$ & $*$ & $*$ & $*$ & $*$ & $*$ & $\mathrm{~T}$ & $*$ & $*$ & L2 \\
\hline COA6 & $*$ & $*$ & $*$ & $*$ & $*$ & $*$ & $*$ & $*$ & $*$ & $*$ & LA1 \\
\hline COA8 & $*$ & $*$ & $*$ & $*$ & $*$ & $*$ & $*$ & $*$ & $\mathrm{C}$ & $*$ & LG1 \\
\hline COA9 & $*$ & $*$ & $*$ & $*$ & $*$ & $*$ & $*$ & $*$ & $*$ & $*$ & LA1 \\
\hline COA11 & $*$ & $*$ & $*$ & $*$ & $*$ & $*$ & $*$ & $*$ & $\mathrm{C}$ & $*$ & LG1 \\
\hline COA12 & $G$ & $*$ & $\mathrm{~T}$ & A & $\mathrm{T}$ & $\mathrm{T}$ & $\mathrm{A}$ & $*$ & $*$ & $\mathrm{~A}$ & AV3 \\
\hline COA13 & $*$ & $*$ & $*$ & $*$ & $*$ & $*$ & $*$ & $*$ & $*$ & $*$ & LA1 \\
\hline COA14 & $*$ & $\mathrm{~T}$ & $*$ & $*$ & $*$ & $*$ & $*$ & $*$ & C & $*$ & L3 \\
\hline COA15 & $*$ & $*$ & $*$ & $*$ & $*$ & $*$ & $*$ & $*$ & $\mathrm{C}$ & $*$ & LG1 \\
\hline COA18 & G & $*$ & $\mathrm{~T}$ & $\mathrm{~A}$ & $\mathrm{~T}$ & $\mathrm{~T}$ & $\mathrm{~A}$ & * & $*$ & $*$ & AV2 \\
\hline COA19 & $*$ & $*$ & $*$ & $*$ & $*$ & $*$ & $*$ & * & $\mathrm{C}$ & $*$ & LG1 \\
\hline COA20 & G & $*$ & $\mathrm{~T}$ & $\mathrm{~A}$ & $\mathrm{~T}$ & $\mathrm{~T}$ & A & * & $*$ & $*$ & AV2 \\
\hline COA21 & $*$ & $*$ & $*$ & $*$ & $*$ & $*$ & $*$ & $*$ & $*$ & $*$ & LA1 \\
\hline COA25 & $*$ & $*$ & $*$ & $*$ & $*$ & $*$ & $*$ & $*$ & $\mathrm{C}$ & $*$ & LG1 \\
\hline
\end{tabular}

Legende: Ref. = Referenzsequenz, $\mathrm{R}=\mathrm{A}$ oder $\mathrm{G}, \mathrm{A}=$ Adenin, $\mathrm{G}=$ Guanin, $\mathrm{C}=$ Cytosin, $\mathrm{T}=$ Thymin $*=$ stimmt mit der Referenzsequenz überein

Bezüglich der Nukleotid-Diversität zeigte sich kein Unterschied zwischen rezentem und überliefertem Material. Bezüglich der Anzahl gefundener Haplotypen (8/28 gegenüber 8/43) zeigen sich die überlieferten Proben, gemessen an der Stichprobe, jedoch diverser.

\subsection{2srRNA-Gen}

\subsubsection{Rezentes Material}

Die Amplifikation und die Analyse mit dem Hyb-Probe-System konnte nur in 26 der 43 rezenten Proben erfolgreich durchgeführt werden. Auch nach Erhöhen des DNA-Einsatzes und Optimierungsversuchen der Reaktionsparameter, konnte keine Steigerung des Amplifikationserfolges erreicht werden. 
Die SNPs der Proben, die im Sondensysteme Ergebnisse erbrachten, sind in Tabelle 51 dargestellt.

Tabelle 51: Detektierte SNPs im 12srRNA-Gen

\begin{tabular}{|l|l|l|l|l|}
\hline & np 189 & np 193 & np 247 & Spezies \\
\hline La 1 & A & C & A & Lama \\
\hline La 2 & A & C & A & Lama \\
\hline La 3 & A & C & A & Lama \\
\hline La 4 & A & C & A & Lama \\
\hline La 5 & A & C & A & Lama \\
\hline La 6 & A & C & A & Lama \\
\hline Gua 2 & A & T & A & Guanako \\
\hline Alp2 & A & T & G & Alpaka \\
\hline Alp3 & A & T & G & Alpaka \\
\hline Alp4 & A & T & G & Alpaka \\
\hline Alp5 & A & T & G & Alpaka \\
\hline Alp6 & G & T & G & Vikunja \\
\hline Alp7 & A & C & A & Lama \\
\hline Alp8 & G & T & G & Vikunja \\
\hline Alp9 & A & C & A & Lama \\
\hline Alp10 & A & C & A & Lama \\
\hline Alp11 & A & C & A & Lama \\
\hline Alp12 & A & C & A & Lama \\
\hline Vic2 & G & T & G & Vikunja \\
\hline Vic3 & G & T & G & Vikunja \\
\hline Vic4 & G & T & G & Vikunja \\
\hline Vic5 & G & T & G & Vikunja \\
\hline Vic6 & G & T & G & Vikunja \\
\hline Vic7 & G & T & G & Vikunja \\
\hline Vic8 & G & T & G & Vikunja \\
\hline Vic9 & G & T & G & Vikunja \\
\hline
\end{tabular}

Legende: $\mathrm{np}=$ Nukleotidposition, $\mathrm{A}=$ Adenin, $\mathrm{G}=$ Guanin, $\mathrm{C}=$ Cytosin, $\mathrm{T}=$ Thymin

Lamas, Guanakos und Vikunjas konnten sicher als solche bestimmt werden. Vier der elf Alpakas konnten als solche bestimmt werden. Dies entspricht einer Bestimmungsrate für Alpakas von nur $36 \%$.

\subsection{2 Überliefertes Material}

Trotz des schlechten Typisierungserfolges in rezentem Material, fand einmalig eine Amplifikation in Extrakten des überlieferten Materials statt. In elf Proben konnte das Produkt, unter dem Einsatz von $10 \mu \mathrm{l}$ DNA-Extrakt, amplifiziert werden.

Die Cp-Werte (Wert an dem die Fluoreszenz des amplifizierten Produktes erstmalig signifikant ansteigt) lagen zwischen 29 (COA17) und 40 (COA2), der Cp-Wert der rezenten Probe La6, von der lediglich $1 \mu$ l DNA Extrakt eingesetzt wurde, betrug 24 (s. Abb. 52). Der Cp-Wert kann als Maß für den DNA-Gehalt gesehen werden, so dass davon auszugehen ist, dass in den Proben des überlieferten Materials eine geringe Anzahl Zielsequenzen vorlag. Die Sonde, welche die Polymorphismen 189 und 193 detektiert, fiel vollständig aus. Die Sonde zur 
Detektion des Polymorphismus 247 erbrachte auswertbare Ergebnisse. In Abbildung 52 ist exemplarisch das Schmelzprofil der Proben dargestellt.
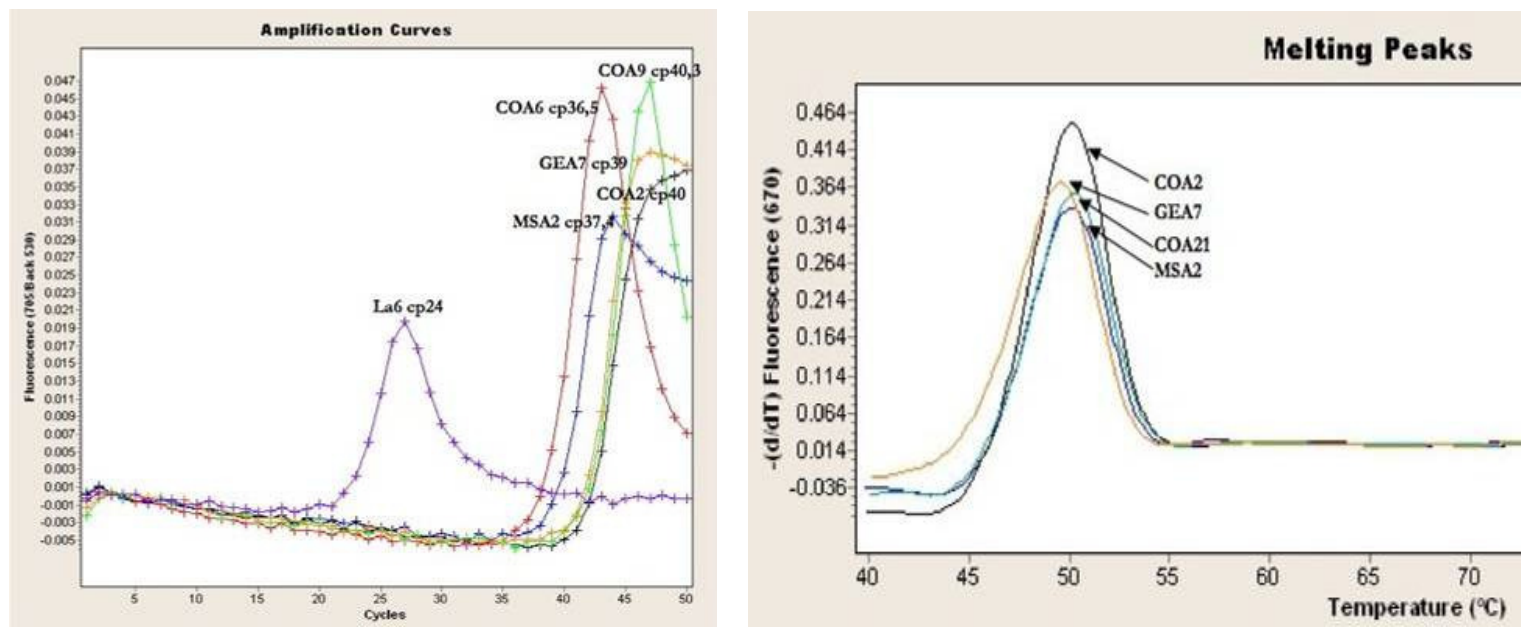

Abbildung 52: Amplifikationskurve (li.) uns Schmelzkurve (re.) der Analyse des 12srRNA-Gens in überliefertem Material

Die Schmezltemperatur der Proben betrug immer $50^{\circ} \mathrm{C}$, ebenso wie in der mitgeführten Kontrollprobe La6, so dass von der Ausprägung der Base Adenin an der Position 247 auszugehen ist. Da diese nur in phänotypischen Lamas und Guanakos vertreten ist und diese allein durch die Position 193 unterschieden werden können (s. Kap. 3.4.4), wurde für die Proben eine Amplifikation des Fragmentes mit einer konventionellen PCR durchgeführt und anschließend ein Restriktionsverdau mit dem Enzym SfcI durchgeführt.

In Abbildung 53 ist die Überprüfung des Amplifikationserfolges und des enzymatischen Verdaus auf einem Agarosegel dargestellt.
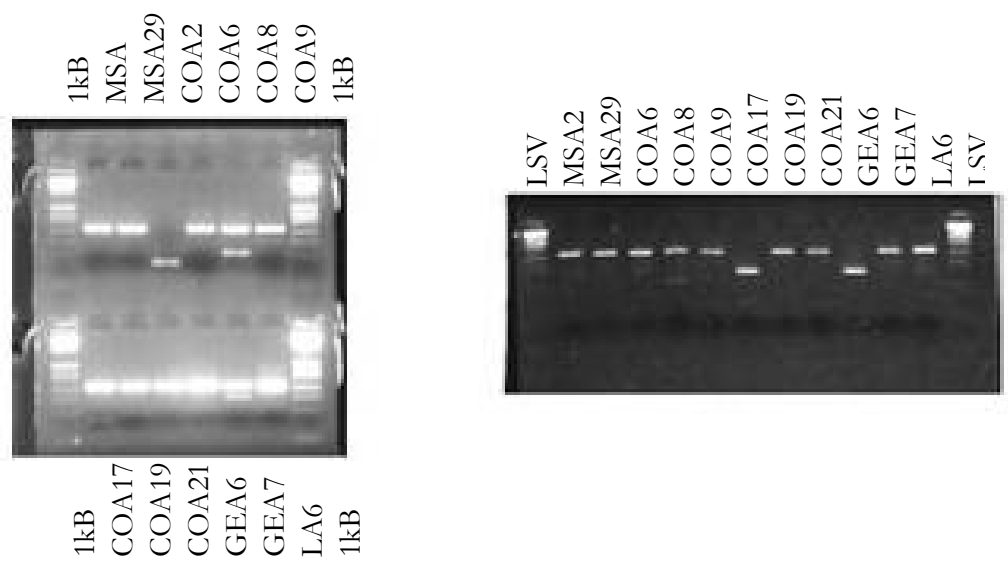

Abbildung 53: links: Überprüfung des Amplifikationserfolg; rechts: Überprüfung des Restriktionsverdaus

Für die Probe COA2, die in der PCR auf dem LightCycler den schlechtesten Cp-Wert aufwies, konnte in der konventionellen PCR kein Produkt amplifiziert werden. Bei dem Restriktions- Verdau zeigten nur die Proben COA17 und GEA6 das geschnittene Produkt (s. Abb. 53) und sind damit als Guanakos anzusprechen. Die Produkte der Proben MSA2, 
MSA29, COA6, COA8, COA9, COA19, COA21, GEA6 und GEA7 wurden nicht geschnitten (s. Abb. 53) und sind damit als Lamas zu bestimmen. In beiden Fällen wäre auch die Spezies Alpaka möglich (siehe Kap. 3.4.4 und 4.4.1).

\subsection{Mikrosatelliten}

\subsubsection{Rezentes Material}

In allen 43 Proben konnte autosomale DNA amplifiziert werden. Die Amplifikation aller Proben wurde viermal, aus zwei unterschiedlichen Extrakten, durchgeführt. In Abbildung 54 sind exemplarisch die Elektropherogramme und die typisierten Allele der Proben Alp2 und La3 dargestellt.

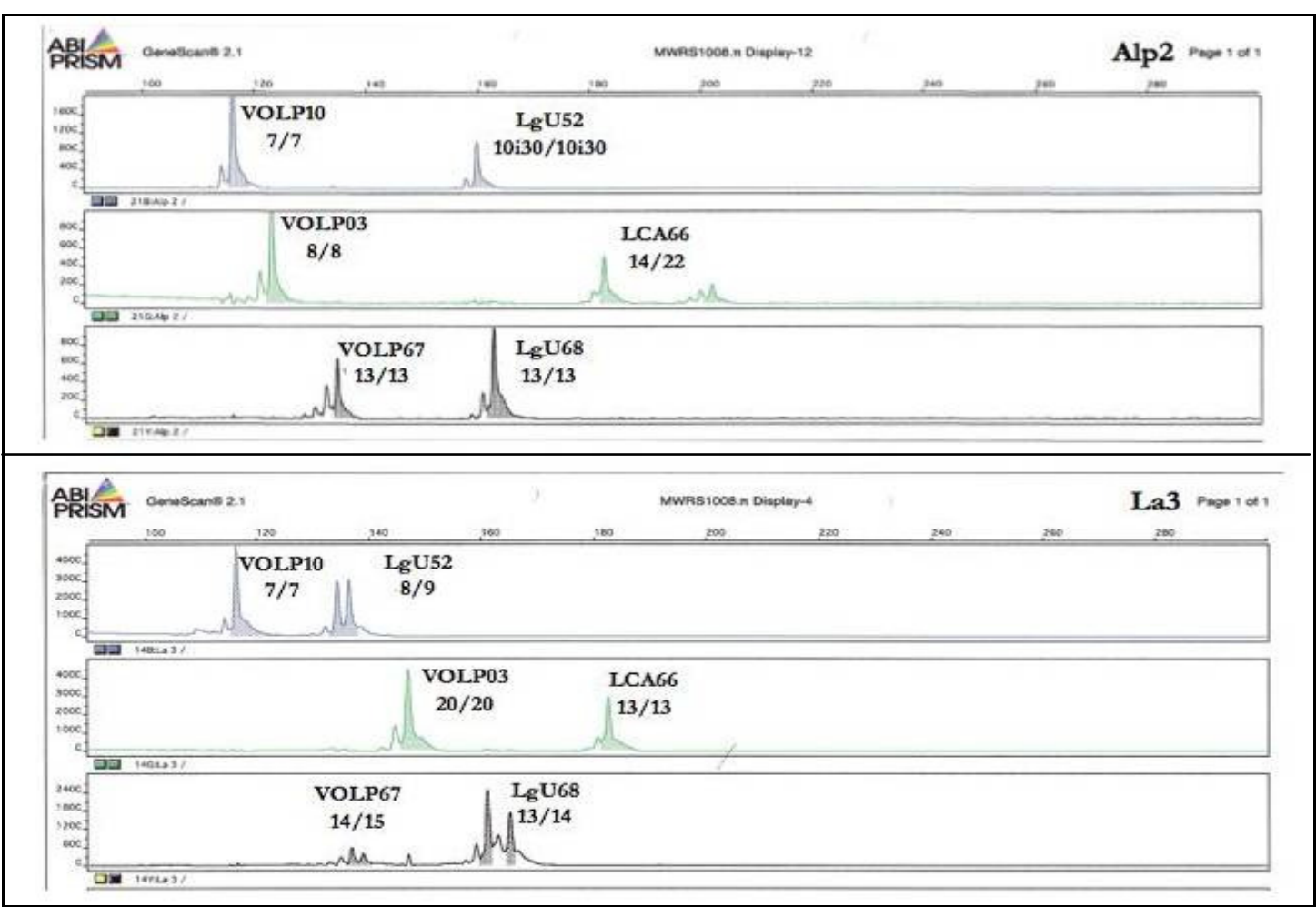

Abbildung 54: Elektropherogramme der Proben Alp2 (oben) und La3 (unten)

Die Systeme VOLP10, LgU52, VOLP03 und LgU68 wiesen zwar Stotter-Peaks auf, jedoch war hier immer eine sichere Zuordnung der Allele möglich. Im System LCA66 stieg die Rate des Stotterns mit zunehmender Allellänge. Der Marker VOLP67 stellte sich trotz kleiner Fragmentlänge, als stark stotternd heraus. In beiden Systemen war jedoch eine Zuordnung der Allele möglich, da hier zwar Vor-Stotterer angetroffen wurden, aber nie Nach-Stotterer, so dass zum Beispiel der hintere Peak im Marker VOLP67 der Probe La3 als Allel 15 angesprochen werden konnte. Die sicher typisierten Allele der einzelnen Proben sind in Tabelle 52 gelistet, die Ergebnisse der Einzeltypisierungen sind im Appendix aufgeführt. 
Tabelle 52: Typisierungsergebnisse mit der Lamaplex an rezentem Material

\begin{tabular}{|c|c|c|c|c|c|c|}
\hline & VOLP10 & LgU52 & VOLP03 & LCA66 & VOLP67 & LgU68 \\
\hline La1 & $7 / 7$ & $9 / 9$ & $20 / 22$ & $-/-$ & $-/-$ & $13 / 13$ \\
\hline La2 & $7 / 7$ & $8 / 8$ & $20 / 20$ & $13 / 13$ & $11 / 12$ & $11 / 13$ \\
\hline La3 & $7 / 7$ & $8 / 9$ & $20 / 20$ & $13 / 13$ & $14 / 15$ & $13 / 14$ \\
\hline $\mathrm{La} 4$ & $7 / 7$ & $8 / 9$ & $20 / 20$ & $13 / 15$ & $11 / 16$ & $13 / 20$ \\
\hline La5 & $7 / 7$ & $8 / 8$ & $20 / 20$ & $-/-$ & $-/-$ & $-/-$ \\
\hline La6 & $7 / 7$ & $8 / 10$ & $20 / 21$ & $11 / 13$ & $12 / 16$ & $11 / 13$ \\
\hline La7 & $7 / 7$ & $8 / 10 \mathrm{i} 30$ & $21 / 21$ & $12 / 13$ & $12 / 16$ & $13 / 20$ \\
\hline $\mathrm{La} 8$ & $7 / 7$ & $8 / 8$ & $22 / 22$ & $15 / 15$ & $-/-$ & $13 / 13$ \\
\hline La9 & $6 / 7$ & $8 / 10 i 30$ & $20 / 20$ & $13 / 13$ & $10 / 10$ & $22 / 22$ \\
\hline La10 & $7 / 7$ & $8 / 9$ & $-/-$ & $-/-$ & $-/-$ & $17 / 17$ \\
\hline Alp1 & $7 / 7$ & $8 / 10$ & $8 / 23$ & $14 / 14$ & $16 / 16$ & $13 / 20$ \\
\hline Alp2 & $7 / 7$ & 10i30/10i30 & $8 / 8$ & $13 / 22$ & $13 / 13$ & $13 / 13$ \\
\hline Alp3 & $7 / 7$ & 10i30/10i30 & $-/-$ & $-/-$ & $-/-$ & $13 / 13$ \\
\hline Alp4 & $7 / 7$ & $10 / 10$ & $23 / 23$ & $14 / 14$ & $17 / 17$ & $13 / 20$ \\
\hline Alp5 & $7 / 7$ & $8 / 8$ & $8 / 21$ & $12 / 22$ & $17 / 17$ & $13 / 20$ \\
\hline Alp6 & $7 / 7$ & $8 / 9$ & $19 / 20$ & $13 / 13$ & $17 / 17$ & $18 / 22$ \\
\hline Alp7 & $7 / 7$ & $8 / 8$ & $21 / 21$ & $11 / 16$ & $13 / 13$ & $18 / 22$ \\
\hline Alp8 & $7 / 7$ & $8 / 9$ & $21 / 22$ & $12 / 16$ & $13 / 13$ & $18 / 22$ \\
\hline Alp9 & $7 / 7$ & $8 / 9$ & $23 / 23$ & $11 / 11$ & $13 / 13$ & $13 / 13$ \\
\hline Alp10 & $7 / 7$ & $8 / 10 i 30$ & $21 / 22$ & $11 / 16$ & $12 / 12$ & $13 / 21$ \\
\hline Alp11 & $6 / 7$ & $8 / 10 \mathrm{i} 30$ & $20 / 21$ & $13 / 19$ & $-/-$ & $13 / 13$ \\
\hline Alp12 & $7 / 7$ & $8 / 10 i 30$ & $20 / 21$ & $13 / 15$ & $-/-$ & $13 / 16$ \\
\hline Alp13 & $9 / 9$ & $8 / 9$ & $24 / 24$ & $14 / 14$ & $-/-$ & $13 / 16$ \\
\hline Alp14 & $7 / 7$ & $-1-$ & $-1-$ & $11 / 14$ & $-/-$ & $-/-$ \\
\hline Gua1 & $7 / 7$ & $8 / 11$ & $21 / 21$ & $27 / 27$ & $7 / 7$ & $10 / 13$ \\
\hline Gua2 & $7 / 7$ & $8 / 11$ & $21 / 21$ & $15 / 15$ & $-/-$ & $10 / 13$ \\
\hline Gua3 & $7 / 8$ & $8 / 8$ & $21 / 24$ & $22 / 27$ & $-/-$ & $13 / 13$ \\
\hline Vic1 & $7 / 7$ & $5 / 10$ & $22 / 22$ & $11 / 12$ & $14 / 19$ & $14 / 15$ \\
\hline Vic2 & $7 / 7$ & $5 / 10$ & $22 / 22$ & $11 / 12$ & $12 / 19$ & $15 / 15$ \\
\hline Vic3 & $7 / 7$ & $10 / 10$ & $19 / 22$ & $11 / 12$ & $-1-$ & $15 / 15$ \\
\hline Vic4 & $7 / 7$ & $7 / 10$ & $19 / 22$ & $11 / 12$ & $13 / 19$ & $15 / 15$ \\
\hline Vic5 & $7 / 7$ & $5 / 10$ & $19 / 22$ & $11 / 12$ & $-/-$ & $15 / 15$ \\
\hline Vic6 & $7 / 7$ & $5 / 10$ & $19 / 22$ & $11 / 12$ & $-1-$ & $15 / 18$ \\
\hline Vic7 & $7 / 7$ & $5 / 10$ & $19 / 22$ & $11 / 12$ & $-/-$ & $15 / 18$ \\
\hline Vic8 & $7 / 7$ & $5 / 10$ & $21 / 21$ & $11 / 11$ & $-/-$ & $15 / 15$ \\
\hline Vic9 & $7 / 7$ & $5 / 7$ & $19 / 22$ & $22 / 22$ & $19 / 19$ & $15 / 15$ \\
\hline Vic10 & $7 / 7$ & $5 / 7$ & $19 / 22$ & $12 / 14$ & $-/-$ & $14 / 15$ \\
\hline Vic11 & $7 / 7$ & $-1-$ & $-1-$ & $-/-$ & $-1-$ & $15 / 15$ \\
\hline Vic12 & $7 / 7$ & $5 / 5$ & $22 / 22$ & $12 / 12$ & $-1-$ & $15 / 18$ \\
\hline Vic13 & $7 / 7$ & $5 / 10$ & $22 / 22$ & $12 / 12$ & $-1-$ & $14 / 15$ \\
\hline Vic14 & $7 / 7$ & $5 / 5$ & $21 / 21$ & $12 / 12$ & $-/-$ & $14 / 15$ \\
\hline Vic15 & $7 / 7$ & $5 / 5$ & $21 / 22$ & $12 / 12$ & $-/-$ & $15 / 15$ \\
\hline Vic16 & $7 / 7$ & $5 / 10$ & $22 / 22$ & $12 / 12$ & $-/-$ & $15 / 15$ \\
\hline
\end{tabular}

Legende: -/- = konnte nicht typisiert werden

Die Mutter-Kind-Paare La3 und La5, La4 und La6 sowie Alp11 und Alp12, teilen sich pro System mindestens jeweils ein Allel.

Fünf der typisierten Proben wiesen nur Teilprofile auf, 23 der Proben erbrachten für den Marker VOLP67 keine Ergebnisse. Im Marker VOLP10 konnten nur vier Allele bestimmt werden. Das Allel 7 war hierbei das häufigste. Als speziesspezifische Allele können das Allel 5 im Marker LgU52 in Vikunjas und das Allel 8 im Marker VOLP03 in Alpakas angesprochen werden. Das Allel $10 i 30$ im Marker LgU52 kommt nur in den domestizierten Spezies vor. 


\subsection{2 Überliefertes Material}

Für 32 Proben konnte ein Amplifikationserfolg erzielt werden. Alle positiven Amplikons entstammen Extrakten aus Knochen und Zähnen. In Abbildung 55 ist die Überprüfung des Amplifikationserfolges auf einem Agarosegel dargestellt.
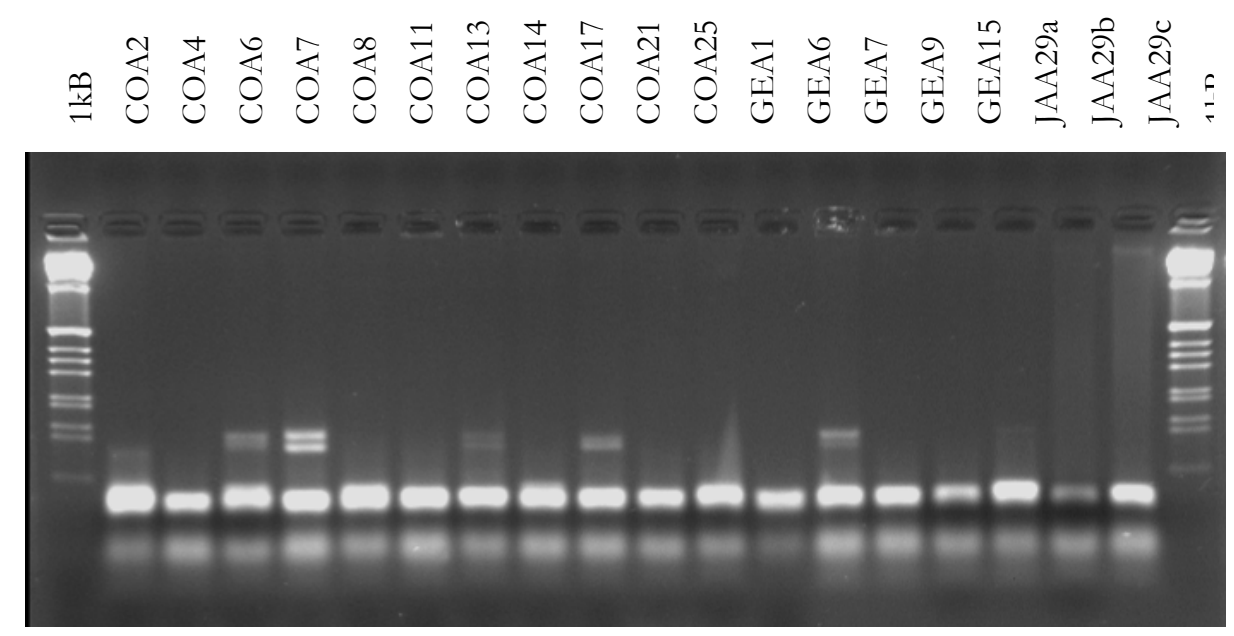

Abbildung 55: Überprüfung des Amplifikationserfolges der PCR AncientMulti4 auf einem Agarosegel

Die Fragmentlängenanalyse zeigte für alle Proben nur Teilprofile. Reproduziert typisiert werden konnten nur einzelne Allele in insgesamt fünf Proben. Diese fünf Proben sind in Tabelle 53 dargestellt. Neben den reproduzierten Allelen (ohne Klammer), sind für diese Proben auch die nicht reproduzierten Allele (mit Klammer) aufgeführt (Tab. 53). Proben, für die nicht reproduzierte Teilprofile auftraten, sind im Appendix aufgeführt.

Tabelle 53: Teilprofile die sich aus der Multiplex für überliefertes Material typisieren ließen

\begin{tabular}{|l|c|c|c|c|c|c|}
\hline & VOLP10 & LgU52 & VOLP03 & LCA66 & VOLP67 & LgU68 \\
\hline MSA29 & $(2) / 7$ & $(8) /-$ & $(20 /-)$ & $-/-$ & $(16) /-$ & $(11 / 19)$ \\
\hline GEA6 & $(4) / 7$ & $8 /-$ & $(19 /-)$ & $-/-$ & $(6 / 11)$ & $-/-$ \\
\hline COA6 & $7 /-$ & $(4) / 9$ & & $-/-$ & $(6 / 8)$ & $(16) /-$ \\
\hline COA8 & $7 /-$ & $(8 / 9)$ & $(20) /-$ & $(19) /-$ & $(6 / 9)$ & $-/-$ \\
\hline COA13 & $(3) / 7$ & $(5 / 7 / 8)$ & $(19) /-$ & $-/-$ & $(6 /-)$ & $-/-$ \\
\hline
\end{tabular}

Legende: $-/-=$ konnte nicht bestimmt werden, ()$=$ konnte nicht reproduziert werden

Es konnten nur in den Systemen VOLP10 und LgU52 Allele reproduziert werden. Die Fragmentlängen liegen zwischen 116-120bp für VOLP10, und 128-160bp für LgU52. In LgU52 sind jedoch nur solche Allele realisiert die unter einer Fragmentlänge von 140bp liegen. Im gleichen Längenbereich wie LgU52 liegen auch VOLP03 und VOLP67, für die Teilergebnisse erzielt wurden. Die langen Systeme LCA66 und LgU68 fielen dagegen komplett oder fast komplett aus. Es ist also davon auszugehen, dass in den Extrakten des überlieferten Materials sehr wenig chromosomale DNA, die stark degradiert vorliegt, enthalten ist. Die angetroffenen Allele sind denen des rezenten Materials ähnlich. Besonders das sehr häufige Allel 7 im Marker VOLP10 tritt hier ebenfalls auf.

Aufgrund der geringen Datenlage wurden die Ergebnisse nicht weiter ausgewertet. 
4.6 Identifikation des Phänotyps

In 27 der 43 rezenten Proben konnte das Fragment des TYRP1-Gens und in 15 Proben das Fragment des ASIP-Gens amplifiziert werden. In Abbildung 56 ist exemplarisch die Überprüfung des Amplifikationserfolges für das Fragment ASIP dargestellt.
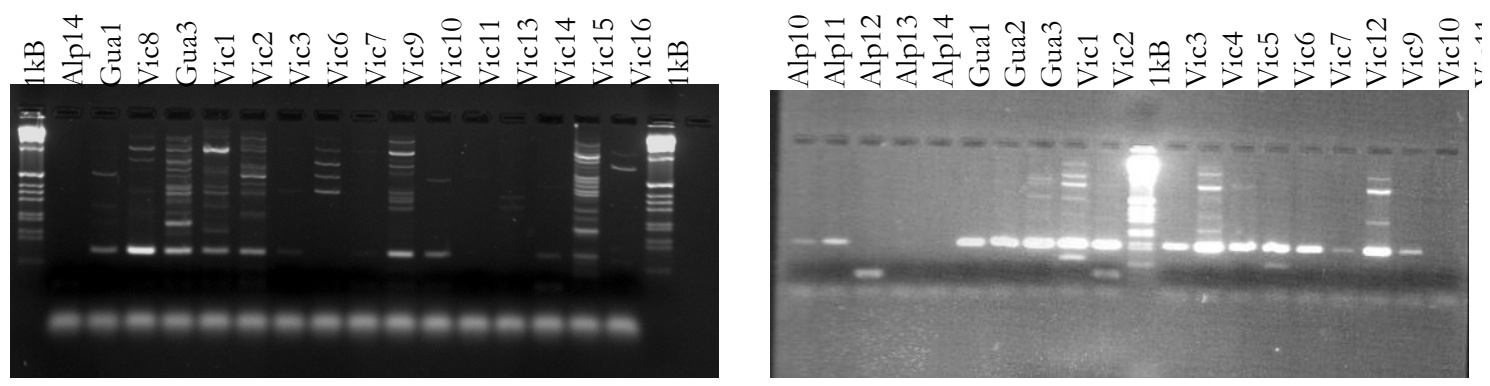

Abbildung 56: Überprüfung des Amplifikationserfolges der PCR ASIP4 (links) und TYRP4 (rechts)

In beiden Amplifikationen traten, trotz angepasster Anneal-Temperaturen in der PCR, starke Nebenprodukte auf. Diese waren in TYRP1 deutlich schwächer und beeinflussten die weitere Analyse nicht. In den Folgeanalysen der ASIP-Amplifikationen störten diese Nebenprodukte erheblich und es wurden nur solche Produkte weiter bearbeitet, die wenig, oder keine Nebenprodukte zeigten.

Für zwölf der 43 rezenten Proben war die SNP-Analyse für die Marker ASIP und TYRP1 möglich. In 15 der 43 Proben konnten nur der SNP im Gen TYRP1, in drei Proben nur der SNP im Gen ASIP bestimmt werden. In Abbildung 57 sind exemplarisch Elektropherogramme der SNP-Typisierung dargestellt. Da die SBE-Primer auf dem komplementären unteren Strang der DNA liegen, sind die angezeigten Basen komplementär zu übersetzen (s. Abb. 57).
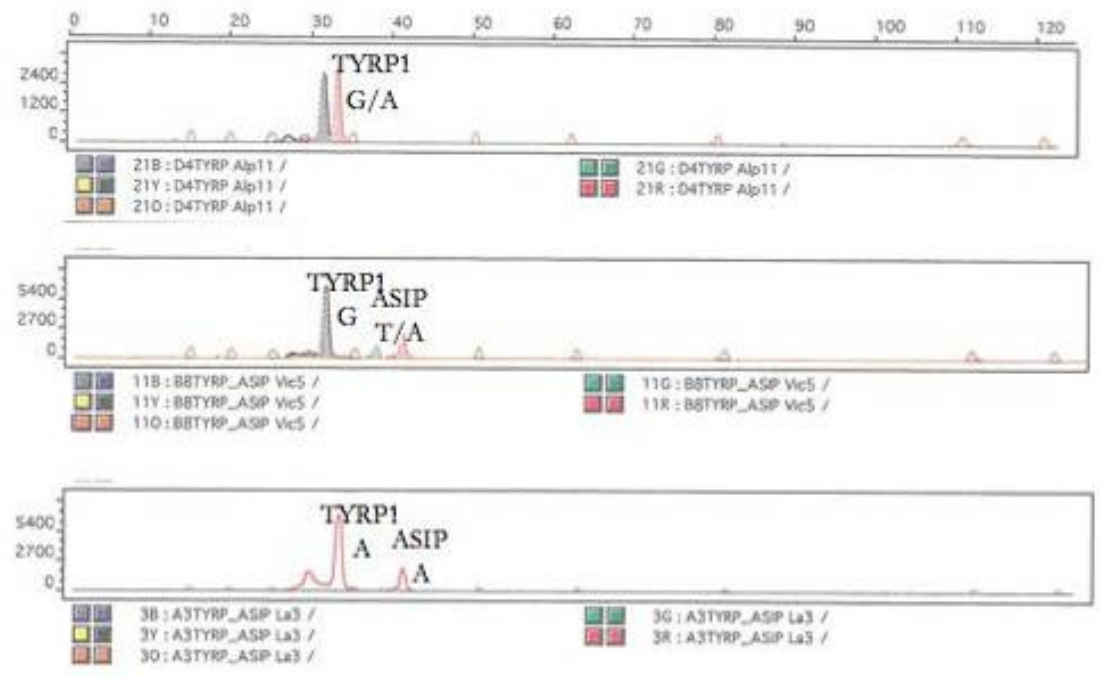

Abbildung 57: Elektropherogramme der SNP-Typisierung der Proben Alp11 (nur TYRP!), Vic5 und La3 (TYRP1 und ASIP). Legende: rot = Tyrosin, schwarz = Cytosin, grün = Adenin, blau = Guanin, orange = LIZStandard 
Im Elektropherogramm zeigte sich für den untersuchten SNP des ASIP-Gens immer ein unspezifisches Produkt bei der Länge 25 bp. Dies konnte jedoch aufgrund seiner Peakmorphologie immer als Artefakt angesprochen werden.

In Tabelle 54 sind die typisierten SNP-Ausprägungen der rezenten Proben sowie ihre Fellfarbe notiert.

Tabelle 54: Typisierte SNPs in den Genen TYRP1 und ASIP

\begin{tabular}{|c|c|c|c|c|}
\hline & TYRP1 & ASIP & phänot. Spezies & Fellfarbe \\
\hline La1 & $-/-$ & A/A & Lama & weiß \\
\hline La3 & A/A & A/A & Lama & weiß \\
\hline La4 & A/A & $-/-$ & Lama & hellbraun \\
\hline La6 & A/A & $-/-$ & Lama & weiß \\
\hline La7 & A/A & $-/-$ & Lama & rotbraun \\
\hline Alp2 & G/G & A/A & Alpaka & rotbraun \\
\hline Alp3 & $-/-$ & A/A & Alpaka & rotbraun \\
\hline Alp4 & G/G & A/A & Alpaka & rotbraun \\
\hline Alp6 & G/G & A/A & Alpaka & dunkelbraun \\
\hline Alp7 & G/A & $-/-$ & Alpaka & graubraun \\
\hline Alp8 & G/G & $-/-$ & Alpaka & hellbraun \\
\hline Alp10 & G/A & $-/-$ & Alpaka & graubraun \\
\hline Alp11 & G/A & $-/-$ & Alpaka & graubraun \\
\hline Alp12 & $-/-$ & A/A & Alpaka & schwarz \\
\hline Alp13 & G/G & $-/-$ & Alpaka & rotbraun \\
\hline Gua1 & A/A & A/A & Guanako & hellrotbraun beige \\
\hline Gua2 & A/A & $-/-$ & Guanako & hellrotbraun beige \\
\hline Gua3 & A/A & $-/-$ & Guanako & hellrotbraun beige \\
\hline Vic1 & G/G & $-/-$ & Vikunja & hellrotbraun beige \\
\hline Vic2 & G/G & $-/-$ & Vikunja & hellrotbraun beige \\
\hline Vic3 & G/G & A/A & Vikunja & hellrotbraun beige \\
\hline Vic4 & G/G & T/A & Vikunja & hellrotbraun beige \\
\hline Vic5 & G/G & T/A & Vikunja & hellrotbraun beige \\
\hline Vic6 & G/G & $-/-$ & Vikunja & hellrotbraun beige \\
\hline Vic7 & G/G & $-/-$ & Vikunja & hellrotbraun beige \\
\hline Vic8 & G/G & T/A & Vikunja & hellrotbraun beige \\
\hline Vic10 & G/G & A/A & Vikunja & hellrotbraun beige \\
\hline Vic12 & G/G & A/A & Vikunja & hellrotbraun beige \\
\hline
\end{tabular}

Legende: $\mathrm{G}=$ Guanin, $\mathrm{A}=$ Adenin, $\mathrm{T}=$ Thymin, $-/$ - = nicht typisiert

Der Marker TYRP1 lässt sich nicht direkt mit der Fellfarbe assoziieren, könnte jedoch auf die Ausprägung von Piebaldie hindeuten, da in Guanakos, die in der Regel ein schwarzes Gesicht haben, ein A realisiert. In Vikunjas, die eine beige Fellfärbung im Gesicht aufweisen, ist dieser Polymorphismus nicht anzutreffen. Der untersuchte SNP im Gen ASIP scheint nicht mit der Fellfarbe zu korrelieren, da in Tieren gleicher Farbe unterschiedliche Basen realisiert sein können. Seine Assoziation mit einer anderen Funktion ist jedoch nicht ausgeschlossen.

Eine Amplifikation von den Fragmenten in dem überlieferten Material war nicht möglich, hier zeigten sich lediglich unspezifische Produkte. 
5 Auswertung und Beurteilung des Erhaltungszustandes der DNA des überlieferten Probenmaterials

Die folgenden Ableitungen erfolgten unter Betrachtung der Ergebnisse der Analysen mitochondrialer DNA.

Den besten Untersuchungserfolg erbrachte der Fundort Chillo, von dem insgesamt $76 \%$ der Proben typisiert werden konnten. Für den Fundort Montegrande konnten 50 \% der Knochenund Zahn-Proben sowie $28 \%$ der Textilien typisiert werden. Für Los Molinos konnten $8 \%$ der Knochen- und Zahn-Proben und $15 \%$ der Textilien typisiert werden. Für Jauranga konnten $9 \%$ und für Pernil Alto $10 \%$ der Proben typisiert werden. Insgesamt lag der Typisierungserfolg bei $18 \%$, in Knochen und Zahn-Proben bei $22 \%$ und in Textilien bei 19\%. In Abbildung 58 sind die Typisierungserfolge für die einzelnen Fundorte angegeben.

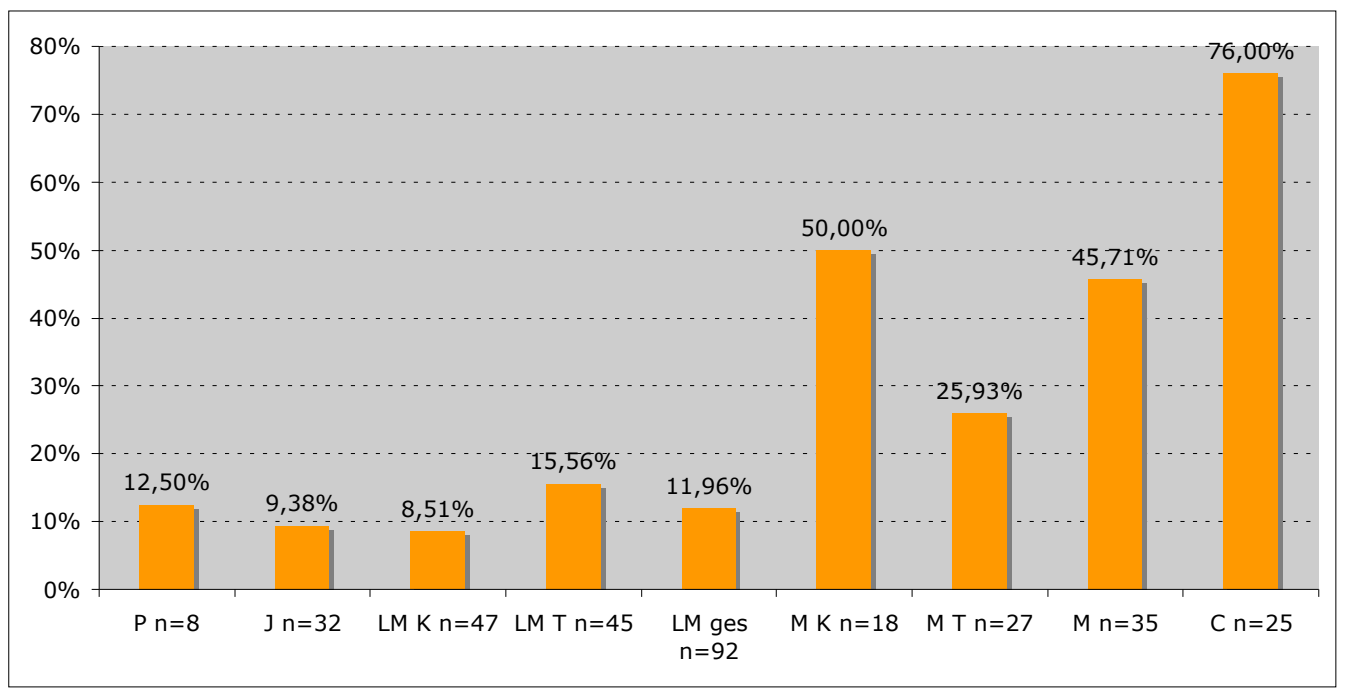

Abbildung 58: Typisierungserfolg nach Fundorten. Legende: $\mathrm{P}=$ Pernil Alto, $\mathrm{J}=$ Jauranga, LM = Los Molinos, $\mathrm{M}=$ Montegrande, $\mathrm{C}=$ Chillo, $\mathrm{K}=$ Knochen und Zähne, $\mathrm{T}=$ Textilien, $\mathrm{n}=$ Stichprobengröße

Die Liegebedingung Feuchtboden war sowohl für den Fundort Jauranga, als auch für Chillo, gegeben. Die Trockenbodenlagerung war für die Fundorte Pernil Alto, Los Molinos und Montegrande gegeben. Die Proben aus Montegrande lagen über mehrere Wochen hinweg an der Oberfläche, was an einer deutlichen Bleiche der Proben erkennbar war. Die Extrakte der Fundorte entstammten alle vergleichbaren Skelettelementen.

Um einen Vorstellung über die DNA-Erhaltung, bezogen auf das beprobte Skelettelement und einem eventuellen Zusammenhange zum Fundort zu erhalten, wurden diese in Abbildung 59 graphisch dargestellt. 


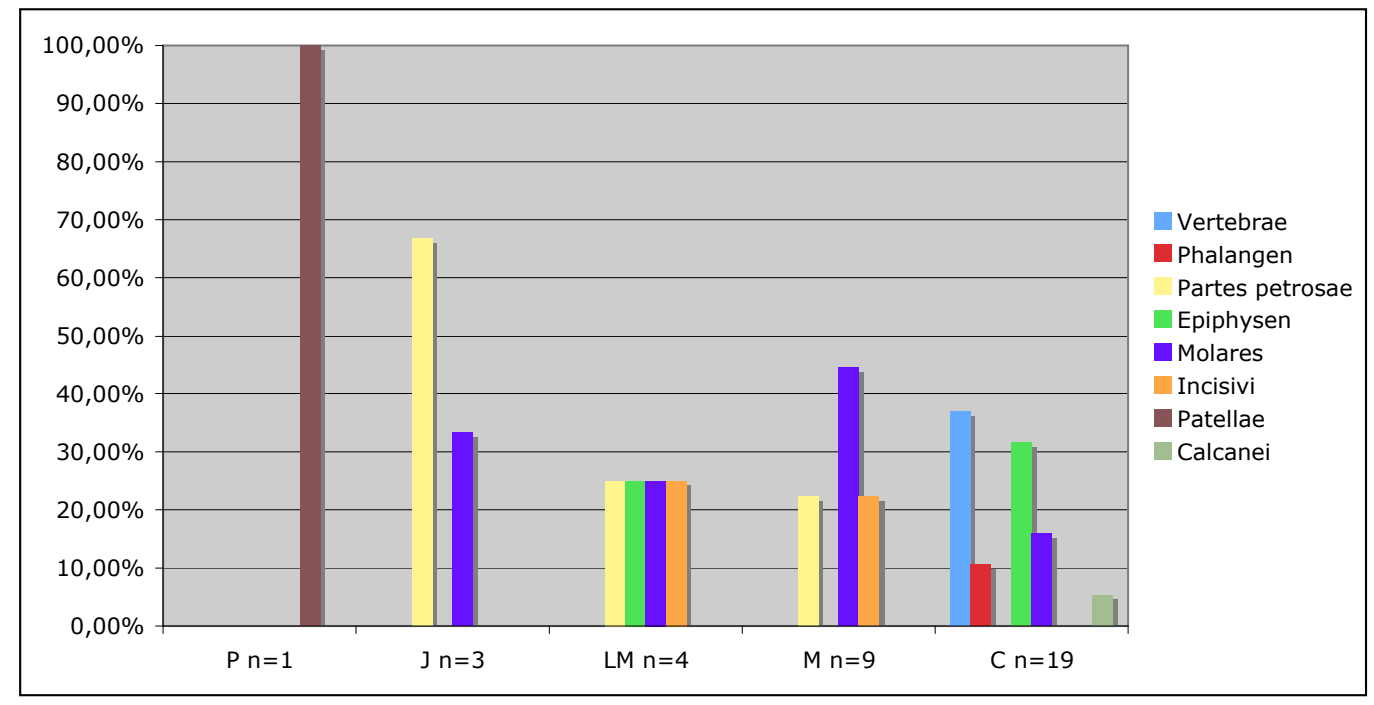

Abbildung 59: Typisierungserfolg bezüglich des beprobten Skelettelements. Legende: $\mathrm{P}=$ Pernil Alto, $\mathrm{J}=$ Jauranga, $\mathrm{LM}=$ Los Molinos, $\mathrm{M}=$ Montegrande, $\mathrm{C}=$ Chillo

Den besten Erhalt der DNA wiesen Molaren auf, Epiphysen und Vertebrae zeigten sich ebenfalls als geeignete DNA-Quelle. Jedoch gelang es auch aus dem Calcaneus oder Patellae DNA zu gewinnen. Für die Fundorte Jauranga, Los Molinos und Chillo waren alle aufgeführten Skelettelemente in der Stichprobe vertreten. Die Fundorte mit der Liegebedingung Feuchtboden (Jauranga und Chillo) unterscheiden sich bezüglich auf die typisierbaren Skelettelemente. In Jauranga konnten nur Zähne und Partes petrosae typisiert werden, in Chillo zeigten Vertebrae den besten Typisierungserfolg. Demzufolge kann kein Zusammenhang zwischen Liegebedingungen und DNA-Erhaltung in den Skelettelementen festgestellt werden.

Gemessen an der gesamten Stichprobe zeigen Incisivi die beste DNA- Erhaltung (s. Abb. 60). Epiphysen und Vertebrae zeigten eine gute Erhaltung der DNA. Molaren haben gegenüber Incisivi eine schlechtere DNA-Erhaltung. DNA aus Partes petrosae erwies sich in der vorliegenden Arbeit als weniger gut analysierbar. Phalangen und Patellae zeigten die schlechteste DNA-Erhaltung. Der einzige Calcaneus der Stichprobe zeigte eine gute DNAErhaltung. Diese Ergebnisse entsprechen im Wesentlichen den Beobachtungen an menschlichen Knochen (s. z.B. Kleindorp 2006). Die schlechtere DNA-Erhaltung in Molaren kann auf die Proben selbst zurückgeführt werden. Diese lagen meist nicht intakt oder integriert in Mandibulae oder Maxillae vor, sondern waren meist zerbrochen. Die Incisivi dagegen waren überwiegend intakt. 


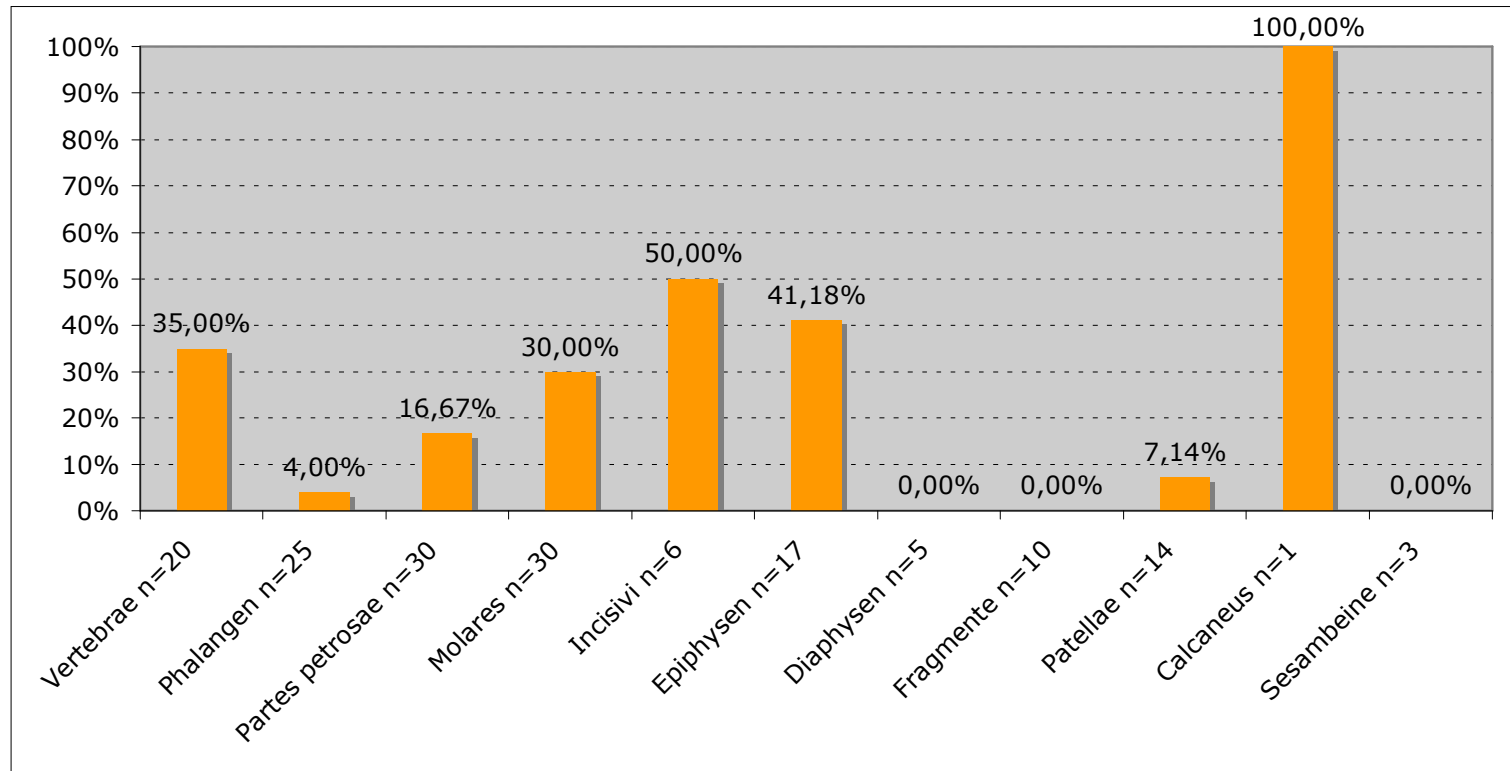

Abbildung 60: Skelettelemente die typisierbar waren im Verhältnis zur gesamten Stichprobe; Legende: $\mathrm{n}=$ Stichprobengröße

Für die Textilien konnte festgestellt werden, dass $50 \%$ der typisierbaren DNA Extrakten aus Fasern mit roter Färbung entstammten, je $14 \%$ entfallen auf blaue und schwarze Fasern, und je $7 \%$ auf grüne, gelbe und braune Fasern. Gemessen an der Gesamtanzahl beprobter Fasern ergibt sich folgendes Bild (Abb. 61).

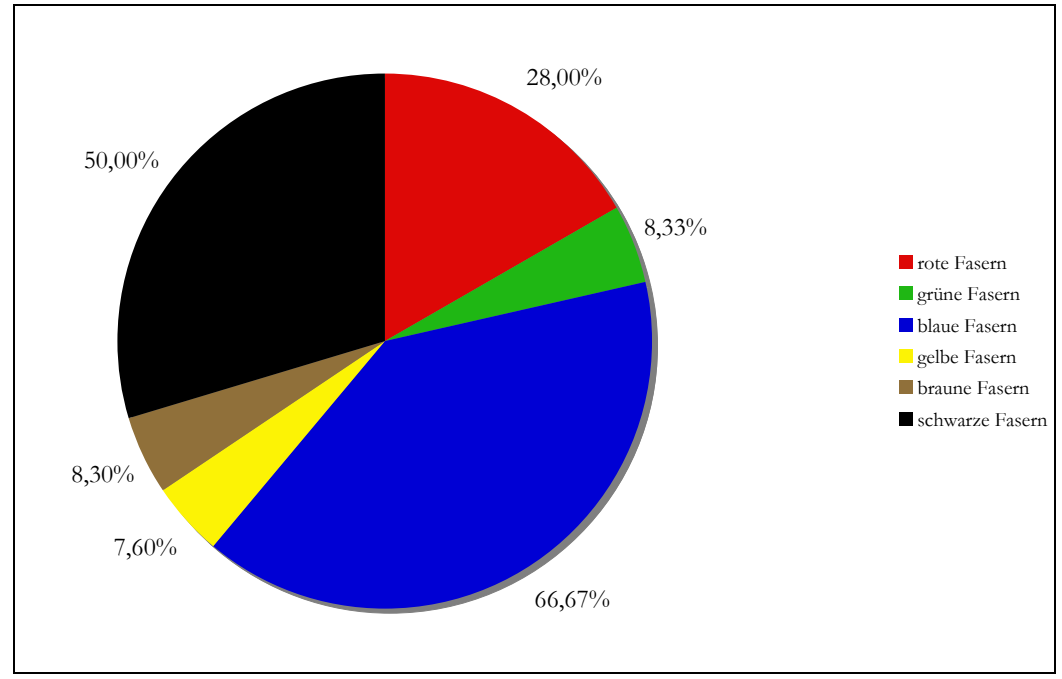

Abbildung 61: Typisierungserfolg in Textilien gemessen an der Gesamtanzahl beprobter Fasern (sortiert nach Farben)

Die DNA-Erhaltung in blauen Fasern stellte sich insgesamt als am Besten heraus, gefolgt von schwarzen und roten Fasern (s. Abb. 61). In Extrakten von gelben und grünen Fasern war der Typisierungserfolg am Geringsten. Es kann eine Abhängigkeit zur Farbe der Textilien festgestellt werden. Ein Zusammenhang zur Verarbeitungstechnik, wie z.B. geflochtenen gegenüber gewebten Textilien war nicht feststellbar. 
Die Typisierbarkeit, in Abhängigkeit zur Länge des typisierten Fragmentes, wurde ebenfalls betrachtet. Für jede zu typisierende Probe wurde die Länge der erfolgreich amplifizierten Produkte einzeln betrachtet.

Tabelle 55: Typisierungserfolg der historischen Proben im Bezug auf die Länge des zu amplifizierenden Systems

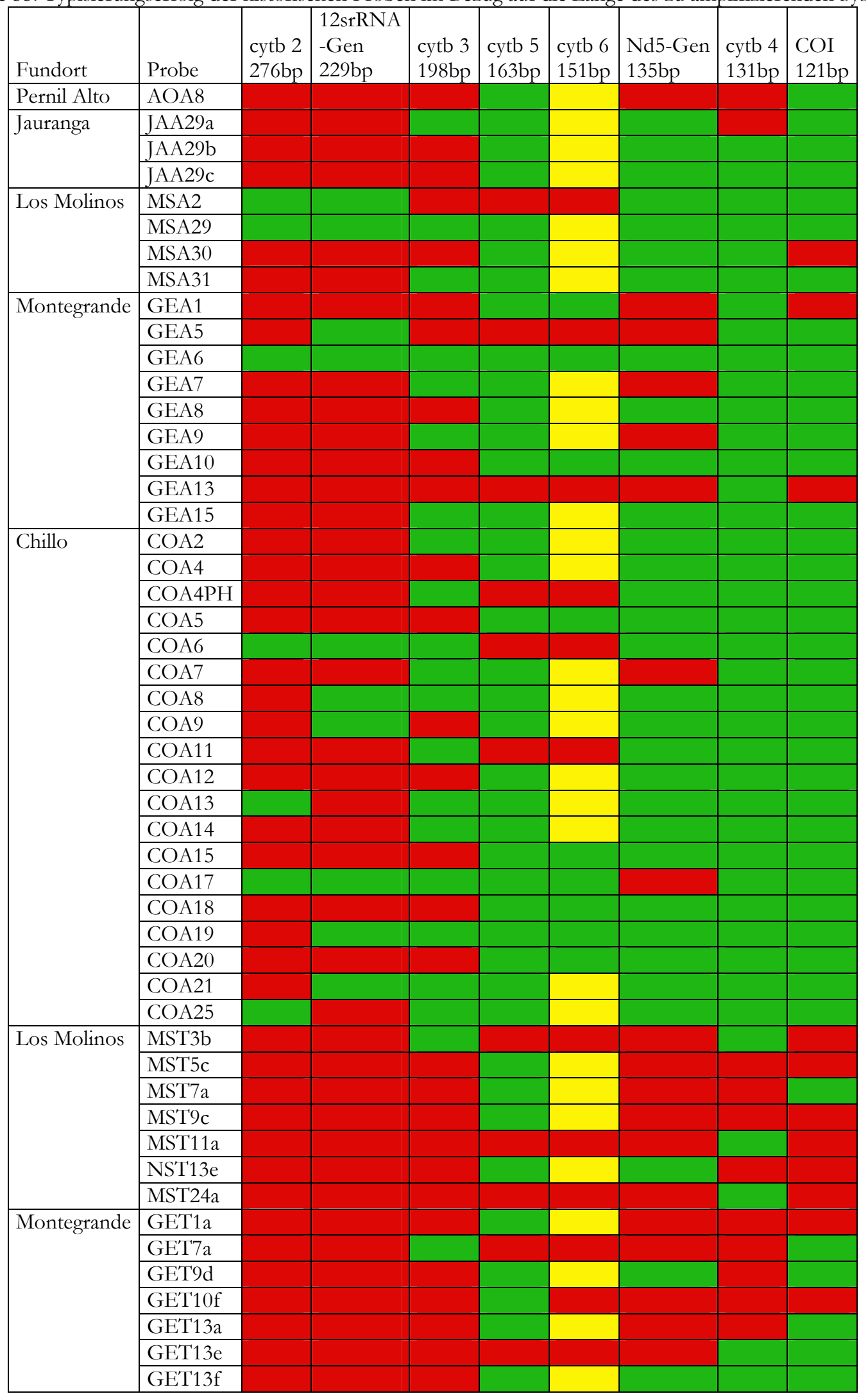

Legende: rot $=$ kein Typisierungserfolg, grün $=$ Typisierungserfolg, gelb = Fragment wurde nicht typisiert 
In den Textilien konnten Fragmente unterhalb von 200 bp typisiert werden. Es konnte kein Zusammenhang zwischen Fundort und Länge der zu amplifizierenden Fragmente hergestellt werden (s. Tab. 55).

Es konnten überwiegend Fragmente unter 163bp amplifiziert werden (s. Tab. 55 und Abb. 62). In fast allen Proben war der Amplifikationserfolg für das Fragment cytb 5 (163 bp) besser, als der des kürzeren Fragmentes des Nd5-Gens (135 bp). Der beste Amplifikationserfolg in Knochen- und Zahn-Proben konnte für die 131 bp langen Fragmente des cytb erzielt werden. In Textilien war die Amplifikation des 121 bp langen Fragmentes des COI-Gens am Erfolgreichsten.

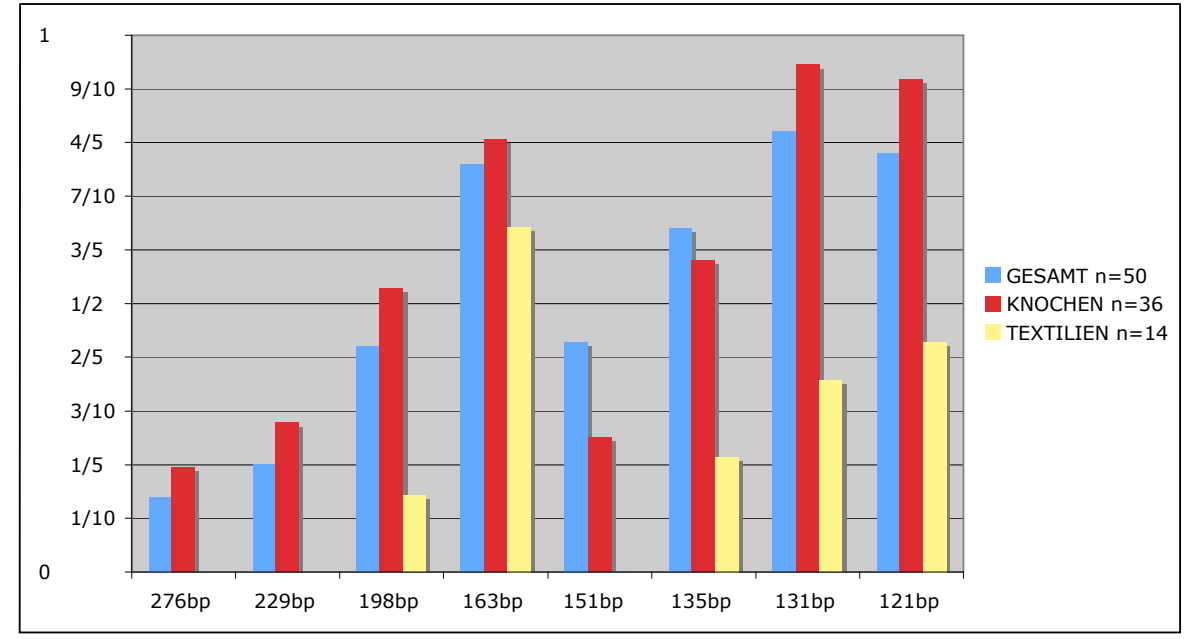

Abbildung 62: Darstellung des Amplifikationserfolges in Abhängigkeit zur Fragmentlänge

Der Degradierungsgrad der untersuchten DNA ist also als sehr hoch zu betrachteten. Dieser scheint innerhalb des mitochondrialen Genoms unterschiedlich stark ausgeprägt zu sein, da z.B. das Gen Nd5 schlechter zu amplifizieren war als das Fragment cytb-5, obwohl dieses Fragment 28 Basenpaare länger war. 
6 Auswertung zur Speziesidentifikation

Die Detektion von Polymorphismen, die eine sichere Speziesidentifikation erlauben, war nicht möglich. Selbst im 12srRNA-Gen, das zumindest die Unterscheidung von drei Spezies erlaubt, könnten auch immer Tiere der Spezies Alpaka falsch bestimmt werden. Um für das überlieferte Material trotzdem eine genotypische Bestimmung der Spezies zu ermöglichen, wurden die Haplotypen der untersuchten mitochondrialen Systeme in Gesamtheit betrachtet und aus ihnen eine Konsensus-Spezies bestimmt.

In Abbildung 63 sind die vorkommenden Haplotypen der phänotypischen Spezies zusammengefasst dargestellt.
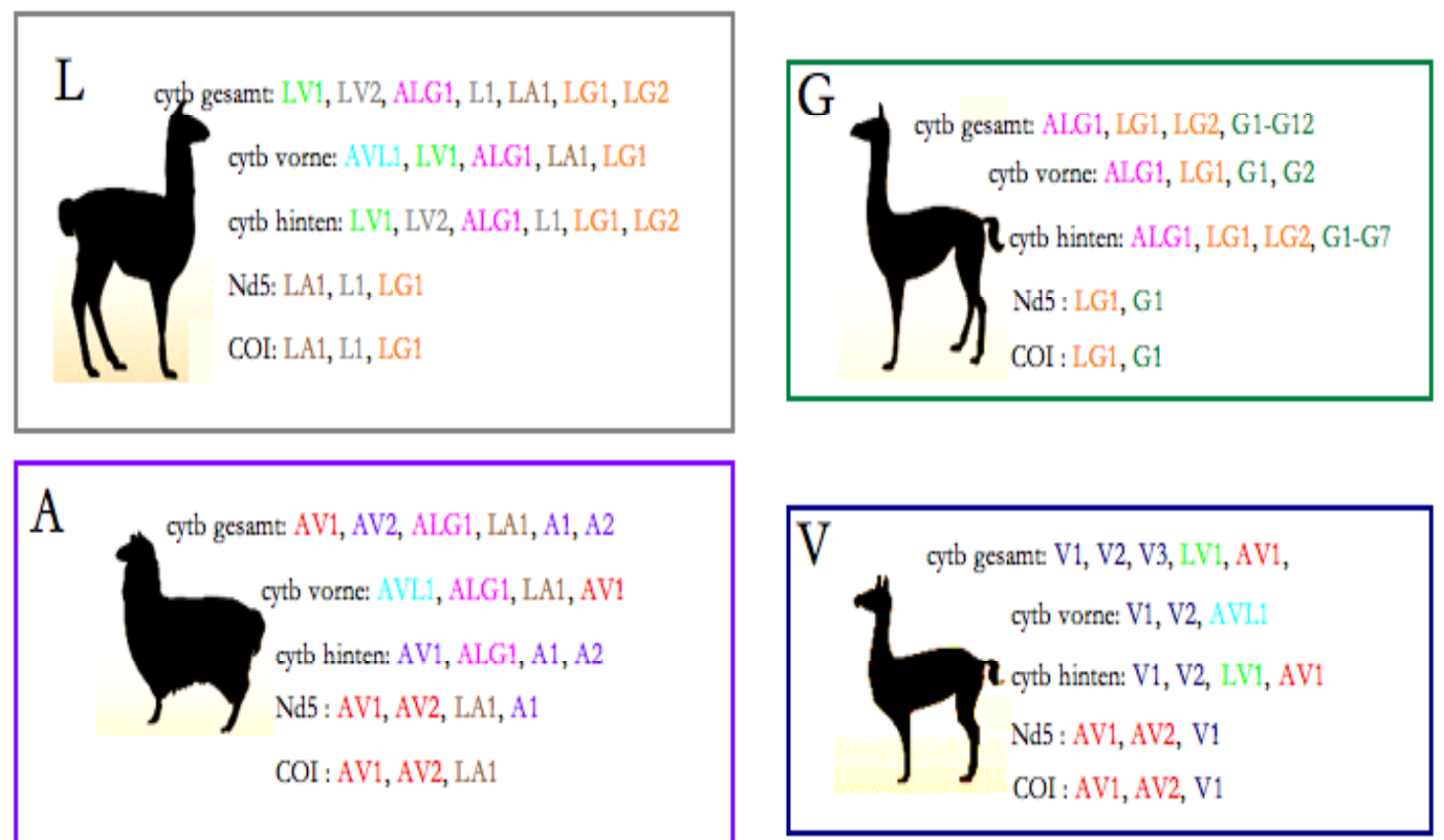

Abbildung 63: Vorkommende Haplotypen in phänotypischen Spezies. Legende: $\mathrm{L}=\mathrm{Lama}, \mathrm{G}=\mathrm{Guanako}, \mathrm{A}=$ Alpaka, V = Vikunja. Farbcode der geteilten Haplotypen: hellgrün $=\mathrm{L} / \mathrm{V}$, braun $=\mathrm{L} / \mathrm{A}$, orange $=\mathrm{L} / \mathrm{G}$, magenta $=\mathrm{L} / \mathrm{A} / \mathrm{G}$, Zyan $=\mathrm{A} / \mathrm{V} / \mathrm{L}$, rot $=\mathrm{A} / \mathrm{V}$. Farbcode der einzigartigen Haplotypen: dunkelblau $=\mathrm{V}$, dunkelgrün $=$ $\mathrm{G}$, grau $=\mathrm{L}$, lila $=\mathrm{A}$

Jede Spezies weist neben einzigartige Haplotypen auch geteilte Haplotypen auf. Weist ein Individuum z.B. den Haplotyp G8 im Gesamt-Fragment des cytb-Gens auf, so ist dieses eindeutig als Guanako anzusprechen, da dieser nur in Guanakos vertreten ist. Weist ein Individuum z.B. den Haplotyp LV1 im hinteren Fragment des cytb-Gens, der in Lamas und Vikunjas realisiert sein kann, auf und im Nd5-Gen den Haplotyp AV1, der in Alpakas und Vikunjas vertreten sein kann, so ist dieses Individuum eindeutig als Vikunja anzusprechen, da nur hier eine solche Kombination auftreten kann. In allen rezenten Tieren sowie für die Referenzdaten aus der Datenbank NCBI (s. Kap. 3.1) wurden auf diese Weise genotypische Spezies bestimmt. 
In Tabelle 56 sind die sich ergebenden genotypischen Spezies des rezenten Probenmaterials ihren phänotypischen Spezies gegenübergestellt

Tabelle 56: Gegenüberstellung phänotypischer und genotypischer Spezies

\begin{tabular}{|c|c|c|c|c|c|c|c|c|}
\hline Probe & $\begin{array}{l}\text { phän. } \\
\text { Spezies }\end{array}$ & $\begin{array}{l}\text { gen. } \\
\text { Spezies }\end{array}$ & Probe & $\begin{array}{l}\text { phän. } \\
\text { Spezies }\end{array}$ & $\begin{array}{l}\text { gen. } \\
\text { Spezies }\end{array}$ & Probe & $\begin{array}{l}\text { phän. } \\
\text { Spezies }\end{array}$ & $\begin{array}{l}\text { gen. } \\
\text { Spezies }\end{array}$ \\
\hline La1 & $\mathrm{L}$ & $\mathrm{L}$ & Alp3 & A & A & Vic4 & $\mathrm{V}$ & $\mathrm{V}$ \\
\hline $\mathrm{La} 2$ & $\mathrm{~L}$ & $\mathrm{~L}$ & Alp4 & $\mathrm{A}$ & $\mathrm{V}$ & Vic5 & $\mathrm{V}$ & $\mathrm{V}$ \\
\hline $\mathrm{La3}$ & $\mathrm{L}$ & $\mathrm{L}$ & Alp5 & $\mathrm{A}$ & $\mathrm{V}$ & Vic6 & $\mathrm{V}$ & $\mathrm{V}$ \\
\hline $\mathrm{La} 4$ & $\mathrm{~L}$ & $\mathrm{~L}$ & Alp6 & $A$ & A & Vic7 & $\mathrm{V}$ & $\mathrm{V}$ \\
\hline La5 & $\mathrm{L}$ & $\mathrm{L}$ & Alp7 & $\mathrm{A}$ & $\mathrm{L}$ & Vic8 & $\mathrm{V}$ & $\mathrm{V}$ \\
\hline $\mathrm{La6}$ & $\mathrm{L}$ & $\mathrm{L}$ & Alp8 & $\mathrm{A}$ & $\mathrm{A}$ & Vic9 & $\mathrm{V}$ & $\mathrm{V}$ \\
\hline La7 & $\mathrm{L}$ & $\mathrm{L}$ & Alp9 & $\mathrm{A}$ & LA & Vic10 & $\mathrm{V}$ & $\mathrm{V}$ \\
\hline $\mathrm{La} 8$ & $\mathrm{~L}$ & $\mathrm{~L}$ & Alp10 & $\mathrm{A}$ & LA & Vic11 & $\mathrm{V}$ & $\mathrm{A}$ \\
\hline $\mathrm{La9}$ & $\mathrm{L}$ & $\mathrm{L}$ & Alp11 & $\mathrm{A}$ & $\mathrm{L}$ & Vic12 & $\mathrm{V}$ & $\mathrm{A}$ \\
\hline La10 & $\mathrm{L}$ & $\mathrm{L}$ & Alp12 & $\mathrm{A}$ & $\mathrm{L}$ & Vic13 & $\mathrm{V}$ & $\mathrm{A}$ \\
\hline Gua1 & $G$ & $\mathrm{~L}$ & Alp13 & $\mathrm{A}$ & $\mathrm{V}$ & Vic14 & $\mathrm{V}$ & $\mathrm{V}$ \\
\hline Gua2 & $G$ & $G$ & Alp14 & $\mathrm{A}$ & $\mathrm{A}$ & Vic15 & $\mathrm{V}$ & $\mathrm{V}$ \\
\hline Gua3 & G & $G$ & Vic1 & $\mathrm{V}$ & $\mathrm{V}$ & Vic16 & $\mathrm{V}$ & $\mathrm{V}$ \\
\hline Alp1 & A & A & Vic2 & $\mathrm{V}$ & $\mathrm{V}$ & & & \\
\hline Alp2 & A & A & Vic3 & $\mathrm{V}$ & $\mathrm{V}$ & & & \\
\hline
\end{tabular}

Legende: $\mathrm{L}=$ Lama, $\mathrm{G}=$ Guanako, $\mathrm{A}=$ Alpaka, $\mathrm{V}=$ Vikunja

In Betrachtung der in Tabelle 56 dargestellten Daten sowie den Referenzdaten ergeben sich für die angewandte Methodik folgende Bestimmungswahrscheinlichkeiten. Für die Mehrzahl der Proben stimmen die Ergebnisse überein (70 \%), eine Differenz zwischen den Spezies gibt es in $30 \%$ der untersuchten Tiere, rund $60 \%$ davon entfallen auf Alpakas. Zwei der Alpakas lassen sich genotypisch als Hybride ansprechen, da sie nicht eindeutig der Gruppe Lama oder Alpaka angehören. In Guanakos ergibt sich eine sichere Bestimmung von 85 \%. Eine sichere Bestimmung von Alpakas (in $44 \%$ der Tiere) ist nur möglich, wenn sie einen Haplotypen aufweisen, der nur bei ihnen vorkommt oder wenn in ihnen eine Zusammensetzung aus geteilten Haplotypen unterschiedlicher Spezies auftritt. Vikunjas können zu 78 \% und Lamas zu $83 \%$ sicher bestimmt werden.

Die oben beschriebene Methode wurde auf die Ergebnisse des überlieferten Materials angewendet. In Abbildung 64 sind die so gewonnene Angaben über mögliche Spezies des überlieferten Materials dargestellt. Die Haplotypen sind farblich wie in Abbildung 63 markiert. 


\section{AOA8}

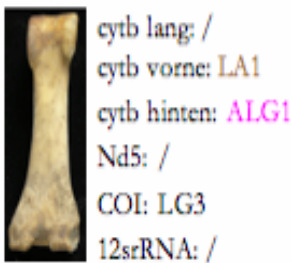

= Lama

\section{MSA2}

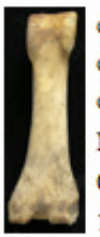

cytb lang: LA1 cytb vorne: $L A 1$ cytb hinten: ALG1

Nd5: LG1

COI: LG1

12srRNA: Lama

= Lama

MST3b

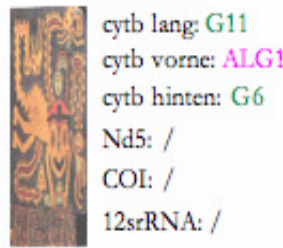

$=$ Guanako

MST11a

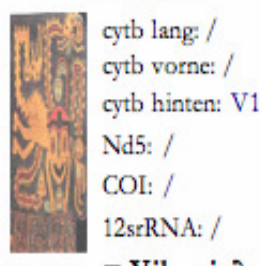

= Vikunja?

\section{GEA1}

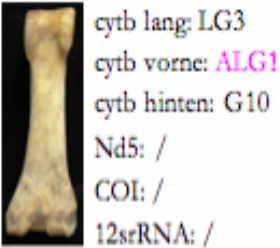

$=$ Guanako

\section{GEA8}

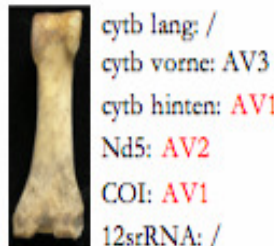

JAA29a

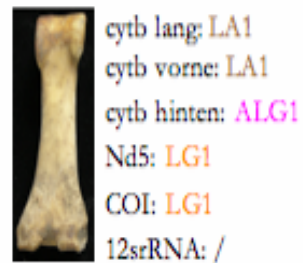

= Lama

MSA29

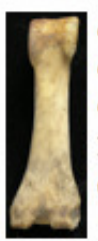

cytb lang: LA1

cytb vorne: $L A 1$

cytb hinten: ALG1

Nd5: LG1

COI: LG1

12ssRNA: Lama

= Lama

MST5c

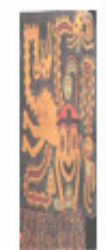

cytb lang: /

cytb vorne: $\mathrm{V} 3$

cytb hinten: /

Nd5: /

COI: /

12srRNA: /

= Vikunja?

MST13a

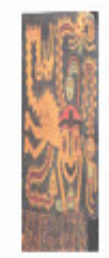

cytb lang: /

cytb vorne: V2

cytb hinten: /

Nd5: /

COI: /

12srRNA: /

= Vikunja?

\section{GEA5}

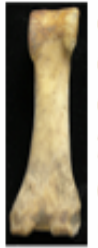

cytb lang: /

cytb vorne: /

cytb hinten: G10

Nd5: /

COI: LG2

12s:RNA: /

$=$ Guanako

\section{GEA9}

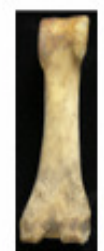

cytb lang: G14

cytb vorne: $L G 1$

cytb hinten: G9

Nd5: /

COI: G1

12seRNA: /

$=$ Guanako
JAA29b

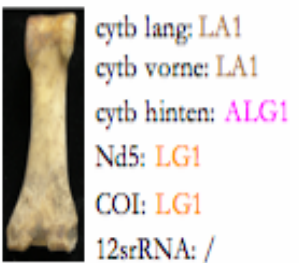

= Lama

MSA30

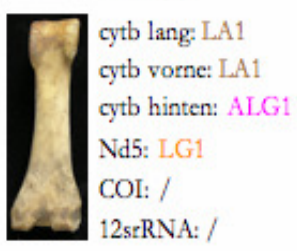

= Lama

MST7a

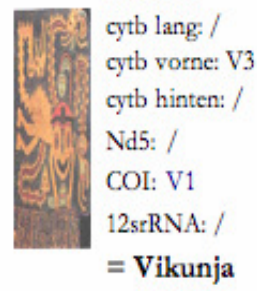

MST24a

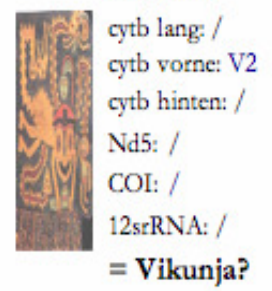

GEA6

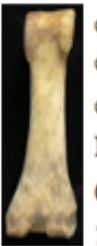

cytb lang: G13

cytb vorne: ALG2

cytb hinten: G11

Nd5: LA1

COI: G2

12stRNA: Guanako

\section{$=$ Guanako}

\section{GEA10}

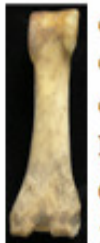

cytb lang: /

cytb vorne: ALG1

cytb hinten: ALG1

Nd5: LG1

COI: LA1

12stRNA: /

= Lama
JAA2\%c

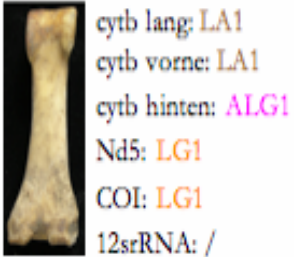

= Lama

\section{MSA31}

cytb lang:

cytb vorne: ALG1

cytb hinten: ALG1

Nd5: G1

COI: G1

12seRNA: /

$=$ Guanako

\section{MST9c}

cytb lang: / cytb vorne: V2

cytb hinten: /

Nd5: /

COI: /

12srRNA: /

= Vikunja?

= Vikunja/Alpaka?

Abbildung 64: Speziesidentifikation an überliefertem Material 


\section{GEA15}

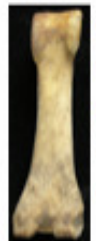

cytb lang: L.3

cytb vorne: ALG

cytb hinten: L.2

Nd5: LG1

COI: LG1

12s:RNA: /

$=$ Lama

GET10f

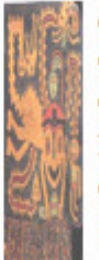

cytb lang: /

cytb vorne: /

cytb hinten: V1

Nd5: /

COI: /

12s:RNA: /

= Vikunja?

$\mathrm{COA} 2$

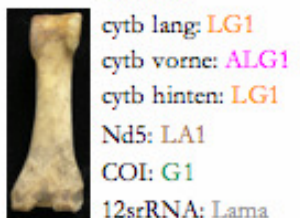

$=$ Guanako

COA6

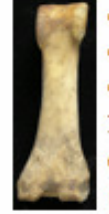

cytb lang: L2

cytb vorne: LA1

cytb hinten: L2

Nd5: LA1

COI: LA1

12srRNA: /

= Lama

COA11

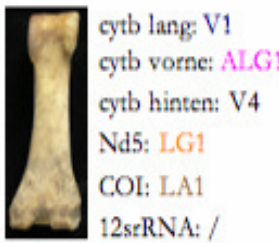

= Alpaka

\section{COA15}

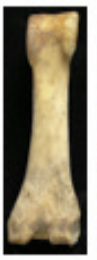

cytb lang:

cytb vorne: ALG

cytb hinten: ALG1

Nd5: LG1

COI: LA1

12srRNA: /

= Lama

\section{GET1a}

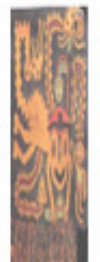

cytb vorne: LA1

cytb hinten: /

Nd5: /

COI: LA1

12s:RNA: /

= Lama/Alpaka?

GET13a

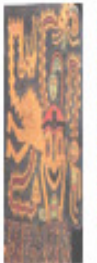

cytb lang:

cytb vorne: AV2

cytb hinten: /

Nd5: /

COI: AV1

12 srRNA: /

= Vikunja/Alpaka?

\section{COA4}

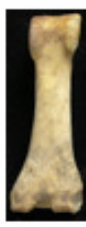

cytb lang: G13

cytb vorne: ALG2

cytb hinten: G8

Nd5: LA1

COI: G2

12srRNA: /

= Guanako

\section{COA7}

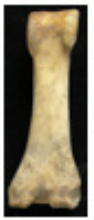

cytb lang: G14

cytb vorne: LG1

cytb hinten: G9

Nd5: /

COI: G1

12srRNA: /

= Guanako

\section{COA12}

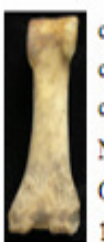

cytb lang: /

cytb vorne: AV;

cytb hinten: LV1

Nd5: AV3

COI: AV1

12seRNA: /

= Vikunja?

\section{COA17}

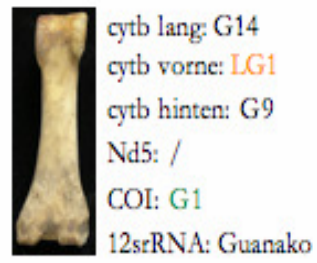

= Guanako
GET7a

cytb lang: /

cytb vorne: AV2

cytb hinten: /

Nd5: /

COI: /

12s:RNA: /

= Vikunja/Alpaka?

GET13e

cytb lang: /

cytb vorne: /

cytb hinten: AV1

Nd5: /

COI: /

12srRNA: /

= Vikunja/Alpaka?

COA4Ph

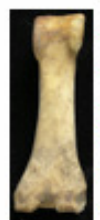

cytb lang: /

cytb vorne: ALG1

cytb hinten: ALG1

Nd5: LG1

COI: LA1

12srRNA: /

= Lama

COA8

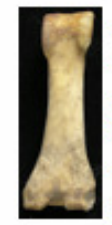

cytb lang: L.3

cytb vorne: G3

cytb hinten: L2

Nd5: LG1

COI: LG1

12srRNA: Lama

= Lama

COA13

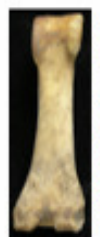

cytb lang: G14

cytb vorne: $\mathrm{LG}$ 1

cytb hinten: G9

Nd5: LA1

COI: G1

12stRNA: /

$=$ Guanako

COA18

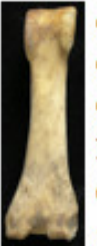

cytb lang: /

cytb vorne: AV4

cytb hinten: V3

Nd5: AV2

COI: AV3

12srRNA: /

= Vikunja/Alpaka?

\section{GET9d}

cytb lang: /

cytb vorne: LA1

cytb hinten: ALG1

Nd5: /

COI: AV1

12stRNA: /

= Alpaka

GET13f

cytb lang: /

cytb vorne: LA1

cytb hinten: ALG1

Nd5: /

COI: LA1

12srRNA: /

= Lama/Alpaka?

\section{COA5}

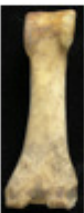

cytb lang:

cytb vorne: $L A 1$

cytb hinten: ALG1

Nd5: L2

COI: LA1

12srRNA: Lama

= Lama

\section{COA9}

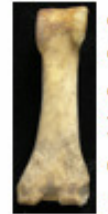

cytb lang: /

cytb vorne: LA1

cytb hinten: L3

Nd5: LA1

COI: LA1

12srRNA: Lama

= Lama

\section{COA14}

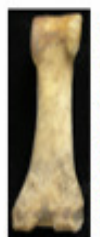

cytb lang: ALG! cytb vorne: ALG1 cytb hinten: ALG1

Nd5: LG!

COI: G9

12seRNA: /

= Guanako

\section{COA19}

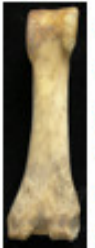

cytb lang: /

cytb vorne: $\mathrm{LG} 2$

cytb hinten: L2

Nd5: LG1

COI: LA2

12srRNA: Lama

= Lama

Abbildung 64: Speziesidentifikation an überliefertem Material, Fortsetzung 

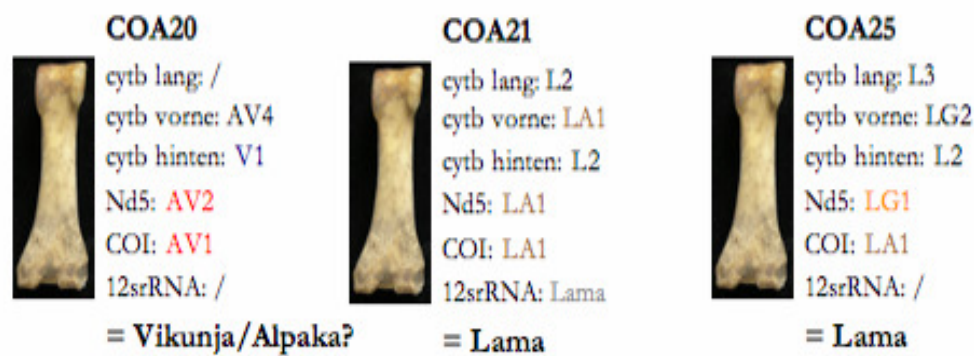

Abbildung 64: Speziesidentifikation an überliefertem Material, Fortsetzung

Anhand der so gewonnenen Daten wurden die Anteile der einzelnen Spezies in dem überlieferten Material bestimmt. Für Knochen- und Zahnproben, konnten überwiegend Lamas $(52 \%)$ und Guanakos (31\%) ermittelt werden. Die restlichen $17 \%$ entfallen auf Alpakas, Vikunjas und Proben für die keine genaue Speziesbestimmung möglich war (s. Abb. $65)$.

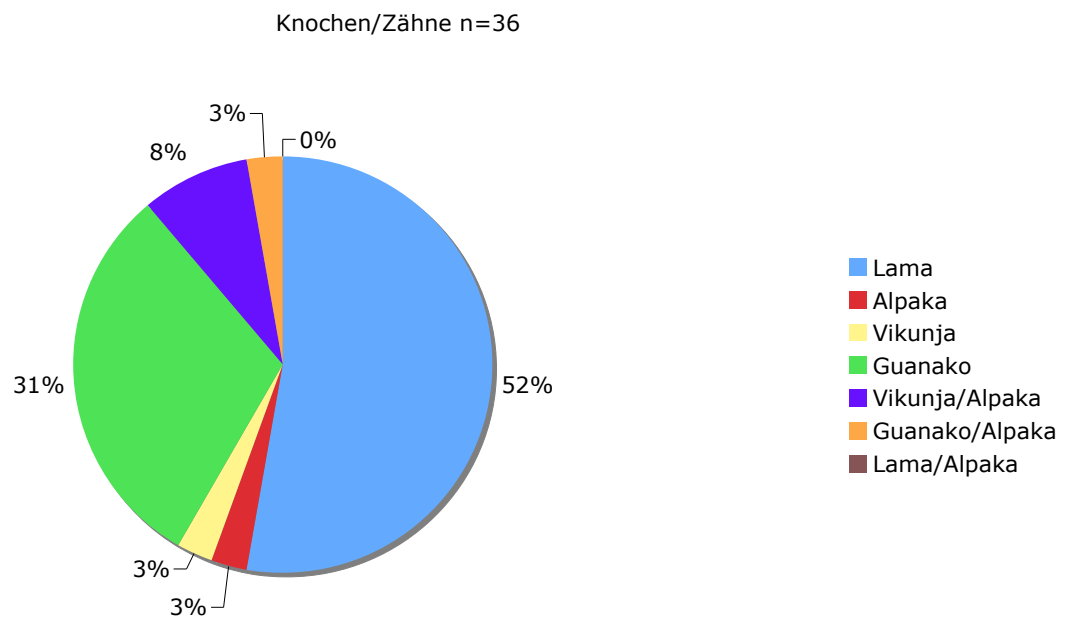

Abbildung 65: Speziesdistribution in Knochen- und Zahn-Proben

Für Textilien konnten überwiegend die Spezies Vikunja (51 \%) und der Mischtyp Vikunja/Alpaka bestimmt werden (s. Abb. 66).
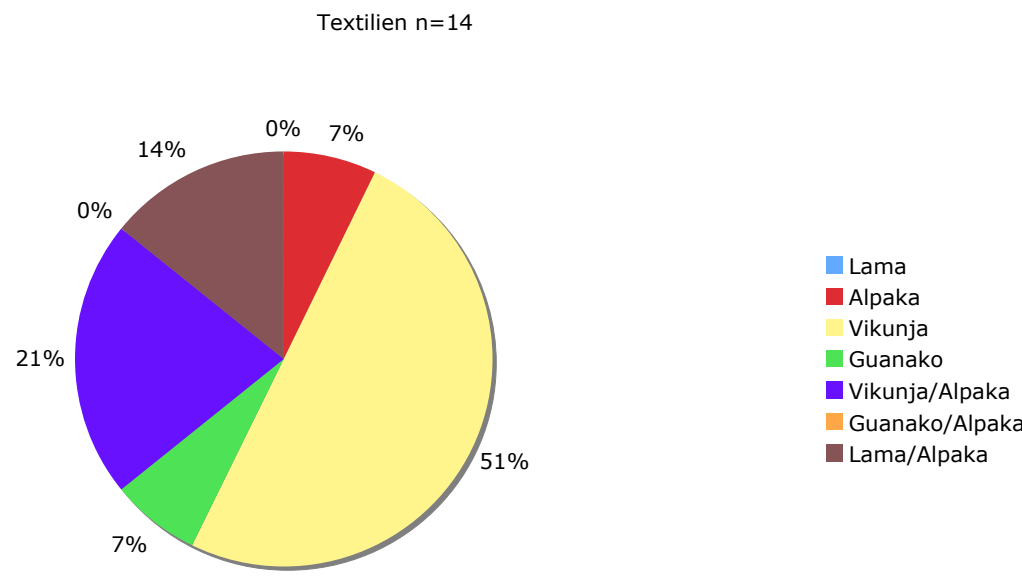

Abbildung 66: Speziesdistribution in textilen Proben 
Um Aussagen über die Nutzung von Camelidae in der Nasca-Zeit und einer möglichen Intensivierung zu untersuchen, werden die Speziesdistributionen in dem Probenmaterial der einzelnen Fundorte verglichen. In Abbildung 67 ist die Verteilung der Spezies der einzelnen Fundorte als prozentualer Wert, bezogen auf die Gesamtanzahl der bestimmten Proben des Fundortes, dargestellt.

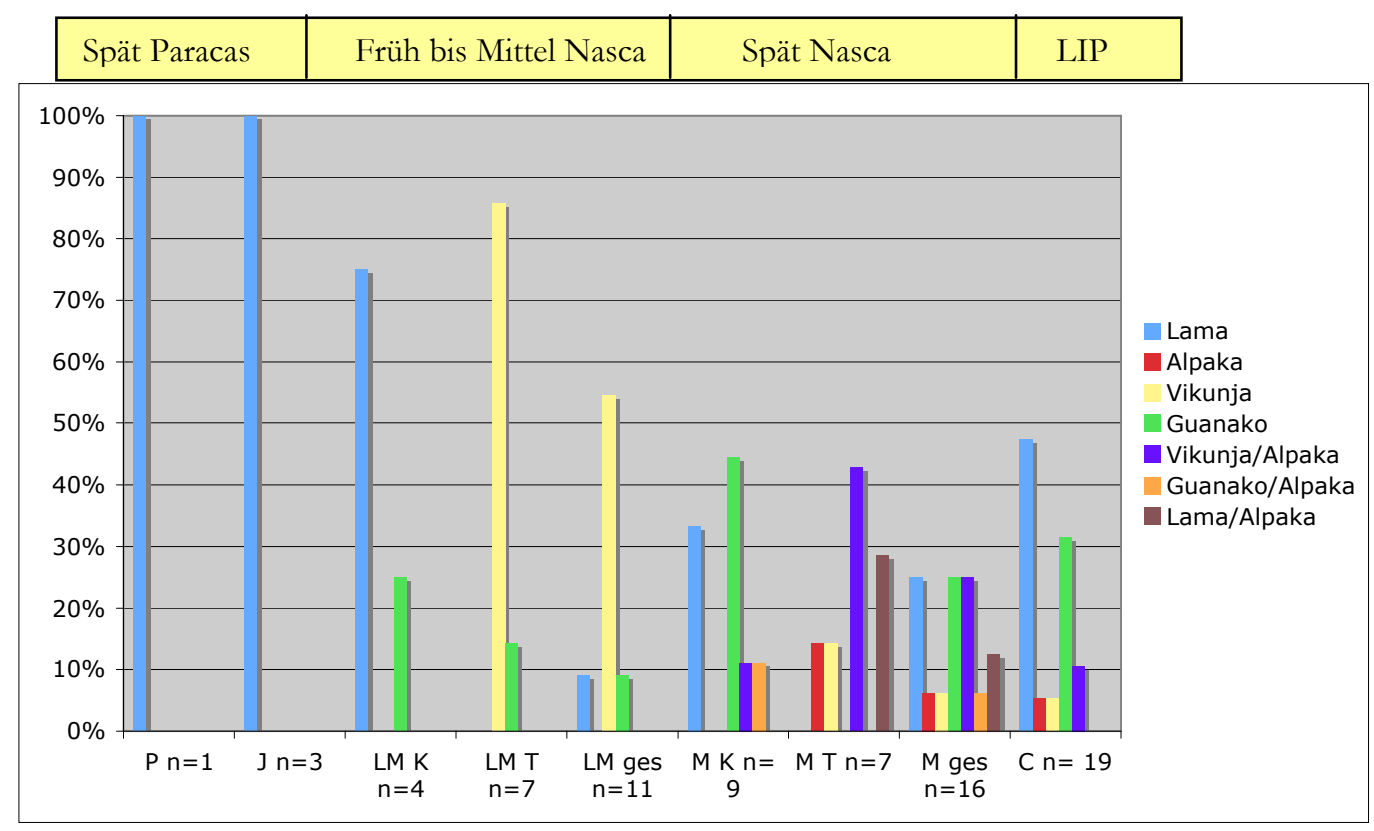

Abbildung 67: Anteile der Spezies an den jeweiligen Fundorten. Legende: $\mathrm{P}=$ Pernil Alto, J = Jauranga, LM = Los Molinos, $\mathrm{M}=$ Montegrande, $\mathrm{C}=$ Chillo, $\mathrm{K}=$ Knochen und Zähne, $\mathrm{T}=$ Textilien

Für den Fundort Pernil Alto und Jauranga ist die Stichprobenzahl sehr niedrig, es kommen hier nur Lamas vor. Für den Fundort Los Molinos konnte in den Knochen- und Zahn-Proben neben Lamas auch ein Guanako ausgemacht werden. Für Montegrande wurden im Knochenund Zahn-Material Lamas, Guanakos sowie zwei Mischformen gefunden. In Chillo waren alle vier Spezies vertreten, sowie zwei Mischformen.

Für textiles Material konnte eine gleichgroße Anzahl Proben typisiert werden. Die Textilien aus Los Molinos scheinen nur aus Wolle der Wildtypen Vikunja und Guanako gefertigt zu sein. Die Proben aus Montegrande weisen bezüglich ihrer Speziesdistribution eine höhere Variabilität auf. Hier sind neben Vikunjas auch Alpakas und Alpaka-Mischtypen anzutreffen, die Textilien wurden also auch aus Wolle einer domestizierten Spezies angefertigt.

Der Fundort Chillo weist eine Speziesvariabilität auf, die der des gesamten Probenmaterials, also Knochen- und Zahn-Proben sowie Textilien, aus Montegrande ähnelt. Für den Fundort Chillo kann also belegt werden, dass Vikunjas und Alpakas importiert wurden, am Fundort Montegrande jedoch wurde nur deren Wolle importiert. Ein Anstieg der Speziesvariabilität über die Zeit ist also am Skelettmaterial zu beobachten. 
7 Populationsgenetische Auswertung

Im Folgenden werden die gefundenen genetischen Zusammensetzungen hinsichtlich ihrer Diversität betrachtet und eine Zusammenführung der in rezentem und überliefertem Material gefundenen Haplotypen erfolgt. Diese sollen der Erfassung der genetischen Variabilität sowie mögliche Veränderungen dieser dienen. Die AMOVA und die Bestimmung der Diversitäten erfolgten mit Hilfe der Software Arlequin ${ }^{\circ}$ Excoffier 1998-2007, MEGA Software Version 4.0. und DnaSP4.10. Die Erstellung der Minimal Spanning Netzwerke erfolgte mit Hilfe der Software Geneious (Biomatters), unter den Bedingungen UPGMA bootstrap und der DistanzBerechnung nach Nei (s. Kap. 2.3).

7.1 AMOVA und Diversitäten der gefundenen Haplotypen in rezenten Material

\section{Cytochrom b-Gen}

Die Diversitäten (nucleotide diversity) der phänotypischen Spezies sind am Größten innerhalb der Alpakas (0,036), gefolgt von den Lamas $(0,030)$. Guanakos haben einen Diversitätswert von 0,014 und Vikunjas von 0,010. Hieraus ergibt sich ein Gesamt-Wert der genetischen Distanz von 0,025 (MEGA) bis 0,035 (Geneious).

Die per AMOVA berechneten $\Phi_{\mathrm{ST}}$-Werte (Index der Fixierung) zeigen eine Abgrenzung der Populationen Vikunja und Guanako $(0,819)$. Vikunjas und Lamas zeigen ebenfalls eine Abgrenzung (0,788). Die Werte der Beziehungen der einzelnen Populationen liegen ansonsten zwischen 0,4 und 0,6. Alle weisen einen Wert für $\mathrm{N}_{\mathrm{m}}$ (numbers of migrations) von kleiner als 1 auf, dies deutet auf ein geringes $\mathrm{Ma}$ an Migrationen zwischen den Populationen hin. In Tabelle 57 sind die $\Phi_{\text {ST }}$ sowie die $\mathrm{N}_{\mathrm{m}}$ Werte gelistet.

Tabelle 57: $\Phi_{\mathrm{ST}}$ und $\mathrm{N}_{\mathrm{m}}$-Werte der einzelnen Populationen

\begin{tabular}{|l|l|l|l|l|l|l|}
\hline & \multicolumn{2}{|l|}{ Guanako } & \multicolumn{2}{l|}{ Vikunja } & \multicolumn{2}{l|}{ Lama } \\
\hline & $\Phi_{\mathrm{ST}}$ & $\mathrm{N}_{\mathrm{m}}$ & $\Phi_{\mathrm{ST}}$ & $\mathrm{N}_{\mathrm{m}}$ & $\Phi_{\mathrm{ST}}$ & $\mathrm{N}_{\mathrm{m}}$ \\
\hline Alpaka & 0,619 & 0,154 & 0,396 & 0,381 & 0,452 & 0,303 \\
\hline Guanako & & & 0,819 & 0,055 & 0,604 & 0,164 \\
\hline Vikunja & & & & & 0,788 & 0,067 \\
\hline
\end{tabular}

Legende: $\Phi_{\mathrm{ST}}=$ Index der Fixierung, $\mathrm{N}_{\mathrm{m}}=\mathrm{Maß}$ der Migrationsanzahl

Die Anzahl an Migrationen ist am Höchsten zwischen den Populationen Alpaka und Vikunja.

Die Populationen Lama zu Vikunja sowie Vikunja zu Guanako weisen ein hohes Maß an

Differenzierung auf, was auf einen geringen Genfluss zwischen den Populationen hindeutet. 


\section{COI}

Der Gesamt-Wert der genetischen Distanz zwischen den phänotypischen Spezies beträgt 0,025. Die Nukleotid-Diversität ist am Höchsten innerhalb der Alpakas $(0,019)$ und Guanakos $(0,02)$.

Es wurden folgende $\Phi_{\mathrm{ST}}-$ und $\mathrm{N}_{\mathrm{m}}$-Werte berechnet (Tab. 58).

Tabelle 58: $\Phi_{\mathrm{ST}}-$ und $\mathrm{N}_{\mathrm{m}}$-Werte die anhand der Sequenzen des COI-Fragmentes

\begin{tabular}{|l|l|l|l|l|l|l|}
\hline & \multicolumn{3}{|l|}{ Guanako } & \multicolumn{2}{l|}{ Vikunja } & \multicolumn{2}{l|}{ Lama } \\
\hline & $\Phi_{\mathrm{ST}}$ & $\mathrm{N}_{\mathrm{m}}$ & $\Phi_{\mathrm{ST}}$ & $\mathrm{N}_{\mathrm{m}}$ & $\Phi_{\mathrm{ST}}$ & $\mathrm{N}_{\mathrm{m}}$ \\
\hline Alpaka & 0,361 & 0,443 & 0,258 & 0,719 & 0,527 & 0,224 \\
\hline Guanako & & & 0,687 & 0,114 & 0,573 & 0,186 \\
\hline Vikunja & & & & & 0,815 & 0,057 \\
\hline
\end{tabular}

Legende: $\Phi_{\mathrm{ST}}=$ Index der Fixierung, $\mathrm{N}_{\mathrm{m}}=\mathrm{Maß}$ der Migrationsanzahl

Zwischen Vikunja und Alpakas ist der $\mathrm{N}_{\mathrm{m}}$-Wert erhöht. Dieser deutet auf einen zwar gemäßigten, jedoch vorhandenen genetischen Austausch zwischen beiden Populationen. Die $\mathrm{N}_{\mathrm{m}}$-Werte zwischen den weiteren Populationen liegen alle unter 1, was auf einen geringen Genfluss schließen lässt.

\section{Nd5}

Der Gesamt-Wert der genetischen Distanz der phänotypischen Spezies beträgt 0,032. Die Nukleotid-Diversität ist innerhalb der Alpakas am Höchsten (0,03). In den drei anderen phänotypischen Spezies liegt diese unter 0,01.

Es ergeben sich folgende $\Phi_{\mathrm{ST}}-$ und $\mathrm{N}_{\mathrm{m}}$-Werte (Tab. 59).

Tabelle 59: $\Phi_{\mathrm{ST}}-$ und $\mathrm{N}_{\mathrm{m}}$-Werte aufgrund der Sequenzabfolge im Nd5-Gen

\begin{tabular}{|l|l|l|l|l|l|l|}
\hline & \multicolumn{2}{|l|}{ Guanako } & \multicolumn{2}{l|}{ Vikunja } & \multicolumn{2}{l|}{ Lama } \\
\hline & $\boldsymbol{\Phi}_{\text {ST }}$ & $\mathrm{N}_{\mathrm{m}}$ & $\boldsymbol{\Phi}_{\text {ST }}$ & $\mathrm{N}_{\mathrm{m}}$ & $\boldsymbol{\Phi}_{\text {ST }}$ & $\mathrm{N}_{\mathrm{m}}$ \\
\hline Alpaka & 0,423 & 0,341 & 0,304 & 0,572 & 0,530 & 0,222 \\
\hline Guanako & & & 0,904 & 0,027 & 0,682 & 0,117 \\
\hline Vikunja & & & & & 0,918 & 0,022 \\
\hline
\end{tabular}

Legende: $\Phi_{\mathrm{ST}}=$ Index der Fixierung, $\mathrm{N}_{\mathrm{m}}=\mathrm{Maß}$ der Migrationsanzahl

Für keine der Konstellationen konnte ein erhöhter $\mathrm{N}_{\mathrm{m}}$-Wert festgestellt werden, dies bedeutet dass wenig bis kein Genfluss existiert. Jedoch ist auch hier, wie für das cytb- und COI-Gen, der Wert zwischen Alpakas und Vikunjas am Höchsten. 
7.2 AMOVA, Diversitäten und Netzwerke der gefundenen Haplotypen in überliefertem Material

\section{Cytochrom b - Gesamt}

Die Nukleotid-Diversität beträgt 0,007 für Lamas und für Gunakos 0,013. Der Mittelwert der Nukleotid-Diversität liegt bei 0,007. Guanakos weisen also eine höhere Diversität auf als Lamas. Es konnten nur Guanakos und Lamas in die AMOVA Berechnung mit einbezogen werde, da die Stichprobenanzahl für Alpakas und Vikunjas nicht ausreichend war. Der $\Phi_{\mathrm{ST}}-$ Wert betrug 0,724, der $\mathrm{N}_{\mathrm{m}}$-Wert 0,095. Es konnte also kein Genfluss zwischen den Populationen festgestellt werde.

Für die phylogenetischen Beziehungen unter den gefundenen Haplotypen ergibt sich folgendes Netzwerk (s. Abb. 68).

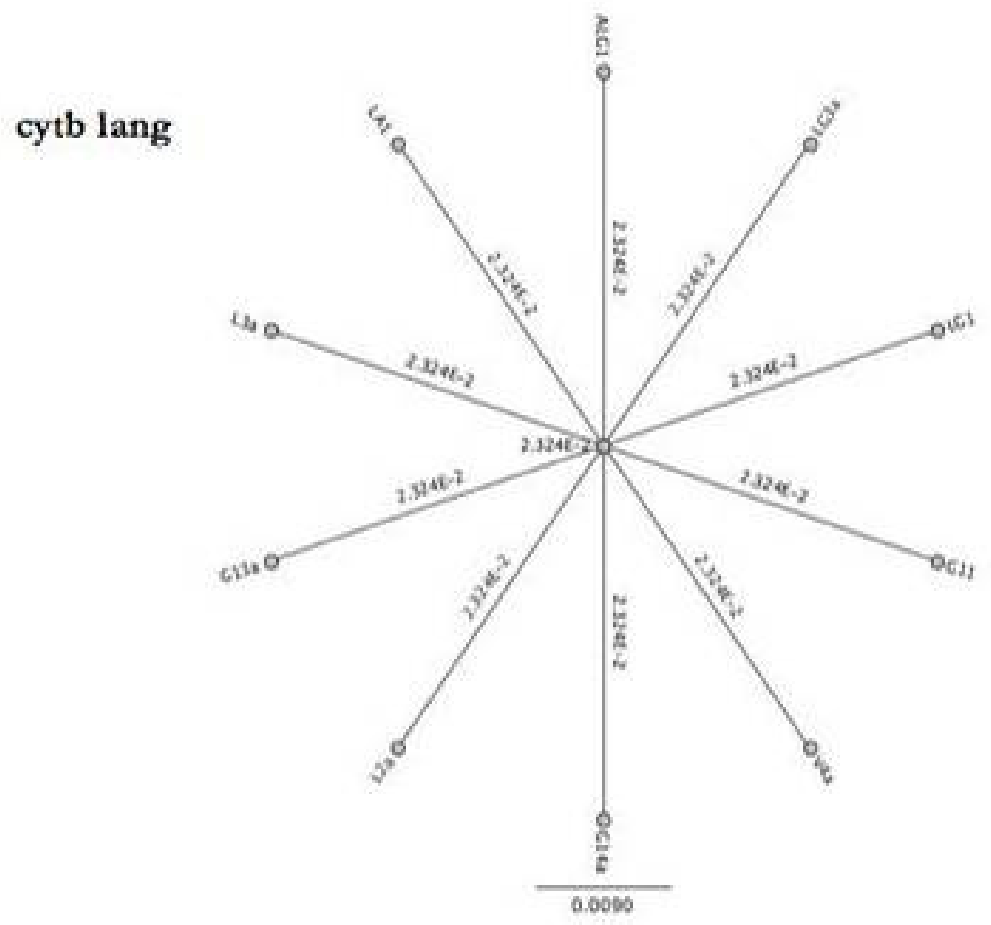

Abbildung 68: Minimal Spanning Netzwerk der Haplotypen der Fragmente des Cytochrom b -Gen (näheres im Text)

Die Haplotypen gruppieren alle um einen nicht bekannten Haplotyp. Dies bedeutet, dass sich die gefundenen Sequenzen alle auf einen gemeinsamen Vorfahren zurückführen lassen. Die sternförmige Anordnung könnte bedeutet, das für die im Cytochrom b-Gen typisierten Lamas, Guanakos und Alpakas, eine genetische Drift (Gründer- oder bottleneck-Ereignis) stattgefunden hat. 


\section{Cytochrom b - Vorderer Bereich}

Die Nukleotid-Diversität beträgt für Lamas 0,013, für Alpakas 0,036, für Vikunjas 0,009 und für Guanakos 0,023. Dies entspricht einer Gesamt-Nukleotid-Diversität von 0,02. Alpakas zeigen sich deutlich variabel, Vikunjas dagegen haben eine geringe Variabilität. Folgende $\Phi_{\mathrm{ST}}-$ und $\mathrm{N}_{\mathrm{m}}$-Werte konnten berechnet werden (s. Tab. 60).

Tabelle 60: $\Phi_{\mathrm{ST}}-$ und $\mathrm{N}_{\mathrm{m}}$-Werte der AMOVA des vorderen Bereiches des cytb-Gens

\begin{tabular}{|l|l|l|l|l|l|l|}
\hline & \multicolumn{2}{|l|}{ Guanako } & \multicolumn{2}{l|}{ Vikunja } & \multicolumn{2}{l|}{ Lama } \\
\hline & $\Phi_{\mathrm{ST}}$ & $\mathrm{N}_{\mathrm{m}}$ & $\Phi_{\mathrm{ST}}$ & $\mathrm{N}_{\mathrm{m}}$ & $\Phi_{\mathrm{ST}}$ & $\mathrm{N}_{\mathrm{m}}$ \\
\hline Alpaka & 0,412 & 0,357 & 0,341 & 0,483 & 0,469 & 0,283 \\
\hline Guanako & & & 0,706 & 0,104 & 0,389 & 0,393 \\
\hline Vikunja & & & & & 0,806 & 0,060 \\
\hline
\end{tabular}

Es konnte kein Genfluss zwischen den Populationen $\left(\mathrm{N}_{\mathrm{m}}<1\right)$ festgestellt werden.

Aus den gefundenen Haplotypen ergab sich folgendes Netzwerk (s. Abb. 69).

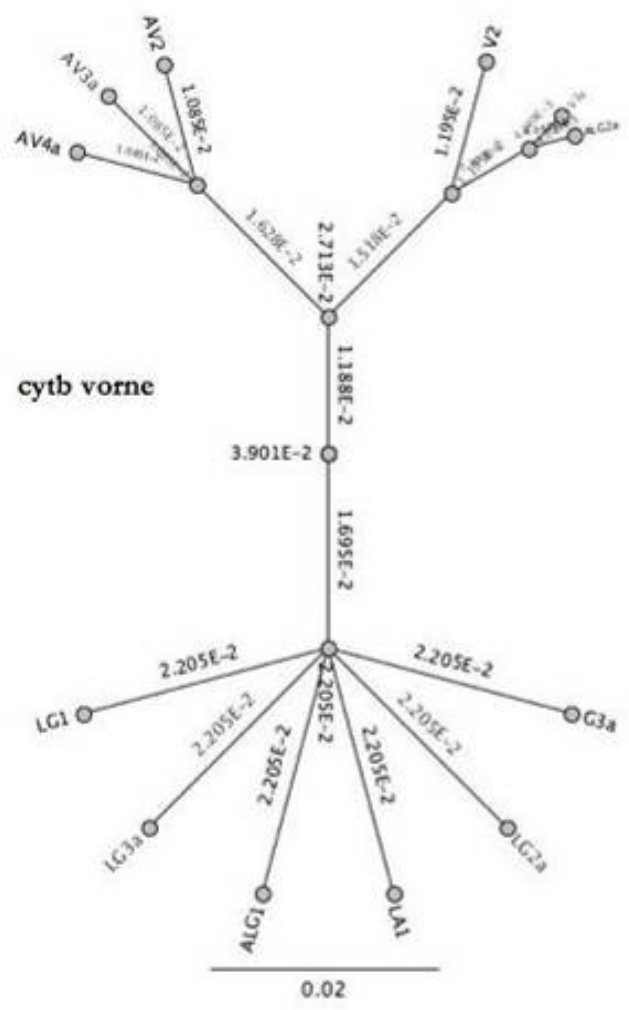

Abbildung 69: Minimal Spanning Netzwerk das sich aus den gefundenen Haplotypen des vorderen Bereiches im cytb-Gen ergibt (näheres im Text)

Die Haplotypen gruppieren sich in zwei Großgruppen: Die Gruppe Alpaka -Vikunja (oben) und die Gruppe Lama-Alpaka-Guanako (unten). Für die Haplogruppe G3 erfolgte eine Gruppierung zu Vikunja, aber auch zur Lama-Alpaka-Guanako-Gruppe. Dies bedeutet, dass die verwandtschaftliche Beziehung dieses Haplotypus nicht zu klären ist. Beide Gruppen sind 
über drei unbekannte Haplotypen zu verknüpfen. Die genetische Distanz zwischen den beiden Gruppen beträgt 2,96 x $10^{-2}$.

\section{Cytochrom b - Hinterer Bereich}

Die Nukleotid-Diversitäten betragen 0,011 für Lamas, 0,039 für Alpakas, 0,024 für Guanakos und 0,016 für Vikunjas. Der Mittelwert der Nukleotid-Diversität beträgt 0,022. Alpakas zeigen sich als sehr variabel. Folgende $\Phi_{\mathrm{ST}^{-}}$und $\mathrm{N}_{\mathrm{m}}$-Werte ergaben sich (s. Tab. 61)

Tabelle 61: $\Phi_{\mathrm{ST}^{-}}$und $\mathrm{N}_{\mathrm{m}}$-Werte der AMOVA der gefundenen Haplotypen des hinteren Bereiches des cytb-Gens

\begin{tabular}{|l|l|l|l|l|l|l|}
\hline & \multicolumn{2}{|l|}{ Guanako } & \multicolumn{2}{l|}{ Vikunja } & \multicolumn{2}{l|}{ Lama } \\
\hline & $\Phi_{\text {ST }}$ & $\mathrm{N}_{\mathrm{m}}$ & $\Phi_{\text {ST }}$ & $\mathrm{N}_{\mathrm{m}}$ & $\Phi_{\text {ST }}$ & $\mathrm{N}_{\mathrm{m}}$ \\
\hline Alpaka & 0,607 & 0,162 & 0,068 & 3,432 & 0,722 & 0,096 \\
\hline Guanako & & & 0,738 & 0,089 & 0,629 & 0,148 \\
\hline Vikunja & & & & & 0,870 & 0,037 \\
\hline
\end{tabular}

Legende: $\Phi_{\mathrm{ST}}=$ Index der Fixierung, $\mathrm{N}_{\mathrm{m}}=\mathrm{Ma}$ der Migrationsanzahl

Zwischen Vikunjas und Alpakas besteht ein hohes Maß an Genfluss. Zwischen den anderen Populationen kann kein Genfluss nachgewiesen werden. Anhand der gefundenen Haplotypen konnte folgendes Netzwerk erstellt werden (s. Abb. 70).

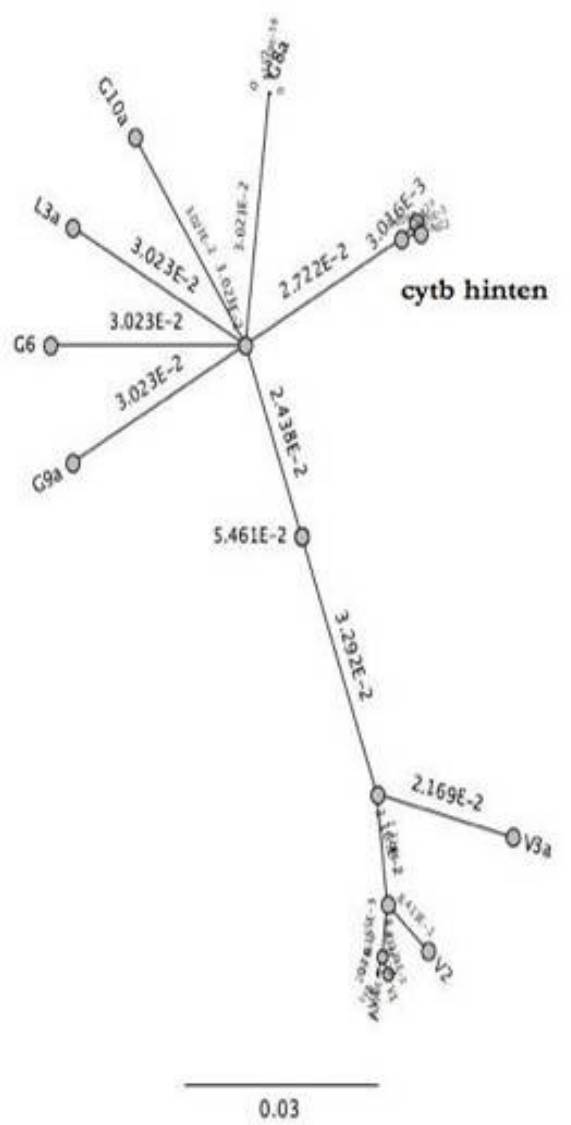

Abbildung 70: Minimal Spanning Netzwerk der im hinteren Bereich gefundenen Haplotypen des cytb-Gens (näheres im Text) 
Es entstehen zwei Großgruppen die jeweils auf einen unbekannten Haplotypen zurück zu führen sind. Die genetische Distanz zwischen den Gruppen Alpaka-Vikunja (unten) und Lama-Alpaka-Guanako (oben) beträgt 5,72 x $10^{-2}$.

\section{COI}

Die Nukleotid-Diversität beträgt für Lamas 0,007, für Alpakas 0,019 und für Guanakos 0,004. Dies entspricht einem Mittelwert der Nukleotid-Diversität von 0,01. In der Stichprobe die erfolgreich typisiert werden konnten, lagen keine Vikunjas vor.

Folgende $\Phi_{\mathrm{ST}^{-}}$und $\mathrm{N}_{\mathrm{m}}$-Werte ergaben sich (s. Tab. 62).

Tabelle 62: $\Phi_{\mathrm{ST}^{-}}$und $\mathrm{N}_{\mathrm{m}}$-Werte der AMOVA der gefundenen Haplotypen des COI-Gens

\begin{tabular}{|c|c|c|c|c|}
\hline & \multicolumn{2}{|c|}{ Guanako } & \multicolumn{2}{|l|}{ Lama } \\
\hline & $\Phi_{\mathrm{ST}}$ & $\mathrm{N}_{\mathrm{m}}$ & $\Phi_{\mathrm{ST}}$ & $\mathrm{N}_{\mathrm{m}}$ \\
\hline Alpaka & 0,735 & 0,090 & 0,815 & 0,057 \\
\hline Guanako & & & 0,829 & 0,052 \\
\hline
\end{tabular}

Legende: $\Phi_{\mathrm{ST}}=$ Index der Fixierung, $\mathrm{N}_{\mathrm{m}}=$ Maß der Migrationsanzahl

Es konnte kein Genfluss $\left(\mathrm{N}_{\mathrm{m}}<1\right)$ festgestellt werden. Aus den gefundenen Haplotypen ergab sich folgendes Netzwerk (s. Abb. 71)

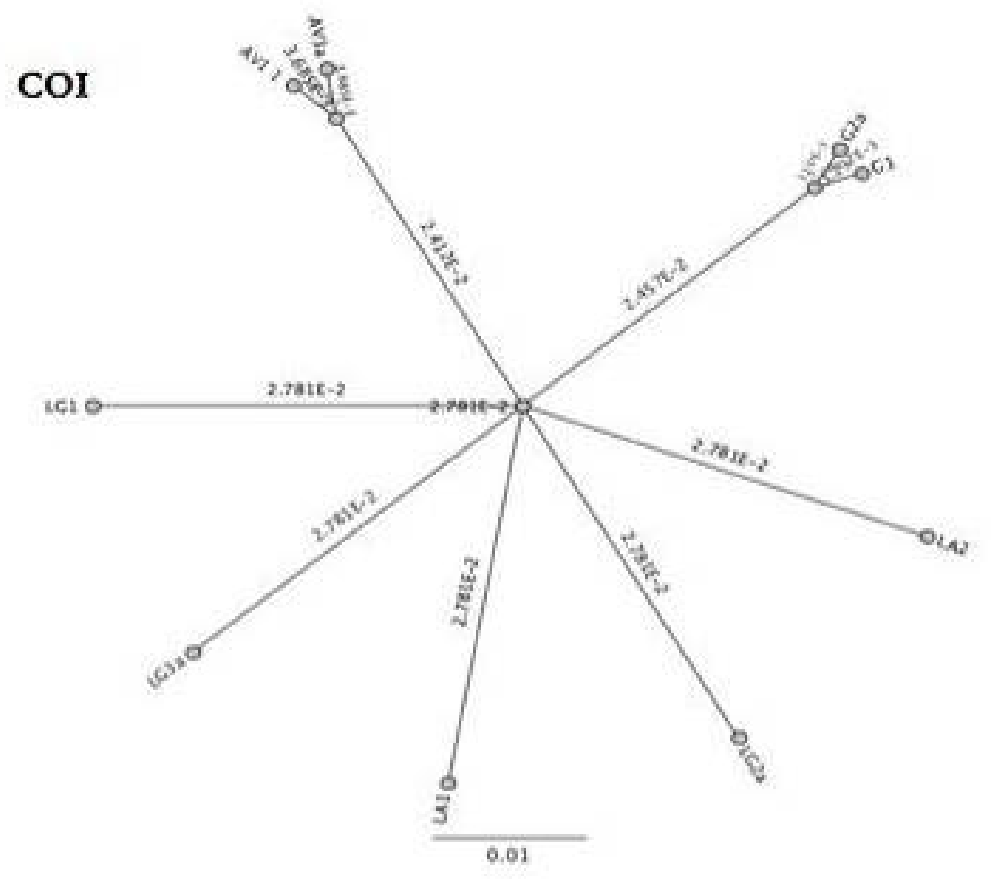

Abbildung 71: Minimal Spanning Netzwerk der Haplotypen des COI-Gens (näheres im Text)

Alle gefundenen Haplotypen gruppieren um einen unbekannten Haplotypen. Die genetische Distanz beträgt ca. 2,6 x 10-2. Die Alpaka-Vikunja Haplotypen AV (links oben) weisen keine höhere Distanz zu den anderen Haplotypen, als Guanako und Lama Haplotypen unter einander, auf. Dies deutet auf eine nahe Verwandtschaft. Die sterförmige Anordnung deutet 
auf genetische Drift, oder ist ein Artefakt resultierend aus der geringen Anzahl von Alpaka und Vikunjas in der Stichprobe.

\section{Nd5}

Die Nukleotid-Diversitäten betragen für Lamas 0,008, für Alpakas 0,039 und für Guanakos 0,005. Vikunjas waren in der Stichprobe der typisierbaren Individuen für das Gen Nd5 nicht vertreten. Der Mittelwert der Nukleotid-Diversität beträgt 0,017 . Folgende $\Phi_{\mathrm{ST}^{-}}$und $\mathrm{N}_{\mathrm{m}^{-}}$ Werte ergaben sich (s. Tab. 63).

Tabelle 63: $\Phi_{\mathrm{ST}^{-}}$und $\mathrm{N}_{\mathrm{m}}$-Werte der AMOVA der gefundenen Haplotypen des Nd5-Gens

\begin{tabular}{|c|c|c|c|c|}
\hline & \multicolumn{2}{|c|}{ Guanako } & \multicolumn{2}{|l|}{ Lama } \\
\hline & $\Phi_{\mathrm{ST}}$ & $\mathrm{N}_{\mathrm{m}}$ & $\Phi_{\mathrm{ST}}$ & $\mathrm{N}_{\mathrm{m}}$ \\
\hline Alpaka & 0,407 & 0,364 & 0,519 & 0,232 \\
\hline Guanak & & & 0,441 & 0,317 \\
\hline
\end{tabular}

Legende: $\Phi_{\mathrm{ST}}=$ Index der Fixierung, $\mathrm{N}_{\mathrm{m}}=\mathrm{Ma} \beta$ der Migrationsanzahl

Es konnte kein Genfluss zwischen den Populationen festgestellt werden.

Aus den gefundenen Haplotypen ergab sich folgendes Netzwerk (s. Abb. 72).

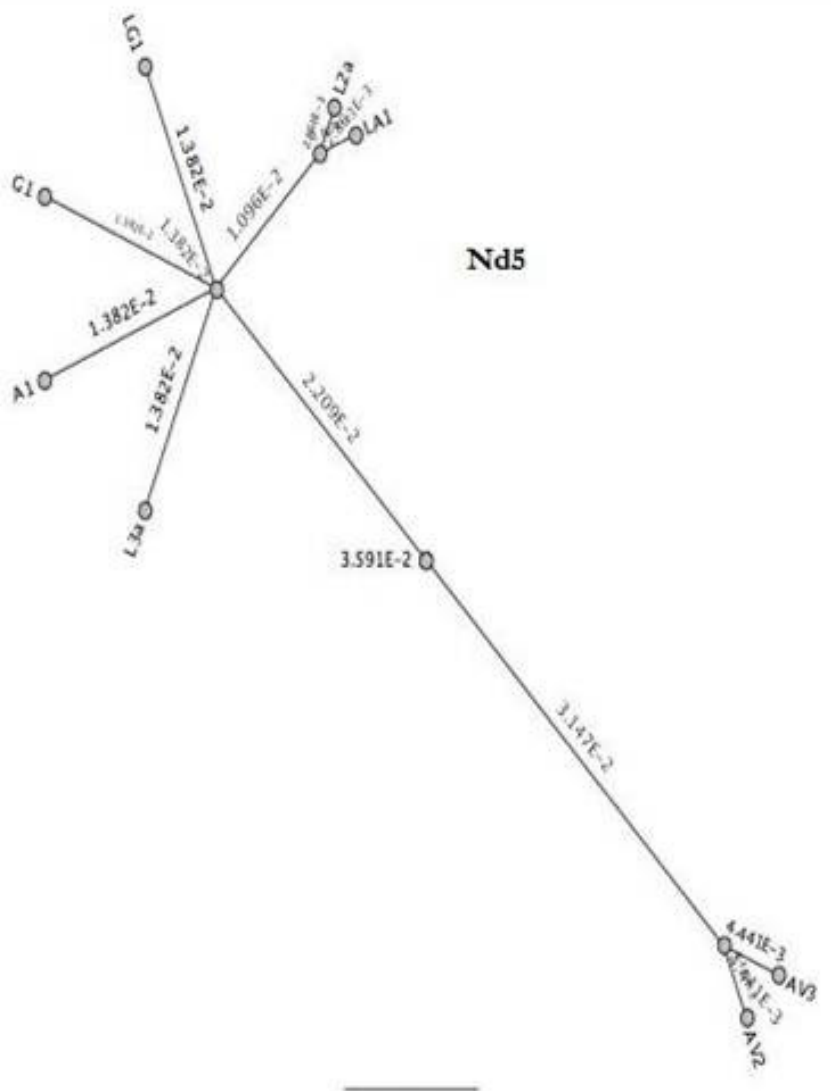


Die Alpaka Haplotypen AV2 und AV3 gruppieren zusammen und weisen eine genetische Distanz von 5,35 x $10^{-2}$ zu den übrigen Haplotypen auf. Die Lama-Alpaka-Guanako Gruppe (oben) kann über einen unbekannten Haplotypen verknüpft werden, die genetische Distanz innerhalb dieser Gruppe liegt bei ca. 1,3 x 10-2. Eine solche sternförmige Gruppierung kann aus genetischer Drift resultieren.

Zusammengefasst kann man sagen, dass für alle betrachteten mitochondrialen Gene genetische Drift in Frage käme, da die Netzwerke sternförmig gruppieren. Die NukleotidDiversität ist immer am Höchsten für Alpakas, wenn diese in der Stichprobe vorlagen. Für den hinteren Bereich des Cytochrom b-Gens, in dem die Stichprobe jeder Spezies insgesamt am Größten ist (s. Kap. 4.1.1), kann ein Genfluss zwischen Alpakas und Vikunjas festgestellt werden.

\subsection{Zusammenführung der Ergebnisse des rezenten und überlieferten Materials}

Anhand der Ergebnisse für mitochondriale Gene des untersuchten Materials wurden Netzwerke zur Feststellung phylogenetischer Distanz der rezenten und historischen Populationen erstellt. Für die gefundenen Haplotypen wurde eine gemeinsame AMOVA pro analysiertem mitochondrialen Locus durchgeführt. Die Kombination der Daten historischer und rezenter Populationen repräsentiert eine höhere Anzahl möglicher Haplotypen und zeigt damit ein genaueres Bild der Spezies-Variabilität auf.

\subsubsection{Netzwerke}

\section{Cytochrom b Gesamt}

Alle in überliefertem Material typisierten Haplotypen gruppieren mit denen der rezenten Proben. Eine Ausnahme bildet hier die Probe COA11, diese weist den Haplotyp V4 auf der zwischen den beiden Großgruppen Vikunja (oben) und Guanako (unten) liegt. Die Benennung des Haplotyp erfolgte aufgrund der Polymorphismen 645G und 648G, die nur in Vikunjas angetroffen werden. Die genetische Distanz zur Gruppe Guanako $\left(1,8 \times 10^{-2}\right)$ ist nur geringfügig kleiner als zur Gruppe Vikunja $\left(1,9 \times 10^{-2}\right)$, so dass hier von einem GuanakoVikunja-Mischhaplotyp gesprochen werden kann. Die weiteren Haplotypen historischer Proben, gehen alle auf einen gemeinsamen Ursprung mit denen rezenter Haplotypen zurück (s. Abb. 73). 


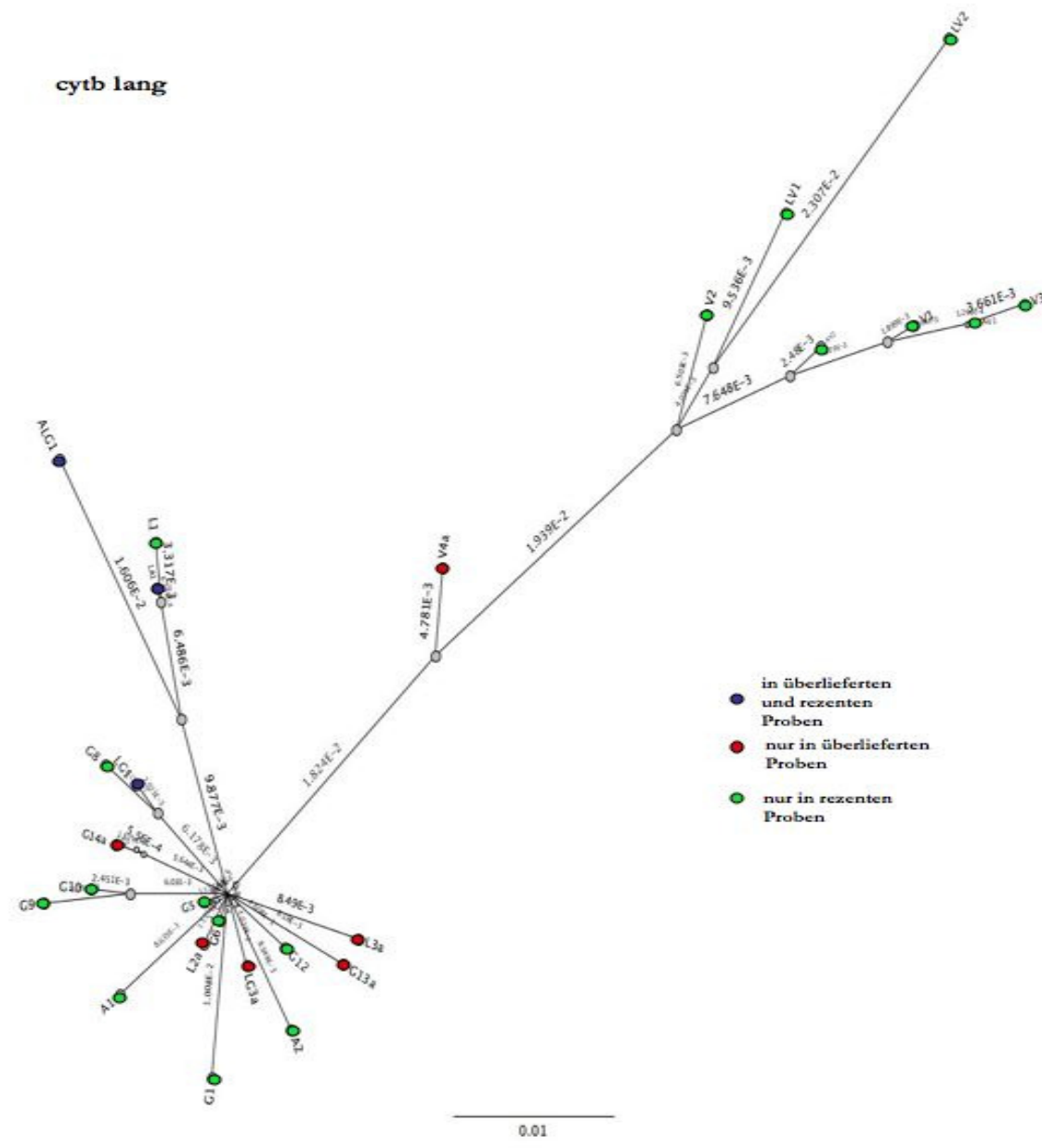

Abbildung 73: Netzwerk, das sich aus den Distanzen der Haplotypen des langen cytb-Fragmentes ergibt (näheres im Text)

\section{Cytochrom b - Vorderer Bereich}

Für die Großgruppen Guanako (oben) und Vikunja (unten) entstehen sternförmige Anordnungen. Dies zeigt, dass der Haplotyp des letzten gemeinsamen Vorfahrens nicht angetroffen werden konnte. Die genetische Distanz zwischen beiden Gruppen kann mit 3,2 x $10^{-2}$ angegeben werden. Für den Haplotyp G2, der nur in rezentem Material typisiert wurde, konnte der Haplotyp G3, der nur in alten Proben typisiert wurde, als Ursprungs-Haplotyp bestimmt werden (s. Abb. 74). 


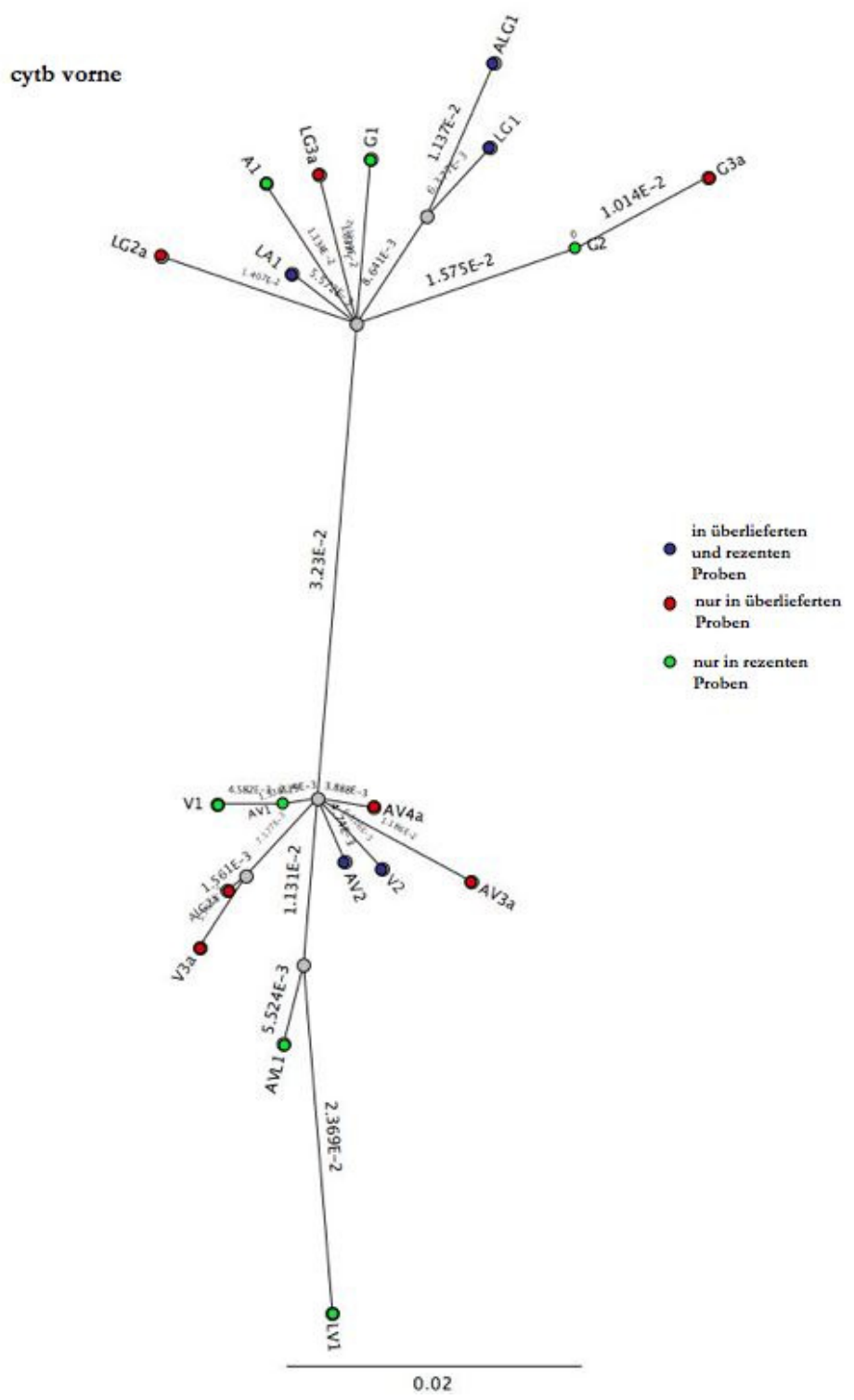

Abbildung 74: Minimal Spanning Netzwerk aller typisierten Haplotypen des vorderen Bereiches des cytb-Gens (näheres im Text)

\section{Cytochrom b - Hinterer Bereich}

Es ergeben sich zwei Großgruppen deren Distanz mit 5,8 x $10^{-2}$ angegeben werden kann. Der Haplotyp LG1 (zentral oben) repräsentiert den nächsten Verwandten zum Haplotyp AV1 (zentral unten). Die Haplotypen des historischen Materials gruppieren alle mit denen rezenter Tiere (s. Abb. 75). 


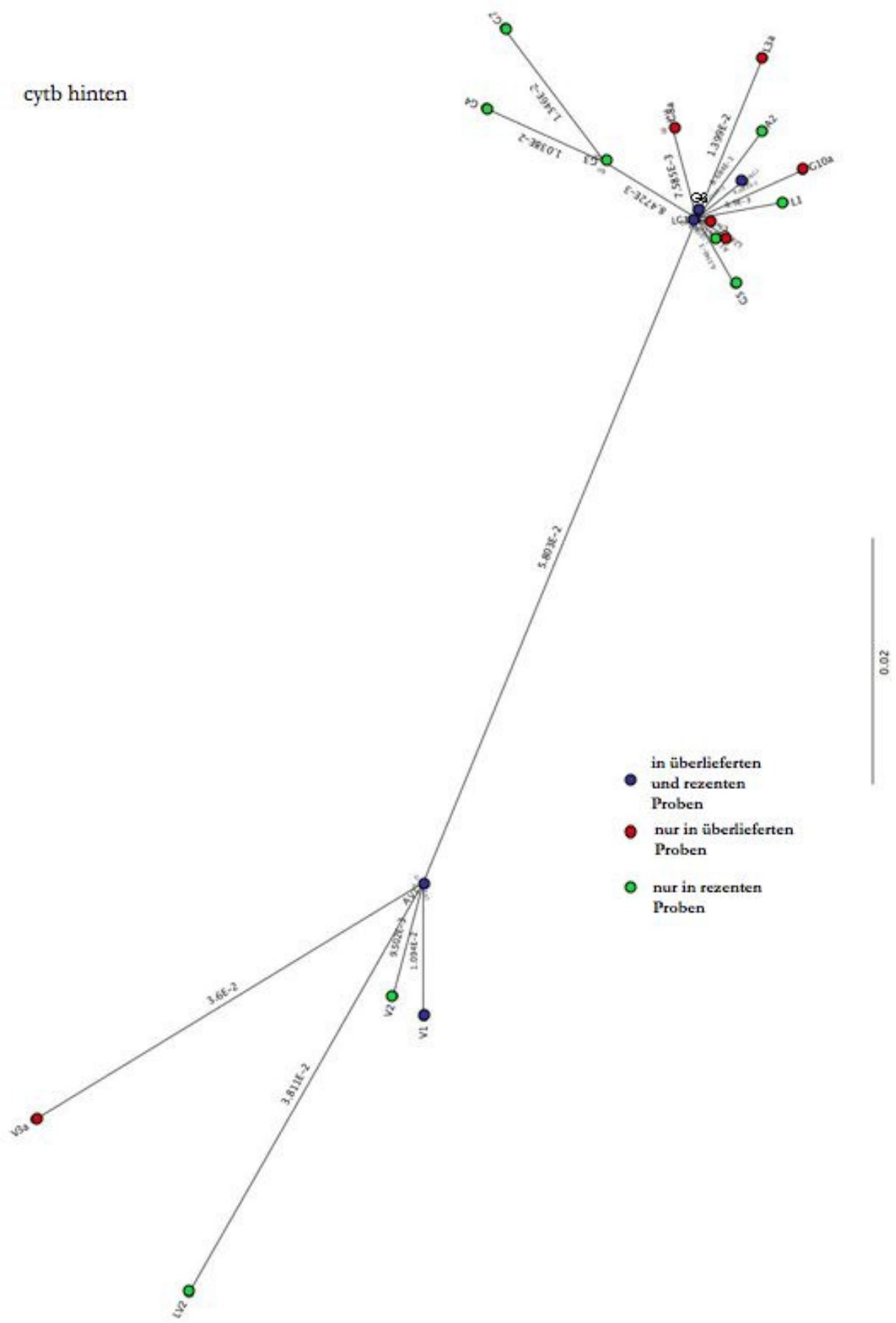

Abbildung 75: Minimal Spanning Netzwerk aller typisierten Haplotypen des den hinteren Bereich des cytb-Gens (näheres im Text)

\section{COI}

Die Haplotypen gruppieren in drei Hauptgruppen: Vikunja und Alpaka (oben), Guanako und Lama- Alpaka (mittig) sowie die Gruppe Lama-Guanako (unten). Die genetische Distanz zwischen dem Haplotypen LA1 und den Vikunja-Alpaka-Haplotypen beträgt 9,1 x 10 $0^{-3}$, die zu den Guanako-Haplotypen 1,5 x 10-2 und die zu den Lama-Guanako Mischhaplotypen 1,5 x $10^{2}$ (s. Abb. 76). Die nur in überliefertem Material gefundenen Halotypen stellen immer ancestrale dar, aus denen sich die heute anzutreffenden Haplotypen, entwickelt haben. 


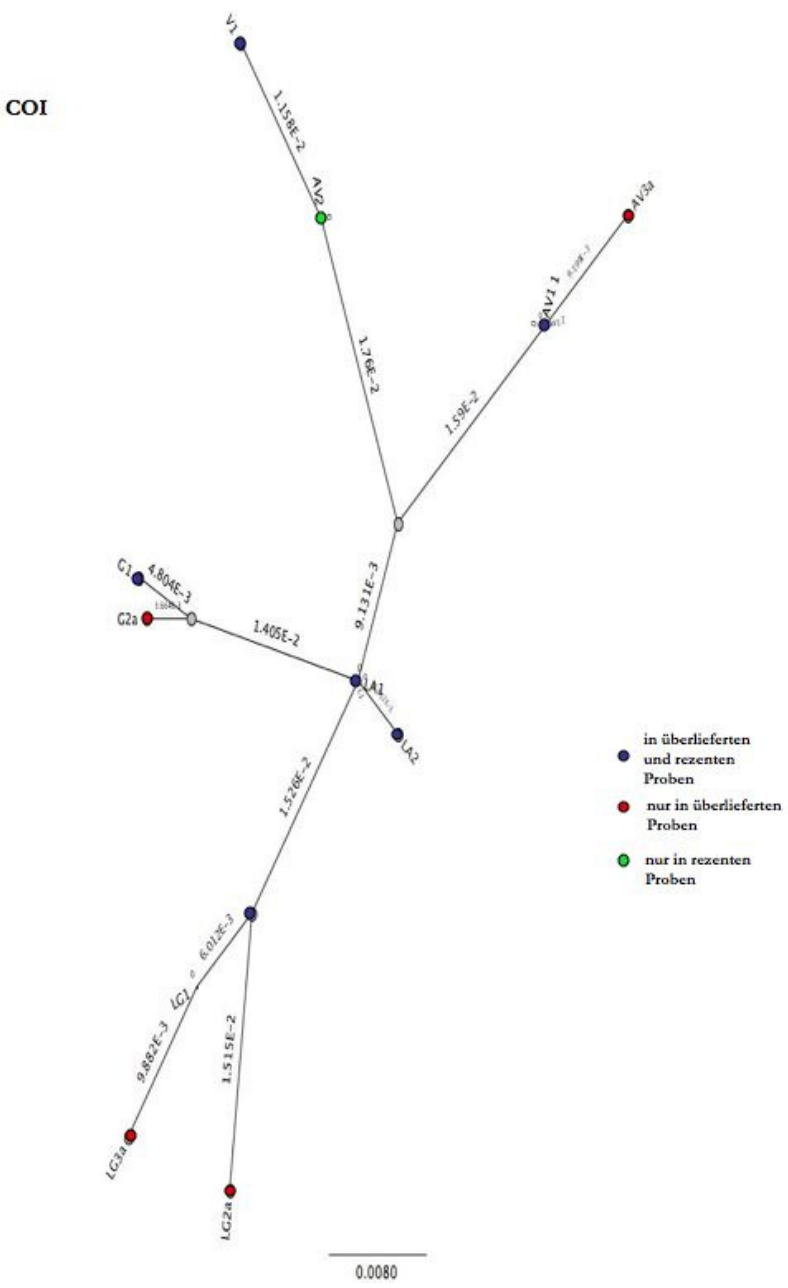

Abbildung 76: Minimal Spanning Netzwerk der gefundenen Haplotypen im COI-Gen (näheres im Text)

\section{Nd5}

Es können zwei Großgruppen ausgemacht werden: Vikunja-Alpaka (oben) und Lama-AlpakaGuanako (unten). Dazwischen liegt der Haplotyp G1. Die genetische Distanz zwischen dem Haplotyp G1 zur Vikunja-Gruppe kann mit 4,2 × $10^{-2}$ angegeben werden, die zur LamaAlpaka-Guanako-Gruppe mit 1,2 × 10-2. Die in überliefertem Material gefundenen Haplotypen gruppieren mit den rezent gefundenen Haplotypen und stellen im Falle der Vikunja-Gruppe einen direkten Vorfahr der gefundenen Haplogruppe AV2, aus der wiederum die Haplogruppe AV1, unter Einbeziehung der Haplogruppe V1, hervorgeht (s. Abb. 77). 


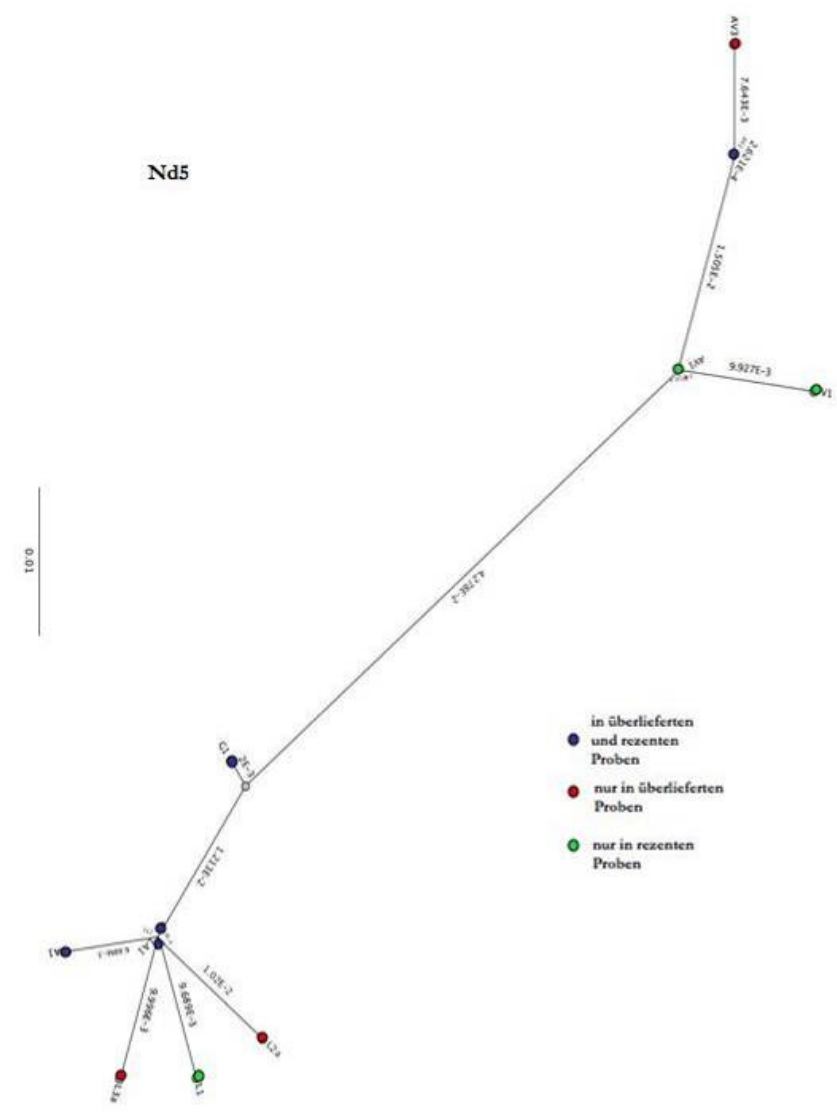

Abbildung 77: Minimal Spanning Netzwerk der bestimmten Haplotypen im Nd5-Gen

\subsubsection{Diversitäten und AMOVA}

Die Unterschiede der Diversitäten in mitochondrialen Systemen, zwischen rezenten und historischen Populationen, wurden anhand ihrer Nukleotid-Diversitäten verglichen (s. Abb. 78).

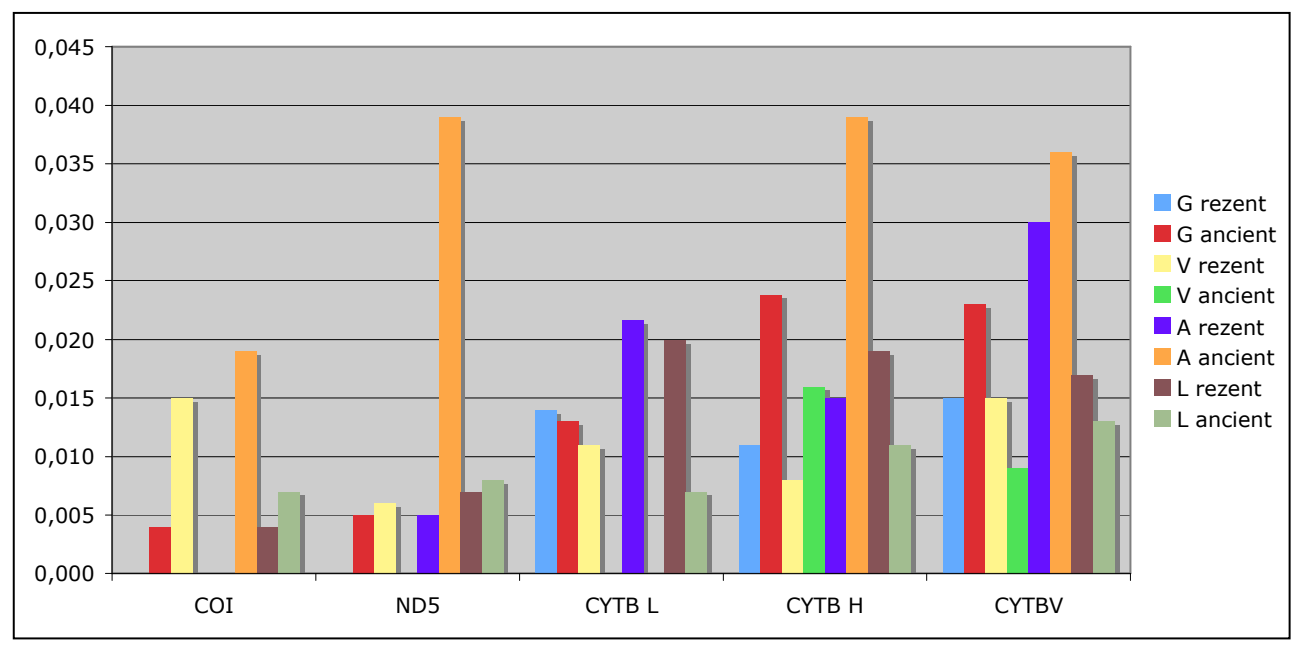

Abbildung 78: Nukleotid-Diversitäten im Vergleich der Populationen. Legende: $G=$ Guanako, V = Vikunja, A $=$ Alpaka, $\mathrm{L}=$ Lama, rezent $=$ rezentes Probenmaterial, ancient $=$ historisches Probenmaterial 
Ein Unterschied in den Diversitätswerte ist für Alpakas zu belegen. Sie weisen in den alten Proben eine deutlich höhere Diversität in ihren Sequenzen als in denen rezenter Populationen auf. Im Falle der Lamas verhält es sich komplementär, jedoch nicht so stark ausgeprägt wie bei den Alpakas. Vikunjas und Guanakos zeigen beide eine reduzierte Diversität in den rezenten Proben.

Betrachtet man die Gene ohne Berücksichtigung der Spezies so lässt sich erhöhte Diversität für das cytb-Gen in rezenten Tieren, für die Gene COI und Nd5 in prähistorischen Tieren, belegen (s. Abb. 79).

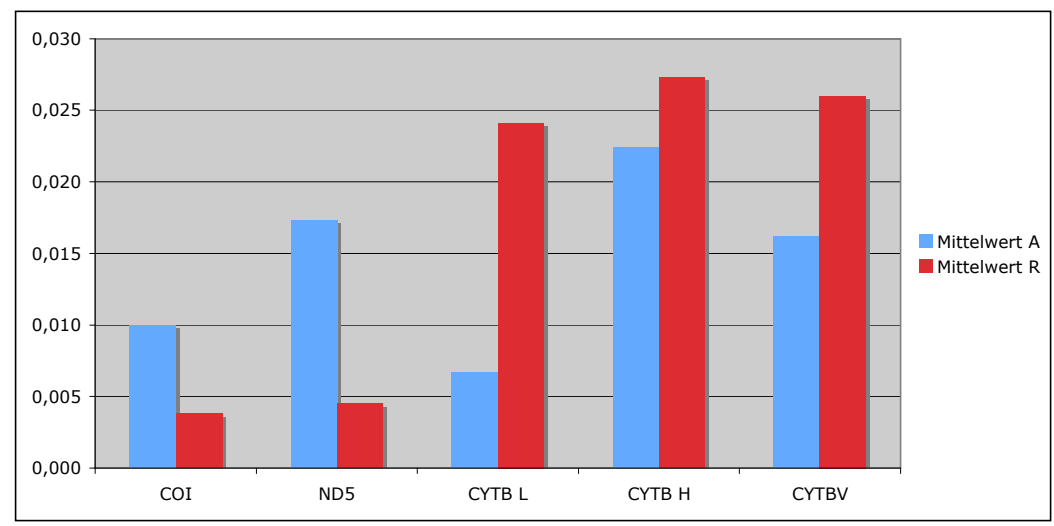

Abbildung 79: Vergleich der Gesamt-Diversität zwischen dem überlieferten (A) und rezenten Material (R)

Um zu überprüfen ob die gefundenen Werte für den Genfluss, unter Kombination der rezenten und historischen Populationen, Veränderungen aufweisen, wurden die Daten erneut einer AMOVA (Arlequin) unterzogen.

In Tabelle 64 sind die sich ergebenden $\boldsymbol{\Phi}_{\mathrm{ST}}$-Werte der Einzelsysteme sowie der sich ergebende Gesamtwert dargestellt.

Tabelle 64: $\Phi_{\mathrm{ST}_{\mathrm{T}}}$-Werte unter Einbeziehung der Ergebnisse des überlieferten Materials

\begin{tabular}{|l|r|r|l|l|r|r|}
\hline $\boldsymbol{\Phi}_{\text {ST }}$ & cytb vorne & cytb hinten & Nd5 & COI & cytb lang & Gesamt \\
\hline A vs. G & 0,586 & 0,757 & 0,684 & 0,807 & 0,736 & 0,714 \\
\hline A vs. V & 0,399 & 0,178 & 0,213 & 0,174 & 0,174 & 0,228 \\
\hline A vs. L & 0,586 & 0,747 & 0,748 & 0,836 & 0,697 & 0,723 \\
\hline V vs. G & 0,761 & 0,836 & 0,897 & 0,74 & 0,8139 & 0,810 \\
\hline V vs. L & 0,781 & 0,827 & 0,879 & 0,811 & 0,78 & 0,816 \\
\hline G vs. L & 0,376 & 0,663 & 0,186 & 0,082 & 0,615 & 0,384 \\
\hline
\end{tabular}

Legende: $\Phi_{\mathrm{ST}}=$ Index der Fixierung, vs. = versus, $\mathrm{A}=$ Alpaka, $\mathrm{G}=$ Guanako, $\mathrm{V}=$ Vikunja, $\mathrm{L}=$ Lama

Die $\boldsymbol{\Phi}_{\mathrm{ST}_{\mathrm{T}}}$-Werte sind insgesamt niedriger als die für die Einzelbetrachtungen rezenter und historischer Populationen. Aus den $\boldsymbol{\Phi}_{\mathrm{ST}}$-Werte wurde das $\mathrm{Maß}$ an Genfluss zwischen den Populationen berechnet (s. Tab. 65). 
Tabelle 65: $\mathrm{N}_{\mathrm{m}}$-Werte unter Einbeziehung der Ergebnisse des überlieferten Materials

\begin{tabular}{|l|r|r|r|l|l|r|}
\hline $\mathrm{N}_{\mathrm{m}}$ & cytb lang & cytb hinten & cytb vorne & COI & Nd5 & Gesamt \\
\hline A zu G & 0,090 & 0,080 & 0,177 & 0,060 & 0,115 & 0,104 \\
\hline A zu V & 1,187 & 1,154 & 0,377 & 1,187 & 0,924 & 0,966 \\
\hline A zu L & 0,109 & 0,085 & 0,177 & 0,049 & 0,084 & 0,101 \\
\hline V zu G & 0,057 & 0,049 & 0,079 & 0,088 & 0,029 & 0,060 \\
\hline V zu L & 0,071 & 0,052 & 0,070 & 0,058 & 0,034 & 0,057 \\
\hline G zu L & 0,157 & 0,127 & 0,415 & 2,799 & 1,094 & 0,918 \\
\hline & 0,278 & 0,258 & 0,216 & 0,707 & 0,380 & 0,368 \\
\hline
\end{tabular}

Legende: $\mathrm{N}_{\mathrm{m}}=\mathrm{Maß}$ der Migrationsanzahl, $\mathrm{A}=$ Alpaka, $\mathrm{G}=$ Guanako, $\mathrm{V}=$ Vikunja, $\mathrm{L}=$ Lama

Ein erhöhtes Maß an Genfluss liegt zwischen den Populationen Vikunja und Alpaka sowie Guanako und Lama vor. Zwischen Guanakos und Alpakas, Vikunjas und Guanakos, Vikunjas und Lamas sowie Lamas und Alpakas existiert wenig Migration, so dass hier von einer länger andauernden Isolation der Populationen auszugehen ist. Die Gesamt-Distanz zwischen den vier betrachteten Gruppen ist in Tabelle 66 aufgeführt.

Tabelle 66: Genetische Distanz zwischen den vier Gruppen

\begin{tabular}{|c|c|}
\hline Gen & genetische Distanz \\
\hline cytb lang & 0,025 \\
\hline cytb vorne & 0,022 \\
\hline cytb hinten & 0,058 \\
\hline Nd5 & 0,039 \\
\hline COI & 0,029 \\
\hline Gesamt & 0,046 \\
\hline
\end{tabular}

Diese Distanzwerte deuten an, dass es sich bei den untersuchten Gruppen um Sub-Spezies handeln könnte (s. Kap. 9).

7.4 Variabilität der Mikrosatelliten in phänotypischen und genotypischen Spezies

\section{Auswertung nach phänotypischer Spezieseinteilung}

Aus den in Kapitel 4.5 vorgestellten Typisierungsergebnissen der Mikrosatelliten in rezenten Neuwelt-Camelidae ergaben sich folgende Heterozygotenraten (Tab. 67 und Abb. 80) und Variabilitätsdaten (Tab. 68 und Abb. 81).

Tabelle 67: Heterozygotenraten der Systeme so wie die Gesamt-Rate in phänotypischen Spezies

\begin{tabular}{|l|r|r|r|r|r|r|r|}
\hline & VOLP10 & LgU52 & VOLP03 & LCA66 & VOLP67 & LgU68 & Gesamt \\
\hline Lama $\mathrm{n}=10$ & 0,10 & 0,60 & 0,11 & 0,29 & 0,83 & 0,56 & 0,65 \\
\hline Guanako n=3 & 0,33 & 0,67 & 0,33 & 0,33 & 0,00 & 0,67 & 0,38 \\
\hline Vicugna $\mathrm{n}=16$ & 0,00 & 0,73 & 0,54 & 0,53 & 0,75 & 0,44 & 0,50 \\
\hline Alpaka n=14 & 0,08 & 0,62 & 0,58 & 0,62 & 0,00 & 0,62 & 0,42 \\
\hline Gesamt n=34 & 0,07 & 0,66 & 0,44 & 0,73 & 0,40 & 0,54 & 0,47 \\
\hline
\end{tabular}




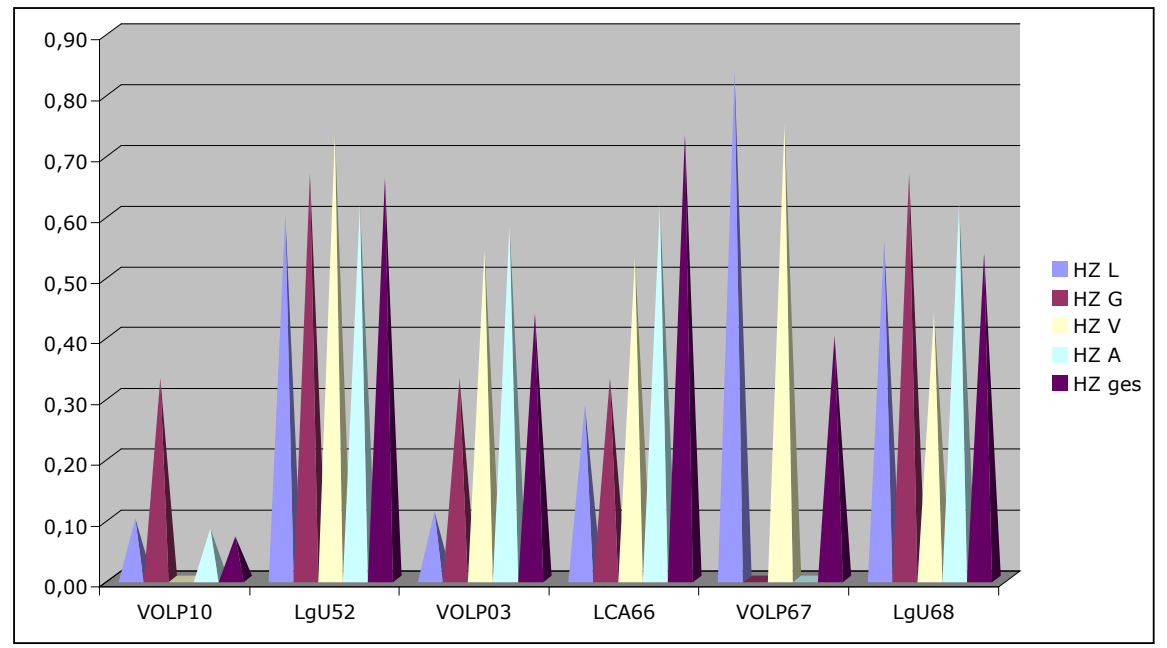

Abbildung 80: Darstellung der Heterozygotenraten der phänotypischen Spezies (näheres im Text). Legende: HZ = Heterozygotenrate, $\mathrm{L}=$ Lama, $\mathrm{G}=$ Guanako, $\mathrm{V}=$ Vikunja, $\mathrm{A}=$ Alpaka, ges = Gesamt

Tabelle 68: Variabilität der phänotypischen Spezies anhand ihrer Genotypenfrequenzen

\begin{tabular}{|l|r|r|r|r|r|r|r|}
\hline Varianz in Gt & VOLP10 & LgU52 & VOLP03 & LCA66 & VOLP67 & LgU68 & Gesamt \\
\hline Lama N=10 & 0,20 & 0,50 & 0,44 & 0,57 & 0,83 & 0,67 & 0,54 \\
\hline Guanako N=3 & 0,67 & 0,67 & 0,67 & 1,00 & 1,00 & 0,67 & 0,78 \\
\hline Vicugna N=16 & 0,06 & 0,33 & 0,27 & 0,33 & 1,00 & 0,19 & 0,36 \\
\hline Alpaka N=14 & 0,21 & 0,46 & 0,75 & 0,77 & 0,44 & 0,46 & 0,52 \\
\hline Gesamt N=34 & 0,09 & 0,29 & 0,36 & 0,49 & 0,70 & 0,34 & 0,38 \\
\hline
\end{tabular}

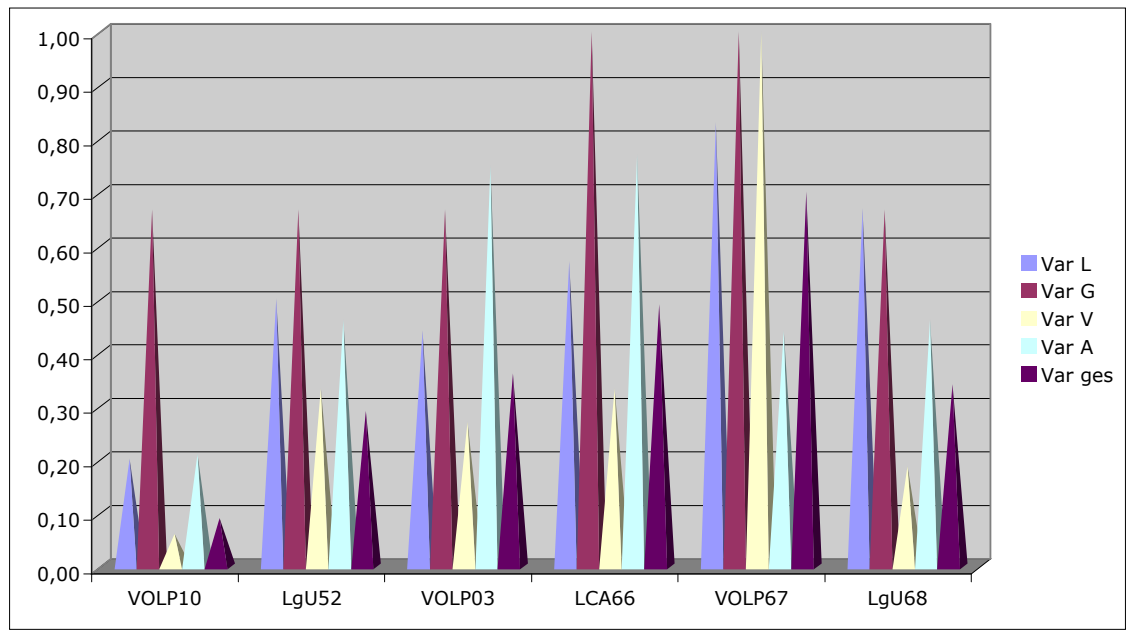

Abbildung 81: Variabilität in phänotypischen Spezies bezogen auf das Einzelsystem (näheres im Text). Legende: $\mathrm{HZ}=$ Heterozygotenrate, Var $=$ Variabilität, $\mathrm{L}=$ Lama, $\mathrm{G}=$ Guanako, $\mathrm{A}=$ Alpaka, $\mathrm{V}=$ Vikunja, ges $=$ Gesamt

Die höchste Heterozygotenrate weisen Guanakos und Lamas auf. Die Stichprobe Guanako ist jedoch so klein, dass sich die Variabilität insgesamt als verringert darstellt. Obwohl Alpakas eine höhere Heterozygotenrate als Vikunjas aufweisen, zeigen sie deutlich weniger Variabilität. Insgesamt sind die Heterozygotenraten als niedrig einzustufen. Der Marker VOLP10 ist am Wenigsten variabel und weist kaum Heterozygotie auf. Aufgrund der hier vorliegenden 
Ergebnisse ist er in Vikunjas als monomorphisch zu bezeichnen. Der Marker VOLP67 ist am Variabelsten. Insgesamt stellen sich die Populationen als wenig variabel dar.

\section{Auswertung nach genotypischer Spezieseinteilung}

Es erfolgte eine neue Berechnung der Heterozygotie nach der Speziesbeurteilung nach dem Genotyp (s. Kap. 6). Die Berechnung erfolgte mit der Software Arlequin, die zusätzlich zum observierten Wert der Heterozygoten, einen zu erwartenden Wert berechnet. Darüber hinaus wird der p-Wert, der ein Maß der Signifikanz der Werte ist, angegeben (Tab. 69).

Tabelle 69: Heterozygotenraten und Variabilität in genotypischen Spezies

\begin{tabular}{|c|c|c|c|c|c|c|c|c|c|c|c|c|}
\hline & \multicolumn{4}{|l}{ Lama $\mathrm{n}=15$} & \multicolumn{3}{|c|}{ Alpaka $\mathrm{n}=7$} & \multicolumn{3}{l|}{ Guanako $\mathrm{n}=2$} & \multicolumn{3}{c|}{ Vikunja $\mathrm{n}=16$} \\
\hline Marker & $\mathrm{HZ}_{\mathrm{O}}$ & $\mathrm{HZ}_{\mathrm{E}}$ & $\mathrm{p}$ & $\mathrm{HZ}$ & $\mathrm{HZ}$ & $\mathrm{p}$ & $\mathrm{HZ}_{\mathrm{O}}$ & $\mathrm{HZ}_{\mathrm{E}}$ & $\mathrm{p}$ & $\mathrm{HZ}_{\mathrm{O}}$ & $\mathrm{HZ}_{\mathrm{E}}$ & \\
\hline VOLP10 & 0,133 & 0,129 & 1 & 0,571 & 0,846 & 0 & 0,5 & 0,5 & 1 & 0 & 0,121 & 0,031 \\
\hline LgU52 & 0,6 & 0,57 & 0,886 & 0,429 & 0,78 & 0,018 & 0,5 & 0,5 & 1 & 0,688 & 0,698 & 0,074 \\
\hline VOLP03 & 0,214 & 0,688 & 0,001 & 0,571 & 0,802 & 0,022 & 0,5 & 0,5 & 1 & 0,563 & 0,74 & 0 \\
\hline LCA66 & 0,384 & 0,775 & 0,001 & 0 & 0,622 & 0,189 & 0,5 & 0,83 & 0,325 & 0,563 & 0,718 & 0,024 \\
\hline VOLP67 & 0,545 & 0,874 & 0 & 0,71 & 0,835 & 0,014 & 0,5 & 0,5 & 0 & 0,5 & 0,758 & 0,162 \\
\hline LgU68 & 0,6 & 0,706 & 0,133 & 0,45 & 0,77 & 0,084 & 0,5 & 0,567 & 1 & 0,438 & 0,56 & 0,023 \\
\hline Mittelwert & 0,413 & 0,623 & 0,337 & 0,571 & 0,846 & 0,065 & 0,5 & 0,5 & 0,665 & 0,458 & 0,599 & 0,052 \\
\hline
\end{tabular}

Legende: $\mathrm{p}=\mathrm{Ma}$ der Signifikanz der Abweichung zwischen erwarteter und observierter Heterozygotenrate,

$\mathrm{HZ}_{\mathrm{O}}=$ Observierte Heterozygotenrate, $\mathrm{HZ}_{\mathrm{E}}=$ Erwartete Heterozygotenrate

Die Abweichungen zwischen erwarteter und observierter Heterozygotie sind insgesamt nicht signifikant, in Einzelsystemen dagegen sind sie signifikant $(p<0,05)$ und zeigen eine Abweichung zum postulierten Hardy-Weinberg-Gleichgewicht. Für Lamas kann eine Abweichung gegenüber der erwarteten Heterozygotenrate für die Marker VOLP03, LCA66 und VOLP67 festgestellt werden, für Alpakas in den Markern VOLP10, LgU52, VOLP03 und VOLP67. Die Marker VOLP10, LgU52, VOLP03, LCA66 und LGU68 weichen in Vikunjas signifikant von der erwarteten Heterozygotenrate ab. Für Vikunjas ist die Abweichung insgesamt am Größten.

Die reduzierten Heterozygotenraten sind ein Hinweis auf eine genetische Drift.

Ein Vergleich der Gesamt-Heterozygotie zwischen phänotypischen und genotypischen Spezies (Abb. 82) zeigt, dass in Vikunjas und Lamas genotypisch eine leichte Reduktion auftritt, für Gunakos und Alpakas steigt die Rate. Jedoch bleiben die Raten insgesamt niedrig. 


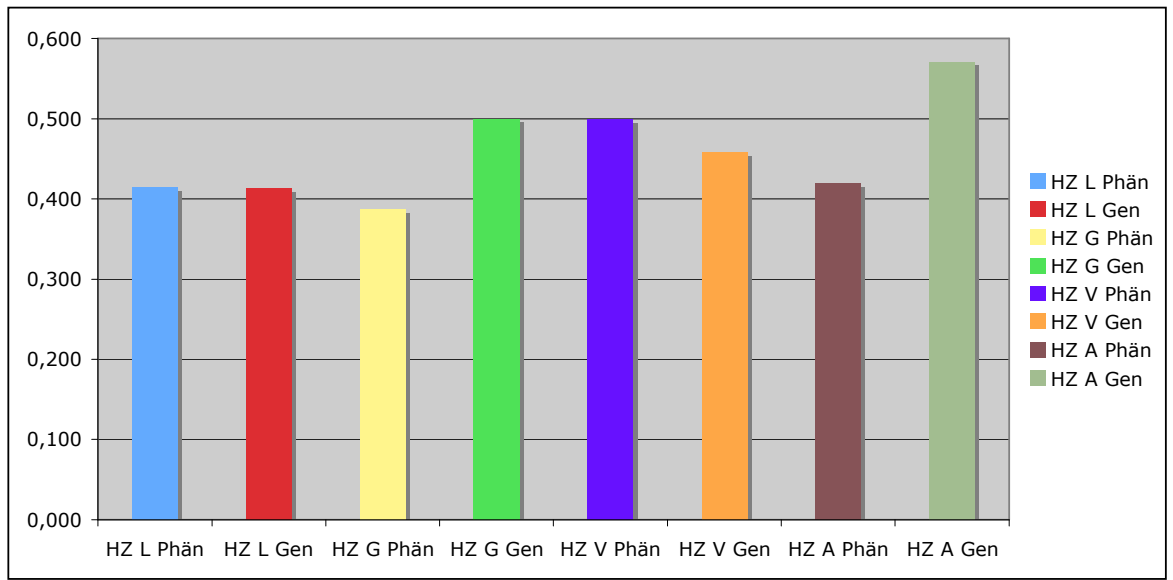

Abbildung 82: Vergleich der Heterozygotenraten in phänotypischen und genotypischen Spezies. Legende: HZ = Heterozygotenrate, $\mathrm{L}=$ Lamas, $\mathrm{G}=$ Guanakos, $\mathrm{V}=$ Vikunjas, $\mathrm{A}=$ Alpakas, Phän = Phänotypische Spezies, Gen $=$ Genotypische Spezies

\section{AMOVA der genotypischen Spezies}

In Tabelle 70 sind die $\mathrm{F}_{S T}$-Werte und der resultierende Genfluss innerhalb der Spezies aufgeführt.

Tabelle 70: $\mathrm{F}_{\mathrm{ST}_{\mathrm{T}}}-$ Werte innerhalb der genotypischen Populationen und Genfluss

\begin{tabular}{|l|r|r|r|r|}
\hline & $\mathrm{F}_{\mathrm{ST}} \mathrm{L}$ & $\mathrm{F}_{\mathrm{ST}} \mathrm{A}$ & $\mathrm{F}_{\mathrm{ST}} \mathrm{G}$ & $\mathrm{F}_{\mathrm{ST}} \mathrm{V}$ \\
\hline VOLP10 & $-0,066$ & 0,000 & $-3,132$ & 0,000 \\
\hline LgU52 & 0,278 & $-0,071$ & 0,367 & 0,116 \\
\hline VOLP03 & 0,149 & 0,035 & 0,381 & 0,084 \\
\hline LCA66 & 0,077 & 0,045 & 0,012 & 0,145 \\
\hline VOLP67 & 0,002 & 0,290 & 0,000 & 0,135 \\
\hline LgU68 & 0,118 & $-0,044$ & 0,375 & 0,300 \\
\hline Mittelwert & 0,125 & 0,093 & 0,227 & 0,155 \\
\hline Genfluss & 1,750 & 0,021 & 1,175 & 1,36 \\
\hline \multicolumn{4}{|c}{ Legende: FST = Index der Fixierung }
\end{tabular}

Für die Populationen Lama, Guanako und Vikunja ergibt sich ein Genfluss innerhalb der Populationen. Alpakas weisen keinen Genfluss auf. Dies deutet daraufhin, dass die untersuchte Alpaka-Population eine drastische Reduktion des Genpools erfahren hat.

In Tabelle 71 sind die $\mathrm{F}_{\mathrm{ST}}$ sowie die $\mathrm{N}_{\mathrm{m}}$-Werte zwischen den Populationen aufgeführt.

Tabelle 71: $\mathrm{F}_{\mathrm{ST}^{-}}$und $\mathrm{N}_{\mathrm{m}}$-Werte zwischen den genotypischen Populationen und Genfluss

\begin{tabular}{|l|l|l|l|l|l|l|}
\hline & \multicolumn{2}{|l|}{ Guanako } & \multicolumn{2}{l|}{ Vikunja } & \multicolumn{2}{l|}{ Lama } \\
\hline & $\mathbf{F}_{\mathrm{ST}}$ & $\mathrm{N}_{\mathrm{m}}$ & $\mathbf{F}_{\mathrm{ST}}$ & $\mathrm{N}_{\mathrm{m}}$ & $\mathbf{F}_{\mathrm{ST}}$ & $\mathrm{N}_{\mathrm{m}}$ \\
\hline Alpaka & 0,118 & 1,879 & 0,271 & 0,673 & 0,065 & 3,596 \\
\hline Guanako & & & 0,432 & 0,329 & 0,207 & 0,958 \\
\hline Vikunja & & & & & 0,369 & 0,428 \\
\hline
\end{tabular}


Der höchste Genfluss zwischen den Populationen kann für Lama und Alpakas festgestellt werden, ebenfalls erhöht ist der genetische Austausch zwischen Guanakos und Alpakas. Auch zwischen Lama und Guanako ist ein Genfluss belegbar. Vikunjas zeigen zu keiner der weiteren Populationen Genfluss. 
8 Interpretation und Diskussion

8.1 DNA-Extraktion, Erhaltungszustand und Amplifikationserfolg

\section{Rezentes Material}

Das Probenmaterial der rezenten Tiere zeigte sich insgesamt als gut geeignet für molekulargenetische Untersuchungen. Die Blutprobe erwies sich als am Besten geeignet, so dass diese immer als Kontrollprobe mitgeführt wurde. Für die Analyse autosomaler DNA stellten sich Extrakte aus Haaren nachteilig dar. Auch wenn das Extraktionsprotokoll mit dem Extraktionspuffer von Pfeiffer et al. (2004) in allen Proben die Analyse mitochondrialer DNA erlaubte, konnte chromosomale DNA nur in Teilen reproduziert werden. Dies ist nicht auf die Extraktion, viel mehr auf das Material selbst, zurückzuführen. Telogene Haare, welche die Mehrzahl der bearbeiteten rezenten Proben ausmachten, enthalten in der Regel keine bzw. nicht ausreichend chromosomale DNA enthalten (s. z.B. McNevin et al. 2005), mitochondriale DNA kann jedoch auch aus solchen Haaren gewonnen werden (Pfeiffer 2007). Durch eine, der Extraktion vorausgehende, äußerliche Inspektion der Haare wurde versucht in jeder Extraktion auch anagene Haare einzusetzen, dies war jedoch nicht für alle Individuen möglich. In den Fällen in denen autosomale DNA nur teilweise zu analysieren war, ist davon auszugehen, dass keine Haarwurzeln oder anhaftende körpereigene Zellen der Tiere vorhanden waren. Prinzipiell war also bereits die Bearbeitung rezenter Proben ein Arbeiten mit degradiertem Probenmaterial. Gemessen an dieser ungünstigen Ausgangsituation, ist der Extraktionserfolg als überwiegend gut zu bezeichnen.

\section{Überliefertes Material}

Die Extraktion aus Knochen und Zähnen war nur bedingt erfolgreich. In nur $22 \%$ der Proben konnte eine erfolgreiche Typisierung erreicht werden. Auch Versuche der Optimierung der Extraktionsmethode, wie z.B. das Einsetzen von mehr und weniger Knochen- bzw. Zahn-Pulver, Verlängerung der Inkubationszeit, oder das Variieren der zugesetzten Menge von Proteinase $\mathrm{K}$, führten nicht $\mathrm{zu}$ einer Steigerung des Extraktionserfolges. Die Ursache für den mäßigen Amplifikationserfolg ist also in der DNAErhaltung der Probe selbst zu sehen. Jedoch konnten keine Zusammenhänge zwischen Liegebedingungen und DNA-Erhaltung festgestellt werden (s. Kap. 5). Ein erheblicher Anstieg der Degradierung der DNA, nachdem das Probenmaterial geborgen wurde, wäre denkbar. Hummel (2003) beschreibt, dass durch die Lagerung bei Raumtemperatur eine starke 
Degradierung des Probenmaterials in kurzen Zeiträumen erfolgt. Sie schlägt vor, archäologisches Material, das molekulargenetisch untersucht werden soll, möglichst direkt nach der Bergung gekühlt zu lagern. Das hier bearbeitete Material lagerte nach der Ausgrabung ca. 2-4 Jahre nicht nur bei Raumtemperatur (Museo Nacional de Antropología, Arqueología e Historia, Lima), sondern zum Teil auch bei deutlich höheren Temperaturen (ca. $\left.30^{\circ} \mathrm{C}\right)$ im Grabungshaus. Eine mögliche Lagerung in einem Kühlschrank o.ä. war aufgrund der Situation vor Ort nicht gegeben. Für die Oberflächenfunde aus Montegrande, die einen relativ guten Erhaltungszustand aufwiesen, ist nicht bekannt, wie lange diese an der Oberfläche gelegen haben. Hier wurden jedoch nur Zähne und Felsenbeine für die Extraktion verwendet, die in der Regel einen besseren Erhaltungszustand aufweisen (Kleindorp 2006). Der Fundort Chillo stellt den zuletzt ergrabenen Fundort dar und weist den besten Erhaltungszustand auf. Die Lagerungsbedingungen des Probenmaterials könnten also Auswirkungen auf den Erhaltungszustand der DNA gehabt haben.

Eine weitere Ursache für den mäßigen Erhalt von DNA im Probenmaterial, könnte der Wandel der Umweltbedingungen des Palpa-Tals über die letzten 3000 Jahre sein. Es wird davon ausgegangen, dass zwischen starken Dürre-Phasen auch immer Phasen monsoonartiger Niederschläge existierten (Eitel et al. 2006). Dies bedeutet, dass der Boden, der heute als Feuchtboden angesprochen wird, nicht immer ein solcher gewesen sein muss. Es wäre also denkbar, dass diese wechselnden Eigenschaften des Bodens $\mathrm{zu}$ wechselnden LiegeBedingungen des Materials geführt haben. Die Dekomposition von menschlichen Überresten im Boden verläuft annähernd parallel zu der in ihm herrschenden Temperatur (Hunger 1978), ein hohes $\mathrm{Maß}$ an Feuchtigkeit dagegen verhindert den Abbau von Weichgewebe. Hohe Temperaturen und ein hohes Maß an Feuchtigkeit wirken sich negativ auf den Erhalt von DNA im Knochen aus (Perry et al. 1988). MacHugh et al. (2000) geben an, dass der Erhalt von DNA bei trockenen, kalten und stabilen Umweltbedingungen am Besten sei. Die Instabilität der Umweltbedingungen im Palpa-Tal kann also durchaus zum schlechten Erhalt der DNA geführt haben. Trotz allem ist der Erfolg der vorliegenden Arbeit als positiv zu betrachten, da sie belegt, das auch DNA-Extraktionen aus Material semi-arider Regionen möglich ist.

In sechs Proben traten Heteroplasmien in den Sequenzen der mitochondrialen DNA auf. Nach Lutz et al. (1996) können Heteroplasmien durch die Anwesenheit von Deaminierungsartefakten auftreten. Diese Artefakte betreffen meist nur einen der Stränge der DNA-Doppelhelix und nicht jede vorliegende Zielsequenz muss davon betroffen sein. In den Proben COA21 und COA25 konnte die Position 14112 des mitochondrialen Genoms auf 
dem oberen Strang als Heteroplasmie $(R=A / G)$ angesprochen werden. Bei der Sequenzierung auf dem unteren Strang konnte diese Position jedoch immer als G bestimmt werden. Somit ist diese Position nicht als Heteroplasmie, sondern als Deaminierungsartefakt anzusprechen. In den Proben MSA2 und MST3b war die Position 14112 auf beiden Strängen heteroplasmisch ausgebildet, so dass hier eine echte Heteroplasmie vorliegen könnte. Insgesamt scheint die Position 14112 jedoch eine häufig mutierende Stelle zu sein, so dass auch für die Proben MSA2 und MST3b die heteroplasmische Position als Deaminierungsartefakt angesprochen wird. Die Probe COA5 wies an der Position 14472 entweder ein $\mathrm{C}$ oder ein T auf. Der eigentliche Polymorphismus dieser Position ist C oder G. Binladen et al. (2006) geben an, dass Substitutionen von C nach T die häufigsten Deaminierungsartefakte sind. Die Position 14472 in der Probe COA5 wird als Deaminierungsartefakt gedeutet. Die Probe GEA10 zeigte im Nd5-Gen an der Position 12584 eine Heteroplasmie, die auf beiden Strängen gleichermaßen ausgebildet ist, so dass hier entweder eine echte Heteroplasmie oder ein Artefakt ausgebildet ist.

Die beobachteten Deaminierungsartefakte sind ein weiterer Indikator für den hohen Degradierungsgrad der DNA des überlieferten Materials.

Der Erfolg der Extraktion von DNA aus Textilien stellte sich als mäßig dar. In 20,3\% der Proben konnten reproduzierte Ergebnisse erzielt werden. Dies entsprach den Erwartungen im Vorfeld, denn die Textilien bestehen überwiegend aus telogenen Haaren, die einer starken Bearbeitung während der Textil-Produktion ausgesetzt waren. Die Herstellungsweise der Textilien hätte ebenfalls zur DNA-Degradierung führen können. Die Proben, die Amplifikationserfolg zeigten, erwiesen sich als nicht inhibiert, jedoch zeigten sie insgesamt einen hohen Degradierungsgrad, der in der Fragmentlänge (<163bp) und in der Anzahl amplifizierbarer Marker (1-3) ersichtlich wurde. Konnte in einer Probe z.B. das Fragment 4 (163 bp) des Cytochrom b-Gens amplifiziert werden, so bedeutete dies nicht zwangsläufig eine gute Amplifikation der Gene COI (121 bp) und Nd5 (135 bp). Auch war meist nur das vordere oder das hintere Fragment des Cytochrom b-Gens amplifizierbar. Dies bedeutet, dass die vorliegende DNA-Degradierung innerhalb des Genoms unterschiedlich ausgeprägt ist. Die Färbung der Textilien scheint, neben den bereits oben bezüglich der Lagerungsbedingungen der Proben aufgeführten Faktoren, eine Auswirkung auf die DNA-Erhaltung zu haben. In Tabelle 72 ist ein Vergleich der Textil-Färbungen und dem Typisierungserfolg von Haaren aus entsprechend gefärbten Proben für die Fundorte Los Molinos und Monte Grande dargestellt. 
Tabelle 72: Typisierungserfolg in Textilien in Abhängigkeit zur Farbe

\begin{tabular}{|l|c|c|c|c|c|c|c|c|c|}
\hline Farbe & \multicolumn{3}{|l|}{ Los Molinos } & \multicolumn{3}{l|}{ Monte Grande } & \multicolumn{3}{l|}{ Gesamt } \\
\hline & Anzahl & Typisierbar & in $\%$ & Anzahl & Typisierbar & in $\%$ & Anzahl & Typisierbar & in $\%$ \\
\hline rot & 18 & 4 & 22 & 7 & 3 & 43 & 25 & 7 & 28 \\
\hline grün & 9 & 1 & 11 & 3 & 0 & 0 & 12 & 1 & 8 \\
\hline blau & 3 & 2 & 67 & 0 & 0 & 0 & 3 & 2 & 67 \\
\hline gelb & 7 & 0 & 0 & 6 & 1 & 16 & 13 & 1 & 7,6 \\
\hline braun & 5 & 0 & 0 & 7 & 1 & 14 & 12 & 1 & 8 \\
\hline schwarz & 2 & 0 & 0 & 2 & 2 & 100 & 4 & 2 & 50 \\
\hline
\end{tabular}

Für die Paracas- und die Nasca-Zeit erfolgte die rote Textilfärbung mit Hilfe von tierischem Rot, das Cochineal (dt. Karmin) genannt wird und aus Dactylopius spec. gewonnen wird, oder pflanzlichem Rot, das aus Rubia spec. gewonnen wird und Relbunium genannt wird. Cochineal wurde deutlich seltener verwendet als Relbunium (Wouters und Rosario-Chirinos 1992). Für die Wari-Kultur kann eine gleichmäßige Verwendung beider Farbstoffe belegt werden, in der LIP ist ein Übergang zu Cochineal belegbar (Wallert und Boytner 1996). Ein Hauptbestandteil des Cochineal ist die Karmin-Säure, die in der Lage ist, mit DNA zu interkalieren (Comanici et al. 2006). Interkalierungen können in der Regel durch Alkohole oder chaotropische Salze gelöst werden. Bei der Extraktion im EZ1 Biorobot (Qiagen) werden sowohl Alkohol als auch das Salz Guanidiumthiocynat hinzu gegeben. Es wäre denkbar, dass die Interkalierung zwischen Karmin-Säure und vorhandener DNA nicht in allen Proben effektiv gelöst wurde und diese eine Amplifikation verhinderten.

Blaue Färbung wurde in der Paracas und Nasca Zeit hauptsächlich über den Farbstoff Indigo aus Indigofera spec. erzielt (Wouters und Rosario-Chirinos 1992). Über den enthaltenden Bestandteil Indigotin sind keine DNA schädigenden Wirkungen bekannt. Ähnliches gilt für den Inhaltsstoff Tannin, der in Färbemitteln, die eine dunkle Färbung bewirken, vorkommt. Gelbe Färbungen wurden über Flavonoide wie z.B. Luteolin erreicht, die hierfür genutzten Pflanzen sind nicht bekannt (Wouters und Boytner 1996). Luteolin führt bei In-vitro-Zellen zur Apoptose und verursacht hierbei starke DNA-Strangbrüche (Michels et al. 2005). Ein solcher Effekt wäre auch in den hier untersuchten Textilien denkbar und würde eine Begründung für den schlechten Extraktions-Erfolg in gelben sowie grünen Textilien erklären. Die Faktoren bezüglich der Färbetechnik, gepaart mit den Lagerungsbedingungen sowie einer generell niedrigeren Zahl an Zielsequenzen bei telogenen Haaren, sind geeignet den schlechten Typisierungserfolg zu erklären. Ein Zusammenhang zwischen der Anwesenheit von Baumwolle und dem Typisierungserfolg konnte nicht hergestellt werden. 


\subsection{Analysemethoden}

\subsubsection{Mitochondriale DNA}

Die gewählten Methoden zur Analyse der DNA sind weitestgehend als geeignet einzuordnen. Das Analysieren unterschiedlicher Abschnitte der mitochondrialen DNA hat die Speziesidentifikation des Materials ermöglicht, darüber hinaus konnten eine Vielzahl Erkenntnisse bezüglich der Phylogenetik der Tiere gewonnen werden (s. Kap. 9). Die Verkürzung der Produktlängen für die Amplifikation des Cytochrom b-Gens (s. Kap. 3.4.1) ermöglichte eine Analyse in einem weiteren Teil des Probenmaterials. Die erarbeiteten Systeme ließen sich also auf die Anwendung in aDNA übertragen.

Eine Ausnahme bildet hier das System zur Analyse der SNPs in dem Gen der 12srRNA. Das Hyb-Probe-Verfahren macht das Unterschreiten einer bestimmten Produktlänge unmöglich. Es müssen immer rund 40 Basen für die Sonden sowie mindestens weitere 40 Basen für die Primer eingerechnet werden. Zwischen Primer und Sonde sollte darüber hinaus ebenfalls ein Abstand gewährleistet sein, so dass Produktlängen von mindestens 100 bp gefordert werden. Im vorliegenden Fragment kam erschwerend hinzu, dass zwei interessante Polymorphismen mit einem Abstand von nur 40 Basen auftraten. Die so erhaltende Gesamtlänge von 229 bp war nicht zu unterschreiten. Bereits in rezentem Material konnte die Analyse nicht für alle Proben erfolgreich durchgeführt werden. In altem Material waren nur solche Proben zu analysieren, die generell eine bessere DNA-Erhaltung aufwiesen. Ein weiteres Problem verursachten die Sonden selbst. Ihre Fluoressenzeigenschaft war nach kurzer Lagerung und 12maliger Anwendung erheblich reduziert. Dies ist in der Eigenschaft begründet, dass ihre Fluoreszenz unter Tageslicht deutlich zurückgeht. Es wurde darauf geachtet, dass die Sonden keinem direkten Tageslicht ausgesetzt wurden, jedoch scheint die kurze Exponierung während des Ansetzens der PCR bereits zu einer Reduktion der Fluoreszenz zu führen. Eine Optimierung des Umgangs mit den betreffenden Chemikalien ist erforderlich, konnte jedoch während dieser Arbeit nicht erbracht werden. Insgesamt ist die Methode bei stabilen Sonden jedoch gut geeignet, um schnell und effizient Proben zu typisieren.

Die weiteren etablierten Systeme zur Untersuchung der mitochondrialen DNA sind als sehr gut einzustufen. Sie funktionierten stabil und lieferten reproduziert gute Ergebnisse. Trotz Camelidae-spezifischer Primer traten vereinzelt Kontaminationen mit menschlicher DNA auf. Da diese nicht vom Bearbeiter selbst stammten, ist hier von einer Kontamination der verwendeten Reaktionsgefäße, oder Chemikalien auszugehen. Da Homo sapiens - DNA jedoch sehr gut gegen Camelidae abzugrenzen ist, führten diese Kontaminationen nicht zu Fehltypisierungen. 


\subsubsection{Mikrosatelliten}

Das entwickelte Multiplex-System zur Analyse autosomaler DNA erwies sich als geeignetes System zur Individualtypisierung. Trotz der bereits erwähnten möglichen Schwierigkeiten bei der Auswertung von Dinukleotid-Wiederholungen, wie z.B. höhere Stotter-Raten (s. Kap. 2.1.2), war diese möglich. Dies ist auf die gewählten PCR-Parameter sowie die gewählten Gele zur Auftrennung der Fragmente zurückzuführen. Die Sequenzierung der Wiederholungseinheiten waren allesamt guter Qualität, auch wenn hierfür zunächst eine Optimierung der Sequenzier-PCR-Paramter erforderlich war. Die Sequenzierung beider Stränge ermöglichte ein sicheres Auszählen der Einheiten und es konnte so eine Nomenklatur der angetroffen Allele erfolgen (s. Kap. 3.5). Dies erleichterte die Auswertung nachfolgender Analysen.

In überliefertem Material konnten nur Teilprofile erlangt werden. Einzelne Allele waren typisierbar, jedoch selten reproduzierbar. Dies kann in der schlechten DNA-Erhaltung der Proben begründet werden.

Eine Besonderheit bildet ein Allel im System LgU52. Hier traten je fünf Wiederholungseinheiten, getrennt von einer Insertion von 30 Basenpaaren, auf. Dieses Allel trat in den Proben La7, La9, Alp2, Alp3, Alp10, Alp11 und Alp12 auf. Genotypisch sind diese Proben als Lamas (La7, La9, Alp11 und Alp12), Alpakas (Alp2 und Alp3) oder als LamaAlpaka-Mischtypus (Alp10) zu bestimmen. Das Allel konnte auch in überliefertem Material typisiert waren. Es lag in der Probe GEA10 und COA4Ph vor, die beide genotypisch als Lamas angesprochen werden konnten, das Allel konnte hier jedoch nicht reproduziert werden. Das Allel tritt also nur in domestizierten Tieren auf. Der Entstehungszeitraum des Allels könnte also in der Domestikationsphase der Tiere liegen.

\subsubsection{Phänotypisch assoziierte SNPs}

Die in dieser Arbeit entwickelten Systeme zur Untersuchung phänotypisch assoziierter SNPs stellten ein mäßig geeignetes Analysesystem dar. Die cross-species-Amplifikation zur Detektion phänotypisch assoziierter SNPs war in nur drei Fragmenten möglich, so dass davon auszugehen ist, dass die Camelidae in einigen der untersuchten Gene Polymorphismen aufweisen, die nicht bei Bos spec., Homo sapiens, Mus musculus, Ovis aries und Capra bircus anzutreffen sind. Die Sequenzierung des MC1R-Gens war zwar erfolgreich, aber es wurden keine möglichen phänotypisch assoziierten SNPs detektiert. Ein Vergleich mit der im September 2007 veröffentlichten Referenzsequenz für dieses Gen zeigte, dass die 
Sequenzierung des richtigen Gens erfolgt war, aber auch mit diesem Abgleich konnten keine SNPs ausgemacht werden, die mit der Fellfarbe assoziiert sind.

Das Auftreten einer hohen Anzahl unspezifischer Nebenprodukte in der Amplifikation des ASIP- und TYRP1-Gens war auch durch die Optimierung der PCR-Parameter nicht zu erreichen. Der gewählte Bereich des Gens ASIP weist einen hohen GC-Gehalt auf. Dies führte trotz der Wahl relativ kurzer Primer zu einer optimalen Anlagerungstemperatur von $65^{\circ} \mathrm{C}$. Eine Duplex-Amplifikation gemeinsam mit dem Marker TYRP1, der eine optimale Anlagerungstemperatur von $55^{\circ} \mathrm{C}$ aufweist, war so nicht möglich. Eine gemeinsame Weiterverarbeitung der amplifizierten Probe in der Aufreinigung sowie der SNapshot-Reaktion war dagegen erfolgreich. Die Ergebnisse waren gut auswertbar, die gefundenen Polymorphismen konnten jedoch nicht direkt mit dem Phänotyp assoziiert werden.

Der Polymorphismus im Gen TYRP1 könnte auf eine eventuelle Assoziation dieser mit der Ausprägung einer schwarzen Gesichtsbehaarung und Wildtyp-Fellfarbe hindeuten. Diese ist in Guanakos, Lamas und Alpakas möglich, in Vikunjas existiert diese Merkmalskombination nie. In anderen Spezies konnten Polymorphismen in dem Gen TYRP1 mit Piebaldie assoziiert werden. Cargill et al. (2005) konnten z.B. nachweisen, dass ein SNP im Gen TYRP1 mit der Ausprägung der schwarzen Fell-Flecken bei Dalmatinern assoziiert ist. In Soay-Schafen bedingt eine Mutation im Exon 4 des Gens TYRP1 die typische Ausprägung einer schwarzweißen Gesichtsbehaarung und der rotbraunen Fellfarbe (Gratten et al. 2006). Eine Assoziation mit der oben beschriebenen Fellfarben-Ausprägung bei Neuwelt-Camelidae wäre also denkbar.

Das Gen ASIP konnte in der vorliegenden Arbeit nicht mit der Fellfarbgebung der NeuweltCamelidae in Verbindung gebracht werden. Voisey und van Daal (2002) berichten über einen Zusammenhang zwischen Fettleibigkeit und der erhöhten Expression von ASIP, die durch eine Mutation hervorgerufen wird. In Menschen korreliert die Ausschüttung der Proteine des ASIP-Gens mit dem Body-Maß-Index in Frauen (Voisey et al. 2002). In drei der sechs typisierten Vikunjas (s. S. 123) konnte für das ASIP-Gen ein SNP gefunden werden, der weder in Lamas, noch Alpakas oder Guanakos auftritt. Vikunjas sind die kleinsten und leichtesten Tiere der Neuwelt-Camelidae und sind an ein Leben in der Höhe und kältere Temperaturen angepasst. Eine Assoziation zwischen Körpermasse und dem gefundenen Polymorphismus wäre also denkbar.

Die hier vorliegende Untersuchung konnte keine direkten Assoziationen zwischen den bestimmten SNPs und Fellfarben-Ausprägung feststellen. Dies könnte in der Wahl der Marker sowie der Stichprobe begründet sein. Die Ergebnisse liefern jedoch erste Hinweise auf 
mögliche Assoziationen zwischen Phänotyp und spezifischen Mutationen der Gene ASIP und TYRP1.

Zusammenfassend lässt sich sagen, dass die hier etablierten Methoden gut geeignet für die Untersuchung der genetischen Komposition von Neuwelt-Camelidae sind. Die Untersuchung dieser Marker in überliefertem Material war aufgrund der schlechten DNA-Erhaltung nur für einen geringen Anteil von Proben möglich.

\subsection{Variabilität der untersuchten Neuwelt-Camelidae}

Die Nukleotid-Diversitäten sind ein Maß für die Variabilität. Der Mittelwert der NukleotidDiversität für rezentes Probenmaterial ist 0,009 und für überliefertes Material 0,012. Hsieh et al. (2001) geben an, dass die gefundene innerartliche Sequenzvariabilität eines 420 bp langen Fragmentes des Cytochrom b-Gens, also die Anzahl der gefundenen polymorphen Stellen, gemessen an der Länge der untersuchten Sequenz, bei 0,25-2,74 \% liegt. Diese Werte wurden in der vorliegenden Studie deutlich überschritten. Für phänotypische Alpakas betrug die Sequenzvariabilität des Cytochrom b-Gens $6 \%$, für Lamas $3 \%$. Das Cytochrom b-Gen weist je nach betrachtetem Bereich unterschiedliche Diversitäten auf. Im vorderen Bereich sind 17 und im hinteren Bereich 25 unterschiedliche Haplotypen, mit insgesamt 44 polymorphen Stellen, auszumachen. Dies entspricht einer Sequenzvariabilität im vorderen Bereich von 13\%, im hinteren Bereich von $16 \%$. Betrachtet man die Sequenz über einen Gesamtbereich von 238 bp so nimmt die Variabilität ab und beträgt $6 \%$. Sarno et al. (2001) konnten bei der Untersuchung von 415 bp des Cytochrom b-Gens 21 Haplotypen allein in Guanakos unterscheiden. Diese hohen Diversitätswerte könnten auf die Anwesenheit unterschiedlicher Spezies hindeuten, jedoch können solche Variabilitäten auch in anderen Spezies beobachtet werden. Meadows et al. (2005) konnten in Schafen im gesamten Cytochrom b-Gen eine Variabilität von 2,78 \%, beobachten. Eine Begründung für die hohe Diversität im Cytochrom b - Gen scheint die unterschiedlich hohe Mutationsrate des Gens selbst zu sein. McClellan und McCracken (2001) geben an, dass bei Cetartiodactyla verschiedene Bereiche des cytb unterschiedlich schnell mutieren. Auch die Rate an nicht-synonymen Mutationen kann stark variieren. Die Ursache hierfür ist bisher nicht eindeutig geklärt, positive Selektion scheint jedoch ein wichtiger Faktor zu sein (McClellan und McCracken 2001).

Ein Grund für die unterschiedliche Sequenzausprägung der betrachteten Gene könnte in der Besetzung unterschiedlicher ökologischen Nischen der Neuwelt-Camelidae liegen. So sind Vikunjas erst in Höhenlagen von ca. 4000 m anzutreffen, Guanakos und Lamas halten sich 
eher unter $4000 \mathrm{~m}$ auf, Alpakas sind in allen Höhenlagen haltbar. Xu et al. (2005) berichten von einer starken positiven Selektion auf das COI-Gen in Tibetischen Antilopen, die Sequenzvariationen deuten sie als Höhenadaption. DiRocco et al. (2006) konnten für das COII-Gen der Camelidae eine, gegenüber anderen Cetartiodactyla-Spezies, erhöhte Evolutionsrate feststellen. Es wäre also denkbar, dass die gefundenen Unterschiede der vier Gruppen auf ihre natürliche Umgebung zurückzuführen sind.

Ein weiterer Faktor für die hohe Variabilität der mitochondrialen Marker könnte in der Geschlechter-Verteilung der Stichprobe zu finden sein. Da Herden in der Regel aus einem Männchen und mehreren Weibchen bestehen, konnten überwiegend nur Haare weiblicher Tiere $(74 \%)$ akquiriert werden. Männchen stellen sich jedoch durchschnittlich als variabler heraus als Weibchen. Dies lässt darauf schließen, dass die Weibchen lokal zusammen bleiben, Männchen jedoch in die Gruppe einwandern (Matrilokalität). Die hohe Variabilität ist also nicht mit dem Vorkommen überwiegend weiblicher Individuen in der Stichprobe zu erklären.

Die reduzierte Variabilität in den autosomalen STRs lässt sich mit der Herkunft der typisierten Tiere begründen. In Abbildung 83 sind, zum besseren Verständnis, die Heterozygotenraten für die einzelnen Standorte dargestellt.

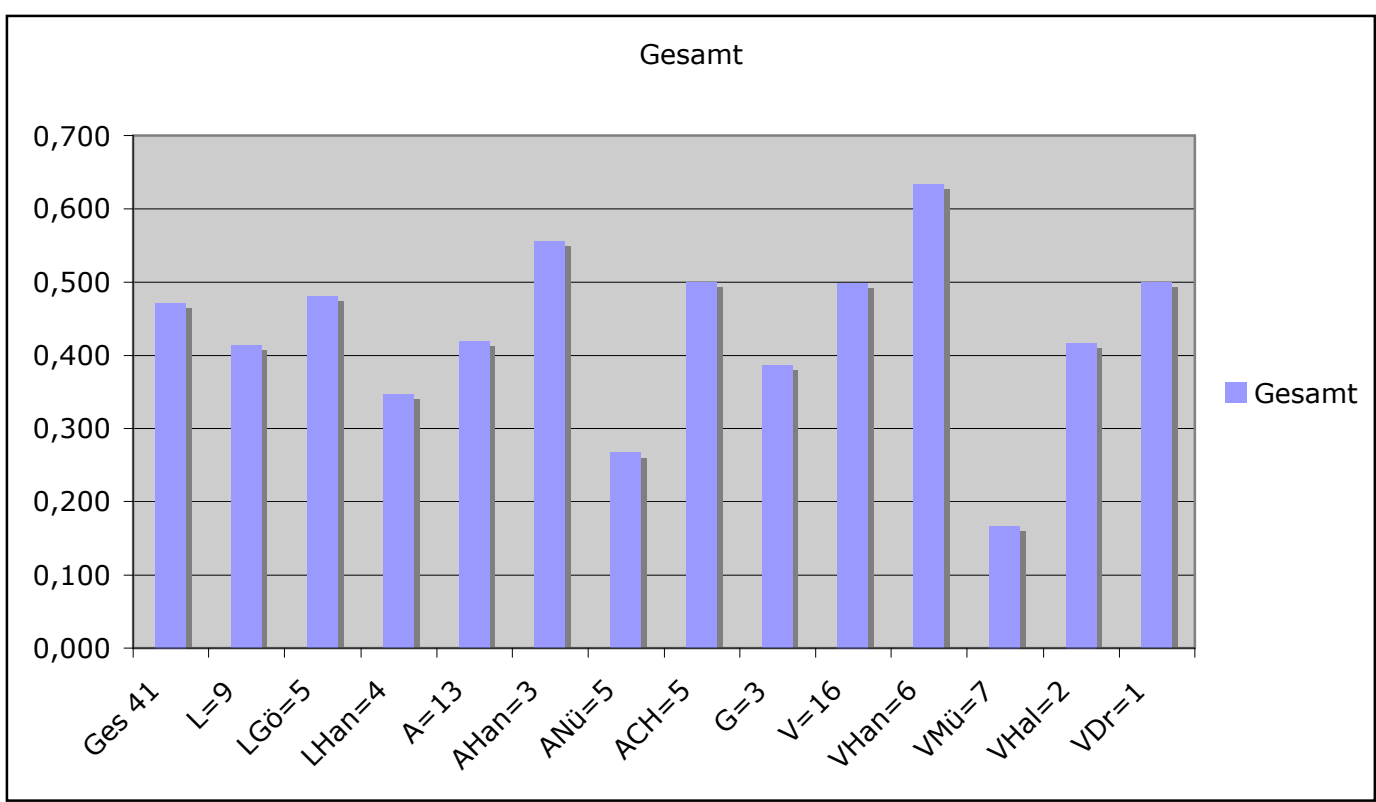

Abbildung 83: Heterozygotenraten in abhängig zum Standort. Legende: Ges = Gesamt, L = Lama, A = Alpaka, $\mathrm{V}=$ Vikunja, $\mathrm{G}=$ Guanako, Gö = Göttingen, Han = Hannover, Nü = Nürnberg, $\mathrm{CH}=$ Schweiz, Mü = München, $\mathrm{Hal}=$ Halle, $\mathrm{Dr}=$ Dresden

Die Zootiere aus Bayern weisen eine reduzierte Heterozygotenrate gegenüber denen aus Norddeutschland auf. Die Tiere der privaten Züchter aus Göttingen und der Schweiz dagegen wiesen eine deutlich höhere Heterozygotenrate auf. Die Reduktion von Heterozygotenraten und Imbalancen zwischen der Allelverteilung, wie z.B. Monomorphie in einem Marker, 
können ein Hinweis auf eine Populationsexpansion nach einem oder mehren bottleneckEreignisse sein (Kimmel et al. 1998). Die Zoohaltung führt zu einer Reduktion der Variabilität. In Alpakas ist der Unterschied zwischen der Zoopopulation und der des Züchters aus der Schweiz deutlich zu sehen. Die Tiere aus der Schweiz wurden erst vor kurzer Zeit aus Peru importiert. Die Ergebnisse für Alpakas des Zoo Hannover sind vermutlich ein Stichprobenartefakt, da nur drei Tiere beprobt wurden. Eine ähnliches Phänomen beschreiben Sarno et al. (2004). Sie beobachteten eine Reduktion der Heterozygotenrate in südamerikanischen Vikunjas, die in Wildgehegen leben. Signifikante Werte (p-Wert) in den Unterschieden zwischen erwarteter und beobachteter Heterozygotenrate werden für Vikunjas und Alpakas $(\mathrm{p}<0,05)$ angetroffen. In Abbildung 84 sind die gefundenen $\mathrm{p}$-Werte, zum besseren Vergleich, graphisch dargestellt.

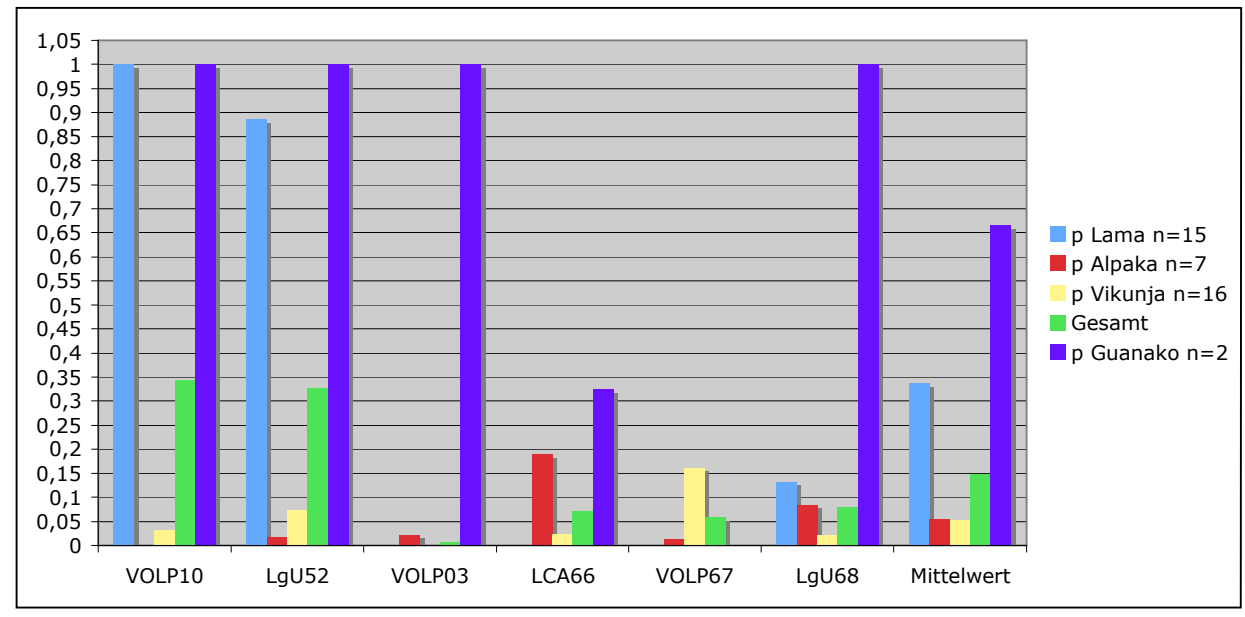

Abbildung 84: p-Werte der vier Typen sowie der Gesamtwert

Die Werte der Guanakos sind nicht repräsentativ, da ihre Stichprobe $(\mathrm{n}=2)$ zu gering ist. In allen Markern weichen die Heterozygotenraten unterschiedlich signifikant vom erwarteten Wert ab. Dies könnte darauf hindeuten, dass die Reduktion der Einzel-Populationen unterschiedlich stark ausgeprägt war. Vikunjas weisen insgesamt die signifikanteste Abweichung auf. Hier scheint die Population nach dem bottleneck-Ereignis eine geringere Expansion erfahren zu haben. Dieses trifft auch für Alpakas zu. In Lamas dagegen scheint eine Populationsexpansion, die in einigen Markern zu einem Anstieg der Diversität führte, stattgefunden zu haben. Dies ist überraschend, da eine solche Begebenheit für beide domestizierte Typen anzunehmen wäre, da sie bis heute gezüchtet werden. Eine mögliche Begründung könnte hier in der Unterteilung der Spezies nach dem Genotyp im mitochondrialen Genom liegen. In die genotypische Gruppe Lama fallen auch drei phänotypische Alpakas, in die Gruppe Alpakas fallen auch drei phänotypische Vikunjas. Es wäre also denkbar, dass beide domestizierten Arten eine Steigerung der Diversität erfahren 
haben, die mit dem hier gewählten Verfahren nicht zu detektieren ist. Betrachtet man nur die phänotypischen Gruppen so weisen Lamas und Alpakas eine ähnliche Gesamt-Variabilität auf (0,535:0,515), Vikunjas sind weniger variabel (0,364). Die gefundenen Ergebnisse deuten also auf ein oder mehrere bottleneck-Ereignis, von denen sich die Populationen nicht vollständig erholt haben, da ihre Gesamt-Variabilitäten gering sind.

Die Variabilität mitochondrialer Gene des historischen Probenmaterials ist höher als die des rezenten Materials. In ihnen konnten mehr Haplotypen angetroffen werden. Die Anordnung in sternförmigen Gruppierungen in den Minimum Spanning Netzwerken ist ein Hinweis auf eine rezente Expansion nach starker Reduktion der Variabilität (Calafell et al. 2001). Dies resultiert wahrscheinlich aus dem bottleneck-Ereignis, das durch die spanische Invasion und der mit ihr verbundenen Ausrottung eines Großteils der Tiere hervorgerufen wurde.

In dem überliefertem Material sind deutlich weniger Vikunja-ähnliche Tiere anzutreffen als Guanako-ähnliche, dies führt zu einer sternförmigen Anordnung der Netwerke des COI- und Cytochrom b-Gens (s. Kap. 7.2 und 7.3), dass als Artefakt und nicht als Hinweis auf rezente Expansion verstanden werden muss.

Zusammenfassend war die angetroffene Variabilität der Tiere deutlich höher als erwartet. Es ist zu berücksichtigen, dass die Tiere unterschiedlichen Lebensräumen entstammen und sich dies in ihrem mitochondrialen Genom als adaptive Sequenzausprägungen widerspiegelt. Die Ausprägung der Variabilität in autosomalen Systemen war dagegen reduziert, was auf die Isolation in Zucht und Zoologischen Gärten zurückgeführt werden kann. Autosomale STRs zeigen sich hierbei deutlich schneller reduziert, als die mitochondrialen Gene. Für die Camelidae ist anhand des Vergleiches zwischen rezenten und alten Proben ein bottleneckEreignis zu belegen (s. Kap. 7.3). 
9 Diskussion: Speziesidentifikation und Phylogenetik der Neuwelt-Camelidae

Das Ziel der Speziesidentifikation konnte nur in Teilen erreicht werden. Eine Bestimmung über die Analyse eines einzelnen Systems war nicht möglich. Die Untersuchung mitochondrialer Gene ermöglichte zwar meist die Unterscheidung von Lamas, Guanakos und Vikunjas, Alpakas dagegen konnten häufig genotypisch keiner Spezies eindeutig zu geordnet werden. Einige Lamas, Guanakos und Vikunjas wiesen ebenfalls Ergebnisse auf, die keine eindeutige genotypische Speziesidentifikation zuließen. Nur in rund 81\% der Referenzdaten der Datenbank und 70\% der in dieser Arbeit untersuchten rezenten Tiere stimmten Phänotyp und Genotyp überein. Diese Ergebnisse decken sich mit denen von Stanley et al. (1994), die Haplotypen in Lamas und Alpakas identifizierten, die sonst nur in den Wildtypen typisiert werden konnten. In der vorliegenden Arbeit konnten jedoch auch Fehlbestimmungen von Vikunjas und Guanakos beobachtet werden. Guanakos wiesen in diesen Fällen nur LamaHaplotypen und Vikunjas nur Alpaka-Haplotypen auf. Dies spricht für die Abstammung des Lamas von dem Guanako und des Alpakas von dem Vikunja.

Die Betrachtung des Genflusses zwischen Alpakas und den anderen Spezies in rezenten Tieren, ergab ein erhöhtes Maß an Genfluss in mitochondrialer DNA zwischen Alpakas und Vikunjas, in autosomaler DNA hingegen zwischen Alpakas und Lamas sowie Alpakas und Guanakos. Dies ermöglicht Rückschlüsse auf Hybridisierungen von Alpakas. Überwiegend scheinen nur Vikunja-Weibchen eingekreuzt zu werden, da diese nur auf mitochondrialer Ebene in Alpaka-Hybriden nachzuweisen sind. Mitochondrial zeigen Alpakas auch Haplotypen die in Guanakos und Lamas realisiert sind. Die Kreuzung zwischen männlichen Alpakas und weiblichen Lamas und Guanakos kommt demzufolge ebenfalls in Frage, jedoch konnte kein reger mitochondrialer Genfluss zwischen den in dieser Arbeit untersuchten Populationen dieser Spezies festgestellt werden. Zwischen Lama, Guanako und Alpaka weist der autosomale Genfluss auf freie Kreuzung der drei Spezies hin. Vila et al. (2005) geben an, dass eine großer Allelrange auf zahlreiche Einkreuzungen wilder Spezies in domestizierte zurückgeht. Darüber hinaus geben sie an, dass die Einkreuzung junger männlicher Tiere einfacher sei, da diese leichter in Gruppen integriert werden könnten. Auf Alpakas kann dies nicht uneingeschränkt übertragen werden, da diese auch eine Einkreuzung weiblicher Vikunjas erfahren. Insgesamt zeigten Alpakas immer die höchste Nukleotid-Diversität in mitochondrialen Loci und die höchste Variabilität der untersuchten Tiere in autosomalen Loci. Dies ist ein weiterer Hinweis auf zahlreiche Einkreuzungen anderer Spezies.

In Lamas konnte sowohl für mitochondriale als auch für chromosomale DNA ein Genfluss mit Guanakos festgestellt werden. Dies deutet auf Kreuzungen dieser beiden unabhängig vom 
Geschlecht der Tiere. Lamas teilen sich jedoch auch mitochondriale Haplotypen mit Vikunjas und Alpakas, so dass hier die Einkreuzung weiblicher Alpakas und Vikunjas belegt wird, die jedoch nicht in den Werten des Genflusses nachweisbar sind. Autosomal kann auch ein Genfluss zwischen Lamas und Alpakas nachgewiesen werden.

In Abbildung 85 sind diese Beziehungen der Neuwelt-Camelidae untereinander dargestellt. Gestrichelte Linien bezeichnen hierbei den Genfluss sowie das Kreuzungsverhalten zwischen den vier Spezies. Gerade Linien zeigen die Abstammungslinie. Der gepunktete Pfeil bezeichnet den Genfluss der nur aufgrund geteilter mitochondrialer Haplotypen vermutet wird.

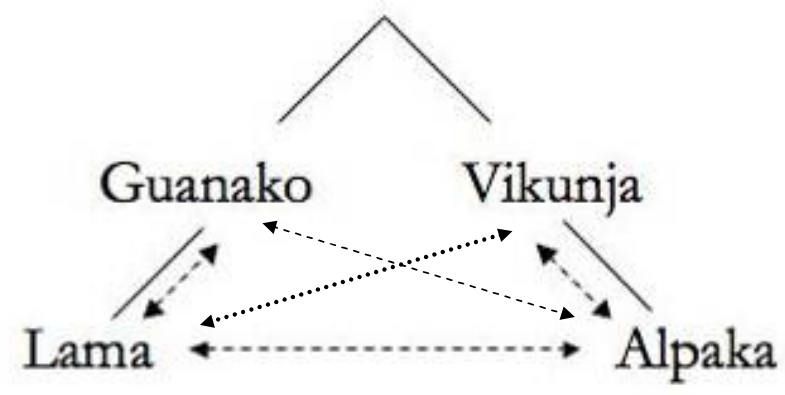

Abbildung 85: Postulierte verwandtschaftliche Beziehung sowie Kreuzungsverhalten zwischen den vier NeuweltCamelidae (näheres im Text)

Die genetischen Distanzen zwischen den vier Gruppen liegen zwischen 0,03 und 0,05. Nach Johns und Avise (1998) sind alle Spezies, die genetische Distanzen unter 0,06 im Cytochrom b Gen aufweisen, als congenerisch anzusehen. Des Weiteren geben sie an, dass SchwesterSpezies Distanz-Werte bis zu 0,14 aufweisen können, gehäuft treten sie jedoch ab DistanzWerten von 0,09 auf. Inoue et al. (2007) konnten in Fuchspopulationen Distanz-Werte des Cytochrom b-Gens von 0,027 ausmachen. In Subspezies der Spezies Cervus elaphus reichen die Distanz-Werte im Cytochrom b-Gen von 0,04-0,06 (Ludt et al. 2003). Betrachtet man nur die Ergebnisse des Cytochrom b-Gens der Neuwelt-Camelidae so ergibt sich eine GesamtDistanz von 0,025 - 0,035 (Anwendung zwei verschiedener Distanzberechnungen), für den hinteren Bereich des Fragmentes steigt dieser, aufgrund anteilig mehr polymorphen Positionen bezogen auf die Gesamtlänge des Fragmentes, auf 0,058, im vorderen Bereich liegt er bei 0,032. Eine Einteilung der Neuwelt-Camelidae in zwei Gattungen ist also, aufgrund der in dieser Arbeit erzielten Ergebnisse im Cytochrom b-Gen, nicht haltbar. Diese Daten werden durch die Ergebnisse der weiteren untersuchten mitochondrialen Gene bestätigt. Lamas und Alpakas bilden keine eigenen Spezies, da sie Genfluss sowohl zu Guanako und Vikunja als auch untereinander aufweisen. Sie sind also nicht reproduktiv isoliert und sollten nach dem biologischen Artbegriff als Varianten angesprochen werden. 
Die Beurteilung der phylogenetischen Beziehung zwischen Vikunja und Guanako ist dagegen schwieriger. Hier konnte kein Genfluss festgestellt werden. Mayr (2000) gibt an, dass zwei Populationen die geographisch getrennt leben, als potentiell artbildend gesehen werden können und molekulare Divergenz sowie Nischenanpassung auch unabhängig von reproduktiver Isolation einsetzen können. Letztendlich sei jedoch genau der Punkt des Bestehens der Reproduktionsfähigkeit das entscheidende Kriterium. Meier und Willmann (2000) geben an, dass besonders der Zusatz der potentiellen Reproduktion in der biologischen Speziesdefinition hervorzuheben sei, denn ohne ihn sei geographische Isolation gleichzusetzen mit reproduktiver Isolation. Folgt man diesen Kriterien streng, so müssen Vikunjas und Guanakos einer Spezies zugeordnet werden. Es ist jedoch denkbar, dass die existente geographische Isolation zu einer reproduktiven Isolation führt. Eine genetische Isolation zwischen beiden ist sowohl in den mitochondrialen Genen wie auch auf autosomaler Ebene nachweisbar. In den typisierten chromosomalen Markern teilen sich beide Gruppen nur sehr wenige Allele. Dies bedeutet, dass kein genetischer Austausch zwischen beiden Gruppen stattfindet. Aber das Teilen einiger weniger Allele bedeutet auch, dass genetischer Austausch zu einem bestimmten Zeitpunkt stattgefunden haben muss, oder sie einen gemeinsamen Verwandten haben. Der Genfluss zwischen beiden kann für mitochondriale DNA mit 0,065 und für autosomale DNA mit 0,329 angegeben werden. Dies deutet die mögliche Divergenz zwischen beiden Populationen an. Entweder man begreift diese genetischen Unterschiede als mögliche geographische Variabilitäten, oder sieht beide als zwei Spezies einer Gattung an. Da jedoch kein Nachweis einer reproduktiven Isolation vorliegt, werden die Zugehörigkeit zu einer Spezies und das Begreifen der südamerikanischen Camelidae als Cline vorgeschlagen.

Als weiteres stützendes Element sei daran erinnert, dass die Unterteilung in zwei Gattungen einzig und allein auf die unterschiedliche Ausprägung der Incisivi beruht. Bei Homo sapiens ist die Agenese von Zähnen ein variabler Faktor. In rund $20 \%$ der Gesamtbevölkerung tritt die Agenese eines oder mehrere Zähne auf (Stockton et al. 2000). Besonders häufig ist die Agenese der Weisheitszähne. In Bantu-stämmigen Populationen treten in nur 0,2 \% Agenese der Weisheitszähne auf, in indigenen Mexikanern dagegen in $100 \%$ der Fälle (Daten aus Pereira et al. 2005). Eine Einordnung dieser zwei Bevölkerungsgruppen in zwei Spezies erfolgt trotz allem nicht, viel eher wird dieser Prozess als evolutiv-adaptiv gesehen, der in einigen Gruppen früher einsetzt als in anderen. Eine solche Beurteilung der morphologischen Variation der Zähne in Vikunjas, als evolutiv-adaptive Notwendigkeit an die zugängigen Nahungsquellen, würde das hier postulierte Begreifen der Neuwelt-Camelidae als Cline bestätigen. 
Zusammengefasst kann man sagen, dass sich die Neuwelt-Camelidae durch die Kombination verschiedener mitochondrialer Gene unterscheiden lassen, die Distanzen zwischen den Gruppen jedoch nicht ausreichend sind um vier Spezies zu benennen. Bei der Determination einer der vier Typen (Alpaka, Lama, Guanako und Vikunja), kann der Genotyp vom Phänotyp abweichen. Dies muss besonders bei der Interpretation der Ergebnisse des überlieferten Materials berücksichtigt werden.

Die vier vorkommenden Typen der Neuwelt-Camelidae wären nach den vorgestellten Daten als eine Cline einer Spezies zu bezeichnen. Die Unterteilung in Sub-Spezies wäre im Falle der Guanakos und Vikunjas denkbar. Für Lamas und Alpakas sollte neben der Speziesbezeichnung nach ihrer Abstammungsspezies, den Zusatz familiaris als Kennzeichnung ihres Status als domestizierte Form erhalten. 
10 Interpretation der erzielten Ergebnisse präkolumbischer Neuwelt-Camelidae und Kontextualisierung dieser mit den Ergebnissen des Gesamtprojektes

Die Ergebnislage für Stichproben der Phasen vor Nasca8 ist sehr gering. Die hier getroffenen Interpretationen bezüglich dieser Phasen sind also unter Vorbehalt zu betrachten, jedoch geben sie erste Hinweise in bestimmte Direktionen die im Folgenden diskutiert werden.

\section{Résumé der Ergebnisse der vorliegenden Arbeit}

Proben aus der Paracas Zeit, repräsentiert durch den Fundort Pernil-Alto und Jauranga, zeigen nur die Anwesenheit von Lamas. Für die frühe und mittlere Nasca-Zeit, repräsentiert durch den Fundort Los Molinos konnten in den Skelettüberresten neben Lamas auch ein Guanako, in den Textilien Vikunjas und ein Guanako identifiziert werden. Für die späte Nasca-Zeit konnten im Skelettmaterial Lamas, Guanakos sowie Vikunja-Alpaka und Guanako-Alpaka Mischtypen, in den Textilien Vikunjas, Alpakas sowie Vikunja-Alpaka und Lama-Alpaka Mischtypen, bestimmt werden. Für die LIP, repräsentiert durch den Fundort Chillo, konnten alle vier Typen sowie Vikunja-Alpaka Mischtypen identifiziert werden.

Lamas sind also in allen Knochen- und Zahn-Proben der Fundorte repräsentiert. In textilen Proben konnten sie jedoch nicht nachgewiesen werden. Demzufolge wurden sie wahrscheinlich überwiegend für den Verzehr, als Lasttiere oder andere Produkte, wie z.B. ihr Dung, genutzt. Ihr Fell wurde scheinbar nicht zur Herstellung von Textilien verwendet.

Guanakos sind in der Früh-Nasca-Zeit sowohl in Skelettüberresten als auch in Textilien nachzuweisen. In der Spät-Nasca sowie der LIP sind sie ausschließlich in Skelettüberresten anzutreffen. Die Guanakos wurden also in Los Molinos sowohl zum Verzehr o.ä. als auch für die Wollproduktion verwendet. In Montegrande und Chillo wurden sie nur noch zum Verzehr genutzt.

Vikunjas können in Los Molinos (Früh- bis Mittel-Nasca) nur in Textilien nachgewiesen werden. Dies impliziert einen Import von Vikunja Wolle. In Chillo (LIP) sind sie in den Skelettüberresten zu finden. Dies bedeutet, dass hier ein Import der Tiere erfolgte.

Alpaka-Wolle wurde in Montegrande importiert, ein Import der Tiere an sich ist für den Fundort Chillo zu belegen.

Das Auftreten von Typen die genotypisch nicht eindeutig zu zuordnen sind, ist für die Fundorte Montegrande und Chillo zu belegen. Es könnten hier Züchtungen vorliegen, die in rezentem Material nicht mehr anzutreffen sind. Dies belegt sowohl ein bottleneck-Ereignis, als 
auch die Wichtigkeit der Untersuchung von historischem Material in der Domestikationsforschung.

Nach Miller und Burger (1995) ist das Vorkommen von wenig Kopf- und Fuß-Knochen ein Beleg für den char'ki-Konsum, das im Hochland produziert und ins Tiefland transportiert wird (Schlepp-Effekt) (s. Kap. 1.5). Für alle Tiere jeder Zeitstellung der hier untersuchten Fundorte sind jedoch Knochen der Autopodien und des Cranium zu finden, so dass kein Hinweis auf den Import von char'ki vorliegt.

Für alle Fundort wurden von Proben der Langknochen histologische Schnitte angefertigt. Am Fundort Chillo sind überwiegend plexiformer und Mischtypen aus plexiformen und osteonischen Knochenstrukturen zu identifizieren (s. Abb. 86). Plexiformer Knochen kommt hauptsächlich in jungen Tieren vor, der im Übergang zur Maturität umgewandelt wird (Herrmann et al. 2007). Es könnte sich bei den in Chillo gefundenen Knochen also überwiegend um Überreste von jungen Tieren handeln. Eine Häufung junger männlicher Knochen kann ein Hinweis auf vermehrten Verzehr sowie Domestikationsereignisse sein (Legge 1996). Die mögliche Anwesenheit einer Vielzahl junger Tiere in Chillo gibt also einen Hinweis auf die Nutzung der Camelidae zum Verzehr.

Das Fertigungsmaterial der Textilien des Fundortes Los Molinos ist ein anderes, als das der Textilien aus Montegrande. Während in Los Molinos nur Wolle der Wildtypen verarbeitet wurde, sind in der Wolle aus Montegrande auch domestizierte Spezies vertreten. Dransart (1991) gibt an, dass Vikunja-Wolle bei den Inkas nur von der elitären Oberschicht genutzt wurde. Die Textilien aus Los Molinos stellen also Ausdruck einer besonderen Totenfürsorge, durch die Ausstattung mit besonderer Wolle, dar. Dies könnte auf eine Stratifizierung der Gesellschaft hindeuten. Das Nutzen von domestizierten Spezies zur Textil-Produktion in Montegrande kann auf einen Bevölkerungsanstieg und einem damit verbundenen höheren Woll-Bedarf hinweisen. Der Fundort Montegrande belegt einen Anstieg der Handelsbeziehungen ins Hochland.

Teilergebnisse des Verbund-Projektes "Nasca"

Im Rahmen des Gesamt-Projektes konnte belegt werden, dass der Wüstenrand des Palpa-Tals stetigen Schwankungen unterzogen war (Eitel und Mächtle 2006). Bis ca. 1800 v. Chr. lag dieser sehr niedrig, was für die Existenz feuchten Klimas spricht, zwischen 200 v. Chr. und 700 n. Chr. näherte sich der Wüstenrand stetig dem Andenrand, erst für die Phase zwischen 
1400-1600 n. Chr. (LIP) konnte ein erneuter Rückgang des Wüstenrandes belegt werden. Die Archäologie belegt, dass zwischen der Phase Nasca 8 und der LIP keine Siedlungen im PalpaTal existierten. Davor unterlag die Region des Palpa-Tals einem dynamischen Umweltwandel, der mit dem Siedlungswandel korrelierte. Die Siedlungen Los Molinos und La Muña beispielsweise wurden wegen erhöhtem Niederschlag und vermuteter Dürreperioden aufgegeben (Reindel und Isla 2001/2006). Die Bearbeitung der humanen Überreste des PalpaTals (Fehren-Schmitz in prep.) belegt eine Durchmischung der Populationen mit andinen Bevölkerungen ab der Nasca-Zeit. In der Initialzeit zeichnen sich die Populationen überwiegend durch die mitochondriale Haplogruppe D aus. In der Nasca-Zeit kommen daneben in kleinen Anteilen die Haplogruppe A, C und B dazu. Die Haplogruppe B kommt hauptsächlich in andinen Bevölkerungen vor.

\section{Kontextualisierung der Ergebnisse}

In der Paracas- und frühen Nasca-Zeit existieren im Palpa-Tal homogene menschliche Populationen, die jedoch schon einen Austausch mit dem Hochland vollzogen, da bereits die domestizierten Camelidae-Art Lama nachgewiesen werden kann. Die Nasca-Zeit ist geprägt durch instabile Umweltbedingungen, gleichzeitig werden die Populationen heterogener. Die Textilien belegen für diese Zeit einen Import von Vikunja-Wolle aus dem Hochland. Ihre Verwendung als Grabbeigaben, der Handel sowie die Bestattungsform (s. Kap. 3.2.3 und 3.2.4) deuten auf eine stratifizierte Gesellschaft hin. Die späte Nasca-Zeit ist geprägt durch die Auflassung vieler Siedlungen und einem Annähern des Wüstenrandes an den Andenrand. Über die gesamte Nasca-Zeit ist das Anlegen von Geoglyphen, die als Symbol eines Wasserkultes verstanden werden, zu belegen (Lambers 2006). In den tierischen Überresten sind nun auch Alpakas bzw. Alpaka-ähnliche Individuen anzutreffen. Das textile Material wird nun auch aus Wolle domestizierter Tiere hergestellt. Dies spricht für einen Anstieg der Handelsbeziehungen. In der LIP waren die Umweltbedingungen des Palpa-Tals wieder geeignet für eine Besiedlung durch den Menschen. Die dort angetroffenen tierischen Überreste zeigen alle Typen der Camelidae, so dass nicht nur die Rückkehr von Menschen aus dem Hochland, sondern auch intensiver Austausch zwischen Populationen bestanden haben muss. Die Rückbesiedlung in der LIP separiert zwar die Bevölkerungen geographisch, Handelskontakte bleiben jedoch bestehen.

Der Kulturwandel der Region des Palpa-Tals korrelierte stark mit dem Umweltwandel und Handelsbeziehungen zum Hochland können in allen Zeitstufen belegt werden. Die Wandlung der Nutzung der Tiere in den späten Phasen der Nasca-Zeit sowie der LIP, könnte auch auf 
einen Anstieg der Bevölkerung deuten, der die Nutzung einer höheren Anzahl Tiere erforderte. Eine ansteigende Dependenz der im Palpa-Tal ansässigen Bevölkerung zu andinen Bevölkerungen wäre also denkbar. Darüber hinaus kann der Anstieg von Vikunjas und Alpakas in den Skelettüberresten aus Montegrande auch auf eine Wollproduktion vor Ort hindeuten. Die Ansammlung einer Vielzahl von Knochen unterschiedlicher Camelidae-Typen in Montegrande, könnte Ausdruck einer Siedlung sein, die Wolle und Fleisch produziert hat. Damit wäre das Ausprägen von Spezialisierung an diesem Ort Ausdruck einer stratifizierten Gesellschaft. Auch wäre eine Arbeitsteilung der verschiedenen Siedlungen der Nasca-Zeit denkbar, so dass in bestimmten Orten spezifische Produkte hergestellt wurden. Eine eindeutige Klärung der Bedeutung des Fundortes Montegrande ist jedoch ohne Ausgrabungen nicht möglich.

Für das Palpa-Tal kann also belegt werden, dass Neuwelt-Camelidae während der Nasca-Zeit und der LIP wichtiger Bestandteil der Subsistenzstrategie waren. Sie repräsentieren darüber hinaus ein kulturelles Gut in ihrer Verwendung als Grabbeigabe und belegen bestehende Handelsbeziehungen ins Hochland. 


\section{Zusammenfassung}

Die Rekonstruktion der sozio-kulturellen Begebenheiten (prä-)historischer Populationen ist zentrales Interesse der Archäologie. Die Kooperation der Geistes- und Naturwissenschaften bietet hierbei die Möglichkeit der Generierung einer Vielzahl unterschiedlicher Daten über Umweltbedingungen, Subsistenzstrategien und biologische Zusammensetzungen der untersuchten Populationen. Die Transzendenz der so gewonnenen Erkenntnisse offeriert die Zeichnung eines zusammenhängenden Bildes der Lebensstrategien und Lebensbedingungen vergangener Kulturen.

Das Palpa-Tal (Peru) bietet mit einem belegten Siedlungszeitraum von der Initialzeit (1800-800 v. Chr.) bis zur frühen Zwischenperiode (200 v. Chr.- 600 n. Chr.) sowie einer erneuten Besiedlung in der späten Zwischenperiode (LIP, 1000-1400 n. Chr.) die Erforschung eines historischen Zeitfensters über rund 2500 Jahre mit mindestens drei Kulturstufen. Das hier angesiedelte Forschungsprojekt "NTG Projektverbund Nasca. Entwicklung und Adaption archäometrischer Techniken zur Erforschung der Kulturgeschichte“ zielte unter der Verknüpfung archäologischer und naturwissenschaftlicher Methodik auf die Rekonstruktion der Umwelt- und Kulturgeschichte sowie ihrem Wandel im beschriebenen Zeitfenster ab. Das Teilprojekt der molekulargenetischen Untersuchung der tierischen Überreste sollte zur Klärung der Subsistenzstrategie sowie möglicher Handelsbeziehungen ins Hochland beitragen.

Die vorliegende Arbeit befasste sich mit den Überresten von Neuwelt-Camelidae in der beschriebenen Region. Hierunter fallen neben Skelettresten auch Textilien. Derzeit werden vier Spezies benannt, das Lama guanicoe und das Vicugna vicugna als Wildformen sowie das Lama glama und das Lama pacos als domestizierte Formen. Die Phylogenetik der vier Spezies ist nicht eindeutig geklärt. Ziel war zunächst die Speziesidentifikation, über die dann Interpretationen bezüglich dieser Fragestellung ermöglicht werden sollten. Die Bestimmung genetischer Variabilität sollte zusätzlich einen Beitrag zur Klärung der phylogenetischen Beziehung der Tiere leisten und Aussagen bezüglich der präkolumbischen Diversität ermöglichen.

Zur Methodenentwicklung war zunächst die Gewinnung und Untersuchung eines rezenten Probenkollektivs nötig, da der Wissensstand über die Genetik der Neuwelt-Camelidae noch im Anfangsstadium ist. Es wurden Analysesysteme für mitochondriale DNA (COI, Nd5 und Cytochrom b), chromosomale Short-Tandem-Repeats (STRs) und phänotypisch assoziierter SingleNucleotide-Polymorphisms (SNPs) entwickelt. 
Die Ergebnisse der rezenten Tiere für Gene der mitochondrialen DNA sowie der erstellten Multiplex zur Analyse autosomaler STRs, verdeutlichten die Schwierigkeiten der exakten Speziesbestimmung sowie der phylogenetischen Problematik. Die nicht vorhandene reproduktive Isolation der Tiere führt zu einem genetischen Mosaik, so dass Genotyp und Phänotyp sich nicht immer entsprachen. Alpakas können immer fehlerhaft als Vikunjas, Lamas oder Guanakos interpretiert werden, Vikunjas auch als Alpakas, Lamas auch als Guanakos und Guanakos auch als Lamas. Die genetischen Distanzen sprechen für die Zugehörigkeit der vier Typen zu einer Gattung. Die Raten an Genfluss zwischen den vier Spezies sprechen für eine Abstammung des Lamas vom Guanako und des Alpakas vom Vikunja. Darüber hinaus zeigen sie, dass die Einteilung von Lamas und Alpakas in zwei separate Spezies nicht sinnvoll ist. Auch zwischen Lamas und Alpakas ist ein Genfluss zu detektieren, so dass auch hier ein weiterer Beleg für die nicht vorhandene reproduktive Isolation existiert. Dies bedeutet jedoch auch, dass Guanakos und Vikunjas ebenfalls nahe verwandt sind. Hier besteht zwar geographische Isolation, jedoch keine reproduktive. Es wird vorgeschlagen die Neuwelt-Camelidae als Cline einer Spezies zu verstehen, in der Vikunja und Guanako eventuell eine reproduktive Barriere aufbauen könnten, jedoch ist diese derzeit nicht vorhanden.

Insgesamt zeigten sich die rezenten Tiere in ihrer genetischen Komposition als variabel. Die hohe Variabilität in mitochondrialen Systemen lässt sich nur mit der ökologischen Adaption der Tiere erklären. Die Untersuchung phänotypisch assoziierter SNPs erbrachte keine direkten Korrelationen mit der Fellfarbe. Für den Marker TYRPI ist eine Assoziation mit der Gesichtsfärbung denkbar. Der Marker ASIP zeigte keinerlei Assoziation mit Fellfarbausprägung.

Generell zeigte sich eine gute Übertragbarkeit der entwickelten Systeme auf überliefertes Material. Der Erhaltungszustand der DNA in ihnen ist als schlecht zu beurteilen. Insgesamt konnten nur 21\% der Proben erfolgreich analysiert werden. Die DNA-Erhaltung in Knochen- und ZahnMaterial war nur geringfügig besser als in Textilien. Es konnten keine Zusammenhänge zwischen Liegebedingungen und DNA-Erhaltung festgestellt werden, jedoch sind Zusammenhänge mit der Lagerung nach der Ausgrabung sowie der verwendeten Färbetechnik der Textil-Produktion nicht auszuschließen. Die Amplifikation von chromosomaler DNA war nur partiell möglich und lieferte nur Teilprofile für die untersuchten STRs, so dass hier keine statistische Auswertung erfolgen konnte.

Die Typisierungsergebnisse der mitochondrialen DNA zeigten eine höhere Variabilität als rezente Tiere bezüglich der angetroffenen Haplotypen. Dies bestätigt das bottleneck-Ereignis durch die spanische Invasion, dass zur Ausrottung eines Großteils der Tiere geführt hat und eine Reduktion der genetischen Variabilität bewirkte. 
Unter Einbeziehung aller typisierbaren Marker einer Probe wurde eine Konsensusspezies eruiert. Rund $38 \%$ der Proben konnten als Lamas, $24 \%$ als Guanakos, $16 \%$ als Vikunjas und nur $4 \%$ als Alpakas angesprochen werden. Darüber hinaus konnten $18 \%$ als Mischtyp aus Alpaka und einem weiteren Typus bestimmt werden. In Knochen ist der Anteil von Lamas und Guanakos am Höchsten, in Textilien dominieren Vikunjas, Alpakas und Alpaka-Mischtypen. Dies belegt eine Nutzung der Lama und Guanakos als Fleischlieferanten oder Tragetiere im Falle der Lamas und eine überwiegende Nutzung von Vikunjas und Alpakas als Wolllieferanten. Am Fundort Los Molinos konnten lediglich Textilien aus der Wolle von Vikunjas und Guanakos ausgemacht werden. Dies zeugt von einer besonderen Totenfürsorge und könnte auf eine stratifizierte Gesellschaft hindeuten.

Ein Wandel über die Zeit konnte beobachtet werden. Domestizierte Spezies waren seit der frühen Nasca-Zeit Teil der Subsistenzstrategie im Palpa-Tal, wo hingegen in der frühen bis mittleren Nasca-Zeit überwiegend Wildformen als Wolllieferant dienten, sind in der späten Nasca-Zeit auch domestizierte Formen zu belegen. In den Skelettüberresten zeigt sich in der späten Nasca-Zeit die Nutzung aller vier Typen. Dies kann auf einen Populationsanstieg oder einer zunehmenden Nutzung tierischer Produkte deuten. Die Ergebnisse des LIP-zeitlichen Fundortes Chillo zeigen die höchste Durchmischung der Typen im Skelettmaterial.

Handel zwischen Hochland und Tiefland ist also für den gesamten Siedlungszeitraum zu belegen. Dieser erfährt eine Zunahme zeitgleich mit dem Auftreten instabiler Umweltbedingungen. Es ist also möglich, dass die Palpa-Tal Bewohner gezwungen waren ihre Handelsbeziehungen auszudehnen, um ihr Überleben zu sichern. Die Anwesenheit von Vikunja sowie AlpakaMischtypen neben Lamas und Guanakos im Material des Fundortes Montegrande, könnte auf Spezialisierung wie z.B. Wollproduktion oder Fleischproduktion hindeuten. In seiner Gesamtheit sind dieser zunehmende Handel und die mögliche Spezialisierung ein Hinweis auf die Existenz stratifizierter Gesellschaften. Dies fügt sich gut in das beobachtete Bild der Archäologen ein.

Die hier gewählten Methoden ermöglichten die Erfassung einer Vielzahl genetischer Informationen, die einen Beitrag zur Klärung der Phylogenetik der Tiere leisten konnten. Darüber hinaus tragen die Ergebnisse in Kontextualisierung mit denen des Gesamt- Projektes zur Rekonstruktion der Subsistenzstrategie und sozi-ökonomischen Begebenheiten der (prä-) historischen Populationen des Palpa-Tals bei. Eine Ausdehnung des Projektes über die Grenzen des Palpa-Tals hinaus und eine Fortführung der hier begonnenen Erfassung genetischer Variabilität über die Zeit wäre wünschenswert und könnte einen Beitrag zur letztendlichen Klärung der Phylogenetik der Camelidae und ihrer Domestikations- und Nutzungsgeschichte liefern. 
12 Literatur

Adler (2006) Degradierungsmuster alter DNA - Quantifizierung von DNA-Erhaltung unterschiedlicher chromosomaler Lokalisation durch Real-Time-PCR. Diplom-Arbeit, Universität Göttingen

Aldenderfer MS (1989) The Archaic Period in the South-Central Andes. Journal of World Prehistory 3(2): 117-158

Aldenderfer MS (1998) Montane Foragers: Asana and the South-Central-Andean Archaic. University of Iowa Press, Iowa

Alley RB (2002) The Two-Millennia Time Machine: Ice Cores, Abrupt Climatic Change and our Future. Princeton University Press, Princeton and Tectonic Events. Annu Rev Ecol Syst 24: 467-500

Bandelt HJ, Kong QP, Parson W, Salas A (2005) More evidence for non-maternal inheritance of mitochondrial DNA? J Med Genet 42 (12): 957-960

Barnosky AD, Koch PL, Feranec RS, Wing SL, Shabel AB (2004) Assessing the Causes of Late Pleistocene Extinctions on the Continents. Science 306 (5693): 70-75

Beja-Pereira A, Caramelli D, Lalueza-Fox C, Vernesi C, Ferrand N, Casoli A, Goyache F, Royo LJ, Conti S, Lari M, Martini A, Ouragh L, Magid A, Atash A, Zsolnai A, Boscato P, Triantaphylidis C, Ploumi K, Sineo L, Mallegni F, Taberlet P, Erhardt G, Sampietro L, Bertranpetit J, Barbujani G, Luikart G, Bertorelle G (2006) The origin of European cattle: evidence from modern and ancient DNA. Proc Natl Acad Sci USA 103(21): 8113-8118

Belyaev DK (1979) Destabilizing selection as a factor in domestication. J Hered 70: 301-308

Benix R (1960) Max Weber. An intellectual portrait. Heinemann, London

Benson EP, Cook AG (2001) Ritual Sacrifice in Ancient Peru. University of Texas Press Austin

Berryere TG, Schmutz SM, Schimpf RJ, Cowan CM, Potter J (2003) TYRP1 is associated with dun coat colour in Dexter cattle or how now brown cow? Anim Genet 34(3): 169-175

Bicalho MSC, Pimental CG, Mendes IKP, Penal HP, Queiroz EM, Penal SDJ (2006)

Determination of ancestral proportions in synthetic bovine breeds using commonly employed microsatellite markers. Genet Mol Res 5 (3) 432-437

Biermann D (2001) Tejidos de la cultura Nasca - informe intermedio de los objetos textiles de las excavaciones en Palpa. In: Solanilla V (Hrsg.) II Jornadas internacionales sobre textiles precolombinos. Barcelona: Departamento de Arte de la Universidad Autónoma de Barcelona. S. 347-358.

Binford LR (2001) Constructing frames of reference. University of California Press. Berkley

Binladen J, Wiuf C, Gilbert MT, Bunce M, Barnett R, Larson G, Greenwood AD, Haile J, Ho SY, Hansen AJ, Willerslev E (2006) Assessing the fidelity of ancient DNA sequences amplified from nuclear genes. Genetics 172(2): 733-741 
Bjornerfeldt S, Webster MT, Vila C (2006) Relaxation of selective constraint on dog mitochondrial DNA following domestication. Genome Res 16(8): 990-994

Blumler MA (1996) Ecology, Evolutionary Theory and Agricultural Origins. In: Harris DR (Hrsg.) The Origins and Spread of Agriculture and Pastoralism in Eurasia. Kap.3 UCL Press, London

Bollongino R, Burger J, Alt KW (2003) Import oder sekundäre Domestikation? Der Ursprung der europäischen Hausrinder im Spiegel molekulargenetischer Analysen an neolithischen Knochenfunden. Beitr z Archäozool u Prähist Anthrop IV: 211-217

Bonacic CS (1991) Características biólogicas y productivas des los camélidos sudamericanos. Avances en Medicinia Veterinaria 6 (2): 3-15

Bonavia D, Monge C (1999) El hombre Andino. In: Rojas Rabiela T, Murra J (Hrsg.) Historia General de América Latina. Volume I: Las sociedades originarias. S. 343-357, UNESCO, Trotta, Paris

Bonilla C, Boxill LA, Donald SA, Williams T, Sylvester N, Parra EJ, Dios S, Norton HL, Shriver MD, Kittles RA (2005) The 8818G allele of the agouti signaling protein (ASIP) gene is ancestral and is associated with darker skin color in African Americans. Hum Genet 116(5): 402-406

Box NF, Wyeth JR, Mayne CJ, O’Gorman LE, Martin NG, Sturm RA (1998) Complete sequence and polymorphism study of the human TYRP1 gene encoding tyrosinase-related protein 1. Mamm Genome 9 (1): 50-53

Brinkmann B, Klintschar M, Neuhuber F, Hühne J, Rolf B (1998) Mutation Rate in Human Microsatellites: Influence of the Structure and Length of the Tandem Repeat. Am J Hum Genet 62: 1408-1415

Brooks N (2004) Beyond Collapse: the Role of Climatic Desiccation in the Emergence of Complex Societies in the Middle Holocene. Leroy S, Costa P (Hrsg.) First Joint Meeting of ICSU Dark Nature and IGCP 490. Mauritania: 26-30

Brooks N (2006) Cultural responses to aridity in the Middle Holocene and increased social complexity. Quaternary International 151: 29-49

Browman DL (1989) Origins and Development of Andean Pastoralism: an Overview of the Past 6000 Years. Clutton-Brock J (Hrsg.) London: Unnin Hyman, 256-68.

Bruford MW, Bradley DG, Luikart G (2003) DNA markers reveal the complexity of livestock domestication. Nat Rev Genet 4(11): 900-910

Burger J, Hummel S, Pfeiffer I, Herrmann B (2000) Palaeogenetic analysis of (pre)historic artefacts and its significance for anthropology. Anthropol Anz 58(1): 69-76

Burger R (1992) Chavin and the Origin of the Andean Civilization. Thames \& Hudson Verlag, London

Burger RL (1985) Prehistoric Stylistic Change and Cultural Development at Huaricoto, Peru. National Geographic Research 1(4): 505-534 
Busca R, Balotti R (2000) Cycling AMP a key messenger in the regulation of skin pigmentation. Pigment Cell Res 13(2): 60-69

Buselmeier W, Tariverdian G (2006) Humangenetik für Biologen. Springer Verlag, Heidelberg

Buselmeier W, Tariverdian G (2007) Humangenetik. 4.Auflage, Springer Medizin Verlag, Heidelberg

Butler JM (2001) Forensic DNA typing. Biology \& Technology behind STR Markers. Academic Press. San Diego, San Francisco, New York, Boston, London, Sydney, Tokyo

Calafell F, Comas D, Bertranpetit J (2002) Why Names. Genome Res 12: 219-221

Campero JR (2004) Lama (Lama glama L.) and Guanaco (Lama guanicoe M.): General perspective. ICAR Technical Series 11: 11-18

Cancik H, Gladogow B, Kohl KH (1998) Handbuch relegionswissenschaftlicher Grundbegriffe. Band IV Kultbild-Rolle. W. Kohlhammer Verlag, Stuttgart, Berlin, Köln

Cargill EJ, Famula TR, Schnabel RD, Strain GM, Murphy KE (2005) The color of a Dalmatian's spots: linkage evidence to support the TYRP1 gene. BMC Vet Res 1: 1

Carneiro RL (2000) The muse of history and the science of culture. Kluwer Academics Plenum Publications. New York

Cartajena I, Núnez L, Grosjean M (2007) Camelid domestication on the western slope of the Puna de Atacama, northern Chile. Anthropozoologica 42 (2): 155-173

Cavalli-Sforza LL (1996) The spread of agriculture and nomadic pastoralism: insights from genetics, linguistics and archaeology. In: Harris DR (Hrsg.) The Origins and Spread of Agriculture and Pastoralism in Eurasia. UCL Press, London

Cecchi T, Cozzali C, Passamanti P, Ceccarelli P. Pucciarelli F, Gargialo AM, Frank EN, Renieri C (2004) Melanins and melanosomes from Llama (Lama glama). Pigment Cell Res 173: 307-311

Clayton TM, Whitaker JP, Sparkes R, Gill P (1997) Analysis and interpretation of mixed forensic stains using DNA STR profiling. Forensic Sci Int 91: 55-70

Clutton-Brock J (1999) A natural history of Domesticated Mammals. Cambridge University Press, Cambridge

Comanici R, Gabel B, Gustavsson T, Markovitsi D, Cornaggia C, Pommeret S, Rusu C, Kryschi C (2006) Femtosecond spectroscopic study of carminic acid-DNA interactions. Chemical Physics 325: 509-518

Coyne JA (1985) The genetic basis of Haldane's rule. Nature 314(25): 736-738

Crarcraft J (1983) Species concepts and speciation analysis. Current Ornithology 1: 159-187

Crawford MH (1998) The Origins of Native Americans. Evidence from anthropological genetics. Cambridge University Press, Cambridge 
Darwin C (2001) The variation of Animals and Plants under Domestication. Kapitel XXV, 10. Aufl., Project Gutenberg Literary Archive Foundation, PMB113 1883 Oxford

Darwin C (1859) On the Origin of species by means of natural selection: or the preservation of favoured races in the struggle of life. London

Deng WD, Yang SL, Huo YQ, Gou X, Shi XW, Mao HM (2006) Physiological and genetic characteristics of black-boned sheep (Ovis aries). Anim Genet 37 (6): 586-588

Diamond J (2002) Evolution, consequences and future of plant and animal domestication. Nature 418: 700-707

Diamond JM (2005) Guns, germs and steel: The fates of human societies. Norton, New York

Dillehay TD (2000) The settlement of the Americas. Basic Books, New York

DiRocco L, Parisi G, Zambelli A, Vidal-Rioja L (2006) Rapid evolution of cytochrome c oxidase subunit II in camelids (Tylopoda, Camelidae). J Bioenerg Biomembr 38(5-66): 293-297

Dixon RB (1928) The Building of Culture. Scribner, New York

Dobzhansky T (1939) Die genetischen Grundlagen der Artbildung. Fischer Verlag, Jena

Douzery EJP, Snell EA, Bapteste E, Delsuc F, Philippe H (2004) The timing of eukaryotic evolution: Does a relaxed molecular clock reconcile proteins and fossils? Proc Natl Acad Sci USA 101(43): 15386-15391

Dransart PZ (1991) Llamas, herders and the exploitation of raw materials in the Atacama Desert. World archaeology 22: 304-319

Edwars A, Civitello A, Hammond HA, Caskey CT (1991) DNA typing and genetic mapping with trimeric and tetrameric tandem repeats. Am J Hum Genet 46:746-756

Egito AA, Paiva SR, do Soccoro M, Alberquerque M, Mariante AS, Almeida LD, Castro SR, Crattapaglia D (2007) Microsatellite based genetic diversity and relationships among ten creole and commercial cattle breeds raised in Brazil. BMC Genetics 8: 83

Eitel B, Mächtle B (2006) Holozäner Umweltwandel in der nördlichen Atacama und sein Einfluss auf die Nasca-Kultur (Südperu) Geographischen Rundschau 58 (4)

Eldrege N, Gould SJ (1972) Punctuated Equilibria: An Alternative to Phyletic Gradualism. In: Schoppf TJM, Freeman C (Hrsg.) Models in Paleobiology. S.82-115, San Francisco

Eshleman JA, Malhi RS, Smith DG (2003) Mitochondrial DNA Studies of Native Americans: Conceptions and Misconceptions of the Population Prehistory of the Americas.

Evolutionary Anthropology 12: 7-18

Excoffier L (2000) Arlequin: a software for population genetics data analysis. Handbook. http://lgb.unige.ch/arlequin/ 
Excoffier L, Smouse PE, Quattro JM (1992) Analysis of molecular variance inferred from metric distance among DNA-Haplotypes: Application to human mitochondrial DNA restriction Data. Genetics 131(2): 479-491

Fehren-Schmitz L (in prep) Molekularanthropologische Untersuchungen zur präkolumbischen Besiedlungsgeschichte des südlichen Perus am Beispiel der Palpa-Region. Dissertation, Universität Göttingen

Fellmann J, Getis A, Getis J (1996) Human geography: Landscapes of Human. Brown Verlag, Dubuque

Fontanesi L, Tazzoli M, Beretti F, Russo V (2006) Mutations in the melanocortin 1 receptor (MC1R) gene are associated with coat colours in the domestic rabbit (Oryctolagus cuniculus). Anim Genet 37(5): 489-493

Fowler ME (1998) Medicine and Surgery of South American Camelidae - Llama, Alpaca, Vicuna, Guanaco. 2.Aufl., Blackwell Publishing, Ames

Frame M (2001) Blood, fertility and Transformation: Interwoven Themes in the Paracas Necropolis Embroideries. In: Benson EP, Cook AG (Hrsg.) Ritual Sacrifice in Ancient Peru. University of Texas Press, Austin

Gentry AJ, Clutton-Brock J, Groves CP (2004) The naming of wild animals and their domestic derivatives. J Arch Sci 31: 645-51

Gilbert MT, Willerslev E, Hansen AJ, Barnes I, Rudbeck L, Lynnerup N, Cooper A (2003) Distribution patterns of postmortem damage in human mitochondrial DNA. Am J Hum Genet 72(1): 32-47

Gilbert MTP, Barnes I, Collins MJ, Smith C, Eklund J, Goudsmit J, Poiner H, Cooper A (2005) Long-term survival of ancient DNA in Egypt: response to Zink and Nerlich (2003). Am J Phys Anthropol 128(1): 110-114

Gomez-Raya, L, Priest K, Rauw WM, Okomo-Adhiambo M, Thain D, Bruce B, Rink A, Torell, R, Grellman, L, Narayanan R, Beattie CWJ (2008) The value of DNA paternity identification in beef cattle: examples from Nevada's free-range ranches. J Anim Sci 86(1): $17-24$

Gonzales BA, Palma RE, Zapata B, Marín JC (2006) Taxonomic and biogeographically status of guanaco Lama guanicoe (Artiodactyla, Camelidae). Mamm Rev 36(2): 157-178

Graffy EA, Foran DR (2005) A simplified method for mitochondrial DNA extraction from head hair shafts. J Forensic Sci 50(5): 1119-1122

Gratten J, Beraldi D, Lowder BV, McRae AF, Visscher PM, Pemberton JM, Slate J (2007) Compelling evidence that a single nucleotide substitution in TYRP1 is responsible for coatcolour polymorphism in a free-living population of Soay sheep. Proc Biol Sci 274(1610): 619-626

Green ARW (2003) The Storm-God in the ancient Near East. Eisenbrauns, Winona Lake Indiana 
Groh D (1999) Anthropologische Dimensionen der Geschichte. Suhrkamp, Frankfurt am Main Gronenborn D (1999) A Variation on a Basic Theme: The Transition to Farming in Southern Central Europe. Journal of World Prehistory 13(2): 123-210

Gutmann WF (1995) Die Evolution hydraulischer Konstruktionen - organismische Wandlung statt altdarwinistischer Anpassung. 2.Aufl., E. Schweizerbart'sche Verlagsbuchhandlung, Science Publisher, Stuttgart

Haeckel E (1874) Anthropogenie oder Entwicklungsgeschichte des Menschen. Wilhelm Engelmann Verlag, Leipzig

Hauge XY, Litt M (1993) A study on the origin of shadow bands seen when typing dinuecleotide repeat polymorphisms by the PCR. Hum Mol Genet 2: 411-415

Hesse B (1982) Archaeological evidence for camelid exploitation in the Chilenean Andes. Säugetierkundliche Mitteilungen 30: 201-211

Herrmann B, Grosskopf B, Fehren-Schmitz L, Schoon R (2007) Der Knochen als Spurenträger. In: Herrmann B, Saternus KS (Hrsg.) Biologische Spurenkunde - Kriminalbiologie. Springer Verlag, New York, Heidelberg, Berlin

Hiendleder S, Mainz K, Plante Y, Lewalski H (1998) Analysis of mitochondrial DNA indicates that domestic sheep are derived from two different ancestral maternal sources: no evidence for contributions from urial and argali sheep. J Hered 89(2): 113-120

Hite JM, Eckert KA, Cheng KC (1996) Factors effecting fidelity of DNA synthesis during PCR amplifications of d(C-A)n d(G-T)n microsatellite repeats. Nucleic Acid Res 24: 2429-2432

Hofreiter M, Jaenicke V, Serre D, Haeseler Av A, Pääbo S (2001) DNA sequences from multiple amplifications reveal artifacts induced by cytosine deamination in ancient DNA. Nucleic Acids Res 29(23): 4793-4799

Höss M, Jaruga P, Zastawny TH, Dizdaroglu M, Pääbo S (1996) DNA damage and DNA sequence retrieval from ancient tissues. Nucleic Acids Res 7:1304-1307

Hsieh HM, Chiang HL, Tsai LC, Lai SY, Huang NE, Linacre A, Lee JC (2001) Cytochrome b gene for species identification of the conservation animals. Forensic Sci Int 122(1): 7-18

Hummel S (2003) Ancient DNA Typing Methods. Strategies and Applications. Springer Verlag, Heidelberg, Berlin, New York

Hunger H (1978) Identifikation. Berlin, Heidelberg, New York, Springer Verlag.

Hutton J (1959) Theory of the Earth: With proofs and illustrations. Reprint. Engelmann, Weinheim

Huxley J (1975) Evolution: A Modern Synthesis. 3. Aufl., Allen \& Unwin, London

Huxley J (1938) Clines an auxiliary taxonomic principle. Nature 142: 219-220 
Ingold T (1996) Growing plants and raising animals: an anthropological perspective on domestication. In: Harris DR (Hrsg.) The Origins and Spread of Agriculture and Pastoralism in Eurasia. Kap.2 UCL Press, London

Inoue T, Nonaka N, Mizuno A, Morishima Y, Sato H, Katakura K, Oku Y (2007) Mitochondrial DNA Phylogeography of the Red Fox (V ulpes vulpes) in Northern Japan. Zoolog Sci 24(12): 1178-1186

Isla J, Reindel M (2006) Burial Pattern and Sociopolitical Organization in Nasca 5 Society. In: Isbell WH, Silverman H (Hrsg.) Andean Archaeology III, North and South. S. 374-400. Springer Verlag, Heidelberg, Berlin, New York.

Issar AS, Zohar M (2004) Climate Change - Environment and Civilization in the Middle East. Springer Verlag, Berlin Heidelberg, New York

Janis CM (1993) Tertiary Mammal Evolution in the Context of Changing Climates, Vegetation,

Jarne P, Lagode PJL (1996) Microsatellites, from molecule to populations and back. Trends Ecol Evol 11:424-429

Jianlin H, Mburu D, Ochieng J, Kaufmann B, Rege JEO, Hanotte O (2000) Application of New World Camelidae microsatellite primers for amplification of polymorphic loci in Old World camelids. Anim Genet 31(6): 404-406

Johns GC, Avise JC (1998) A Comparative Summary of genetic Distances in the Vertebrates from the Mitochondrial Cytochrome B gene. Mol Biol Evol 15(11): 1481-1490

Kadwell M, Fernandez M, Stanley HF, Baldi R, Wheeler JC, Rosadio R, Bruford MW (2001) Genetic analysis reveals the wild ancestors of the llama and the alpaca. Proc Biol Sci 268(1485): 2575-2584

Kerns JA, Newton J, Berryere TG, Rubin EM, Cheng JF, Schmutz SM, Barsh GS (2004) Characterization of the dog Agouti gene and a nonagouti mutation in German Shepherd Dogs. Mamm Genome 15(10): 798-808

Kessler M, Gauly M, Frese C, Hiendleder S (2002) DNA-Studies on South American Camelids. In: Gerken M, Renieri C (Hrsg.) Proceedings of the 2nd European Symposium on South American Camelids, Camerino, S. 269-278

Keyser-Tracqui C, Blandin-Frappin P, Francfort HP, Ricaut FX, Lepetz S, Crubezy E, Samashev Z, Ludes B (2005) Mitochondrial DNA analysis of horses recovered from a frozen tomb (Berel site, Kazakhstan, 3rd Century BC). Anim Genet 36(3): 203-209

Kim TH, Choi BH, Beever JE (2004) Polymorphism in the porcine agouti signalling protein (ASIP) gene. Anim Genet 35(5): 418-420

Kimmel M, Chakraborty R, King JP, Bamshad M, Watkins WS, Jorde LB (1998) Signatures of Population Expansion in Microsatellite Repeat Data. Genetics 148: 1921-1930

Kimpton CP, Gill P, Walton A, Urquhart AJ, Millican ES, Adams S (1993) Automated DNA profiling employing multiplex amplification of short tandem repeat loci. PCR Met Appl 3: 13-22 
Kitano T, Umetsu K, Tian W, Osawa M (2007) Two universal primer sets for species identification among vertebrates. Int J Legal Med 121(5): 423-427

Kleindorp R (2006) Vergleichende Untersuchung der DNA-Erhaltung in verschiedenen Skelettelementen. Diplom-Arbeit, Universität Göttingen

Klungland H, Roed KH, Nesbo CL, Jakobsen KS, Vage DI (1999) The melanocyte-stimulating hormone receptor (MC1-R) gene as a tool in evolutionary studies of artiodactyles. Hereditas 131(1): 39-46

Kobayashi T, Vieira WD, Potter B, Sakai C, Imokawa G, Hearing VJ (1995) Modulation of melanogenic protein expression during the switch from eu- to pheomelanogenesis. J Cell Sci 108(6): 2301-2309

Koch F (2006) Typisierung der Cytochrom B-Sequenzen von Neuweltcameliden. Entwicklung eines Analysesystems zur Speziesidentifikation an archäologischen Knochenmaterial aus Peru. Staatsexamensarbeit, Universität Göttingen

Korpelainen H (2004) The evolutionary processes of mitochondrial and chloroplast genomes differ from those of nuclear genomes. Naturwissenschaften 91(11): 505-518

Krause J, Dear PH, Pollack JL, Slatkin M, Spriggs H, Barnes I, Lister AM, Ebersberger I, Pääbo S, Hofreiter M (2005) Multiplex amplification of the mammoth mitochondrial genome and the evolution of Elephantidae. Nature 439: 724-727

Krings M, Salem AE, Bauer K, Geisert H, Malek AK, Chaix L, Simon C, Welsby D, Di Rienzo A, Utermann G, Sajantila A, Pääbo S, Stoneking M (1999) mtDNA analysis of Nile River Valley populations: A genetic corridor or a barrier to migration? Am J Hum Genet 64(4): 1166-1176

Kreskas DC (2005) On the evolutionary significance of encephalization in some eutherian mammals: effects of adaptive radiation, domestication, and feralization. Brain Behav Evol 65(2): 73-108

Kuch M, Rohland N, Betancourt JL, Latorre C (2002) Molecular analysis of an 11,700-year-old rodent midden from the Atacama Desert, Chile. Mol Ecol 11(5): 913-24

Lai SJ, Chen SY, Liu YP, Yao YG (2007) Mitochondrial DNA sequence diversity and origin of Chinese domestic yak. Anim Genet 38(1): 77-80

Lambers K (2006) The Geoglyphs of Palpa, Peru - Documentation, Analysis, and Interpretation. Forschung zur Archäologie Außereuropäischer Kulturen, Band 2. , LINDEN SOFT Verlag, Bielefeld

Legge T (1996) The beginning of caprine domestication in Southwest Asia In: Harris DR (Hrsg.) The Origins and Spread of Agriculture and Pastoralism in Eurasia. Kap.13 UCL Press, London

Leonard JA, Wayne RK, Wheeler J, Valadez R, Guillen S, Vila C (2002) Ancient DNA evidence for Old World origin of New World dogs. Science 298(5598): 1613-1616

Levin DA (2000) The origin, expansion, and demise of plant species. Oxford University Press 
Lin Z, Nomura T, Hayashi T, Wada Y, Yasue H (2001) Characterization of a SINE species from vicuna and its distribution in animal species including the family Camelidae. Mamm Genome 12(4): 305-308

Lipinski MJ, Amigues Y, Blasi M, Broad TE, Cherbonnel C, Cho GJ, Sorley S, Daftari P, Delattre DR, Dileanis S, Flynn JM, Grattapaglia D, Guthrie A, Harper C, Karttunen PL, Kimura H, Lewis GM, Longeri M, Merieax JC, Morita M, Morrin-O,Donnell RC, Niini T, Pederson NC, Perotta G, Polli M, Rittler S, Schubert R, Strillacci MG, Van Haeringen H, Van Haeringen W, Lyons LA (2007) An international parentage and identification panel for the domestic cat (Felis cactus). Anim Genet 38: 371-377

Llanos AJ, Riquelme RA, Herrera EA, Ebensperger G, Krause B, Reyes RV, Sanhueza EM, Pulgar VM, Behn C, Cabello G, Parer JT, Giussani DA, Blanco CE, Hanson MA (2007) Evolving in thin air-Lessons from the llama fetus in the altiplano. Respir Physiol Neurobiol 158(2-3): 298-306

Lowe A, Harris S, Ashton P (2004) Ecological Genetics - Desing, Analysis and Application. Blackwell Publishing Group, Oxford

Ludt CH, Schroeder W, Rottmann O, Kuchn R (2003) Mitochondrial DNA phylogeography of red deer (Cervus elaphus). Mol Phyl Evol 31: 1064-1083

Luikart G, Sherwin WB, Steele BM, Allendorf FW (1998) Usefulness of molecular markers for detecting population bottlenecks via monitoring genetic change. Mol Ecol 7(8): 963-974

Lutz S, Weisser HJ, Heizmann J, Pollak S (1996) mtDNA as a tool for identification of human remains. Identification using mtDNA. Int J Legal Med 109(4): 205-209

Lyell C (1850) Principals of geology. 8. Aufl., London

Lyons LA, Foe IT, Rah HC, Grahn RA (2005) Chocolate coated cats: TYRP1 mutations for brown color in domestic cats. Mamm Genome 16(5): 356-366

MacHugh DE, Edwards CJ, Bailey JF, Bancroft DR, Bradley DG (2000) The extraction and analysis of ancient DNA from bone and teeth: a survey of current methodologies. Ancient Biomolecules 3: 81-102

Marchant R, Hooghiemstra H, Islebe C (2004) The Rise and Fall of Peruvian and Central American Civilizations: Interconnections with Holocene Climatic Change - A Necessarily Complex Model. In: Yasuda Y, Shinde V (Hrsg.) Monsoon and Civilization. Kapitel 23, Roli Books, Neu Dehli

Mariasegaram M, Pullenayegum S, Jahabar Ali M, Shah RS, Penedo MCT, Wernery U, Sasse J (2002) Isolation and characterization of eight microsatellite markers in Camelus dromedarius and cross-species amplification in C. bactrianus and Lama pacos. Anim Genet 33(5): 385-387

Marin I, García T, Fajardo V, Rojas M, Hernández PE, González I, Martín R (2007) Technical note: Detection of cat, dog, and rat or mouse tissues in food and animal feed using speciesspecific polymerase chain reaction. J Anim Sci 2007 85(10): 2734-2739 
Marin JC, Casey CS, Kadwell M, Yaya K, Hoces D, Olazabal J, Rosadio R, Rodriguez J, Spotorno A, Bruford MW, Wheeler JC (2007) Mitochondrial phylogeography and demographic history of the Vicuna: implications for conservation. Heredity 99(1): 70-80

Marota I, Basile C, Ubaldi M, Rollo F (2002) DNA decay rate in papyri and human remains from Egyptian archaeological sites. Am J Phys Anthropol 117(4): 310-318

Mate ML, Bustamante A, Giovambattista, de Lamo D, von Thüngen J, Zambelli A, Vidal-Rioja L (2005) Genetic diversity and differentiation of guanaco populations from Argentina inferred from microsatellite data. Anim Genet 36(4): 316-321

Maynard-Smith J, Smith NH, O'Rourke M, Spratt BG (1993) How clonal are bacteria? Proc Natl Acad Sci USA 90: 4384-4388

Mayr E (1947) Systematics and the origin of species: from the viewpoint of a zoologist. 3. Aufl., Columbia University Press, New York

Mayr E (1974) Cladistic analysis or cladistic classification? Zeitschrift für Zoologische Systematik und Evolutionsforschung 12: 94-128

Mayr E (2000) Darwin's influence on modern thoughts. Scientific American. July: 78-83 http://www.udel.edu/anthro/krosenberg/mayr.pdf

Mayr E (2001a) A Critique from the Biological Species Concept Perspective: What is a Species, and What is Not In: Wheeler QD, Meier R (Hrsg.) Species Concept and Phylogenetic Theory. Columbia University Press, New York

Mayr E (2001b) The Biological Species Concept. In: Wheeler QD, Meier R (Hrsg.) Species Concept and Phylogenetic Theory. Columbia University Press, New York

McAdam CR (1966) The evolution of urban society: early Mesopotamia and and prehispanic Mexico. Aldine, Chicago

McClellan DA, McCracken KG (2001) Estimating the Influence of Selection on the Variable Amino Acid Sites of the Cytochrome b Proteins Functional Domains. Mol Biol Evol 18(6): 917-925

McNevin D, Wilson-Wilde L, Robertson J, Kyd J, Lennard C (2005a) Short tandem repeat (STR) genotyping of keratinised hair. Part 1. Review of current status and knowledge gaps. Forensic Sci Int 153(2-3): 237-246

McNevin D, Wilson-Wilde L, Robertson J, Kyd J, Lennard C (2005b) Short tandem repeat (STR) genotyping of keratinised hair. Part 2. An optimised genomic DNA extraction procedure reveals donor dependence of STR profiles. Forensic Sci Int 153(2-3): 247-259

McVean GA (2001) What do patterns of genetic variability reveal about mitochondrial recombination? Heredity 87(6): 613-620

Meadows JRS, Li K, Kantanen J, Tapio M, Sipos W, Pardeshi V, Gupta V, Calvo JH, Wahn V, Norris B, Kijas JW (2005) Mitochondrial Sequence Reveals High Levels of gene Flow Between Breeds of Domestic Sheep from Asia and Europe. J Hered 96(5): 494-501 
Mengoni Gonalons GL (2007) Camelids in ancient Andean societies: A review of the zooarchaeological evidence. doi:10.1016/j.quaint.2007.05022

Mengoni Gonalons GL, Yacobaccio HD (2006) The Domestication of South American Camelids - A view from the South-Central Andes. In: Zeder MA, Bradley DG, Emswhiller E, Smith BD (Hrsg.) Documenting Domestication - New Genetic and Archaeological Paradigms. Kapitel 16, University of California Press, Los Angeles

Merriweather DA, Merriweather AM (2003) Alpaca Color Genetics: The Genetics of White Markings. Alpaca Magazine. Summer 2003

Mevárez J, Salazar CA, Bermingham E, Salcedo C, Jiggins CD, Linares M (2006) Speciation by hybridization in Heliconius butterflies. Nature 441(15): 868-871

Michels G, Wätjen W, Niering P, Steffan B, Tran Thi QH, Chovolou Y, Kampkötter A, Bast A, Proksch P, Kahl R (2005) Pro-apototic effects of the flavonoid luteolin in rat H4IIE cells. Toxicology 206: 337-348

Mignon-Grasteau S, Boissy A, Bouix J, Faure J-M, Fisher AD, Hinch GN, Jemden P, Le Neindre P, Mormede P, Prunet P, Vandeputte M, Beaumont C (2005) Genetics of adaptation and domestication in livestock. Livestock Production Science 93: 3-14

Miller GR, Burger RL (1995) Our father the cayman, our dinner the llama; animal utilization at chavin de huantar, Peru. American Antiquity 60(3): 421-458

Millien V (2006) Morphological Evolution is Accelerated Among Island Mammals. PLoS Biol 4(10): e321. DOI: 10.1371/journal.pbio.0040321

Minelli A (1993) Biological Systematics - The State of the Art. Chapman \& Hall. London

Mishmar D, Ruiz-Pesina E, Golik P, Macaulayd V, Clarke AG, Hosseinib S, Brandona M, Easley K, Cheng E, Brown MB, Sukerniki RI, Olckers A, Wallace DC (2003) Natural selection shaped regional mtDNA variation in humans. Proc Natl Acad Sci USA 100(1): 171-176

Molina JI (1782) Ensayo sobre la Historia Natural de Chile. Online-Ausgabe: http://200.72.159.9/mchilena01//temas/documento_detalle.asp?id=MC0002868

Montiel R, Malgosa A, Francalacci P (2001) Authenticating ancient human mitochondrial DNA. Hum Biol 73: 689-713

Mortola JP, Lanthier C (2005) Breathing frequency in ruminants: a comparative analysis with non-ruminant mammals. Respir Physiol Neurobiol 145(2-3): 265-277

Moseley ME (1972) Subsistence and demography: an example from prehistoric Peru. Southwestern Journal of Anthropology 28: 25-49

Müller PLS (1776) Des Ritters Carl von Linné Königlich Schwedischen Leibsarztes (..) vollständiges Natursystem: nach der zwölften lateinischen Ausgabe und nach Anleitung des holländischen Houttuynischen Werk mit ausführlicher Erklärung. Supplements und Register-Band über alle sechs Theile oder Classen des Thierreichs: Nebst drey Kupfertafeln. Gabriel Nicolaus Raspe, Nürnberg 
Mullis KB, Faloona F (1987) Specific synthesis of DNA in vitro via a polymerase-catalyzed chain reaction. Methods Enzymol 135: 335-350

Mundy NI, Kelly J (2006) Investigation of the role of the agouti signaling protein gene (ASIP) in coat color evolution in primates. Mamm Genome 17(12): 1205-1213

Nakayama K, Soemantri A, Jin F, Dashnyam B, Ohtsuka R, Duanchang P, Isa MN, SettheethamIshida W, Harihara S, Ishida T (2006) Identification of novel functional variants of the melanocortin 1 receptor gene originated from Asians. Hum Genet 119 (3): 322-330

Nei M (1973) Analysis of gene Diversity in Subdivides Populations. Proc Nat Acad Sci USA $70(12, \mathrm{I}): 3321-3323$

Nei M (1978) Estimation of average heterozygosity and genetic distance from a small number of individuals. Genetics 89(3): 583-590

Nei M (1987) Molecular evolutionary genetics. Columbia University Press, New York

Nguyen VK, Su C, Muyldermans S, van der Loo W (2002) Heavy-chain antibodies in Camelidae; a case of evolutionary innovation. Immunogenetics 54(1): 39-47

Norambuene MC, Paredes M (2003) Variabilidad y estructura genética en dos poblaciones de Vicugna vicugna (Camelidae) del norte de chile. Revista Chilena de Historia Natural 76: 99104

Norton HL, Kittles RA, Parra E, McKeigue P, Mao X, Cheng K, Canfield VA, Bradley DG, McEvoy B, Shriver MD (2007) Genetic evidence for the convergent evolution of light skin in Europeans and East Asians. Mol Biol Evol 24(3): 710-722

Obreque V, Coogle L, Henney PJ, Bailey E, Mancilla R, García-Huidobro J, Hinrichsen P, Cothran EG (1998) Characterization of 10 polymorphic alpaca dinucleotide microsatellites. Anim Genet 29(6): 461-462

Odbileg R, Konnai S, Ohashi K, Onuma M (2005) Molecular cloning and phylogenetic analysis of inflammatory cytokines of Camelidae (llama and camel). J Vet Med Sci 67(9): 921-925

Olsson O (2001) The Rise of Neolithic Agriculture. Economics 57: 1-26

Omidfar K, Rasaee MJ, Modjtahedi H, Forouzandeh M, Taghikhani M, Golmakani N (2004) Production of a novel camel single-domain antibody specific for the type III mutant EGFR. Tumor Biol 25(5-6): 296-305

Ostrander EA, Wayne RK (2005) The canine genome. Genome Res 15(12): 1706-1716

Ovchinikov IV, Gotherstrom A. Romanova GP, Kharitonov VM, Lidén K, Goodwin W (2000) Molecular analysis of Neanderthal DNA from the northern Caucasus. Nature 404: 490-493

Pakendorf B, Stoneking M (2005) Mitochondrial DNA and human evolution. Annu Rev Genomics Hum Genet 6: 165-183 
Palma RE, Martin R, Spotorno A (2001) Phylogenetic relationships among South American subspecies of camelids based on sequences of the cytochrome b mitochondrial genes. In: Raunelli MGA (Hrsg.) 3rd European Symposium on South American Camelids and Supreme European Seminar: 44-52, Wageningen Press, Göttingen

Parson T, Shils E (1990) Value and social systems. In: Alexander J, Seidman S (Hrsg.) Culture and Society - Contemporary Debates. Cambridge University Press, New York

Patterson H (1985) The recognition species concept. In: Vrba ES (Hrsg.) Species and Speciation. Prebria Transval Museum Monography No. 4

Paunero RS (2002) The Presence of a Pleistocene Colonizing Culture in La Maria Archaeological Locality, Casa Del Minero. Center for the Studies of the First Americans (CSFA) (Hrsg.) A\&M University Press, Texas: 127-132.

Payer A (2001) Kameliden: Kamele, Lamas, Alpakas, Vicunja. http://www.payer.de/entwlink.htm

Penedo MC, Caetano AR, Cordova K (1999) Eight microsatellite markers for South American camelids. Anim Genet 30(2): 166-167

Pereira TV, Salzano FM, Mostowska A, Trzeciak WH, Ruiz-Linares A, Cies JAB, Saavedra C, Nagamachi C, Hurtado AM, Hill K, Castro-de-Guerra D, Silva-Júnior WA, Bortolini MC (2006) Natural Selection and Molecular Evolution in primate PAX9 gene, a major determinant of tooth development. Proc Natl Acad Sci USA 103(15): 5676-5681

Perry WL, Bass WM, Riggsby WS, Sirotkin K (1988) The autodegradation of deoxyribonucleic acid (DNA) in human rib bone and its relationship to the time interval since death. J Forensic Sci 33(1) : 144-153

Pfeiffer I (2007) Molekulargenetische Bestimmung der einheimischen Faune und CITESgeschützter Tierarten. In: Herrmann B, Saternus KS (Hrsg.) Biologische Spurenkunde Kriminalbiologie. Springer Verlag, New York, Heidelberg, Berlin

Pfeiffer I, Volkel I, Taubert H, Brenig B (2004) Forensic DNA-typing of dog hair: DNAextraction and PCR amplification. Forensic Sci Int 141(2-3): 149-151

Pflumm W (1996) Biologie der Säugetiere. 2.Aufl. Parey Buchverlag, Berlin

Pielou EC (1991) After the Ice Age: The return of life to glaciated North America. University of Chicago Press, Chicago

Pons O, Petit RJ (1996) Measuring and testing genetic differentiation with ordered versus unordered alleles. Genetics 144(3): 1237-1245

Prentiss WC, Chatters C (2003) Cultural Diversification and Decimation in the Prehistoric Record. Current Anthropol 44(1): 33-58

Proulx DA (2001) Ritual Use of Trophy Heads in Ancient Nasca Societies. In: Benson EP, Cook AG (Hrsg.) Ritual Sacrifice in Ancient Peru. University of Texas Press, Austin 
Rabey MA (1989) Are Llama-Herders in the South Central Andes True Pastoralists? In: CluttonBrock J (Hrsg.) The walking larder. Patterns of domestication, pastoralism, and predation. Unnin Hyman, London

Redman CL (1978) Rise of Civilization. Freeman, San Francisco

Rees JL (2000) The melanocortin 1 receptor (MC1R): more than just red hair. Pigment Cell Res 13(3): 135-140

Reindel M, Isla Cuadrado J (2006) Archäologisches Projekt 'Paracas in Palpa', Peru: Ausgrabungen und Forschungen im Jahr 2005. Jahresbericht der SchweizerischLiechtensteinischen Stiftung für Archäologische Forschungen im Ausland (2005): 30-59, Zürich und Vaduz

Reindel M, Isla Cuadrado J, Lambers K (2005) Archäologisches Projekt 'Paracas in Palpa': Ausgrabungen und Forschungen 2004. Jahresbericht der Schweizerisch-Liechtensteinischen Stiftung für Archäologische Forschungen im Ausland (2004). S.25-44, Zürich und Vaduz

Reindel M, Isla J (2001) Los Molinos und La Muña. Zwei Siedlungszentren der Nasca-Kultur in Palpa, Südperu / Los Molinos y La Muña. Dos centros administrativos de la cultura Nasca en Palpa, costa sur del Perú. Beiträge zur Allgemeinen und Vergleichenden Archäologie, 21: 241-319

Remane A (1952) Die Grundlagen des natürlichen Systems, der vergleichenden Anatomie und der Phylogenetik. Akad.Verl.-Ges. Geest \& Portig, Leipzig

Reynafarje C, Faura J, Villavicencio D, Curaca A, Reynafarje B, Oyola L, Contreras L, Vallenas E, Faura A (1975) Oxygen transport of hemoglobin in high-altitude animals (Camelidae). J Appl Physiol 38(5): 806-810

Rieder S, Taourit S, Mariat D, Langlois B, Guerin G (2001) Mutations in the agouti (ASIP), the extension (MC1R), and the brown (TYRP1) loci and their association to coat color phenotypes in horses (Equus caballus). Mamm Genome 12(6): 450-455

Riviere HL, Gentz EJ, Timm KI (1997) Presence of enamel on the incisors of the llama (Lama glama) and alpaca (Lama pacos). Anat Rec 249(4): 441-448

Robin ED, Wong R (1988) Mitochondrial DNA molecules and virtual number of mitochondria per cell in mammalian cells. J Cell Physiol 136:507-13

Rodríguez JB, Wheeler JC, Dodd CS, Bruford MW, Rosadio RA (2004) Determinación de Parentesco en Alpacas (Vicugna pacos) por medio del análisis de ADN microsatélite. Rev Int Vet Perú 15(2): 113-119

Rokas A, Carroll SB (2005) More genes or more taxa? The relative contribution of gene number and taxon number to phylogenetic accuracy. Mol Biol Evol 22(5): 1337-1344

Rokas A, Ladoukakis E, Zouros E (2003) Animal mitochondrial DNA recombination revisited. TRENDS Ecol Evol 18(8): 411-417 
Römpler H, Rohland N, Lalueza-Fox C, Willerslev E, Kuznetsova T, Rabeder G, Bertranpetit J, Schöneberg T, Hofreiter M (2006) Nuclear gene indicates coat-color polymorphism in mammoths. Science 313(5783): 62

Roseberry W (1989) Anthropologies and Histories - Assays in culture, history and political economy. Rutgers University Press, New Brunswick

Royo LJ, Alvarez I, Fernandez I, Arranz JJ, Gomez E, Goyache F (2005) The coding sequence of the ASIP gene is identical in nine wild-type coloured cattle breeds. J Anim Breed Genet 122(5): $357-360$

Rozas J, Sánchez-DelBarrio JC, Messeguer X, Rozas R (2003) DnaSP, DNA polymorphism analyses by the coalescent and other methods. Bioinformatics 19: 2496-2497

Ruiz-Pesini E, Mishmar D, Brandon M, Procaccio V, Wallace DC (2004) Effects of purifying and adaptive selection on regional variation in human mtDNA. Science 303(5655): 223-226

Russel N (2002) The Wild Side of Animal Domestication. Society and Animals 10(3): 285-302

Russo CA, Takezaki N, Nei M (1996) Efficiencies of different genes and different tree-building methods in recovering a known vertebrate phylogeny. Mol Biol Evol 13(3): 525-536

Saitou N, Nei M (1987) The Neighbor-joining method: A new method for reconstructing phylogenetic tress. Mol Biol Evol 4: 406-425

Salas R, Stucchi M, Devries TJ (2003) The presence of Plio-Pleistocene Palaeolama sp. (Artiodactyla: Camelidae) on the southern coast of Peru. Bul. Inst fr études andines 32(2): 347-59

Sanders WT Price BJ (1968) Mesoamerica: The Evolution of a civilization. Random House, New York

Sarno RJ, David VA, Franklin WL, O’Brien SJ, Johnson WE (2000) Development of microsatellite markers in the guanaco, Lama guanicoe: utility for South American camelids. Mol Ecol 9(11): 1922-1924

Sarno RJ, Franklin WL, O'Brien SJ, Johnson WE (2001) Patterns of mtDNA and microsatellite variation in an island and mainland population of guanacos in southern Chile. Ani Cons 4(2): 93-101

Sarno RJ, Villaalba L, Bonacic C, Gonzalez B, Zapata B, MacDonald DW, O'Brien SJ, Johnson WE (2004) Phylogeography and subspecies assessment of Vicugnas in Chile and Bolivia utilizing mtDNA and microsatellite markers: implications for vicugna conservation and management. Conservation Genetics 5(1): 89-102

Savolainen P, Zhang YP, Luo J, Lundeberg J, Leitner T (2002) Genetic evidence for an East Asian origin of domestic dogs. Science 298(5598): 1610-1613

Scheinsohn V (2003) Hunter-Gatherer Archaeology in South America. Annu Rev Anthropol 23: 339-361 
Scherf BD (1995) World watch List for domestic animal diversity. 2.Aufl., Food and Agriculture Organisation of the United Nations, Rom

Schilz F (2006) Molekulargenetische Verwandtschaftsanalyse am prähistorischen Skelettkollektiv der Lichtensteinhöhle. Dissertation, Universität Göttingen

Schilz F, Hummel S, Herrmann B (2004) Desing of a multiplex PCR for genotyping 16 short tandem repeats in degraded DNA samples. Anthropol Anz 62: 369-378

Schmidt D (2004) Entwicklung neuer Markersysteme für die ancient DNA-Analyse. Erweiterung des molekulargenetischen Zugangs zu kultur- und sozialgeschichtlichen Fragestellungen der Prähistorischen Anthropologie. Dissertation, Universität Göttingen

Schmidt-Kuntzel A, Eizirik E, O'Brien SJ, Menotti-Raymond M (2005) Tyrosinase and tyrosinase related protein 1 alleles specify domestic cat coat color phenotypes of the albino and brown loci. J Hered 96(4): 289-301.

Schmutz SM, Berryere TG, Goldfinch AD (2002) TYRP1 and MC1R genotypes and their effects on coat color in dogs. Mamm Genome 13 (7): 380-387

Schneiders W (2001) Das Zeitalter der Aufklärung, 3.Aufl., Beck, München

Schwartz M, Vissing J (2002) Paternal inheritance of mitochondrial DNA. N Engl J Med 347(8): $576-580$

Semorile LC, Crisci JV, Vidal-Rioja L (1994) Restriction site patterns in the ribosomal DNA of camelidae. Genetica 92(2): 115-122

Service ER (1971) Primitive Social Organization: An evolutionary perspective. 2.Aufl., Random House, New York

Shields R (2004) Pushing the envelope on molecular dating. Trends Genet 20: 221-222.

Silverman H, Proulx DA (2002) The Nasca. Blackwell Publishers. Oxford

Simpson GG (1961) Principles of Animal Taxonomy. Columbia Press. NY

Skidmore JA, Billah M, Binns M, Short RV, Allen WR (1999) Hybridizing Old and New World camelids: Camelus dromedarius x Lama guanicoe. Proc Biol Sci 266(1420): 649-656

Smith E, Schreiber KJ (2005) New World States and Empires: Economic and Social Organization. J Arch Res 13(3): 1-54

Smith E, Schreiber KJ (2006) New World States and Empires: Politics, Religion und Urbanism. J Arch Res 14(1): 1-52

Sneath PHA, Sokal RR (1973) Numerical taxonomy: the principles and practice of numerical classification. Freeman, San Francisco

Sokal RR, Crovello IJ (1970) The biological species concept: A critical evaluation. American Naturalist 104: 127-153 
Spradley JP, McCurd DW (1987) Issues in cultural anthropology: Selected readings. 2.Aufl. Prospect Heights Waveland

Stahl PW (2007) Pre-Columbian Andean animal domestication at the edge of the empire. World Archaeology 34(3): 470-483

Stahle DW, Cleaveland MK, Blanton DB, Therrell MD, Gay DA (1998) The Lost Colony and Jamestown droughts. Science 280(5363): 564-567

Stanish C (2006) Prehispanic Agricultural Strategies of intensification in the Titicaca Basin of Peru and Bolivia. In: Marcus J, Stanish C (Hrsg.) Agricultural Strategies. Cotsen Institute of Archaeology. Los Angeles

Stanley HF, Kadwell M, Wheeler JC (1994) Molecular evolution of the family Camelidae: a mitochondrial DNA study. Proc Biol Sci 256 (1345): 1-6.

Steen SW, Gielly L, Taberlet P, Brochmann C (2000) Same parental species, but different taxa: molecular evidence for hybrid origins of the Érare endemics Saxifrage opdalensis and É $S$. svalbardensis (Saxifragaceae). Botannical Journal of the Linnean Society 132(2): 153-164

Steward JH (1976) Theory of cultural change: the methodology of multilinear evolution. 3.Aufl. University of Illinois Press, Urbara

Stockton DW, Das P, Goldenberg M, D`Souza RN, Patel PI (2000) Mutation of PAX9 is associated with oligodontia. Nature Genetics 24: 18-19

Storch V, Welsch U, Wink M (2001) Evolutionsbiologie. Springer Verlag, Berlin, Heidelberg, New York

Storey AA, Ramírez JM, Quiroz D, Burley DV, Addison DJ, Walter R, Anderson AJ, Hunt TL, Athens JS, Huynen L, Matisoo-Smith EA (2007) Radiocarbon and DNA evidence for a preColumbian introduction of Polynesian chickens to Chile. Proc Natl Acad Sci USA 104(25): 10335-10339

Stowasser JM, Petschenig M, Skutsch F (1991) Der kleine Stowasser - Lateinisch-Deutsches Schulwörterbuch. 3.Aufl., R. Oldenbourg Verlag München

Strausberg RL, Feingold EA, Grouse LH, Derge JG, Klausner RD, Collins FS, Wagner L, Shenmen CM, Schuler GD, Altschul SF, Zeeberg B, Buetow KH, Schaefer CF, Bhat NK, Hopkins RF, Jordan H, Moore T, Max SI, Wang J, Hsieh F, Diatchenko L, Marusina K, Farmer AA, Rubin GM, Hong L, Stapleton M, Soares MB, Bonaldo MF, Casavant TL, Scheetz TE, Brownstein MJ, Usdin TB, Toshiyuki S, Carninci P, Prange C, Raha SS, Loquellano NA, Peters GJ, Abramson RD, Mullahy SJ, Bosak SA, McEwan PJ, McKernan KJ, Malek JA, Gunaratne PH, Richards S, Worley KC, Hale S, Garcia AM, Gay LJ, Hulyk SW, Villalon DK, Muzny DM, Sodergren EJ, Lu X, Gibbs RA, Fahey J, Helton E, Ketteman M, Madan A, Rodrigues S, Sanchez A, Whiting M, Madan A, Young AC, Shevchenko Y, Bouffard GG, Blakesley RW, Touchman JW, Green ED, Dickson MC, Rodriguez AC, Grimwood J, Schmutz J, Myers RM, Butterfield YS, Krzywinski MI, Skalska U, Smailus DE, Schnerch A, Schein JE, Jones SJ, Marra MA (2002) Mammalian Gene Collection Program Team Generation and initial analysis of more than 15,000 full-length human and mouse cDNA sequences. Proc Natl Acad Sci USA 99 (26): 16899-16903 
Su C, Nguyen VK, Nei M (2002) Adaptive evolution of variable region genes encoding an unusual type of immunoglobulin in camelids. Mol Biol Evol 19(3): 205-215

Sutovsky P, Moreno RD, Ramalho-Santos J, Dominko T, Simerly C, Schatten G (1999) Ubiquitin tag for sperm mitochondria. Nature 402(6760): 371-372

Sutovsky P, Moreno RD, Ramalho-Santos J, Dominko T, Simerly C, Schatten G (2000)

Ubiquitinated sperm mitochondria, selective proteolysis, and the regulation of

mitochondrial inheritance in mammalian embryos. Biol Reprod 63(2): 582-590

Takase H, Tumennasan K, Hiratsuka K, Chandley AC, Hotta,Y. (2002) Fertility investigation in F1 Hybrid and Backcross Progeny of Cattle (Bos taurus) and Yak (B. gruniens) in Mongolia. II. Little variation in gene products studied in male sterile and fertile animals. Niigata journal of health and walfare 2(1): $42-52$

Tamm E, Kivisild T, Reidla M, Metspalu M, Smith DG, Mulligan CJ, Bravi CM, Rickards O, Martinez-Labarga C, Khusnutdinova EK, Fedorova SA, Golubenko MV, Stepanov MA Gubina MA, Zhadaniv SI, Ossipova LP, Damba L, Voevoda MI, Dipierri JE, Villems R, Mahli RS (2007) Beringian Standstill and Spread of Native American Founders. PloS ONE 9:e829

Tamura K, Dudley J, Nei M, Kumar S (2007) MEGA4: Molecular Evolutionary Genetics Analysis (MEGA) Software Version 4.0., Mol Biol Evol 24: 1596-1599

Tapio M, Grigaliunaite I (2003) Use of mitochondrial DNA as a genetic marker in domesticated mammals. Ekologija 1: 31-33

Templeton AR (1989) The meaning of species and speciation: a gentic perspective. In: Otte D, Endler JA (Hrsg.) Speciation and its consequences. Sinauer associates, Sunderland

Thompson LG, Mosley-Thompson E, Brecher H, Davis M, Leon B, Les D, Lin PN, Mashiotta T, Mountain K (2006) Abrupt tropical climate change: past and present. Proc Natl Acad Sci USA 103(28): 10536-10543

Tomka SA (1992) Vicunas and Llamas: Parallels in Behavioural Ecology and Implications for the Domestication of Andean Camelids. Hum Ecol 20(4): 407-433

Trigger B (2003) Understanding early Civilizations: A comparative study. Cambridge University Press, New York

Trut LN (1999) Early Canid Domestication: The Farm-Fox-Experiment. American Scientist 87: 160-169.

Tylor EB (1958) The origins of culture. Primitive Culture 1. Harper \& Row Verlag, New York

Uchida A (1998) Variation in tooth morphology of Gorilla gorilla. J Hum Evol 34: 55-70

Uerpmann HP (1996) Animal domestication - Accident or intention? In: Harris DR (Hrsg.) The Origins and Spread of Agriculture and Pastoralism in Eurasia. Kap.12, UCL Press, London

Unkel I (2006) AMS-14C-Analysen zur Rekonstruktion der Landschafts- und Kulturgeschichte in der Region Palpa (S-Peru). Dissertation, Universität Heidelberg 
Unkel I, Kadereit A, Mächtle B, Eitel B, Kromer B, Wagner G, Wacker L (2007) Dating methods and geomorphic evidence of palaeoenvironmental changes at the eastern margin of the South Peruvian coastal desert (14³0’S) before and during the Little Ice Age. Quaternary International, doi:10.1016/j.quaint.2007.03.006

Urquart AJ, Oldroyd NJ, Kimpton CP, Gill P (1995) Highly discriminating heptaplex short tandem repeat PCR system for forensic identification. BioTechnique 18:116-121

Urquhart AJ, Kimpton CP, Gill P (1994) Variation in short tandem repeat sequences- a survey of twelve microsatellites loci for use as forensic markers. Int J Legal Med 107: 13-20

Ursing BM, Slack KE, Arnason U (2000) Subordinal artiodactyl relationships in the light of phylogenetic analysis of 12 mitochondrial protein-coding genes. Zoologica Scripta 29(2): 8388

Vage DI, Lu D, Klungland H, Lien S, Adalsteinsson S, Cone RD (1997) A non-epistatic interaction of agouti and extension in the fox, Vulpes vulpes. Nature Genetics 15(3): 311-315

Valdez LM (1988) Los camélidos en la subsistencia Nasca: el caso de Kawachi. Boletín de Lima 57: $31-35$

Valdez LM (2001) Alpacas en el centro ceremonial Nasca de Cahuachi. Bol Mus Arqueol Antropol (UNMSM) 4(3): 59-68

van Asch B, Pereira L, Pereira F, Santa-Rita P, Limas M, Amorim A (2005) MtDNA diversity among four Portuguese autochthonous dog breeds: a fine-scale characterisation. BMC Genet 6(1): 37

van Valen L (1976) Ecological species, multispecies and oaks. Taxon 25: 223-239

Verginelli F, Capelli C, Coia V, Musiani M, Falchetti M, Ottini L, Palmirotta R, Tagliacozzo A, De Grossi Mazzorin I, Mariani-Costantini R (2005) Mitochondrial DNA from prehistoric canids highlights relationships between dogs and South-East European wolves. Mol Biol Evol 22(12): 2541-2551

Vidal-Rioja L, Semorile L, Bianchi NO, Padrón J (1987) DNA composition in South American camelids. I. Characterization and in situ hybridization of satellite DNA fractions. Genetica 72(2): 137-146

Vidal-Rioja L, Zambelli A, Semorile L (1994) An assessment of the relationships among species of Camelidae by satellite DNA comparisons. Hereditas 121(3): 283-290

Vila C, Seddon J, Ellegren H (2005) Genes of domestic mammals augmented by backcrossing with wild ancestors. Trends Genet 21(4): 214-218

Voisey J, Imbeault P, Hutley L, Prins JB, van Daal A (2002) Body Mass Index-Related Human Adipocyte Agouti Expression Is Sex-Specific But Not Depot-Specific. Obesity Research 10(6): 447-452

Voisey J, van Daal A (2002) Agouti: From Mouse to Man, from Skin to Fat. Pigment Cell Res 15: $10-18$ 
Wagner GP, Laubichler MD (2004) Rupert Riedel and the Re-Synthesis of Evolutionary and Developmental Biology: Body Plans and Evolvability. Journal of Experimental Zoology (MOL DEV EVOL) 302B: 92-102

Wallert A, Boytner R (1996) Dyes from the Tumilaca and Chiribaya Cultures, South Coast of Peru. J Arch Sci 23: 853-861

Ward RH, Redd A, Valencia D, Frazier B, Pääbo S (1993) Genetic and linguistic differentation in the Americas. Proc Natl Acad Sci USA 90 (22): 10663-10667

Weber M (1956) Soziologie, weltgeschichtliche Analysen, Politik. Winckelmann J (Hrsg.), 2. Aufl., Kröner, Stuttgart

Wenke RJ (1981) Explaining the Evolution of Cultural Complexity: A Review. In: Schiffer MB (Hrsg.) Advances in Archaeological Method and Theory, Volume 4., S.79-127. Academic Press, New York

Wernery U (2001) Camelid immunoglobulins and their importance for the new-born - a review. J Vet Med B Infect Dis Vet Public Health 48(8): 561-568

Westenthanner M (2006) Optimierung der Real Time PCR zur Charakterisierung der Degradation von ancient DNA (aDNA) in ausgewählten Skelettelementen. Diplom-Arbeit, Universität Göttingen

Westerhof W (2006) The discovery of human melanocyte. Pigment Cell Res 19: 183-193

Wheeler JC, Fernandez M, Rosadio R., Hoces D, Kadwell M, Bruford MW (2002) Genetic diversity and management implications for Vicugna populations in Peru. Results of Grant \#N251 of the Darwin Initiative for the Survival of Species. Final Report

Wheeler JC, Russel AJF, Redden H (1995) Llamas and Alpacas: Pre-conquest Breeds and Postconquest Hybrids. J Archaeol Sci 22: 833-840

Wheeler JC, Russel AJF, Stanley HF (1992) Razas prehispanicas de llamas y alpacas; la medida de lo que se ha perdido. Arch Zootec 41.extra: 467-75.

Whitehouse R, Wilkins J (1986) The making of civilisations: History discovered through archaeology. Alfred a Knopf Verlag, New York

Wiesemüller B, Rothe H, Henke W (2002) Phylogenetische Systematik. Springer Verlag, Berlin Heidelberg New York

Wiley EO (1978) The evolutionary species concept reconsidered. Syst Zool 27: 17-26

Willerslev E, Cooper A (2005) Ancient DNA. Proc Biol Sci 272(1558): 3-16

Wildman R, Meier R (2001a) A Critique from the Hennigian Species Concept Perspective. In: Wheeler QD, Meier R (Hrsg.) Species Concept and Phylogenetic Theory. Columbia University Press, New York

Willmann R, Meier R (2001a) The Hennigian Species Concept. In: Wheeler QD, Meier R (Hrsg.) Species Concept and Phylogenetic Theory. Columbia University Press, New York 
Wilson AC, Cann RL (1992) The recent african genesis of humans. Sci Am 266:22-27

Wittfogel KA (1962) Die orientalische Despotie: Eine vergleichende Untersuchung totaler Macht. Kipeheuer \& Witsch, Köln

Wiuf C (2001) Recombination in human mitochondrial DNA? Genetics 159(2): 749-756

Wolf ER (1982) Europe and the people without history. University of California Press, Los Angeles

Wouters J, Boytner R (1996) Dyes from the Tumulica and Chiribaya Cultures, South Central Coast of peru. J Archaeol Sci 23: 853-861

Wouters J, Rosario-Chirinos N (1992) Dye analysis of Pre-Columbian Peruvian Textiles with High-Performance Liquid Chromatography and Diode-Array Detection. Journal of the American Institute for Conversation 31(2): 237-255

Xu SQ, Yang YZ, Zhou J, Jing GE, Chen YL, Wang J, Yang HM, Wang J, Yu J, Zhong XC, Ge RL (2005) A mitochondrial genome Sequence of the Tibetean Antelope (Phantolops hodgsonii). Geno Prot Bioinfo 3(1): 5-17

Yacobaccio HD (1994) Hilos conductores y nudos gordianos: Problemas y perspectivas en la arqueologia de cazadores-recolectores punetios. Rumitacana. Revista de Anthropología 1: $19-21$

Yacobaccio HD (2000) Inhumación de una cabeza aislada en la Puna argentina. Estudios Sociales de NOA 4: 59-72

Yacobaccio HD (2003) Social dimension of camelid domestication in the southern Andes. Anthropozoologica 39(1): 237-247

Yacobaccio HD, Aschero CA (1999) 20anos despues: Inca Cueva 7 reinterpretado. Cuadernos del instituto Nacional del Anthropología y Penamiento Latinoamericano 18: 7-18

Zardoya R, Meyer A (1996) Phylogenetic performance of mitochondrial protein-coding genes in resolving relationships among vertebrates. Mol Biol Evol 13(7): 933-942

Zeder MA, Emswhiller SE, Smith BD, Bradley DG (2006) Documenting domestication: the intersection of genetics and archaeology. Trends Genet 22(3): 139-155

Zeder MA, Hesse B (2000) The initial domestication of goats (Capra hircus) in the Zagros mountains 10,000 years ago. Science 287(5461): 2254-2257

Zhao X, Haqqi T, Yadav SP (2000) Sequencing Telomeric DNA Template With short tandem repeats using dye terminator cycle sequencing. Journal of Biomolecular Techniques 11.3 (2000): 111-21.

Zuckerkandl E, Pauling LB (1962) Molecular disease, evolution, and genetic heterogeneity. In: Kasha M, Pullman B (Hrsg) Horizons in Biochemistry. Academic Press, New York 
13 Appendix

13.1 Verzeichnis der Einheiten und Abkürzungen

$\begin{array}{ll}\& & \text { und } \\ (\mathrm{w} / \mathrm{v}) & \text { engl. weights per volume } \\ \text { ( } & \text { rechtlich geschützt } \\ \text { 6-FAM } & \text { 6-Carbofluorescein }\end{array}$

Abb. Abbildung

aDNA ancient DNA

Aufl. Auflage

bp Basenpare

BSA Bovine Serum Albumin

bzw. beziehungsweise

${ }^{\circ} \mathrm{C} \quad$ Grad-Celcius

ca. circa

$\mathrm{cm} \quad$ Zentimeter

d.h. das heißt

dATP Desoxyadenosintriphosphat

dCTP Desoxydytidintriphosphat

dGTP Desoxyaguanosintriphosphat

DNA Desoxyribonukleinsäure

dTTP Desoxythymidintriphosphat

EDTA Ethylendinittrotetraacetat Dinatriumsalz-Dihydrat

engl. englisch

et al. et alii= und andere

etc. et cetera

g Gramm

h Stunden

HEX 6-Carboxyl-2',4', 7', 4, 7-Hexachlorofluorescein

Hrsg. Herausgeber

J. v. h. Jahre vor heute

Kap. siehe Kapitel

$\mathrm{kb} \quad$ Kilobasen

m Meter 


\begin{tabular}{|c|c|}
\hline $\mathrm{Mb}$ & Mega Basen \\
\hline $\mathrm{mg}$ & Milligramm \\
\hline $\min$ & Minute \\
\hline $\mathrm{ml}$ & Millimeter \\
\hline M & Molar \\
\hline $\mathrm{MM}$ & Master-Mix \\
\hline $\mathrm{mM}$ & Milimolar \\
\hline$\mu \mathrm{M}$ & Mikromolar \\
\hline mt-DNA & mitochndriale DNA \\
\hline n. b. & nicht bekannt \\
\hline n. Chr. & nach Christus \\
\hline nd & nicht definiert \\
\hline $\mathrm{NEB}$ & NewEnglandBiolabs \\
\hline $\mathrm{NED}^{\mathrm{TM}}$ & n. b. \\
\hline PAA & Polyacriylamid \\
\hline PCR & Polymerase-Chain-Reaction \\
\hline $\mathrm{pH}$ & potentia hydrogenii \\
\hline pmol & picomol \\
\hline RFLP & Restriktionsfragmentlängenpolymorphismus \\
\hline $\mathrm{rpm}$ & rounds per minute \\
\hline rRNA & ribosomale Ribonukleinsäure \\
\hline s & Sekunde \\
\hline s. & siehe \\
\hline SNP & SingleNucleotidePolymorhism \\
\hline STR & ShortTandemReapeat \\
\hline Tab. & Tabelle \\
\hline TM & engl. trademark \\
\hline $\mathrm{U}$ & Unit, Einheit für Enzymaktivität \\
\hline ü. NN. & über Normalnull \\
\hline v. Chr. & vor Christus \\
\hline z. B. & zum Beispiel \\
\hline$\%$ & Prozent \\
\hline$=$ & gleich \\
\hline
\end{tabular}


13.2 Geräte, Chemikalien und Einwegmaterialien

Geräte

ApplePowerMac G4

Demineralisationsanlage Typ LAB-UPW, TKA Wasseraufbereitungsanlagen GmbH

DNA Sequencer Modell 310 mit Genescan Collection Software Version 2.0.2./Sequence Collection Software, PE Applied Biosystems

DNA Thermal Cycler Typ TC1, Perkin Elmer Cetus

DNA-Extraktor EZ1 Biorobot, Qiagen

DNA-Sequencer Modell 373 Stretch mit Genescan Collection Software 672, PE Applied Biosystems

DNA-Thermal-Cycler Typ Mastercycler ${ }^{\circledR}$ Gradient, Eppendorf

DNA-Thermal-Cycler Typ Mastercycler ${ }^{\circledR}$ Personal, Eppendorf

Elektrophoresekammer Horizon ${ }^{\text {TM} 1060 B d ~(11 x 14 c m), ~ G i b c o ~ B R L ~}$

Elektrophoresekammer Horizon ${ }^{\mathrm{TM}} 1060 \mathrm{Bd}$ (5x8cm), Gibco BRL

Gel Jet Imager, INTAS

Glaskapillaren 310Capillaries 47cmx50um 5/pkg, PE Applied Biosystems

K10-Anlage EWL 4900/4950 mit 3,2mm Hochgeschwindigkeitsfräser-Aufsatz, KaVo

Kugelschwingmühle Typ MM2 mit Zirkonium-Mahlbechern, Retsch

LightCycler® 2.0 Instrument, Roche

LightCycler ${ }^{\circledR}$ 2.0 Sample Caroussel and Capillary Releaser

LightCycler ${ }^{\circledR}$ Centrifuge Adapters, Roche

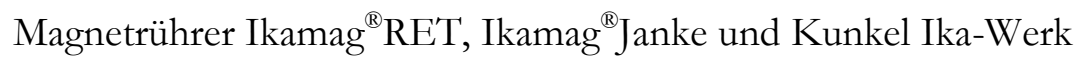

Präzisionswaage excellence Typ E 1200s, Sartorius

Präzisionswaage research, Sartorius

Quadra 650, Apple Computer Inc.

Stromversorgung Typ ST606 Electrophoresis Power Supply, Gibco BRL

Test-Tube-Rotator, Fa Snijders

Thermorüttler Typ 5437, Eppendorf 
Thermostat Typ 5320, Eppendorf

Trockenschrank, Memmert

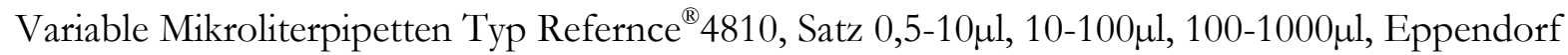

Wasser-Destilliergerät Typ Muldestar, Wagner \& Munz

Zentrifuge minispin, Eppendorf

Zentrifuge Typ5402, Eppendorf

Zentrifuge Typ5415, Eppendorf

Zentrifuge Typ5415R, Eppendorf

\section{Chemikalien}

1kB-Leiter, Life Technologies

310 10X Buffer with EDTA, PE Applied Biosystems

310 POP-4TMPolymer, PE Applied Biosystems

310 POP-6 ${ }^{\text {TM}}$ Polymer, PE Applied Biosystems

Acrylamid/Bisacrylamid 29:1, 40\% (w/v)

Agarose Roti ${ }^{\circledR}$ Ultra Qualität, Roth

Alconox (Detergenz), Aldrich

Ammoniumpersulfat, ACS grade, Amresco ${ }^{\circledR}$

Ampuwa $^{\circledR}$, Fresenius

Aqua bidest, eigene Herstellung

Borsäure, p.a., Merck

Bromphenolblau Natriumsalz, p.a., Serva

$\mathrm{CaCl}$, entwässert und gepulvert, Merck

Dextran-Blau, Fluka

1,4-Dithiothreit, (DT'T)Merck

EDTA (Ethylendinittrotetraacetat Dinatriumsalz-Dihydrat): Titriplex ${ }^{\circledR} \mathrm{III}$, Merck 
Ethanol, absolut, p.a., Abgabestelle der Bindesmonopolverwaltung: Zander-Göttingen, Nordbrand-Nordhausen (Abfüllung Universitätklinikumsapotheke, Göttingen)

Ethidiumbromid, wässrige Lösung 1\% (w/v), 10mg/ml, Serva

Extran ${ }^{\circledR}$ Typ Ap13 alkalisch mit Detergenzien, Merck

Formamid /Deionosiert), AppliedBiosystems

Formamid, Sigma

G2-Puffer, Qiagen

Harnstoff, Rotiphorese ${ }^{\circledR}$, Roth

High-Dye-Formamid, Applied Biosystems

HPLC-Wasser Lichrosolv ${ }^{\circledR}$, Merck

Isopropano p.a., Merck

NaCL, ACS Specification, J.T. Becker

Proteinase K, Qiagen

Salzsäure rauchend 37\%, Merck

Sodium Dodecyl Sulfat (SDS), BioUltra, Fluka

TEMED (Tetramethylendiamin), Fluka

Tris, Trizma TM Base, p.a., Sigma

Tris Hydrochlorid (Tris-HCL), J.T.Baker

\section{PCR-Reagenzien und Enayme}

AmpliTaq Gold ${ }^{\circledR}$ DNA Polymerase, 250 units with Buffer II and MgCl2 solution, PE Applied Biosystems

Ampuwa ${ }^{\circledR}$, Fresenius

BigDye ${ }^{\text {TM}}$ ReadyReactionMix, Sequencing Buffer, Applied Biosystems

ExoI, New England Biolabs

Light Cycler ${ }^{\circledR}$ Multiplex DNA Master Hybprobe Kit, Roche

Mineralöl NUJOL, Perkin Elmer Cetus

Qiagen Multiplex Mastermix, Qiagen 
ScfI, NEB4, 10xBSA, New England Biolabs

dATP, dCTP, dGTP, dT'TP - Set, Sigma-Aldrich

ShrimpalkalinePhosphatase (SAP), Roche

Kits

ABI PRISM ${ }^{\circledR}$ SNaPshot ${ }^{\circledR}$ Multiplex Kit (SNaPshot ${ }^{\circledR}$ Multiplex Kit, GeneScan ${ }^{\text {TM}}-120$ LIZ $^{\text {TM }}$ Size Standard) AppliedBiosystems

EZ1 DNA Tissue Kit, Qiagen

Genescan-500 ${ }^{\text {TM}}$ Rox-Kit, Applied Biosystems

NucleoSEQ Kit, MACHEREY \& NAGEL

QIAquick PCRMiniElute Kit, Qiagen

\section{Einwegmaterial}

Dental-Diamantsägeblätter Typ Diaflex-T H350 220, Horico

Einmaluntersuchungshandschuhe Peha ${ }^{\circledR}$-safe, Peha ${ }^{\circledR}$-soft, Hartmann

Eppendorf-Reaktionsgefäße (0,5ml und $2 \mathrm{ml})$ safe-lock, Eppendorf

Gesichtsmasken Surgine face mask, Johnson \& Johnson

Kimwipes ${ }^{\circledR}$ Präzisionstücher, Kimberley-Clark

Kleenex ${ }^{\circledR}$ Tücher, Kimberley-Clark

LightCycler ${ }^{\circledR}$ Capillaries, Roche

Parafilm ${ }^{\circledR} \mathrm{M}$, American National Can ${ }^{\mathrm{TM}}$

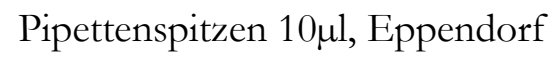

Pipettenspitzen $1 \mathrm{ml}$ und $100 \mu \mathrm{l}$, Sarstedt

\section{Software}

Arlequin ${ }^{\circ}$ Excoffier 1998-2007, CMPG, Zoologisches Institut, Universität Bern (http://cmpg.unibe.ch/software/arlequin3

DnaSP4.10, DNA Sequence Polymorphism, Rozas et al. , Universitat de Barcelona

Geneious - Research in a Flash, Biomatters 
GeneScanAnalysis ${ }^{\mathrm{TM} S o f t w a r e 3.0, ~ P E ~ A p p l i e d ~ B i o s y s t e m s ~}$

Lasergene Software Package, DNAStar Inc.

Light Cycler ${ }^{\circledR}$ Probe Desing 2.0, Roche

Light Cycler ${ }^{\circledR}$ Software 4.1 (Roche)

Molecular Evolutionary Genetics Analysis (MEGA) software version 4.0., Tamura K, Dudley J, Nei M, Kumar S ${ }^{\circledR} 1993-2006$

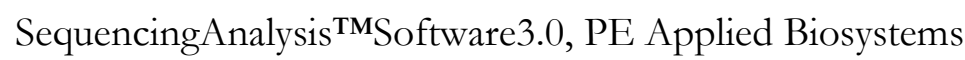

\subsection{Tabellenanhang}

Legende für die Tabellen

$\mathrm{A}=$ Adenin, $\mathrm{C}=$ Cytosin, $\mathrm{G}=$ Guanin, $\mathrm{T}=$ Thymin, $\mathrm{R}=\mathrm{A}$ oder $\mathrm{G}, \mathrm{Y}=\mathrm{C}$ oder $\mathrm{T}$, $\mathrm{nd}=$ nicht definiert, *= entspricht Refernzsequenz, -/-=kein Typisierungsergebnis 
Tabelle 73: Einzeltypisierungen des cytb-Gens in rezenten Proben

\begin{tabular}{|c|c|c|c|c|c|c|c|c|c|c|c|c|c|c|c|c|c|}
\hline 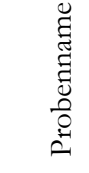 & 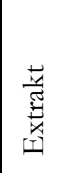 & 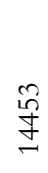 & $\underset{⿱}{\stackrel{+}{J}}$ & 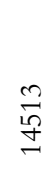 & $\stackrel{\vartheta}{\stackrel{\Xi}{f}}$ & $\begin{array}{l}\stackrel{\infty}{N} \\
\stackrel{J}{+} \\
+\end{array}$ & $\begin{array}{l}\stackrel{a}{ \pm} \\
\stackrel{10}{ \pm}\end{array}$ & $\begin{array}{l}\infty \\
\stackrel{\infty}{0} \\
\stackrel{1}{ \pm} \\
=\end{array}$ & $\begin{array}{l}\stackrel{N}{0} \\
\stackrel{\Gamma}{+}\end{array}$ & $\begin{array}{l}\stackrel{ \pm}{J} \\
\stackrel{+}{ \pm}\end{array}$ & $\begin{array}{l}\text { గ్ర } \\
\underset{+}{+}\end{array}$ & 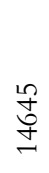 & $\begin{array}{l}\text { 肙 } \\
\stackrel{+}{ \pm}\end{array}$ & $\begin{array}{l}\hat{n} \\
\stackrel{+}{+}\end{array}$ & $\begin{array}{l}\text { 유 } \\
\stackrel{+}{+}\end{array}$ & $\begin{array}{l}\text { N } \\
\stackrel{+}{ \pm}\end{array}$ & 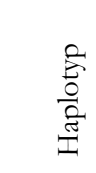 \\
\hline Ref & & A & $\mathrm{C}$ & C & $\mathrm{T}$ & $\mathrm{C}$ & $\mathrm{T}$ & $\mathrm{T}$ & A & $\mathrm{T}$ & $\mathrm{C}$ & A & A & A & A & C & LA1 \\
\hline \multirow[t]{2}{*}{ La 1} & $\mathrm{I}$ & $*$ & $*$ & $*$ & $*$ & $*$ & $*$ & $*$ & $*$ & $*$ & $*$ & $*$ & $*$ & G & * & $*$ & L1 \\
\hline & II & $*$ & $*$ & $*$ & $*$ & * & $*$ & $*$ & $*$ & $*$ & $*$ & * & $*$ & G & $*$ & $*$ & L1 \\
\hline \multirow[t]{2}{*}{$\mathrm{La} 2$} & $\mathrm{I}$ & $*$ & $*$ & $*$ & $*$ & * & $*$ & $*$ & $*$ & $*$ & $*$ & * & $*$ & $*$ & * & $*$ & LA1 \\
\hline & II & $*$ & $*$ & $*$ & $*$ & $*$ & $*$ & $*$ & $*$ & $*$ & $*$ & * & $*$ & $*$ & * & $*$ & LA1 \\
\hline \multirow[t]{2}{*}{$\mathrm{La} 3$} & $\mathrm{I}$ & $*$ & $*$ & $*$ & $*$ & * & $*$ & $*$ & $*$ & $*$ & $*$ & * & $*$ & G & * & $*$ & L1 \\
\hline & II & $*$ & $*$ & $*$ & $*$ & * & $*$ & $*$ & $*$ & $*$ & $*$ & * & $*$ & G & * & $*$ & L1 \\
\hline \multirow[t]{2}{*}{$\mathrm{La} 4$} & I & $*$ & $*$ & $*$ & $*$ & $*$ & $*$ & $*$ & $*$ & $*$ & $*$ & $*$ & $*$ & G & $*$ & $*$ & L1 \\
\hline & II & $*$ & $*$ & $*$ & $*$ & $*$ & $*$ & $*$ & $*$ & $*$ & $*$ & $*$ & $*$ & G & $*$ & $*$ & L1 \\
\hline \multirow[t]{2}{*}{ La 5} & I & $*$ & $*$ & $*$ & $*$ & $*$ & $*$ & $*$ & $*$ & $*$ & $*$ & $*$ & $*$ & $\mathrm{G}$ & $*$ & $*$ & L1 \\
\hline & II & $*$ & $*$ & $*$ & $*$ & $*$ & $*$ & $*$ & $*$ & $*$ & $*$ & $*$ & $*$ & G & $*$ & $*$ & L1 \\
\hline \multirow[t]{2}{*}{$\mathrm{La} 6$} & I & $*$ & $*$ & $*$ & $*$ & $*$ & $*$ & $*$ & $*$ & $*$ & $*$ & $*$ & $*$ & G & $*$ & $*$ & L1 \\
\hline & II & $*$ & $*$ & $*$ & $*$ & $*$ & $*$ & $*$ & $*$ & $*$ & $*$ & * & $*$ & G & * & $*$ & L1 \\
\hline \multirow[t]{2}{*}{$\mathrm{La} 7$} & I & $*$ & $*$ & $*$ & $*$ & $*$ & C & $*$ & $*$ & $*$ & $*$ & $*$ & $*$ & $*$ & $*$ & $*$ & ALG1 \\
\hline & II & $*$ & $*$ & $*$ & $*$ & $*$ & $\mathrm{C}$ & $*$ & $*$ & $*$ & $*$ & * & $*$ & $*$ & * & $*$ & ALG1 \\
\hline \multirow[t]{2}{*}{ La 8} & I & $*$ & $*$ & $*$ & $*$ & $*$ & $C$ & $\mathrm{C}$ & $\mathrm{C}$ & $*$ & $*$ & $*$ & $*$ & $*$ & G & $\mathrm{T}$ & LG1 \\
\hline & II & $*$ & $*$ & $*$ & $*$ & $*$ & $C$ & $\mathrm{C}$ & $\mathrm{C}$ & $*$ & $*$ & $*$ & $*$ & $*$ & G & $\mathrm{T}$ & LG1 \\
\hline \multirow[t]{2}{*}{$\mathrm{La} 9$} & I & $*$ & $*$ & $*$ & $*$ & $*$ & $\mathrm{C}$ & $*$ & $*$ & $*$ & $*$ & $*$ & $*$ & $*$ & $*$ & $*$ & ALG1 \\
\hline & II & * & $*$ & $*$ & $*$ & * & C & * & $*$ & $*$ & * & * & $*$ & * & * & $*$ & ALG1 \\
\hline \multirow[t]{2}{*}{ La 10} & I & $*$ & $*$ & $*$ & $*$ & $*$ & C & $*$ & $*$ & $*$ & $*$ & * & $*$ & $*$ & * & $*$ & ALG1 \\
\hline & II & * & * & $*$ & $*$ & * & C & $*$ & $*$ & $*$ & $*$ & * & $*$ & $*$ & $*$ & $*$ & ALG1 \\
\hline \multirow[t]{2}{*}{ Gua 1} & I & $*$ & $*$ & $*$ & $*$ & $*$ & C & $*$ & $*$ & $*$ & $*$ & * & $*$ & $*$ & $*$ & $*$ & ALG1 \\
\hline & II & * & * & $*$ & $*$ & $*$ & C & * & $*$ & $*$ & * & * & $*$ & $*$ & * & $*$ & ALG1 \\
\hline \multirow[t]{2}{*}{ Gua 2} & I & $*$ & $*$ & $*$ & $*$ & $*$ & C & $\mathrm{C}$ & $\mathrm{C}$ & $*$ & $*$ & $*$ & $*$ & G & G & $\mathrm{T}$ & G8 \\
\hline & II & $*$ & $*$ & $*$ & $*$ & $*$ & C & $\mathrm{C}$ & $\mathrm{C}$ & $*$ & $*$ & $*$ & $*$ & G & G & $\mathrm{T}$ & G8 \\
\hline \multirow[t]{2}{*}{ Gua 3} & $\mathrm{I}$ & $*$ & $*$ & $*$ & $*$ & $*$ & C & $\mathrm{C}$ & $\mathrm{C}$ & $*$ & $*$ & $*$ & $*$ & G & G & $\mathrm{T}$ & G8 \\
\hline & II & * & $*$ & $*$ & $*$ & * & C & $\mathrm{C}$ & $\mathrm{C}$ & $*$ & * & * & $*$ & G & G & $\mathrm{T}$ & G8 \\
\hline \multirow[t]{2}{*}{ Alp1 } & $\mathrm{I}$ & G & $\mathrm{T}$ & $\mathrm{T}$ & C & $\mathrm{T}$ & $*$ & $\mathrm{C}$ & $*$ & C & $\mathrm{T}$ & G & G & $*$ & * & $\mathrm{T}$ & AV1 \\
\hline & II & G & $\mathrm{T}$ & $\mathrm{T}$ & $\mathrm{C}$ & $\mathrm{T}$ & $*$ & $\mathrm{C}$ & $*$ & C & $\mathrm{T}$ & G & G & $*$ & $*$ & $\mathrm{~T}$ & AV1 \\
\hline \multirow[t]{2}{*}{ Alp2 } & I & $\mathrm{G}$ & $\mathrm{T}$ & $\mathrm{T}$ & C & $\mathrm{T}$ & $*$ & $\mathrm{C}$ & $*$ & C & $\mathrm{T}$ & G & G & $*$ & $*$ & $\mathrm{~T}$ & AV1 \\
\hline & II & G & $\mathrm{T}$ & $\mathrm{T}$ & C & $\mathrm{T}$ & $*$ & $\mathrm{C}$ & $*$ & C & $\mathrm{T}$ & G & G & $*$ & $*$ & $\mathrm{~T}$ & AV1 \\
\hline \multirow[t]{2}{*}{ Alp3 } & I & G & $\mathrm{T}$ & $\mathrm{T}$ & C & $\mathrm{T}$ & $*$ & C & $*$ & C & $\mathrm{T}$ & G & G & $*$ & $*$ & $\mathrm{~T}$ & AV1 \\
\hline & II & G & $\mathrm{T}$ & $\mathrm{T}$ & C & $\mathrm{T}$ & $*$ & C & $*$ & C & $\mathrm{T}$ & G & G & $*$ & $*$ & $\mathrm{~T}$ & AV1 \\
\hline \multirow[t]{2}{*}{ Alp4 } & I & $*$ & $\mathrm{~T}$ & $\mathrm{~T}$ & C & G & $\mathrm{C}$ & $\mathrm{C}$ & $*$ & $\mathrm{C}$ & $\mathrm{T}$ & G & G & $*$ & $*$ & $\mathrm{~T}$ & AV2 \\
\hline & II & $*$ & $\mathrm{~T}$ & $\mathrm{~T}$ & C & G & C & $\mathrm{C}$ & $*$ & C & $\mathrm{T}$ & G & G & $*$ & * & $\mathrm{T}$ & AV2 \\
\hline Alp5 & $\mathrm{I}$ & $*$ & $\mathrm{~T}$ & $\mathrm{~T}$ & C & G & C & $\mathrm{C}$ & $*$ & C & $\mathrm{T}$ & G & G & $*$ & $*$ & $\mathrm{~T}$ & AV2 \\
\hline & II & $*$ & $\mathrm{~T}$ & $\mathrm{~T}$ & C & G & C & $\mathrm{C}$ & $*$ & C & $\mathrm{T}$ & G & G & $*$ & $*$ & $\mathrm{~T}$ & AV2 \\
\hline Alp6 & I & $*$ & $\mathrm{~T}$ & $\mathrm{~T}$ & C & $\mathrm{T}$ & $*$ & $\mathrm{C}$ & $*$ & $\mathrm{C}$ & $\mathrm{T}$ & G & G & $*$ & * & $\mathrm{T}$ & AV2 \\
\hline & II & $*$ & $\mathrm{~T}$ & $\mathrm{~T}$ & C & G & C & $\mathrm{C}$ & $*$ & C & $\mathrm{T}$ & G & G & $*$ & $*$ & $\mathrm{~T}$ & AV2 \\
\hline Alp7 & I & $*$ & $*$ & $*$ & $*$ & $*$ & $*$ & $*$ & $*$ & $*$ & $*$ & $*$ & $*$ & $*$ & $*$ & $*$ & LA1 \\
\hline & II & $*$ & $*$ & $*$ & $*$ & $*$ & $*$ & $*$ & $*$ & $*$ & $*$ & $*$ & $*$ & $*$ & $*$ & $*$ & LA1 \\
\hline Alp8 & I & $*$ & $\mathrm{~T}$ & $\mathrm{~T}$ & C & $\mathrm{T}$ & $*$ & $\mathrm{C}$ & $*$ & $\mathrm{C}$ & $\mathrm{T}$ & G & G & $*$ & $*$ & $\mathrm{~T}$ & AV2 \\
\hline & II & $*$ & $\mathrm{~T}$ & $\mathrm{~T}$ & C & $\mathrm{T}$ & $*$ & $\mathrm{C}$ & $*$ & C & $\mathrm{T}$ & G & G & $*$ & $*$ & $\mathrm{~T}$ & AV2 \\
\hline Alp9 & $\mathrm{I}$ & $*$ & $*$ & $*$ & $*$ & $*$ & $*$ & $*$ & $*$ & $*$ & $*$ & $*$ & $*$ & $*$ & $*$ & $*$ & LA1 \\
\hline & II & $*$ & $*$ & $*$ & $*$ & $*$ & $*$ & $*$ & $*$ & $*$ & $*$ & $*$ & $*$ & $*$ & * & $*$ & LA1 \\
\hline
\end{tabular}


Tabelle 73: Einzeltypisierungen des cytb-Gens, Fortsetzung

\begin{tabular}{|c|c|c|c|c|c|c|c|c|c|c|c|c|c|c|c|c|c|}
\hline 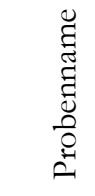 & 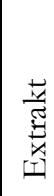 & $\stackrel{\stackrel{\mathscr{\rho}}{f}}{=}$ & $\underset{\stackrel{+}{+}}{\stackrel{+}{ \pm}}$ & $\stackrel{m}{\stackrel{n}{\sim}}$ & $\stackrel{\nabla}{\stackrel{n}{9}}$ & $\begin{array}{l}\stackrel{\infty}{N} \\
\stackrel{N}{+} \\
\sim\end{array}$ & $\begin{array}{l}\stackrel{g}{+} \\
\stackrel{\text { I }}{ت}\end{array}$ & $\begin{array}{l}\infty \\
1 n \\
\stackrel{n}{7} \\
\stackrel{+}{ \pm}\end{array}$ & 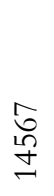 & $\underset{\underset{J}{+}}{\stackrel{+}{\square}}$ & 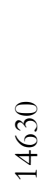 & 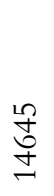 & $\underset{\stackrel{+}{+}}{\stackrel{+}{+}}$ & 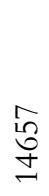 & 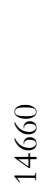 & \begin{tabular}{l}
$\mathfrak{N}$ \\
\multirow{2}{+}{}
\end{tabular} & 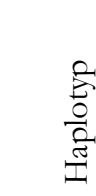 \\
\hline Ref & & A & $\mathrm{C}$ & $\mathrm{C}$ & $\mathrm{T}$ & C & $\mathrm{T}$ & $\mathrm{T}$ & A & $\mathrm{T}$ & $\mathrm{C}$ & A & A & A & A & $C$ & LA1 \\
\hline \multirow[t]{2}{*}{ Alp10 } & I & $*$ & $\mathrm{~T}$ & $\mathrm{~T}$ & C & $\mathrm{T}$ & $*$ & $\mathrm{C}$ & $*$ & C & $\mathrm{T}$ & G & G & $*$ & $*$ & $\mathrm{~T}$ & AV2 \\
\hline & II & $*$ & $\mathrm{~T}$ & $\mathrm{~T}$ & C & $\mathrm{T}$ & $*$ & $\mathrm{C}$ & $*$ & C & $\mathrm{T}$ & $\mathrm{G}$ & $\mathrm{G}$ & $*$ & $*$ & $\mathrm{~T}$ & AV2 \\
\hline \multirow[t]{2}{*}{ Alp11 } & I & $*$ & $*$ & $*$ & $*$ & $*$ & C & $*$ & $*$ & $*$ & $*$ & $*$ & $*$ & $*$ & $*$ & $*$ & ALG1 \\
\hline & II & $*$ & $*$ & $*$ & $*$ & $*$ & C & $*$ & $*$ & $*$ & $*$ & * & $*$ & $*$ & * & $*$ & ALG1 \\
\hline \multirow[t]{2}{*}{ Alp12 } & I & $*$ & $*$ & $*$ & $*$ & $*$ & C & $*$ & $*$ & $*$ & $*$ & $*$ & $*$ & $*$ & * & $*$ & ALG1 \\
\hline & II & $*$ & $*$ & $*$ & $*$ & $*$ & $\mathrm{C}$ & $*$ & $*$ & $*$ & $*$ & $*$ & $*$ & $*$ & * & $*$ & ALG1 \\
\hline \multirow[t]{2}{*}{ Alp13 } & I & $*$ & $\mathrm{~T}$ & $\mathrm{~T}$ & C & $\mathrm{T}$ & $*$ & $\mathrm{C}$ & $*$ & $\mathrm{C}$ & $\mathrm{T}$ & G & G & $*$ & $*$ & $\mathrm{~T}$ & AV2 \\
\hline & II & $*$ & $\mathrm{~T}$ & $\mathrm{~T}$ & $\mathrm{C}$ & $\mathrm{T}$ & $*$ & $\mathrm{C}$ & $*$ & C & $\mathrm{T}$ & $G$ & $\mathrm{G}$ & $*$ & $*$ & $\mathrm{~T}$ & AV2 \\
\hline \multirow[t]{2}{*}{ Alp14 } & I & $*$ & $\mathrm{~T}$ & $\mathrm{~T}$ & C & $\mathrm{T}$ & $*$ & $\mathrm{C}$ & $*$ & $\mathrm{C}$ & $\mathrm{T}$ & G & G & $*$ & $*$ & $\mathrm{~T}$ & AV2 \\
\hline & II & $*$ & $\mathrm{~T}$ & $\mathrm{~T}$ & $\mathrm{C}$ & $\mathrm{T}$ & $*$ & $\mathrm{C}$ & $*$ & C & $\mathrm{T}$ & G & $\mathrm{G}$ & $*$ & $*$ & $\mathrm{~T}$ & AV2 \\
\hline \multirow[t]{2}{*}{ Vic1 } & $\mathrm{I}$ & G & $\mathrm{T}$ & $\mathrm{T}$ & $\mathrm{C}$ & G & $\mathrm{C}$ & $\mathrm{C}$ & $*$ & $\mathrm{C}$ & $\mathrm{T}$ & G & G & $*$ & $*$ & $\mathrm{~T}$ & V1 \\
\hline & II & G & $\mathrm{T}$ & $\mathrm{T}$ & $\mathrm{C}$ & G & C & $\mathrm{C}$ & $*$ & C & $\mathrm{T}$ & G & G & $*$ & $*$ & $\mathrm{~T}$ & V1 \\
\hline \multirow[t]{2}{*}{ Vic2 } & I & G & $\mathrm{T}$ & $\mathrm{T}$ & $\mathrm{C}$ & $\mathrm{T}$ & $*$ & $\mathrm{C}$ & $*$ & C & $\mathrm{T}$ & G & G & $*$ & $*$ & $*$ & V3 \\
\hline & II & G & $\mathrm{T}$ & $\mathrm{T}$ & $\mathrm{C}$ & $\mathrm{T}$ & $*$ & $\mathrm{C}$ & $*$ & C & $\mathrm{T}$ & G & G & $*$ & $*$ & $*$ & V3 \\
\hline \multirow[t]{2}{*}{ Vic3 } & $\mathrm{I}$ & G & $\mathrm{T}$ & $\mathrm{T}$ & $\mathrm{C}$ & $\mathrm{T}$ & $*$ & $\mathrm{C}$ & $*$ & C & $\mathrm{T}$ & G & G & $*$ & $*$ & $*$ & V3 \\
\hline & II & G & $\mathrm{T}$ & $\mathrm{T}$ & C & $\mathrm{T}$ & $*$ & $\mathrm{C}$ & $*$ & $\mathrm{C}$ & $\mathrm{T}$ & G & G & $*$ & $*$ & $*$ & V3 \\
\hline \multirow[t]{2}{*}{ Vic4 } & I & G & $\mathrm{T}$ & $\mathrm{T}$ & C & $\mathrm{T}$ & $*$ & $\mathrm{C}$ & $*$ & C & $\mathrm{T}$ & G & G & $*$ & $*$ & $*$ & V3 \\
\hline & II & G & $\mathrm{T}$ & $\mathrm{T}$ & C & $\mathrm{T}$ & $*$ & C & $*$ & C & $\mathrm{T}$ & G & G & $*$ & $*$ & $*$ & V3 \\
\hline \multirow[t]{2}{*}{ Vic5 } & I & G & $\mathrm{T}$ & $\mathrm{T}$ & $\mathrm{C}$ & $\mathrm{T}$ & $*$ & $\mathrm{C}$ & $*$ & C & $\mathrm{T}$ & G & G & $*$ & $*$ & $*$ & V3 \\
\hline & II & G & $\mathrm{T}$ & $\mathrm{T}$ & $C$ & $\mathrm{~T}$ & $*$ & $\mathrm{C}$ & $*$ & C & $\mathrm{T}$ & G & G & $*$ & $*$ & $*$ & V3 \\
\hline \multirow[t]{2}{*}{ Vic6 } & I & G & $\mathrm{T}$ & $\mathrm{T}$ & $\mathrm{C}$ & $\mathrm{T}$ & $*$ & $\mathrm{C}$ & $*$ & C & $\mathrm{T}$ & G & G & $*$ & $*$ & $*$ & V3 \\
\hline & II & G & $\mathrm{T}$ & $\mathrm{T}$ & $\mathrm{C}$ & $\mathrm{T}$ & $*$ & $\mathrm{C}$ & $*$ & C & $\mathrm{T}$ & G & G & $*$ & $*$ & $*$ & V3 \\
\hline \multirow[t]{2}{*}{ Vic7 } & I & G & $\mathrm{T}$ & $\mathrm{T}$ & C & $\mathrm{T}$ & $*$ & $\mathrm{C}$ & $*$ & C & $\mathrm{T}$ & G & G & $*$ & $*$ & $*$ & V3 \\
\hline & II & $\mathrm{G}$ & $\mathrm{T}$ & $\mathrm{T}$ & C & $\mathrm{T}$ & $*$ & $\mathrm{C}$ & $*$ & C & $\mathrm{T}$ & $G$ & $\mathrm{G}$ & $*$ & $*$ & $*$ & V3 \\
\hline \multirow[t]{2}{*}{ Vic8 } & I & $\mathrm{G}$ & $\mathrm{T}$ & $\mathrm{T}$ & C & $\mathrm{T}$ & $*$ & $\mathrm{C}$ & $*$ & C & $\mathrm{T}$ & G & $\mathrm{G}$ & $*$ & $*$ & $*$ & V3 \\
\hline & II & $\mathrm{G}$ & $\mathrm{T}$ & $\mathrm{T}$ & $\mathrm{C}$ & $\mathrm{T}$ & $*$ & $\mathrm{C}$ & $*$ & C & $\mathrm{T}$ & G & $\mathrm{G}$ & $*$ & $*$ & $*$ & V3 \\
\hline \multirow[t]{2}{*}{ Vic9 } & I & G & $\mathrm{T}$ & $\mathrm{T}$ & $\mathrm{C}$ & $\mathrm{T}$ & $*$ & $\mathrm{C}$ & $*$ & C & $\mathrm{T}$ & G & G & $*$ & $*$ & $*$ & V3 \\
\hline & II & $\mathrm{G}$ & $\mathrm{T}$ & $\mathrm{T}$ & $\mathrm{C}$ & $\mathrm{T}$ & $*$ & $\mathrm{C}$ & $*$ & C & $\mathrm{T}$ & G & G & $*$ & $*$ & $*$ & V3 \\
\hline \multirow[t]{2}{*}{ Vic10 } & I & G & $\mathrm{T}$ & $\mathrm{T}$ & $\mathrm{C}$ & G & C & $\mathrm{C}$ & $*$ & C & $\mathrm{T}$ & G & G & $*$ & $*$ & $\mathrm{~T}$ & V1 \\
\hline & II & G & $\mathrm{T}$ & $\mathrm{T}$ & $\mathrm{C}$ & G & C & $\mathrm{C}$ & $*$ & C & $\mathrm{T}$ & G & G & $*$ & $*$ & $\mathrm{~T}$ & V1 \\
\hline \multirow[t]{2}{*}{ Vic11 } & I & G & $\mathrm{T}$ & $\mathrm{T}$ & C & G & C & $\mathrm{C}$ & $*$ & C & $\mathrm{T}$ & G & G & $*$ & $*$ & $\mathrm{~T}$ & V1 \\
\hline & II & $\mathrm{G}$ & $\mathrm{T}$ & $\mathrm{T}$ & C & $G$ & C & $\mathrm{C}$ & $*$ & C & $\mathrm{T}$ & $G$ & $\mathrm{G}$ & $*$ & $*$ & $\mathrm{~T}$ & V1 \\
\hline \multirow[t]{2}{*}{ Vic12 } & I & $\mathrm{G}$ & $\mathrm{T}$ & $\mathrm{T}$ & $\mathrm{C}$ & G & $\mathrm{C}$ & $\mathrm{C}$ & $*$ & $\mathrm{C}$ & $\mathrm{T}$ & G & $\mathrm{G}$ & $*$ & $*$ & $\mathrm{~T}$ & V1 \\
\hline & II & G & $\mathrm{T}$ & $\mathrm{T}$ & $\mathrm{C}$ & G & C & $\mathrm{C}$ & $*$ & C & $\mathrm{T}$ & $\mathrm{G}$ & G & $*$ & $*$ & $\mathrm{~T}$ & V1 \\
\hline \multirow[t]{2}{*}{ Vic13 } & I & G & $\mathrm{T}$ & $\mathrm{T}$ & $\mathrm{C}$ & $\mathrm{T}$ & $*$ & $\mathrm{C}$ & $*$ & C & $\mathrm{T}$ & G & G & $*$ & $*$ & $*$ & V3 \\
\hline & II & G & $\mathrm{T}$ & $\mathrm{T}$ & $\mathrm{C}$ & $\mathrm{T}$ & $*$ & $\mathrm{C}$ & $*$ & C & $\mathrm{T}$ & G & G & $*$ & $*$ & $*$ & V3 \\
\hline Vic14 & $\mathrm{I}$ & G & $\mathrm{T}$ & $\mathrm{T}$ & $\mathrm{C}$ & $\mathrm{T}$ & $*$ & $\mathrm{C}$ & $*$ & C & $\mathrm{T}$ & $\mathrm{G}$ & G & $*$ & $*$ & $*$ & V3 \\
\hline & II & G & $\mathrm{T}$ & $\mathrm{T}$ & $\mathrm{C}$ & $\mathrm{T}$ & $*$ & $\mathrm{C}$ & $*$ & C & $\mathrm{T}$ & $G$ & G & $*$ & $*$ & $*$ & V3 \\
\hline Vic15 & I & G & $\mathrm{T}$ & $\mathrm{T}$ & $\mathrm{C}$ & $\mathrm{T}$ & $*$ & $\mathrm{C}$ & $*$ & C & $\mathrm{T}$ & G & G & * & $*$ & $\mathrm{~T}$ & AV1 \\
\hline & II & $\mathrm{G}$ & $\mathrm{T}$ & $\mathrm{T}$ & $\mathrm{C}$ & $\mathrm{T}$ & $*$ & $\mathrm{C}$ & $*$ & $\mathrm{C}$ & $\mathrm{T}$ & $G$ & $\mathrm{G}$ & $*$ & $*$ & $\mathrm{~T}$ & AV1 \\
\hline Vic16 & I & G & $\mathrm{T}$ & $\mathrm{T}$ & C & $\mathrm{T}$ & $*$ & $\mathrm{C}$ & $*$ & C & $\mathrm{T}$ & G & G & * & $*$ & $\mathrm{~T}$ & AV1 \\
\hline & & G & $\mathrm{T}$ & $\mathrm{T}$ & $\mathrm{C}$ & $\mathrm{T}$ & $*$ & $\mathrm{C}$ & $*$ & C & $\mathrm{T}$ & G & G & $*$ & $*$ & $\mathrm{~T}$ & AV1 \\
\hline
\end{tabular}




\begin{tabular}{|c|c|c|c|c|c|c|c|c|c|c|c|c|c|c|c|c|c|c|c|c|c|c|c|c|c|c|c|c|c|}
\hline & 尔 & $\stackrel{8}{\stackrel{8}{ \pm}}$ & $\underset{⿱}{\mathbb{Z}}$ & 売 & 胥 & $\begin{array}{l}\stackrel{0}{8} \\
\stackrel{8}{8}\end{array}$ & 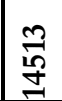 & 疍 & $\begin{array}{l}\mathbb{J} \\
\stackrel{\mathbb{Z}}{\Xi}\end{array}$ & 岕 & 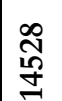 & 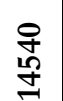 & 商 & 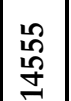 & 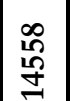 & 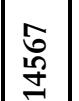 & 筞 & $\stackrel{\widetilde{J}}{\mathcal{J}}$ & 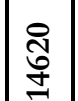 & $\mid$\begin{tabular}{l}
$\mathbb{J}$ \\
\multirow{J}{*}{}
\end{tabular} & 恿 & 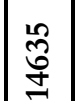 & 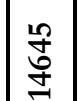 & \begin{tabular}{l}
$\infty$ \\
\multirow{J}{*}{} \\
\multirow{2}{*}{}
\end{tabular} & $\mid \begin{array}{l}\vec{r} \\
\vec{Z} \\
\end{array}$ & $\begin{array}{l}\text { : } \\
\text { 竎 }\end{array}$ & 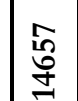 & 悤 & J \\
\hline on & A & 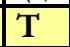 & G & $\mathrm{C}$ & A & $\pi$ & IC & $T$ & $\pi$ & G & & $T$ & $\pi$ & & $T$ & $A$ & $\pi$ & G & $C$ & $\bar{\sigma}$ & $\vec{C}$ & C & $\mathbf{A}$ & $\mathrm{A}$ & $T$ & G & A & A & $\mathrm{C}$ \\
\hline & & & & & & & & & & & & & c & & & ( & & & & & & & d d & nd & nd & ad & nd & hd & $\mathrm{nd}$ \\
\hline & & & & $n$ & & nd & nd & & $n$ & $\mathrm{n}$ & nd & $\mathrm{nd}$ & $\mathrm{n}$ & & $\mathrm{nc}$ & nd & $\mathrm{d}$ & nd & nd & nd & & & & & & & & $\bar{G}$ & - \\
\hline & & & & $\bar{x}$ & & & 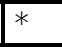 & & & & & & C & & & & & & & $\mathrm{d}$ & $\mathrm{a}$ & & 4 & $\mathrm{id}$ & & $\mathrm{dd}$ & $\mathrm{nd}$ & nd & 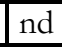 \\
\hline & & & & $\bar{x}$ & & & 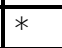 & & & & & & & & $\overline{\mathrm{d}}$ & nd & $\overline{\mathrm{d}}$ & & nd & nd & id & nd & nd & nd & $n$ & nd & nd & nd & $\overline{n d}$ \\
\hline & & & & & & nd & $\mathrm{n}$ & & nd & nd & d & nd & nd & $\mathrm{nd}$ & & nd & nd & & $\overline{n d}$ & & & & & & & & & G & $\overline{\mathrm{T}}$ \\
\hline & & & & $*$ & & * & * & & $*$ & * & & & C & $\overline{\mathrm{nd}}$ & $\mathrm{nc}$ & d & nd & $\mathrm{id}$ & $\mathrm{d}$ & Ia & nd & $\mathrm{d}$ & nd & nd & $\mathrm{d}$ & nd & nd & $\mathrm{id}$ & $\overline{n d}$ \\
\hline & & & & & & & & & & $\mathrm{n}$ & & & & & & & & & & & & & & & & & * & & 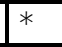 \\
\hline & & & & $\overline{7}$ & & & 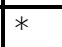 & & & $*$ & & & & $\bar{d}$ & nd & nd & Id & nd & nd & $\mathrm{d}$ & nd & & $\mathrm{d}$ & nd & nd & ad & nd & $\mathrm{id}$ & $\mathrm{nd}$ \\
\hline & & & & 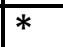 & 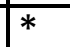 & $*$ & 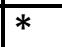 & & 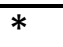 & 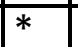 & & & & & $\mathrm{C}$ & C & & & & & & & & & & & * & G & $\mathbf{T}$ \\
\hline & & & & $*$ & $\overline{7}$ & * & ${ }^{*}$ & & * & 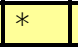 & & & C & & & & & $\bar{A}$ & & $\mathrm{~d}$ & nd & & $\mathrm{d}$ & nd & $\mathrm{d}$ & $\mathrm{dd}$ & nd & $\mathrm{id}$ & $\mathrm{nd}$ \\
\hline & & & & & & & & & & $n$ & & & $\mathrm{n}$ & nd & nd & nd & & A & & & & & & $*$ & C & & $*$ & $G$ & $\mathrm{~T}$ \\
\hline & & & & & & & & & & & & & $\mathrm{n}$ & & ne & d & & & & & & & & & & & * & $\mathrm{G}$ & $\bar{T}$ \\
\hline & & & $t^{*}$ & $\bar{x}$ & & * & 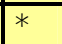 & & $\bar{*}$ & 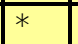 & & & $\mathrm{C}$ & nd & nd & nd & d & $\mathrm{n}$ & & & $\mathrm{n}$ & & nd & d & $\bar{d}$ & $\mathrm{~d}$ & d & $\bar{d}$ & nd \\
\hline & $\mathrm{n}$ & & * & $*$ & 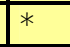 & * & * & & * & E & & & & $\mathrm{n}$ & $n$ & d & $\mathrm{d}$ & nd & & d & $\mathrm{nd}$ & nd & d & $\pi$ & $\mathrm{d}$ & nd & nd & $\mathrm{id}$ & nd \\
\hline & & & & $n$ & & $\mathrm{n}$ & nd & & nd & $\mathrm{nc}$ & $\mathrm{n}$ & 1 & nd & nd & nd & nd & C & * & * & * & * & * & * & * & C & * & $*$ & $G$ & $\mathrm{~T}$ \\
\hline & & & $*$ & * & $=$ & $*$ & * & & * & & & - & C & & C & C & & $\mathbf{A}$ & & & & 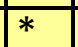 & & & & & * & $\mathbf{G}$ & $\bar{T}$ \\
\hline & & & & & & & & & & & & & $n$ & & ne & nd & & & nd & & & & & & & & * & & $*$ \\
\hline & & & & & & nd & & & $\mathrm{n}$ & 11 & $\mathrm{nc}$ & $\mathrm{n}$ & 111 & & \begin{tabular}{|l|} 
nd \\
\end{tabular} & $\mathrm{n}$ & nd & nd & d & $\overline{\mathrm{id}}$ & & & & * & $*$ & T & * & T & * \\
\hline & $\mathrm{n}$ & $\mathrm{r}$ & $=$ & $F$ & 7 & - & * & & $*$ & 5 & & * & C & nd & \begin{tabular}{|l|} 
nd \\
\end{tabular} & + & nd & nd & nd & nd & nd & nd & \begin{tabular}{|l|} 
nd \\
\end{tabular} & nd & nd & nd & nd & $\mathrm{d}$ & nd \\
\hline & & & * & 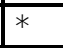 & 3 & * & 7 & & $t^{2}$ & & & & & & nd & $\mathrm{n}$ & $\mathrm{d}$ & nd & d & $\mathrm{d}$ & nd & nd & $\mathrm{d}$ & nd & $\overline{\mathrm{d}}$ & nd & nd & $\overline{\mathrm{hd}}$ & $\overline{n d}$ \\
\hline & & & & * & & 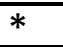 & 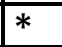 & & 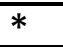 & & & & & nd & \begin{tabular}{|l|} 
nd \\
\end{tabular} & nd & 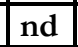 & 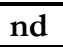 & nd & $\begin{array}{ll}d \\
d\end{array}$ & & * & & & 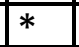 & & $*$ & $*$ & * \\
\hline & & & $\bar{T}$ & * & * & * & * & 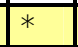 & * & & & & & nd & \begin{tabular}{|l|} 
nd \\
\end{tabular} & nd & nd & nd & nd & nd & nd & $1 \mathrm{IdC}$ & d & nd & nd & nd & nd & nd & nd \\
\hline & & & - & & & nd & & & $n$ & $\mathrm{n}$ & $\mathrm{n}$ & $\mathrm{n}$ & nd & nd & \begin{tabular}{|l|} 
nd \\
\end{tabular} & nd & & $*$ & * & & $*$ & $\begin{array}{ll}* \\
\end{array}$ & * & * & * & * & $*$ & * & * \\
\hline & & & & & & $\mathrm{n}$ & $n$ & $\mathrm{n}$ & & nd & $\mathrm{n}$ & nd & $F$ & nd & \begin{tabular}{|l|l|} 
nd \\
\end{tabular} & nd & $L^{*}$ & & & & & & & & & & * & & \\
\hline & & & $\bar{c}$ & $*$ & 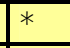 & * & E & 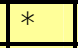 & F & & & L & & & nd & nd & & & & & & & & & nd & & nd & nd & nd \\
\hline & & & & & & $\mathrm{n}$ & & & & & & & $n$ & $\mathrm{n}$ & \begin{tabular}{|l|} 
nd \\
\end{tabular} & nd & * & + & 1 & $*$ & * & $*$ & * & $*$ & * & 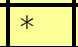 & 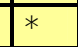 & $*$ & $*$ \\
\hline & $\mathrm{n}$ & nc & $\mathrm{n}$ & & $\mathrm{n}$ & $\mathrm{n}$ & $n$ & $\mathrm{n}$ & $\mathrm{n}$ & $\mathrm{n}$ & nd & nd & nd & $\mathrm{d}$ & \begin{tabular}{|l|} 
nd \\
\end{tabular} & nd & nd & $*$ & * & & $*$ & * & & $*$ & * & & * & * & * \\
\hline & $n$ & 110 & $\mathrm{n}$ & nd & $n$ & $\mathrm{n}$ & nd & 1114 & $\mathrm{n}$ & |nd & 111 & $\mathrm{n}$ & Ind & nd & nd & nd & nd & & & & & | & & & * & & * & & * \\
\hline & & nd & nd & & & $\overline{\mathrm{nd}}$ & & nd & & |11 & nd & & nd & $\mathrm{n}$ & nd & nd & Ind & & & & & 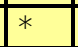 & & & & & * & & * \\
\hline DA5 & + & nd & 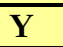 & * & $\pi$ & $*$ & $*$ & | & $*$ & $*$ & $*$ & $*$ & $*$ & nd & \begin{tabular}{|l|} 
nd \\
\end{tabular} & nd & * & * & $*$ & 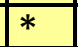 & $*$ & * & * & $*$ & * & * & * & $*$ & * \\
\hline
\end{tabular}




\begin{tabular}{|c|c|c|c|c|c|c|c|c|c|c|c|c|c|c|c|c|c|c|c|c|c|c|c|c|c|c|c|c|c|}
\hline & 促 & 守 & $\underset{\mathrm{V}}{\tilde{V}}$ & 㫭 & $\tilde{g}$ & 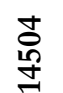 & 姜 & 章 & $\begin{array}{l}\mathbb{J} \\
\underset{d}{\mathbb{d}}\end{array}$ & 敢 & 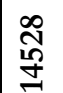 & \begin{tabular}{|l|} 
\\
\\
㝵
\end{tabular} & $\begin{array}{l} \\
\text { 竎 } \\
\end{array}$ & 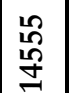 & 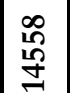 & 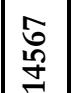 & 筞 & 害 & 产 & 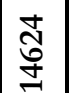 & 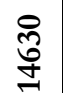 & 黛 & 隹 & \begin{tabular}{|l|} 
\\
舟 \\
\multirow{2}{*}{}
\end{tabular} & $\mid \begin{array}{l}\vec{r} \\
d \\
g\end{array}$ & 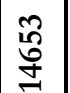 & 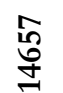 & 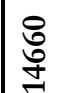 & $\begin{array}{l}\mathbb{S} \\
\text { G }\end{array}$ \\
\hline f Arnason & $\mathbf{A}$ & $T$ & G & C & A & $T$ & C & $T$ & C & G & 5 & $T$ & $T$ & 5 & $T$ & A & T & G & C & $T$ & $\mathrm{C}$ & C & A & A & $T$ & G & A & $\mathbf{A}$ & $\mathrm{C}$ \\
\hline $6 \mathrm{I}$ & * & * & $*$ & * & * & * & * & & * & * & F & & * & & & * & $\bar{c}$ & & nd & nd & nd & nd & nd & nd & nd & nd & nd & nd & nd \\
\hline $6 \mathrm{I}$ & * & * & * & * & * & - & * & * & * & * & * & & * & & & * & & & $*$ & & & 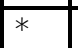 & * & $*$ & 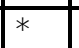 & * & - & 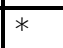 & * \\
\hline COA6 & * & * & * & * & * & * & * & * & 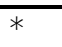 & * & * & * & * & * & 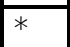 & * & C & $\mathrm{A}$ & nd & nd & nd & nd & nd & nd & nd & nd & nd & nd & nd \\
\hline II & $\left.\right|^{*}$ & * & $*$ & * & * & * & Th & & * & $*$ & & * & * & & & 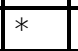 & & $\mathrm{A}$ & nd & nd & nd & nd & nd & nd & nd & nd & nd & nd & nd \\
\hline & $\frac{1}{n d}$ & nd & nd & nd & nd & nd & nd & $\overline{n d}$ & n & nd & $\overline{n d}$ & $\sqrt{n d}$ & nd & nd & nd & nd & nd & nd & nd & & & \begin{tabular}{|l|}
$*$ \\
\end{tabular} & & & * & & * & $*$ & $* *$ \\
\hline II & $\mathrm{n}$ & nd & nd & nd & nd & nd & nd & nd & nd & nd & nd & nd & nd & nd & dd & nd & $\mathrm{C}$ & $\mathrm{A}$ & 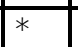 & & $*$ & * & & $*$ & * & & $*$ & * & * \\
\hline $\mathrm{CO}$ & nd & nd & nd & nd & nd & nd & nd & nd & nd & nd & nd & nd & nd & nd & nd & nd & nd & nd & nd & * & * & * & * & * & * & * & * & * & $*$ \\
\hline$\overline{\mathrm{COA} 6 \mathrm{C}}$ & $*$ & 7 & $*$ & * & 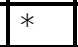 & 4 & 4 & * & - & 5 & 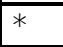 & $F$ & * & * & $*$ & * & C & $\mathrm{A}$ & nd & nd & nd & nd & nd & nd & nd & nd & nd & nd & nd \\
\hline $\mathrm{CC}$ & * & * & * & * & * & * & * & * & * & $*$ & * & * & * & $*$ & $=$ & * & $\mathrm{C}$ & $\mathbf{A}$ & $*$ & & . & * & 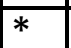 & $*$ & * & $*$ & 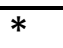 & * & * \\
\hline $6 \mathrm{I}$ & nd & nd & nd & $\mathrm{n}$ & nd & nd & nd & nd & nd & nd & nd & nd & $\mathrm{nc}$ & $\begin{array}{ll}\text { nd } \\
\text { nat }\end{array}$ & nd & nd & * & & * & & & * & & * & * & & * & * & * \\
\hline $6 \mathrm{II}$ & nd & nd & $\mathrm{n}$ & nd & nd & nd & nd & nd & nd & nd & nd & nd & nd & \begin{tabular}{|l|} 
nd \\
\end{tabular} & nd & nd & C & $\mathrm{A}$ & * & * & $*$ & * & * & * & $*$ & * & * & $G$ & $\overline{\mathrm{T}}$ \\
\hline$\overline{\mathrm{COA}}$ & * & $\mathrm{Y}$ & $\mathrm{n}$ & $F$ & * & * & * & $F$ & * & * & * & * & C & * & C & C & C & A & nd & nd & nd & nd & \begin{tabular}{|l|} 
nd \\
\end{tabular} & nd & nd & nd & nd & nd & nd \\
\hline $807 \mathrm{I}$ & nd & $\begin{array}{ll}\text { nd } \\
\text { nat }\end{array}$ & nd & $\begin{array}{l}\text { nd } \\
\end{array}$ & nd & nd & nd & nd & nd & nd & nd & nd & nd & $\begin{array}{ll}\text { nd } \\
\text { nat }\end{array}$ & \begin{tabular}{|l|} 
nd \\
\end{tabular} & nd & nd & nd & nd & nd & $\overline{-}$ & $*$ & * & $*$ & 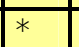 & $*$ & $*$ & $\mathrm{G}$ & $\mathrm{T}$ \\
\hline 7I & nd & nd & + & * & * & * & \begin{tabular}{|l|l|}
$*$ \\
\end{tabular} & * & - & * & * & 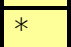 & C & nd & nd & nd & nd & nd & nd & nd & nd & nd & nd & nd & nd & nd & nd & nd & nd \\
\hline 0807II & nd & C & * & * & $*$ & * & $*$ & * & - & * & * & * & 5 & \begin{tabular}{|l|} 
nd \\
\end{tabular} & nd & \begin{tabular}{|l|} 
nd \\
\end{tabular} & nd & nd & nd & nd & nd & \begin{tabular}{|l|} 
nd \\
\end{tabular} & \begin{tabular}{|l|} 
nd \\
\end{tabular} & nd & nd & nd & nd & nd & nd \\
\hline$\vec{T}$ & * & $\mathrm{C}$ & * & | & t* & * & * & $*$ & * & $*$ & * & * & C & $*$ & C & C & C & $\mathbf{A}$ & * & * & 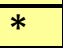 & * & * & * & * & * & $*$ & G & $\mathbf{T}$ \\
\hline$\overline{6 T}$ & 1 & * & * & * & $\bar{G}$ & 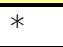 & * & L & 1 & * & L & * & 5 & * & & * & C & $\bar{A}$ & nd & nd & nd & nd & \begin{tabular}{|l|} 
nd \\
\end{tabular} & nd & nd & nd & nd & nd & nd \\
\hline $\mathrm{COA}$ & nd & nd & $\mathrm{n}$ & $\mathrm{n}$ & nd & nd & nd & nd & nd & nd & $\overline{\mathrm{nd}}$ & nd & 1 & nd & nd & nd & nd & nd & nd & & * & 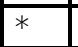 & * & $*$ & * & * & $*$ & * & * \\
\hline $\mathrm{CO}$ & nd & nd & nd & nd & nd & nd & \begin{tabular}{|l|} 
nd \\
\end{tabular} & nd & nd & nd & nd & nd & nd & nd & nd & \begin{tabular}{|l|} 
nd \\
\end{tabular} & C & $\mathrm{A}$ & 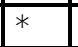 & * & * & * & * & * & * & * & * & * & * \\
\hline & nd & nd & nd & $\mathrm{nc}$ & nd & nd & \begin{tabular}{|l|} 
nd \\
\end{tabular} & nd & nd & nd & nd & nd & nd & \begin{tabular}{|l|} 
nd \\
\end{tabular} & nd & nd & nd & nd & * & * & * & * & * & * & * & $*$ & $*$ & * & $*$ \\
\hline & nd & nd & * & * & $\bar{~}$ & * & \begin{tabular}{|l|l}
$*$ \\
\end{tabular} & * & $\bar{T}$ & \begin{tabular}{|l|l}
$*$ & \\
\end{tabular} & * & \begin{tabular}{|l|} 
\\
\end{tabular} & $\bar{C}$ & nd & nd & nd & nd & nd & nd & nd & nd & \begin{tabular}{|l|} 
nd \\
\end{tabular} & $\sqrt{n d}$ & nd & nd & $\sqrt{n d}$ & nd & nd & $\overline{\mathrm{nd}}$ \\
\hline D7II & nd & nd & 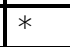 & 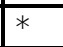 & G & * & * & * & 1 & * & L & $*$ & C & nd & nd & nd & nd & nd & nd & nd & nd & nd & \begin{tabular}{|l|} 
nd \\
\end{tabular} & nd & nd & nd & nd & nd & nd \\
\hline $\mathrm{CO}$ & * & $\sqrt{4}$ & * & * & G & * & 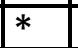 & * & $T$ & * & 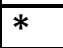 & * & 10 & * & * & * & $\mathrm{C}$ & $\mathbf{A}$ & * & * & $*$ & * & * & * & * & * & $*$ & * & $*$ \\
\hline 07I & nd & * & * & $F$ & * & * & 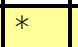 & * & - & * & $\left.\right|^{2}$ & * & * & \begin{tabular}{|l|} 
nd \\
\end{tabular} & nd & nd & nd & nd & nd & nd & nd & nd & \begin{tabular}{|l|} 
nd \\
\end{tabular} & nd & nd & nd & nd & nd & nd \\
\hline & nd & nd & nd & Ind & nd & nd & nd & nd & nd & nd & nd & nd & nd & nd & nd & Ind & nd & nd & nd & nd & * & $\begin{array}{ll}* \\
\end{array}$ & * & $*$ & \begin{tabular}{|l|l}
$*$ & \\
\end{tabular} & $\mathrm{~A}$ & * & $*$ & * \\
\hline & nd & nd & $\vec{C}$ & $\begin{array}{ll}* \\
\end{array}$ & 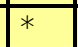 & 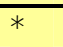 & \begin{tabular}{|l|l|}
$*$ & \\
\end{tabular} & * & $*$ & \begin{tabular}{|l|}
$*$ \\
\end{tabular} & $F$ & * & $*$ & \begin{tabular}{|l|} 
nd \\
\end{tabular} & nd & \begin{tabular}{|l|} 
nd \\
\end{tabular} & $\overline{\mathrm{nc}}$ & nd & nd & nd & nd & nd & \begin{tabular}{|l|} 
nd \\
\end{tabular} & nd & nd & $\mathrm{nd}$ & $\mathrm{d}$ & nd & nd \\
\hline $07 \mathrm{II}$ & nd & nd & nd & nd & nd & nd & nd & nd & nd & nd & nd & nd & nd & nd & nd & nd & 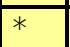 & $*$ & * & * & * & * & * & * & * & * & * & * & F \\
\hline COA9 0807I & nd & nd & nd & nd & nd & nd & nd & nd & nd & nd & nd & nd & nd & nd & nd & nd & nd & * & * & * & * & 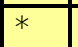 & $*$ & * & * & * & $*$ & * & * \\
\hline \begin{tabular}{|l} 
COA9 0807I \\
\end{tabular} & nd & nd & * & * & $*$ & - & * & * & * & * & $F$ & * & * & nd & nd & nd & nd & nd & nd & nd & nd & nd & nd & nd & nd & nd & nd & nd & nd \\
\hline COA9 & nd & * & * & * & * & * & * & * & * & * & * & * & * & * & nd & nd & nd & nd & nd & nd & & $*$ & * & 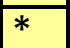 & * & A & $*$ & * & \\
\hline
\end{tabular}


Tabelle 74: Einzeltypisierungen cytb von Extrakten der Knochen- und Zahn-Proben des Fundortes Chillo, Fortsetzung

\begin{tabular}{|c|c|c|c|c|c|c|c|c|c|c|c|c|c|c|c|c|c|c|c|c|c|c|c|c|c|c|c|c|c|}
\hline obe Extrakt & 岱 & 拿 & 封 & 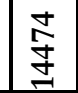 & $\frac{2}{\tilde{J}}$ & \begin{tabular}{|l} 
\\
䓪
\end{tabular} & 常 & $\frac{\sqrt{3}}{\sqrt[3]{7}}$ & $\mid \begin{array}{l}\mathbb{J} \\
\text { 总 }\end{array}$ & $\begin{array}{l}\stackrel{N}{7} \\
\text { I }\end{array}$ & \begin{tabular}{|l}
$\infty$ \\
$\stackrel{1}{1}$ \\
$\stackrel{N}{=}$ \\
\end{tabular} & \begin{tabular}{|l} 
早 \\
等
\end{tabular} & \begin{tabular}{|l}
$\stackrel{9}{+}$ \\
$\stackrel{9}{+}$ \\
\end{tabular} & \begin{tabular}{|l} 
足 \\
照 \\
\end{tabular} & 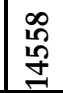 & 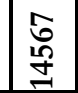 & 莕 & 胥 & స్ర్తి & 芯 & $\mid$\begin{tabular}{l}
0 \\
$\hat{\delta}$ \\
\multirow{2}{*}{}
\end{tabular} & 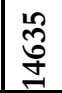 & 谋 & 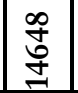 & \begin{tabular}{|l}
$\overrightarrow{3}$ \\
$\stackrel{0}{0}$ \\
\end{tabular} & $\begin{array}{l}\stackrel{n}{8} \\
\stackrel{d}{d}\end{array}$ & 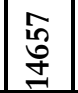 & 悤 & 趈 \\
\hline son & \begin{tabular}{|l|}
$\mathbf{A}$ \\
\end{tabular} & $T$ & G & C & $\mathbf{A}$ & $T$ & $\mathrm{C}$ & $T$ & C & G & C & $T$ & $T$ & $\mathbf{A}$ & $\mathrm{T}$ & $\mathbf{A}$ & $T$ & G & $\mathrm{C}$ & $T$ & C & C & $\mathbf{A}$ & $\mathbf{A}$ & $T$ & G & $\mathbf{A}$ & $\mathbf{A}$ & C \\
\hline$\overline{06 \mathrm{I}}$ & & nd & nd & nd & nd & nd & nd & nd & nd & nd & nd & nd & nd & nd & nd & nd & $\mathrm{C}$ & $\mathrm{A}$ & & C & $\mathrm{T}$ & & $\bar{G}$ & G & & & * & $*$ & $\mathrm{~T}$ \\
\hline $7 \mathrm{I}$ & & nd & nd & nd & nd & * & * & * & * & * & & 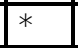 & C & & 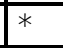 & * & $\mathrm{C}$ & 11 & nd & nd & nd & nd & nd & nd & nd & nd & nd & nd & nd \\
\hline OA11 0807I & nd & nd & nd & nd & nd & nd & nd & nd & nd & nd & nd & nd & nd & nd & nd & nd & nd & nd & & 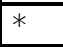 & * & * & 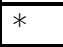 & * & * & 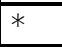 & * & * & * \\
\hline COA1 & nd & nd & d & id & \begin{tabular}{|l|} 
nd \\
\end{tabular} & $*$ & * & * & $*$ & $*$ & $*$ & \% & C & & * & * & C & $\mathbf{A}$ & & C & $\mathrm{T}$ & & G & G & & 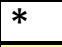 & $*$ & * & $T$ \\
\hline $7 \mathrm{I}$ & $\mathrm{nc}$ & n & 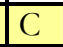 & $\mathrm{T}$ & * & * & $\mathrm{T}$ & $\mathrm{C}$ & 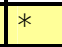 & 7 & $\mathrm{~T}$ & * & & nd & nd & nd & nd & nd & nd & nd & nd & nd & nd & nd & nd & nd & nd & nd & nd \\
\hline & nd & nd & nd & nd & $\mathrm{nc}$ & nd & nd & nd & nd & $\mathrm{nc}$ & nd & nd & nd & nd & nd & nd & C & $t^{\prime}$ & * & C & $\bar{T}$ & & G & $\mathrm{G}$ & $*$ & & 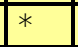 & $*$ & * \\
\hline$\overline{D 7 I I}$ & 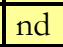 & nd & nd & nd & nd & nd & nd & nd & nd & nd & nd & nd & nd & nd & nd & nd & C & * & 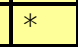 & 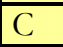 & $\mathrm{T}$ & * & G & $\mathrm{G}$ & * & * & * & * & * \\
\hline COA & nd & nd & (c) & $T$ & * & * & $T$ & C & $*$ & * & $T$ & * & $*$ & nd & nd & nd & C & * & 2 & C & $\mathrm{T}$ & & G & G & * & F & ${ }^{*}$ & * & * \\
\hline $6 \mathrm{6I}$ & 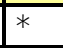 & C & * & * & * & * & * & * & $y$ & 7 & 7 & $*$ & $t$ & 7 & C & To & C & ${ }^{*}$ & & & $*$ & & nd & nd & nd & nd & nd & nd & nd \\
\hline & 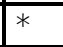 & C & $*$ & * & * & * & * & * & 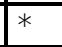 & * & $*$ & $*$ & $t$ & 7 & C & tr & C & & & & $*$ & & & * & + & $*$ & \begin{tabular}{|l|}
$*$ \\
\end{tabular} & $G$ & $\mathrm{~T}$ \\
\hline $\mathrm{CC}$ & * & C & $*$ & $1 *$ & 5 & * & * & * & * & * & * & $*$ & C & * & C & Ic & C & $\mathrm{A}$ & $\mathrm{d}$ & nd & nd & nd & nd & \begin{tabular}{|l|} 
nd \\
\end{tabular} & nd & nd & \begin{tabular}{|l|} 
nd \\
\end{tabular} & nd & nd \\
\hline II & nd & $n$ & * & * & $E$ & * & * & * & * & 1 & * & $*$ & C & & C & C & C & $A$ & nd & nd & nd & nd & nd & \begin{tabular}{|l|} 
nd \\
\end{tabular} & nd & nd & nd & nd & nd \\
\hline$\overline{77 \mathrm{I}}$ & $\overline{\mathrm{nd}}$ & nd & nd & $\overline{\text { nd }}$ & $\mathrm{n}$ & nd & $\mathrm{nd}$ & nd & $\mathrm{nc}$ & $\overline{\mathrm{n}}$ & $\overline{\mathrm{nd}}$ & nd & nd & nd & nd & nd & C & $\bar{A}$ & & & $*$ & & & \begin{tabular}{|l|}
$*$ \\
\end{tabular} & $F$ & $*$ & \% & $\mathrm{G}$ & $\mathrm{T}$ \\
\hline$\overline{77 \mathrm{II}}$ & nd & nd & Ind & nd & the & Ind & nd & no & Ind & nd & nd & nd & |nd & nd & nd & nd & nd & Ind & & & * & & & * & 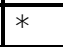 & 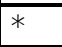 & & $G$ & $\mathrm{~T}$ \\
\hline $7 \mathrm{II}$ & * & C & $*$ & 1* & * & \%* & $\mathrm{G}$ & * & F & T* & $*$ & ${ }_{*}^{*} *$ & C & $*$ & C & T* & C & * & $*$ & * & * & * & nd & $\mathrm{d}$ & nd & nd & nd & nd & nd \\
\hline & * & * & 1 & * & * & $4 *$ & \%* & * & * & * & * & $*$ & C & * & \begin{tabular}{|l|l} 
C \\
\end{tabular} & C & C & $\mathrm{A}$ & nd & nd & nd & nd & nd & $\mathrm{d}$ & nd & nd & nd & nd & nd \\
\hline $07 \mathrm{I}$ & $\mathrm{nc}$ & 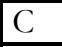 & * & * & * & * & * & $F^{7}$ & $*$ & * & 7 & $*$ & C & nd & nd & nd & nd & nd & nd & nd & nd & nd & nd & \begin{tabular}{|l|} 
nd \\
\end{tabular} & nd & nd & \begin{tabular}{|l|} 
nd \\
\end{tabular} & nd & nd \\
\hline $\mathrm{COA}$ & * & 0 & * & $a^{*}$ & * & * & ]$^{*}$ & * & * & * & * & 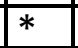 & C & 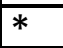 & 8 & C & C & 4 & & & 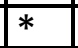 & & $*$ & * & * & * & * & G & $T$ \\
\hline $\mathrm{CC}$ & nd & nd & nd & nd & nd & nd & nd & nd & nd & nd & nd & nd & nd & nd & nd & nd & nd & nd & 1 & 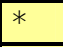 & + & $*$ & \begin{tabular}{|l} 
\\
\end{tabular} & * & * & * & * & * & * \\
\hline & nd & 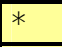 & $1 \%$ & * & $T *$ & 14 & ** & $\sqrt{*}$ & t & $1 *$ & * & 14 & C & \begin{tabular}{|l|l}
$*$ \\
\end{tabular} & $\begin{array}{l}* \\
\end{array}$ & * & C & $\mathrm{A}$ & nd & nd & nd & nd & nd & nd & nd & nd & nd & nd & nd \\
\hline & $\mathrm{n}$ & $\bar{n}$ & $n$ & $\bar{n}$ & $\bar{n}$ & 1 & $\sqrt{n}$ & nd & $n$ & $n$ & nd & nd & nd & nd & nd & nd & & & * & & & & & \begin{tabular}{|l|}
$*$ \\
\end{tabular} & 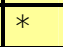 & & 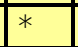 & 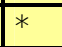 & 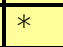 \\
\hline $6 \mathrm{GI}$ & $\mathrm{n}$ & $\mathrm{n}$ & nd & $\mathrm{n}$ & $\mathbf{u}$ & da & nd & 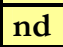 & nd & nd & $\mathrm{d}$ & nd & nd & nd & d & nd & nd & d & 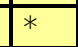 & 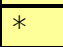 & 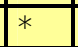 & * & 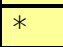 & 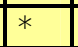 & $\left.\right|^{*}$ & 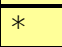 & 1 & * & 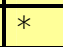 \\
\hline $\mathrm{CO}_{\mathrm{H}}$ & nd & nd & nd & nd & nd & * & $*$ & * & * & * & * & * & C & nd & nd & nd & nd & nd & nd & nd & nd & nd & nd & \begin{tabular}{|l|} 
nd \\
\end{tabular} & nd & nd & nd & nd & nd \\
\hline $807 \mathrm{I}$ & nd & 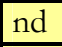 & nd & nd & nd & nd & nd & nd & nd & nd & nd & nd & nd & nd & nd & nd & $*$ & \begin{tabular}{|l|l}
$*$ \\
\end{tabular} & * & $*$ & $\begin{array}{ll}* \\
\end{array}$ & $*$ & $*$ & * & \% & $*$ & 1 & $*$ & \\
\hline $07 \mathrm{II}$ & nd & nd & Ind & nd & Ind & nd & nd & nd & nd & nd & nd & nd & Ind & nd & nd & nd & 个 & $*$ & * & $\pi$ & * & $T^{\top}$ & 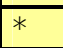 & * & $*$ & * & * & * & * \\
\hline $87 \mathrm{II}$ & nd & $\mathrm{nc}$ & |nd & $\mathrm{n}$ & nc & nd & 7 & 111 & nd & $\mathrm{n}$ & ne & $\mathrm{n}$ & nd & 5 & nd & $\mathrm{n}$ & nd & 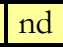 & ]$^{*}$ & $L^{*}$ & * & * & * & * & $*$ & * & $*$ & * & * \\
\hline$\overline{O A}$ & nd & $*$ & $*$ & * & $*$ & * & * & $*$ & * & * & $*$ & 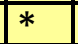 & C & * & $*$ & * & * & * & * & * & * & $*$ & $*$ & * & * & * & $*$ & * & * \\
\hline
\end{tabular}




\begin{tabular}{|c|c|c|c|c|c|c|c|c|c|c|c|c|c|c|c|c|c|c|c|c|c|c|c|c|c|c|c|c|c|}
\hline Probe Extrakt & 帒 & 旁 & $\underset{\mathbb{N}}{\mathbb{N}}$ & \begin{tabular}{|l|l} 
\\
\multirow{2}{*}{} \\
\end{tabular} & 昰 & $\begin{array}{l}\stackrel{8}{8} \\
\text { 量 }\end{array}$ & 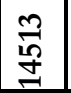 & $\frac{\sqrt{3}}{\sqrt[3]{7}}$ & 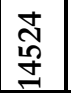 & $\begin{array}{l}\stackrel{N}{7} \\
\text { I }\end{array}$ & 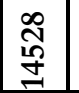 & 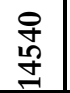 & 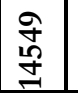 & $\begin{array}{l}10 \\
10 \\
\qquad \\
\end{array}$ & 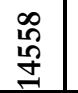 & 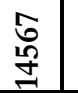 & 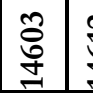 & స్తి & స్త్రి & 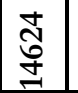 & 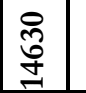 & 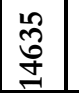 & 尊 & 㺼 & \begin{tabular}{|l}
$\overrightarrow{3}$ \\
$\stackrel{0}{0}$ \\
\end{tabular} & \begin{tabular}{l} 
గ్ర \\
\multirow{2}{0}{}
\end{tabular} & 佫 & 兽 & 勇 \\
\hline on & $\mathbf{A}$ & $\mathrm{T}$ & G & $\vec{C}$ & A & $T$ & $\mathbf{C}$ & $\mathrm{T}$ & C & G & C & & $T$ & $\mathbf{A}$ & $\pi$ & $\bar{A}$ & $\mathrm{~T}$ & $\mathbf{G}$ & $\mathrm{C}$ & $T$ & $\mathrm{C}$ & C & $\mathbf{A}$ & $\mathbf{A}$ & $\mathrm{T}$ & G & $\mathbf{A}$ & $\mathbf{A}$ & C \\
\hline & & nd & & & $\overline{\text { nd }}$ & $n d$ & nd & nd & $n d$ & nd & nd & nd & $\overline{n d}$ & $\mathrm{~d}$ & nd & $\mathrm{nd}$ & \begin{tabular}{l|l} 
nd & $n$ \\
\end{tabular} & nd & & & & & & & & & & & \\
\hline & & nd & nd & & nd & nd & nc & nd & nd & nd & nd & nd & nd & nd & nd & nd & \begin{tabular}{l|l} 
nd & $n$ \\
\end{tabular} & nd & $\mathrm{d}$ & nd & d & $\mathrm{hd}$ & & & & & & & \\
\hline COA1 & nd & $*$ & 5 & * & * & * & $*$ & * & * & $*$ & * & & & nd & nd & nd & \begin{tabular}{l|l} 
nd & $n$ \\
\end{tabular} & nd & nd & nd & nd & nd & nd & nd & nd & nd & nd & nd & nd \\
\hline $\mathrm{COH}$ & & & x & & * & & N & * & & & t & & & d & nd & nd & \begin{tabular}{l|l} 
nd & $n$ \\
\end{tabular} & nd & nd & nd & nd & nd & nd & nd & nd & nd & nd & nd & nd \\
\hline & & & & & nd & nd & $\mathrm{n}$ & $\overline{\mathrm{nd}}$ & nd & d & nd & nd & -1 & $\mathrm{id}$ & nd & nd & \begin{tabular}{l|l|} 
nd & $*$ \\
\end{tabular} & & & & & & & & & & & & \\
\hline & & $*$ & * & * & * & * & * & * & & $*$ & * & & & nd & nd & nd & \begin{tabular}{l|l} 
nd & $n$ \\
\end{tabular} & nd & $\mathrm{d}$ & nd & id & nd & nd & nd & id & nd & $\mathrm{id}$ & nd & nd \\
\hline $\mathrm{CO}$ & 5 & * & * & * & * & * & * & * & * & 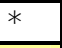 & * & * & $\mathrm{C}$ & nd & nd & nd & \begin{tabular}{|l|l|} 
nd & $n$ \\
\end{tabular} & nd & * & * & * & * & $*$ & * & * & & * & * & $*$ \\
\hline & & C & $x^{*}$ & * & * & & * & * & & * & $y$ & & & & $\mathrm{C}$ & $\mathrm{C}$ & C & $A$ & & & & & & * & * & * & & $\mathrm{G}$ & $\mathrm{T}$ \\
\hline & & C & & & * & & & 7 & $\mathrm{~A}$ & & & & & & 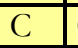 & & \begin{tabular}{l|l} 
nd & $n$ \\
\end{tabular} & \begin{tabular}{l|l} 
nd & 1 \\
\end{tabular} & nd & nd & nd & nd & nd & nd & nd & nd & $\mathrm{id}$ & nd & nd \\
\hline & & & & & & & $n$ & & $\mathrm{n}$ & & & $\mathrm{n}$ & nd & nd & nd & nd & 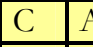 & 4 & & & & & & & & & & $\mathrm{G}$ & $\mathrm{T}$ \\
\hline & 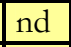 & $\mathrm{n}$ & $\mathrm{n}$ & nd & nd & nd & nd & nd & nd & $\mathrm{n}$ & nd & nd & nd & nd & nd & nd & \begin{tabular}{l|l} 
nd & $n$ \\
\end{tabular} & \begin{tabular}{l|l} 
nd & 1 \\
\end{tabular} & nd & nd & nd & * & 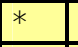 & * & 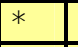 & * & * & G & $\mathrm{T}$ \\
\hline & $T$ & $\mathrm{C}$ & * & * & * & ${ }^{*}$ & * & * & & * & 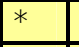 & & C & nd & nd & nd & \begin{tabular}{l|l} 
nd & $n$ \\
\end{tabular} & \begin{tabular}{l|l} 
nd & 1 \\
\end{tabular} & nd & nd & nd & nd & nd & nd & nd & nd & \begin{tabular}{|l|} 
nd \\
\end{tabular} & nd & nd \\
\hline & nd & & $\mathrm{I}$ & nd & $D_{0}$ & $\mathrm{r}$ & nd & nd & $\mathrm{nd}$ & $\mathrm{n}$ & nd & $\mathrm{nd}$ & nd & nd & nd & nd & \begin{tabular}{l|l} 
nd & $n$ \\
\end{tabular} & \begin{tabular}{l|l} 
nd & 1
\end{tabular} & nd & nd & & $*$ & & * & $*$ & & * & $\mathrm{G}$ & $\mathrm{T}$ \\
\hline & nd & $\mathrm{C}$ & $7 \times$ & * & * & & 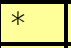 & * & & $*$ & & & $E$ & $\mathrm{nc}$ & nd & \begin{tabular}{l|l} 
nd & \\
\end{tabular} & \begin{tabular}{l|l} 
nd & $n$ \\
\end{tabular} & \begin{tabular}{l|l} 
nd & 1
\end{tabular} & nd & nd & nd & nd & nd & nd & nd & nd & nd & nd & nd \\
\hline & \begin{tabular}{|l|} 
nd \\
\end{tabular} & nd & $\mathrm{n}$ & $\mathrm{nc}$ & $\mathrm{nc}$ & $\mathrm{nc}$ & nd & $\mathrm{nc}$ & $\mathrm{n}$ & nd & $\mathrm{nc}$ & nd & nd & nd & nd & nd & C & $*$ & $*$ & \begin{tabular}{|l|l}
$*$ \\
\end{tabular} & $*$ & $*$ & 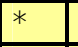 & 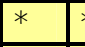 & $\leftarrow$ & - & * & $\mathrm{G}$ & $G$ \\
\hline & * & C & $\bar{F}$ & * & * & * & * & * & & 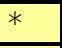 & * & $*$ & C & * & C & $\mathrm{C}$ & \begin{tabular}{l|l} 
nd & $n$ \\
\end{tabular} & \begin{tabular}{l|l} 
nd & 1
\end{tabular} & nd & nd & nd & nd & nd & nd & nd & nd & nd & nd & nd \\
\hline & & $F$ & * & 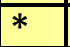 & 5 & $=$ & 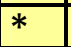 & * & & 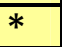 & * & & C & * & C & $\bar{C}$ & $\bar{C}$ & $\overline{\mathbf{A}}$ & 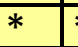 & & 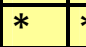 & 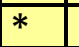 & & * & 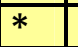 & * & 4 & $\mathbf{G}$ & $T$ \\
\hline & $\mathrm{nc}$ & $\mathrm{n}$ & & nc & $\mathrm{n}$ & 1 & $\mathrm{nc}$ & 5 & $\mathrm{n}$ & $\mathrm{n}$ & L & nd & $\mathrm{n}$ & $n$ & nd & nd & \begin{tabular}{l|l} 
nd & $n$ \\
\end{tabular} & nd & $\mathrm{T}$ & & 1 & $\mathrm{~T}$ & $c$ & & & * & & $*$ & $\mathrm{~T}$ \\
\hline 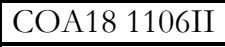 & \begin{tabular}{|l|} 
nd \\
\end{tabular} & 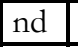 & nd & nd & nd & nd & nd & nd & nd & nd & nd & nd & \begin{tabular}{|l|l} 
nd \\
\end{tabular} & nd & nd & nd & \begin{tabular}{l|l} 
nd & $n$ \\
\end{tabular} & \begin{tabular}{l|l} 
nd & 1
\end{tabular} & nd & nd & nd & ${ }^{*}$ & $G$ & 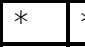 & $*$ & $*$ & + & T & $\mathrm{T}$ \\
\hline & 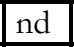 & nd & & * & * & & $\mathrm{T}$ & C & & $*$ & $\mathrm{~T}$ & & $\sqrt{*}$ & nd & nd & nd & \begin{tabular}{l|l} 
nd & $n$ \\
\end{tabular} & \begin{tabular}{l|l} 
nd & 1
\end{tabular} & nd & nd & nd & nd & nd & nd & nd & nd & \begin{tabular}{ll|} 
nd \\
\end{tabular} & nd & nd \\
\hline & $\mathrm{nc}$ & $\mathrm{n}$ & & 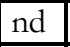 & nd & & 7 & $F$ & & 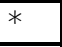 & $\mathrm{T}$ & & + & $\mathrm{nc}$ & nd & nd & \begin{tabular}{l|l} 
nd & $n$ \\
\end{tabular} & \begin{tabular}{l|l} 
nd & 1
\end{tabular} & nd & tat & nd & 1110 & $111 \mathrm{du}$ & nd & $111 \mathrm{a}$ & nd & nd & nd & nd \\
\hline & + & $\mathrm{n}$ & & $\mathrm{nc}$ & & 1 & nd & nd & $\mathrm{n}$ & $\mathrm{n}$ & nd & $\mathrm{n}$ & 5 & 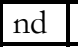 & nd & nd & \begin{tabular}{l|l} 
nd & $n$ \\
\end{tabular} & nd & - & 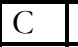 & $\mathrm{T}$ & $*$ & G & $\vec{G}$ & $*$ & $\begin{array}{ll}* \\
\end{array}$ & $1 *$ & $*$ & $\mathrm{~T}$ \\
\hline $\mathrm{CO}$ & $\mathrm{n}$ & $\mathrm{n}$ & $*$ & $*$ & 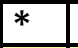 & * & $\begin{array}{l} \\
\end{array}$ & $C$ & $*$ & * & $\mathrm{T}$ & 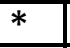 & - & \begin{tabular}{|l|} 
nd \\
\end{tabular} & \begin{tabular}{l|} 
nd \\
\end{tabular} & \begin{tabular}{l|l} 
nd \\
\end{tabular} & \begin{tabular}{l|l} 
nd & . \\
\end{tabular} & 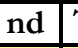 & $T$ & $C$ & $T$ & 1 & $\mathbf{G}$ & $G$ & 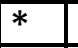 & - & * & 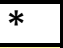 & $\mathrm{T}$ \\
\hline$\overline{\mathrm{CO}}$ & \begin{tabular}{|l|} 
nd \\
\end{tabular} & 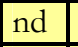 & nd & nd & nd & nd & nd & nd & nd & nd & nd & nd & \begin{tabular}{|l|l} 
nd \\
\end{tabular} & nd & nd & \begin{tabular}{l|l} 
nd \\
\end{tabular} & \begin{tabular}{l|l} 
nd & $n$ \\
\end{tabular} & nd & $*$ & $*$ & $\sqrt{*}$ & $*$ & $*$ & * & $*$ & * & * & * & * \\
\hline & nd & $\mathrm{n}$ & I & nd & $n$ & nd & nd & nd & nd & nd & nd & nd & nd & nd & nd & nd & C & $\mathrm{A}$ & 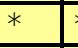 & & $\pi$ & 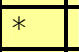 & & 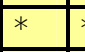 & * & 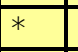 & & * & \\
\hline & nc & * & & T. & * & & * & * & & * & * & & C & 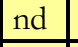 & nd & nd & \begin{tabular}{l|l} 
nnd & $n$ \\
\end{tabular} & nd & $\mathrm{nc}$ & $\square$ & nd & nd & 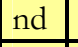 & $\mathrm{d}$ & 110 & 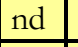 & nd & 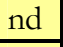 & nd \\
\hline & nc & $\mathrm{n}$ & I & $\mathrm{nc}$ & nd & 1 & nd & nd & $n$ & $\mathrm{f}$ & nd & nd & nd & $\mathrm{nc}$ & $n d$ & $\mathrm{nd}$ & \begin{tabular}{l|l} 
nd & $n$ \\
\end{tabular} & \begin{tabular}{l|l} 
nd & 1 \\
\end{tabular} & nd & & * & * & - & - & & . & $*$ & * & \\
\hline $\mathrm{COA}$ & \begin{tabular}{|l|} 
nd \\
\end{tabular} & nd & C & * & * & 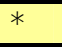 & * & 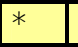 & * & * & (*) & 4 & 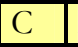 & nd & nd & nd & \begin{tabular}{l|l} 
nd & $n$ \\
\end{tabular} & \begin{tabular}{l|l} 
nd &
\end{tabular} & nd & nd & nd & nd & nd & nd & nd & nd & $\begin{array}{ll}\text { nd } \\
\end{array}$ & nd & nd \\
\hline$\overline{\text { COA19 }}$ & nd & \begin{tabular}{|l|} 
nd \\
nat
\end{tabular} & 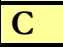 & & & & & & & & & & & \begin{tabular}{|l|l} 
nd \\
\end{tabular} & \begin{tabular}{l|l} 
nd \\
\end{tabular} & \begin{tabular}{l|l} 
nd \\
\end{tabular} & 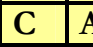 & $\mathbf{A}$ & & & & & & & & & & & \\
\hline
\end{tabular}


Tabelle 74: Einzeltypisierungen cytb von Extrakten der Knochen- und Zahn-Proben des Fundortes Chillo, Fortsetzung

\begin{tabular}{|c|c|c|c|c|c|c|c|c|c|c|c|c|c|c|c|c|c|c|c|c|c|c|c|c|c|c|c|c|c|}
\hline obe Extrakt & 尔 & $\stackrel{8}{8}$ & 胥 & 売 & ğ & \begin{tabular}{|l} 
\\
量 \\
年
\end{tabular} & $\stackrel{m}{\stackrel{m}{9}}$ & $\frac{10}{d}$ & 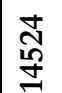 & $\begin{array}{l}\text { Nั } \\
\text { I্ } \\
\end{array}$ & 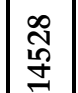 & 亭 & 亮 & 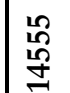 & 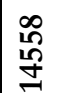 & 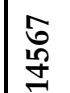 & 柋 & 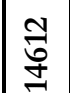 & 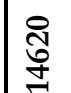 & 志 & 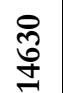 & 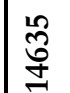 & 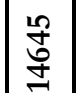 & 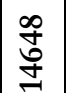 & \begin{tabular}{|l}
$\overrightarrow{8}$ \\
$\stackrel{8}{g}$ \\
\end{tabular} & 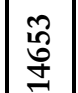 & $\begin{array}{l}\sqrt{n} \\
\stackrel{\delta}{J}\end{array}$ & 悤 & 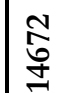 \\
\hline & 5 & & & $\mathrm{C}$ & & $T$ & C & & C & G & $\bar{C}$ & $T$ & $T$ & $\bar{A}$ & $T$ & $\mathbf{A}$ & $\bar{T}$ & G & $\mathrm{C}$ & & $\mathrm{C}$ & C & $\mathbf{A}$ & $\mathbf{A}$ & $T$ & G & & $\mathbf{A}$ & C \\
\hline & & & & & & & $n$ & & & 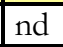 & & & nd & & & nd & $\overline{n d}$ & ad & & & & & & & & & & & $\bar{T}$ \\
\hline & & & & & & & & & & & & & $\mathrm{hd}$ & nd & & nd & & & & & & & & & & & & & $\mathrm{T}$ \\
\hline & & & & * & & $*$ & $\mathrm{~T}$ & & $*$ & & $\mathrm{~T}$ & & & nd & d & $\mathrm{dd}$ & & d & nd & $\mathrm{d}$ & nd & nd & $\mathrm{d}$ & nd & nd & ad & nd & nd & nd \\
\hline & & & & $\mathrm{n}$ & & $*$ & $\mathrm{~T}$ & ( & 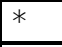 & & 1 & & & nd & dd & $\mathrm{nd}$ & nd & nd & nd & $\mathrm{nd}$ & nd & nd & nd & nd & nd & nd & nd & nd & nd \\
\hline & & & & $*$ & & & 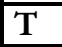 & & & & & & & 110 & d & nd & & & & & & & & & & & & $*$ & $T$ \\
\hline & 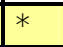 & 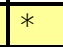 & & $\bar{x}$ & & & & & 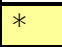 & & & & & & * & & t & & & & & & & & & & & & * \\
\hline & * & \pm & * & * & & * & * & & * & & & & I & * & & & & $\mathrm{R}$ & & & & & 7 & * & $x^{\prime}$ & * & * & 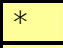 & * \\
\hline & & & & & & $\mathrm{n}$ & & $\mathrm{n}$ & & & nd & nd & & nd & nd & nd & C & & & 3 & & & 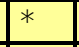 & & 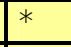 & $x^{*}$ & 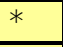 & * & * \\
\hline & $n$ & & & & & & & & & & $\mathrm{n}$ & & & nd & 5 & nd & nd & & & & & & & & & & & 7 & * \\
\hline & & & & & & & & & & & nc & & & $\mathrm{n}$ & & nd & c & & & & & & & & & & & & * \\
\hline & $\mathrm{n}$ & & * & * & * & * & * & * & * & $x^{*}$ & * & * & $=$ & nd & nd & nd & nd & nd & nd & $\mathrm{d}$ & nd & nd & d & $\mathrm{n}$ & $\mathrm{d}$ & nd & nd & $\mathrm{id}$ & nd \\
\hline & $\mathrm{n}$ & & C & * & * & * & * & * & * & 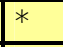 & * & & & nd & 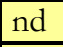 & $\mathrm{n}$ & nd & nd & $\mathrm{d}$ & $\mathrm{n}$ & nd & nd & nd & nd & $\mathrm{d}$ & $t$ & nd & nd & nd \\
\hline & $\mathrm{n}$ & & $*$ & ${ }^{*}$ & 3 & $*$ & s. & & 7 & & & & & nd & nd & nd & nd & $\mathrm{d}$ & nd & nd & $\mathrm{nd}$ & nd & d & nd & nd & nd & nd & nd & nd \\
\hline & & & * & * & & $*$ & $*$ & & $*$ & 5 & 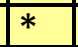 & & & 4 & & $*$ & 4 & $\mathbf{R}$ & - & & & * & & * & * & & * & $*$ & * \\
\hline & * & * & * & * & * & $E$ & * & E & * & A & * & t & & * & & & ( & & nd & $\mathrm{d}$ & nd & nd & id & 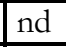 & nd & nd & nd & nd & nd \\
\hline & * & 7 & $\sqrt{4}$ & $*$ & & * & * & & $*$ & A & * & & & * & & & (c) & & & & & & & & * & & $*$ & & * \\
\hline & $\mathrm{n}$ & & $*$ & 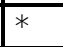 & & * & 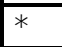 & & * & $\bar{A}$ & & $\overline{7}$ & & & & & 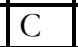 & & & & & & & & & & & & \\
\hline & $n$ & & & & & & & & & & & & & & & + & $E$ & $\mathrm{P}$ & ઋ & $*$ & & * & $y$ & $*$ & $*$ & 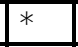 & * & $E$ & * \\
\hline & nd & nd & 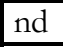 & nd & nd & 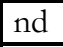 & 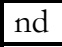 & nd & 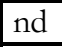 & nd & tive & 5 & nd & nd & nd & nd & 5 & 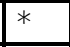 & 5 & $*$ & - & \begin{tabular}{|l|l}
$*$ \\
\end{tabular} & * & * & $*$ & * & - & * & $*$ \\
\hline & * & * & 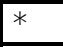 & 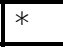 & * & * & \% & * & \begin{tabular}{|l|l|}
$*$ \\
\end{tabular} & $\mathrm{~A}$ & * & $\begin{array}{ll}* \\
\end{array}$ & C & * & & 14 & $\mathrm{C}$ & $\mathrm{R}$ & nd & nd & nd & nd & nd & $\mathrm{n}$ & $\mathrm{d}$ & nd & nd & $\mathrm{d}$ & nd \\
\hline & $*$ & 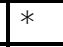 & $*$ & $*$ & 3 & 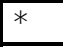 & * & 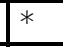 & $*$ & $\mathrm{~A}$ & L & & $c$ & & & & 10 & II & d & nde & nd & $\mathrm{nd}$ & nd & $\mathrm{nd}$ & $\mathrm{nd}$ & nd & nd & nd & $\mathrm{nd}$ \\
\hline & $\mathrm{n}$ & & $*$ & * & $\bar{x}$ & * & $*$ & $*$ & * & $\mathrm{A}$ & * & & C & nd & & & & +1 & & & & & & & & & & $\mathrm{~d}$ & nd \\
\hline$\overline{\mathrm{OA}}$ & * & * & * & * & $*$ & * & L & * & 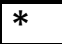 & $\mathbf{A}$ & * & $*$ & C & I & 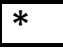 & * & C & $\mathbf{R}$ & * & I. & 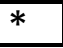 & * & $\left.\right|^{*}$ & 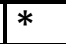 & $D^{*}$ & $D^{*}$ & $*$ & \begin{tabular}{|l|l} 
\\
\end{tabular} & \\
\hline
\end{tabular}




\begin{tabular}{|c|c|c|c|c|c|c|c|c|c|c|c|c|c|c|c|c|c|c|c|c|c|c|c|c|c|c|c|c|c|}
\hline Probe Extrakt & $\begin{array}{l}0 \\
\text { 㝵 } \\
\end{array}$ & $\begin{array}{l}\text { 字 } \\
\text { J }\end{array}$ & $\begin{array}{r}\mathcal{N} \\
\stackrel{F}{J} \\
\end{array}$ & $\begin{array}{l}\frac{J}{J} \\
\\
\end{array}$ & 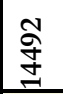 & $\begin{array}{l} \\
\text { 㕝 } \\
\text { 足 }\end{array}$ & 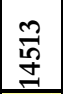 & 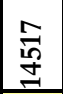 & 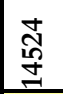 & $\begin{array}{l}\text { N } \\
\text { İ } \\
\end{array}$ & 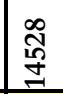 & 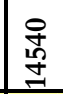 & $\begin{array}{l}\text { 竎 } \\
\text { 岁 }\end{array}$ & \begin{tabular}{|l}
$\stackrel{0}{0}$ \\
量 \\
\end{tabular} & 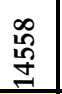 & \begin{tabular}{|l|} 
\\
总 \\
\end{tabular} & 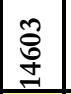 & \begin{tabular}{|l|} 
\\
\multirow{J}{J}{} \\
\end{tabular} & 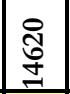 & 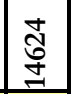 & 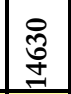 & 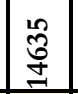 & $\begin{array}{l}\frac{1}{2} \\
\text { J } \\
\end{array}$ & 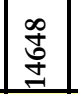 & \begin{tabular}{|l|}
$\vec{r}$ \\
0 \\
$⿱ 亠 䒑$ \\
\end{tabular} & 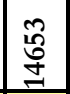 & 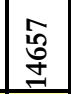 & 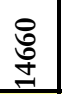 & \begin{tabular}{l}
$\tilde{N}$ \\
\multirow{6}{*}{}
\end{tabular} \\
\hline f Arnason & $\mathbf{A}$ & $\mathrm{T}$ & G & C & A & $T$ & C & $\mathrm{T}$ & C & G & C & $\mathrm{T}$ & $T$ & A & $T$ & A & $T$ & G & C & $T$ & C & C & A & $\mathbf{A}$ & $T$ & G & $\mathbf{A}$ & A & \begin{tabular}{|l|} 
C \\
\end{tabular} \\
\hline GEA1 1206I & nd & nd & nd & nd & nd & nd & nd & nd & nd & nd & nd & nd & nd & nd & nd & nd & nd & nd & * & * & * & 5 & 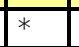 & 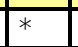 & C & $*$ & * & $\bar{G}$ & $\bar{T}$ \\
\hline GEA1 1206I & nd & * & 5 & 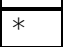 & $*$ & * & * & * & * & 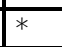 & $*$ & + & t & nd & nd & nd & nd & nd & nd & nd & nd & nd & nd & nd & nd & nd & nd & nd & nd \\
\hline GEA1 0807I & nd & * & * & * & $F$ & 5 & $F$ & $F$ & 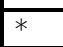 & 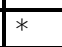 & * & IC & C & nd & nd & nd & nd & nd & nd & nd & nd & nd & nd & nd & nd & nd & nd & nd & nd \\
\hline GEA1 0807I & nd & nd & nd & nd & nd & nd & nd & nd & nd & nd & nd & nd & nd & nd & nd & nd & C & + & 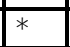 & * & * & * & $*$ & 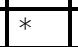 & C & 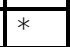 & 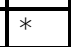 & \begin{tabular}{l|l}
$\mathrm{G}$ & \\
\end{tabular} & $\mathrm{T}$ \\
\hline GEA1 & nd & . & * & * & $*$ & * & * & * & * & * & * & $*$ & C & * & * & $F_{0}$ & * & * & * & * & * & $t_{*}$ & * & * & C & * & * & G & $\mathrm{T}$ \\
\hline GEA & nd & nd & nd & nd & nd & nd & nd & nd & nd & nd & nd & nd & nd & nd & nd & nd & nd & nd & nd & nd & nd & * & * & * & C & * & * & $\mathrm{G}$ & $\mathrm{T}$ \\
\hline GEA & nd & nd & nd & nd & nd & nd & nd & nd & nd & nd & nd & nd & nd & nd & nd & nd & C & nd & nd & nd & nd & nd & nd & nd & nd & nd & nd & nd & nd \\
\hline GEA5 & nd & nd & nd & nd & nd & nd & nd & nd & nd & nd & nd & nd & \begin{tabular}{|l|} 
nd \\
\end{tabular} & nd & nd & \begin{tabular}{|l|} 
nd \\
\end{tabular} & \begin{tabular}{|l|} 
nd \\
\end{tabular} & \begin{tabular}{|l|} 
nd \\
\end{tabular} & \begin{tabular}{|l|} 
nd \\
\end{tabular} & nd & nd & * & * & * & C & * & $F_{*}$ & G & \begin{tabular}{|l|}
$T$ \\
\end{tabular} \\
\hline GEA & * & * & * & * & * & * & * & * & * & * & * & C & C & * & C & C & C & 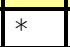 & * & * & 楼 & * & * & * & C & + & * & $\bar{G}$ & $\mathrm{~T}$ \\
\hline$\overline{\mathrm{GE} / \mathrm{t}}$ & nd & nd & nd & nd & nd & nd & nd & nd & nd & nd & nd & nd & \begin{tabular}{|l|} 
nd \\
\end{tabular} & nd & nd & nd & \begin{tabular}{|l|} 
nd \\
\end{tabular} & \begin{tabular}{|l|} 
nd \\
\end{tabular} & 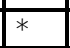 & + & * & 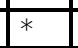 & * & * & C & * & * & $\bar{G}$ & \begin{tabular}{|l|}
$\mathrm{T}$ \\
\end{tabular} \\
\hline GEA & nd & nd & nd & nd & nd & nd & nd & nd & nd & nd & nd & nd & \begin{tabular}{|l|} 
nd \\
\end{tabular} & nd & nd & nd & C & A & * & * & 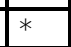 & * & * & * & C & * & * & $\bar{G}$ & T \\
\hline$\overline{\mathrm{GE}} \mathrm{I}$ & n & nd & nd & nd & nd & nd & nd & nd & nd & nd & nd & nd & \begin{tabular}{|l|} 
nd \\
\end{tabular} & nd & nd & nd & C & A & * & * & * & * & * & 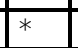 & C & * & $\left.\right|^{*}$ & $\bar{G}$ & \begin{tabular}{|l|}
$\mathrm{T}$ \\
\end{tabular} \\
\hline GEA6 & $E$ & * & * & * & * & * & $*$ & $*$ & 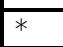 & * & * & C & C & * & 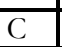 & C & C & A & \begin{tabular}{|l|} 
nd \\
\end{tabular} & nd & nd & nd & nd & \begin{tabular}{|l|} 
nd \\
\end{tabular} & \begin{tabular}{|l|} 
nd \\
\end{tabular} & nd & nd & nd & nd \\
\hline GE & $\mathrm{n}$ & nd & $=$ & * & * & * & * & * & * & * & * & C & C & 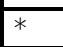 & C & C & C & A & nd & nd & nd & nd & \begin{tabular}{|l|} 
nd \\
\end{tabular} & \begin{tabular}{|l|} 
nd \\
\end{tabular} & \begin{tabular}{|l|} 
nd \\
\end{tabular} & nd & nd & nd & nd \\
\hline GEA6 & nd & $E$ & * & * & 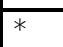 & + & $F$ & $E$ & * & * & * & C & 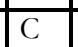 & nd & nd & \begin{tabular}{|l|} 
nd \\
\end{tabular} & nd & \begin{tabular}{|l|} 
nd \\
\end{tabular} & \begin{tabular}{|l|} 
nd \\
\end{tabular} & nd & nd & nd & \begin{tabular}{|l|} 
nd \\
\end{tabular} & \begin{tabular}{|l|} 
nd \\
\end{tabular} & \begin{tabular}{|l|} 
nd \\
\end{tabular} & nd & nd & nd & nd \\
\hline GE & nd & nd & - & * & * & * & * & * & * & * & * & C & C & nd & nd & nd & \begin{tabular}{|l|} 
nd \\
\end{tabular} & \begin{tabular}{|l|} 
nd \\
\end{tabular} & nd & nd & nd & nd & \begin{tabular}{|l|} 
nd \\
\end{tabular} & \begin{tabular}{|l|} 
nd \\
\end{tabular} & nd & nd & nd & nd & nd \\
\hline GEA & 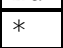 & $F$ & * & * & * & 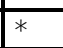 & $E$ & * & * & * & * & C & C & $\rightarrow$ & 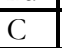 & 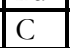 & \begin{tabular}{|l|} 
nd \\
\end{tabular} & \begin{tabular}{|l|} 
nd \\
\end{tabular} & \begin{tabular}{|l|} 
nd \\
\end{tabular} & nd & nd & nd & \begin{tabular}{|l|} 
nd \\
\end{tabular} & \begin{tabular}{|l|} 
nd \\
\end{tabular} & \begin{tabular}{|l|} 
nd \\
\end{tabular} & nd & nd & nd & nd \\
\hline $07 \mathrm{II}$ & nd & nd & E & * & * & * & * & * & * & * & * & C & C & * & $\mathrm{C}$ & $\mathrm{C}$ & nd & \begin{tabular}{|l|} 
nd \\
\end{tabular} & nd & nd & nd & nd & \begin{tabular}{|l|} 
nd \\
\end{tabular} & \begin{tabular}{|l|} 
nd \\
\end{tabular} & \begin{tabular}{|l|} 
nd \\
\end{tabular} & nd & nd & nd & nd \\
\hline GEAC & - & * & * & * & * & * & * & * & * & * & * & C & $\mid \mathrm{C}$ & * & C & C & \begin{tabular}{|l|} 
C \\
\end{tabular} & A & + & * & * & 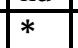 & 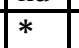 & * & C & * & * & G & \begin{tabular}{|l|}
$T$ \\
\end{tabular} \\
\hline$\overline{\mathrm{Gl}}$ & nd & nd & nd & nd & nd & nd & nd & \begin{tabular}{|l|} 
nd \\
\end{tabular} & nd & $\overline{\mathrm{nd}}$ & $\mathrm{nd}$ & nd & nd & nd & nd & \begin{tabular}{|l|} 
nd \\
\end{tabular} & \begin{tabular}{|l|} 
nd \\
\end{tabular} & \begin{tabular}{|l|} 
nd \\
\end{tabular} & \begin{tabular}{|l|} 
nd \\
\end{tabular} & nd & * & 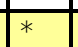 & * & 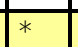 & 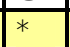 & 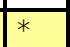 & - & - & $*$ \\
\hline GEA & nd & nd & nd & nd & nd & nd & nd & nd & nd & nd & nd & nd & \begin{tabular}{|l|} 
nd \\
\end{tabular} & nd & nd & nd & \begin{tabular}{|l|} 
nd \\
\end{tabular} & \begin{tabular}{|l|} 
nd \\
\end{tabular} & + & + & 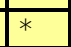 & $T^{2}$ & 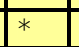 & 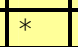 & 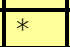 & 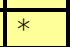 & * & * & * \\
\hline$\overline{\text { GEA }}$ & nd & nd & nd & nd & nd & nd & nd & nd & nd & nd & nd & nd & \begin{tabular}{|l|} 
nd \\
\end{tabular} & nd & nd & \begin{tabular}{|l|} 
nd \\
\end{tabular} & C & A & * & * & 5 & + & 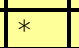 & + & 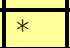 & * & * & * & * \\
\hline GEA7 & nd & * & * & * & * & * & * & $F$ & $\square$ & $\square$ & * & * & C & nd & nd & nd & nd & \begin{tabular}{|l|} 
nd \\
\end{tabular} & \begin{tabular}{|l|} 
nd \\
\end{tabular} & nd & nd & nd & \begin{tabular}{|l|} 
nd \\
\end{tabular} & \begin{tabular}{|l|} 
nd \\
\end{tabular} & \begin{tabular}{|l|} 
nd \\
\end{tabular} & \begin{tabular}{|l|} 
nd \\
\end{tabular} & nd & nd & nd \\
\hline GEA7 0807I & nd & nd & & * & * & * & * & * & $*$ & 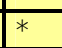 & 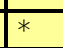 & + & C & . & 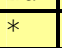 & & C & A & nd & nd & nd & nd & \begin{tabular}{|l|} 
nd \\
\end{tabular} & \begin{tabular}{|l|} 
nd \\
\end{tabular} & nd & nd & nd & nd & nd \\
\hline GEA & nd & nd & $\cdot$ & * & * & * & * & * & * & $*$ & * & * & $\mathrm{C}$ & $I^{\top}$ & * & $D^{\top}$ & C & A & * & * & * & 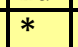 & * & * & * & * & * & - & 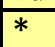 \\
\hline GEA8 1206I & nd & nd & nd & nd & nd & nd & nd & nd & nd & nd & nd & nd & nd & nd & nd & nd & \begin{tabular}{|l|} 
nd \\
\end{tabular} & nd & nd & $C$ & T & * & $\mathrm{G}$ & $\mathrm{G}$ & 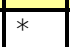 & 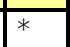 & - & * & $\mathrm{T}$ \\
\hline GEA & nd & nd & nd & nd & nd & nd & \begin{tabular}{|l|} 
nd \\
\end{tabular} & nd & nd & nd & nd & nd & nd & nd & nd & nd & nd & \begin{tabular}{|l|} 
nd \\
\end{tabular} & nd & nd & nd & nd & \begin{tabular}{|l|} 
nd \\
\end{tabular} & nd & $\mid{ }^{*}$ & 和 & $\left.\right|^{*}$ & & \\
\hline GEA8 0807I & nd & & C & $\mathrm{T}$ & $*$ & * & $\mathrm{T}$ & C & * & + & $\mathrm{T}$ & 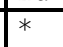 & + & nd & nd & nd & nd & nd & nd & nd & nd & nd & \begin{tabular}{|l|l} 
nd \\
\end{tabular} & nd & nd & nd & nd & nd & nd \\
\hline $07 \mathrm{II}$ & nd & 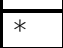 & 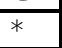 & $\mathrm{T}$ & * & $\left.\right|^{*}$ & \begin{tabular}{|l}
$\mathrm{T}$ \\
\end{tabular} & C & * & |* & $\mathrm{T}$ & $\left.\right|^{4}$ & $D^{2}$ & nd & nd & nd & \begin{tabular}{|l|l|} 
nd \\
\end{tabular} & nd & nd & nd & nd & nd & \begin{tabular}{|l|} 
nd \\
\end{tabular} & nd & nd & nd & nd & nd & nd \\
\hline GEA8 0807II & nd & nd & nd & nd & nd & nd & nd & nd & nd & nd & nd & nd & nd & nd & nd & nd & nd & * & 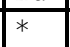 & C & $\mathrm{T}$ & 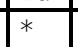 & G & $\mathrm{G}$ & 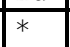 & 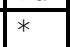 & * & - & 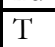 \\
\hline GEA8 & nd & * & C & $\mathrm{T}$ & 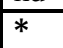 & | & $\mathrm{T}$ & \begin{tabular}{|l}
$\mathrm{C}$ \\
\end{tabular} & 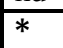 & * & $\mathrm{T}$ & * & * & nd & nd & nd & \begin{tabular}{|l|l|} 
nd \\
\end{tabular} & \begin{tabular}{|l|} 
nd \\
\end{tabular} & nd & C & $T$ & * & G & | & * & * & * & * & 1 \\
\hline
\end{tabular}


Tabelle 75: Einzeltypisierungen cytb von Extrakten in Knochen- und Zahn-Proben des Fundortes Montegrande, Fortsetzung

\begin{tabular}{|c|c|c|c|c|c|c|c|c|c|c|c|c|c|c|c|c|c|c|c|c|c|c|c|c|c|c|c|c|c|}
\hline trakt & 筞 & 守 & $\underset{\mathbb{S}}{\mathbb{N}}$ & 龸 & $\widetilde{d}$ & 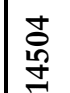 & $\frac{m}{8}$ & 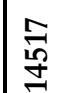 & \begin{tabular}{|l}
$\underset{J}{J}$ \\
d
\end{tabular} & 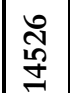 & $\begin{array}{l}\stackrel{8}{~} \\
\underset{d}{+}\end{array}$ & \begin{tabular}{|l|} 
\\
孛 \\
年
\end{tabular} & 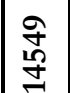 & 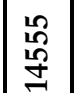 & 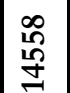 & $\begin{array}{l}\text { 今్ } \\
\text { g్ }\end{array}$ & 筞 & 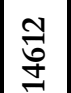 & 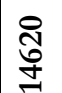 & 芯 & 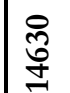 & 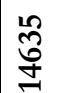 & 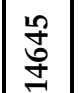 & 累 & $\begin{array}{l}\vec{r} \\
\text { d }\end{array}$ & 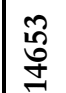 & 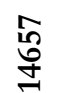 & 鰙 & 尧 \\
\hline Ref Arnason & $\mathbf{A}$ & $T$ & G & C & A & 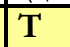 & C & $T$ & C & G & C & $T$ & $T$ & A & $T$ & $\mathbf{A}$ & $T$ & G & C & $\mathbf{T}$ & C & $\mathrm{C}$ & A & A & $T$ & G & $\mathbf{A}$ & $\mathbf{A}$ & C \\
\hline GEA9 1206I & nd & nd & nd & nd & nd & nd & nd & nd & nd & nd & nd & nd & nd & nd & nd & nd & C & & - & & * & & * & * & $*$ & * & * & G & T \\
\hline GEA9 1206I & nd & nd & nd & nd & nd & nd & Ind & nd & nd & nd & nd & Ind & nd & nd & nd & nd & nd & nd & nd & nd & nd & nd & nd & * & * & * & * & $\mathrm{G}$ & $\mathrm{T}$ \\
\hline GEA9 1206II & nd & nd & $\mathrm{nc}$ & nd & nd & nd & Ind & nd & Ind & nd & nd & Ind & nd & nd & nd & nd & C & A & & & $*$ & & $*$ & * & * & $L$ & * & G & 1 \\
\hline 6II & 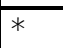 & $\mathrm{C}$ & * & * & * & $*$ & + & * & $*$ & $*$ & $t_{-}$ & $\psi_{*}$ & $S^{\prime}$ & * & 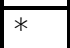 & * & 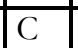 & $\mathrm{A}$ & nd & nd & nd & nd & nd & nd & nd & nd & nd & nd & nd \\
\hline$\overline{\text { GEA }}$ & nd & nd & $\bar{C}$ & * & * & $F_{*}$ & * & * & * & * & * & * & C & nd & nd & nd & nd & nd & nd & nd & nd & nd & nd & nd & nd & nd & nd & nd & nd \\
\hline GEA9 0807I & nd & nd & C & * & * & * & * & * & $t_{*}$ & * & * & * & C & nd & nd & nd & nd & nd & nd & nd & nd & nd & \begin{tabular}{|l|} 
nd \\
\end{tabular} & nd & nd & nd & nd & nd & nd \\
\hline GE & nd & nd & * & * & * & * & * & * & * & * & * & * & C & + & C & C & nd & nd & nd & nd & nd & nd & nd & nd & nd & nd & nd & nd & nd \\
\hline $77 \mathrm{II}$ & * & C & * & * & * & * & * & * & * & * & * & * & $\mathrm{C}$ & * & $\mathrm{C}$ & C & nd & nd & nd & nd & nd & nd & \begin{tabular}{|l|} 
nd \\
\end{tabular} & nd & nd & nd & nd & nd & nd \\
\hline GEA & * & 0 & * & ${ }^{\circ}$ & $*$ & * & 1. & $*$ & T & * & 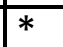 & $J^{\circ}$ & C & * & C & C & C & A & $E$ & * & * & * & * & * & * & * & * & G & $T$ \\
\hline $06 \mathrm{I}$ & nd & nd & $\overline{\mathrm{nd}}$ & nd & nd & nd & nd & nd & nd & nd & nd & nd & nd & nd & nd & nd & nd & nd & 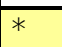 & * & * & 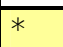 & * & * & * & * & * & * & * \\
\hline $7 \mathrm{II}$ & nd & nd & nd & nd & nd & nd & nd & nd & nd & nd & nd & nd & nd & nd & \begin{tabular}{|l|} 
nd \\
\end{tabular} & nd & nd & nd & * & C & $\mathrm{T}$ & * & G & $\bar{G}$ & - & * & * & $*$ & $\mathrm{~T}$ \\
\hline $07 \mathrm{I}$ & nd & * & \% & $E$ & 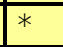 & * & * & * & * & * & 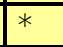 & $\square$ & C & nd & nd & nd & nd & nd & nd & nd & nd & nd & nd & nd & nd & nd & nd & nd & nd \\
\hline $07 \mathrm{II}$ & nd & nd & $\overline{\mathrm{nc}}$ & nd & nd & nd & nd & nd & nd & nd & nd & nd & nd & nd & \begin{tabular}{|l|} 
nd \\
\end{tabular} & nd & * & * & $*$ & + & * & $*$ & * & * & * & * & $*$ & * & * \\
\hline $\mathrm{GE} f$ & nd & nd & nd & nd & nd & nd & nd & nd & nd & nd & nd & nd & nd & nd & nd & nd & nd & nd & nd & nd & * & * & * & * & * & * & * & * & * \\
\hline$\overline{\text { D7II }}$ & nd & nd & nd & $\mathrm{n}$ & nd & nd & nd & nd & nd & nd & nd & nd & nd & nd & nd & nd & nd & * & * & $F$ & * & $F_{*}$ & * & * & * & * & * & * & * \\
\hline GE & nd & * & * & * & * & $*$ & * & * & * & \begin{tabular}{|l|}
$*$ \\
\end{tabular} & * & * & C & nd & \begin{tabular}{|l|} 
nd \\
\end{tabular} & nd & * & * & $H^{*}$ & * & $*$ & * & * & * & * & * & * & * & * \\
\hline GE & nd & nd & $\overline{n d}$ & nd & nd & nd & nd & nd & nd & nd & nd & nd & nd & nd & nd & nd & nd & nd & $T_{0}$ & C & $\mathrm{T}$ & - & $G$ & $\bar{G}$ & * & * & * & * & $\mathrm{T}$ \\
\hline $206 \mathrm{II}$ & nd & nd & nd & \begin{tabular}{|l|} 
nd \\
\end{tabular} & nd & nd & nd & nd & nd & nd & nd & nd & nd & nd & nd & nd & C & A & $*$ & $\bar{C}$ & $\mathrm{~T}$ & * & G & $\bar{G}$ & * & * & * & * & $\mathrm{T}$ \\
\hline $07 \mathrm{I}$ & nd & nd & nd & $\mathrm{n}$ & nd & nd & nd & nd & nd & nd & nd & nd & nd & nd & nd & nd & nd & nd & * & * & * & * & 1 & * & * & * & * & * & * \\
\hline & $E_{n}{ }^{\prime}$ & nd & nd & nd & nd & nd & nd & nd & Ind & nd & nd & Ind & nd & nd & nd & nd & C & $\mathbf{A}$ & * & C & $\bar{T}$ & * & G & G & * & * & * & * & $T$ \\
\hline D6I & nd & 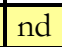 & $\mathrm{n}$ & $\mathrm{n}$ & nd & nd & nd & nd & nd & nd & nd & nd & nd & nd & nd & nd & nd & nd & nd & nd & nd & nd & * & * & * & * & * & * & * \\
\hline $1206 \mathrm{II}$ & nd & nd & nd & nd & nd & nd & nd & nd & nd & nd & nd & nd & nd & nd & nd & nd & nd & $\mathrm{A}$ & * & 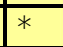 & * & * & * & * & * & * & $*$ & * & * \\
\hline$\overline{\text { GEA }}$ & nd & nd & 7 & * & $F_{*}$ & * & * & * & * & 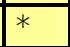 & * & * & C & * & - & $*$ & C & $\mathrm{A}$ & nd & nd & nd & nd & $\begin{array}{ll}\text { nd } \\
\end{array}$ & nd & nd & nd & nd & nd & $\overline{n d}$ \\
\hline $07 \mathrm{I}$ & nd & nd & * & $\mathrm{E}$ & * & $\left.\right|^{*}$ & $*$ & * & * & * & * & * & $\bar{C}$ & nd & nd & nd & nd & nd & nd & nd & nd & nd & nd & nd & nd & nd & nd & nd & nd \\
\hline EA15 & nd & nd & * & * & * & * & * & * & * & * & $*$ & * & C & $*$ & * & * & C & A & * & 5 & * & 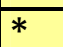 & * & $*$ & * & * & $*$ & $*$ & \\
\hline
\end{tabular}


Tabelle 76: Einzeltypisierungen cytb von Extrakten aus Knochen- und Zahn-Proben der Fundorte Jauranga, Los Molinos, La Muña und Pernil Alto

\begin{tabular}{|c|c|c|c|c|c|c|c|c|c|c|c|c|c|c|c|c|c|c|c|c|c|c|c|c|c|c|c|c|c|}
\hline & 尔 & 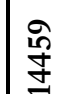 & $\underset{\mathrm{J}}{\mathrm{N}}$ & 莽 & 守 & $\begin{array}{l}\stackrel{+}{8} \\
\stackrel{\square}{g}\end{array}$ & $\stackrel{m}{\frac{9}{98}}$ & $\frac{5}{80}$ & $\begin{array}{l}\stackrel{+}{J} \\
\text { İ }\end{array}$ & 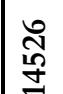 & \begin{tabular}{l}
$\infty$ \\
\multirow{N}{0}{} \\
$\stackrel{f}{ \pm}$
\end{tabular} & $\begin{array}{l}\stackrel{9}{9} \\
\text { G }\end{array}$ & 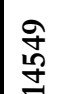 & 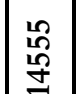 & 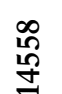 & \begin{tabular}{|l}
$\hat{\circ}$ \\
$\stackrel{8}{9}$
\end{tabular} & 柋 & İ & $\begin{array}{l}\text { त్ర్రి } \\
\text { J }\end{array}$ & 志 & గ్రి & $\begin{array}{l}\text { గొ } \\
\stackrel{\sigma}{+}\end{array}$ & 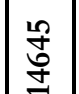 & 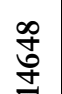 & \begin{tabular}{|l}
$\overrightarrow{i n g}$ \\
$\stackrel{0}{+}$
\end{tabular} & 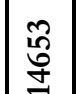 & \begin{tabular}{l}
$\hat{n}$ \\
\multirow{Z}{Z}{}
\end{tabular} & 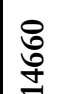 & 范 \\
\hline ef Arnason & 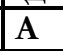 & $T$ & 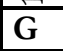 & C & $\mathbf{A}$ & $\mathrm{T}$ & $\mathrm{C}$ & $T$ & C & G & C & $T$ & $T$ & A & $T$ & A & $T$ & G & C & $T$ & $\mathrm{C}$ & C & $\mathbf{A}$ & A & $T$ & G & A & A & C \\
\hline$\overline{\mathrm{A} 2}$ & $n$ & nd & nd & $\mathrm{n}$ & nd & nd & nd & nd & nd & nd & nd & nd & nd & nd & nd & nd & & & $*$ & $\bar{x}$ & * & $*$ & 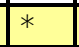 & & * & * & $*$ & * & * \\
\hline II & i & & nd & nd & nd & nd & nd & nd & nd & nd & nd & nd & nd & nd & nd & nd & nd & nd & & 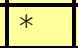 & & & $\bar{x}$ & & * & * & & $*$ & * \\
\hline & * & 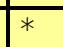 & $*$ & * & * & * & * & & $*$ & * & * & * & $*$ & 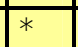 & $*$ & 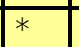 & $*$ & 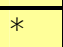 & $*$ & 3 & & $*$ & * & & * & * & * & * & * \\
\hline $\mathrm{A}$ & nd & 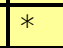 & * & * & * & 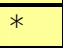 & * & * & * & * & * & 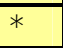 & * & $F_{7}$ & & * & & & $*$ & * & & $*$ & 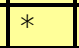 & & $*$ & * & $*$ & * & * \\
\hline II & nd & 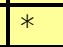 & * & * & * & * & * & * & * & * & * & * & C & nd & nd & nd & nd & nd & nd & nd & nd & nd & nd & nd & nd & nd & nd & nd & nd \\
\hline$\overline{\mathrm{TAA2} 2}$ & * & * & * & * & * & * & * & * & * & * & * & * & * & * & 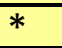 & * & $*$ & * & 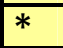 & * & * & * & * & 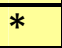 & * & * & * & * & * \\
\hline 07I & nd & $\mathrm{n}$ & nd & nd & nd & nd & Ind & nd & nd & nd & nd & nd & nd & nd & nd & nd & nd & nd & $*$ & * & * & $*$ & * & & * & * & & * & * \\
\hline 77II & $\mathrm{n}$ & & nc & nc & nd & ne & nd & nc & ne & nd & nc & $\mathrm{nc}$ & nd & nd & nd & nd & nd & nd & & & & & s. & & * & & & * & * \\
\hline & * & t & F & * & * & * & 5 & * & $*$ & * & * & * & F & * & $*$ & 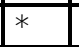 & * & * & * & * & * & 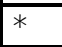 & * & * & Th & * & * & * & * \\
\hline III & nd & $*$ & * & * & * & * & * & * & $*$ & * & * & * & C & nd & nd & nd & nd & nd & nd & nd & nd & nd & nd & nd & nd & nd & nd & nd & nd \\
\hline TAA29b & * & * & E & * & * & * & * & * & - & * & * & * & * & $*$ & - & * & $E$ & $*$ & $*$ & * & $*$ & $*$ & $*$ & $*$ & * & * & * & * & * \\
\hline 07I & $\mathrm{n}$ & nd & nd & nd & nd & nd & ne & nd & nd & nd & nd & nd & nd & nd & nd & nd & nd & nd & nd & nd & nd & nd & $*$ & * & * & * & $*$ & * & * \\
\hline $77 \mathrm{II}$ & nd & 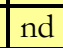 & nd & nd & nd & nd & nd & nd & nd & nd & nd & nd & nd & \begin{tabular}{|l|} 
nd \\
\end{tabular} & nd & nd & nd & nd & * & 1 & * & * & * & * & * & * & * & * & * \\
\hline & nd & t & nd & $n$ & nd & nd & nd & nd & nd & nd & nd & nd & nd & $\mathrm{d}$ & nd & nd & nd & nd & nd & nd & nd & $L^{*}$ & * & * & * & * & * & * & * \\
\hline 7II & 1 & E & * & * & * & T & * & * & 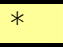 & * & * & * & $\overline{C O}$ & nd & nd & nd & nd & nd & nd & nd & nd & nd & nd & nd & nd & nd & nd & nd & nd \\
\hline JAA29 & nd & F & * & L & * & * & * & * & * & * & * & 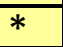 & C & nd & nd & nd & nd & nd & * & 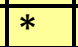 & * & * & * & * & $*$ & * & * & * & * \\
\hline MSA & * & F & 5 & 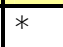 & * & - & * & * & * & * & * & $*$ & * & * & 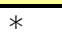 & 5 & $\bar{R}$ & * & * & * & * & $*$ & * & * & * & * & * & * & * \\
\hline $\mathrm{II} \mathrm{fr}$ & * & * & * & 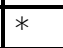 & * & * & * & * & * & * & * & * & * & * & * & * & $\bar{R}$ & * & 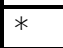 & * & * & * & * & * & * & $*$ & * & * & * \\
\hline & 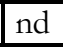 & $\mathrm{n}$ & - & 5 & nd & 8 & nd & nd & $\mathrm{nc}$ & nd & $\mathrm{n}$ & nd & nd & \begin{tabular}{|l|} 
nd \\
\end{tabular} & nd & nd & $\overline{\mathrm{R}}$ & * & * & * & * & * & F & * & * & * & * & * & * \\
\hline $\mathrm{II} \mathrm{fr}$ & * & * & * & $\left.\right|^{\prime \prime}$ & * & * & * & * & * & * & * & 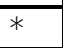 & $F$ & * & * & 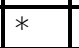 & $\bar{R}$ & * & * & * & * & * & * & * & * & * & * & * & * \\
\hline MSA & * & * & * & 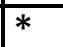 & $*$ & * & * & $*$ & * & * & * & * & * & * & $*$ & * & $\overline{\mathbf{R}}$ & $*$ & * & . & $*$ & * & * & $*$ & * & * & $*$ & * & * \\
\hline $\mathrm{MSA}$ & * & $t_{*}$ & * & 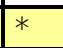 & * & $*$ & $*$ & * & * & \% & * & * & * & * & * & * & C & * & nd & nd & nd & nd & nd & nd & nd & nd & nd & nd & nd \\
\hline & 5 & & $\mathrm{n}$ & $\mathrm{n}$ & $\mathrm{nc}$ & nd & nd & 11 & nd & $\mathrm{nc}$ & $\mathrm{n}$ & nd & nd & nd & nd & nd & nd & nd & nd & \% & 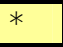 & $\frac{}{*}$ & * & $*$ & * & * & 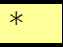 & * & * \\
\hline & $\mathrm{n}$ & $\mathrm{n}$ & 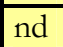 & nd & $\overline{\text { nd }}$ & ne & $\mathrm{n}$ & $\mathrm{n}$ & $\mathrm{n}$ & nd & $\mathrm{nc}$ & $\mathrm{n}$ & nd & nd & nd & nd & nd & & * & * & * & * & * & * & * & * & * & * & * \\
\hline II & * & * & * & * & * & $*$ & * & * & $\uparrow$ & * & * & * & * & * & * & * & F & $*$ & * & * & * & * & * & * & * & * & * & * & * \\
\hline 0807I & nd & 7 & * & * & 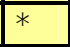 & * & * & * & - & * & * & * & * & nd & nd & nd & nd & nd & nd & nd & nd & nd & nd & nd & nd & nd & nd & nd & nd \\
\hline $87 \mathrm{II}$ & nd & $*$ & * & * & * & * & * & * & - & $*$ & * & * & * & nd & nd & nd & nd & nd & nd & nd & nd & nd & nd & nd & nd & nd & nd & nd & nd \\
\hline ISA29 & . & $*$ & * & * & * & $*$ & * & * & $*$ & * & * & * & $*$ & * & $*$ & * & $*$ & * & $*$ & * & $*$ & $*$ & * & $*$ & $*$ & * & $*$ & $*$ & * \\
\hline
\end{tabular}


Tabelle 76: Einzeltypisierungen cytb von Extrakten aus Knochen- und Zahn-Proben der Fundorte Jauranga, Los Molinos, La Muña und Pernil Alto, Fortsetzung

\begin{tabular}{|c|c|c|c|c|c|c|c|c|c|c|c|c|c|c|c|c|c|c|c|c|c|c|c|c|c|c|c|c|c|}
\hline & 黛 & 字 & $\frac{\mathbb{N}}{\mathcal{J}}$ & 苦 & $\underset{\mathcal{g}}{\stackrel{g}{g}}$ & 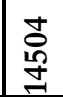 & $\stackrel{m}{\stackrel{m}{g}}$ & $\frac{5}{78}$ & 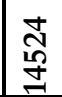 & $\begin{array}{l}\mathbb{N} \\
\stackrel{\overbrace{}}{g}\end{array}$ & 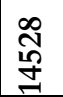 & $\begin{array}{l}\stackrel{9}{+} \\
\stackrel{9}{g}\end{array}$ & 啇 & 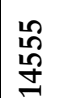 & 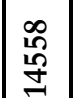 & 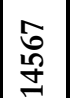 & 隹 & 趈 & స్ర్తి & 売 & 茯 & 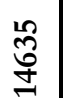 & 隹 & 离 & 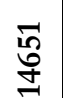 & 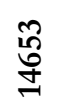 & 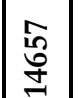 & 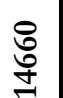 & 勇 \\
\hline son & $\mathbf{A}$ & T & G & C & A & $T$ & C & $\mathrm{T}$ & C & G & $\mathrm{C}$ & $T$ & $T$ & A & $T$ & A & $T$ & G & C & $\bar{T}$ & C & $\bar{C}$ & $\mathbf{A}$ & $\mathbf{A}$ & $\mathbf{T}$ & $\mathbf{G}$ & $\mathbf{A}$ & $\overline{\mathbf{A}}$ & C \\
\hline $6 \mathrm{II}$ & & $*$ & * & 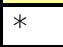 & 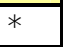 & * & * & * & & & * & $*$ & & nd & nd & nd & nd & nd & nd & nd & nd & nd & nd & nd & nd & nd & nd & nd & nd \\
\hline$\overline{\mathrm{MS} A}$ & nd & nd & nd & nd & nd & nd & nd & nd & nd & |nd & nd & nd & nd & $\mathrm{d}$ & nd & nd & nd & nd & nd & nd & & & $*$ & & & $*$ & * & $*$ & $*$ \\
\hline MSA & $\mathrm{nd}$ & & * & 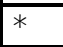 & * & 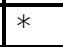 & * & * & * & $*$ & $*$ & $*$ & & d & nd & nd & nd & nd & nd & nd & nd & nd & nd & nd & nd & nd & nd & id & nd \\
\hline & Ind & nd & nd & nd & nd & nd & nd & nd & nd & nd & nd & nd & nd & nd & nd & nd & & & & & $*$ & & & $*$ & & $*$ & $*$ & $\bar{G}$ & 5 \\
\hline$\overline{\text { II }}$ & $\left.\right|^{ \pm}$ & nd & nd & nd & nd & nd & nd & nd & nd & nd & nd & nd & nd & nd & nd & nd & nd & $*$ & & $*$ & * & & $*$ & * & & * & 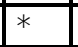 & * & * \\
\hline & nd & $*$ & $*$ & * & * & * & * & 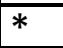 & * & * & 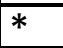 & $*$ & * & * & * & 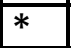 & $*$ & 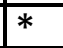 & $*$ & * & * & $*$ & * & * & * & * & * & * & * \\
\hline $06 \mathrm{~J}$ & nd & nd & nd & $\mathrm{nd}$ & $\mathrm{nd}$ & n & nd & nd & nd & nd & nd & nd & nd & nd & nd & nd & nd & nd & nd & nd & * & & * & * & * & * & * & * & * \\
\hline $807 \mathrm{I}$ & nd & * & * & * & 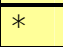 & 7 & $*$ & * & * & i* & * & * & $\bar{C}$ & nd & nd & nd & nd & nd & nd & nd & nd & id & nd & nd & nd & nd & nd & nd & nd \\
\hline $07 \mathrm{II}$ & nd & * & * & 7 & * & * & W & * & 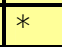 & * & * & 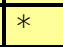 & C & nd & nd & nd & nd & nd & nd & nd & nd & nd & nd & nd & nd & nd & nd & nd & nd \\
\hline $27 \mathrm{II}$ & nd & nd & nn & $\sqrt{\mathrm{nc}}$ & nd & nd & $\bar{n}$ & nd & nd & nd & nd & $\mathrm{nc}$ & $n$ & nd & $\mathrm{n}$ & $\mathrm{d}$ & $*$ & * & * & 5 & 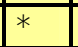 & * & $*$ & $*$ & * & $*$ & * & - & $*$ \\
\hline & nd & & $*$ & 7 & * & $*$ & $*$ & * & 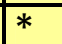 & ${ }^{*}$ & $*$ & & C & nd & nd & \begin{tabular}{|l|} 
nd \\
\end{tabular} & nd & nd & nd & nd & * & * & $*$ & * & $*$ & $*$ & * & * & * \\
\hline MAA1 & $\mathrm{nc}$ & nd & $\boldsymbol{I}$ & nd & nd & $n$ & nd & 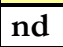 & nd & nd & dd & nd & nd & nd & nd & nd & * & 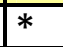 & $*$ & 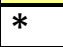 & * & * & * & * & $*$ & $*$ & * & $\overline{\mathbf{S}}$ & $\mathbf{Y}$ \\
\hline$\overline{\mathrm{AC}}$ & $\mathrm{n}$ & * & * & * & 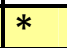 & 1 & * & * & * & * & * & * & * & nd & \begin{tabular}{|l|} 
nd \\
\end{tabular} & nd & nd & nd & nd & nd & nd & nd & nd & $\bar{d}$ & nd & nd & d & nd & nd \\
\hline $\mathrm{AO}$ & nd & $*$ & 17 & * & * & $1 \%$ & $*$ & * & $*$ & $*$ & $*$ & * & $*$ & nd & nd & nd & nd & nd & nd & nd & nd & nd & nd & nd & nd & nd & nd & nd & nd \\
\hline & nd & nd & $\mathrm{nc}$ & nc & $\mathrm{n}$ & \begin{tabular}{|l|} 
nd \\
nat
\end{tabular} & nd & nd & $\mathrm{nc}$ & Ind & nd & nd & Ind & nd & nd & nd & $*$ & * & * & * & * & * & $*$ & * & $*$ & $*$ & * & $*$ & \\
\hline & $\mathrm{n}$ & nd & $1 \mathrm{Ida}$ & $\mathrm{nd}$ & ne & nd & $\mathrm{n}$ & nd & nc & Ind & nd & Ind & IId & nd & nd & nd & * & $*$ & . & $*$ & $\bar{x}$ & & * & * & & * & * & * & \\
\hline AOA8 & nd & 更 & |* & $*$ & * & * & * & * & * & * & 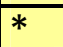 & ${ }^{*}$ & $*$ & nd & nd & nd & 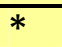 & 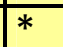 & * & * & 1 & * & $*$ & 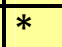 & $*$ & $*$ & * & * & * \\
\hline
\end{tabular}


Tabelle 77: Einzeltypisierungen cytb von Extrakten der Textilien des Los Molinos

\begin{tabular}{|c|c|c|c|c|c|c|c|c|c|c|c|c|c|c|c|c|c|c|c|c|c|c|c|c|c|c|c|c|c|}
\hline & 伃 & 亮 & \begin{tabular}{l}
$\mathbb{N}$ \\
\multirow{Z}{*}{}
\end{tabular} & 吾 & $\underset{\tilde{J}}{\tilde{g}}$ & 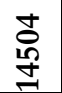 & 曽 & $\stackrel{5}{7}$ & $\begin{array}{l}\mathbb{U} \\
\stackrel{\mathbb{Z}}{+}\end{array}$ & 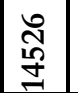 & 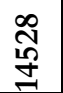 & $\begin{array}{l}\text { 导 } \\
\text { 㝵 }\end{array}$ & 高 & 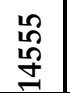 & 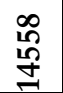 & 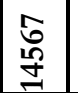 & 兽 & 恿 & 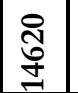 & 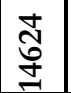 & 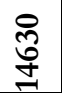 & 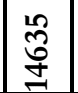 & 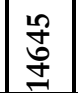 & \begin{tabular}{l}
$\infty$ \\
$\stackrel{+}{+}$ \\
\multirow{2}{*}{}
\end{tabular} & 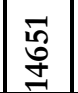 & 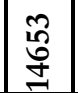 & 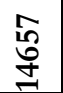 & 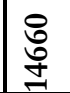 & 茓 \\
\hline Ref Arnason & A & $T$ & $\bar{G}$ & C & $\bar{A}$ & $\mathrm{~T}$ & C & $\mathrm{T}$ & $\mathrm{C}$ & G & $\mathrm{C}$ & $T$ & $T$ & $\mathbf{A}$ & $T$ & $\mathbf{A}$ & $T$ & G & C & $\mathrm{T}$ & $\bar{C}$ & C & A & $\mathbf{A}$ & $\mathrm{T}$ & G & $\mathbf{A}$ & $\mathbf{A}$ & C \\
\hline MST3b 1 & 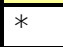 & * & $\bar{x}$ & 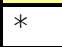 & * & - & 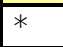 & 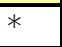 & 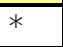 & 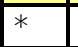 & - & * & C & G & $\mathrm{C}$ & C & $\mathrm{C}$ & $\mathrm{R}$ & 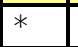 & & - & 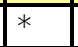 & * & * & \% & * & $\bar{G}$ & G & $\mathrm{T}$ \\
\hline MST3b 1 r & * & * & * & * & * & * & * & * & * & $*$ & 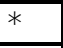 & * & C & G & $\mathrm{C}$ & C & C & $\mathrm{R}$ & * & * & * & 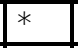 & * & * & $1 \%$ & * & $\mathrm{G}$ & G & $\mathrm{T}$ \\
\hline $\mathrm{MS}^{\prime}$ & * & * & * & * & $\bar{x}$ & 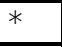 & * & & * & * & $*$ & $y$ & C & $\mathrm{G}$ & $\mathrm{C}$ & C & L & $\mathrm{R}$ & nd & nd & nd & nd & nd & nd & nd & nd & nd & nd & nd \\
\hline MST & * & F & - & * & * & * & * & * & * & * & & * & ${ }^{\circ}$ & $G$ & $\bar{C}$ & C & $\mathrm{C}$ & $\mathrm{R}$ & nd & nd & nd & nd & nd & nd & nd & nd & nd & nd & nd \\
\hline MST & * & * & * & 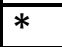 & 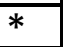 & 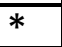 & * & * & * & * & * & * & C & $\mathbf{G}$ & $\mathrm{C}$ & C & C & $\mathbf{R}$ & * & * & * & * & * & * & * & * & G & G & $\mathbf{T}$ \\
\hline MST5c 1 & nd & * & * & * & $\bar{x}$ & $\mathrm{C}$ & $\mathrm{T}$ & $\mathrm{C}$ & * & * & G & * & C & nd & nd & nd & nd & nd & nd & nd & nd & nd & nd & nd & nd & nd & nd & nd & nd \\
\hline $\mathrm{MS}$ & nd & * & * & * & $\bar{x}$ & $\mathrm{C}$ & $\mathrm{T}$ & $\mathrm{C}$ & * & * & $\mathrm{G}$ & * & C & nd & nd & nd & nd & nd & nd & nd & nd & nd & nd & nd & nd & nd & nd & nd & nd \\
\hline MST5 & |nd & * & * & * & t & $\bar{C}$ & $T$ & $\bar{C}$ & * & * & $\bar{G}$ & * & C & nd & nd & nd & nd & \begin{tabular}{|l|l} 
nd \\
\end{tabular} & nd & nd & nd & nd & nd & nd & nd & nd & nd & nd & nd \\
\hline MST7a 2 & $\mathrm{n}$ & $\bar{x}$ & * & | & * & $\bar{C}$ & $\mathrm{~T}$ & $\bar{C}$ & 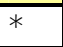 & * & G & * & C & nd & nd & nd & nd & nd & nd & nd & nd & nd & nd & nd & nd & nd & nd & nd & nd \\
\hline MST7a 4 & nd & * & * & * & * & $\mathrm{C}$ & $\mathrm{T}$ & $\mathrm{C}$ & * & * & $\mathrm{G}$ & * & C & nd & nd & nd & nd & nd & nd & nd & nd & nd & nd & nd & nd & nd & nd & nd & nd \\
\hline MS & nd & * & $*$ & * & * & $\mathrm{C}$ & $T$ & $\mathrm{C}$ & * & * & $\mathbf{G}$ & * & C & nd & nd & nd & nd & nd & nd & nd & nd & nd & nd & nd & nd & nd & nd & nd & nd \\
\hline$\overline{\mathrm{MS}^{\prime}}$ & $\mathrm{n}$ & * & * & $\sqrt{T}$ & 7 & $\bar{C}$ & $\mathrm{~T}$ & $\mathrm{C}$ & - & * & $\mathrm{G}$ & * & C & nd & nd & nd & nd & nd & nd & nd & nd & nd & nd & nd & nd & nd & nd & nd & nd \\
\hline MST9c 5 & nd & * & * & $\mathrm{T}$ & * & $\mathrm{C}$ & $\mathrm{T}$ & $\bar{C}$ & * & * & G & * & C & nd & nd & nd & nd & \begin{tabular}{|l|} 
nd \\
\end{tabular} & nd & nd & nd & nd & nd & nd & nd & nd & nd & nd & nd \\
\hline MST9c & nd & * & * & $\mathrm{T}$ & * & $\mathrm{C}$ & $\mathrm{T}$ & $\mathrm{C}$ & $\pi$ & * & $\mathrm{G}$ & * & C & nd & nd & nd & nd & nd & nd & nd & nd & nd & nd & nd & nd & nd & nd & nd & nd \\
\hline $\begin{array}{l}\text { MST11a } 2 \\
\end{array}$ & nd & nd & nd & nd & nd & nd & nd & nd & nd & nd & nd & nd & nd & nd & nd & nd & C & $\mathrm{A}$ & $\sqrt{4}$ & C & $\mathrm{T}$ & ** & $\mathrm{G}$ & $\mathrm{G}$ & * & $\left.\right|^{*}$ & * & * & $\mathrm{T}$ \\
\hline 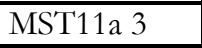 & nd & nd & nd & nd & nd & nd & nd & nd & nd & nd & nd & nd & nd & nd & nd & nd & C & $\mathrm{A}$ & $*$ & C & $\mathrm{T}$ & * & $\mathrm{G}$ & $\bar{G}$ & * & * & * & * & $\mathrm{T}$ \\
\hline MS & nd & nd & nd & nd & nd & nd & nd & nd & nd & \begin{tabular}{|l|} 
nd \\
\end{tabular} & nd & nd & \begin{tabular}{|l|l|} 
nd \\
\end{tabular} & nd & nd & nd & C & $\mathbf{A}$ & * & C & $T$ & * & G & G & * & * & $*$ & * & $\mathbf{T}$ \\
\hline $\begin{array}{l}\text { MST13e } 1 \\
\end{array}$ & nd & $*$ & * & $\mathrm{T}$ & * & $\mathrm{C}$ & $\mathrm{T}$ & $\mathrm{C}$ & * & * & $\bar{G}$ & * & C & nd & nd & nd & nd & nd & nd & nd & nd & nd & nd & nd & nd & nd & nd & nd & nd \\
\hline MST13e 4 & nd & * & * & $\mathrm{T}$ & * & $\mathrm{C}$ & $\mathrm{T}$ & $\mathrm{C}$ & 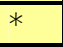 & * & $\mathrm{G}$ & * & C & nd & nd & nd & nd & nd & nd & nd & nd & nd & nd & nd & nd & nd & nd & nd & nd \\
\hline $\mathrm{MS}$ & nd & $\bar{x}$ & * & $T$ & * & $\bar{C}$ & $T$ & $\bar{C}$ & * & * & $\bar{G}$ & * & C & nd & nd & nd & nd & \begin{tabular}{l|l} 
nd \\
\end{tabular} & nd & nd & nd & nd & nd & nd & nd & nd & nd & nd & nd \\
\hline & nd & * & * & $\mathrm{T}$ & * & C & $\mathrm{T}$ & $\mathrm{C}$ & * & * & $\bar{G}$ & * & C & nd & nd & nd & nd & nd & nd & nd & nd & nd & nd & nd & nd & nd & nd & nd & nd \\
\hline $\begin{array}{l}\text { MST24a } 2 \\
\end{array}$ & nd & * & * & $\mathrm{T}$ & * & $\mathrm{C}$ & $\mathrm{T}$ & $\bar{C}$ & * & * & $\bar{G}$ & * & C & nd & nd & nd & nd & \begin{tabular}{l|l} 
nd \\
\end{tabular} & nd & nd & nd & nd & nd & nd & nd & nd & nd & nd & nd \\
\hline MST24a & nd & 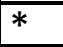 & * & $T$ & * & $\mathrm{C}$ & $T$ & $\mathrm{C}$ & $*$ & * & $\mathbf{G}$ & $*$ & C & nd & nd & nd & nd & \begin{tabular}{|l|l|} 
nd \\
\end{tabular} & nd & nd & nd & nd & nd & nd & nd & nd & nd & nd & nd \\
\hline
\end{tabular}




\begin{tabular}{|c|c|c|c|c|c|c|c|c|c|c|c|c|c|c|c|c|c|c|c|c|c|c|c|c|c|c|c|c|c|}
\hline & 隹 & 㐘 & \begin{tabular}{l}
$\mathbb{N}$ \\
\multirow{Z}{*}{}
\end{tabular} & 売 & $\underset{\tilde{J}}{\tilde{J}}$ & $\begin{array}{l}\text { 莒 } \\
\text { g }\end{array}$ & 番 & $\stackrel{5}{\frac{1}{8}}$ & $\begin{array}{l}\mathbb{J} \\
\stackrel{\mathbb{J}}{+}\end{array}$ & 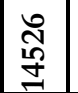 & 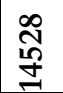 & $\begin{array}{l}\text { 导 } \\
\text { 夏 }\end{array}$ & 尌 & 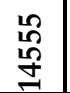 & $\begin{array}{l}\infty \\
: 0 \\
\stackrel{8}{q} \\
\end{array}$ & $\begin{array}{l}\tilde{O} \\
\stackrel{0}{\alpha} \\
\end{array}$ & 苂 & $\underset{\mathcal{J}}{\mathcal{Z}}$ & 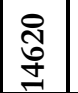 & \begin{tabular}{l}
$\mathbb{Z}$ \\
\multirow{J}{*}{} \\
\end{tabular} & 䆩 & 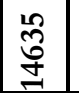 & $\begin{array}{l}\text { Po } \\
\text { d } \\
\end{array}$ & \begin{tabular}{l}
$\infty$ \\
\multirow{J}{+}{} \\
\multirow{2}{*}{}
\end{tabular} & $\begin{array}{l}\vec{i} \\
\stackrel{0}{+} \\
\end{array}$ & $\mid \begin{array}{l}n \\
0 \\
d \\
d\end{array}$ & $\begin{array}{l}\text { in } \\
\text { do } \\
\end{array}$ & 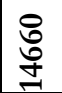 & لَّ \\
\hline Ref Arnason & A & $T$ & $\bar{G}$ & C & $\mathbf{A}$ & $\mathrm{T}$ & C & $\mathrm{T}$ & $\mathrm{C}$ & G & $\mathrm{C}$ & $T$ & $T$ & $\mathbf{A}$ & $T$ & $\mathbf{A}$ & $T$ & $\mathbf{G}$ & C & $\mathrm{T}$ & $\mathrm{C}$ & C & $\mathbf{A}$ & $\mathbf{A}$ & $T$ & G & $\mathbf{A}$ & $\mathbf{A}$ & $\mathbf{C}$ \\
\hline GET1a 1 & nd & 5 & $\bar{x}$ & $\mathrm{~T}$ & * & - & $\mathrm{T}$ & $\sqrt{e}$ & * & * & $\mathrm{C}$ & * & * & nd & nd & nd & nd & nd & nd & nd & nd & nd & nd & nd & nd & nd & nd & nd & nd \\
\hline GET1a 3 & nd & * & * & $\mathrm{T}$ & * & * & $\mathrm{T}$ & C & * & * & C & * & * & nd & nd & nd & nd & nd & nd & nd & nd & nd & nd & nd & nd & nd & nd & nd & nd \\
\hline $\mathrm{EE}$ & $\mathrm{n}$ & & * & $T$ & * & * & $T$ & C & * & * & 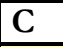 & * & * & nd & nd & nd & nd & nd & nd & nd & nd & nd & nd & nd & nd & nd & nd & nd & nd \\
\hline GET & nd & 3 & * & * & $\bar{x}$ & * & * & * & * & * & * & * & 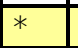 & nd & nd & nd & nd & nd & nd & nd & nd & nd & nd & nd & nd & nd & nd & nd & nd \\
\hline GET & $n$ & nd & nd & nd & nd & nd & nd & nd & nd & nd & nd & nd & nd & nd & nd & nd & $*$ & $*$ & 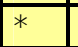 & $*$ & * & 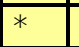 & * & * & 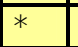 & $*$ & - & 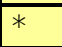 & * \\
\hline GETS & $\mathrm{n}$ & nd & nd & nd & nd & nd & nd & nd & nd & nd & nd & nd & nd & nd & nd & nd & * & * & 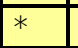 & * & * & * & * & * & * & * & * & * & * \\
\hline $\mathbf{G E}$ & nd & $\sqrt{*}$ & * & * & * & * & * & * & * & 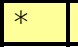 & $*$ & 4 & * & nd & nd & nd & * & * & * & * & * & * & * & * & $L$ & * & * & $*$ & * \\
\hline GE? & * & * & * & * & * & * & * & * & 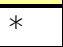 & * & * & * & * & * & $\bar{x}$ & 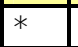 & $\mathrm{C}$ & $\mathrm{A}$ & nd & nd & nd & nd & nd & nd & nd & nd & nd & nd & nd \\
\hline GET7a 2 & * & * & * & * & * & * & 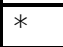 & * & * & * & * & * & * & * & * & * & $\mathrm{C}$ & $\mathrm{A}$ & nd & nd & nd & nd & nd & nd & nd & nd & nd & nd & nd \\
\hline GET7a & * & * & * & * & * & * & * & * & * & * & $*$ & * & * & * & * & * & C & $\mathbf{A}$ & nd & nd & nd & nd & nd & nd & nd & nd & nd & nd & nd \\
\hline$\overline{\mathrm{GH}}$ & nd & nd & nd & nd & nd & nd & nd & nd & nd & nd & nd & nd & nd & nd & nd & nd & C & $\mathrm{A}$ & \begin{tabular}{l|l}
$*$ & \\
\end{tabular} & C & $\mathrm{T}$ & 4 & G & $\mathrm{G}$ & * & * & * & * & $\mathrm{T}$ \\
\hline GE & nd & $\bar{d}$ & nd & nd & nd & nd & nd & nd & nd & nd & nd & nd & nd & nd & nd & nd & $\bar{C}$ & $\bar{A}$ & * & C & $\overline{\mathrm{T}}$ & * & G & $\bar{G}$ & * & * & * & * & $\mathrm{T}$ \\
\hline $\mathbf{G E}^{\prime}$ & |nd & nd & nd & nd & nd & nd & nd & nd & nd & \begin{tabular}{|l|} 
nd \\
\end{tabular} & nd & nd & \begin{tabular}{|l|} 
nd \\
\end{tabular} & nd & nd & nd & C & $\mathbf{A}$ & * & C & $T$ & $*$ & G & G & * & * & $*$ & $*$ & $\mathrm{~T}$ \\
\hline GET13a 2 & nd & $*$ & * & $\mathrm{T}$ & * & * & $\mathrm{T}$ & C & 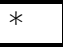 & * & C & 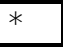 & * & nd & nd & nd & nd & nd & nd & nd & nd & nd & nd & nd & nd & nd & nd & nd & nd \\
\hline GE? & nd & * & * & $\mathrm{T}$ & * & * & $\mathrm{T}$ & C & 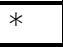 & * & C & * & $*$ & nd & nd & nd & nd & nd & nd & nd & nd & nd & nd & nd & nd & nd & nd & nd & nd \\
\hline $\mathbf{G E}^{\prime}$ & nd & * & * & $T$ & * & * & $T$ & C & + & * & C & * & - & nd & nd & nd & nd & nd & nd & nd & nd & nd & nd & nd & nd & nd & nd & nd & nd \\
\hline GE & nd & nd & nd & nd & nd & nd & nd & nd & nd & nd & nd & nd & nd & nd & nd & nd & nd & $\pi$ & 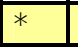 & C & $\mathrm{T}$ & * & $\mathrm{G}$ & $\mathrm{G}$ & * & * & * & * & $\bar{T}$ \\
\hline GET13e 4 & nd & nd & nd & nd & nd & nd & nd & nd & nd & nd & nd & nd & nd & nd & nd & nd & nd & * & * & C & $\mathrm{T}$ & * & $G$ & $\mathrm{G}$ & \begin{tabular}{|l}
$*$ \\
\end{tabular} & * & * & * & $\mathrm{T}$ \\
\hline GET13e & nd & nd & nd & nd & nd & nd & nd & nd & nd & nd & nd & nd & nd & nd & nd & nd & nd & * & * & C & $T$ & $*$ & G & $\mathbf{G}$ & * & $*$ & * & * & $\mathrm{T}$ \\
\hline $\mathrm{GE}$ & nd & nd & nd & nd & nd & nd & nd & nd & nd & nd & nd & nd & nd & nd & nd & nd & nd & nd & nd & nd & * & * & * & * & * & * & ${ }^{*}$ & * & * \\
\hline & nd & $*$ & * & * & $=$ & * & * & * & * & * & * & * & * & nd & nd & nd & nd & nd & nd & nd & nd & nd & nd & nd & nd & nd & nd & nd & $\mathrm{id}$ \\
\hline GET13f 4 & nd & * & * & * & * & * & * & * & * & * & * & * & * & nd & nd & nd & nd & nd & nd & nd & nd & nd & nd & nd & nd & nd & nd & nd & nd \\
\hline GET13f & nd & * & * & * & * & * & * & * & * & $\sqrt{2}$ & L & * & $\sqrt{4}$ & nd & nd & nd & nd & nd & nd & nd & & * & * & 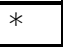 & * & * & * & & $*$ \\
\hline
\end{tabular}


Tabelle 79: Einzeltypisierunggsergebnisse rezenten Materials im Gen COI

\begin{tabular}{|c|c|c|c|c|c|c|c|c|}
\hline & 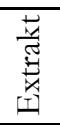 & $\overrightarrow{\tilde{f}}$ & 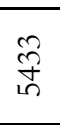 & $\stackrel{\text { Y }}{\stackrel{Y}{n}}$ & 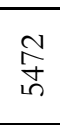 & $\begin{array}{l}\infty \\
+ \\
\dot{+}\end{array}$ & 守 & 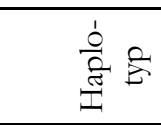 \\
\hline Referenz & & $\mathrm{C}$ & A & A & G & $\mathrm{C}$ & $\mathrm{C}$ & LA1 \\
\hline \multirow[t]{2}{*}{ La 1} & II & $*$ & $*$ & $*$ & $*$ & $*$ & $*$ & LA1 \\
\hline & III & $*$ & $*$ & $*$ & $*$ & $*$ & $*$ & LA1 \\
\hline \multirow[t]{2}{*}{ La 2} & II & $*$ & $*$ & $*$ & $*$ & $*$ & $*$ & LA1 \\
\hline & III & $*$ & $*$ & $*$ & $*$ & $*$ & $*$ & LA1 \\
\hline \multirow[t]{2}{*}{ La 3} & II & $*$ & $*$ & $*$ & $*$ & $*$ & $*$ & LA1 \\
\hline & III & $*$ & $*$ & $*$ & $*$ & $*$ & $*$ & LA1 \\
\hline \multirow[t]{2}{*}{$\mathrm{La} 4$} & II & $*$ & $*$ & $*$ & $*$ & $*$ & $*$ & LA1 \\
\hline & III & $*$ & $*$ & $*$ & $*$ & $*$ & $*$ & LA1 \\
\hline \multirow[t]{2}{*}{ La 5} & II & $*$ & $*$ & $*$ & $*$ & $*$ & $*$ & LA1 \\
\hline & III & $*$ & $*$ & $*$ & $*$ & $*$ & $*$ & LA1 \\
\hline \multirow[t]{2}{*}{$\mathrm{La} 6$} & II & $*$ & $*$ & $*$ & $*$ & $*$ & $*$ & LA1 \\
\hline & III & $*$ & $*$ & $*$ & $*$ & $*$ & $*$ & LA1 \\
\hline \multirow[t]{2}{*}{$\mathrm{La} 7$} & II & $*$ & $*$ & G & $\mathrm{A}$ & $*$ & $*$ & L1 \\
\hline & III & $*$ & $*$ & G & $\mathrm{A}$ & $*$ & $*$ & L1 \\
\hline \multirow[t]{2}{*}{ La 8} & II & $*$ & $*$ & $*$ & $*$ & $*$ & $*$ & LA1 \\
\hline & III & $*$ & $*$ & $*$ & $*$ & $*$ & $*$ & LA1 \\
\hline \multirow[t]{2}{*}{ La 9} & II & $*$ & $*$ & G & $*$ & $*$ & $*$ & LG1 \\
\hline & III & $*$ & $*$ & G & $*$ & $*$ & $*$ & LG1 \\
\hline \multirow[t]{2}{*}{ La 10} & II & $*$ & $*$ & G & $*$ & $*$ & $*$ & LG1 \\
\hline & III & $*$ & $*$ & G & $*$ & $*$ & $*$ & LG1 \\
\hline \multirow[t]{2}{*}{ Gua 1} & II & $*$ & $*$ & G & $*$ & $*$ & $*$ & LG1 \\
\hline & III & $*$ & $*$ & G & $*$ & $*$ & $*$ & LG1 \\
\hline \multirow[t]{2}{*}{ Gua 2} & II & $*$ & $*$ & $*$ & $\mathrm{~A}$ & $*$ & $*$ & G1 \\
\hline & III & $*$ & $*$ & $*$ & $\mathrm{~A}$ & $*$ & $*$ & G1 \\
\hline \multirow[t]{2}{*}{ Gua 3} & II & $*$ & $*$ & $*$ & $\mathrm{~A}$ & $*$ & $*$ & G1 \\
\hline & III & $*$ & $*$ & $*$ & A & * & $*$ & G1 \\
\hline \multirow[t]{2}{*}{ Alp1 } & II & $*$ & $*$ & $*$ & $\mathrm{~A}$ & $\mathrm{~T}$ & $\mathrm{~T}$ & AV1 \\
\hline & III & $*$ & $*$ & $*$ & $\mathrm{~A}$ & $\mathrm{~T}$ & $\mathrm{~T}$ & AV1 \\
\hline \multirow[t]{2}{*}{ Alp2 } & II & $*$ & $*$ & $*$ & $\mathrm{~A}$ & $\mathrm{~T}$ & $\mathrm{~T}$ & AV1 \\
\hline & III & $*$ & $*$ & $*$ & $\mathrm{~A}$ & $\mathrm{~T}$ & $\mathrm{~T}$ & AV1 \\
\hline \multirow[t]{2}{*}{ Alp3 } & II & $*$ & $*$ & $*$ & $\mathrm{~A}$ & $\mathrm{~T}$ & $\mathrm{~T}$ & AV1 \\
\hline & III & $*$ & $*$ & $*$ & $\mathrm{~A}$ & $\mathrm{~T}$ & $\mathrm{~T}$ & AV1 \\
\hline \multirow[t]{2}{*}{ Alp4 } & II & $\mathrm{T}$ & $*$ & $*$ & $\mathrm{~A}$ & $\mathrm{~T}$ & $\mathrm{~T}$ & AV2 \\
\hline & III & $\mathrm{T}$ & $*$ & $*$ & $\mathrm{~A}$ & $\mathrm{~T}$ & $\mathrm{~T}$ & AV2 \\
\hline \multirow[t]{2}{*}{ Alp5 } & II & $\mathrm{T}$ & $*$ & $*$ & $\mathrm{~A}$ & $\mathrm{~T}$ & $\mathrm{~T}$ & AV2 \\
\hline & III & $\mathrm{T}$ & $*$ & $*$ & $\mathrm{~A}$ & $\mathrm{~T}$ & $\mathrm{~T}$ & AV2 \\
\hline Alp6 & II & $*$ & $*$ & $*$ & $\mathrm{~A}$ & $\mathrm{~T}$ & $\mathrm{~T}$ & AV1 \\
\hline & III & $*$ & $*$ & $*$ & $\mathrm{~A}$ & $\mathrm{~T}$ & $\mathrm{~T}$ & AV1 \\
\hline Alp7 & II & $*$ & $*$ & $*$ & $*$ & $*$ & $*$ & LA1 \\
\hline & III & $*$ & $*$ & $*$ & $*$ & $*$ & $*$ & LA1 \\
\hline Alp8 & II & $*$ & $*$ & $*$ & A & $\mathrm{T}$ & $\mathrm{T}$ & AV1 \\
\hline & III & $*$ & $*$ & $*$ & A & $\mathrm{T}$ & $\mathrm{T}$ & AV1 \\
\hline Alp9 & II & $*$ & $*$ & $*$ & $*$ & $*$ & $*$ & LA1 \\
\hline & III & $*$ & $*$ & $*$ & * & $*$ & $*$ & LA1 \\
\hline Alp10 & II & $*$ & $*$ & $*$ & $*$ & $*$ & $*$ & LA1 \\
\hline & III & $*$ & $*$ & $*$ & $*$ & $*$ & $*$ & LA1 \\
\hline Alp11 & II & $*$ & $*$ & $*$ & $*$ & $*$ & $*$ & LA1 \\
\hline & III & $*$ & $*$ & $*$ & $*$ & $*$ & $*$ & LA1 \\
\hline Alp12 & II & $*$ & $*$ & $*$ & $*$ & $*$ & $*$ & LA1 \\
\hline & III & $*$ & $*$ & $*$ & $*$ & $*$ & $*$ & LA1 \\
\hline Alp14 & II & $*$ & $*$ & $*$ & $\mathrm{~A}$ & $\mathrm{~T}$ & $\mathrm{~T}$ & AV1 \\
\hline & III & $*$ & $*$ & $*$ & $\mathrm{~A}$ & $\mathrm{~T}$ & $\mathrm{~T}$ & AV1 \\
\hline
\end{tabular}


Tabelle 79: Einzeltypisierunggsergebnisse rezenten Materials im Gen COI, Fortsetzung

\begin{tabular}{|c|c|c|c|c|c|c|c|c|}
\hline & 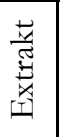 & $\overrightarrow{\tilde{g}}$ & ڤै) & $\underset{\text { Y }}{\text { In }}$ & $\frac{N}{\stackrel{N}{N}}$ & $\frac{\infty}{\dot{\infty}}$ & ڤે & 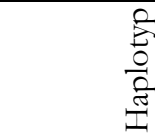 \\
\hline Referenz & & $\mathrm{C}$ & $\mathrm{A}$ & $\bar{A}$ & $G$ & $\mathrm{C}$ & $\mathrm{C}$ & LA1 \\
\hline \multirow[t]{2}{*}{ Vic1 } & II & $\mathrm{T}$ & G & $*$ & A & $\mathrm{T}$ & $\mathrm{T}$ & V1 \\
\hline & III & $\mathrm{T}$ & $\mathrm{G}$ & $*$ & A & $\mathrm{T}$ & $\mathrm{T}$ & V1 \\
\hline \multirow[t]{2}{*}{ Vic2 } & II & $*$ & $*$ & $*$ & $\mathrm{~A}$ & $\mathrm{~T}$ & $\mathrm{~T}$ & AV1 \\
\hline & III & $*$ & $*$ & * & $\mathrm{A}$ & $\mathrm{T}$ & $\mathrm{T}$ & AV1 \\
\hline \multirow[t]{2}{*}{ Vic3 } & II & $*$ & $*$ & $*$ & $\mathrm{~A}$ & $\mathrm{~T}$ & $\mathrm{~T}$ & AV1 \\
\hline & III & $*$ & $*$ & $*$ & $\mathrm{~A}$ & $\mathrm{~T}$ & $\mathrm{~T}$ & AV1 \\
\hline \multirow[t]{2}{*}{ Vic4 } & II & $*$ & $*$ & $*$ & $\mathrm{~A}$ & $\mathrm{~T}$ & $\mathrm{~T}$ & AV1 \\
\hline & III & $*$ & $*$ & $*$ & $\mathrm{~A}$ & $\mathrm{~T}$ & $\mathrm{~T}$ & AV1 \\
\hline \multirow[t]{2}{*}{ Vic5 } & II & $*$ & $*$ & $*$ & $\mathrm{~A}$ & $\mathrm{~T}$ & $\mathrm{~T}$ & AV1 \\
\hline & III & $*$ & $*$ & $*$ & A & $\mathrm{T}$ & $\mathrm{T}$ & AV1 \\
\hline \multirow[t]{2}{*}{ Vic6 } & II & $*$ & $*$ & $*$ & $\mathrm{~A}$ & $\mathrm{~T}$ & $\mathrm{~T}$ & AV1 \\
\hline & III & $*$ & $*$ & $*$ & $\mathrm{~A}$ & $\mathrm{~T}$ & $\mathrm{~T}$ & AV1 \\
\hline \multirow[t]{2}{*}{ Vic7 } & II & $*$ & $*$ & $*$ & $\mathrm{~A}$ & $\mathrm{~T}$ & $\mathrm{~T}$ & AV1 \\
\hline & III & $*$ & $*$ & $*$ & $\mathrm{~A}$ & $\mathrm{~T}$ & $\mathrm{~T}$ & AV1 \\
\hline \multirow[t]{2}{*}{ Vic8 } & II & $*$ & $*$ & $*$ & $\mathrm{~A}$ & $\mathrm{~T}$ & $\mathrm{~T}$ & AV1 \\
\hline & III & $*$ & $*$ & $*$ & $\mathrm{~A}$ & $\mathrm{~T}$ & $\mathrm{~T}$ & AV1 \\
\hline \multirow[t]{2}{*}{ Vic9 } & II & $\mathrm{T}$ & $*$ & $*$ & $\mathrm{~A}$ & $\mathrm{~T}$ & $\mathrm{~T}$ & AV2 \\
\hline & III & $\mathrm{T}$ & $*$ & $*$ & $\mathrm{~A}$ & $\mathrm{~T}$ & $\mathrm{~T}$ & AV2 \\
\hline \multirow[t]{2}{*}{ Vic10 } & II & $\mathrm{T}$ & $G$ & $*$ & A & $\mathrm{T}$ & $\mathrm{T}$ & V1 \\
\hline & III & $\mathrm{T}$ & $G$ & $*$ & A & $\mathrm{T}$ & $\mathrm{T}$ & V1 \\
\hline \multirow[t]{2}{*}{ Vic12 } & II & $*$ & $*$ & $*$ & A & $\mathrm{T}$ & $\mathrm{T}$ & AV1 \\
\hline & III & $*$ & $*$ & $*$ & A & $\mathrm{T}$ & $\mathrm{T}$ & AV1 \\
\hline \multirow[t]{2}{*}{ Vic13 } & II & $*$ & $*$ & $*$ & $\mathrm{~A}$ & $\mathrm{~T}$ & $\mathrm{~T}$ & AV1 \\
\hline & III & $*$ & $*$ & $*$ & $\mathrm{~A}$ & $\mathrm{~T}$ & $\mathrm{~T}$ & AV1 \\
\hline \multirow[t]{2}{*}{ Vic14 } & II & $*$ & $*$ & $*$ & $\mathrm{~A}$ & $\mathrm{~T}$ & $\mathrm{~T}$ & AV1 \\
\hline & III & $*$ & $*$ & * & $\mathrm{A}$ & $\mathrm{T}$ & $\mathrm{T}$ & AV1 \\
\hline \multirow[t]{2}{*}{ Vic15 } & II & $\mathrm{T}$ & $G$ & $*$ & $\mathrm{~A}$ & $\mathrm{~T}$ & $\mathrm{~T}$ & V1 \\
\hline & III & $\mathrm{T}$ & $G$ & $*$ & A & $\mathrm{T}$ & $\mathrm{T}$ & V1 \\
\hline \multirow[t]{2}{*}{ Vic16 } & II & $\mathrm{T}$ & $G$ & $*$ & A & $\mathrm{T}$ & $\mathrm{T}$ & V1 \\
\hline & III & $\mathrm{T}$ & $G$ & $*$ & A & $\mathrm{T}$ & $\mathrm{T}$ & V1 \\
\hline
\end{tabular}


Tabelle 80: Einzeltypisierunggsergebnisse des Gens COI in Extrakten des historischen Materials

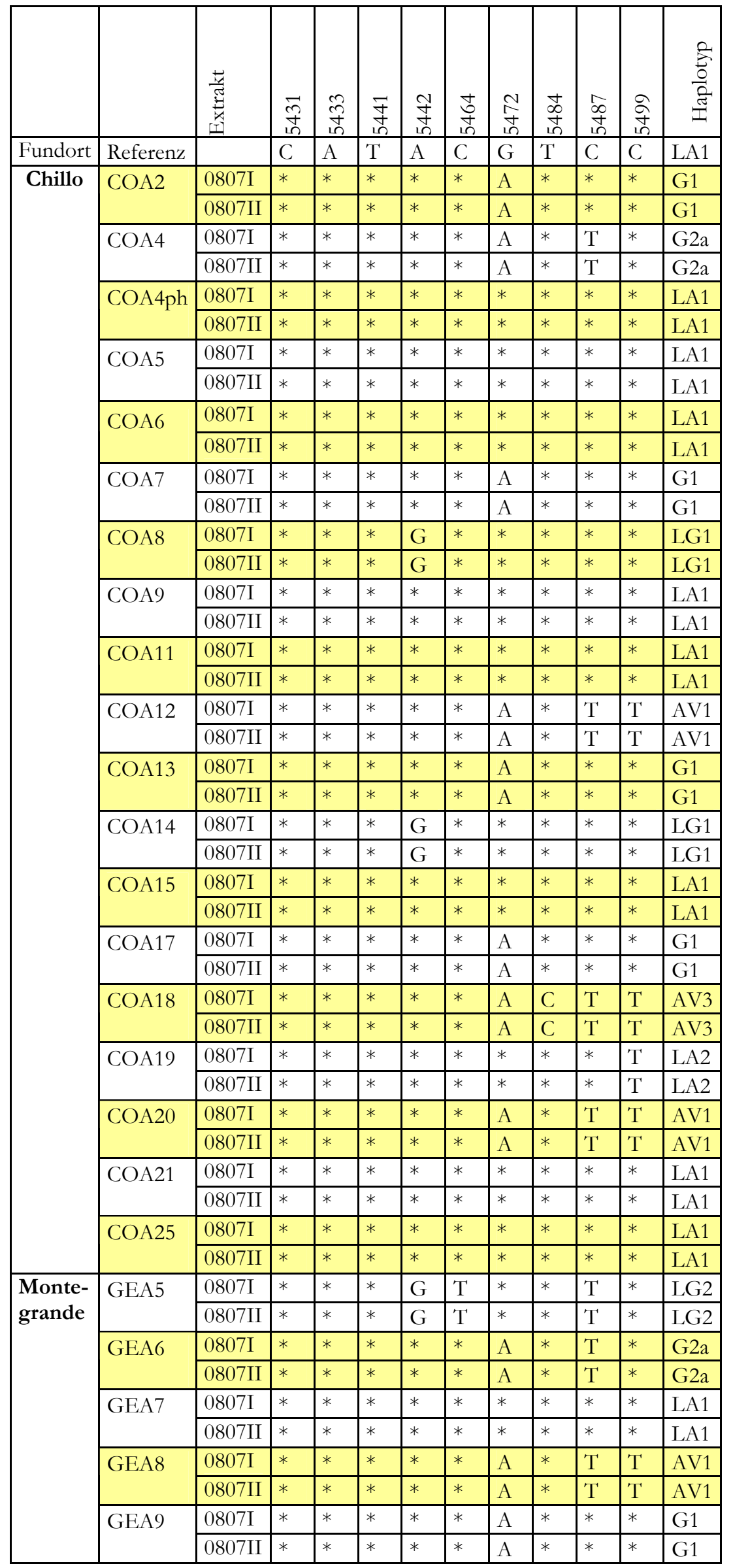


Tabelle 80: Einzeltypisierunggsergebnisse des Gens COI in Extrakten des historischen Materials, Fortsetzung

\begin{tabular}{|c|c|c|c|c|c|c|c|c|c|c|c|c|}
\hline & & 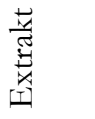 & $\underset{\stackrel{5}{+}}{\bar{H}}$ & $\stackrel{\widetilde{m}}{\tilde{H}}$ & 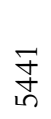 & $\underset{\stackrel{Y}{f}}{\stackrel{Y}{5}}$ & \begin{tabular}{l}
\multirow{5}{0}{} \\
ț
\end{tabular} & $\underset{\leftarrow}{\stackrel{f}{+}}$ & $\underset{\text { 市 }}{\stackrel{+}{+}}$ & 京 & 㐫 & $\frac{\overrightarrow{0}}{\frac{0}{0}}$ \\
\hline Fundort & Referenz & & $\mathrm{C}$ & $\mathrm{A}$ & $\mathrm{T}$ & A & $\mathrm{C}$ & $G$ & $\mathrm{~T}$ & $\mathrm{C}$ & $\mathrm{C}$ & LA1 \\
\hline \multirow{4}{*}{$\begin{array}{l}\text { Monte- } \\
\text { grande }\end{array}$} & \multirow[t]{2}{*}{ GEA10 } & 0807I & * & * & * & G & $*$ & * & * & * & * & LG1 \\
\hline & & 0807II & $*$ & $*$ & * & G & $*$ & $*$ & $*$ & $*$ & $*$ & LG1 \\
\hline & \multirow[t]{2}{*}{ GEA15 } & $0807 \mathrm{I}$ & $*$ & $*$ & $*$ & $\mathrm{G}$ & $*$ & $*$ & $*$ & $*$ & $*$ & LG1 \\
\hline & & 0807II & $*$ & $*$ & * & G & $*$ & $*$ & $*$ & $*$ & $*$ & LG1 \\
\hline \multirow[t]{6}{*}{ Jauranga } & \multirow[t]{2}{*}{ JAA29a } & $0807 \mathrm{I}$ & $*$ & * & * & $G$ & * & * & $*$ & * & * & LG1 \\
\hline & & 0807II & $*$ & $*$ & * & G & * & $*$ & $*$ & * & $*$ & LG1 \\
\hline & \multirow[t]{2}{*}{$\mathrm{JAA} 29 \mathrm{~b}$} & $0807 \mathrm{I}$ & $*$ & $*$ & $*$ & $G$ & $*$ & $*$ & $*$ & $*$ & $*$ & LG1 \\
\hline & & 0807II & $*$ & $*$ & $*$ & G & $*$ & $*$ & $*$ & $*$ & $*$ & LG1 \\
\hline & \multirow[t]{2}{*}{ JAA29c } & 0807I & $*$ & * & * & $G$ & * & * & $*$ & * & $*$ & LG1 \\
\hline & & 0807II & $*$ & $*$ & * & $\mathrm{G}$ & * & $*$ & $*$ & $*$ & $*$ & LG1 \\
\hline \multirow{6}{*}{$\begin{array}{c}\text { Los } \\
\text { Molinos }\end{array}$} & \multirow[t]{2}{*}{ MSA2 } & $0807 \mathrm{I}$ & $*$ & $*$ & * & $*$ & $*$ & $*$ & $*$ & $*$ & $*$ & LA1 \\
\hline & & 0807II & $*$ & $*$ & $*$ & $*$ & $*$ & $*$ & $*$ & $*$ & $*$ & LA1 \\
\hline & \multirow[t]{2}{*}{ MSA29 } & $0807 \mathrm{I}$ & $*$ & $*$ & $*$ & $*$ & * & $*$ & $*$ & $*$ & $*$ & LA1 \\
\hline & & 0807II & $*$ & $*$ & $*$ & $*$ & $*$ & $*$ & $*$ & $*$ & $*$ & LA1 \\
\hline & \multirow[t]{2}{*}{ MSA31 } & 0807I & $*$ & $*$ & $*$ & $*$ & $*$ & A & $*$ & $*$ & $*$ & G1 \\
\hline & & 0807II & $*$ & $*$ & $*$ & $*$ & $*$ & A & $*$ & $*$ & $*$ & G1 \\
\hline \multirow{2}{*}{$\begin{array}{l}\text { Pernil } \\
\text { Alto }\end{array}$} & \multirow[t]{2}{*}{ AOA8 } & 0807I & $*$ & * & $\mathrm{C}$ & G & * & $*$ & $*$ & $*$ & $*$ & LG3 \\
\hline & & 0807II & * & $*$ & $\mathrm{C}$ & G & $*$ & $*$ & $*$ & $*$ & $*$ & LG3 \\
\hline \multirow{2}{*}{$\begin{array}{c}\text { Los } \\
\text { Molinos }\end{array}$} & \multirow[t]{2}{*}{ MST7a } & 2 & $\mathrm{~T}$ & $G$ & $*$ & $*$ & $*$ & A & $*$ & $\mathrm{~T}$ & $\mathrm{~T}$ & V1 \\
\hline & & 4 & $\mathrm{~T}$ & G & $*$ & $*$ & $*$ & A & $*$ & $\mathrm{~T}$ & $\mathrm{~T}$ & V1 \\
\hline \multirow{8}{*}{$\begin{array}{l}\text { Monte- } \\
\text { grande }\end{array}$} & \multirow[t]{2}{*}{ GET7a } & 1 & $*$ & $*$ & $*$ & $*$ & $*$ & $*$ & $*$ & $*$ & $*$ & LA1 \\
\hline & & 2 & $*$ & * & $*$ & $*$ & * & * & $*$ & $*$ & $*$ & LA1 \\
\hline & \multirow[t]{2}{*}{ GET9d } & 2 & $*$ & * & $*$ & $*$ & $*$ & A & $*$ & $\mathrm{~T}$ & $\mathrm{~T}$ & AV1 \\
\hline & & 5 & $*$ & $*$ & * & $*$ & $*$ & $\mathrm{~A}$ & $*$ & $\mathrm{~T}$ & $\mathrm{~T}$ & AV1 \\
\hline & \multirow[t]{2}{*}{ GET13a } & 2 & $*$ & $*$ & $*$ & $*$ & $*$ & A & $*$ & $\mathrm{~T}$ & $\mathrm{~T}$ & AV1 \\
\hline & & 3 & $*$ & $*$ & $*$ & $*$ & $*$ & A & $*$ & $\mathrm{~T}$ & $\mathrm{~T}$ & AV1 \\
\hline & \multirow[t]{2}{*}{ GET 13f } & 3 & $*$ & $*$ & $*$ & $*$ & $*$ & $*$ & $*$ & $*$ & $*$ & LA1 \\
\hline & & 4 & $*$ & $*$ & $*$ & $*$ & $*$ & $*$ & $*$ & $*$ & $*$ & LA1 \\
\hline
\end{tabular}


Tabelle 81: Einzeltypisierungsergebnisse des Nd5-Gen in Extrakten rezenten Materials

\begin{tabular}{|c|c|c|c|c|c|c|c|c|c|c|c|c|}
\hline & 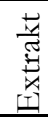 & $\stackrel{0}{\stackrel{0}{n}}$ & 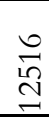 & 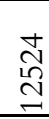 & $\begin{array}{l}\stackrel{10}{+} \\
\stackrel{1}{\Omega} \\
\end{array}$ & $\begin{array}{l}\sqrt[]{n} \\
\stackrel{n}{\Omega} \\
\end{array}$ & 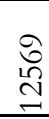 & $\begin{array}{l}N \\
\stackrel{N}{\Omega} \\
\stackrel{ }{-}\end{array}$ & \begin{tabular}{l}
10 \\
in \\
\multirow{I}{+}{}
\end{tabular} & 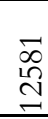 & 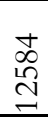 & 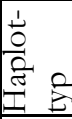 \\
\hline Referenz & & $G$ & $G$ & $\mathrm{~A}$ & $\mathrm{C}$ & $G$ & $\mathrm{C}$ & $\mathrm{C}$ & $G$ & $\mathrm{~T}$ & $G$ & LA1 \\
\hline \multirow[t]{2}{*}{ La 1} & II & * & $*$ & $*$ & * & * & $*$ & * & * & $*$ & * & LA1 \\
\hline & III & $*$ & * & $*$ & * & * & * & * & * & $*$ & * & LA1 \\
\hline \multirow[t]{2}{*}{$\mathrm{La} 2$} & II & $*$ & $*$ & $*$ & * & $*$ & $*$ & * & * & $*$ & * & LA1 \\
\hline & III & $*$ & $*$ & * & * & $*$ & $*$ & * & * & $*$ & * & LA1 \\
\hline \multirow[t]{2}{*}{ La 3} & II & $*$ & * & $*$ & $*$ & $*$ & $*$ & $*$ & * & $*$ & $*$ & LA1 \\
\hline & III & $*$ & $*$ & $*$ & * & $*$ & $*$ & * & * & $*$ & * & LA1 \\
\hline \multirow[t]{2}{*}{$\mathrm{La} 4$} & II & $*$ & $*$ & $*$ & $*$ & $*$ & $*$ & $*$ & * & $*$ & $*$ & LA1 \\
\hline & III & $*$ & $*$ & $*$ & $*$ & $*$ & $*$ & $*$ & * & $*$ & $*$ & LA1 \\
\hline \multirow[t]{2}{*}{ La 5} & II & $*$ & $*$ & $*$ & * & $*$ & $*$ & * & * & $*$ & * & LA1 \\
\hline & III & $*$ & * & $*$ & $*$ & * & $*$ & $*$ & * & $*$ & $*$ & LA1 \\
\hline \multirow[t]{2}{*}{$\operatorname{La} 6$} & II & $*$ & $\mathrm{~A}$ & $*$ & $*$ & $*$ & $*$ & $*$ & * & $*$ & $*$ & L1 \\
\hline & III & $*$ & A & $*$ & * & $*$ & $*$ & $*$ & $*$ & $*$ & * & L1 \\
\hline \multirow[t]{2}{*}{$\mathrm{La} 7$} & II & $*$ & $*$ & $*$ & * & $*$ & $*$ & * & $*$ & $\mathrm{C}$ & $*$ & LG1 \\
\hline & III & $*$ & $*$ & $*$ & $*$ & $*$ & $*$ & $*$ & $*$ & $\mathrm{C}$ & $*$ & LG1 \\
\hline \multirow[t]{2}{*}{ La 8} & II & $*$ & $*$ & $*$ & $*$ & $*$ & $*$ & $*$ & * & $*$ & $*$ & LA1 \\
\hline & III & $*$ & $*$ & $*$ & $*$ & $*$ & $*$ & $*$ & * & $*$ & $*$ & LA1 \\
\hline \multirow[t]{2}{*}{ La 9} & II & $*$ & $*$ & $*$ & $*$ & $*$ & $*$ & * & $*$ & $\mathrm{C}$ & $*$ & LG1 \\
\hline & III & $*$ & $*$ & $*$ & $*$ & $*$ & $*$ & $*$ & $*$ & $\mathrm{C}$ & $*$ & LG1 \\
\hline \multirow[t]{2}{*}{ La 10} & II & $*$ & $*$ & $*$ & $*$ & $*$ & $*$ & $*$ & $*$ & $\mathrm{C}$ & $*$ & LG1 \\
\hline & III & $*$ & $*$ & $*$ & $*$ & $*$ & $*$ & $*$ & * & $\mathrm{C}$ & $*$ & LG1 \\
\hline \multirow[t]{2}{*}{ Gua 1} & II & $*$ & $*$ & $*$ & $*$ & $*$ & $*$ & $*$ & $*$ & $\mathrm{C}$ & $*$ & LG1 \\
\hline & III & $*$ & $*$ & $*$ & $*$ & $*$ & $*$ & * & * & $\mathrm{C}$ & $*$ & LG1 \\
\hline \multirow[t]{2}{*}{ Gua 2} & II & $*$ & $*$ & $*$ & $*$ & $*$ & $*$ & $\mathrm{~T}$ & $*$ & $\mathrm{C}$ & $*$ & G1 \\
\hline & III & $*$ & $*$ & $*$ & $*$ & $*$ & $*$ & $\mathrm{~T}$ & $*$ & $\mathrm{C}$ & $*$ & G1 \\
\hline \multirow[t]{2}{*}{ Gua 3} & II & $*$ & * & $*$ & $*$ & $*$ & $*$ & $\mathrm{~T}$ & * & $\mathrm{C}$ & $*$ & G1 \\
\hline & III & $*$ & $*$ & $*$ & $*$ & $*$ & $*$ & $\mathrm{~T}$ & * & $\mathrm{C}$ & $*$ & G1 \\
\hline \multirow[t]{2}{*}{ Alp1 } & II & $*$ & $*$ & $*$ & $\mathrm{~T}$ & $\mathrm{~A}$ & $\mathrm{~T}$ & $\mathrm{~T}$ & $\mathrm{~A}$ & $*$ & * & AV1 \\
\hline & III & $*$ & $*$ & $*$ & $\mathrm{~T}$ & A & $\mathrm{T}$ & $\mathrm{T}$ & A & $*$ & $*$ & AV1 \\
\hline \multirow[t]{2}{*}{ Alp2 } & II & $*$ & $*$ & $*$ & $\mathrm{~T}$ & A & $\mathrm{T}$ & $\mathrm{T}$ & A & $*$ & * & AV1 \\
\hline & III & $*$ & $*$ & $*$ & $\mathrm{~T}$ & $\mathrm{~A}$ & $\mathrm{~T}$ & $\mathrm{~T}$ & $A$ & $*$ & $*$ & AV1 \\
\hline \multirow[t]{2}{*}{ Alp3 } & II & $*$ & $*$ & $*$ & $\overline{\mathrm{T}}$ & $\mathrm{A}$ & $\mathrm{T}$ & $\mathrm{T}$ & $\mathrm{A}$ & $*$ & $*$ & AV1 \\
\hline & III & $*$ & $*$ & $*$ & $\mathrm{~T}$ & A & $\mathrm{T}$ & $\mathrm{T}$ & $A$ & $*$ & $*$ & AV1 \\
\hline \multirow[t]{2}{*}{ Alp4 } & II & $*$ & $*$ & $*$ & $\mathrm{~T}$ & A & $\mathrm{T}$ & $\mathrm{T}$ & $\mathrm{A}$ & $*$ & $*$ & AV1 \\
\hline & III & $*$ & $*$ & $*$ & $\mathrm{~T}$ & $\mathrm{~A}$ & $\mathrm{~T}$ & $\mathrm{~T}$ & $\mathrm{~A}$ & $*$ & $*$ & AV1 \\
\hline Alp5 & II & $*$ & $*$ & $*$ & $\overline{\mathrm{T}}$ & $\mathrm{A}$ & $\mathrm{T}$ & $\mathrm{T}$ & $\mathrm{A}$ & $*$ & $*$ & AV1 \\
\hline & III & $*$ & $*$ & $*$ & $\mathrm{~T}$ & $\mathrm{~A}$ & $\mathrm{~T}$ & $\mathrm{~T}$ & $\mathrm{~A}$ & $*$ & * & AV1 \\
\hline Alp6 & II & $*$ & $*$ & $G$ & $\mathrm{~T}$ & A & $\mathrm{T}$ & $\mathrm{T}$ & $A$ & $*$ & $*$ & AV2 \\
\hline & III & $*$ & $*$ & $G$ & $\mathrm{~T}$ & A & $\mathrm{T}$ & $\mathrm{T}$ & A & $*$ & * & AV2 \\
\hline Alp7 & II & $*$ & $*$ & $*$ & $*$ & $*$ & $*$ & $*$ & $*$ & $*$ & $*$ & LA1 \\
\hline & III & $*$ & $*$ & $*$ & * & $*$ & $*$ & $*$ & $*$ & $*$ & * & LA1 \\
\hline Alp8 & II & $*$ & $*$ & $G$ & $\mathrm{~T}$ & A & $\mathrm{T}$ & $\mathrm{T}$ & $A$ & $*$ & $*$ & AV2 \\
\hline & III & $*$ & $*$ & $G$ & $\mathrm{~T}$ & A & $\mathrm{T}$ & $\mathrm{T}$ & $\mathrm{A}$ & $*$ & $*$ & AV2 \\
\hline Alp9 & II & $*$ & $*$ & $*$ & $*$ & $*$ & $*$ & $*$ & * & $*$ & * & LA1 \\
\hline & III & $*$ & $*$ & $*$ & $*$ & $*$ & $*$ & $*$ & $*$ & $*$ & $*$ & LA1 \\
\hline Alp10 & II & $*$ & $*$ & $*$ & $*$ & $*$ & $*$ & $*$ & $*$ & $*$ & $*$ & LA1 \\
\hline & III & $*$ & $*$ & $*$ & $*$ & $*$ & $*$ & $*$ & $*$ & $*$ & $*$ & LA1 \\
\hline Alp11 & II & $*$ & $*$ & $*$ & $*$ & $*$ & $*$ & $*$ & * & $\mathrm{C}$ & A & A1 \\
\hline & III & $*$ & * & $*$ & * & $*$ & $*$ & $*$ & $*$ & $\mathrm{C}$ & $\mathrm{A}$ & A1 \\
\hline Alp12 & II & $*$ & $*$ & $*$ & $*$ & $*$ & $*$ & $*$ & $*$ & $\mathrm{C}$ & A & A1 \\
\hline & III & $*$ & $*$ & $*$ & * & $*$ & $*$ & * & $*$ & $\mathrm{C}$ & $\mathrm{A}$ & A1 \\
\hline
\end{tabular}


Tabelle 81: Einzeltypisierungsergebnisse des Nd5-Gens in Extrakten rezenten Materials, Fortsetzung

\begin{tabular}{|c|c|c|c|c|c|c|c|c|c|c|c|c|}
\hline & 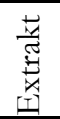 & 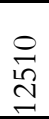 & 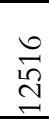 & 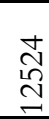 & 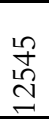 & 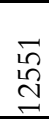 & 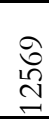 & $\begin{array}{l}\stackrel{N}{N} \\
\stackrel{2}{\sim}\end{array}$ & $\begin{array}{l}\text { in } \\
i n \\
\stackrel{1}{ \pm} \\
\end{array}$ & 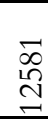 & 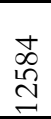 & 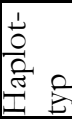 \\
\hline Referenz & & G & $G$ & $\mathrm{~A}$ & $\mathrm{C}$ & $G$ & $\mathrm{C}$ & $\mathrm{C}$ & $G$ & $\mathrm{~T}$ & G & LA1 \\
\hline \multirow[t]{2}{*}{ Alp13 } & II & * & & G & $\mathrm{T}$ & A & $\mathrm{T}$ & $\mathrm{T}$ & A & $*$ & * & $\overline{\mathrm{AV} 2}$ \\
\hline & III & * & * & $\mathrm{G}$ & $\mathrm{T}$ & A & $\mathrm{T}$ & $\mathrm{T}$ & A & $*$ & * & AV2 \\
\hline \multirow[t]{2}{*}{ Alp14 } & II & * & $*$ & $G$ & $\mathrm{~T}$ & $\mathrm{~A}$ & $\mathrm{~T}$ & $\mathrm{~T}$ & $\mathrm{~A}$ & $*$ & $*$ & $\mathrm{AV2}$ \\
\hline & III & * & * & $G$ & $\mathrm{~T}$ & $\mathrm{~A}$ & $\mathrm{~T}$ & $\mathrm{~T}$ & $\mathrm{~A}$ & $*$ & $*$ & AV2 \\
\hline \multirow[t]{2}{*}{ Vic1 } & II & * & 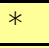 & $\uparrow$ & $\mathrm{T}$ & $\mathrm{A}$ & $\mathrm{T}$ & $\mathrm{T}$ & $\mathrm{A}$ & $*$ & * & AV1 \\
\hline & III & $*$ & $*$ & $*$ & $\mathrm{~T}$ & $\mathrm{~A}$ & $\mathrm{~T}$ & $\mathrm{~T}$ & A & $*$ & * & AV1 \\
\hline \multirow[t]{2}{*}{ Vic2 } & II & * & * & G & $\mathrm{T}$ & $\mathrm{A}$ & $\bar{T}$ & $\overline{\mathrm{T}}$ & $\mathrm{A}$ & $*$ & * & AV2 \\
\hline & III & $*$ & $*$ & $G$ & $\mathrm{~T}$ & $\mathrm{~A}$ & $\mathrm{~T}$ & $\mathrm{~T}$ & $\mathrm{~A}$ & $*$ & $*$ & AV2 \\
\hline \multirow[t]{2}{*}{ Vic3 } & II & $*$ & $*$ & G & $\mathrm{T}$ & A & $\mathrm{T}$ & $\mathrm{T}$ & A & $*$ & * & AV2 \\
\hline & III & $*$ & $*$ & G & $\mathrm{T}$ & A & $\mathrm{T}$ & $\mathrm{T}$ & A & $*$ & * & AV2 \\
\hline \multirow[t]{2}{*}{ Vic4 } & II & $*$ & $*$ & G & $\mathrm{T}$ & $\mathrm{A}$ & $\mathrm{T}$ & $\mathrm{T}$ & A & * & * & AV2 \\
\hline & III & $*$ & * & G & $\mathrm{T}$ & $\mathrm{A}$ & $\mathrm{T}$ & $\mathrm{T}$ & $\mathrm{A}$ & $*$ & $*$ & AV2 \\
\hline \multirow[t]{2}{*}{ Vic5 } & II & $*$ & $*$ & $G$ & $\mathrm{~T}$ & $\mathrm{~A}$ & $\mathrm{~T}$ & $\mathrm{~T}$ & $\mathrm{~A}$ & $*$ & * & AV2 \\
\hline & III & $*$ & $*$ & $G$ & $\mathrm{~T}$ & $\mathrm{~A}$ & $\mathrm{~T}$ & $\mathrm{~T}$ & $\mathrm{~A}$ & $*$ & $*$ & AV2 \\
\hline \multirow[t]{2}{*}{$\overline{\text { Vic6 }}$} & II & $*$ & $*$ & $G$ & $\mathrm{~T}$ & $\mathrm{~A}$ & $\mathrm{~T}$ & $\mathrm{~T}$ & $\mathrm{~A}$ & $*$ & $*$ & AV2 \\
\hline & III & $*$ & $*$ & G & $\mathrm{T}$ & $\mathrm{A}$ & $\mathrm{T}$ & $\mathrm{T}$ & A & $*$ & * & AV2 \\
\hline \multirow[t]{2}{*}{ Vic7 } & II & $*$ & $*$ & $G$ & $\mathrm{~T}$ & $\mathrm{~A}$ & $\mathrm{~T}$ & $\mathrm{~T}$ & A & $*$ & $*$ & AV2 \\
\hline & III & $*$ & $*$ & G & $\mathrm{T}$ & A & $\mathrm{T}$ & $\mathrm{T}$ & A & $*$ & $*$ & AV2 \\
\hline \multirow[t]{2}{*}{ Vic8 } & II & $*$ & $*$ & $G$ & $\mathrm{~T}$ & A & $\mathrm{T}$ & $\mathrm{T}$ & $\mathrm{A}$ & $*$ & $*$ & AV2 \\
\hline & III & $*$ & $*$ & $G$ & $\mathrm{~T}$ & A & $\mathrm{T}$ & $\mathrm{T}$ & A & $*$ & $*$ & AV2 \\
\hline \multirow[t]{2}{*}{ Vic9 } & II & $*$ & $*$ & $G$ & $\mathrm{~T}$ & $\mathrm{~A}$ & $\mathrm{~T}$ & $\mathrm{~T}$ & $\mathrm{~A}$ & $*$ & $*$ & AV2 \\
\hline & III & $*$ & $*$ & $G$ & $\mathrm{~T}$ & $\mathrm{~A}$ & $\mathrm{~T}$ & $\mathrm{~T}$ & A & $*$ & $*$ & AV2 \\
\hline \multirow[t]{2}{*}{ Vic10 } & II & $\mathrm{C}$ & $*$ & $*$ & $\mathrm{~T}$ & $\mathrm{~A}$ & $\mathrm{~T}$ & $\mathrm{~T}$ & $\mathrm{~A}$ & $*$ & $*$ & V1 \\
\hline & III & $\mathrm{C}$ & $*$ & $*$ & $\mathrm{~T}$ & A & $\mathrm{T}$ & $\mathrm{T}$ & $\mathrm{A}$ & $*$ & $*$ & V1 \\
\hline \multirow[t]{2}{*}{ Vic11 } & II & $*$ & * & * & $\mathrm{T}$ & $\mathrm{A}$ & $\mathrm{T}$ & $\mathrm{T}$ & A & $*$ & $*$ & AV1 \\
\hline & III & $*$ & $*$ & $*$ & $\mathrm{~T}$ & $\mathrm{~A}$ & $\mathrm{~T}$ & $\mathrm{~T}$ & $\mathrm{~A}$ & $*$ & $*$ & AV1 \\
\hline \multirow[t]{2}{*}{ Vic12 } & II & $*$ & $*$ & $G$ & $\mathrm{~T}$ & $\mathrm{~A}$ & $\mathrm{~T}$ & $\mathrm{~T}$ & $\mathrm{~A}$ & $*$ & $*$ & AV2 \\
\hline & III & $*$ & $*$ & G & $\mathrm{T}$ & A & $\mathrm{T}$ & $\mathrm{T}$ & A & $*$ & $*$ & AV2 \\
\hline \multirow[t]{2}{*}{ Vic13 } & II & $*$ & $*$ & G & $\mathrm{T}$ & A & $\mathrm{T}$ & $\mathrm{T}$ & A & $*$ & $*$ & AV2 \\
\hline & III & $*$ & $*$ & $G$ & $\mathrm{~T}$ & $\mathrm{~A}$ & $\mathrm{~T}$ & $\mathrm{~T}$ & $\mathrm{~A}$ & $*$ & $*$ & AV2 \\
\hline \multirow[t]{2}{*}{ Vic14 } & II & $*$ & $*$ & $G$ & $\mathrm{~T}$ & $\mathrm{~A}$ & $\mathrm{~T}$ & $\mathrm{~T}$ & $\mathrm{~A}$ & $*$ & $*$ & AV2 \\
\hline & III & $*$ & $*$ & $G$ & $\mathrm{~T}$ & $\mathrm{~A}$ & $\mathrm{~T}$ & $\mathrm{~T}$ & $\mathrm{~A}$ & $*$ & $*$ & AV2 \\
\hline \multirow[t]{2}{*}{ Vic15 } & II & $*$ & $*$ & $*$ & $\mathrm{~T}$ & $\mathrm{~A}$ & $\mathrm{~T}$ & $\mathrm{~T}$ & $\mathrm{~A}$ & $*$ & $*$ & AV1 \\
\hline & III & $*$ & $*$ & $*$ & $\mathrm{~T}$ & A & $\mathrm{T}$ & $\mathrm{T}$ & A & $*$ & $*$ & AV1 \\
\hline \multirow[t]{2}{*}{ Vic16 } & II & $*$ & $*$ & $*$ & $\mathrm{~T}$ & $\mathrm{~A}$ & $\mathrm{~T}$ & $\mathrm{~T}$ & $\mathrm{~A}$ & $*$ & $*$ & AV1 \\
\hline & III & $*$ & $*$ & $*$ & $\mathrm{~T}$ & $\mathrm{~A}$ & $\mathrm{~T}$ & $\mathrm{~T}$ & $\mathrm{~A}$ & $*$ & $*$ & AV1 \\
\hline
\end{tabular}


Tabelle 82: Einzeltypisierungen des Nd5-Gens in Extrakten des historischen Materials

\begin{tabular}{|c|c|c|c|c|c|c|c|c|c|c|c|c|c|c|c|}
\hline & & 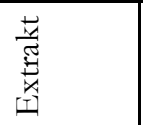 & $\stackrel{\stackrel{ }{コ}}{\stackrel{\text { In }}{\longrightarrow}}$ & 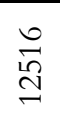 & 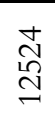 & 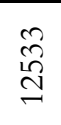 & 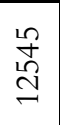 & $\begin{array}{l}\overrightarrow{i n} \\
\stackrel{\sim}{N} \\
\stackrel{-}{I}\end{array}$ & \begin{tabular}{l}
$\hat{\sigma}$ \\
$\stackrel{\leftrightarrow}{\cong}$ \\
\multirow{}{*}{}
\end{tabular} & $\begin{array}{l}\mathfrak{N} \\
\stackrel{N}{\simeq} \\
\stackrel{\sim}{\sim}\end{array}$ & 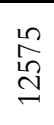 & 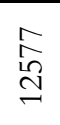 & $\begin{array}{l}\vec{\infty} \\
\stackrel{1}{\sim} \\
\sim\end{array}$ & $\begin{array}{l}\stackrel{+}{\infty} \\
\stackrel{\leftrightarrow}{n} \\
\stackrel{\sim}{\longrightarrow}\end{array}$ & $\begin{array}{l}\text { 柋 } \\
0 \\
0 \\
\text { 荡 }\end{array}$ \\
\hline Fundort & Referenz & & $G$ & $G$ & A & $\mathrm{C}$ & $\mathrm{C}$ & $G$ & $\mathrm{C}$ & $\mathrm{C}$ & $G$ & $\mathrm{C}$ & $\mathrm{T}$ & $G$ & LA1 \\
\hline \multirow[t]{34}{*}{ Chillo } & \multirow[t]{2}{*}{ COA2 } & 0807I & * & $*$ & * & * & $*$ & $*$ & $*$ & $*$ & * & * & $*$ & * & LA1 \\
\hline & & 0807II & $*$ & $*$ & $*$ & $*$ & $*$ & $*$ & $*$ & $*$ & $*$ & $*$ & $*$ & $*$ & LA1 \\
\hline & COA4 & 0807I & $*$ & $*$ & $*$ & $*$ & $*$ & $*$ & $*$ & $*$ & $*$ & $*$ & $*$ & $*$ & LA1 \\
\hline & & 0807II & $*$ & $*$ & * & $*$ & $*$ & $*$ & $*$ & $*$ & * & $*$ & $*$ & $*$ & LA1 \\
\hline & \begin{tabular}{|l|}
$\mathrm{COA} 4 \mathrm{ph}$ \\
\end{tabular} & 0807I & $*$ & $*$ & * & $*$ & $*$ & $*$ & $*$ & $*$ & $*$ & $*$ & $\mathrm{C}$ & $*$ & LG1 \\
\hline & & 0807II & $*$ & $*$ & $*$ & $*$ & $*$ & $*$ & $*$ & $*$ & $*$ & $*$ & $\mathrm{C}$ & $*$ & LG1 \\
\hline & COA5 & 0807I & $*$ & $*$ & $*$ & $*$ & $*$ & $*$ & $*$ & $*$ & $*$ & $\mathrm{~T}$ & $*$ & $*$ & L2 \\
\hline & & 0807II & $*$ & $*$ & * & $*$ & $*$ & $*$ & * & $*$ & $*$ & $\mathrm{~T}$ & $*$ & * & L2 \\
\hline & COA6 & 0807I & $*$ & $*$ & $*$ & $*$ & $*$ & $*$ & $*$ & $*$ & $*$ & $*$ & $*$ & $*$ & LA1 \\
\hline & & 0807II & $*$ & $*$ & $*$ & $*$ & $*$ & $*$ & $*$ & $*$ & $*$ & $*$ & $*$ & $*$ & LA1 \\
\hline & COA8 & 0807I & * & $*$ & $*$ & $*$ & $*$ & $*$ & $*$ & $*$ & $*$ & $*$ & $\mathrm{C}$ & $*$ & LG1 \\
\hline & & 0807II & $*$ & $*$ & $*$ & $*$ & $*$ & $*$ & $*$ & $*$ & $*$ & * & $\mathrm{C}$ & $*$ & LG1 \\
\hline & COA9 & 0807I & $*$ & $*$ & * & $*$ & $*$ & $*$ & $*$ & $*$ & $*$ & * & $*$ & $*$ & LA1 \\
\hline & & 0807II & $*$ & $*$ & $*$ & $*$ & $*$ & $*$ & $*$ & $*$ & $*$ & $*$ & $*$ & $*$ & LA1 \\
\hline & COA11 & 0807I & $*$ & $*$ & $*$ & $*$ & $*$ & $*$ & $*$ & $*$ & $*$ & $*$ & $\mathrm{C}$ & $*$ & LG1 \\
\hline & & 0807II & $*$ & $*$ & $*$ & $*$ & $*$ & $*$ & $*$ & $*$ & $*$ & $*$ & $\mathrm{C}$ & $*$ & LG1 \\
\hline & COA12 & 0807I & $*$ & $*$ & $G$ & $*$ & $\mathrm{~T}$ & A & $\mathrm{T}$ & $\mathrm{T}$ & A & $*$ & $*$ & $\mathrm{~A}$ & AV3 \\
\hline & & 0807II & $*$ & $*$ & G & $*$ & $\mathrm{~T}$ & A & $\mathrm{T}$ & $\mathrm{T}$ & A & $*$ & $*$ & $\mathrm{~A}$ & AV3 \\
\hline & COA13 & 0807I & $*$ & $*$ & $*$ & $*$ & $*$ & $*$ & $*$ & $*$ & $*$ & $*$ & $*$ & $*$ & LA1 \\
\hline & & 0807II & $*$ & $*$ & $*$ & $*$ & $*$ & $*$ & $*$ & $*$ & $*$ & $*$ & $*$ & $*$ & LA1 \\
\hline & COA14 & 0807I & $*$ & $*$ & $*$ & $\mathrm{~T}$ & $*$ & $*$ & $*$ & $*$ & $*$ & $*$ & $\mathrm{C}$ & $*$ & L3 \\
\hline & & 0807II & $*$ & $*$ & $*$ & $\mathrm{~T}$ & $*$ & $*$ & $*$ & $*$ & $*$ & $*$ & $\mathrm{C}$ & $*$ & L3 \\
\hline & COA15 & 0807I & $*$ & $*$ & $*$ & $*$ & $*$ & $*$ & $*$ & $*$ & $*$ & $*$ & $\mathrm{C}$ & $*$ & LG1 \\
\hline & & 0807II & $*$ & $*$ & $*$ & $*$ & $*$ & $*$ & $*$ & $*$ & $*$ & $*$ & $\mathrm{C}$ & $*$ & LG1 \\
\hline & COA18 & 0807I & $*$ & $*$ & $G$ & $*$ & $\mathrm{~T}$ & $\mathrm{~A}$ & $\mathrm{~T}$ & $\mathrm{~T}$ & A & $*$ & $*$ & $*$ & AV2 \\
\hline & & 0807II & $*$ & $*$ & $G$ & $*$ & $\mathrm{~T}$ & $\mathrm{~A}$ & $\mathrm{~T}$ & $\mathrm{~T}$ & $\mathrm{~A}$ & $*$ & $*$ & $*$ & AV2 \\
\hline & COA19 & 0807I & $*$ & $*$ & $*$ & $*$ & $*$ & $*$ & $*$ & $*$ & $*$ & * & $\mathrm{C}$ & $*$ & LG1 \\
\hline & & 0807II & $*$ & $*$ & $*$ & $*$ & $*$ & $*$ & $*$ & $*$ & $*$ & $*$ & $\mathrm{C}$ & $*$ & LG1 \\
\hline & COA20 & 0807I & $*$ & $*$ & $G$ & $*$ & $\mathrm{~T}$ & $\mathrm{~A}$ & $\mathrm{~T}$ & $\mathrm{~T}$ & $\mathrm{~A}$ & $*$ & $*$ & $*$ & AV2 \\
\hline & & 0807II & $*$ & $*$ & $G$ & $*$ & $\mathrm{~T}$ & A & $\mathrm{T}$ & $\mathrm{T}$ & A & $*$ & $*$ & $*$ & AV2 \\
\hline & \begin{tabular}{|l} 
COA21 \\
\end{tabular} & 0807I & $*$ & $*$ & $*$ & $*$ & $*$ & $*$ & $*$ & $*$ & $*$ & $*$ & $*$ & $*$ & LA1 \\
\hline & & 0807II & $*$ & $*$ & $*$ & $*$ & $*$ & $*$ & $*$ & $*$ & $*$ & $*$ & $*$ & $*$ & LA1 \\
\hline & COA25 & 0807I & $*$ & $*$ & $*$ & $*$ & $*$ & $*$ & $*$ & $*$ & $*$ & $*$ & $\mathrm{C}$ & $*$ & LG1 \\
\hline & & 0807II & $*$ & $*$ & $*$ & $*$ & $*$ & $*$ & $*$ & $*$ & $*$ & $*$ & $\mathrm{C}$ & $*$ & LG1 \\
\hline Monte- & GEA6 & 0807I & $*$ & $*$ & $*$ & $*$ & $*$ & $*$ & $*$ & $*$ & $*$ & $*$ & $*$ & $*$ & LA1 \\
\hline grande & & 0807II & $*$ & $*$ & $*$ & $*$ & $*$ & $*$ & $*$ & $*$ & $*$ & $*$ & $*$ & $*$ & LA1 \\
\hline & GEA8 & 0807I & $*$ & $*$ & $G$ & $*$ & $\mathrm{~T}$ & $\mathrm{~A}$ & $\mathrm{~T}$ & $\mathrm{~T}$ & $\mathrm{~A}$ & $*$ & $*$ & $*$ & AV2 \\
\hline & & 0807II & $*$ & $*$ & $G$ & $*$ & $\mathrm{~T}$ & $\mathrm{~A}$ & $\mathrm{~T}$ & $\mathrm{~T}$ & $\mathrm{~A}$ & $*$ & $*$ & $*$ & AV2 \\
\hline & GEA10 & 0807I & $*$ & $*$ & $*$ & $*$ & $*$ & $*$ & $*$ & $*$ & $*$ & $*$ & $\mathrm{C}$ & $\mathrm{R}$ & A1 \\
\hline & & $0807 \mathrm{I} \mathrm{r}$ & $*$ & $*$ & $*$ & $*$ & $*$ & $*$ & $*$ & $*$ & $*$ & $*$ & $\mathrm{C}$ & $\mathrm{R}$ & A1 \\
\hline & & 0807II & $*$ & $*$ & $*$ & $*$ & $*$ & $*$ & $*$ & $*$ & $*$ & $*$ & $\mathrm{C}$ & $\mathrm{R}$ & A1 \\
\hline & & 0807II r & $*$ & $*$ & $*$ & $*$ & $*$ & $*$ & $*$ & $*$ & $*$ & $*$ & $\mathrm{C}$ & $\mathrm{R}$ & A1 \\
\hline & GEA15 & 0807I & $*$ & $*$ & * & $*$ & $*$ & $*$ & $*$ & $*$ & $*$ & $*$ & $\mathrm{C}$ & $*$ & LG1 \\
\hline & & 0807II & $*$ & $*$ & * & * & * & * & * & $*$ & * & * & $\mathrm{C}$ & $*$ & LG1 \\
\hline Jauranga & JAA29a & 0807I & $*$ & $*$ & $*$ & $*$ & $*$ & $*$ & $*$ & $*$ & $*$ & $*$ & $\mathrm{C}$ & $*$ & LG1 \\
\hline & & 0807II & $*$ & $*$ & $*$ & $*$ & $*$ & $*$ & $*$ & $*$ & $*$ & $*$ & $\mathrm{C}$ & $*$ & LG1 \\
\hline & JAA29b & 0807I & $*$ & $*$ & $*$ & $*$ & $*$ & $*$ & $*$ & $*$ & $*$ & $*$ & $\mathrm{C}$ & $*$ & LG1 \\
\hline & & 0807II & $*$ & $*$ & $*$ & * & $*$ & * & * & $*$ & $*$ & $*$ & $\mathrm{C}$ & $*$ & LG1 \\
\hline & JAA29c & 0807I & $*$ & $*$ & $*$ & $*$ & $*$ & $*$ & $*$ & $*$ & $*$ & $*$ & $\mathrm{C}$ & $*$ & LG1 \\
\hline & & 0807II & $*$ & $*$ & $*$ & * & $*$ & $*$ & * & $*$ & $*$ & $*$ & $\mathrm{C}$ & $*$ & LG1 \\
\hline
\end{tabular}


Tabelle 82: Einzeltypisierungen des Nd5-Gnes in Extrakten des historischen Materials, Fortsetzung

\begin{tabular}{|c|c|c|c|c|c|c|c|c|c|c|c|c|c|c|c|}
\hline & & 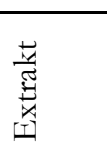 & $\stackrel{0}{\stackrel{0}{\mathfrak{n}}}$ & $\begin{array}{l}\text { 믐 } \\
\stackrel{\text { I }}{\sim}\end{array}$ & 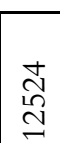 & 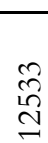 & 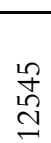 & $\begin{array}{l}\sqrt{n} \\
\stackrel{1}{\Im} \\
\end{array}$ & 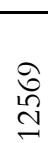 & 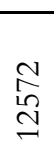 & $\begin{array}{l}n \\
\stackrel{10}{2} \\
\stackrel{1}{I}\end{array}$ & 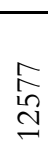 & $\begin{array}{l}\vec{\infty} \\
\stackrel{1}{\Omega} \\
\end{array}$ & $\begin{array}{l}+ \\
\infty \\
\stackrel{1}{త} \\
\text { I }\end{array}$ & 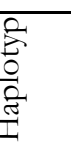 \\
\hline Fundort & Referenz & & G & $G$ & A & $\mathrm{C}$ & $\mathrm{C}$ & G & $\mathrm{C}$ & $\mathrm{C}$ & G & $\mathrm{C}$ & $\mathrm{T}$ & G & LA1 \\
\hline \multirow{10}{*}{$\begin{array}{c}\text { Los } \\
\text { Molinos }\end{array}$} & MSA2 & 0807I & $*$ & * & * & $*$ & * & $*$ & * & $*$ & $*$ & * & $*$ & $*$ & LA1 \\
\hline & & 0807II & $*$ & $*$ & $*$ & $*$ & $*$ & $*$ & $*$ & $*$ & $*$ & $*$ & $*$ & $*$ & LA1 \\
\hline & MSA29 & 0807I & $*$ & $*$ & $*$ & $*$ & * & $*$ & $*$ & $*$ & $*$ & * & * & $*$ & LA1 \\
\hline & & 0807II & $*$ & $*$ & * & $*$ & $*$ & $*$ & $*$ & $*$ & $*$ & $*$ & $*$ & $*$ & LA1 \\
\hline & MSA30 & 0807I & $*$ & $*$ & * & $*$ & $*$ & * & $*$ & $*$ & * & * & $*$ & $*$ & LA1 \\
\hline & & 0807II & $*$ & $*$ & * & $*$ & $*$ & * & * & $*$ & * & $*$ & $*$ & $*$ & LA1 \\
\hline & MSA31 & 0807I & $*$ & $*$ & $*$ & $*$ & $*$ & $*$ & $*$ & $*$ & $\mathrm{~T}$ & $*$ & $\mathrm{C}$ & $*$ & G1 \\
\hline & & 0807II & $*$ & $*$ & $*$ & $*$ & $*$ & $*$ & $*$ & $*$ & $\mathrm{~T}$ & $*$ & $\mathrm{C}$ & $*$ & G1 \\
\hline & MST13e & 1 & $*$ & $*$ & $G$ & $*$ & $\mathrm{~T}$ & $\mathrm{~A}$ & $\mathrm{~T}$ & $\mathrm{~T}$ & A & * & $*$ & $*$ & AV2 \\
\hline & & 4 & $*$ & $*$ & $G$ & $*$ & $\mathrm{~T}$ & $\mathrm{~A}$ & $\mathrm{~T}$ & $\mathrm{~T}$ & A & $*$ & $*$ & $*$ & AV2 \\
\hline \multirow{4}{*}{$\begin{array}{l}\text { Monte- } \\
\text { grande }\end{array}$} & GET9d & 2 & $*$ & $*$ & $*$ & $*$ & $*$ & $*$ & $*$ & $*$ & $*$ & $*$ & $*$ & $*$ & LA1 \\
\hline & & 5 & $*$ & $*$ & $*$ & $*$ & $*$ & $*$ & $*$ & $*$ & $*$ & $*$ & $*$ & $*$ & LA1 \\
\hline & GET 13f & 3 & $*$ & * & $*$ & $*$ & $*$ & $*$ & $*$ & $*$ & $*$ & $*$ & $*$ & $*$ & LA1 \\
\hline & & 4 & $*$ & * & $*$ & $*$ & $*$ & $*$ & * & $*$ & $*$ & * & $*$ & $*$ & LA1 \\
\hline
\end{tabular}


Tabelle 83: Polymorphismen des 12srRNA-Gens in Extrakten rezenter Proben, vorderer und hintere Bereich, 2xanalysiert

\begin{tabular}{|c|c|c|c|c|c|c|c|c|c|c|c|c|c|c|c|c|c|c|c|c|c|}
\hline 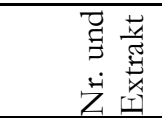 & 望 & ถิ & तु & $\stackrel{\infty}{\infty}$ & $\cong$ & $\widehat{\vartheta}$ & 尔 & $\begin{array}{l}\infty \\
\infty \\
\cdots \\
N\end{array}$ & $\underset{m}{+}$ & 8 & Iิ & 字 & $\infty$ & กี & $\stackrel{\infty}{0}$ & $\underset{\infty}{ \pm}$ & 官 & $\stackrel{?}{\infty}$ & $\underset{\infty}{+}$ & 卢 & $\begin{array}{l}3 \\
\infty\end{array}$ \\
\hline Referenz & $\mathrm{C}$ & $\mathrm{T}$ & $\mathrm{A}$ & $\mathrm{A}$ & $\mathrm{C}$ & $\mathrm{T}$ & $\mathrm{A}$ & $\mathrm{T}$ & A & $G$ & C & $\mathrm{C}$ & $\mathrm{C}$ & C & $G$ & $G$ & $\mathrm{C}$ & $\mathrm{A}$ & G & $G$ & $\mathrm{C}$ \\
\hline La 1 I/II & * & * & $*$ & $*$ & * & $*$ & $*$ & * & * & * & * & * & $*$ & * & * & * & $*$ & * & * & * & $*$ \\
\hline La 2 I/II & $*$ & * & $*$ & $*$ & $*$ & $*$ & $*$ & $*$ & $*$ & $*$ & $*$ & $*$ & $*$ & $*$ & $*$ & $*$ & $*$ & $*$ & $*$ & $*$ & $*$ \\
\hline La 3 I/II & * & 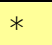 & * & * & * & * & * & * & * & * & * & * & * & * & * & * & * & * & * & * & * \\
\hline $\mathrm{La} 4 \mathrm{I} / \mathrm{II}$ & $*$ & * & * & $*$ & * & * & $*$ & * & * & $*$ & * & * & * & * & * & * & * & * & $*$ & * & $*$ \\
\hline La 5 I/II & $*$ & * & $*$ & $*$ & $*$ & $*$ & $*$ & $*$ & $*$ & $*$ & * & $*$ & $*$ & $*$ & $*$ & * & * & * & * & * & $*$ \\
\hline La 6 I/II & $*$ & $*$ & $*$ & $*$ & $*$ & $*$ & $*$ & $*$ & $*$ & $*$ & * & $*$ & $*$ & $*$ & $*$ & $*$ & $*$ & $*$ & $*$ & $*$ & $*$ \\
\hline La 7 I/II & * & $*$ & * & $*$ & * & $*$ & * & * & * & * & * & * & $*$ & $*$ & * & * & * & * & * & * & $*$ \\
\hline La 8 I/II & * & * & $*$ & * & $*$ & $*$ & * & $*$ & * & $*$ & * & $*$ & $*$ & $*$ & * & * & * & * & * & $*$ & $*$ \\
\hline La 9 I/II & $*$ & * & $*$ & $*$ & $*$ & $*$ & $*$ & $*$ & * & $*$ & * & $*$ & $*$ & $\mathrm{~T}$ & $*$ & * & $*$ & * & $*$ & $*$ & $*$ \\
\hline $\mathrm{La} 10 \mathrm{I} / \mathrm{II}$ & $*$ & $*$ & $*$ & $*$ & $*$ & $*$ & $*$ & $*$ & * & $*$ & $*$ & $*$ & $*$ & $*$ & $*$ & $*$ & $*$ & $*$ & $*$ & $*$ & $*$ \\
\hline Gua $1 \mathrm{I} / \mathrm{II}$ & $*$ & * & $*$ & $*$ & $\mathrm{~T}$ & $*$ & $*$ & $*$ & * & $*$ & $*$ & $\mathrm{~T}$ & $*$ & $\mathrm{~T}$ & $*$ & $*$ & $*$ & * & $*$ & $*$ & $*$ \\
\hline Gua 2 I/II & $*$ & $*$ & $*$ & $*$ & $\mathrm{~T}$ & $*$ & $*$ & $*$ & * & $*$ & * & $\mathrm{T}$ & $\mathrm{T}$ & $\mathrm{T}$ & $*$ & $*$ & $*$ & $*$ & $*$ & $*$ & $*$ \\
\hline Gua 3 I/II & $*$ & $*$ & $*$ & $*$ & $\mathrm{~T}$ & $*$ & $*$ & $*$ & * & $*$ & $*$ & $\mathrm{~T}$ & $\mathrm{~T}$ & & $*$ & C & $*$ & * & $*$ & $*$ & $*$ \\
\hline Alp1 I/II & $*$ & $*$ & $*$ & $*$ & $*$ & $*$ & $*$ & $*$ & * & $*$ & * & $*$ & $*$ & $\mathrm{~T}$ & $*$ & $*$ & $\mathrm{~T}$ & G & $\mathrm{A}$ & $\mathrm{A}$ & $\mathrm{T}$ \\
\hline Alp2 I/II & $*$ & * & G & $*$ & $\mathrm{~T}$ & $\mathrm{C}$ & $G$ & $\mathrm{C}$ & $\mathrm{T}$ & A & $\mathrm{T}$ & $\mathrm{T}$ & $*$ & & * & * & $*$ & * & * & * & $*$ \\
\hline Alp3 I/II & $*$ & $*$ & $G$ & $*$ & $\mathrm{~T}$ & $\mathrm{C}$ & $G$ & $\mathrm{C}$ & $\mathrm{T}$ & $\mathrm{A}$ & $\mathrm{T}$ & $\mathrm{T}$ & $*$ & $\mathrm{~T}$ & $*$ & $*$ & $\mathrm{~T}$ & G & $\mathrm{A}$ & $\mathrm{A}$ & $*$ \\
\hline Alp4 I/II & $*$ & $*$ & $*$ & $*$ & $\mathrm{~T}$ & * & $G$ & $\mathrm{C}$ & $\mathrm{T}$ & $\mathrm{A}$ & $\mathrm{T}$ & $\mathrm{T}$ & $*$ & & * & $*$ & $*$ & $*$ & $*$ & $*$ & $*$ \\
\hline Alp5 I/II & $*$ & $*$ & $*$ & $*$ & $\mathrm{~T}$ & $*$ & $G$ & $\mathrm{C}$ & $\mathrm{T}$ & A & $\mathrm{T}$ & $\mathrm{T}$ & $*$ & & * & $*$ & $*$ & $*$ & * & * & $*$ \\
\hline Alp6 I/II & $*$ & $\mathrm{Y}$ & $*$ & G & $\mathrm{T}$ & $\mathrm{C}$ & $G$ & $\mathrm{C}$ & $\mathrm{T}$ & $\mathrm{A}$ & $\mathrm{T}$ & $\mathrm{T}$ & $\mathrm{T}$ & $\mathrm{T}$ & $*$ & $*$ & $\mathrm{~T}$ & G & $\mathrm{A}$ & $\mathrm{A}$ & $\mathrm{T}$ \\
\hline Alp7 I/II & $*$ & $*$ & $*$ & $*$ & $*$ & $*$ & $*$ & $*$ & $*$ & & $*$ & $*$ & $*$ & $*$ & $*$ & $*$ & $*$ & $*$ & $*$ & $*$ & $*$ \\
\hline Alp8 I/II & $*$ & $\mathrm{C}$ & $*$ & G & $\mathrm{T}$ & $\mathrm{C}$ & $G$ & $\mathrm{C}$ & $\mathrm{T}$ & $\mathrm{A}$ & $\mathrm{T}$ & $\mathrm{T}$ & $*$ & & * & $*$ & $*$ & * & * & $*$ & $*$ \\
\hline Alp9 I/II & $*$ & $*$ & $*$ & $*$ & $*$ & $*$ & $*$ & $*$ & $*$ & $*$ & $*$ & $*$ & $*$ & $*$ & $*$ & $*$ & $*$ & $*$ & $*$ & $*$ & $*$ \\
\hline Alp10 I/II & $*$ & $*$ & $*$ & $*$ & $*$ & $*$ & $*$ & $*$ & $*$ & $*$ & * & $*$ & $*$ & $*$ & $*$ & $*$ & $*$ & $*$ & $*$ & $*$ & $*$ \\
\hline Alp11 I/II & $\mathrm{T}$ & $*$ & $*$ & $*$ & * & $*$ & $*$ & $*$ & * & $*$ & * & $\mathrm{T}$ & $*$ & & * & * & $*$ & * & * & $*$ & $*$ \\
\hline Alp12 I/II & $\mathrm{T}$ & $*$ & $*$ & $*$ & $*$ & $*$ & $*$ & $*$ & * & $*$ & * & $\mathrm{T}$ & $*$ & $*$ & $*$ & $*$ & $*$ & $*$ & $*$ & $*$ & $*$ \\
\hline Alp13 I/II & $*$ & $*$ & $*$ & $*$ & $*$ & $*$ & $*$ & $*$ & $*$ & $*$ & * & $*$ & $\mathrm{~T}$ & $\mathrm{~T}$ & $*$ & $*$ & $\mathrm{~T}$ & G & $\mathrm{A}$ & $\mathrm{A}$ & $\mathrm{T}$ \\
\hline Alp14 I/II & $*$ & $*$ & $*$ & $*$ & $*$ & $*$ & $*$ & $*$ & $*$ & $*$ & $*$ & $*$ & $\mathrm{~T}$ & $\mathrm{~T}$ & $*$ & $*$ & $\mathrm{~T}$ & G & $\mathrm{A}$ & $\mathrm{A}$ & $\mathrm{T}$ \\
\hline Vic1 I/II & $*$ & $\mathrm{C}$ & $*$ & G & $\mathrm{T}$ & $\mathrm{C}$ & $G$ & $\mathrm{C}$ & $\mathrm{T}$ & $\mathrm{A}$ & $\mathrm{T}$ & $\mathrm{T}$ & $\mathrm{T}$ & $\mathrm{T}$ & $*$ & $*$ & $\mathrm{~T}$ & G & $\mathrm{A}$ & $\mathrm{A}$ & $\mathrm{T}$ \\
\hline Vic2 I/II & $*$ & C & $*$ & G & $\mathrm{T}$ & C & G & C & $\mathrm{T}$ & A & $\mathrm{T}$ & $\mathrm{T}$ & $\mathrm{T}$ & $\mathrm{T}$ & * & $*$ & $\mathrm{~T}$ & G & A & A & $\mathrm{T}$ \\
\hline Vic3 I/II & $*$ & $\mathrm{C}$ & $*$ & G & $\mathrm{T}$ & $\mathrm{C}$ & $G$ & $\mathrm{C}$ & $\mathrm{T}$ & $\mathrm{A}$ & $\mathrm{T}$ & $\mathrm{T}$ & $\mathrm{T}$ & $\mathrm{T}$ & $*$ & C & $\mathrm{T}$ & G & $\mathrm{A}$ & $\mathrm{A}$ & $\mathrm{T}$ \\
\hline Vic4 I/II & $*$ & $\mathrm{C}$ & $*$ & G & $\mathrm{T}$ & $\mathrm{C}$ & $G$ & $\mathrm{C}$ & $\mathrm{T}$ & $\mathrm{A}$ & $\mathrm{T}$ & $\mathrm{T}$ & $\mathrm{T}$ & $\mathrm{T}$ & $*$ & $*$ & $\mathrm{~T}$ & G & $\mathrm{A}$ & $\mathrm{A}$ & $\mathrm{T}$ \\
\hline Vic5 I/II & $*$ & $\mathrm{C}$ & $*$ & G & $\mathrm{T}$ & $\mathrm{C}$ & $G$ & $\mathrm{C}$ & $\mathrm{T}$ & $\mathrm{A}$ & $\mathrm{T}$ & $\mathrm{T}$ & $\mathrm{T}$ & $\mathrm{T}$ & $*$ & C & $\mathrm{T}$ & G & $\mathrm{A}$ & $\mathrm{A}$ & $\mathrm{T}$ \\
\hline Vic6 I/II & $*$ & $\mathrm{C}$ & $*$ & G & $\mathrm{T}$ & $\mathrm{C}$ & $G$ & $\mathrm{C}$ & $\mathrm{T}$ & $\mathrm{A}$ & $\mathrm{T}$ & $\mathrm{T}$ & $\mathrm{T}$ & $\mathrm{T}$ & $*$ & $\mathrm{C}$ & $\mathrm{T}$ & $G$ & A & $\mathrm{A}$ & $\mathrm{T}$ \\
\hline Vic7 I/II & $*$ & $\mathrm{C}$ & $*$ & G & $\mathrm{T}$ & $\mathrm{C}$ & $G$ & $\mathrm{C}$ & $\mathrm{T}$ & $\mathrm{A}$ & $\mathrm{T}$ & $\mathrm{T}$ & $\mathrm{T}$ & $\mathrm{T}$ & $*$ & C & $\mathrm{T}$ & G & A & $\mathrm{A}$ & $\mathrm{T}$ \\
\hline Vic8 I/II & $*$ & $\mathrm{C}$ & $*$ & G & $\mathrm{T}$ & $\mathrm{C}$ & $G$ & $\mathrm{C}$ & $\mathrm{T}$ & $\mathrm{A}$ & $\mathrm{T}$ & $\mathrm{T}$ & $\mathrm{T}$ & $\mathrm{T}$ & * & C & $\mathrm{T}$ & G & $\mathrm{A}$ & $\mathrm{A}$ & $\mathrm{T}$ \\
\hline Vic9 I/II & $*$ & $\mathrm{C}$ & $*$ & $G$ & $\mathrm{~T}$ & $\mathrm{C}$ & $G$ & $\mathrm{C}$ & $\mathrm{T}$ & $\mathrm{A}$ & $\mathrm{T}$ & $\mathrm{T}$ & $\mathrm{T}$ & $\mathrm{T}$ & $*$ & $*$ & $\mathrm{~T}$ & G & $\mathrm{A}$ & $\mathrm{A}$ & $\mathrm{T}$ \\
\hline Vic10 I/II & $*$ & $\mathrm{C}$ & $*$ & G & $\mathrm{T}$ & $\mathrm{C}$ & $G$ & $\mathrm{C}$ & $\mathrm{T}$ & $\mathrm{A}$ & $\mathrm{T}$ & $\mathrm{T}$ & $\mathrm{T}$ & $\mathrm{T}$ & $*$ & $*$ & $\mathrm{~T}$ & G & $*$ & $\mathrm{~A}$ & $\mathrm{~T}$ \\
\hline Vic11 I/II & $*$ & $\mathrm{C}$ & $*$ & G & $\mathrm{T}$ & $\mathrm{C}$ & $G$ & $\mathrm{C}$ & $\mathrm{T}$ & A & $\mathrm{T}$ & $\mathrm{T}$ & $\mathrm{T}$ & $\mathrm{T}$ & $*$ & $*$ & $\mathrm{~T}$ & G & $*$ & $\mathrm{~A}$ & $\mathrm{~T}$ \\
\hline Vic12 I/II & $*$ & $\mathrm{C}$ & $*$ & G & $\mathrm{T}$ & $\mathrm{C}$ & $G$ & $\mathrm{C}$ & $\mathrm{T}$ & $\mathrm{A}$ & $\mathrm{T}$ & $\mathrm{T}$ & $\mathrm{T}$ & $\mathrm{T}$ & $\mathrm{A}$ & C & $\mathrm{T}$ & G & $*$ & $\mathrm{~A}$ & $\mathrm{~T}$ \\
\hline Vic13 I/II & $*$ & $\mathrm{C}$ & $*$ & G & $\mathrm{T}$ & $\mathrm{C}$ & $G$ & $\mathrm{C}$ & $\mathrm{T}$ & $\mathrm{A}$ & $\mathrm{T}$ & $\mathrm{T}$ & $\mathrm{T}$ & $\mathrm{T}$ & * & * & $\mathrm{T}$ & $G$ & $\mathrm{~A}$ & $\mathrm{~A}$ & $\mathrm{~T}$ \\
\hline Vic14 I/II & $*$ & $\mathrm{C}$ & $*$ & G & $\mathrm{T}$ & $\mathrm{C}$ & $G$ & $\mathrm{C}$ & $\mathrm{T}$ & A & $\mathrm{T}$ & $\mathrm{T}$ & $\mathrm{T}$ & $\mathrm{T}$ & $*$ & $*$ & $\mathrm{~T}$ & G & A & A & $\mathrm{T}$ \\
\hline Vic15 I/II & $*$ & $\mathrm{C}$ & $*$ & G & $\mathrm{T}$ & $\mathrm{C}$ & $G$ & $\mathrm{C}$ & $\mathrm{T}$ & A & $\mathrm{T}$ & $\mathrm{T}$ & $\mathrm{T}$ & $\mathrm{T}$ & A & C & $\mathrm{T}$ & $G$ & $*$ & $\mathrm{~A}$ & $\mathrm{~T}$ \\
\hline Vic16 I/II & $*$ & $\mathrm{C}$ & $*$ & G & $\mathrm{T}$ & $\mathrm{C}$ & $G$ & $\mathrm{C}$ & $\mathrm{T}$ & A & $\mathrm{T}$ & $\mathrm{T}$ & $\mathrm{T}$ & $\mathrm{T}$ & * & * & $\mathrm{T}$ & G & * & A & $\mathrm{T}$ \\
\hline
\end{tabular}


Tabelle 84: Proben die nicht reproduziert werden konnten

\begin{tabular}{|l|l|l|l|}
\hline Probennummer & Amplifikationszeitraum & Fragment & putativ Spezies \\
\hline GET2d & Jul07 & 5 & n.d. \\
\hline GET4IIe & Nov05 & 2 & n.d. \\
\hline GET4IId & Jun07/Jul07 & $5 / 5$ & n.d. \\
\hline MST5a & Aug06 & 2 & n.d. \\
\hline MST5e & Nov05/Jul07 & $2 / 5$ & Alpaka/n.d. \\
\hline MST9b & Jul07/Okt06 & $2 / 2$ & Vikunja/Lama \\
\hline MST16d & Nov05/Jan06 & $2 / 2$ & Alpaka/Vikunja \\
\hline MST17f & Nov05 & 2 & n.d. \\
\hline MST19a & Nov05/Mar06 & $2 / 2$ & n.d./n.d. \\
\hline MST22a & Ju107 & 2 & n.d. \\
\hline MST24b & Jul06/Okt06 & $2 / 2$ & Alpaka/Vikunja \\
\hline MST24e & Jul07 & 2 & n.d. \\
\hline MSA10 & Nov05 & 2 & Lama \\
\hline JAA2 & Nov06 & 2 & n.d. \\
\hline JAA6 & Nov05 & 2 & n.d. \\
\hline MAA10 & Aug06/Apr07 & $2 / 5$ & Alpaka/Mischtypus \\
\hline COA16 & Sep06/Dez07 & $2 /$ COI & Lama/Lama \\
\hline
\end{tabular}

Tabelle 85: Typisierung der Mikrosatellitenmarker in Extrakten historischen Materials

\begin{tabular}{|c|c|c|c|c|c|c|}
\hline & VOLP10 & LgU52 & VOLP03 & LCA66 & VOLP67 & LgU68 \\
\hline COA2 1106II & $(4) / 8$ & $-/-$ & $-/-$ & $-1-$ & $-/-$ & $-/-$ \\
\hline COA2 0807I & $-/-$ & $-1-$ & $-1-$ & $-/-$ & $-/-$ & $-/-$ \\
\hline COA2 & $-/-$ & $-1-$ & $-1-$ & $-/-$ & $-/-$ & $-/-$ \\
\hline COA4 1106II & $3 / 6$ & $-1-$ & $-1-$ & $-/-$ & $-/-$ & $-/-$ \\
\hline COA4 0807I & $-/-$ & $-1-$ & $-1-$ & $-/-$ & $-/-$ & $-/-$ \\
\hline COA4 & $-1-$ & $-1-$ & $-1-$ & $-/-$ & $-/-$ & $-/-$ \\
\hline COA4Ph1106I & $7 / 11$ & 10i30/- & $-1-$ & $-1-$ & $-1-$ & $-1-$ \\
\hline COA4Ph0807I & $-/-$ & $-/-$ & $-1-$ & $-/-$ & $-/-$ & $-/-$ \\
\hline COA4Ph & $-/-$ & $-1-$ & $-1-$ & $-/-$ & $-/-$ & $-1-$ \\
\hline COA5 1106II & $-/-$ & $5 / 8$ & $-1-$ & $13 /-$ & $-/-$ & $-/-$ \\
\hline COA5 0807I & $-/-$ & $-1-$ & $-1-$ & $-/-$ & $-/-$ & $-/-$ \\
\hline COA5 & $-/-$ & $-1-$ & $-/-$ & $-/-$ & $-/-$ & $-/-$ \\
\hline COA6 1106II & $7 /-$ & $4 / 9$ & $-1-$ & $-/-$ & $-/-$ & $16 /-$ \\
\hline COA6 0807I & $7 /-$ & $9 /-$ & $-1-$ & $-/-$ & $6 / 8$ & $-/-$ \\
\hline COA6 & $7 /-$ & $9 /-$ & $-1-$ & $-/-$ & $-1-$ & $-1-$ \\
\hline COA7 1106II & $4 / 7$ & $10 / 11$ & $-1-$ & $-/-$ & $-/-$ & $-/-$ \\
\hline COA7 0807I & $-/-$ & $-/-$ & $-1-$ & $-1-$ & $-1-$ & $-1-$ \\
\hline COA7 & $-1-$ & $-1-$ & $-1-$ & $-/-$ & $-1-$ & $-1-$ \\
\hline COA8 1106II & $7 / 8$ & $8 /-$ & $-1-$ & $19 /-$ & $-/-$ & $18 /-$ \\
\hline COA8 0807I & $7 /-$ & $9 /-$ & $20 /-$ & $-/-$ & $6 / 9$ & $-/-$ \\
\hline COA8 & $7 /-$ & $-1-$ & $-1-$ & $-/-$ & $-/-$ & $-1-$ \\
\hline COA9 1106II & $-/-$ & $-1-$ & $-/-$ & $-/-$ & $9 /-$ & $-/-$ \\
\hline COA9 0807I & $-/-$ & $-/-$ & $-/-$ & $-/-$ & $-/-$ & $-/-$ \\
\hline COA9 & $-/-$ & $-1-$ & $-/-$ & $-/-$ & $-/-$ & $-/-$ \\
\hline COA11 1106II & $3 /-$ & $-1-$ & $-1-$ & $-/-$ & $-/-$ & $-/-$ \\
\hline COA110807I & $-/-$ & $-/-$ & $-/-$ & $-/-$ & $-/-$ & $-/-$ \\
\hline COA11 & $-/-$ & $-1-$ & $-1-$ & $-1-$ & $-1-$ & $-1-$ \\
\hline COA12 1106II & $6 /-$ & $-1-$ & $-1-$ & $-/-$ & $-/-$ & $-1-$ \\
\hline COA12 0807I & $-1-$ & $-1-$ & $-1-$ & $-/-$ & $-1-$ & $-/-$ \\
\hline COA12 & $-1-$ & $-1-$ & $-1-$ & $-/-$ & $-/-$ & $-/-$ \\
\hline COA13 1106II & $3 / 7$ & $5 / 7$ & $-/-$ & $-/-$ & $-/-$ & $-/-$ \\
\hline COA13 0807I & $7 /-$ & $7 /-$ & $19 /-$ & $-/-$ & $6 /-$ & $-/-$ \\
\hline COA13 & $7 /-$ & $7 /-$ & $-/-$ & $-/-$ & $-/-$ & $-/-$ \\
\hline COA14 1106II & $-/-$ & $6 / 7$ & $-/-$ & $-/-$ & $-/-$ & $-/-$ \\
\hline COA14 807I & $-1-$ & $-/-$ & $-1-$ & $-/-$ & $-1-$ & $-/-$ \\
\hline COA14 & $-1-$ & $-1-$ & $-1-$ & $-/-$ & $-1-$ & $-1-$ \\
\hline
\end{tabular}


Appendix

Tabelle 85: Typisierung der Mikrosatellitenmarker in Extrakten historischen Materials, Fortsetzung

\begin{tabular}{|c|c|c|c|c|c|c|}
\hline & VOLP10 & LgU52 & VOLP03 & LCA66 & VOLP67 & $\mathrm{LgU68}$ \\
\hline CO15 1106II & $3 / 4$ & $6 /-$ & $7 /-$ & $-/-$ & $12 /-$ & $-/-$ \\
\hline COA15 0807I & $-/-$ & $-/-$ & $-/-$ & $-1-$ & $-/-$ & $-/-$ \\
\hline COA15 & $-/-$ & $-1-$ & $-/-$ & $-/-$ & $-/-$ & $-/-$ \\
\hline COA17 1106II & $-/-$ & $13 /-$ & $-/-$ & $9 / 12$ & $-/-$ & $-/-$ \\
\hline COA17 0807I & $7 /-$ & $-/-$ & $-/-$ & $-/-$ & $6 / 7$ & $-/-$ \\
\hline COA17 & $-/-$ & $-/-$ & $-/-$ & $-/-$ & $-/-$ & $-/-$ \\
\hline COA18 1106I & $4 / 7$ & $5 / 7$ & $-/-$ & $-1-$ & $11 /-$ & $14 / 16$ \\
\hline COA18 0807I & $-/-$ & $-/-$ & $-1-$ & $-1-$ & $-/-$ & $-/-$ \\
\hline COA18 & $-1-$ & $-1-$ & $-/-$ & $-/-$ & $-/-$ & $-/-$ \\
\hline COA19 1106II & $7 /-$ & $4 / 7$ & $9 /-$ & $-/-$ & $-/-$ & $-/-$ \\
\hline COA19 0807I & $-/-$ & $-1-$ & $-/-$ & $-/-$ & $-/-$ & $-/-$ \\
\hline COA19 & $-/-$ & $-1-$ & $-/-$ & $-/-$ & $-/-$ & $-/-$ \\
\hline COA20 1106II & $3 /-$ & $4 / 6$ & $-/-$ & $-/-$ & $8 / 13$ & $-/-$ \\
\hline COA20 0807I & $-1-$ & $-1-$ & $-/-$ & $-/-$ & $-1-$ & $-1-$ \\
\hline COA20 & $-/-$ & $-/-$ & $-/-$ & $-/-$ & $-/-$ & $-/-$ \\
\hline COA21 1106II & $-/-$ & $4 /-$ & $-/-$ & $-/-$ & $-/-$ & $-/-$ \\
\hline COA21 0807I & $-/-$ & $-/-$ & $-1-$ & $-/-$ & $-/-$ & $-/-$ \\
\hline COA21 & $-/-$ & $-/-$ & $-/-$ & $-/-$ & $-/-$ & $-/-$ \\
\hline COA25 1106II & $2 / 8$ & $10 /-$ & $-/-$ & $-/-$ & $7 /-$ & $-/-$ \\
\hline COA25 0807I & $-/-$ & $-/-$ & $-/-$ & $-/-$ & $-1-$ & $-/-$ \\
\hline $\mathrm{COA} 25$ & $-/-$ & $-1-$ & $-/-$ & $-/-$ & $-/-$ & $-/-$ \\
\hline GEA5 1206II & $8 /-$ & $5 /-$ & $-/-$ & $-/-$ & $4 /-$ & $-/-$ \\
\hline GEA5 0807I & $-/-$ & $-/-$ & $-/-$ & $-/-$ & $-1-$ & $-/-$ \\
\hline GEA5 & $-/-$ & $-/-$ & $-/-$ & $-1-$ & $-/-$ & $-/-$ \\
\hline GEA6 1206II & $4 / 7$ & $8 /-$ & $8 /-$ & $-1-$ & $-/-$ & $-/-$ \\
\hline GEA6 0807I & $7 /-$ & $8 /-$ & $19 /-$ & $-/-$ & $-/-$ & $6 / 11$ \\
\hline GEA6 & $7 /-$ & $8 /-$ & $-/-$ & $-/-$ & $-/-$ & $-/-$ \\
\hline GEA7 1206II & $4 / 7$ & $9 / 10$ & $-1-$ & $-/-$ & $16 /-$ & $17 /-$ \\
\hline GEA7 0807I & $-/-$ & $-/-$ & $-/-$ & $-/-$ & $-/-$ & $-/-$ \\
\hline GEA7 & $-/-$ & $-/-$ & $-/-$ & $-/-$ & $-/-$ & $-/-$ \\
\hline GEA8 1206II & $8 /-$ & $4 / 12$ & $-/-$ & $-/-$ & $-/-$ & $17 /-$ \\
\hline GEA8 0807I & $-/-$ & $-/-$ & $-/-$ & $-/-$ & $-/-$ & $-/-$ \\
\hline GEA8 & $-/-$ & $-/-$ & $-/-$ & $-/-$ & $-/-$ & $-/-$ \\
\hline GEA9 1206II & $7 /-$ & $10 / 11$ & $-1-$ & $-/-$ & $-/-$ & $9 /-$ \\
\hline GEA9 0807I & $-/-$ & $-/-$ & $-/-$ & $-/-$ & $-/-$ & $-/-$ \\
\hline GEA9 & $-/-$ & $-/-$ & $-/-$ & $-/-$ & $-/-$ & $-/-$ \\
\hline MSA2 1106II & $8 /-$ & $7 /-$ & $-/-$ & $22 /-$ & $18 /-$ & $16 /-$ \\
\hline MSA2 0807I & $-/-$ & $-/-$ & $-/-$ & $-/-$ & $-/-$ & $-/-$ \\
\hline MSA2 & $-/-$ & $-/-$ & $-/-$ & $-/-$ & $-/-$ & $-/-$ \\
\hline MSA291106II & $2 / 7$ & $8 /-$ & $-/-$ & $-/-$ & $16 /-$ & $11 /-$ \\
\hline MSA29 0807I & $7 /-$ & $-/-$ & $20 /-$ & $-/-$ & $-/-$ & $-/-$ \\
\hline MSA29 & $7 /-$ & $-/-$ & $-/-$ & $-/-$ & $-/-$ & $-/-$ \\
\hline MSA31 1106II & $2 /-$ & $7 / 8$ & $-/-$ & $-/-$ & $-/-$ & $-/-$ \\
\hline MSA31 0807I & $-/-$ & $-1-$ & $-/-$ & $-/-$ & $-/-$ & $-/-$ \\
\hline MSA31 & $-/-$ & $-/-$ & $-/-$ & $-/-$ & $-/-$ & $-/-$ \\
\hline JAA29a 0107 & $4 /-$ & $4 / 5$ & $-/-$ & $-/-$ & $19 /-$ & $-/-$ \\
\hline JAA29a 0807I & $-/-$ & $-/-$ & $-/-$ & $-/-$ & $-/-$ & $-/-$ \\
\hline JAA29a & $-/-$ & $-/-$ & $-/-$ & $-/-$ & $-/-$ & $-/-$ \\
\hline JAA29b 0107 & $7 /-$ & $8 / 10$ & $18 /-$ & $-/-$ & $-/-$ & $-/-$ \\
\hline JAA29b 0807I & $-/-$ & $-/-$ & $-/-$ & $-/-$ & $-/-$ & $-/-$ \\
\hline JAA29b & $-/-$ & $-/-$ & $-/-$ & $-/-$ & $-/-$ & $-/-$ \\
\hline JAA29c 0107 & $3 / 7$ & $9 / 10$ & $-/-$ & $-/-$ & $14 /-$ & $-/-$ \\
\hline JAA29c 0807I & $-1-$ & $-/-$ & $-/-$ & $-/-$ & $-/-$ & $-/-$ \\
\hline JAA29c & $-1-$ & $-/-$ & $-/-$ & $-/-$ & $-1-$ & $-/-$ \\
\hline
\end{tabular}


Tabelle 86: Einzeltypisierungen der Mikrosatelliten in Extrakten rezenten Materials

\begin{tabular}{|c|c|c|c|c|c|c|c|}
\hline & Extrakt & VOLP10 & LgU52 & VOLP03 & LCA66 & VOLP67 & LgU68 \\
\hline La1 & I & $7 /-$ & $9 /-$ & $20 / 22$ & $-/-$ & $-/-$ & $13 /-$ \\
\hline La1 & I & $7 /-$ & $9 /-$ & $20 / 22$ & $-/-$ & $-1-$ & $13 /-$ \\
\hline La1 & III & $7 /-$ & $9 /-$ & $20 / 22$ & $13 /-$ & $-1-$ & $13 /-$ \\
\hline La1 & III & $7 /-$ & $9 /-$ & $20 / 22$ & $-1-$ & $-1-$ & $13 /-$ \\
\hline La1 & & $7 / 7$ & $9 / 9$ & $20 / 22$ & $-/-$ & $-/-$ & $13 / 13$ \\
\hline $\mathrm{La} 2$ & $\mathrm{I}$ & $7 /-$ & $8 /-$ & $20 /-$ & $13 /-$ & $11 / 12$ & $11 / 13$ \\
\hline $\mathrm{La} 2$ & $\mathrm{I}$ & $7 /-$ & $8 /-$ & $20 /-$ & $13 /-$ & $11 / 12$ & $11 / 13$ \\
\hline $\mathrm{La} 2$ & III & $7 /-$ & $8 /-$ & $20 /-$ & $13 /-$ & $11 / 12$ & $11 / 13$ \\
\hline $\mathrm{La} 2$ & III & $7 /-$ & $8 /-$ & $20 /-$ & $13 /-$ & $11 / 12$ & $11 / 13$ \\
\hline La2 & & $7 / 7$ & $8 / 8$ & $20 / 20$ & $13 / 13$ & $11 / 12$ & $11 / 13$ \\
\hline La3 & I & $7 /-$ & $8 / 9$ & $20 /-$ & $13 /-$ & $14 / 15$ & $13 / 14$ \\
\hline $\mathrm{La} 3$ & I & $7 /-$ & $8 / 9$ & $20 /-$ & $13 /-$ & $14 / 15$ & $13 / 14$ \\
\hline La3 & III & $7 /-$ & $8 / 9$ & $20 /-$ & $13 /-$ & $14 / 15$ & $13 / 14$ \\
\hline La3 & III & $7 /-$ & $8 / 9$ & $20 /-$ & $13 /-$ & $14 / 15$ & $13 / 14$ \\
\hline La3 & & $7 / 7$ & $8 / 9$ & $20 / 20$ & $13 / 13$ & $14 / 15$ & $13 / 14$ \\
\hline $\mathrm{La} 4$ & $\mathrm{I}$ & $7 /-$ & $8 / 9$ & $20 /-$ & $13 / 15$ & $11 / 16$ & $13 / 20$ \\
\hline $\mathrm{La} 4$ & $\mathrm{I}$ & $7 /-$ & $8 / 9$ & $20 /-$ & $15 /-$ & $11 / 16$ & $13 / 20$ \\
\hline $\mathrm{La} 4$ & III & $7 /-$ & $8 / 9$ & $20 /-$ & $15 /-$ & $11 / 16$ & $13 / 20$ \\
\hline $\mathrm{La} 4$ & III & $7 /-$ & $8 / 9$ & $20 /-$ & $13 / 15$ & $11 / 16$ & $13 / 20$ \\
\hline La4 & & $7 / 7$ & $8 / 9$ & $20 / 20$ & $13 / 15$ & $11 / 16$ & $13 / 20$ \\
\hline La5 & $\mathrm{I}$ & $7 /-$ & $8 /-$ & $20 /-$ & $-1-$ & $-1-$ & $-1-$ \\
\hline $\mathrm{La} 5$ & I & $7 /-$ & $8 /-$ & $20 /-$ & $-1-$ & $-1-$ & $-1-$ \\
\hline $\mathrm{La} 5$ & III & $7 /-$ & $8 /-$ & $20 /-$ & $-1-$ & $11 /-$ & $-1-$ \\
\hline La5 & III & $7 /-$ & $8 /-$ & $20 /-$ & $-1-$ & $-/-$ & $14 /-$ \\
\hline La5 & & $7 / 7$ & $8 / 8$ & $20 / 20$ & $-/-$ & $-/-$ & $-/-$ \\
\hline La6 & $\mathrm{I}$ & $7 /-$ & $8 / 10$ & $20 / 21$ & $11 / 13$ & $12 / 16$ & $11 / 13$ \\
\hline La6 & $\mathrm{I}$ & $7 /-$ & $8 / 10$ & $20 / 21$ & $11 / 13$ & $12 / 16$ & $11 / 13$ \\
\hline La6 & III & $7 /-$ & $8 / 10$ & $20 / 21$ & $11 / 13$ & $12 / 16$ & $11 / 13$ \\
\hline La6 & III & $7 /-$ & $8 / 10$ & $20 / 21$ & $11 / 13$ & $12 / 16$ & $11 / 13$ \\
\hline La6 & & $7 / 7$ & $8 / 10$ & $20 / 21$ & $11 / 13$ & $12 / 16$ & $11 / 13$ \\
\hline $\mathrm{La} 8$ & I & $7 /-$ & $8 /-$ & $22 /-$ & $15 /-$ & $-1-$ & $13 /-$ \\
\hline $\mathrm{La} 8$ & I & $7 /-$ & $8 /-$ & $22 /-$ & $15 /-$ & $-1-$ & $13 /-$ \\
\hline $\mathrm{La} 8$ & III & $7 /-$ & $8 /-$ & $22 /-$ & $15 /-$ & $-1-$ & $13 /-$ \\
\hline $\mathrm{La} 8$ & III & $7 /-$ & $8 /-$ & $22 /-$ & $15 /-$ & $-1-$ & $13 /-$ \\
\hline La8 & & $7 / 7$ & $8 / 8$ & $22 / 22$ & $15 / 15$ & $-/-$ & $13 / 13$ \\
\hline La9 & $\mathrm{I}$ & $6 / 7$ & $8 / 10$ i30 & $20 /-$ & $13 /-$ & $10 /-$ & $22 /-$ \\
\hline La9 & $\mathrm{I}$ & $6 / 7$ & $8 / 10 \mathrm{i} 30$ & $20 /-$ & $13 /-$ & $10 /-$ & $22 /-$ \\
\hline La9 & III & $6 / 7$ & $8 / 10 \mathrm{i} 30$ & $20 /-$ & $13 /-$ & $10 /-$ & $22 /-$ \\
\hline La9 & III & $6 / 7$ & $8 / 10 \mathrm{i} 30$ & $20 /-$ & $13 /-$ & $10 /-$ & $22 /-$ \\
\hline La9 & & $6 / 7$ & $8 / 10 \mathrm{i} 30$ & $20 / 20$ & $13 / 13$ & $10 / 10$ & $22 / 22$ \\
\hline La10 & I & $7 /-$ & $8 / 9$ & $-1-$ & $-1-$ & $-1-$ & $17 /-$ \\
\hline La10 & I & $7 /-$ & $8 / 9$ & $-/-$ & $-1-$ & $-1-$ & $17 /-$ \\
\hline La10 & III & $7 /-$ & $8 / 9$ & $-1-$ & $-1-$ & $-1-$ & $17 /-$ \\
\hline La10 & III & $7 /-$ & $8 / 9$ & $-/-$ & $-1-$ & $-1-$ & $17 /-$ \\
\hline La10 & & $7 / 7$ & $8 / 9$ & $-/-$ & $-/-$ & $-/-$ & $17 / 17$ \\
\hline Alp1 & $\mathrm{I}$ & $7 /-$ & $8 / 10$ & $8 / 23$ & $14 /-$ & $16 /-$ & $13 / 20$ \\
\hline Alp1 & $\mathrm{I}$ & $7 /-$ & $8 / 10$ & $8 / 23$ & $14 /-$ & $16 /-$ & $13 / 20$ \\
\hline Alp1 & III & $7 /-$ & $8 / 10$ & $8 / 23$ & $14 /-$ & $16 /-$ & $13 / 20$ \\
\hline Alp1 & III & $7 /-$ & $8 / 10$ & $8 / 23$ & $14 /-$ & $16 /-$ & $13 / 20$ \\
\hline Alp1 & & $7 / 7$ & $8 / 10$ & $8 / 23$ & $14 / 14$ & $16 / 16$ & $13 / 20$ \\
\hline Alp2 & I & $7 /-$ & 10i30/- & $8 /-$ & $13 / 22$ & $13 /-$ & $13 /-$ \\
\hline Alp2 & $\mathrm{I}$ & $7 /-$ & $10 \mathrm{i} 30 /-$ & $8 /-$ & $13 / 22$ & $13 /-$ & $13 /-$ \\
\hline Alp2 & III & $7 /-$ & 10i30/- & $8 /-$ & $13 / 22$ & $13 /-$ & $13 /-$ \\
\hline Alp2 & III & $7 /-$ & $10 \mathrm{i} 30 /-$ & $8 /-$ & $13 / 22$ & $13 /-$ & $13 /-$ \\
\hline Alp2 & & $7 / 7$ & 10i30/10i30 & $8 / 8$ & $13 / 22$ & $13 / 13$ & $13 / 13$ \\
\hline
\end{tabular}


Tabelle 86: Einzeltypisierungen der Mikrosatelliten in Extrakten rezenten Materials, Fortsetzung

\begin{tabular}{|c|c|c|c|c|c|c|c|}
\hline & Extrakt & VOLP10 & LgU52 & VOLP03 & LCA66 & VOLP67 & LgU68 \\
\hline Alp3 & I & $7 /-$ & $10 \mathrm{i} 30 /-$ & $8 /-$ & $-/-$ & $-1-$ & $13 /-$ \\
\hline Alp3 & I & $7 /-$ & $10 \mathrm{i} 30 /-$ & $-/-$ & $-/-$ & $16 /-$ & $13 /-$ \\
\hline Alp3 & III & $7 /-$ & 10i30/- & $-1-$ & $-/-$ & $-1-$ & $13 /-$ \\
\hline Alp3 & III & $7 /-$ & 10i30/- & $-/ 19$ & $-1-$ & $-1-$ & $13 /-$ \\
\hline Alp3 & & $7 / 7$ & 10i30/10i30 & $-/-$ & $-/-$ & $-/-$ & $13 / 13$ \\
\hline Alp4 & I & $7 /-$ & $10 /-$ & $23 /-$ & $14 /-$ & $17 /-$ & $13 / 20$ \\
\hline Alp4 & I & $7 /-$ & $10 /-$ & $23 /-$ & $14 /-$ & $17 /-$ & $13 / 20$ \\
\hline Alp4 & III & $7 /-$ & $10 /-$ & $23 /-$ & $14 /-$ & $17 /-$ & $13 / 20$ \\
\hline Alp4 & III & $7 /-$ & $10 /-$ & $23 /-$ & $14 /-$ & $17 /-$ & $13 / 20$ \\
\hline Alp4 & & $7 / 7$ & $10 / 10$ & $23 / 23$ & $14 / 14$ & $17 / 17$ & $13 / 20$ \\
\hline Alp5 & $\mathrm{I}$ & $7 /-$ & $8 /-$ & $8 / 21$ & $12 / 22$ & $17 /-$ & $13 / 20$ \\
\hline Alp5 & $\mathrm{I}$ & $7 /-$ & $8 /-$ & $8 / 21$ & $12 / 22$ & $17 /-$ & $13 / 20$ \\
\hline Alp5 & III & $7 /-$ & $8 /-$ & $8 / 21$ & $12 / 22$ & $17 /-$ & $13 / 20$ \\
\hline Alp5 & III & $7 /-$ & $8 /-$ & $8 / 21$ & $12 / 22$ & $17 /-$ & $13 / 20$ \\
\hline Alp5 & & $7 / 7$ & $8 / 8$ & $8 / 21$ & $12 / 22$ & $17 / 17$ & $13 / 20$ \\
\hline Alp6 & I & $7 /-$ & $8 / 9$ & $19 / 20$ & $13 /-$ & $17 /-$ & $18 / 22$ \\
\hline Alp6 & I & $7 /-$ & $8 / 9$ & $19 / 20$ & $13 /-$ & $17 /-$ & $18 / 22$ \\
\hline Alp6 & III & $7 /-$ & $8 / 9$ & $19 / 20$ & $13 /-$ & $17 /-$ & $18 / 22$ \\
\hline Alp6 & III & $7 /-$ & $8 / 9$ & $19 / 20$ & $13 /-$ & $17 /-$ & $18 / 22$ \\
\hline Alp6 & & $7 / 7$ & $8 / 9$ & $19 / 20$ & $13 / 13$ & $17 / 17$ & $18 / 22$ \\
\hline Alp7 & $\mathrm{I}$ & $7 /-$ & $8 /-$ & $21 /-$ & $11 / 16$ & $13 /-$ & $18 / 22$ \\
\hline Alp7 & $\mathrm{I}$ & $7 /-$ & $8 /-$ & $21 /-$ & $11 / 16$ & $13 /-$ & $18 / 22$ \\
\hline Alp7 & III & $7 /-$ & $8 /-$ & $21 /-$ & $11 / 16$ & $13 /-$ & $18 / 22$ \\
\hline Alp7 & III & $7 /-$ & $8 /-$ & $21 /-$ & $11 / 16$ & $13 /-$ & $18 / 22$ \\
\hline Alp7 & & $7 / 7$ & $8 / 8$ & $21 / 21$ & $11 / 16$ & $13 / 13$ & $18 / 22$ \\
\hline Alp8 & I & $7 /-$ & $8 / 9$ & $21 / 22$ & $12 / 16$ & $13 /-$ & $18 / 22$ \\
\hline Alp8 & I & $7 /-$ & $8 / 9$ & $21 / 22$ & $12 / 16$ & $13 /-$ & $18 / 22$ \\
\hline Alp8 & III & $7 /-$ & $8 / 9$ & $21 / 22$ & $12 / 16$ & $13 /-$ & $18 / 22$ \\
\hline Alp8 & III & $7 /-$ & $8 / 9$ & $21 / 22$ & $12 / 16$ & $13 /-$ & $18 / 22$ \\
\hline Alp8 & & $7 / 7$ & $8 / 9$ & $21 / 22$ & $12 / 16$ & $13 / 13$ & $18 / 22$ \\
\hline Alp9 & I & $7 /-$ & $8 / 9$ & $23 /-$ & $11 /-$ & $13 /-$ & $13 /-$ \\
\hline Alp9 & I & $7 /-$ & $8 / 9$ & $23 /-$ & $11 /-$ & $13 /-$ & $13 /-$ \\
\hline Alp9 & III & $7 /-$ & $8 / 9$ & $23 /-$ & $11 /-$ & $13 /-$ & $13 /-$ \\
\hline Alp9 & III & $7 /-$ & $8 / 9$ & $23 /-$ & $11 /-$ & $13 /-$ & $13 /-$ \\
\hline Alp9 & & $7 / 7$ & $8 / 9$ & $23 / 23$ & $11 / 11$ & $13 / 13$ & $13 / 13$ \\
\hline Alp10 & I & $7 /-$ & $8 / 10 \mathrm{i} 30$ & $21 / 22$ & $11 / 16$ & $12 /-$ & $13 / 21$ \\
\hline Alp10 & I & $7 /-$ & 8/10i30 & $21 / 22$ & $11 / 16$ & $12 /-$ & $13 / 21$ \\
\hline Alp10 & III & $7 /-$ & 8/10i30 & $21 / 22$ & $11 / 16$ & $12 /-$ & $13 / 21$ \\
\hline Alp10 & III & $7 /-$ & $8 / 10 \mathrm{i} 30$ & $21 / 22$ & $11 / 16$ & $12 /-$ & $13 / 21$ \\
\hline Alp10 & & $7 / 7$ & 8/10i30 & $21 / 22$ & $11 / 16$ & $12 / 12$ & $13 / 21$ \\
\hline Alp12 & I & $7 /-$ & $8 / 10 \mathrm{i} 30$ & $20 / 21$ & $13 / 15$ & $-1-$ & $13 / 16$ \\
\hline Alp12 & I & $7 /-$ & 8/10i30 & $20 / 21$ & $13 / 15$ & $-/-$ & $13 / 16$ \\
\hline Alp12 & III & $7 /-$ & 8/10i30 & $20 / 21$ & $13 / 15$ & $-1-$ & $13 / 16$ \\
\hline Alp12 & III & $7 /-$ & $8 / 10$ i30 & $20 / 21$ & $13 / 15$ & $-1-$ & $13 / 16$ \\
\hline Alp12 & & $7 / 7$ & $8 / 10 \mathrm{i} 30$ & $20 / 21$ & $13 / 15$ & $-/-$ & $13 / 16$ \\
\hline Alp13 & $\mathrm{I}$ & $9 /-$ & $8 / 9$ & $24 /-$ & $14 /-$ & $-1-$ & $13 / 16$ \\
\hline Alp13 & I & $9 /-$ & $8 / 9$ & $24 /-$ & $14 /-$ & $-1-$ & $13 / 16$ \\
\hline Alp13 & III & $9 /-$ & $8 / 9$ & $24 /-$ & $14 /-$ & $-1-$ & $13 / 16$ \\
\hline Alp13 & III & $9 /-$ & $8 / 9$ & $24 /-$ & $14 /-$ & $-1-$ & $13 / 16$ \\
\hline Alp13 & & $9 / 9$ & $8 / 9$ & $24 / 24$ & $14 / 14$ & $-/-$ & $13 / 16$ \\
\hline Alp14 & I & $7 /-$ & $-1-$ & $-/-$ & $11 / 14$ & $-1-$ & $-1-$ \\
\hline Alp14 & $\mathrm{I}$ & $7 /$ & $8 /-$ & $-/-$ & $11 / 14$ & $-1-$ & $-/-$ \\
\hline Alp14 & III & $7 /$ & $-/-$ & $-/-$ & $11 / 14$ & $-/-$ & $-/-$ \\
\hline Alp14 & III & $7 /$ & $-1-$ & $-1-$ & $11 / 14$ & $-1-$ & $-1-$ \\
\hline Alp14 & & $7 / 7$ & $-/-$ & $-/-$ & $11 / 14$ & $-/-$ & $-/-$ \\
\hline
\end{tabular}


Tabelle 86: Einzeltypisierungen der Mikrosatelliten in Extrakten rezenten Materials, Fortsetzung

\begin{tabular}{|c|c|c|c|c|c|c|c|}
\hline & Extrakt & VOLP10 & LgU52 & VOLP03 & LCA66 & VOLP67 & $\mathrm{LgU68}$ \\
\hline Gua1 & I & $7 /-$ & $8 / 11$ & $21 /-$ & $27 /-$ & $7 /-$ & $10 / 13$ \\
\hline Gua1 & I & $7 /-$ & $8 / 11$ & $21 /-$ & $27 /-$ & $7 /-$ & $10 / 13$ \\
\hline Gua1 & III & $7 /-$ & $8 / 11$ & $21 /-$ & $27 /-$ & $7 /-$ & $10 / 13$ \\
\hline Gua1 & III & $7 /-$ & $8 / 11$ & $21 /-$ & $27 /-$ & $7 /-$ & $10 / 13$ \\
\hline Gua1 & & $7 / 7$ & $8 / 11$ & $21 / 21$ & $27 / 27$ & $7 / 7$ & $10 / 13$ \\
\hline Gua2 & I & $7 /-$ & $8 / 11$ & $21 /-$ & $15 /-$ & $-/-$ & $10 / 13$ \\
\hline Gua2 & I & $7 /-$ & $8 / 11$ & $21 /-$ & $15 /-$ & $-1-$ & $10 / 13$ \\
\hline Gua2 & III & $7 /-$ & $8 / 11$ & $21 /-$ & $15 /-$ & $-/-$ & $10 / 13$ \\
\hline Gua2 & III & $7 /-$ & $8 / 11$ & $21 /-$ & $15 /-$ & $-1-$ & $10 / 13$ \\
\hline Gua2 & & $7 / 7$ & $8 / 11$ & $21 / 21$ & $15 / 15$ & $-/-$ & $10 / 13$ \\
\hline Gua3 & $\mathrm{I}$ & $7 / 8$ & $8 /-$ & $21 / 24$ & $22 / 27$ & $-1-$ & $13 /-$ \\
\hline Gua3 & I & $7 / 8$ & $8 /-$ & $21 / 24$ & $22 / 27$ & $-1-$ & $13 /-$ \\
\hline Gua3 & III & $7 / 8$ & $8 /-$ & $21 / 24$ & $22 / 27$ & $-1-$ & $13 /-$ \\
\hline Gua3 & III & $7 / 8$ & $8 /-$ & $21 / 24$ & $22 / 27$ & $-1-$ & $13 /-$ \\
\hline Gua3 & & $7 / 8$ & $8 / 8$ & $21 / 24$ & $22 / 27$ & $-/-$ & $13 / 13$ \\
\hline Vic1 & I & $7 /-$ & $5 / 10$ & $22 /-$ & $11 / 12$ & $14 / 19$ & $14 / 15$ \\
\hline Vic1 & I & $7 /-$ & $5 / 10$ & $22 /-$ & $11 / 12$ & $14 / 19$ & $14 / 15$ \\
\hline Vic1 & III & $7 /-$ & $5 / 10$ & $22 /-$ & $11 / 12$ & $14 / 19$ & $14 / 15$ \\
\hline Vic1 & III & $7 /-$ & $5 / 10$ & $22 /-$ & $11 / 12$ & $14 / 19$ & $14 / 15$ \\
\hline Vic1 & & $7 / 7$ & $5 / 10$ & $22 / 22$ & $11 / 12$ & $14 / 19$ & $14 / 15$ \\
\hline Vic2 & I & $7 /-$ & $5 / 10$ & $22 /-$ & $11 / 12$ & $12 / 19$ & $15 /-$ \\
\hline Vic2 & $\mathrm{I}$ & $7 /-$ & $5 / 10$ & $22 /-$ & $11 / 12$ & $12 / 19$ & $15 /-$ \\
\hline Vic2 & III & $7 /-$ & $5 / 10$ & $22 /-$ & $11 / 12$ & $12 / 19$ & $15 /-$ \\
\hline Vic2 & III & $7 /-$ & $5 / 10$ & $22 /-$ & $11 / 12$ & $12 / 19$ & $15 /-$ \\
\hline Vic2 & & $7 / 7$ & $5 / 10$ & $22 / 22$ & $11 / 12$ & $12 / 19$ & $15 / 15$ \\
\hline Vic3 & I & $7 /-$ & $10 /-$ & $19 / 22$ & $11 / 12$ & $-/-$ & $15 /-$ \\
\hline Vic3 & I & $7 /-$ & $10 /-$ & $19 / 22$ & $11 / 12$ & $-1-$ & $15 /-$ \\
\hline Vic3 & III & $7 /-$ & $10 /-$ & $19 / 22$ & $11 / 12$ & $-1-$ & $15 /-$ \\
\hline Vic3 & III & $7 /-$ & $10 /-$ & $19 / 22$ & $11 / 12$ & $-1-$ & $15 /-$ \\
\hline Vic3 & & $7 / 7$ & $10 / 10$ & $19 / 22$ & $11 / 12$ & $-/-$ & $15 / 15$ \\
\hline Vic4 & I & $7 /-$ & $7 / 10$ & $19 / 22$ & $11 / 12$ & $13 / 19$ & $15 /-$ \\
\hline Vic4 & I & $7 /-$ & $7 / 10$ & $19 / 22$ & $11 / 12$ & $13 / 19$ & $15 /-$ \\
\hline Vic4 & III & $7 /-$ & $7 / 10$ & $19 / 22$ & $11 / 12$ & $13 / 19$ & $15 /-$ \\
\hline Vic4 & III & $7 /-$ & $7 / 10$ & $19 / 22$ & $11 / 12$ & $13 / 19$ & $15 /-$ \\
\hline Vic4 & & $7 / 7$ & $7 / 10$ & $19 / 22$ & $11 / 12$ & $13 / 19$ & $15 / 15$ \\
\hline Vic5 & I & $7 /-$ & $5 / 10$ & $19 / 22$ & $11 / 12$ & $-/-$ & $15 /-$ \\
\hline Vic5 & I & $7 /-$ & $5 / 10$ & $19 / 22$ & $11 / 12$ & $-1-$ & $15 /-$ \\
\hline Vic5 & III & $7 /-$ & $5 / 10$ & $19 / 22$ & $11 / 12$ & $-/-$ & $15 /-$ \\
\hline Vic5 & III & $7 /-$ & $5 / 10$ & $19 / 22$ & $11 / 12$ & $-1-$ & $15 /-$ \\
\hline Vic5 & & $7 / 7$ & $5 / 10$ & $19 / 22$ & $11 / 12$ & $-/-$ & $15 / 15$ \\
\hline Vic6 & I & $7 /-$ & $5 / 10$ & $19 / 22$ & $11 / 12$ & $-1-$ & $15 / 18$ \\
\hline Vic6 & I & $7 /-$ & $5 / 10$ & $19 / 22$ & $11 / 12$ & $-1-$ & $15 / 18$ \\
\hline Vic6 & III & $7 /-$ & $5 / 10$ & $19 / 22$ & $11 / 12$ & $-/-$ & $15 / 18$ \\
\hline Vic6 & III & $7 /-$ & $5 / 10$ & $19 / 22$ & $11 / 12$ & $-1-$ & $15 / 18$ \\
\hline Vic6 & & $7 / 7$ & $5 / 10$ & $19 / 22$ & $11 / 12$ & $-/-$ & $15 / 18$ \\
\hline Vic7 & I & $7 /-$ & $5 / 10$ & $19 / 22$ & $11 / 12$ & $-1-$ & $15 / 18$ \\
\hline Vic7 & I & $7 /-$ & $5 / 10$ & $19 / 22$ & $11 / 12$ & $-/-$ & $15 / 18$ \\
\hline Vic7 & III & $7 /-$ & $5 / 10$ & $19 / 22$ & $11 / 12$ & $-/-$ & $15 / 18$ \\
\hline Vic7 & III & $7 /-$ & $5 / 10$ & $19 / 22$ & $11 / 12$ & $-/-$ & $15 / 18$ \\
\hline Vic7 & & $7 / 7$ & $5 / 10$ & $19 / 22$ & $11 / 12$ & $-/-$ & $15 / 18$ \\
\hline Vic8 & I & $7 /-$ & $5 / 10$ & $21 /-$ & $11 /-$ & $-1-$ & $15 /-$ \\
\hline Vic8 & $\mathrm{I}$ & $7 /-$ & $5 / 10$ & $21 /-$ & $11 /-$ & $-1-$ & $15 /-$ \\
\hline Vic8 & III & $7 /-$ & $5 / 10$ & $21 /-$ & $11 /-$ & $-1-$ & $15 /-$ \\
\hline Vic8 & III & $7 /-$ & $5 / 10$ & $21 /-$ & $11 /-$ & $-/-$ & $15 /-$ \\
\hline Vic8 & & $7 / 7$ & $5 / 10$ & $21 / 21$ & $11 / 11$ & $-/-$ & $15 / 15$ \\
\hline
\end{tabular}


Tabelle 86: Einzeltypisierungen der Mikrosatelliten in Extrakten rezenten Materials, Fortsetzung

\begin{tabular}{|c|c|c|c|c|c|c|c|}
\hline & Extrakt & VOLP10 & LgU52 & VOLP03 & LCA66 & VOLP67 & $\mathrm{LgU68}$ \\
\hline Vic9 & I & $7 /-$ & $5 / 7$ & $19 / 22$ & $22 /-$ & 19/- & $15 /-$ \\
\hline Vic9 & I & $7 /-$ & $5 / 7$ & $19 / 22$ & $22 /-$ & $19 /-$ & $15 /-$ \\
\hline Vic9 & III & $7 /-$ & $5 / 7$ & $19 / 22$ & $22 /-$ & $19 /-$ & $15 /-$ \\
\hline Vic9 & III & $7 /-$ & $5 / 7$ & $19 / 22$ & $22 /-$ & $19 /-$ & $15 /-$ \\
\hline Vic9 & & $7 / 7$ & $5 / 7$ & $19 / 22$ & $22 / 22$ & $19 / 19$ & $15 / 15$ \\
\hline Vic10 & $\mathrm{I}$ & $7 /-$ & $5 / 7$ & $19 / 22$ & $12 / 14$ & $-/-$ & $14 / 15$ \\
\hline Vic10 & $\mathrm{I}$ & $7 /-$ & $5 / 7$ & $19 / 22$ & $12 / 14$ & $-1-$ & $14 / 15$ \\
\hline Vic10 & III & $7 /-$ & $5 / 7$ & $19 / 22$ & $12 / 14$ & $-/-$ & $14 / 15$ \\
\hline Vic10 & III & $7 /-$ & $5 / 7$ & $19 / 22$ & $12 / 14$ & $-1-$ & $14 / 15$ \\
\hline Vic10 & & $7 / 7$ & $5 / 7$ & $19 / 22$ & $12 / 14$ & $-/-$ & $14 / 15$ \\
\hline Vic11 & I & $7 /-$ & $5 /-$ & $-1-$ & $-/-$ & $-1-$ & $15 /-$ \\
\hline Vic11 & I & $7 /-$ & $-1-$ & $-1-$ & $-1-$ & $-1-$ & $15 /-$ \\
\hline Vic11 & III & $7 /-$ & $-1-$ & $-1-$ & $-/-$ & $-1-$ & $15 /-$ \\
\hline Vic11 & III & $7 /-$ & $-1-$ & $-1-$ & $-1-$ & $-1-$ & $15 /-$ \\
\hline Vic11 & & $7 / 7$ & $-/-$ & $-/-$ & $-/-$ & $-/-$ & $15 / 15$ \\
\hline Vic12 & $\mathrm{I}$ & $7 /-$ & $5 /-$ & $22 /-$ & $12 /-$ & $-1-$ & $15 / 18$ \\
\hline Vic12 & I & $7 /-$ & $5 /-$ & $22 /-$ & $12 /-$ & $-1-$ & $15 / 18$ \\
\hline Vic12 & III & $7 /-$ & $5 /-$ & $22 /-$ & $12 /-$ & $-/-$ & $15 / 18$ \\
\hline Vic12 & III & $7 /-$ & $5 /-$ & $22 /-$ & $12 /-$ & $-1-$ & $15 / 18$ \\
\hline Vic12 & & $7 / 7$ & $5 / 5$ & $22 / 22$ & $12 / 12$ & $-/-$ & $15 / 18$ \\
\hline Vic13 & I & $7 /-$ & $5 / 10$ & $22 /-$ & $12 /-$ & $-1-$ & $14 / 15$ \\
\hline Vic13 & I & $7 /-$ & $5 / 10$ & $22 /-$ & $12 /-$ & $-1-$ & $14 / 15$ \\
\hline Vic13 & III & $7 /-$ & $5 / 10$ & $22 /-$ & $12 /-$ & $-1-$ & $14 / 15$ \\
\hline Vic13 & III & $7 /-$ & $5 / 10$ & $22 /-$ & $12 /-$ & $-1-$ & $14 / 15$ \\
\hline Vic13 & & $7 / 7$ & $5 / 10$ & $22 / 22$ & $12 / 12$ & $-/-$ & $14 / 15$ \\
\hline Vic14 & I & $7 /-$ & $5 /-$ & $21 /-$ & $12 /-$ & $-1-$ & $14 / 15$ \\
\hline Vic14 & $\mathrm{I}$ & $7 /-$ & $5 /-$ & $21 /-$ & $12 /-$ & $-1-$ & $14 / 15$ \\
\hline Vic14 & III & $7 /-$ & $5 /-$ & $21 /-$ & $12 /-$ & $-/-$ & $14 / 15$ \\
\hline Vic14 & III & $7 /-$ & $5 /-$ & $21 /-$ & $12 /-$ & $-/-$ & $14 / 15$ \\
\hline Vic14 & & $7 / 7$ & $5 / 5$ & $21 / 21$ & $12 / 12$ & $-/-$ & $14 / 15$ \\
\hline Vic15 & $\mathrm{I}$ & $7 /-$ & $5 /-$ & $21 / 22$ & $12 /-$ & $-1-$ & $15 /-$ \\
\hline Vic15 & I & 7/- & $5 /-$ & $21 / 22$ & $12 /-$ & $-/-$ & $15 /-$ \\
\hline Vic15 & III & $7 /-$ & $5 /-$ & $21 / 22$ & $12 /-$ & $-1-$ & $15 /-$ \\
\hline Vic15 & III & $7 /-$ & $5 /-$ & $21 / 22$ & $12 /-$ & $-1-$ & $15 /-$ \\
\hline Vic15 & & $7 / 7$ & $5 / 5$ & $21 / 22$ & $12 / 12$ & $-/-$ & $15 / 15$ \\
\hline Vic16 & I & $7 /-$ & $5 / 10$ & $22 /-$ & $12 /-$ & $-1-$ & $15 /-$ \\
\hline Vic16 & I & $7 /-$ & $5 / 10$ & $22 /-$ & $12 /-$ & $-1-$ & $15 /-$ \\
\hline Vic16 & III & $7 /-$ & $5 / 10$ & $22 /-$ & $12 /-$ & $-/-$ & $15 /-$ \\
\hline Vic16 & III & $7 /-$ & $5 / 10$ & $22 /-$ & $12 /-$ & $-/-$ & $15 /-$ \\
\hline Vic16 & & $7 / 7$ & $5 / 10$ & $22 / 22$ & $12 / 12$ & $-/-$ & $15 / 15$ \\
\hline Alp11 & II & $6 / 7$ & $8 / 10 \mathrm{i} 30$ & $20 / 21$ & $13 / 19$ & $-1-$ & $13 /-$ \\
\hline Alp11 & II & $6 / 7$ & 8/10i30 & $20 / 21$ & $13 / 19$ & $-1-$ & $13 /-$ \\
\hline Alp11 & III & $6 / 7$ & 8/10i30 & $20 / 21$ & $13 / 19$ & $-/-$ & $13 /-$ \\
\hline Alp11 & III & $6 / 7$ & $8 / 10 \mathrm{i} 30$ & $20 / 21$ & $13 / 19$ & $-1-$ & $13 /-$ \\
\hline Alp11 & & $6 / 7$ & $8 / 10 \mathrm{i} 30$ & $20 / 21$ & $13 / 19$ & $-/-$ & $13 / 13$ \\
\hline La7 & II & $7 /-$ & $8 / 10 \mathrm{i} 30$ & $21 /-$ & $12 / 13$ & $12 / 16$ & $13 / 20$ \\
\hline La7 & II & $7 /-$ & $8 / 10 \mathrm{i} 30$ & $21 /-$ & $12 / 13$ & $12 / 16$ & $13 / 20$ \\
\hline La7 & III & $7 /-$ & 8/10i30 & $21 /-$ & $12 / 13$ & $12 / 16$ & $13 / 20$ \\
\hline La7 & III & $7 /-$ & $8 / 10 \mathrm{i} 30$ & $21 /-$ & $12 / 13$ & $12 / 16$ & $13 / 20$ \\
\hline La7 & & $7 / 7$ & $8 / 10 \mathrm{i} 30$ & $21 / 21$ & $12 / 13$ & $12 / 16$ & $13 / 20$ \\
\hline
\end{tabular}


13.4 Dokumentation der Histologischen Knochenstruktur von Neuweltcamelidae (exemplarisch)

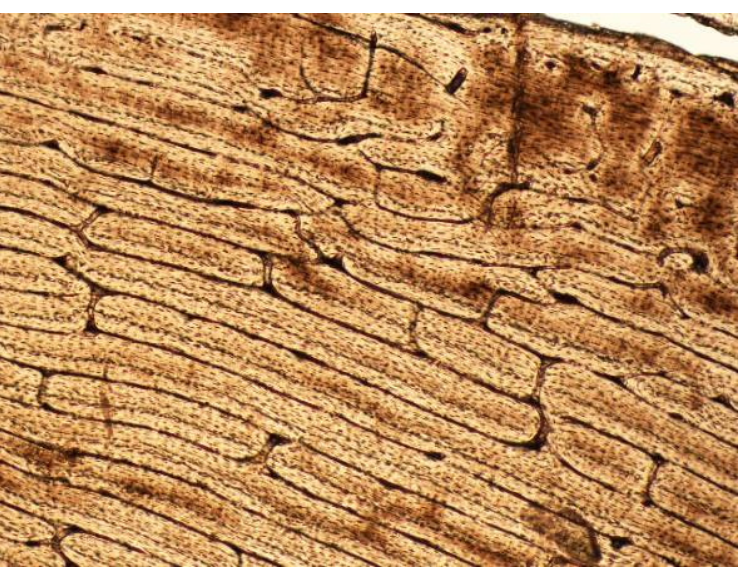

a

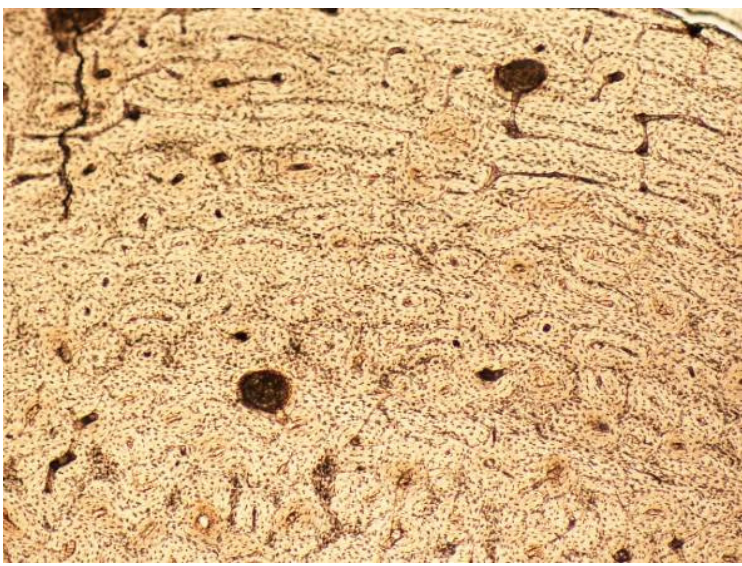

C

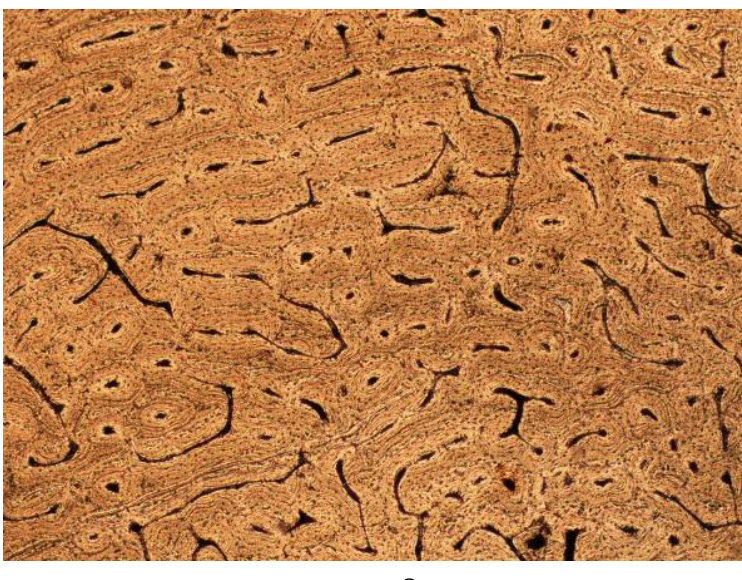

e

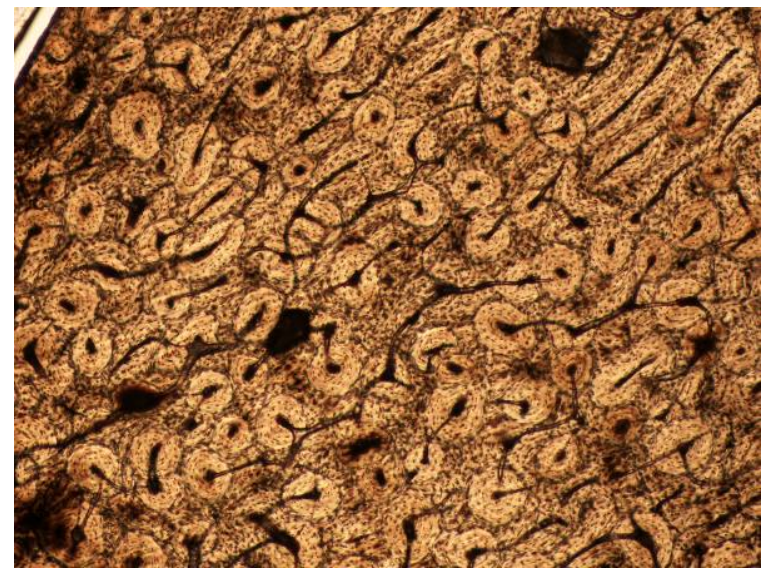

b

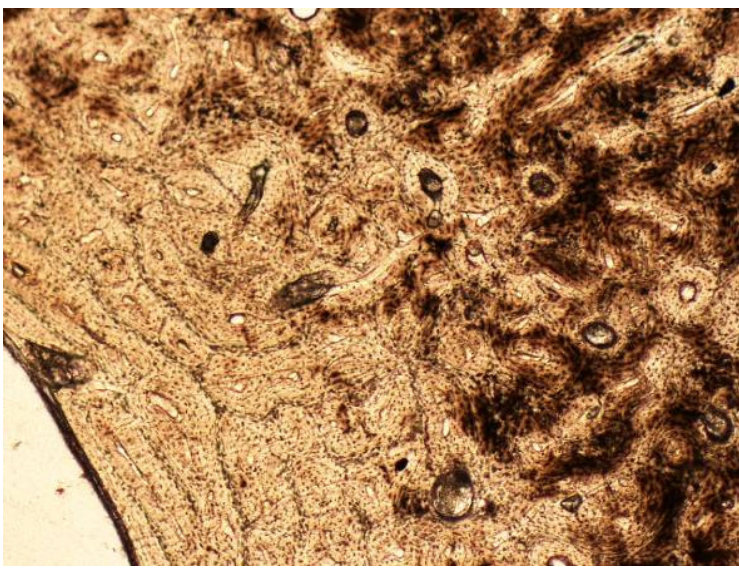

d

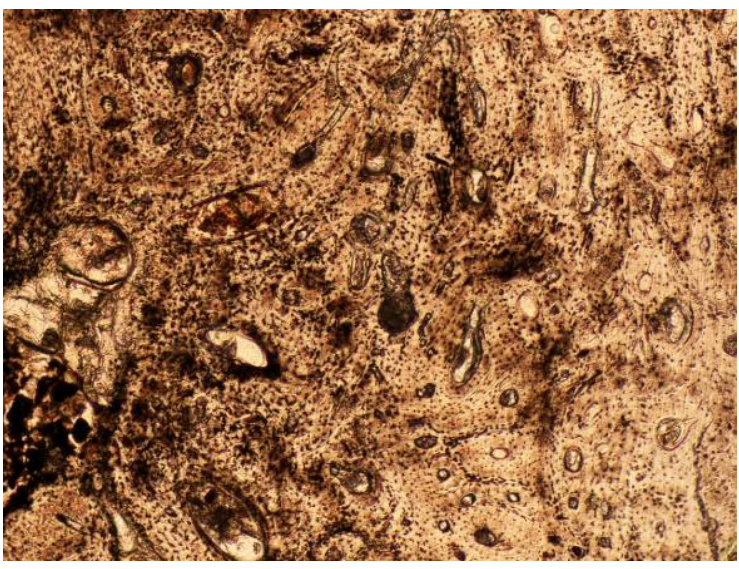

f

Abbildung 86: Knochenmikrostruktur von Neuweltcamelidae. a; Diaphysenkompakta der Probe COA18

(Vikunja/Alpaka) plexiforme Struktur, b; Kompakta des Kanonenbeins COA21 (Guanako), Mischstruktur, c:

Phalngeskompakta COA4Ph (Lama) plexiforme Struktur, d Kanonenbeinkompakta der Probe COA20

(Vikunja/Alpaka) Mischstruktur, e: Diaphysenkompakta der Probe JAA15, plexiforme Struktur f:

Diaphysenkompakte der Probe COA 17 (Guanako); alle ca. 20-fache Vergrößerung 
Danksagung

An erster Stelle möchte ich mich bei allen Kollegen des Anthropologischen Instituts für die gute Zusammenarbeit in den letzten Jahren bedanken.

Herrn Prof. Dr. Bernd Herrmann danke ich für die Betreuung dieser Arbeit, die Bereitstellung des Arbeitsplatzes, die fachlichen Ratschläge sowie die Begleitung meines Werdeganges.

Herzlich bedanken möchte ich mich bei Frau Dr. Susanne Hummel für ihre Unterstützung seit meiner Studienzeit und die Vermittlung der Kenntnisse der aDNA-Analytik. Darüber hinaus bedanke ich mich bei ihr für die vielen konstruktiven Gespräche jeglicher Art.

Ich bedanke mich bei: Sybille Hourticolon für die Fotodokumentation der Knochen, Ulla Schulz für die Anfertigung der histologischen Präparate, Dr. Birgit Großkopf für die Hilfestellung bei der Interpretation der Knochenstrukturen, Katharina Boufaden für die Hilfe in administrativen Angelegenheiten. Besonders Ed George danke ich für seine Hilfsbereitschaft und die vielen Kunstwerke.

Desweitern danke ich den Mitgliedern des Projektverbundes "Nasca“, besonders Dr. Markus Reindel für die Einführung in die Südamerika-Archäologie und die Diskussionen bezüglich der Neuwelt-Camelidae, Johnny Isla für die Hilfsbereitschaft im Feldaufenthalt, Prof. Dr. Peter Horn und Prof. Dr. Stefan Hölzl für die gute und stets freundliche Zusammenarbeit sowie Dr. Jörg Faßbinder für eine Einführung in die magnetische Welt und den Gedankenaustausch.

Für die Bereitstellung des Probenmaterials bedanke ich mich bei den Zoos Hellabrunn München, Nürnberg, Dresden, Halle und Hannover, der Haustiergenetik Göttingen und bei einem AlpakaZüchter aus der Schweiz.

Lars Fehren-Schmitz möchte ich danken für die unzähligen Gespräche, die gegenseitige Unterstützung in allen Lebenslagen, die uneingeschränkten Akzeptanz meiner Person und die stets erheiternden Zugfahrten. Bei Dr. Felix Schilz und Joana Schilz bedanke ich mich für unsere Freundschaft, die stetige Hilfsbereitschaft und Unterstützung in den letzten Jahren. Jutta Pepperl danke ich für die stets gute Zusammenarbeit und den regen fachlichen Austausch.

Ebenso möchte ich mich bei Friederike Koch und Jenny Schawacht für ihre Unterstützung bei der anfallenden Laborarbeit bedanken. Bei Michaela Riesen, Stefanie Huhn und Sandra 
Melchisedech bedanke ich mich für die gute Zusammenarbeit und die Konversationen über dies und jenes.

Judith Kara, Judith Stauch und meiner Familie danke ich sehr für ihre Unterstützung, ihr Verständnis und grenzenloses Vertrauen. Ohne dieses stützende Element, wäre ich nicht das was ich bin.

Meinem Ehemann Thomas danke ich für seine Geduld, seinen Beistand und seinem Glauben an meine Fähigkeiten. Er ist mein Lebenselixier und "Patronus".

Diese Arbeit wurde aus Mittel des Bundesministeriums für Bildung und Forschung (BMBF; FKZ: 03HEX1VP) finanziert.

In Memoriam

Dr. Jan Cierny

†21. März 2006 in Palpa (Peru) 


\section{Lebenslauf}

Name: Rebecca Renneberg (geb.Schütt)

Geburtsdatum: 03.08.1980

Geburtsort: Remscheid-Lennep

Familienstand: verheiratet

1986-1990 Besuch der Grundschule an den Türmen/Fritzlar

1990-1999 Besuch des Gymnasiums König-Heinrich-Schule/Fritzlar

1999 Abiturprüfung mit den Hauptfächern Biologie und Deutsch Gesamtnote 2,5

1999 Aufnahme des Biologiestudium an der Julius-Maximilians-Universität Würzburg

2000 Studienortwechsel an die Georg-August-Universität Göttingen

2002 Diplomvorprüfung in den Fächern Zoologie, Mikrobiologie, Chemie und Physik. Gesamtnote „Gut“

2002-2005 beschäftigt als studentische Hilfskraft am Institut für Anthropologie und Humanökologie

2004 Diplomprüfung im Hauptfach Anthropologie sowie den Nebenfächern Zoologie und Humangenetik

2004-2005 Anfertigung der Diplomarbeit am Institut für historische Anthropologie und Humanökologie/Universität Göttingen mit dem Thema: „Molekulargenetische Methoden zur Individualbefundung und Verwandtschaftsrekonstruktion am Beispiel einer keltischen Sonderbestattung aus Manching“.

2005 Erlangung des Diploms. Gesamtnote „Sehr Gut“

2005 beschäftigt als wissenschaftliche Hilfskraft am Institut für historische Anthropologie und Humanökologie/Universität Göttingen

2005-2008 wissenschaftliche Mitarbeiterin am Institut für Anthropologie und Humanökologie, im Rahmen des durch das BMBF geförderte NTG-

Verbundprojekt „Nasca“ 